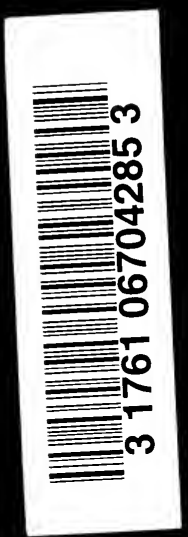




$$
\begin{aligned}
& \text { Ox L Librí } \\
& \text { Pskar Chlotz }
\end{aligned}
$$




\section{1}

Qunes:
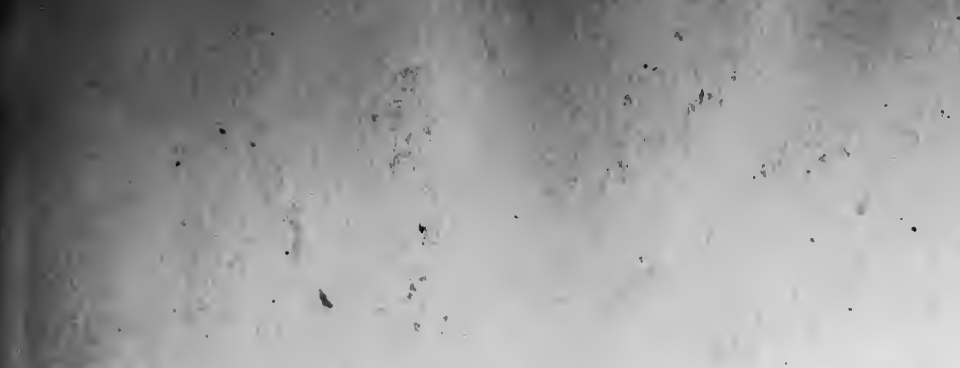

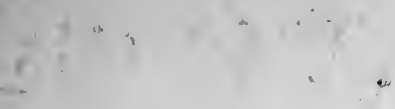


. . . . 


\section{DISEASES OF}

\section{THE TH Y ROID GLA N D}

$$
\text { A } \times \text { D }
$$

THEIR SURGICAL TREATMEN'T 

$B$

\title{
DISEASES OF
}

\section{THE THYROID GLAND}

AND

\section{THEIR SURGICAL TREATMENT}

BY

\author{
J A M E S B B R R Y \\ B.S. LoND., F.R.C.S.
}

SURGEON TO THE ROYAL FREE HOSPITAL AND LECTERER ON SCKGIXRY

AT THE LONDON (ROYAL FREE HOSPITAL) SCHOOL

OF MEDICANE FOR WOMEN; SURGEON TO THE

ALEXANDRA IIOSPITAL FOR HIP DISEASE

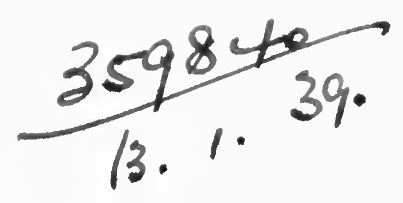

PHILADELPHIA

P. BLAKISTON'S SON \& CO.

1012 WALNUT STREET

1901 



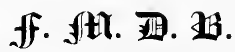

IN GRATEFUL AND AFFECTIONATE

RECOGNITION OF MUCH VALUABLE HELP

IN ITS PREP.IR.ATION

TIIS BOOK IS DEDICATED 
Digitized by the Internet Archive in 2007 with funding from Microsoft Corporation 


\section{PREFACE.}

This book is based upon the Essay to which the Jacksonian Prize of the Royal College of Surgeons for 1886 was awarded. The essay in its original form was never published because I felt that at that time I had had so little personal experience of thyroid operative surgery, that it was undesirable to commit my observations to print. During the last fourteen years, however, I have enjoyed unusual facilities for the study of this branch of surgery, and much of what was written in the original essay has been entirely rewritten, by the light of further experience.

The Hunterian Lectures, which I had the honour of delivering at the Royal College of Surgeons in 1891, have also been incorporated in the present work.

I am fully aware of the many imperfections in, and omissions from, the book, and should have liked to wait for further experience before publishing it. But further waiting seems undesirable, as there would always be something wanting, something new to be added.

I trust that those who read the book will deal gently with it, and remember that it is an honest attempt to set forth as clearly and concisely as possible what is known by myself and others about a difficult and somewhat obscure branch of surgery.

I have to thank numerous friends for the help they have afforded me; some by sending cases for treatment, or for examination, others by supplying local information about the distribution of endemic goitre.

The illustrations are mainly from my own photographs, supplemented by some others taken by friends. 'To Mr. Charles 
Cosens I am especially indebted for all the micro-photographs, and for much invaluable help in photography. The drawings are mainly by Miss G. Bulkeley-Johnson, who has bestowed an amount of care and attention upon them for which I an most grateful. A few are from the skilful pencil of Dr. Ethel Vaughan; for a very few I am myself responsible. 'The patients from. whom the photographs have been taken (excepting those shown in Figs. 15 and 83) have all been under my own observation, and most of thenn have been under my own care.

'The blocks (with the exception of those from which Figs. 85, 111 and 112 have been taken), have been prepared by Messis. Godart of Maiden Lane, Strand.

Several of the illustrations have appeared elsewhere, illustrating papers contributed by myself to the British Medical Journal, Polyctinic Jourmal, Transactions of the Pathological Soricty, and st. Bartholomecis Hospital Reports, and for permission to use these I have to express my thanks.

'To Mr. Einest Shaw I am indebted for much help in the preparation of microscopic sections.

My best thanks are due to my firiends Mr. Anthony Bowlby and Mr. Edmund Roughton for much valuable advice, and for the trouble they have taken in revising the proof sheets.

21 Wimpole St., London, W.

Fel. 1901 . 


\title{
CON'TEN'TS.
}

\author{
CHAPTER I.
}

ANATOMY.

Lateral lobes-Upper and lower horns-Isthmus-Pyramid-RelationsArteries-Veins-Lymphatics-Nerves-Internal structure-Accessory thyroids-Parathyroids . . . . . . . . Pp. 1-13

\section{CHAPTER II.}

\section{CONGENITAL AFFECTIONS.}

Congenital malformations-Cumplete absence-Absence of one lobe-Absence of isthmus-Accessory thyroids-Congenital goitre in man, in lower animals-Treatment of congenital goitre . . . . . Pp. 14-19

\section{CHAPTER III.}

\section{ATROPHY AND HYPER'TROPHY.}

Atrophy: in old age--Myxcedema-Treatment-Cretinism-Sporadic and endemic-Fatty tumours of cretinism. Hypertrophy: CompensatoryPhysiological-Relation to menstruation-Pregnancy-Puberts-Thyroid of stout and thin persons . . . . . . . . . Pp. 20-35

\section{CHAPTER IV.}

\section{GOITRE AND ITS VARIETIES.}

Meaning of the word goitre-Parenchymatous-Cystic-Fibrous-Adenomatous (fœetal and cystic adenomata)-Malignant-Exophthalmic-Hæmorrhagic-Colloid-"Vascular"-Endemic-Sporadic-Epidemic-AcuteSuffocating-Substernal-Intra-thoracic-Retro-tracheal-Retro-œesophageal 


\section{C'HAP'TER V.}

\section{ENDEMIC GOITRE-CALSATION AND NISTRIBUIION.}

Alleged causes-Climate-Physical configuration of soil-" Want of air and sunshine" theory - Erroneous nature of-Relation to geology-Geological and geographical distribution in England-Relation to calcareous rocks and waters derived from them-Lime-Magnesia-Iron-Organic impurities-Epidemic goitre-Goitre wells-Artificial production of goitreGoitre in lower animals-Habits of life, exertion, strain, \&c.-Heredity('onclusions

Pp. ${ }^{49-71}$

\section{CHAP'TER VI.}

\section{SYMPTOMS AND DIAGNOSIS OF THYROID ENLARGEMENTS -PHYSICAL SIGNS.}

Mobility-Shape-Size-Position with regard to muscles, great vessels, sternum-Pulsation-Diagnosis from aneurism-Consistence-Pressure effects, on veins, recurrent laryngeal nerve, sympathetic, cervical and brachial plexuses, larynx and trachea. (esophagus and pharynx

P1). $72-104$

\section{CHAPTER VII.}

\section{THE DYSPNGA CAUSED lYY GOITRE.}

Frequency and importance-Pressure upon trachea-Lateral compressionScabbard-shaped trachea-Effect on trachea of bilateral goitre, unilateral, median--Softening of tracheal wall--Pressure upon recurrent nervesDirect extension to trachea-Rupture of cyst or abscess-CEdema of glottis-Swelling of tracheal mucous membrane-Varieties of goitre most likely to cause dyspnira; relation to age and sex-Danger of bilateral goitre of puberty and of deeply seated goitres-Table of cases of goitre causing death by suffocation . . . . . Pp. 105-129

\section{('HAP'TER VIII.}

\section{N F L A M M A 'T' O N.}

Acute idliopashic inflammation -Typhoid fever-Rhenmatism-Py:mia-Traumatic inflammation -Symptoms-Results of suppuration-DiagnosisTreatment. Chronire inflammation-Primary chronic inflammation-Diagnosis from malignant disease--Treatment . . . . Pp. 1:30-145

\section{('HAP'TER IX.}

\section{T'TBERCLE AND SYPHILIS.}

Tubercle : Miliary-Usually secondary-Caseating-Rarity of-Extirpation of tuberculous goitre. Syphilis : frequently affects thyroid in form of slight «reneral enlargement-Gummata rare-Congenital syphilis Pp. 146-151 


\section{CHAPTER X.}

\section{CYSTIC DISEASE.}

Frequency-Age-Modes of origin-Transition of adenomata into cystsSingle and multiple cysts-Hæmorrhagic cysts-Structure of cyst wallOf contents-Vacuolation of colloid-Intra-cystic growths-Malignant nature of-False intra-cystic growths . . . . . Pp. 152-164

\section{CHAPTER XI.}

\section{HYDATIDS.}

Rarity of-Museum specimen-Age-Sex-Absorption of gland by pressureSymptoms-Suppuration-Diagnosis-Urticaria-Rupture into tracheaTreatment-Table of cases . . . . . . Pp. 165-175

\section{CHAPTER XII.}

EXOPHTHALMIC GOITRE AND ITS TREATMENT. (GRAVES'S DISEASE; BASEDOW'S DISEASE.)

Age-Sex-Pathology-Morbid anatomy-Characteristic appearance on section-Microscopical appearance-Absence of accumulated colloidSecondary changes-Exophthalmos-Cause of -Enlargement of thymusSymptoms and Diagnosis-"Formes frustes"-Treatment: Medical, Surgical-Operations upon the thyroid-Extirpation-Results-Exothyropexy -Operation upon vessels-Operation upon sympathetic-Section-Resection - Unilateral - Bilateral - Results - Mortality-Prognosis without operation-Conclusions . . . . . . . . . Pp. 176-196

\section{CHAPTER XIII.}

\section{MALIGNANT DISEASE AND ITS TREATMENT.}

Affects both normal and goitrous thyroid-Age-Sex-Varieties-Sarcoma and carcinoma-Relative frequency-Symptoms and diagnosis-Infiltration of neighbouring parts-Skin rarely involved-Duration of the disease -Mode of death-Unusual forms of malignant disease-" Malignant adenoma "-_Papilliferous cyst_Treatment_Extirpation-Difficulties and dangers-Often incomplete-Results of operations-Recurrence-Statistics -Slowly growing forms-Palliative treatment-Partial removal--Simple incision-Tracheotomy-Difficulties-Dangers of sepsis-Treatment of dysphagia. and pain-Conclusions

Pp. 197-226

\section{CHAPTER XIV.}

\section{TREATMENT OF INNOCENT GOITRE-NON-OPERATIVE.}

General-Removal of cause-Medicinal-Iodine-Thyroid extract-Other drugs-Cases suitable for-Local-External applications-Indian method 


\section{CHAPTER XV.}

TREATMENT BY TAPPING-INJECTION-INCISION-SETONLIGATURE OF THYROID ARTERIES-EXOTHYROPEXY.

Tapping: For cystic goitre-Occasionally cures-Risks of-Hæmorrhage. Injection: Of parenchymatous goitre-Directions-Risks-Fatal casesOf cystic goitre-Directions-Risks-Results. Incision : Rarely desirable -Cases suitable for. Seton: Dangers of. Ligature of thyroid arteries: Historical-Recent revival-Methods of operating. Exothyropexy : Historical-Objects of-Objections-Methods of operating-ResultsComplications-Mortality . . . . . . . . Pp. 231-249

\section{CHAPTER XVI.}

\section{DIVISION OR RESECTION OF THE THYROID ISTHMUS.}

Early cases - "Atrophy" of lateral lobes-Explanation of-Dyspncea not due to backward pressure of isthmus-Results of the operation-Re-appearance of goitre-Conclusions

Pp. 250-256

\section{CHAPTFR XVII.}

\section{'TREATMENT' BY EXTIRPATION ('THYROIDECTOMY).}

Difference between extirpation and enucleation-Partial extirpation-Ṕreparation of patient-Question of general anæsthetic-Local anæstheticl'osition of patient-Skin incision : oblique, vertical, transverse-Treatment of infra-hyoid muscles-Recognition of gland-Isolation of lobeLigature of thyroid vessels-Veins often thin and liable to tear-Treatment of inferior thyroid artery - Avoiclance of recurrent nerve-Treatment of isthmus-Arrest of hæmorrhage-Cleansing of wound-Asepsis better than antisepsis-Suture of muscles, of skin-Question of drainageDressings - Use of sponge-Fixation of head and neck-Position of patient after operation-After-treatment-Convalescence . . Pp. 25i-274

\section{('HAPTER XVIII.}

MODIFICATIONS OF EXTIRPATION-RESECTION-RESECTIONEXTIRPATION-AIIPLTATION.

Mikulicz's resection-Description-Results - Kocher's resection-extırpationComparison of the two operations-Advantages over other operationsAmputation

Yp. $275-279$

\section{('HAP'TYR XIX.}

\section{'TREATHENT BY INTRA-GLANIILAR ENUCLEATION AND ITS MODIFICATIONS.}

Intra-glandular enucleation: History-Cases suitable for-Description of operation-Hiemorrhage-Suture of gland. Resection-enucleation : Cases 
suitable for-Description-Advantages and disadvantages. Intra-capsular enucleation. "Bloodless" enucleation. "Évidernent": Cases suitable for

Pp. 280-294

\section{CHAP'TER XX.}

\section{COMPLICATIONS OF OPERATIONS FOR REMOVAL OF NON-MALIGNANT GOJTRE.}

I. Accidents occurring during the operation: Sudder death-Causes ofCases-Importance of avoiding tracheotomy, if possib!e-Primary hæmorrhage in extirpation, in enucleation - Injury to nerves - Recurrent laryngeal nerve, sympathetic, vagus-Injury to trachea, pleura, pharynx and œsophagus. II. Complications occurring shortly after the operation: Secondary hæmorrhage-Recurrent hæmorrhage-Sepsis-Treatment ofRapid pulse with restlessness-Causes of - Late compression of recurrent nerve by scar-Tetany . . . . . . . Pp. 295-317

\section{CHAP'TER XXI.}

\section{REMOTE COMPLICATIONS-CACHEXIA STRUMIPRIVA.}

Historical-Reverdin and Kocher-Horsley's cxperiments-Early observation of Paul Sick-Symptoms-Relation to complete removal, to partial removal - Hypertrophy after partial removal - Treatment of cachexia strumipriva

Pp. 318-327

\section{CHAPTER XXII. \\ RESULTS OF OPERATIONS.}

Gradual improvement-Mortality after removal of innocent goitre-Liebrecht's and Reverdin's statistics-Mortality after partial extirpation, after enucleation-Complicated cases-Author's results-Causes of deathRelief from dyspnœa-Question of recurrence after extirpation, after enucleation-Effects upon voice-Effect upon general health-Healing of the wound-Scar.

APpendix : Table of the last 100 operations performed by the author for removal of goitre . . . . . . . . . Pp. 328-353 


\section{I.IS'T OF IILUS'TRA'TIONS.}

Fis:

1, 2. Parenchymatous goitre showing relation to larynx, trachea, and thyroid vessels

3. Pyramid, not enlarged 2,3

4. Prramid, enlarged, in parenchymatous goitre . . . . . . 5

5 Variations in form and size of human thyroid (from Marshall) . 6, 7

i. Diagram to show suspensory ligament . . . . . . . . . 8

7. Diagram of thyroid veins (from Kocher) . . . . . . . . 11

8. Accessory thrroids, situation of . . . . . . . 12

$9,10,11$. Congenital goitres . . . . . . . . . 17,18

12. Thyroid gland of myxudema . . . . . . . . . . . 22

13. Microscopical appeararices of the same . . . . . 23

14. Clinical features of myxudema. . . 23

15. 16. Myxurdema before and after thyroid treatment . . . . 24

17. Non-goitrous cretinism . . . . . . . . 25

1․ Goitrous cretinism . . . . . . . . 29

19, 20. Re-enlargement of thyroirl after partial removal . . . . 32, 33

21. Parenchymatous goitre in a man . . . . . . 37

2.2. 2:3. Parenchymatous goitre in a woman _ . . . . . . . 38, 39

21, 2.5. Bilateral goitre, mainly parenchrmatous . . . . 40

26. Section of parenchymatous goitre . . . . . . . 41

27 . Coitre with multiple adenomata . . . . . 42

2. Large solid adenoma. . . . . . . . 43

29. Jirtal thyroir (normal) . . . . . 44

:31). Firtal adenoma . . . . . . 45

:31. Cystic adenoma. . . . . . . . 45

:32. Goitre with arlenomata and fibrosis . . . . . . 46

:3: "Iremorrhagic" thyroid cyst . . . . . . . 4 47

:31. 35, 34. Large parenchymatous goitre, treated by extirpation $77,78,79$

$: ; 7$. The same patient after operation . . . . . 80

:3. Bilateral goitre causing much dyspnia . . . . . . 81

3:4, 40. Swiss peasant with large goitre . . . . . . . . 82

41. Thyroid tumour in unusual situation . . . . . . 84

1.2. Small prominent tlyroirl cyst . . . . . . . . . . 85

1:1, 11. Pendulous arlenoma . . . . . . . . . 86

15. Goitre showing lrolongation into thorax . . . . . . . 90

$4 i, 47$. Cioitre of large size . . . . . . . . . . . . . . 94 
FIGS.

PAGES

48. Calcareous material from an old goitre

96

49, 50. Parenchymatous goitre before extirpation .

51. The same patient, after operation . . . . . . $\quad . \quad 100$

$52,53,54$. Tracheas showing deformity produced by goitre . . $\quad 110$

55,56 . Large adenoma simulating parenchymatous goitre . . . . 111

57. The same patient, a week after enucleation . . . . . $\quad 112$

58. Diagrams of tracheal rings showing flattening produced by goitre . 113

59. Primary chronic inflammation of the thyroid .

$60,61,62$. Specimens illustrating the transformation of a solid adenoma into a cyst

153,154

63. Thyroid cyst with remains of adenoma . . . . . . . . 155

64. Cystic adenoma . . . . . . . . . . . . 155

65. Woman with large thyroid cyst . . . . . . . . . 156

66. The same, a week after enucleation . . . . . . . . 157

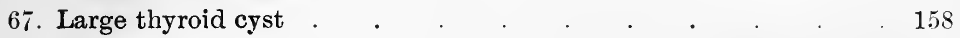

68. Parenchymatous goitre showing masses of colloid . . . . 162

69. Parenchymatous goitre with cysts . . . . . . . . 163

70. Exophthalmic goitre (Graves's disease) . . . . . . . . 177

71. Thyroid and thymus from a case of exophthalmic goitre . . . $\quad 179$

72. The same, from behind . . . . . . . . 180

73. Microscopical section of parenchymatous foitre . . . . . 181

74. Microscopical section of exophthalmic goitre . . . . . . . 181

75, 76. Spindle-celled sarcoma of thyroid _ . _ . . . . 200, 201

77. Spindle-celled sarcoma in a young man . . . . . . . 202

78. Museum specimen of sarcoma of thyroid . . . . . . . 203

79. Microscopical section of carcinoma of thyroid . . 204

80. Museum specimen of malignant thyroid . . . . . . . 206

81. Sarcoma of thyroid causing paralysis of sympathetic . . . 208

82. Unusually large malignant tumour of thyroid .. . . . . 209

83, 84. Papilliferous cystic carcinoma of thyroir . . . . . 210, 211

85. Koenig's tracheotomy tube . . . . . . . . 225

86. Fistula after injection of goitre . . . . . . 239

87,88 . Large solid adenoma, before operation . . . . . 261

89. The same patient, after operation . . . . . . . . 263

9.0. Tumour removed from the preceding . . . . . . . 263

91, 92. Solid adenoma in middle line of neck, before operation . . $\quad 265$

93. The same patient after operation, showing transverse scar . . $\quad 266$

94. Parencliymatous goitre before extirpation . . . . . 272

95. The same patient, six days after operation . . . . . 273

96. 'Iransverse scar after enucleation of cystic adenoma . . . . 281

97. Right lobe of thyroid showing a cystic adenoma . . . . . . . 283

98. Goitre scoops . . . . . . . . . . 284

99, 100. Patient before and after enucleation of a solid adenoma . . $\quad 285$

101. Large solid adenoma simulating a bilateral goitre, before operation $28 \tau$

102. The same, one week after operation . . . . . . . 287

103. Cystic adenoma before enucleation . . . . . . . . . . . 289

104. The same patient, one week after enucleation, oblique scar . . 289

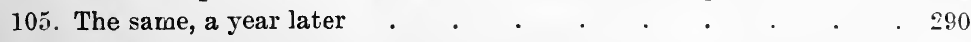


FIG.S.

106, 107. Diagrams illustrating resection-enucleation

PAGES

108. Cachexia strumipriva (operative myxoedema) .

109. Another case of cachexia strumipriva

110. Re-enlargement of thyroid after almost complete removal

111. Bilateral mainly adenomatous goitre before operation

112. The same patient, twelve days later, showing oblique scar

113. Tumour removed from the preceding

114,115 . Solid adenoma, before enucleation

116. A good transverse scar after an enucleation

117. A bad oblique scar after an enucleation

118. A good vertical scar after an extirpation

119,120 . Bilateral goitre causing much dyspnua, before ope:ation

121. Deeply depressed and ugly scar after extensive bilateral operation upen preceding 


\section{CHAP'TER I.}

\section{ANATOMY.}

Lateral lóbes-Upper and lower horns -Isthmus-Pyramid-Relations -Arteries-Veins-Lymphatics-Nerves-Internal structure-Accessory thyroids-Parathyroids.

THE thyroid gland in the human subject consists of two lateral lobes united by an intervening portion named the isthmus. The right lobe is usually slightly larger than the left. The weight of the whole gland is about one ounce. The general shape of the gland bears some resemblance to that of a horseshoe, the concavity being directed upwards.

Each lateral lobe is roughly pyriform in shape. The upper end is the smaller; it is directed upwards and slightly backwards and usually extends as high as the middle of the posterior border of the thyroid cartilage; sometimes it extends as high as the upper border. The lower end is broader and more rounded. It commonly extends as low as the sixth ring of the trachea. Its relation to the upper border of the sternum varies according to the position of the head and the length of the neck. When the head is extended the lower part of the gland is from half an inch to an inch above the upper border of the sternum. During flexion of the head it descends down to or below this level.

The upper horn of the gland is that part of the lateral lobe which lies above the level of the upper border of the isthmus. Similarly the lower horn is that part which lies below the lower border of the isthmus; it is usually much smaller than the upper horn ; frequently it is altogether absent.

The isthmus varies greatly in size in different subjects. In rare cases it is entirely absent, the two lateral lobes being quite separate from each other. 'This is the normal condition in many of the lower animals. It may, on the other hand, be thick and 
broad, covering several rings of the trachea and part of the larynx. Between these two extremes every variety in the size

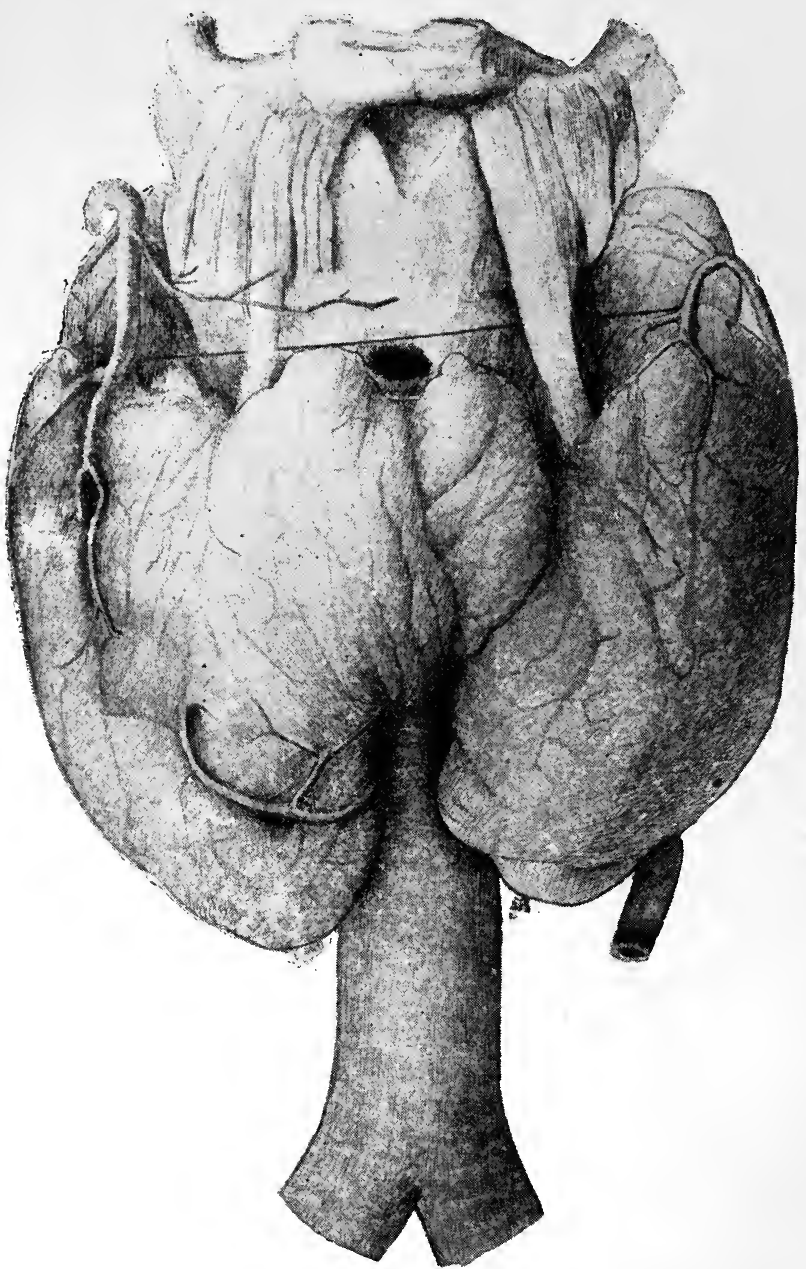

Fitis. 1 and 2.-An Enlarged Thyroid Gland (Parenchymatous

Goitre) showing the manner in which it usually produces dyspnoea ly pressing upon the trachea. The gland has preserved its natural shape, lut is miformly and considerably enlarged. The trachea is ereatly narrowed later.lly at a point one inch below the larynx. The

and shape of the isthmus may be found. The isthmus usually covers two or more of the first four rings of the trachea. 
The pyramid of Lalouette, often known as the middle lobe, is an elongated portion of gland which, when present, ${ }^{*}$ extends

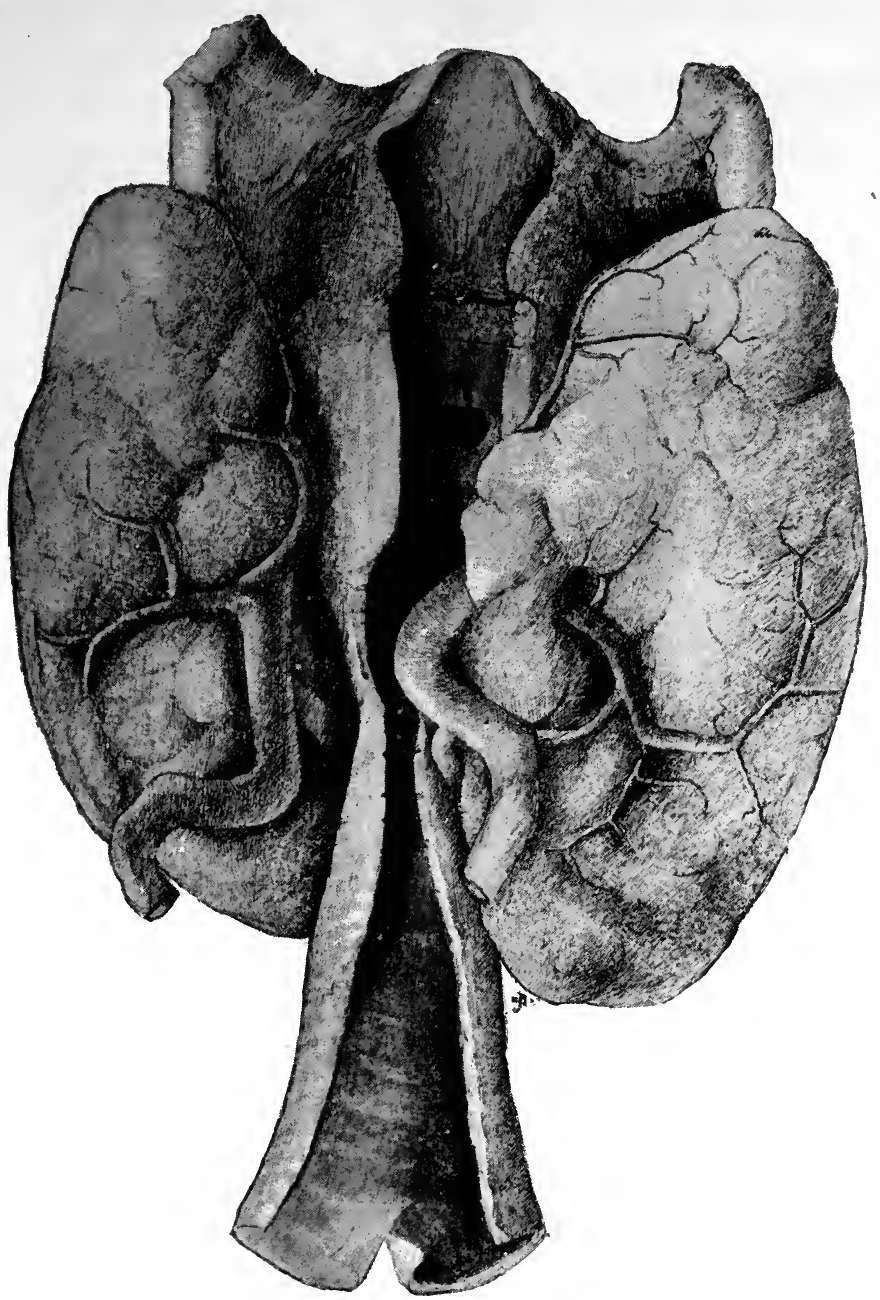

superior and inferior thyroid arteries and their relative sizes are well seen (the left superior artery is, however, abnormally small). (From a boy aged 14, who died of dyspnoea produced by the goitre. St. Bart. Hosp. Arus. No. 2310. Nat. size.) (See also pp. 108, 127.)

from the isthmus upwards in front of the larynx for a variable him.

* Marshall found a pyramid in 43 per cent. of the sixty.cases examined by 
distance. Sometimes it reaches the hyoid bone; more often it covers only the lower part of the laryux. From its tip a band of connective-tissue frequently extends upwards to the back of

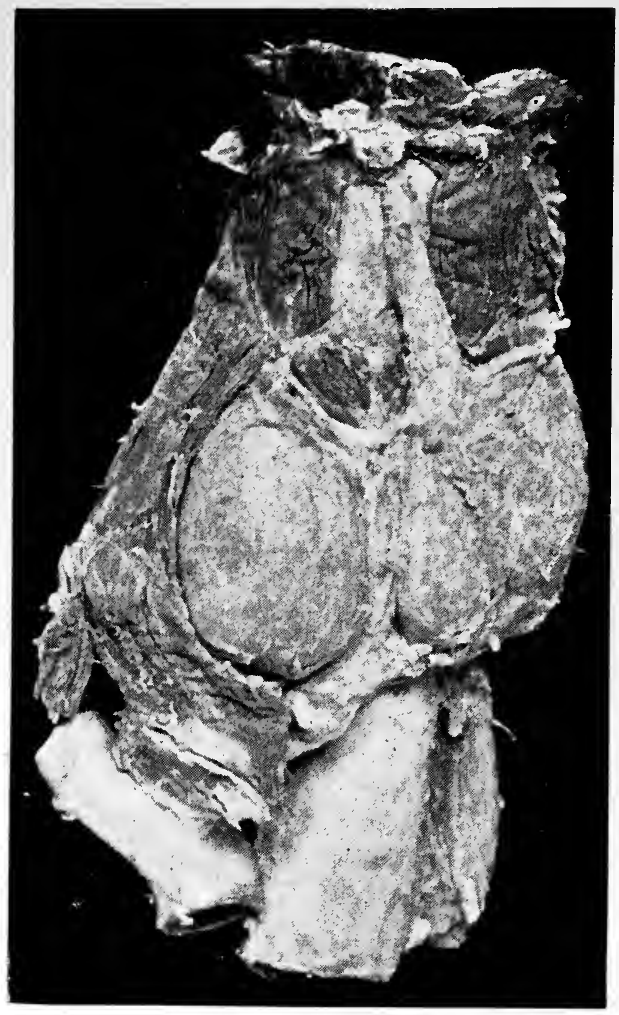

FIa, 3.-Laryux, Trachea, Thyroid Gland and neighloouring purts showing on the left sicle the process of ylandular tissne termed the pyramid of Lalonette. It is seen to extend from the upper border of the left lobe, near the isthmus, upwards to the hyoid bone. The right lobe of the gland is a little enlareed and contains a cyst. (st. Bart. Hosp. Mus. No. 2314D.) (Relue(ed $\frac{5}{6}$.) the hyoid bone. Usually the pyramid is present on one side only, most commonly the left. Rarely two pyramids are present, in which case one at least will be very small. In Fig. 3 a pyramid is seen on the left side, extending from the junction of the isthmus and left upper horn upwards to the hyoid bone. The pyramid becomes enlarged like the rest of the thyroid gland when this organ becomes the seat of general enlargement. It may thus, by covering up the crico-thyroid membrane and other parts of the larynx. become a source of considerable trouble in such operations as tracheotomy for parenchymatous goitre. (See Fig. 4.)

Some of the principal variations in the form and position of the isthmus and pyramid are shown in Fig. 5 (pp. 6 and 7), which has been taken from Dr. C. F. Marshall's paper.*

* "Variations in the Form of the Thyroid Gland in Man."-Journ. of Anat. and Physiol., vol. xxix. p. 234. 
The hilus is a term used to denote that place, at the inner and back part of each lateral lobe, at which the inferior thyroid artery enters the gland. Here the recurrent laryngeal nerve comes into close contact with the gland, lying in the space between it and the trachea and oesophagus.

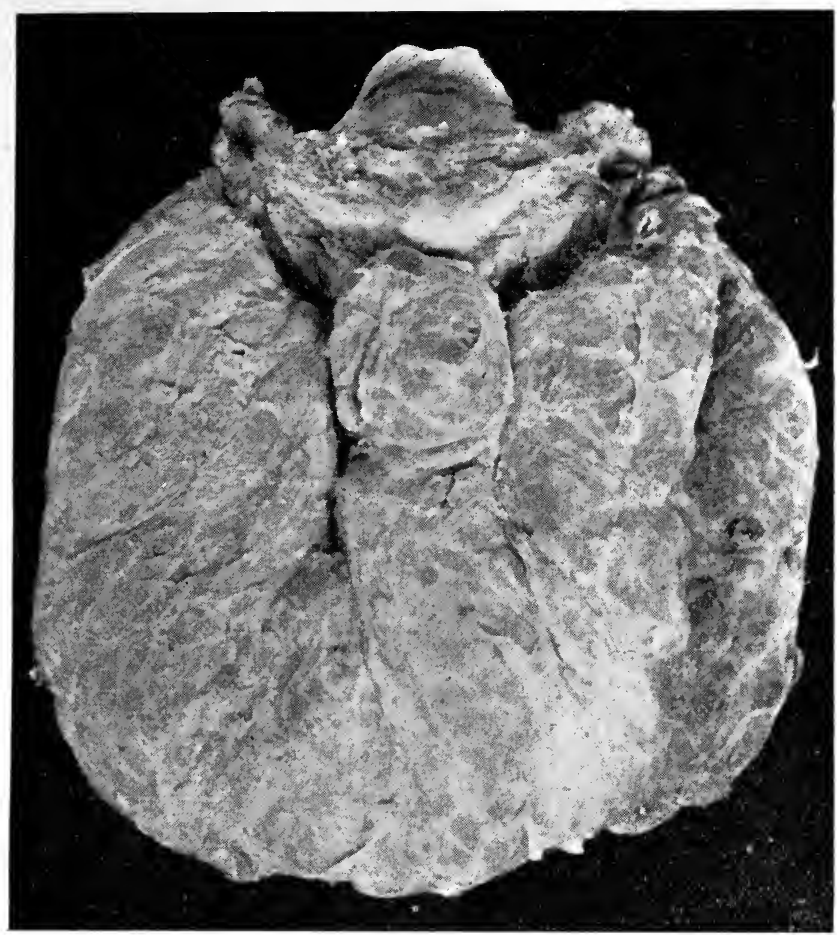

Fig, t.-Thyroid Gland, Larynx, \&e, showing Parenchymatous Goitre. The dise:ase involves the whole gland, including the pyramid. The latter corers the anterior surf tce of the larynx, and extends upwards nearly to the hyoid bone. The figmre also illust rates the diffienlty that would be met with in performing tracheotomy in eases in which the pyramid is enlargel. (From a specimen in St. B.rt. Hosp. Mlus, No. 2314c.) (Reduced $\frac{7}{8}$.)

Relations.-The convex anterior surface of each lateral lobe is covered by the sterno-hyoid and sterno-thyroid muscles, and overlapped by a portion of the sterno-mastoid.

On the outer side is the carotid artery, enclosed in its sheath with the internal jugular vein and pneumogastric nerve. Posteriorly, in the concavity formed by the isthmus and the two 
lateral lobes, lie the trachea, œsophagus, and recurrent laryngeal nerves. Small portions of the larynx and pharynx are embraced by the upper horns, which lie on either side of these structures.
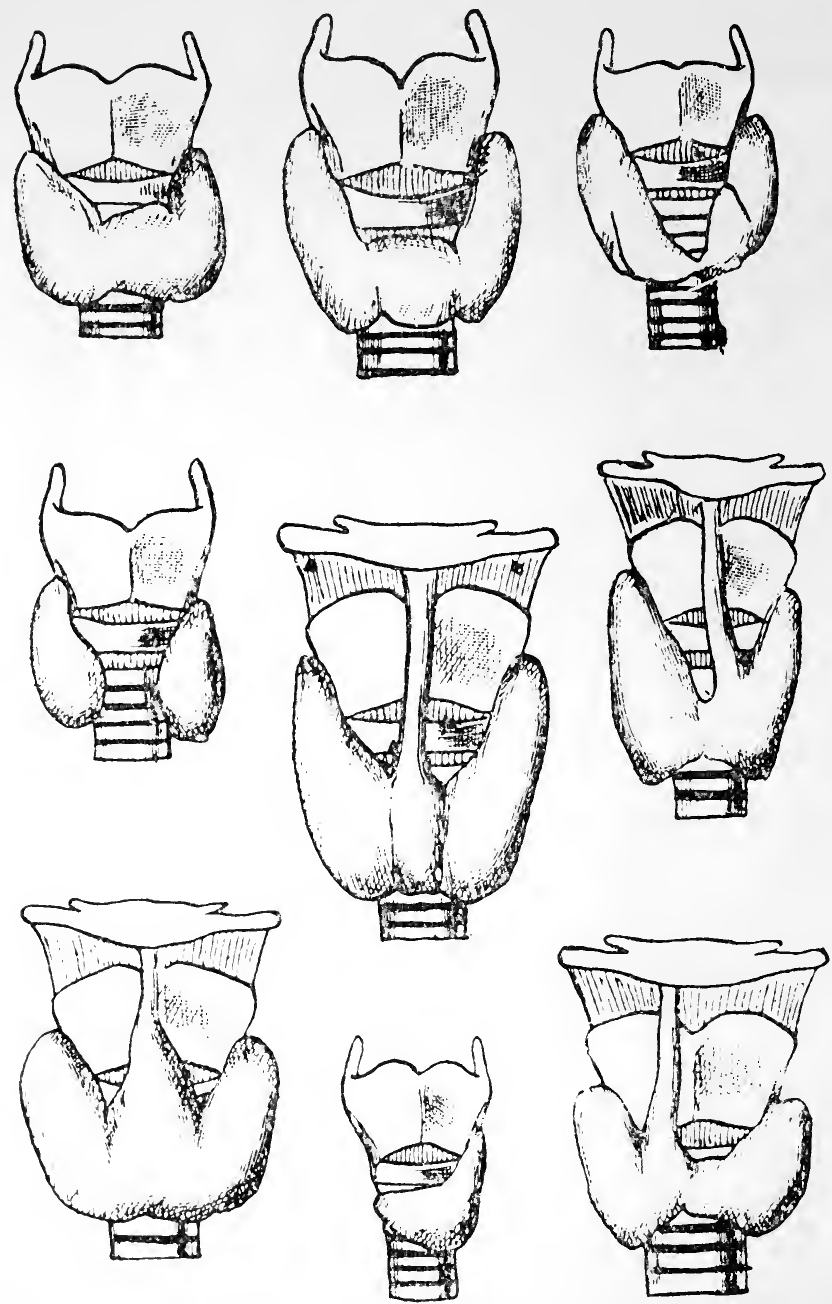

Fic. 5.-Variations in size and Form of the Homan

'The posterior borcler of each lateral lobe is in contact with the spine and pre-vertebral muscles.

'The gland is invested by a delicate but distinct capsule of connective-tissue. 'This covers uniformly the anterior and 
lateral aspects of the organ. Passing round the side of the gland to its posterior surface this capsule then splits into two portions. One remains in contact with the gland and invests
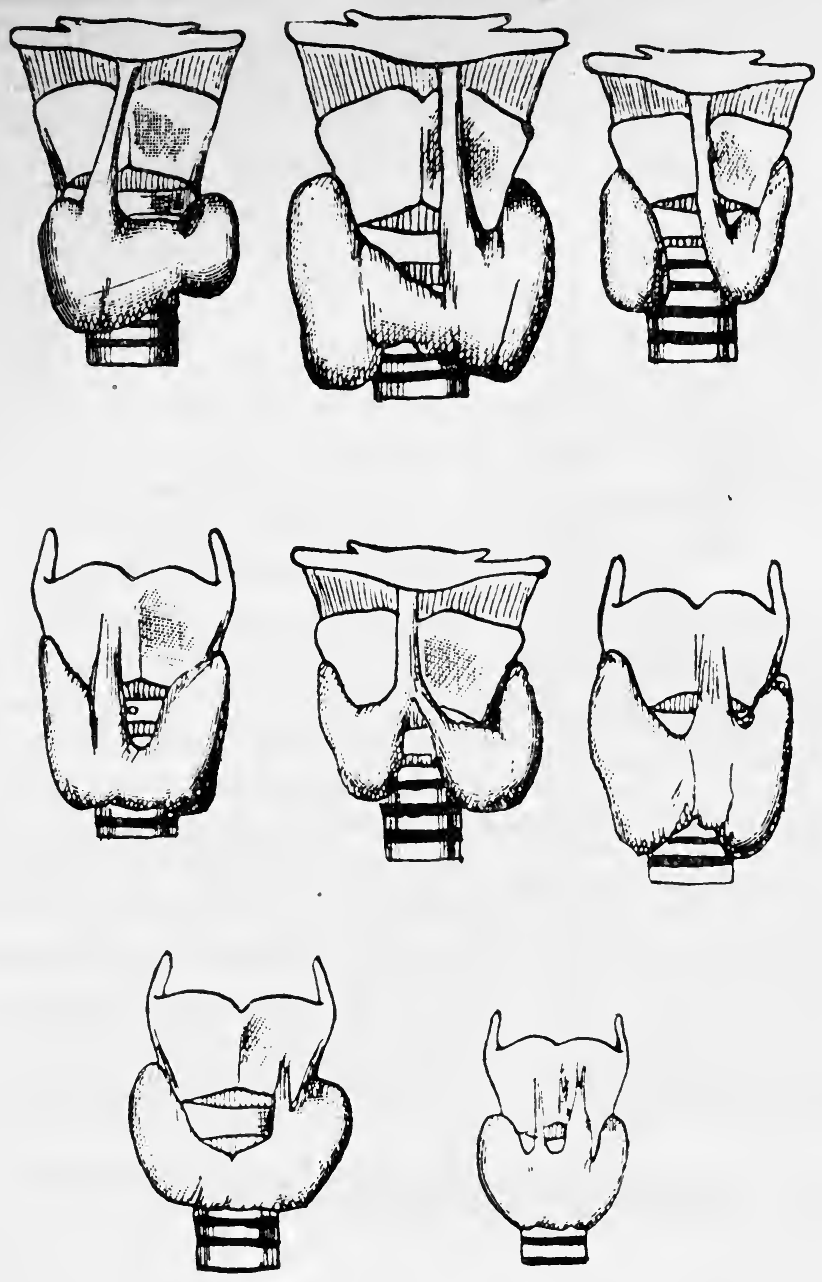

Thyroid Gland. (From Dr. C. F. Marshall's paper.)

its posterior surface. The other, the thicker of the two, passes to the posterior surface of the pharynx and nesophagus, thus enclosing them with the larynx, trachea and thyroid gland, in a common' sheath. 'This is an anatomical point which, as will be 
seen hereafter, is of considerable importance in connection with operations for removal of the diseased gland.

To the cricoid cartilage the gland is most firmly connected on each side by a band of comnective-tissue termed the suspensory ligament, shown in the accompanying figure* (Fig. 6). This

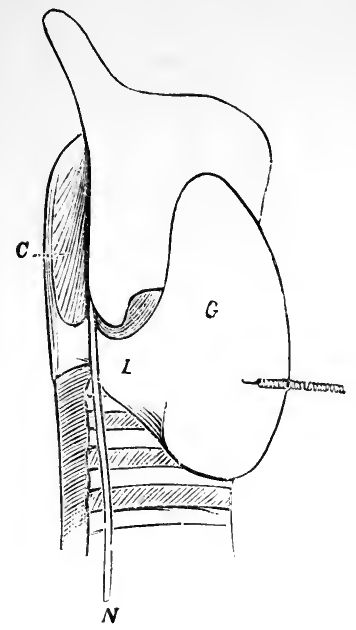

Futi, 6.-Dingram to show the

Suspensory Ligament of the Tlyroid (ilind and it: Relation to the Recurrent L:aryoneal Nerve, $L$, smspensory ligament ; $\lambda$, recurrent larmgeal nerve; $\quad$; right lone of thyroid gland drawn forwards: 6 : rico-arytenoidens posticus muscle. (From as sketell kiuclly made for me by Ir. (. I. Iackwood.)

passes from the inner and back part of the lateral lobe upwards to the cricoid cartilage. Blending below with the capsule of the gland, these two bands form the upper ends of a kind of sling in which the organ is suspended and by which it is firmly fixed to the larvnx.

When the gland has undergone great enlargement and is much increased in weight, these ligaments become of considerable importance. 'They form strong cords, supporting the tumour, which otherwise, by reason of its weight, would tend to fall away from the larynx. It should be added that the recurrent laryngeal nerve lies in immediate contact with this ligament on its outer or posterior surface.

When enlarged to a moderate extent the gland also comes into relation above with the omohyoid muscle and below with the upper part of the sternum and the inner ends of the clavicles.

Blood-vessels. - The thyroid gland has a relatively large blood supply.

'The chief arteries are the superior' and inferior thyroid, the former derived from the external carotid, the latter from the throid axis, a branch of the first part of the subclavian.

'The superior thyroid artery meets the gland at the tip of its upper horn. Here the artery frequently gives off a large branch

* From my parper in the Juurn. of Anat. and Plyysiol., vol. xxii. See also

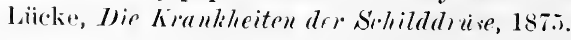


which passes down to the back of the gland. 'The artery then continues its course downwards and inwards along the inner and anterior border of the horn until it reaches the isthmus where, much diminished in size, it forms an anastomosis with the corresponding artery of the opposite side, along the upper border of the isthmus. In its course it gives off', besides branches to neighbouring organs, a series of branches which run downwards over the anterior surface of the gland. The smaller branches penetrate the gland and anastomose freely with the other thyroid arteries.

The inferior thyroid artery, usually considerably larger than the superior, runs at first upwards; it then turns abruptly inwards, runs behind the carotid sheath and the sympathetic nerve and reaches the back of the gland. Here it breaks up into several branches, some of which enter the hilus, while others spread out upon the posterior surface of the gland. The close proximity of the artery to the recurrent laryngeal nerve is of much importance. Usually the main trunk of the artery passes behind the nerve; sometimes the artery breaks up before reaching the nerve; in this case one or more of the branches may pass in front of it. Much less commonly the main trunk or all its branches will be found to lie in front of the nerve.

'The relation of the inferior thyroid arteries to the gland is shown in Fig. 2.

Occasionally the thyroid arteries are reinforced by an additional artery, the thyroidea ima. This when present is usually derived from the innominate artery. It may come, however, from the aorta or the common carotid, or some other neighbouring vessel. It. runs upwards and inwards, and is distributed to the lower part of the gland.

All the thyroid arteries communicate freely with each other. When one is small or absent the others are usually large in inverse proportion.

It is worth noting that nearly all the larger branches ramify on the surface of the gland just beneath the capsule. Only the smaller branches penetrate to the interior.

The thyroid veins * form at first a well-marked plexus on the

* The description here given of the thyroid veins is not quite the same as that given in most English text-books. I have preferred to follow that given by Kocher.-" Ueber Kropfexstirpation und ihre Folgen" : Langenbeck's Arch. f. llin. Chir., vol. xxix. p. 260. 
surface of the gland; this plexus lies immediately beneath the thin delicate capsule of connective-tissue which encloses the gland. At certain points the veins penetrate this capsule and pass off into neighbouring trunks. 'The chief veins thus leaving the gland are the following:

The superior thyroid vein has a course similar to that of the corresponding artery; it leaves the apex of the superior horn and enters the internal jugular vein a little above this level. The superior thyroid veins are connected with each other by a large transverse branch rumning along the upper border of the isthmus.

At the side of the gland is sometimes found a single vein, the middle thyroid, entering the internal jugular vein; more often, however, the place of this vein is taken by two others known as the superior and inferior accessory thyroid veins. 'The superior comes from the upper horn, a little below the apex; the inferior comes from the lower and back part of the gland; both pass transversely outwards to join the internal jugular. 'The arrangement of the veins which leave the lower border of the gland varies considerably in different bodies. From the isthmus and inner side of the inferior horn comes a vein which descends more or less vertically near the front of the trachea; to this Kocher gives the name of thyroidea ima. On the left side it enters the left innominate vein; on the right it joins either the right or left innominate vein. Frequently this vein is small or absent on one side; frequently the two veins unite to form a single large one, which descends vertically in front of the trachea until it enter's the left innominate. This single vein may sometimes be regarded as an enlarged right thyroidea ima, that of the left side being represented merely by a small accessory vein. At the lower and outer part of the inferior horn there is often a small vein, the inferior thyroid, which runs obliquely downwards to enter the innominate vein at its commencement.

When the thyroid gland is normal in size, many of these veins may seem small and unimportant. But when it is much enlarged by disease, all the veins become greatly enlarged and distended, and assume considerable importance, especially in connection with operative procedures. A diagram showing all the veins above described has been reproduced in Fig. 7 from Kocher's paper, by the kind permission of the author. 
Nerves.-These come from the middle and inferior ganglia of the cervical sympathetic and from the inferior laryngeal nerve. It is said that a branch also comes from the external laryngeal nerve.

Lymphatics.-The lymphatics pass chiefly into the glands that lie in front and at the sides of the trachea; some pass also into the cervical glands at the sides of the thyroid gland. The glands first affected in malignant disease of the thyroid, for

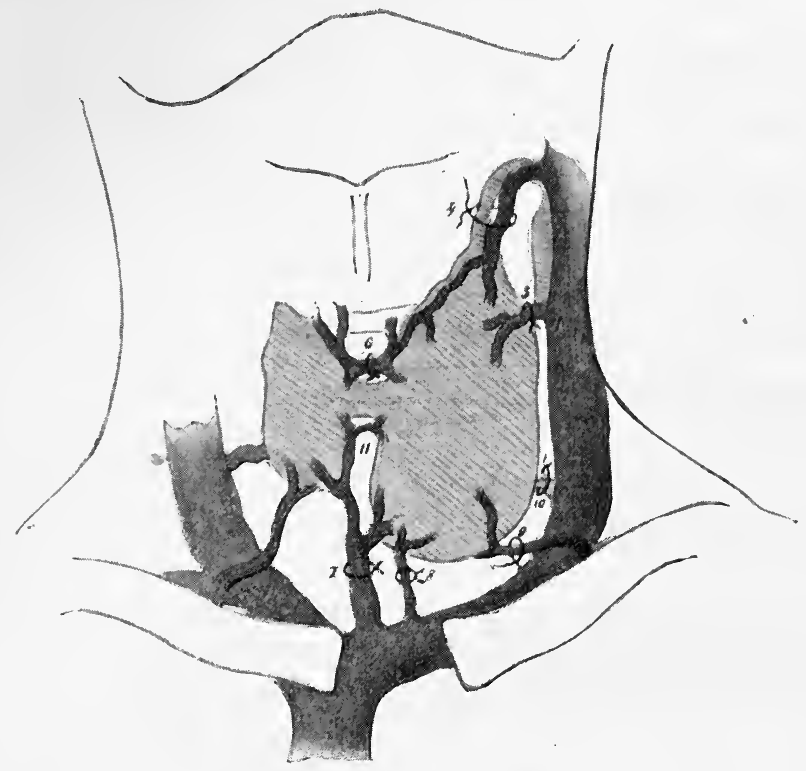

FIG. 7.-Diagram showing a common arrangement of

Thyroid Veins. (From kiocher.)

example, are usually very deeply seated behind the sternum, where they cannot easily be seen or felt.

Structure.-The thyroid gland is composed of a large number of small closed vesicles supported by a framework of connective-tissue, derived from and continuous with, the delicate capsule that surrounds the whole organ.

Lying between the vesicles are masses of round cells which are to be regarded as undeveloped vesicles. 'They are more abundant in the young than in the old, and are often with difficulty distinguished from cells of inflammatory origin. 
The vesicles are lined with cubical epithelium and contain the well-known colloid material, the exact use of which is unknown. The gland has no ducts, but the vesicles communicate with the lymphatic vessels that ramify between them, and it is probably through the medium of the lymphatics that the colloid

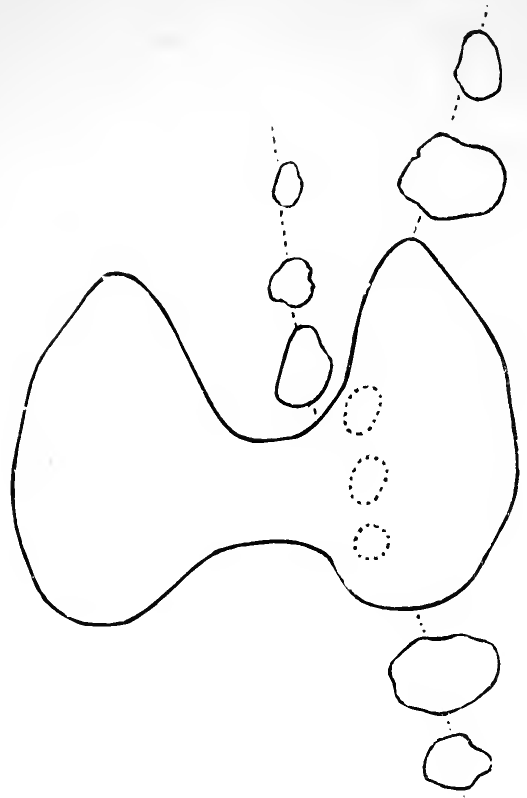

Frie. $x$ - - Dingrum of the Thyroid Gland seen from the front, showing (on the le fit sitle only) the positions in which Accessory Thyroids are most commonly fomm. secretion of the gland reaches the general circulation. 'The existence of colloid material in the lymphatic vessels can easily be demonstrated.

\section{Accessory Thyroid} Glands.-C'Theterm accessory thyroid has been applied to isolated and detached massses of thyroid tissue that are often found lying near the main gland. 'They are analogous to the accessory spleens that are often found in the neighbourhood of the spleen.

Accessory thyroids are most often found in one or other of the following situations (see Fig. 8) :

1. In front of the larynx, anywhere between the upper border of the isthmus and the hyoid bone. Accessory thyroids in this position may be regarded as persistent portions of the pyramid of Lalouette. They are almost always connected below with the main gland and above with the hyoid bone by bands of comective tissue.

2. Above and below the superior and inferior horns respectively. 'These may be regarded as extensions of the horns and are usually connected with them by bands of connective tissue.

3. Near the posterior border of the lateral lobe, lying upon the pharynx or cesophagus. 
Accessory masses of thyroid tissue may also be found occasion ally in more distant parts, as at the root of the tongue, or even within the larynx.

It is desirable that a distinction should be made between true accessory thyroids of congenital origin, and the encapsuled masses of thyroid tissue which have been extruded from the gland. Such tumours are analogous to the pedunculated subperitoneal tumours (fibromyomata) which have been extruded from the uterus.

In both cases the tumours are attached to the main organ by a more or less well-defined pedicle.

Probably most of the cases that have been described as "tumour of an accessory thyroid" are really of this nature, and are not examples of true accessory glands.

Parathyroids are very small glandular masses that lie close to the main gland, generally at the back of it. They differ from the accessory thyroids in not containing vesicles filled with colloid, and their function is supposed by some to be different from that of the thyroid gland itself.*

A specimen showing the parathyroid of a dog may be seen in the museum of St. Thomas's Hospital. $\uparrow$

* Much valuable information concerning parathyroids will be found in Mr. Walter Edrr:unds's papers in the Jour'n. of Pathology and Bacteriology, 1896, 1898,1899 , and 1900 .

$\dagger$ No. $145 \tilde{5}$ A. 


\section{CHAP'TER II.}

\section{CONGENITAL AFFECTIONS.}

Congenital malformations-Complete absence-Absence of one lobeAbsence of isthmus-Accessory thyroids-Congenital goitre in man, in lower animals-Treatment of congenital goitre.

Congenital Malformations.-Congenital malformations of the thyroid are by no means uncommon. Most of them are, however, of little practical importance, provided that there exists a sufficient quantity of healthy gland to carry on the functions of the organ.

'The most serious and important malformation consists in complete absence of the gland. This condition is always associated with the most severe form of cretinism. (See (hap. iii.)

One lobe alone may be completely absent, or present in a rudimentary form. 'This condition may lead to serious results if the opposite healthy lobe become affected by atrophy from disease, or if it be removed by operation on account of disease. In such a case, the patient is deprived of all functionally active thyroid gland and the serious condition known as myxoedema or (achexia strumipriva (see chaps. iii. and xxi.) will certainly supervene. There are no means by which the congenital absence of one lobe can be detected during life, except by actual inspection during the course of a surgical operation.

Absence of the thyroid isthmus is occasionally seen and is of importance chiefly in connection with the operation of division of the thyroid isthmus for the relief of dyspnoea. A case has been recorded in which a surgeon was about to perform this operation, but upon cutting down upon the gland, he found that there was no isthmus. He was obliged to content himself with merely laying bare the trachea. 
Accessory thyroids form another class of congenital malformations of the gland. When enlarged by disease they may form tumours which are difficult to diagnose. They have sometimes been of the greatest service to patients upon whom total extirpation of the thyroid gland has been performed. By undergoing compensatory hypertrophy and assuming the functions of the extirpated gland they have saved such patients from cachexia strumipriva. (See Figs. 19 and 20.)

Congenital Diseases.-Congenital enlargement of the gland is frequently seen in districts where endemic goitre is common. Thus Demme, among 642 cases of goitre seen at the Children's Hospital at Berne, found fifty-three in which the disease was congenital.*

I have myself seen several young infants with congenital goitre.

Usually the enlargement is not very great. It often disappears spontaneously in the course of a few months. 'The mother of a child with congenital goitre has usually herself a goitre.

In 1894 I saw with Dr. Eminson at Scotter, Lincolnshire, a male infant, aged six weeks. At birth a bilateral goitre of considerable size had been noticed, and for the first few days dyspnœa was so marked that it was feared the child would die. After about a fortnight the dyspnoa and stridor gradually subsided and the goitre became much smaller.

Dr. J. G. Colby, of Malton, has given me notes of a child born with a "good sized goitre." 'The mother had a goitre herself, and said that others of her children had been born with the same disease.

Dr. Ormsby, of Slaidburn, has recorded a similar case. $\dagger$

Sometimes the enlargement is considerable and may cause serious or even fatal dyspnoea.

Dr. Maidlow, of Ilminster, has informed me of a case in his practice in which the child died of asphyxia ten hours after birth. In another case of his the dyspnœa was very bad for about thirty hours, but then subsided, after vigorous treatment with iodine and arsenic.

* R. Demme, "Krankheiten der Schilddrüse" in Gerhardt's Handbuch der Kinderkrankheiten, Tübingen, 1878, vol. iii. pt. ii. p. 392.

+ Lancet, February 25, 1888. 
Dr. A. G. Webster, of Golcar, and Dr. T. R. Atkinson, of Madeley, Hereford, have also recorded cases of congenital goitre with severe dyspnoea ending in recovery.*

In the Museum of the Royal College of Surgeons is a specimen $\dagger$ from a male infant who died with cyanosis five days after birth. 'The thyroid gland shows a general enlargement. Its structure to the naked eye resembles that of the normal gland. It weighed $1 \frac{1}{4}$ ounces, and produced a very obvious tumour during life. 'The ductus arteriosus was patent.

In the same museum is another specimen of similar nature. $f$ 'The gland is enlarged in all parts, and a section shows a uniform glandular structure without cysts. There is much compression of trachea and aesophagus. Dr. Lediard, who presented the specimen, has given the following description of the case $\S$ :

"The infant from whom this goitre was taken was born at full term and died on the fifth day. The labour was complicated by hydramnios of very decided proportions. The child was cyanotic, breathed with much difficulty, was unable to swallow, and when it cried the face became very dusky. The neck was very bulky and the middle and lateral portions of the thyroid gland were easily felt to be considerably enlarged. The goitre is seen to surround the windpipe and resophagus like a ring, whilst the latter more especially is compressed. It is interesting to note that the same patient had previously had hydramnios with a nearly stillborn child, which had a very large neck."

Occasionally a congenital goitre presents itself in the form of a huge tumour which occupies the whole of the front of the neck from the sternum to the chin. As a rule in these cases the child is stillborn, or dies soon after birth. A good example, of which Fig. 9 is a photograph, may be seen in St. Bartholomew's Hospital Museum. \| The child was born at full term as a face presentation.

There is a similar specimen in the museum of the Royal College of Surgeons. In this case the goitre presents a markedly cystic structure.

* Leteret. March 17, 1885.

† No. 2896.

$\ddagger$ No. 2896 iB.

$\$$ Puth. Suc. Truns., xl. 1889, p. 299.

$\|$ No. 2319 B. This case is, however, described in the museum catalogue a: one of spindle-celled sarcoma.

I No. 28!6 A. 
Besides the above, I have seen specimens of congenital goitre in several foreign museums.* In most of these cases the lateral lobes were not larger than a walnut, and in some they were much smaller. Most of them presented a solid, almost homo-

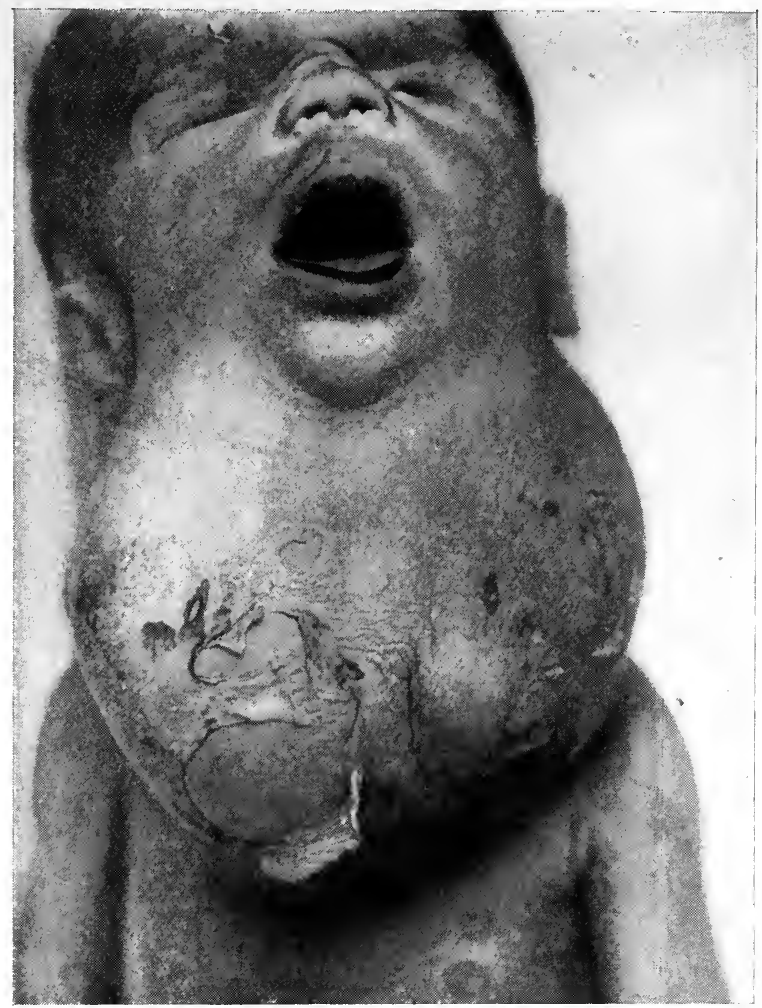

Frg. 9.-Large Congenital Goitre in a stillborn child. 'The coudition of the skin is due to post-mortem changes. (St. Bart. Hosp. MIus. No. 2319B.) (Redneed $\frac{5}{7}$.)

geneous appearance, on section. Figs. 10 and 11 are from drawings of one of the specimens in the Berne Museum.

Congenital goitre has also been observed in the lower animals. Dr. Crisp + has recorded the case of three lion cubs who were

* Prague Path. Mus. (Nos. 3366, 4885B); Munich Mus. of Path. Inst. (No. 201) ; Zurich Mus. of Path. Inst. (two specimens, each about as large as a Tangerine orange); Berne Mus. of Insel Hosp. (four specimens).

$\dagger$ Trans. Path. Soc., vol. xv. p. 260. 
all born dead in a zoological garden. In each the thyroid was enlarged to twenty times its natural size. He refers also to a similar case of a lion cub which lived for several months.

Treatment of Congenital Goitre.-This will naturaliy

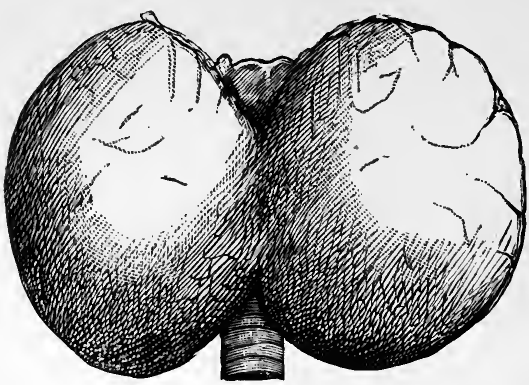

Fia. 10.-A Congenital Goitre in a Young Infant. Front view. (Nat, size.)

depend upon the severity of the symptoms. The slighter cases with little or no dyspnœa require no treatment at all. In others medicinal treatment and treatment of external applications are desirable just as they are in many cases of parenchymatous goitre in older subjects. It is only in cases of exceptional severity that operative measures become necessary. If the symptoms are so severe as to threaten life, the case must be treated on the same principles that guide us in the treatment of goitre in adults.

Lugenbühl, who has given a good account of the operative treatment of congenital goitre, describes a case in which Professor Madelung operated on a child two days old, on account of very severe dyspnoea caused by a bilateral goitre of considerable size. A large part of the goitre was removed, but tracheotomy became

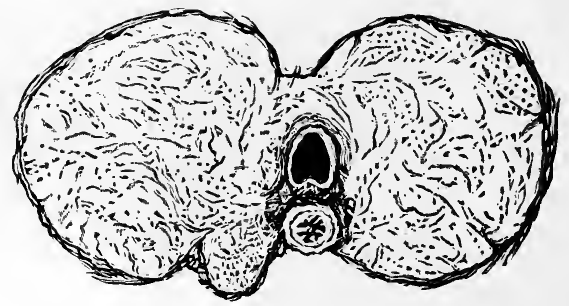

FIG. 11.-The preceiing in horizontal section showing also Trachea and (Esophagus. (From a sprecimen in the P'ath. Mus. at Berne.) (Nat. size.) necessary in the course of the operation, and death occurred on the sixth day from pneumonia. Lugenbühl states that he has not been able to find in literature more than three other cases in which operative interference was undertaken on account of congenital goitre in infancy.

* "Die Operative Behandlung der Struma Congenita," Beitr. z. klin. Chir. Tïbingen, 1895, xiv. p. 713 . 
Malgaigne operated on a child aged three days, who died thirty-six hours later, apparently from hæmorrhage. Bach operated on another case, but death from asphyxia followed in the course of a few hours. Both these cases are, however, ancient ones, occurring before the days of antiseptic surgery. In more recent times Schimmelbusch has operated with success. The patient was one hour and a half old, and was the subject of cyanosis and extreme dyspnœa. The tumour was as large as a hen's egg, hard and nodular, and extended from the chin to the sternum. 'The tumour was shelled out without anæsthesia, and the child made a good recovery. The tumour was "solid, with numerous little cysts," and contained cartilage in places.

On October 11, 1899, M. Genevet* showed at a meeting of the Medical Society of Lyons a male infant, aged eight days, upon whom M. Pollosson had performed, on the day after birth, the operation of exothyropexy for a suffocating congenital goitre. Severe dyspnoea and stridor were present before the operation. The ultimate result is not recorded. 


\section{CHAP'TER III.}

\section{ATROPHY AND HYPERTROPHY.}

Atrophy: In old age-Myxœedema-Treatment-Cretinism-Sporadic and endemic-Fatty tumours of Cretinism. Hypertrophy: Compensatory-Physiological-Relation to menstruation-Pregnancy -Puberty-Thyroid of stout and thin persons.

Aтrophy.

Atrophy of the thyroid gland may conveniently be discussed under the following heads :

1. Old age.

2. Myxoedema.

3. Cretinism.

1. Old Age.- The thyroid like many other glands tends to become smaller as old age supervenes. 'The thyroid gland of an old person, if not affected by cystic degeneration, will frequently be found to be of less than half the weight of a normal adult gland.

In the Museum of the Royal College of Surgeons, ${ }^{*}$ is a wellmarked example of senile atrophy. It was obtained by myself from the body of a woman who died in the Islington Infirmary, at the age of 84 , of dementia and bronchitis, and who had never been the subject of myxodema. The gland is seen to be much diminished in size in all parts. It does not, however, present the shrunken appearance that is seen in the atrophy connected with myxoedema. Each lobe of the gland, although small, is rounded, firm and tolerably thick.

Microscopically, specimens of senile atrophy present the ordinary appearances of a gland that is functionally not very active. The colloid secretion is small in amount and the vesicles and their epithelial cells are small and ill formed. 
According to Wölfler," "the involution of the human thyroid gland is characterised chiefly by sclerosis of the stroma, its change into fibrous tissue, disappearance of the vesicles and their change into masses of atrophied cells with small nuclei."

Senile atrophy of the thyroid does not, so far as I am aware, give rise to any special symptoms.

2. Myxœdema. - In this disease, atrophy of the thyroid gland presents its most characteristic features.

In a well-marked case (see Fig. 12) the gland is greatly reduccd in size and has a flabby, shrunken appearance, due to the more or less complete absence of colloid secretion, of resicles and of epithelium. The glandular elements have atrophied, leaving only the capsule and framework of connectivetissue. Microscopically (see Fig. 13), it is found

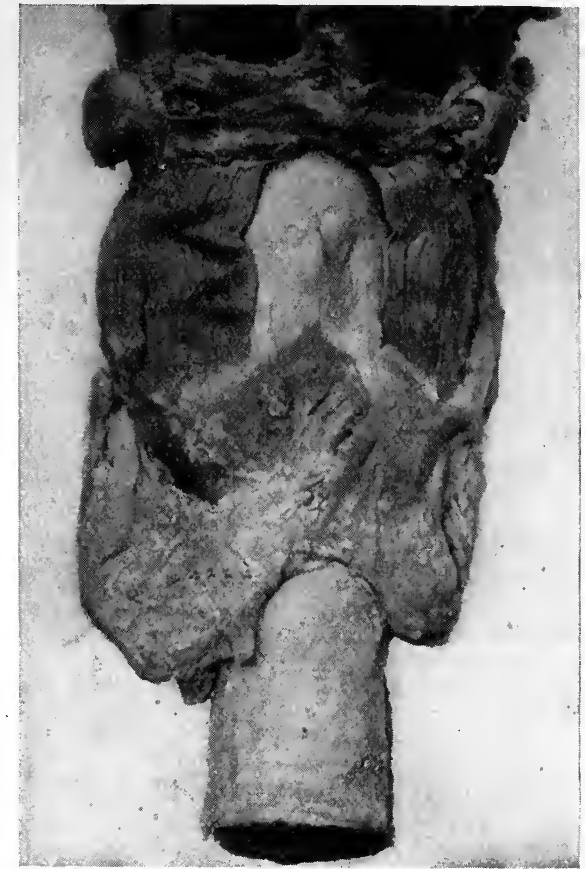

FsG. 12.-Thyroid Gland from a typie:l ease of Myxœdema. The gland is small and represented mainly by conneetive tissue. (St. Bart. Hosp. Mus. No. 2317A.) (Nat. size.) to consist almost entirely of fibrous tissue with a few small round cells. In thirteen cases in which the pathological condition of the gland was investigated by the myxœedema committee of the Clinical Society, $\dagger$ the appearances presented to the naked eye and under the microscope were substantially as above described.

In other unpublished cases which I have had the opportunity * "Ueber die Entwickelung und den Bau des Kropfes," Arch.f. Mlin. Chir., Berlin, 1883, xxix.

$\ddagger$ Truns. Clin. Soc., London, 1888, vol. xxi. Supplementary Report on Myxœedema. 
of investigating post mortem, exactly the same condition of thyroid was found.*

Although the above condition is that which is almost always found in myxœedema, yet it is but right to mention that occasion-

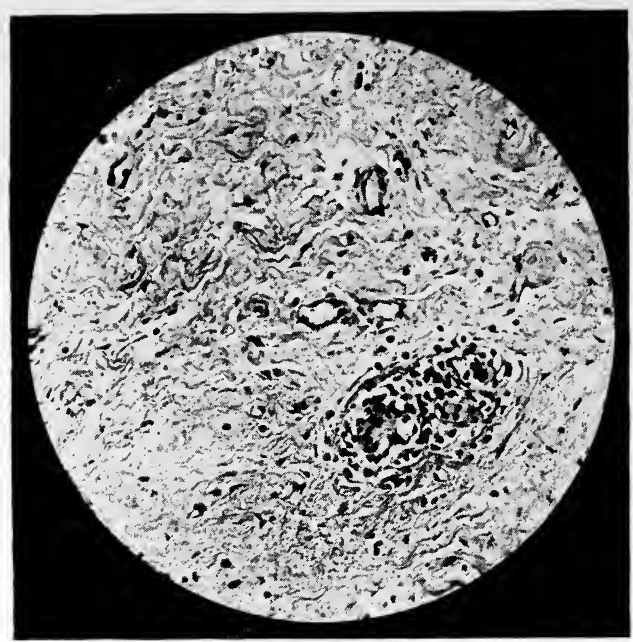

Fig. 13.-Mirros:"opic section of a Thyroid Ghand from a typic:1 case of Myxœdema. The specimen shows connective tisisue with some round-celled infiltration. and rudinents of vesicles. ( $\times 130$ diam.) ally in this disease, the thyroid gland appears clinically to be enlarged. Thus in four of the numerous cases collected by the Clinical Society's committee it was stated that the gland was enlarged, while in one it was (p. 28) "hard, as though calcareous."

Probably in all these cases however there was really atrophy of the glandular elements.

It is universally admitted at the pre-

sent time that the symptoms of the disease are due to loss of function of the thyroirl gland.

With regard to the symptoms of myxoedema it is not necessary to say anything in this book. They are fully described in all recent text-books on Medicine, and have been discussed most exhaustively in the admirable report of the Clinical society above mentioned. 'They concern the physician rather than the surgeon.

The treatment of myxoedema at the present day is both simple and satisfactory. It consists in restoring artificially to the patient the thyroid secretion, the loss of which has been caused by atrophy of the gland. The original methods of transplanting thyroid tissue into the body and of injecting

* Two of these specimens are now in the Museum of the Royal College of Surgeons, Nos. 29060 and $29 \% 6 \mathrm{D}$. 
thyroid secretion hypodermically have been given up in favour of the simpler method of administration by the mouth. The patient may be fed on the thyroid of one of the lower animals, either raw or lightly cooked. A more convenient method, and the one now almost universally adopted, consists in the administration by the mouth of one or other of the numerous extracts, tabloids and other pharmaceutical preparations of the thyroid gland substance. Care should be taken in administering these drugs that they be given at first in small doses; otherwise dangerous and even fatal symptoms may occur.

3. Cretinism. Closely allied to myxodema and, like it, due to impairment or loss of function of the thyroid, is the disease known as cretinism. Myxoedema

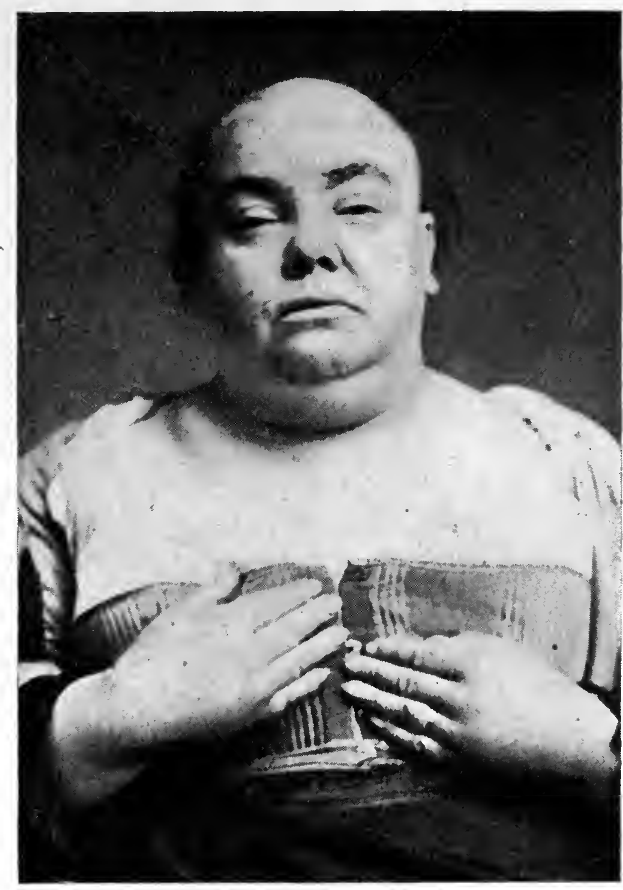

Fig. 14. - A typical case of Myxœdema. A swelling similar to the so-called "fatty tumours" of cretinism is seon in the right supr:a-elavicular region. (From a woman aged 39 , seen at Leytoustone in 1885.)

in its typical form is however a disease of adult life and is due to atrophy of the gland occurring after the body has attained its full size.

In cretinism the disease of the thyroid is congenital or occurs in early infancy. The development of the body is consequently markedly affected. It is in the altered development of the body and especially of the bony skeleton that the chief difference lies between cretinism and myxoedema.

The former shows improper development, the latter degenera- 
tion, of body and mind, both diseases being due to thyroidal atrophy.

'That cretinism and endemic goitre are in some way associated is a fact that has been known for centuries. Wherever goitre is prevalent as an endemic disease there also will cretinism be found.* It is plain that in the vast majority of cases the two diseases are due to the same cause, whatever that may be.

The direct connection, however, which exists between cretinism and atrophy of the thyroid gland was first pointed out by Mr. Curling. He published two cases of sporadic cretinism, in which, on dissection, no trace of a thyroid could be detected. $\uparrow$ Some
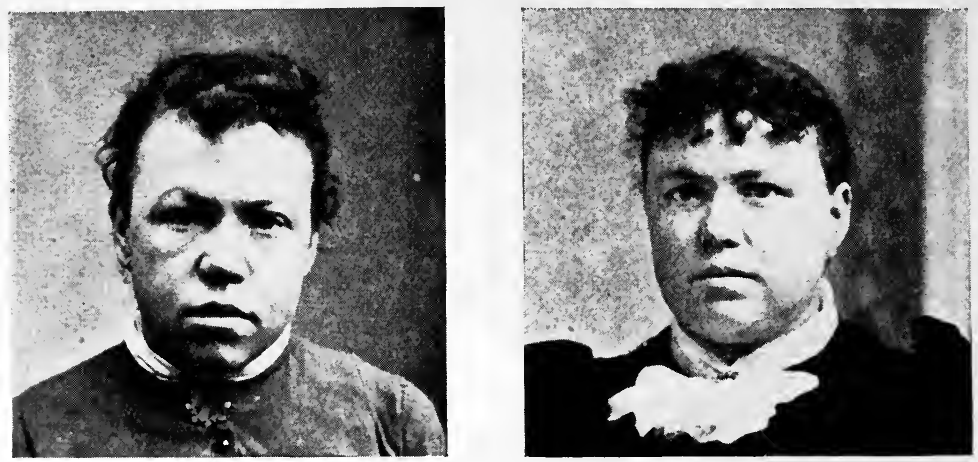

Fig. 15. - . t typical case of Myxœdema. Fig. 16.-The same patient after three months of thyroid tre:tment. (Cnder the care of Dr. Davies. From photographs kindly lent by him.)

years later 1)r. Hilton Fagge laid before the Medical and Chirurgical Society an account of four cases of cretinism in which the thyroid appeared to be absent.+ More recently Dr. Fletcher Beach showed to the Pathological Society, $\S$ two cases of the same disease, in neither of which was there any thyroid gland.

Dr. William Robinson has recorded the case of a cretin aged ten who died in November 1884. At the post-mortem examination, " no trace of a thyroid gland was found."

The publication of these and other similar cases led to the

* Deaf-mutism is also frequently found in association with these two diseates.

† Med. Chir. Trans., vol. xxxiii. p. 303.

$\$$ Puth. Sor. Trans., vol. xxv. p. 26is and vol. xxvii. p. 316.

$\ddagger$ Ibid. vol. liv. p. 155 . 
belief that in sporadic cretinism the thyroid gland was always absent, but the truth of this assertion was disproved by the subsequent post-mortem examination by Dr. Hilton Fagge of one of the four cases published by him ten years previously. In

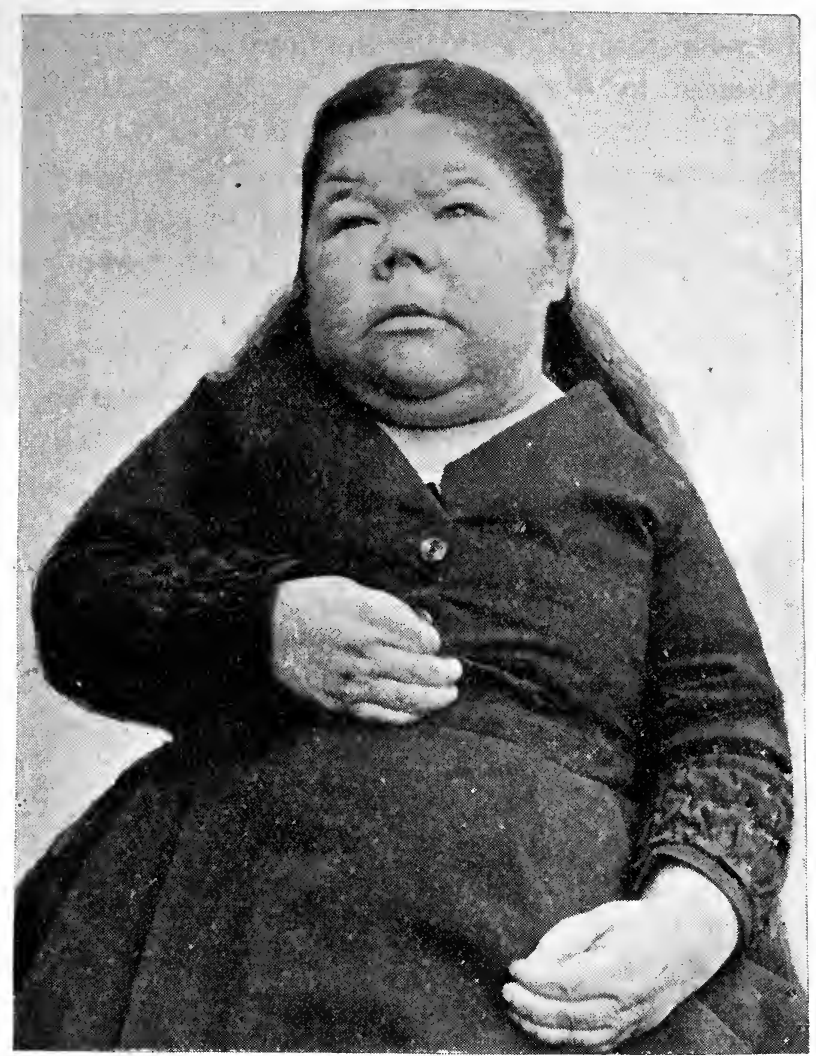

Fig. 17.-Non-Goitrous Cretinism, the worst form of this disense. Showing the similarity between it and accuired Myxoedema. The patient was a native of Steeple Aston, Wiltshire, where she had always lived. She was 25 years of age, but was less intelligeot than most children of three. No thyroid gland could be felt. 'The mother had a goitre.

this case, the first in which he had an opportunity of examining the condition of the gland after death, he found that the thyroid was not absent but that it was actually enlarged, being the seat of a distinct goitre.

It must not be supposed that in all cases of cretinism the 
thyroid gland is smaller than normal. On the contrary the majority of cretins have enlarged thyroid glands (see Fig. 18). 'These glands however are not healthy. They are more or less diseased and they always contain an abnormally small amount of functional gland tissue.

In the worst form of cretinism, the form that is perhaps the most common in this country, the atrophy of the gland is extreme. The organ is either completely absent, or is represented by a mere rudiment consisting chiefly of connective-tissue. This form is usually accompanied by much mucoid degeneration of the subcutaneous tissues and very closely resembles the myxoedema of adults.

In the Royal Free Hospital museum * is a good specimen of the extreme atrophy of the gland that is associated with this most severe form of cretinism. All that remains of the gland is a mere rudiment of comnective-tissue. $\dagger$

In Guy's Hospital museum is another specimen $\ddagger$ of a thyroid gland from a case of cretinism. In this case the gland is somewhat enlarged but has undergone much diegeneration.

Dr. Arthur Hanau, in a paper $\$$ read before the International Medical Congress at Berlin in 1890, describes three specimens in the Ziirich Pathological Museum, obtained post mortem from adult cretins by Prof. Klebs.

The following is his description:

"To the naked eye the texture of the gland shows nothing abnormal; it is lobular on section; in one or two, small cysts appear, and in the largest (taken from a mild case of cretinism) there are well-marked hyperplastic nodes. Microscopically all three exhibit a condition which may be in general described as a deficiency of glandular tissue and an excess of comnective-tissue. 'Two of them are less altered than the third, which is markedly atrophic."

Although cretinism is most often seen in countries where goitre occurs as an endemic disease, yet isolated cases occur sometimes in districts from which goitre is wholly absent. A

* No. xxii. 1.

$\dagger$ A similar specimen has recently been added to the musem of st. Bartholomew's Hospital (No. 2317c).

\pm No. $9 . \%$.

$\S$ Br.it. Med. Journ., Oct. 4,1890 . 
distinction has therefore been made between sporadic and endemic cretinism.

It has been asserted by some that in sporadic cretinism the thyroid gland was absent, while in endemic cretinism a goitre might or might not be present.

Even at the present day, there appears to be a prevalent notion that there is some essential difference between them, and while some observers maintain that this difference is to be found in the condition of the thyroid gland, others consider that it lies in the presence or absence of certain supra-clavicular "fatty tumours," which have been described in connection with sporadic cretinism.*

'These so-called fatty tumours of cretinism appear to have been observed much more often during life than after death, but, nevertheless, there are records of post-mortem examinations of such cases.

During life, the tumour consists of a lump of what is apparently fat, developed in the lower part of the posterior triangle of the neck, just above the clavicle.

Mr. Curling, who appears to have been the first to describe them, says, in his account of the post-mortem examination of his first case "(the swellings) were composed of fat, and occupied the posterior triangle of either side of the neck, dipping downwards behind the clavicles and filling the axillæ. ... They were not enveloped in a capsule, but consisted of fat of a loose lobular nature." In the account of the second case, he says that, during life, "on the sides of the neck beyond the sternocleido-mastoid muscles, were two soft symmetrical swellings, having a doughy feel and incompressible." Post mortem, the swellings in the neck were found to consist of superficial collections of fat tissue, without any investing envelope, and loosely connected to the surrounding parts.

In Dr. Fletcher Beach's case of sporadic cretinism in a child aged three, in which the "usual swellings above the clavicle were present during life, at the autopsy there were no collections of fat or other swellings at either side of the neck." In his other case, "the tumours were not encapsuled, and hence there was

* See observations by Dr. Hilton Fagge, Puth. Soc. Trans., vol. xxr. p. 268. 
some difficulty in defining their limits. . . . 'There was a layer of fat beneath the chin, forming a double chin."

The only museum specimen of the fatty tumours of cretinism that I have been able to find is that of Dr. Hilton Fagge in Guy's Hospital Museum.* 'The tumours were described by him as "soft, well-defined masses looking like fat, but distinctly differing in colour from those in their neighbourhood." Numerous processes also extended in various directions under the clavicle, down into the axillæ, \&c.

Such, then, are the "supra-clavicular fatty tumours," which are said to be so characteristic of sporadic cretinism as to serve as the main point of distinction between this disease and endemic cretinism.

I do not consider that these so-called fatty tumours are by any means characteristic of cretinism, nor do I think that there is any essential difference between endemic and sporadic cretinism.

The post-mortem examinations above mentioned seem to show: (i) That the tumours are much less marked after death than before; (ii) That the tumours are not well defined, but that they consist of fat, which may extend from the axillæ to the chin, in fact over the whole region of the neck and shoulders; (iii) That the apparent formation of a definite tumour depends chiefly upon the natural anatomical structure of the part. 'The absence of bone or large muscles in the supraclavicular regions allows the deep seated fat to protrude more than it can elsewhere. Any excessive development of sub-fascial tissue, whether from fatty infiltration or from the presence of cedema, is likely to cause a protuberance in the posterior triangles of the neck. A good example of this may be seen in Fig. 14, where a "fatty tumour" is shown which is exactly similar to that of cretinism. 'The patient from whom the photograph was taken, was one whom I saw at Leytonstone with Dr. Rotherham Walker, and who was the subject of well-marked myxordema. 'The apparent tumour was due simply to the myxredematous affection of the areolar tissue of that region.

As to there being any essential difference between sporadic and endemic cretinism, I can only say that among numerous 
cases of cretinism which have come under my notice, both in England and in Switzerland, I found not a single point in which the members of one class differed as a whole from those of the other.

I have in my possession two photographs taken from patients

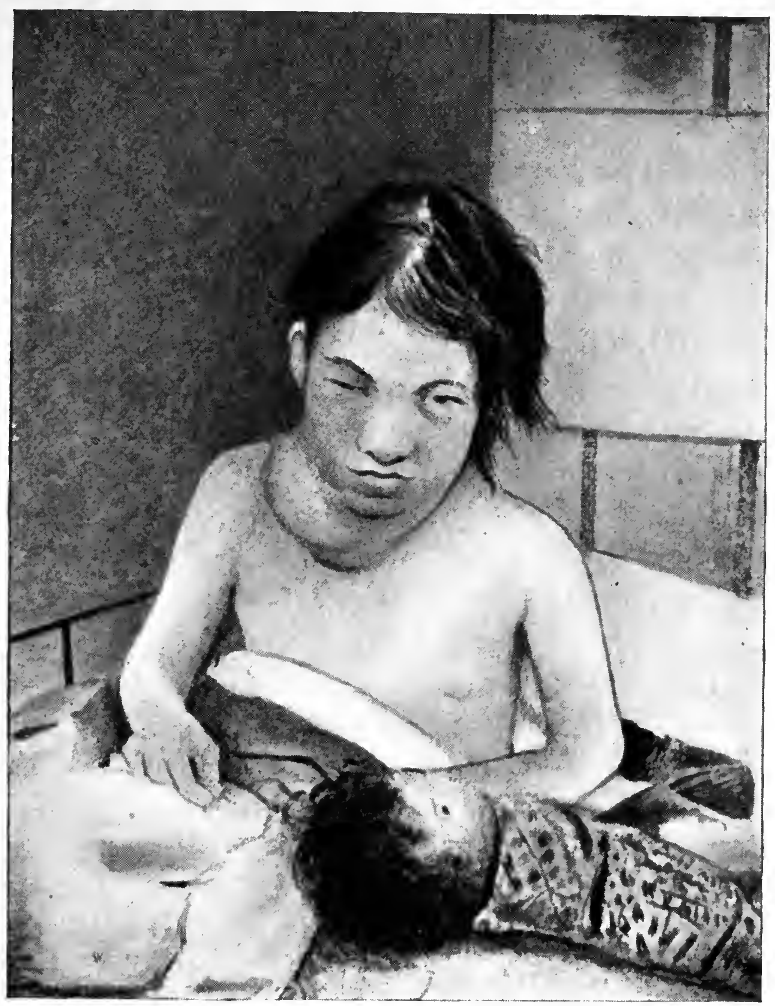

Fig. 18.-Goitrous Cretinism. A female at. 25. She had always lived in London. The goitre had been noticed only within the last few years. Intelligence considerably greater than that of the patient shown in the preceling figure.

who had lived all their lives in this country, the one in Wiltshire, the other in London. Fig. 18 shows the latter case. Both may fairly be considered examples of sporadic cretinism, yet neither has a supra-clavicular tumour, and both have goitres. 'They present exactly the same appearances as did many of the cretins that I saw in Berne. 
Fig. 17 represents another case of sporadic cretinism from a village in Wiltshire. In this case there was some swelling above the clavicles. 'There was no obvious goitre, but the patient's mother was goitrous.

Without dividing cretins into two distinct classes, it may be said that some are much more swollen than others, and more like adult myxœedematous patients. Some have goitres, while others are free from them. Every intermediate grade may, however, be met with. It appears to be a fact that the more swollen a cretin is, the more likely he is to be without a goitre, and vice versâ.

It is said to be a popular belief among the Swiss that the presence of a goitre acts, to a certain extent, as a protective against cretinism.

If the story is to be believed that was told to me by the relatives of the patient shown in Fig. 18, the goitre became larger as the general swelling of the body diminished. I have not, however, been able to find any evidence to confirm this statement, which, if true, is one of considerable interest.

Complete atrophy of the thyroid, then, is not always present in cretinism, whether sporadic or endemic.

There is much reason, however, to believe that in all cases there is some disease of the organ which impairs its function. This disease may be atrophy. In this case, the swollen condition shown in Fig. 17 is most likely to be present. This form of cretinism is very closely allied to, if not absolutely identical with, myxoedema. On the other hand, the disease may show itself as goitrous enlargement and consequent degeneration of the gland. In each case, the gland is in an unhealthy condition.

It is difficult, nevertheless, to understand why some goitrous persons are cretinous, while others enjoy good health.

'The treatment of cretinism is similar to that of myxoedema, and consists in the internal administration of some preparation of thyroid gland. Removal to a region free from goitre is in most cases advisable. If treatment be commenced sufficiently early, and carried on for a sufficient length of time, considerable benefit may be expected, both as regards body and mind. 


\section{HY PERTROPHY.}

The term hypertrophy is frequently applied, loosely and incorrectly, to many forms of enlargement which should be described under other names, such as parenchymatous goitre, adenoma of the thyroid, etc. True hypertrophy in the sense of a general and strictly uniform enlargement of all parts and constituents of the gland is a condition but rarely seen. Indeed it is doubtful whether the term hypertrophy should be used at all, except for those cases in which one part of the gland uıdergoes enlargement as the result of the destruction, by disease or injury, of the other parts. In such cases the remaining portion undergoes compensatory or physiological hypertrophy to enable it to carry on the functions of the normal gland.

The most striking example of the kind that has come under my own notice is that depicted in Figs. 19 and 20. The patient was a young woman from whom almost the whole of a parenchymatous goitre had been removed by operation on account of dyspnœa some two years before I first raw her. 'The operation was supposed to have been a total extirpation and was actually published as such.* Fortunately, however, a small piece of gland was left unnoticed in the neck. This gradually increased in size until it formed a tumour as large as a hen's egg, that is, until it attained the bulk of a normal thyroid. With the hypertrophy of this piece of gland, the symptoms of commencing cachexia strumipriva caused by the removal of the organ gradually disappeared, until eventually the patient regained perfect health. Further details of this case are given at p. 325. $†$ 'This is true physiological or compensatory hypertrophy and is strictly analogous to the hypertrophy of one kidney which occurs after destruction of its fellow by injury or disease.

Another condition closely allied to hypertrophy is the enlargement which occurs in the malady known as Graves's disease, described in chap. xii. In this disease it is the epithelial elements of the gland that are especially developed and form the main portion of the swelling.

A simple enlargement of the gland also takes place under certain conditions which may be mentioned here. It is doubtful 
however whether the term hypertrophy ought to be applied to these conditions. Possibly in some of these cases the enlargement is temporary and is due merely to distension of the gland with increase of its colloid secretion, rather than to actual hypertrophy.

During menstruation, the normal thyroid is said to become

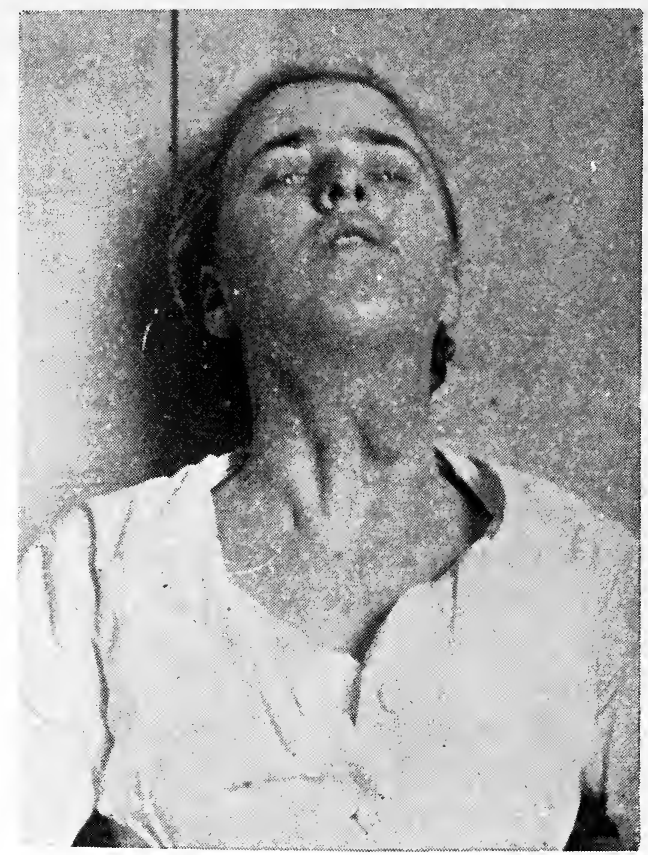

Fisis. 19 and 20.-From a virl, tet. 17, showing re-enlargement of a small portion of a goitre (perhaps an accessory/thyroid gland) that hat been left behind after a supposed complete removal. The operation had been performed at the Middlesex Hospital in 1884 on acconnt of severe dyspmea. A few weeks after the operation the tnmour was as large as a hazel nut, after two years it had attained the size of a

enlarged and if the gland happen to be the seat of pre-existing enlargement, the increased swelling may be sufficient to cause severe respiratory symptoms. Many interesting details with regard to the influence of menstruation upon the thyroid gland may be seen in a paper by Dr. E. W. Jenks.*

During pregnancy, according to some observers, the thyroid

* "On the Relation of Goitre to Pregnancy and Derangement of the Female Generative Organs," by E. W. Jenks, Amer. Journ. of Obst., 1881, vol. xiv. p. 1. 
gland becomes enlarged. That a thyroid already goitrous does usually undergo further enlargement at this time, there can, I think, be no doubt. Over and over again have goitrous patients assured me, when I questioned them upon the point, that the goitre always became larger during menstruation and pregnancy, and the onset of goitre frequently dates from a pregnancy.

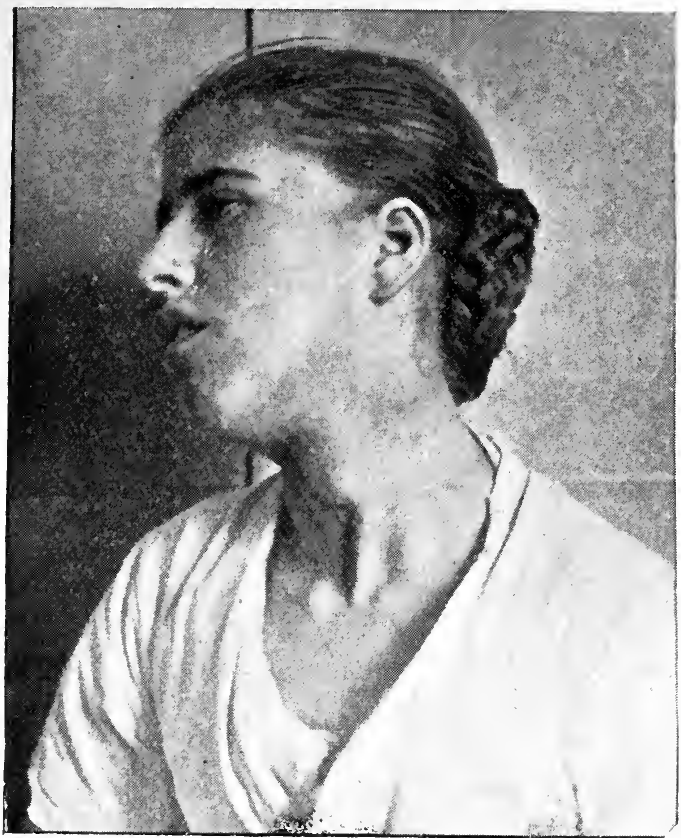

walnut; the photogr.sphs show the condition a year later still, when the tumour was nerrly as lurge as a hen's egg. There was great anæmia and weakness (incipient cachexia strumipriva) for many months after the operation, but as the tumour increased in size these symptoms dis'tppeared and eventually the patient regained perfect health.

But whether a healthy thyroid gland enlarges during pregnancy is not quite so clear. Probably it does to a slight extent. In an attempt to elucidate this point I examined the necks of forty pregnant women. In most of them the pregnaney had advanced to the eighth or ninth month. In two only could I detect any thyroid enlargement. In none of the others was there any perceptible swelling of the gland, nor could the existence be ascertained of any symptoms which could be referred to such an enlargement. 
For further details concerning the relation of pregnancy to the thyroid gland, reference may be made to the papers of Jenks, quoted above, and of Lawson Tait.* 'The latter quotes twelve cases from his own practice in which there was a distinct connection between goitre and pregnancy. In many cases (eleven out of twelve of Lawson Tait's) a distinct tendency to hæmorrhage is found to co-exist with goitre. I have noticed the same tendency in some of my own cases. Dr. Everley Taylor of Scarborongh tells me he has also noticed the same thing. Often a goitre undergoes increase in size with each successive pregnancy, regaining partly but not completely its original size a short time after delivery.

At puberty the thyroid frequently undergoes rapid increase in size. A large number of endemic goitres are found to have first shown themselves at this period.

It will be seen, in a subsequent chapter, how much more often acute swelling of the gland occurs at puberty or soon after, than at any other period of life.

It is said that during sexual excitement considerable increase in the size of the thyroid may occur. In some countries there existed and I believe still exists a curious and well-known custom bearing upon this point. $\dagger$

In a case of my own, that of a young man with a large parenchymatous goitre, the patient assured me that sexual excitement was always followed by increase in the size of his goitre: after a day or two the goitre returned to its usual size. In this case the temporary increase in size was usually sufficient to cause distinct dyspnoea.

Before leaving the subject of atrophy and hypertrophy of the thyroid gland attention may be drawn to the fact that the gland, even when not obviously diseased, varies greatly, not only as regards its size and weight but also in its internal structure as seen on section. Every one who makes systematic post-mortem examinations of a sufficiently large number of thyroid glands will notice that sometimes the gland is found to be firm in consistence and yellow in colour; the vesicles

* "On Enlargement of the Thyroid Body in Pregnancy," by Lawson Tait, Trans. Edin. Obst. Soc., vol. iv. p. 81-95.

$\dagger$ For references to this custom see "Der endemischer Kropf," by Dr. Heinrich Bircher, Basle, 1883, pp. 6 and 7. 
are plainly visible to the naked eye, each being fully distended with its thick yellow colloid secretion; by pressure this can be made to exude slowly from the cut surface. In other cases the gland is dark red, tough and small; few or no vesicles are visibie to the naked eye and there is apparently almost complete absence of colloid substance. Various stages of gradation between these two conditions may be seen.

As a general rule it may be stated that the larger thyroid with much secretion is most often found in the bodies of persons who have died of some wasting disease such as cancer or phthisis.

Conversely, the smaller thyroid with little secretion is usually seen in persons who are stout, with much subcutaneous fat. It is perhaps worthy of note that a more advanced condition of the latter state of thyroid is the extreme atrophy seen in cases of myxœedema. Although the above rules do not by any means universally hold good, yet they seem to point to some inverse relation between the amount of colloid secretion in the thyroid and the development of subcutaneous fat. It may be mentioned also, as a fact that perhaps bears upon this question, that goitre is rarely seen in stout people. 


\section{CHAP'TER IV.}

\section{GOITRE AND ITS VARIETIES.}

Meaning of the word goitre-Parenchymatous-Cystic-FibrousAdenomatous (foetal and cystic adenomata) - Malignant-Exophthalmic-Hæmorrhagic-Colloid-"Vascular"-Endemic-Sporadic -Epidemic-Acute-Suffocating-Substernal-Intra-thoracic-Retrotracheal-Retro-asophageal.

'Iнн term goitre is a corruption of the Latin "guttur," the throat, and was formerly used to denote any swelling, of whatever nature, in the front of the neck. For a long time, however, the term has been restricted to a swelling of one particular part, namely the thyroid gland. Many authors endeavour to restrict still further the meaning of the word, and to limit it to certain forms of swelling of this organ.*

The simplest and at the same time the commonest form of goitre is that to which the term parenchymatous $\dagger$ is applied. All parts of the gland are enlarged equally, or nearly so. 'The goitre, therefore, is always bilateral, and preserves the shape of the normal gland. 'The enlargement is caused partly by accumulation of colloid material within the vesieles, and partly by actual increase in the solid elements of the gland itself. The structure resembles to a considerable extent that of the normal thyroid. It forms the first stage in the formation of nearly all the other varieties of goitre. It is the form that is especially common in

* In relation to the changes in meaning which words gradually undergo, it is interesting to notice that one of the two words commonly employed in Germany to signify goitre, is "struma." In our own language, when applied to swellings in the neck, this word has reference to swellings of the lymphatic glands rather than to those of the thyroid gland. The use of the term goitre to denote enlargement of lymphatic glands has now become entirely obsolete.

$\dagger$ The term "parenchymatous" is not wholly free from objection, since it is not merely the parenchyma of the gland that is affected in this disease. The term is, however, a convenient one and may therefore be retained. 
young people. It is rare to find parenchymatous goitre beginning after middle life.

Figs. 21, 22, and 23 show typical cases of parenchymatous goitre ; in these cases the tumour was extirpated on account of dyspnoa. Figs. 24 and 25 show a somewhat less typical case; the greater enlargement of the left lobe probably indicates the

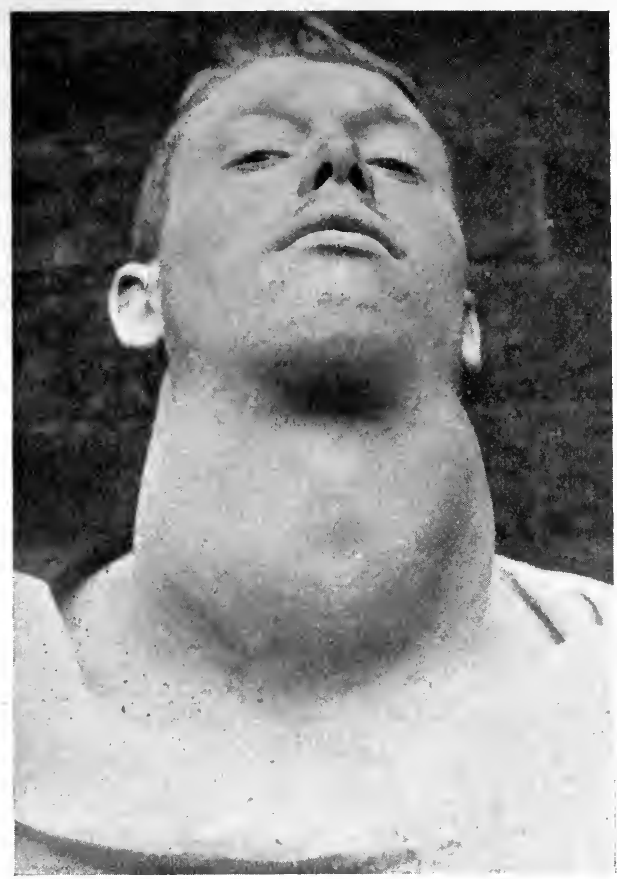

FIG. 21.-Parenchymatous Goitre. The whole gland is miformly and greatly enlarged. The right lobe was removed by operation and is now in the Royal Free Hosp. Mus. No. xxii. 10. (See Appendix, Case 75, p. 348.)

existence of one or more cysts or adenomata in an otherwise purely parenchymatous goitre. Fig. 26 shows the appearance of a typical parenchymatous goitre on section; the vesicular appearance of the gland is well seen. A fresh specimen of a parenchymatous goitre has a soft, spongy feel, and sticky colloid matter readily exudes from its cut surface.

Cystic goitre is the term applied to all those forms of goitre in which the main bulk of the swelling is formed by one 
or more cysts of considerable size. Small cysts may be formed by the over-distension of single vesicles and their coalescence with neighbouring vesicles, but the great majority of thyroid cysts are formed in an entirely different way by the liquefaction

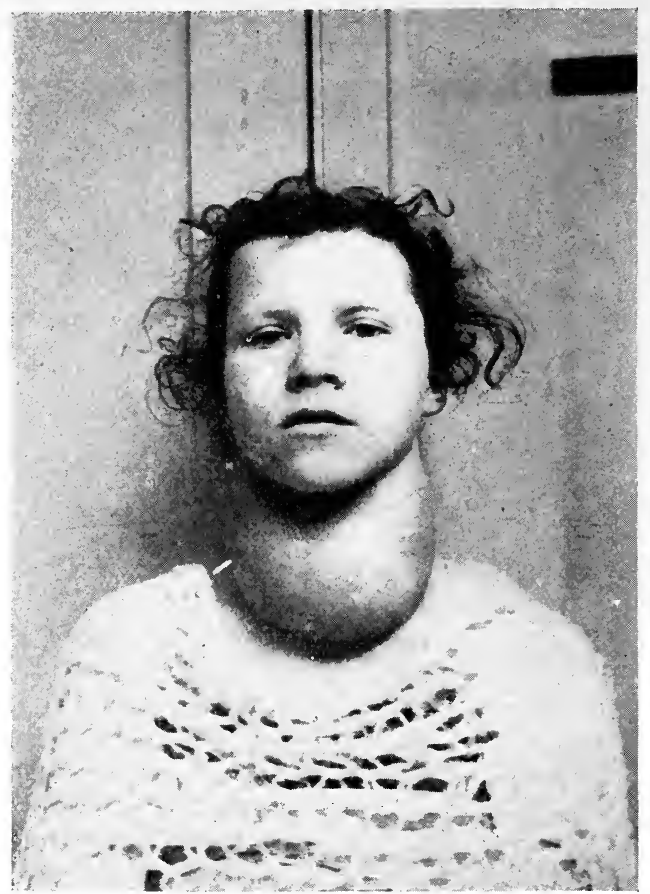

Figs. 22 and 23.-A purely Parenchymatous (ioitre showing slight lobulation and thus simulating a cuse of multiple

and gradual breaking down of solid adenomatous tumours.* Occasionally a thyroid cyst originates in an extravasation of blood into the thyroid tissues.

Adenomatous goitre is one in which the bulk of the enlargement is due to the development of definite encapsuled masses of atypical thyroid tissue imbedded in the gland. Sometimes these adenomata occur in an otherwise healthy thyroid gland, but in the great majority of cases an adenoma is

* For illustrations of this conversion of adenomata into cysts see Figs. 60, 61, and 62 on pp. 153,154 . 
associated with a certain amount of parenchymatous enlargement. Nearly all unilatcral and asymmetrical forms of goitre contain either adenomata or cysts.

Fig. 27 shows a parenchymatous goitre that has been cut

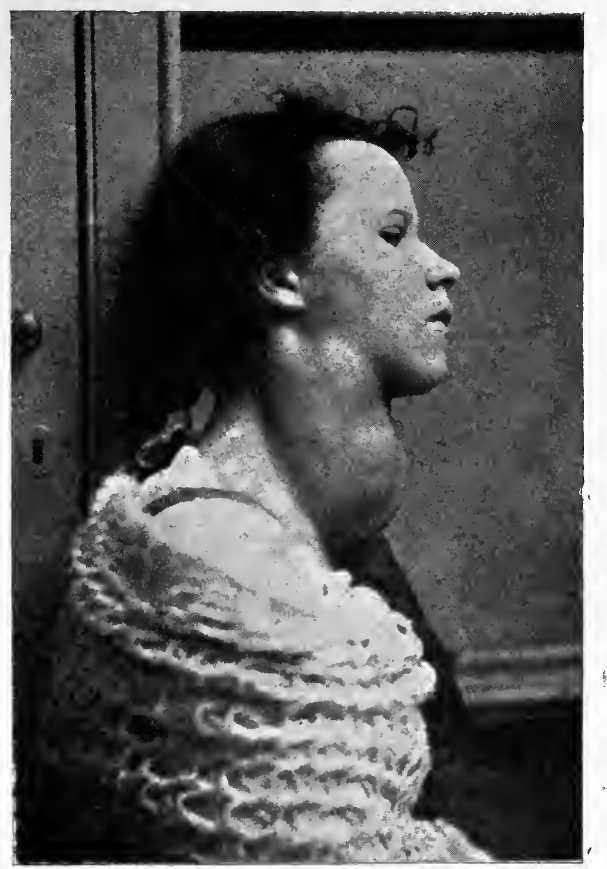

adenomata." (See Appendix, Casi 36, p. 344 and Roy. Free Hosp. Mus. No. xxii. 15.)

transversely. In its interior are seen several adenomatous masses in various stages of formation.

Fig. 28 shows a large solid adenoma in the thyroid gland of an elderly woman.

There are two* principal forms of adenoma, the foetal and the cystic.

The fœtal adenoma is met with chiefly in children and young adults, and is composed, as the name implies, of tissue resembling

* There is a third variety of adenoma that $i$; fortunately extremely rare. This is the so-called malignant "drmoma, which will be discussed more fully in chap. xiii. on malignant disease. 

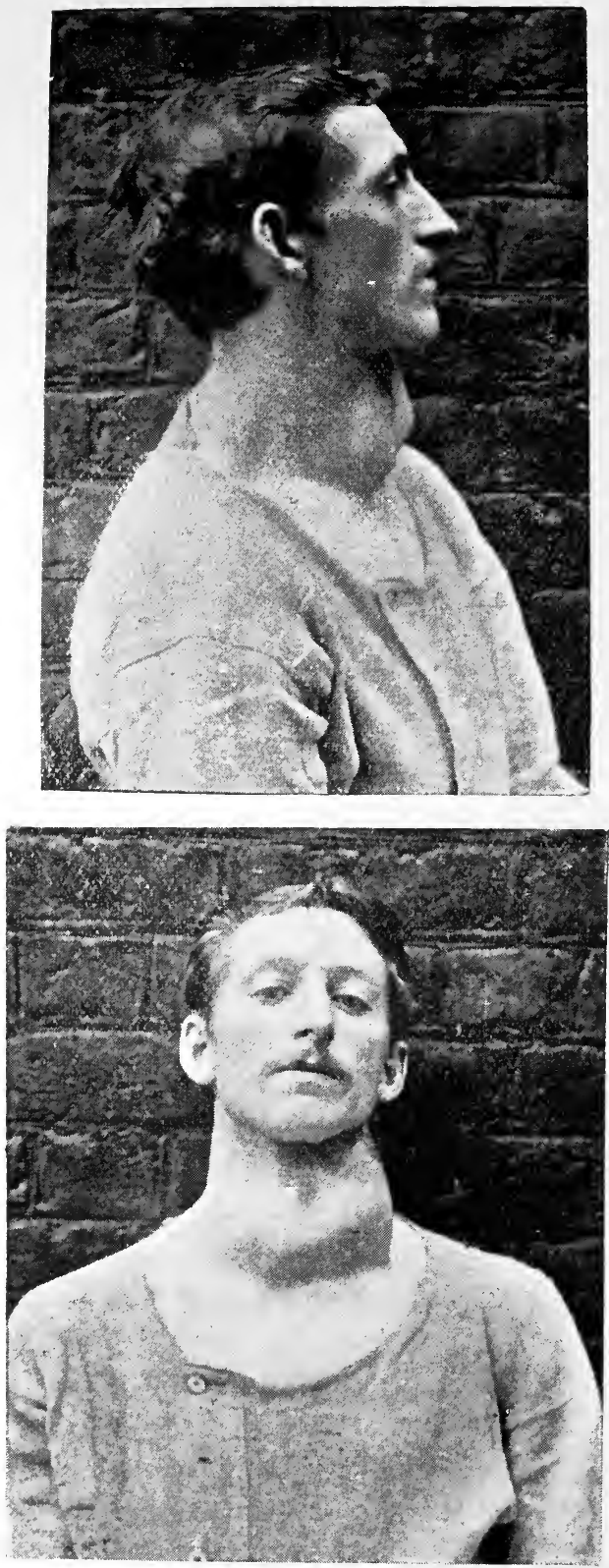

I IGS. 24 and 25.-A Bilateral Goitre, mainly parenchymatous. situated low down and eventully causing very severe dyspnowa. (From an outpatient seen at St. Bartholomew's Hospital.) 
that of the normal foetal thyroid. To the naked eye it presents a solid homogeneous appearance. Microscopically it is composed chiefly of masses of epithelial cells, representing undevel-

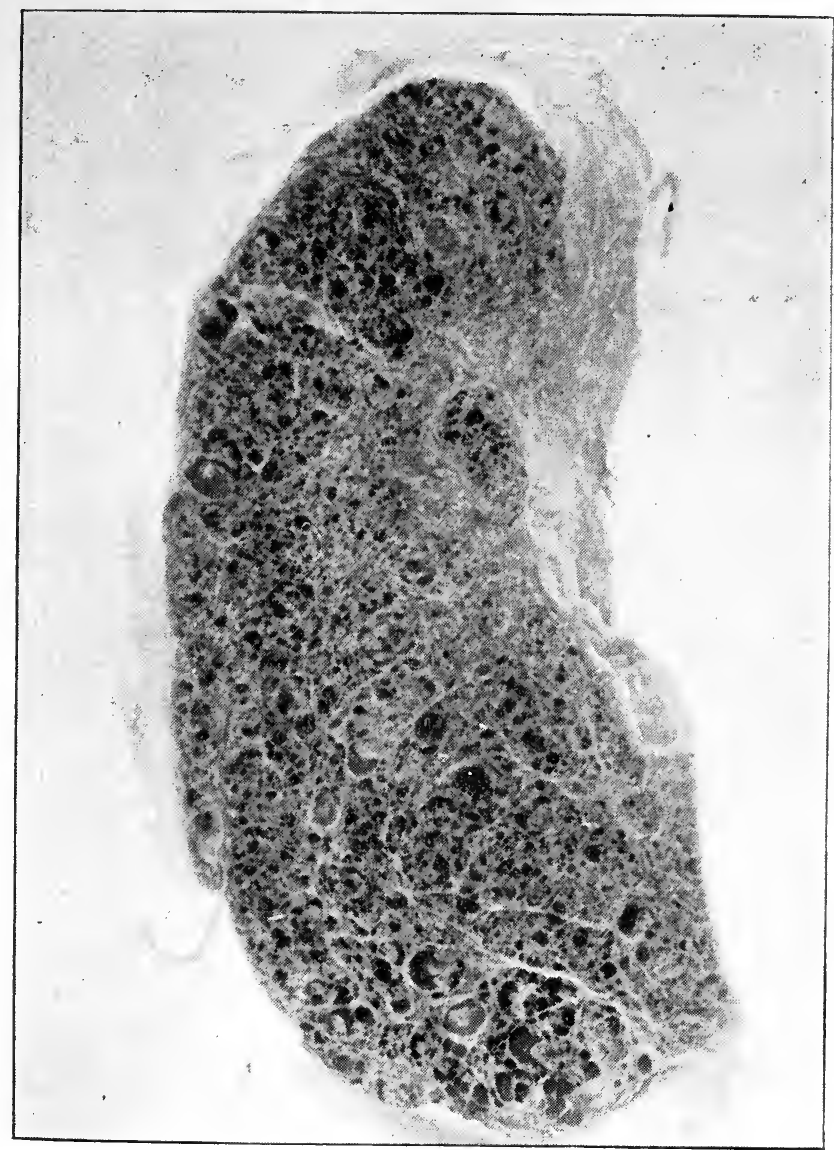

Fig. 26.-Section of a Parenchymatous Goitre removed by operation on account of dyspmea. The dark parts show colloid material distending the thyroil vesicks. From a boy aged 15 (Case 22*). (See Roy. Free Hosp. MIns. No. xxii. 11.) (Natt. size.)

oped thyroid vesicles. Fig. 29 shows a normal thyroid gland from a six months foetus, and is introduced here for comparison with Fig. 50, which shows an ordinary fotal adenoma removed by operation from a goitrous patient aged twenty-five. Fotal

* Published in Brit. Med. Journ., July 7, 1900. 
adenomata seldom attain a large size. The largest that I have myself ever had to remove was not larger than an orange. They are of importance chiefly on account of their vascularity. Opera-

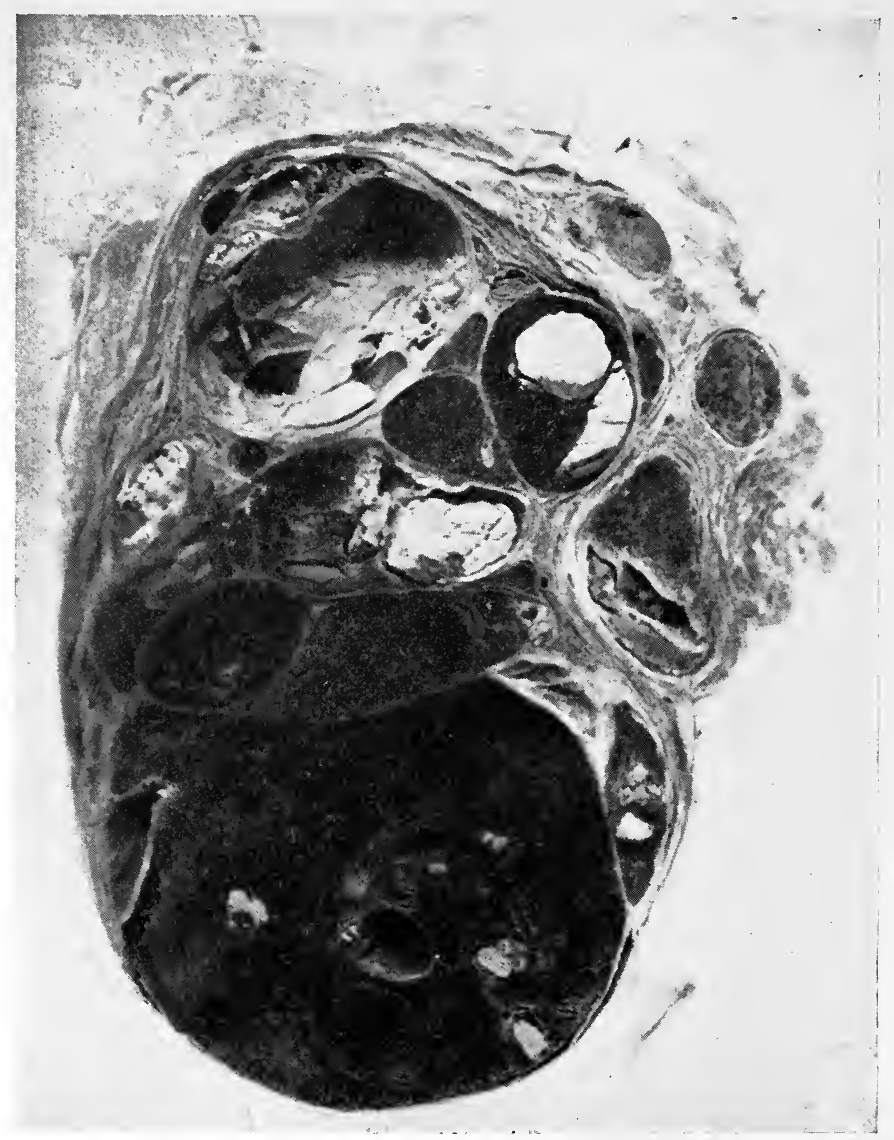

Fic. 27.-Section of Goitre removed by operition, from a woman aged 39, on account of severe dyspnoea. Numerous adenomata of various sizes are seen. The white portions show coagulated colloid. (See Ippendix, Case 30, p. 344 and Royal Free Hosp. Mus. No. xxii. 23.) (Slightly enlarged, $\frac{8}{7}$.)

tions for their removal are apt to be attended by smart hæmorrhage.

'The cystic adenoma is by far the most common form of adenoma. It differs from the preceding in containing numerous 
cavities visible to the naked eye. The microscopic structure (see Fig. 31) resembles to a certain extent that of the normal thyroid, but the vesicles are usually more irregular, and show a tendency to run one into another, owing to the breaking

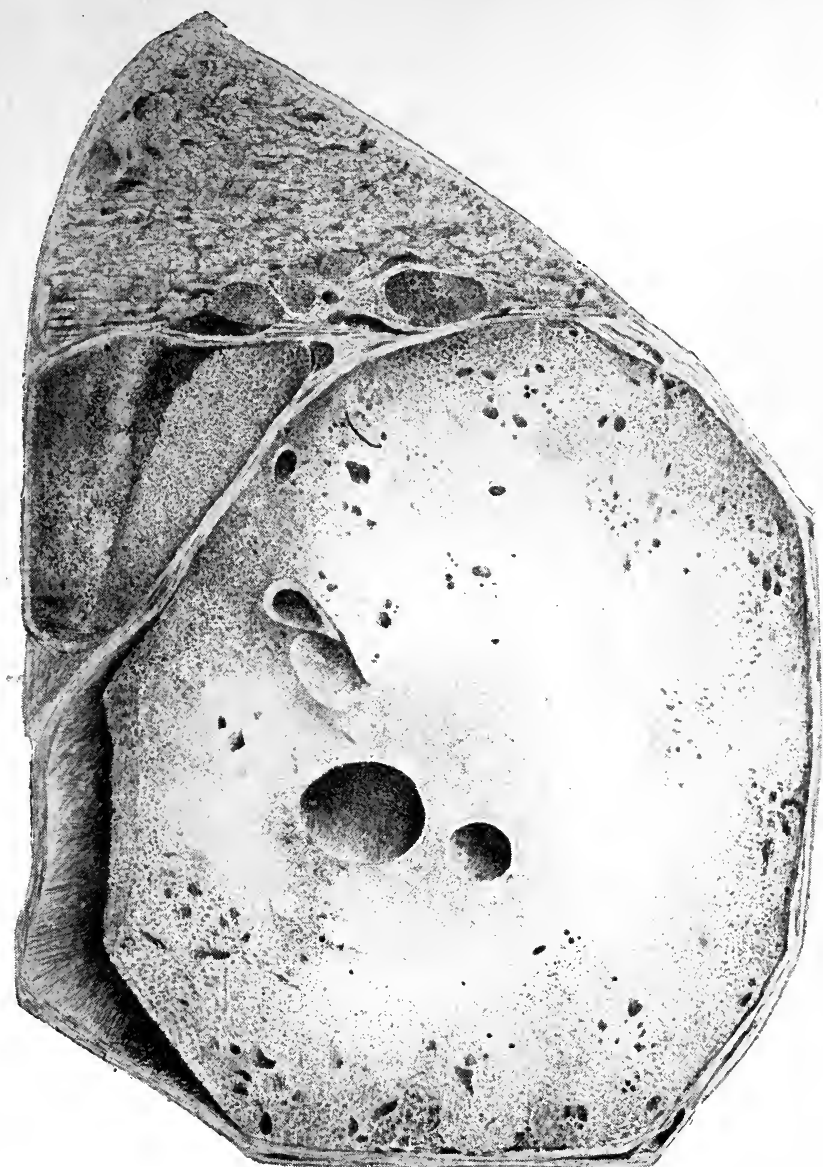

Fig. 28,-Right Lobe of a Thyroid Gland showing at the lower part a large solid Adenoma. (Royal Free Hosp. Mus. No, xxii. 31.) (Enlarged $\frac{4}{3}$.)

down of the intervening tissue. 'The connective-tissue between the vesicles is usually more abundant than in the normal thyroid. Cysts of various sizes are seen in the tumour. 'They contain colloid matter and frequently blood.

Fibrous Goitre.-Occasionally a general increase in the 
amount of connective tissue in the gland forms the bulk of the goitre. To such the name of fibrous goitre may be applied. The purely fibrous goitre is, however, a very much less common form than is generally believed.

All the above-mentioned varieties may run one into another, so that we frequently meet with mixed forms. Thus the parenchymatous goitre almost always contains small cysts, and frequently one or more large ones. So do many adenomata. Both parenchymatous and cystic goitres frequently contain

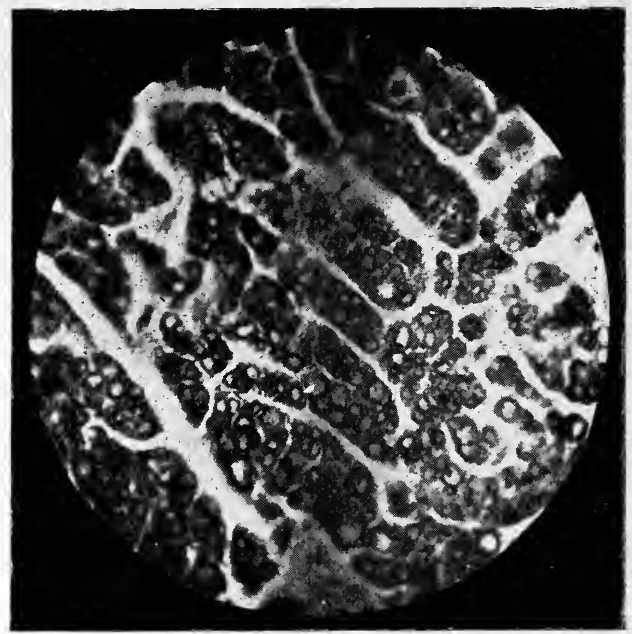

Fre. 29.-Thyroid Gland from a Fotus of Six Months. The gland is arranged in lobules and is almost solid. The rudimentary vesicles contain very little colloill. $(\times 90$ di:m. $)$

much fibrous tissue, and adenomatous nodules may be found in association with any of the preceding varieties. Fig. 32 shows an old goitre with several adenomata and much fibrosis.

'There are two other important varieties of goitre that stand somewhat apart from all the preceding. 'These are malignant goitre, in which the tumour consists wholly or in part of malignant disease (carcinoma or sarcoma), and exophthalmic goitre or the goitre of Graves's disease.

Both these forms of goitre differ widely, both structurally and clinically, from the preceding varieties.

'There are several other minor rarieties which have received 


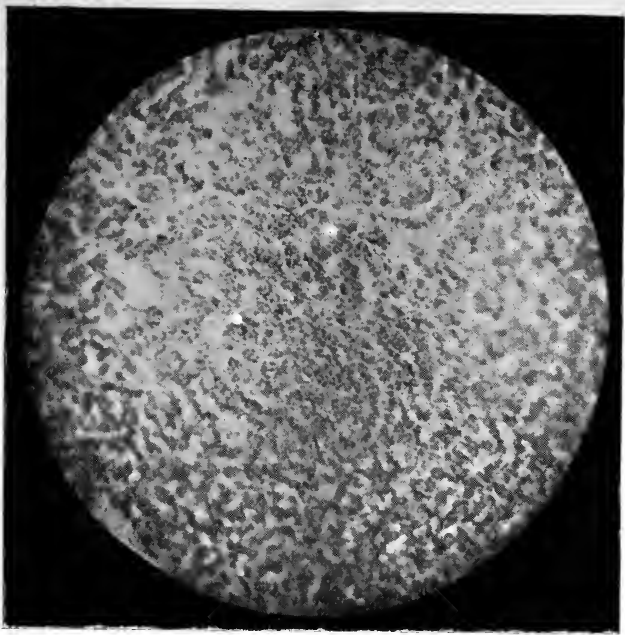

Fig. 30.-A Fœtal Adenoma from a lady ayed 25. It consists chiefly of solid masses of cells, with numerous vascular spaces (white). There are liardly any vesicles and no colloild. ( $\times 90$ diam.) (Cuse 25.)

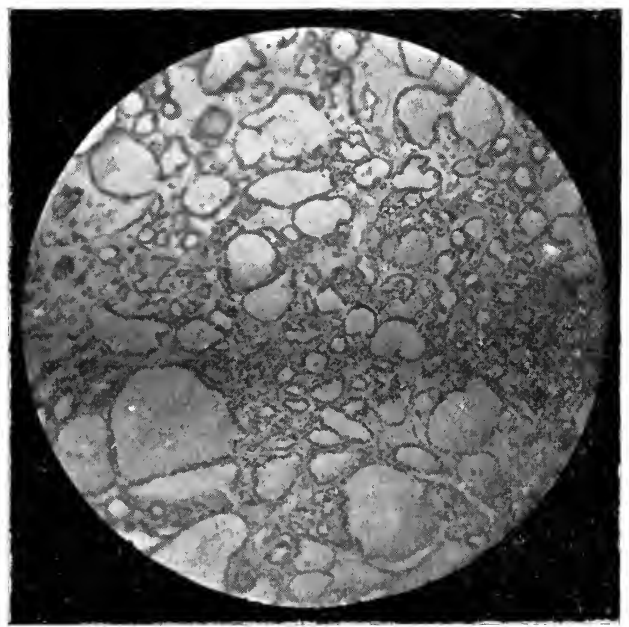

Fig. 31.-Portion of a Cystic Adenoma from a wom:un aged 21. Numerous small cysts of varions sizes and full of colloid are seen lying in a matrix of connestive and glaudular tissues. (Appendix, Case 99, p. 350.) ( $\times 90 \mathrm{di}: \mathrm{m}$. 
separate names. Hæmorrhagic goitre is a term used to signify a condition in which hæmorrhage takes place into a

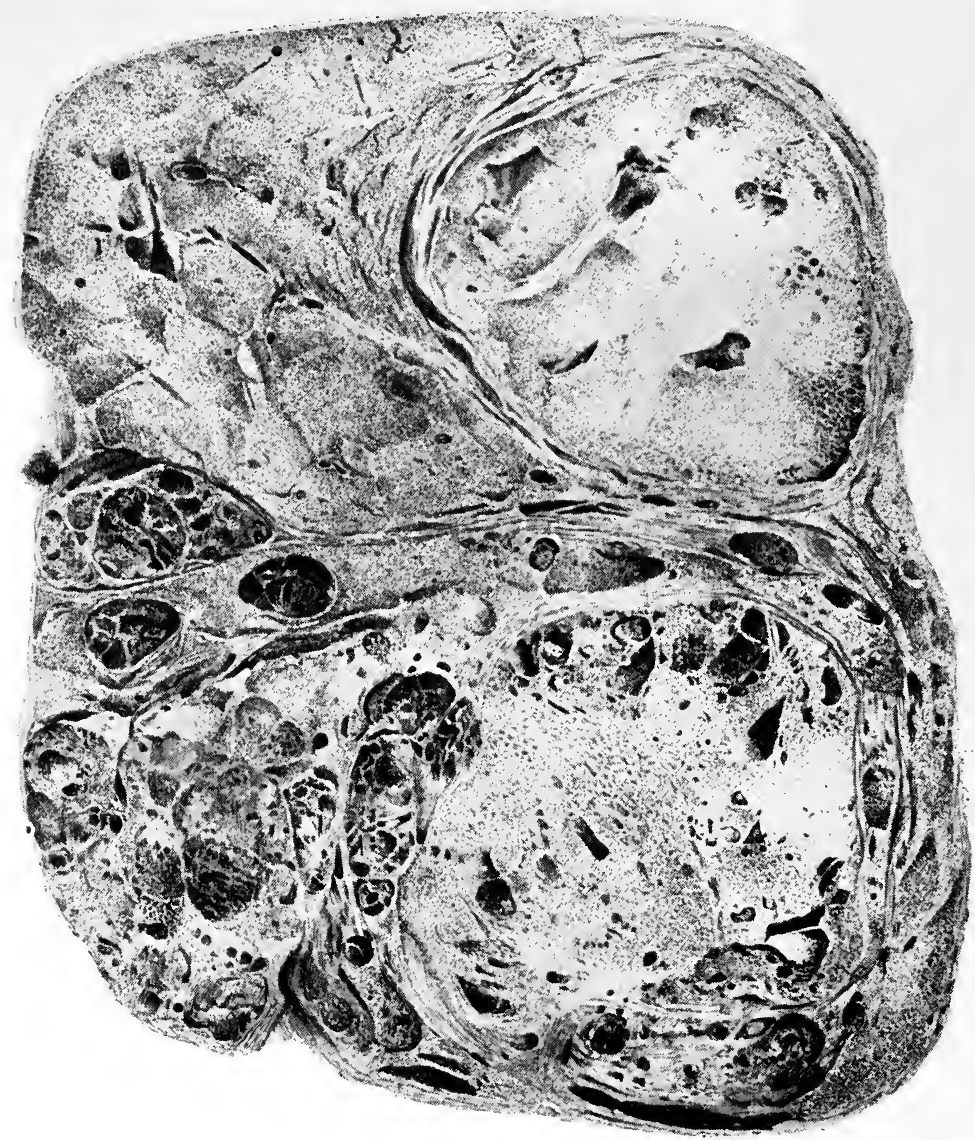

Fig. 32.-Section of part of a Goitre removed by operation from a woman acred 43, on account of severe dyspnœa. Several Adenomata are se'n imbedded in a Parenchymatous Goitre which has nudergone wuch fibroid degeneration. (See Appendix, Case 34, p. 344, and Royal Free Hosp. Mus. No. xxii. 25.) (Slightly enlarged.)

goitre, generally a cystic one, or in which an innocent goitre causes ulceration of the skin over it and bleeds externally. (See Fig. 33.)

Colloid goitre is a term applied by some authors to paren- 
chymatous goitres in which the colloid material is unusually abundant and obvious.*

The term vascular goitre is one that is frequently heard, and is often applied to the goitre of Graves's disease. The term

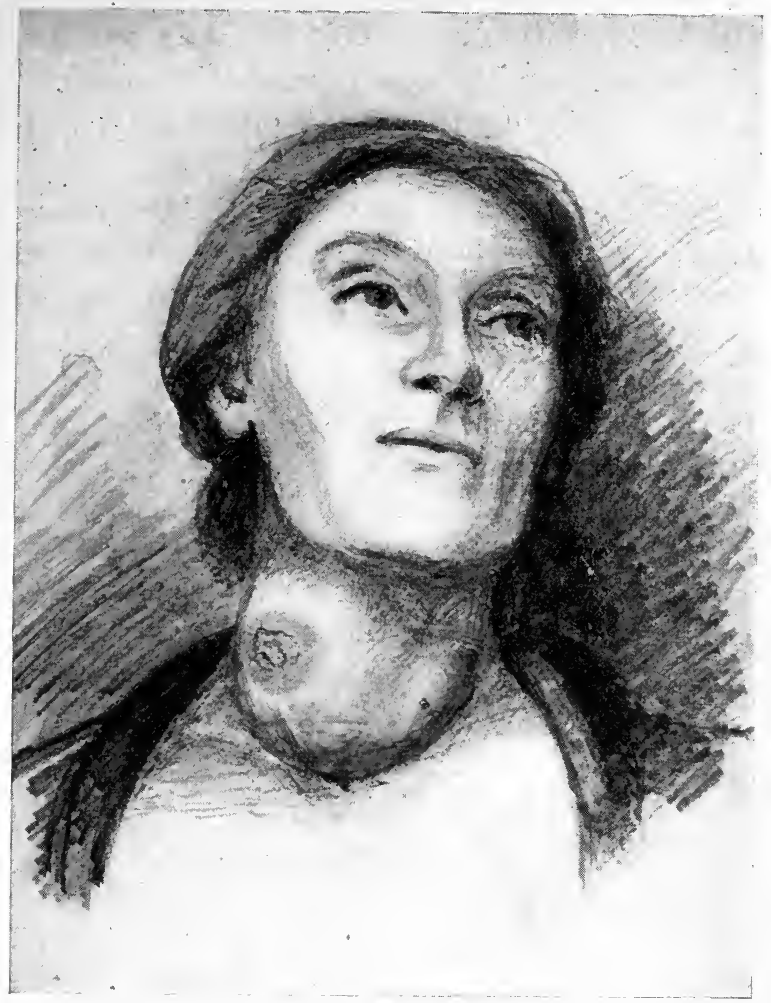

FIG. 33.- "Hæmorrhagic Cyst." The right lobe of the thyroid is occupied by a large eyst, which, after removal, was found to be filled with nearly pure blood. Several severe hamorrhages had taken place from the ulcerated opening on the surface. (From a woman, aged 60, seen at the Kensington Infirmary with Mr. H. P. Potter, under whose care she was. 'The tumour is now in the Musenm of the Royal College of Surgeons, No. 2905A.)

is, however, a bad one, and should, in my opinion, not be employed. If it be intended to signify a goitre composed mainly of blood-vessels, then it is a name for what probably does

* A good example of such a goitre may be seen in the Royal College of Surgeons' Museum, No. 2908D. 
not exist, for there is no evidence of the existence of any such goitre. If it be used for the goitre of Graves's disease, it conveys a false impression that the enlargement that is present in that form of goitre is mainly due to unusual vascularity in the gland. This is an erroneous but widespread belief.

Amyloid, syphilitic, and tuberculous goitre are all of them extremely rare; the names explain themselves. It is to my mind doubtful whether the cases described as amyloid disease of the thyroid are really of that nature.*

The terms endemic and sporadic goitre refer, not to pathological varieties of the disease but to its distribution and causation. The same may be said of epidemic goitre, a term that is used for goitre when it attacks a number of people in the same place and at or about the same time.

Acute goitre is a term used to denote a goitre that develops rapidly, especially in young subjects.

Suffocating goitre is niturally any goitre that produces much dyspnoea.

Substernal, intra-thoracic, retro-tracheal, and retro-œsophageal goitre are terms that explain themselves.

* See remarks on Pr. 34, 35, concerning the yellow waxy looking thyroid found in entaciated persons. 


\section{CHAPTER V.}

\section{ENDEMIC GOITRE-CAUSATION AND DISTRIBUTION.}

Alleged causes-Climate-Physical configuration of soil-" Want of air and sunshine" theory-Erroneous nature of-Relation to geologyGeological and geographical distribution in England-Relation to calcareous rocks and waters derived from them-Lime-MagnesiaIron-Organic impurities-Epidemic goitre-Goitre wells-Artificial production of goitre-Goitre in lower animals-Habits of life, exertion, strain, etc.-Heredity-Conclusions.

Thene can be but little doubt that, in the great majority of cases, goitre is to be regarded as an endemic disease. It is well known that in some parts of the world, the endemicity is present in a high degree. In other parts where the cause or causes are less powerful, the disease is less common and the endemicity is not so obvious. It is exceedingly difficult to know where to draw the line between endemic and sporadic goitre.

Probably in this country, most goitres may fairly be considered to belong to the endemic class, but the endemicity is so widely spread over the country while at the same time it is so slight, that it easily escapes notice, and cases of goitre are often considered to be sporadic which should more correctly be classed as endemic.

One kind of goitre, however, the excphthalmic variety, stands quite apart from all others, both structurally and in its geographical distribution.

This form will be dealt with subsequently in chap. xii.

With the exception of exophthalmic goitre, there is no structural difference between sporadic and endemic goitre.

But although goitre, in most cases, is to be regarded as an endemic disease, caused by a definite poison, whatever that poison may be, it is impossible to assert that all cases of goitre originate from the same cause. To cite an analogous example: 
there are many malarious districts in which a considerable number of the inhabitants suffer from enlargement of the spleen caused by the malarial poison. But enlargement of the spleen may be due to other causes than malaria; and just as we do not consider every case of enlargement of the spleen to be malarious in its origin, so we need not consider every case of goitre, even when it is found in a markedly goitrous district, to be due to the same poison that usually produces the disease.

The number of theories that have been advanced to account for the causation of endemic goitre is very great. St. Lager* in his classical work upon the subject mentions more than forty and occupies no less than four pages of his book in simply enumerating these different theories and the names of the authors who have supported them.

In endeavouring to ascertain the relative frequency of goitre in different parts of England, one is met by this great difficulty that there exists no source from which reliable statistical information can be obtained. In France, Germany, Switzerland and many other foreign countries, there does exist such a source, namely the official returns of the number of young men who have been exempted from military service on account of goitre.

From the statistics thus obtained, maps have been constructed which show fairly accurately the distribution of goitre in these countries. Excellent maps of this kind have been published, for example, in Switzerland by Bircher and in France by Baillarger and Nivet. In this country, however, there exists no such means of obtaining information.

The alleged causes of endemic goitre may be conveniently discussed under the following heads :

(1) Climate and other atmospheric conditions.

(2) Physical configuration of the soil.

(3) Geological structure of the soil, and its influence upon drinking water.

(4) Habits of life, exertion, strain, etc.

(5) Heredity.

(1) Climate.-That climate has little or no influence upon the production of goitre is shown by many facts. Although the

* "Etudes sur les Causes du Crétinisme et du Goitre Endémique," J. St. Lager, Paris, 1867. 
disease appears to be, on the whole, most prevalent in temperate zones, yet it is by no means limited to them. It has been found in extremely cold regions such as the north of Siberia and in the Hudson's Bay 'Territory of North America, and also in the tropics. My friend Dr. Sidney Davies, late of Cairo, informs me that he has seen it among the Egyptians. According to other observers, it occurs also in the Soudan and in the Andes near the equator. It is also well known to be common in some of the hottest parts of India. That heat and cold have no share in the production of the disease, there can thus be but little doubt.

Some authors have endeavoured to show that the prevalence of goitre is dependent upon the amount of rainfall, but I have failed to confirm this statement.

The map published in the Sixth Report of the Rivers Pollution Commission shows that in England the annual rainfall is greatest in the centre of Devonshire and in the Lake district, being over fifty inches in each of these localities. Now the neighbourhood to the south-east of Dartmoor is one from which I know goitre to be almost entirely absent. Similarly, in the neighbourhood of Windermere, goitre is, as I am informed by my friend Dr. John Mason, distinctly rare. On the other hand I have found goitre to be common in parts of Buckinghamshire and Bedfordshire, where the annual rainfall is less than twenty-five inches. Probably the real reason why goitre has been associated with excessive rainfall is because it is chiefly in mountainous regions that goitre is most common, and it is also on mountains that we expect to find the greatest amount of rain.

Rarity of the atmosphere has been assigned as a cause of goitre, chiefly also on account of the known prevalence of the disease' in certain mountainous districts such as the Alps, Pyrenees and Himalayas. But here again, closer examination shows that it is not to the rarity of the atmosphere that goitre is due. In Switzerland it has been shown that in many of the highest inhabited parts of the Alps goitre is absent. In this country I have not been able to find that the disease bears any definite relation to the altitude of the district in which it occurs. It has been stated by some that goitre is unknown upon the sea coast, but I have myself observed cases among people who lived 
and had always lived close to the shores of the Burry estuary in Glamorganshire. Some of these goitrous people liver but a few feet above the sea-level.

(2) Physical Configuration of the Soil.-Allusion has already been made to the prevalence of goitre upon most of the great mountain chains of the world. In France, especially, is this connection apparently striking. Nivet, in his excellent monograph upon goitre, ${ }^{*}$ gives for each department of France, the number of recruits rejected from military service on account of this disease. 'The four departments for which the figures are highest, are Hautes Alpes, Hautes Pyrenees, Aisne and Vosges (9.28, $3 \cdot 33,2 \cdot 84$ and $2 \cdot 7 \%$, per thousand, respectively). It is worthy of notice that three out of four of these departments are occupied, as the very names imply, by well-known mountain chains.

In our own country, too, there are many hilly parts in which goitre is common. The Pennine range in Derbyshire and other countries in the centre and north of England is well known to be a great seat of goitre. Less known, but nevertheless well marked, is the prevalence of the disease among the Cotswold Hills of Gloucestershire and neighbouring countries.

But on the other hand, there are many mountainous countries in which goitre is very rare or altogether absent.

One of the best examples that can be adduced of a mountainous country almost entirely free from goitre, is Norway.

In the highlands of Scotland, too, goitre appears to be almost unknown.

It is not, then, the mountainous nature of a country alone that causes goitre. If one of the mountainous districts in which goitre is prevalent be examined more closely, it will often be found that it is only in certain parts of the mountains that the disease occurs. Thus in Switzerland, the higher parts of the Alps are much less affected than the lower, and, speaking generally, it may be said that goitre is more often found at the foot of a hill or mountain than near the summit.

Bircher of Aarau has constructed, from the military statistics of Switzerland, an excellent map showing the exact distribution

* Yivet "Traité du goitre," Paris, 1880. 
of goitre in every part of that country. It may be seen from this map that in some parts of the country, especially in the cantons of Berne and Fribourg, the percentage of goitre is eighty or even ninety. Now, the highest ground in Switzerland is that occupied by the main chain of the Alps in the southern and south-eastern part of the country. But the district in which goitre is most prevalent is that which lies to the north of the Alps, stretching from the canton Fribourg in a northeasterly direction towards Lake Constance.

It has been asserted that goitre is not so prevalent on the most exposed parts of mountains, but occurs rather in the valleys upon the slopes of the mountains, and this is to a certain extent true. Perhaps, nowhere in the world, is the disease so common as it is in some of the deep valleys of North Italy, on the southern side of the Alps, in that of Aosta, for example. In Savoy, at the western end of the Alps, a similar distribution may be noticed. The Rhone valley, especially between Brieg and Martigny, is a well-known example. In our own comntry a similar prevalence of goitre in valleys may be noticed. Among the Cotswolds, the villages situated in valleys appear to be chiefly affected.

This marked prevalence of goitre in valleys, and especially in the valleys of mountainous regions, has led to a widely accepted, but an entirely erroneous theory of the cause of goitre, namely, that it is due to want of air and sunshine.

At first sight, the theory seems plausible enough. No one who has visited the valleys in Switzerland, in which goitre is so prevalent, can have failed to notice that many of them are deep, narrow, and gloomy.

But if the depth, the narrowness, and the gloominess, of valleys and the consequent lack of air and sunshine in them, were the real cause of the goitre, then we ought to find the disease prevalent in all similar valleys in other parts of the world. Norway may be cited as a country in which such valleys abound. Yet evidence is quite wanting to show that goitre is at all common there. In the course of four visits to the western parts of Norway, I failed to see a single case of goitre.

Again, if want of air and sunshine were the cause of goitre, the disease ought to be common among printers and others 
whose occupations often compel them to work at night in crowded and ill-ventilated work-rooms.

Miners, too, can hardly be supposed to get their full share of sunshine and of good air. But inquiry among them has not shown that they are particularly liable to the disease.*

The horses, too, that work for years in mines, and never see a ray of sunshine, are not especially liable to the disease. Yet horses, as well as other animals, are, like man, subject to goitre, in districts where it is prevalent.

some of our text-books state that goitre is especially common in the overcrowded and poorer parts of our great cities, but the statement does not rest upon any solid foundation of fact. Indeed, it may confidently be asserted that in the east end of London, as well as in the poorer parts of most of the largest English towns, goitre is not nearly so common as it is in many country villages situated far more favourably as regards pure air and sunshine.

In the village of Chacombe, in Northamptonshire, I found numerous cases of goitre. This village is situated in a more or less sheltered hollow among the hills, and it might be supposed that its position alone was the cause of the goitre. But a mile away is a farmhouse situated upon the very top of the hill, in an exposed and open situation; in this house several members of one family have suffered from goitre; one of them actually died from suffocation caused by the disease.

A similar example is afforded by the village of Oberbalm in the canton of Berne. Here the percentage of goitre among the recruits is twenty-three. The village is situated near the top of a hill; on the very summit is a farmhouse; among the inhabitants who had always lived in it during the whole of their lives, I found well-marked goitre. So exposed is the situation of this farm, that from it I could see, on the one side, the glaciers of the Bernese Oberland, forty miles away, while in the opposite direction was visible the equally distant range of the Jura in France.

Were it necessary to do so, many more similar examples

* It should be remembered that some mines naturally exist in goitrous districts, as in the carboniferous limestone regions of Derbyshire and Yorkshire and that in these regions we find goitre just as common among miners as among other inhabitants of the same districts, but not more so. 
might be cited, pointing towards the fact that endemic goitre may be found in elevated and exposed situations, where good air and sunshine are abundant.

It seems clear that, although certain valleys contain a great deal of goitre, yet the disease is quite absent from others which are equally deep, narrow, and gloomy, equally devoid of pure air and sunshine.

(3) Geological Structure of the Soil in relation to goitre.The true explanation of the association of goitre with hills and valleys is to be found, I believe, not in the mere external configuration of the ground but in its geological structure and the influence which this has upon the drinking water of the district.

Water which has percolated through thick masses of pervious and more or less soluble rock contains, cateris paribus, more mineral constituents than water which has not done so. Hence water issuing at the foot of a hill composed of such rock is likely to contain a considerable quantity of mineral matter. The nature and quantity of the minerals will naturally depend upon the nature and solubility of the constituents of the rock.

'I'he close connection between goitre and limestone was pointed out long ago. MacClelland especially has brought forward striking facts to illustrate this point.*

Now it is in limestone and sandstone districts especially that we meet with deep and narrow valleys. At the foot of a great mountain chain we generally find extensive deposits of these rocks, the upper parts of the mountains being often composed of granite, gneiss, and other crystalline rocks. Such is the structure of the Alps. The mountain streams descending rapidly from the higher levels will generally cut deep and narrow valleys in the limestones and sandstones which they meet, and thus are formed the typical valleys in which goitre is most abundant. When the valleys occur anong rocks which do not readily allow of percolation and solution such as those in the West of Norway there we find that goitre is not common in them.

A vast amount of work has been done by those who have laboured to trace a causal connection between goitre and

* "Observations on Goitre," Trans. M. and Phy.s. Sur. Calcutta, 1834, vii. 
geology. That there is a more or less direct connection cannot, I think, be denied. If a comparison be made of two maps of Switzerland, one geological, the other showing the distribution of goitre, it cannot fail to be observed that the area over which goitre is most common corresponds roughly with the region of that great deposit of sandstones, marls and limestones known as the molasse. Further, it is especially upon the marine molasse that the disease is seen to be most plentiful, although there are also other deposits upon which it occurs. It is scarcely possible to resist the conclusion that in Switzerland at least, there must be an intimate causal connection between goitre and the geological nature of the soil upon which it is found, and that the marine molasse is one at least of the geological formations that give rise to goitre.

The conclusions arrived at by Bircher who has studied the subject very carefully in Switzerland are as follows :

(1) Goitre occurs only upon marine deposits and especially upon the marine sediments of the palæozoic, triassic and tertiary periods.

(2) Free from goitre are eruptive rocks, the crystalline rocks of the Archæan group, the sediments of the jurassic, cretaceous and post-tertiary seas as well as all fresh water deposits.

With these conclusions I am on the whole disposed to agree, although as far as England is concerned, it is not correct to assert that jurassic and cretaceous rocks are wholly free from goitre. Endemic goitre does undoubtedly occur upon both these formations, although somewhat sparsely, especially as far as the chalk is concerned.

It may be well to point out that in investigating the relation of geology to goitre, care should be taken to bear the following facts in mind.

Geological formations are classified according to the period at which they were formed and not necessarily accordingly to their chemical composition or mineralogical structure. Hence two rocks totally different in composition may bear the same geological name. It would obviously be wrong to draw conclusions from them respecting goitre, as if they were the same.

On the other hand sometimes even large formations such as the chalk are tolerably uniform in composition and structure 
over wide areas, and these are particularly well suited for purposes of investigation.

Again, the occurrence or not of goitre upon a particular formation depends not merely upon the formation but upon the water supplying the people who live upon it. Thus a village may be seated upon soil not usually the seat of goitre and may yet be affected with the disease. 'The converse is equally true; a village or town situated in a goitrous district upon rocks usually associated with the disease may remain exempt if it derives its water supply from some distant source, from rocks not associated with the disease.

Again, the drinking water supplying any particular village or district may be derived from some very deep seated source quite unconnected with the rocks at the surface. In this case, if the water be such as will produce goitre, it matters not in the least whether the surface rocks are or are not those on which the disease is usually found. Great care must therefore be taken lest erroneous conclusions be drawn.*

The relation between geology and water supply is an exceedingly complex subject and is especially complicated in our own country in which so many different geological formations occur, few of them occupying any very extensive region. $\dagger$

Geological and geographical distribution of goitre in England and Wales.+

The extent to which goitre is associated with each of the geological formations of England will now be briefly discussed. The various geological formations will be taken in descending order.

'The tertiary rocks of England occur in two areas forming the

* I cannot help thinking that some harm has been done by those, who, without any practical knowledge of geology, have drawn hasty conclusions from the simple comparison of surface geological maps, and maps showing distribution of goitre, wiithout taking sufficient care to consider whence the water supply is derived.

$\uparrow$ The subject has been investigated by the Rivers Pollution Commission from whose sixth Report I have derived much valuable information. I am also considerably indebted to De Rance's "Water-supply of England and Wales," Woodward's "Geology of England and Wales," and several other books on similar subjects.

‡ The following account of the distribution of goitre in these countries does not pretend to be complete; concerning many large areas I have at present no information at all. 
London and Hampshire basins. 'Taking the former first, the disease occurs very sparingly over the Bagshot sands in some of the villages between Aldershot and Chertsey, for example at Windlesham, Bagshot and Pirbright. In Essex it does not occur at Loughton or Chigwell, nor in the neighbourhoods of Harwich, Colchester or Chelmsford.

In the Hampshire basin, it is said to occur at Romsey, but it is certainly absent from the neighbourhoods of Lymington, Poole and Bournemouth.

Over the extensive region of the chalk, goitre appears to prevail to a very slight extent but tolerably uniformly. I have found a few cases near Hatfield, Hitchin and Hadham in Hertfordshire, and at Luton in Bedfordshire, and I have been informed that the disease occurs to a slight extent at villages in the north of Essex (Sible Hedingham, Wethersfield) and on the borders of Suffolk, especially in parts of the valley of the Stour (Cavendish Melford, Sudbury and Nayland). It has been asserted that part of Norfolk is affected. Some of the villages a few miles to the west of Swaff'ham are however certainly not affected. I am informed that goitre occurs also upon the chalk in the neighbourhood of Driffield in Yorkshire. In the villages situated upon the chalk of the North Downs there is very little goitre and the same may be said of those upon the South Downs. The chalk is the source of such an abundant water supply that it is worth while to draw attention to the rarity of goitre in connection with it, especially as some text-books even now assert that it is especially prevalent in the "chalky parts of England."

Coming next to the upper greensand and gault which underlie the chalk and come to the surface as a comparatively narrow band, extending from Devonshire to Yorkshire and also skirting the Weald district of Kent, Surrey and Sussex, we find that goitre is rarely present upon either of these rocks. 'The lower greensand area, on the contrary, is one upon which I have found a considerable amount of goitre. In the south of Bedfordshire it forms the low sandy hills in the neighbourhood of Ampthill, itself a known seat of the disease. I have seen cases at Aspley Guise, Ridgmount and Woburn-all villages in this neighbourhood. Examination of the books of the Bedford Infirmary*

* Kindly undertaken for me by my friend Dr. Skelding of Bedford. 
showed that a considerable proportion of the cases of goitre treated there came from these villages and from others such as Moulsoe, Eversholt, and Maulden, all similarly situated. I have been unable to find any goitre in many of the villages situated upon lower greensand in the south of Surrey, but it is said to occur at Haslemere.

With regard to the Wealden area, goitre appears to be tolerably common over the central and more hilly parts.

Several cases came under my notice at Cuckfield, and I have heard of many others from other parts of the same area. I have reasons for believing that the disease is distributed tolerably uniformly, although not very thickly, over the whole of the central (Hastings sand) area of the Weald. I have been told that it is common at Horsham, but I have not personally examined this district. Villages situated upon the Weald clay appear to be slightly affected. I found several cases at Hadlow, and in neighbouring villages. From a similar district further to the east, a small number of cases have been reported to me. I have made personal inquiries at most of the villages on the tract of country extending from near Eastbourne to Steyning, immediately north of the South Downs. These villages are situated upon greensands, gault and Weald clay. I saw no cases of goitre and heard of only an occasional one here and there. Those of the inhabitants who knew what goitre was agreed in saying it was much commoner further north in the Hastings sands area.

Underlying the cretaceous strata, and appearing on the surface in this country to the west and to the north-west of these rocks, comes the great series of the oolites. It has been stated by most of those who have written upon the subject of the distribution of goitre in England that goitre does not occur upon the oolites, except at Helmsley in Yorkshire. My own experience does not lead me to endorse this statement. I have on the contrary found that goitre is tolerably common upon certain members of the oolite series, and is especially frequent in the villages situated just at the junction of the oolites with the lias.

In Somersetshire it is prevalent at Chinnocks, Stoke-underHam, and Chiselborough; the latter village has long been noted 
as a seat of cretinism. Further north $I$ have found it at Corton Denham and neighbouring villages. It is said to be common at Wooton-under-Edge in Gloucestershire. I have seen many cases at and near Stroud, ${ }^{*}$ and in many of the villages situated on the oolites to the east of Cheltenham. Still further east I found that in many of the villages round Northleach, ${ }^{*}$ as well as in Northleach itself, the disease was common. In Yorkshire it is known to occur at Helmsley and $I$ have been informed that it is found also in several villages to the east of Easingwold. I have seen a few cases near Malton.

'The next formation that we have to consider is the lias. The upper members of this series lie immediately under the oolites, and goitre occurs in numerous villages already mentioned, just at the junction of the two formations, being most common apparently upon the sands that are now considered to be the lowest members of the oolites. $\dagger$ Upon the middle lias, the disease, so far as my observations extend, is less common.

I have found a few scattered cases to the west of Chiselborough and Stoke-under-Ham.

In the south of Northamptonshire and the neighbouring parts of Warnickshire, in districts where the oolites are absent, I have nevertheless found a considerable amount of goitre. The village of Chacombe, where goitre is decidedly prevalent, rests upon marlstone (middle lias). 'The Warwickshire villages of Warmington and Avon Dassett, where the disease prevails to a slight extent, are situated at the foot of hills of similar rock. My friend 1)r. Bernard Rice has kindly examined the outpatient books of the Wharncliffe Hospital in that town, in order to ascertain the distribution of the disease in that neighbourhood. He found that out of twenty-two cases that had come from surrounding villages, no fewer than eighteen came from the liassic district to the east and south-east of Leamington. On the other. side of the town is the new red sandstone, and only four cases came from this district. A village in which the disease appears to be especially prevalent is Napton, situated at the

* Two of the patients upon whom I have operated for goitre had always lived within a few miles of stroud and a third came from the neighbourhood of Northleach.

$\doteqdot$ H. B. Woodward, "Geology of England and Wales," 1887, p. 287. 
foot of a hill of marlstone, underlaid and surrounded by lower lias clay and limestone.

So far as I can judge, this district appears to be fairly typical of the distribution of goitre upon the lower lias. 'The disease is either absent altogether or is thinly diffused over it. It must not be forgotten, however, that in many parts of England, as for example in the neighbourhood of Cheltenham, the lias is thickly overlaid with drift oolite, not marked upon an ordinary geological map. The water supply in such regions is frequently derived from shallow wells in this drift and not from the lias at all.

Upon the triassic division of the new red sandstone, goitre appears to occur very sparingly if at all. At Westbury-uponSevern, situated upon this rock near the lias, I could not hear of any. From the region of the triassic rocks of South Derbyshire, it appears to be almost absent-at least such is the case at Findern, Newton Solney, Foremark and Repton, according to information supplied to me by Dr. Cronk and from personal inquiries made in this district.

Its scarcity upon the trias to the west of Leamington has already been mentioned. Over the large area in which this rock comes to the surface in Nottinghamshire, the disease appears to occur but rarely.

The lower division of the new red sandstone is the Permian, often known as the magnesian limestone because a large proportion of its rocks is composed of that material. It occurs in this country chiefly as a narrow band extending from Northumberland to Nottinghamshire.

It has long been a favourite belief that magnesian limestone is especially associated with goitre, but I doubt whether there is much truth in this. In part of the magnesian limestone area of Nottinghamshire I found goitre to be distinctly rare. In other parts it appears to be less common than upon the carboniferous limestone. It is said to be common in the neighbourhood of Knaresborough, in Yorkshire. I ought to mention that the term "magnesian limestone" is used geologically, to denote a large series of marls, sandstones, and limestones, and that it consists by no means wholly of magnesian limestone in the chemical or mineralogical sense of the word. 
Magnesian limestone-using the term in the latter sense-is found in other rocks besides those of the Permian series.

The next series of rocks that engages our attention is the carboniferous. At the top of this series come the coal measures, and upon them goitre appears to occur to a moderate extent. 'The counties best known to me in which this formation occurs are Derbyshire and Yorkshire, and in both of them I found that goitre was fairly common upon the coal measures. I have also found it near Llanelly in Glamorganshire. The millstone grit, on the contrary, appears to be much more free from the disease. I have been informed that at Ilkley goitre does not occur in places upon, or supplied by water from this formation, whereas on the carboniferous limestone not far away, the disease is not uncommon.

At the Saltaire Hospital in one year, out of 780 patients applying for treatment only four did so on account of goitre.

At Chapel-en-le-Frith, in Derbyshire, I was informed that cases of goitre were more often seen in the districts to the southeast of the town, where the carboniferous limestone prevails, than in other districts where millstone grit and Yoredale rocks are found. I was also told that since the introduction of a new water supply from the millstone grit goitre has become less common.

It has been stated that goitre is common in the Peak district of Derbyshire, where the rocks consist chiefly of millstone grit and Yoredale rocks (grits, sandstones and shales with thin earthy limestones). Upon inquiry at Castleton, upon the southerm edge of this district, I was assured that goitre was much less prevalent in the Peak district than on the carboniferous limestones further south. 'The millstone grit formation is the source of water supply to so many of the towns in the north of England that the absence of goitre from it becomes a matter of considerable importance.

The carboniferous limestone regions of England have been described as a very hotbed of goitre, and I am inclined to believe that this is a tolerably accurate statement. Over the whole of this area in Derbyshire, but especially along the eastern border of it, I found numerous cases, for example, in the neighbourhoods of Cromford, Matlock, . Youlgreave, Bakewell, Baslow, and Stony 
Middleton. 'The same may be said of the region on the north side of Ashbourne, and I am told that the disease is also common over the similar districts in the east of Staffordshire.

In Somersetshire it occurs, I am informed, upon this formation at Clevedon, and I have heard of a number of cases upon various parts of the carboniferous limestone of the Mendip Hills. In Northumberland, on the other hand, it appears to be less common, but it is worth noticing that, in the.north of England, this formation loses its markedly calcareous character and is represented largely by sandstones and shales. In the Forest of Dean goitre is said to be common, but I do not know whether upon the carboniferous limestone or upon the other rocks of this region.

With regard to the occurrence of goitre upon Devonian and old red sandstone rocks, my information is chiefly of a negative character, but such information as I have tends to show that the disease occurs but rarely upon either of them. At Ilfracombe and probably over the north of Devonshire generally, goitre does not occur. The same may be said of the western extremity of Somersetshire. I am informed also that in the neighbourhood of 'Talgarth, in Brecknockshire, the disease is not prevalent.

Of the Silurian and Cambrian and pre-Cambrian rocks which form so large a portion of Wales, I have scarcely any practical knowledge, and consequently cannot say much about the occurrence or otherwise of goitre upon them. The little information I have obtained, however, tends to show that here also goitre is rare. In Anglesea, for example, I am informed that goitre does not occur at all in the north-west portion in the neighbourhood of Amlwch, and is probably absent from the whole island. With regard to granite and other igneous rocks, I believe that they are free from goitre; at least, I have never heard of any goitre upon them, and those districts of them that I have been able to examine, such as Widdicombe on Dartmoor, are quite devoid of the disease.

From the foregoing it will be seen that goitre is distributed over a very large surface of this country. Its coincidence everywhere with calcareous rocks, which are also very widely distributed in England, is one of the most marked features of its distribution. It is not only upon limestone but also upon 
calcareous sandstones that goitre is found. Whether it ever occurs as an endemic disease upon non-calcareous rocks is at least doubtful. The igneous, metamorphic, Cambrian, Silurian, Devonian, Yoredale, and millstone grit rocks, and some of the non-calcareous parts of the coal measures and tertiaries, appear to be mainly free from the disease.

Now, speaking generally, the water derived from these rocks, whether it be upland surface water or spring water, or deep well water, differs considerably from water derived from most of the other rocks in containing a smaller quantity of mineral matter and in being less hard. Of eighty-one samples of upland surface water derived from metamorphic, Cambrian, Silurian and Devonian rocks, the Rivers Pollution Commission found that the average total solid impurity was only 5.12 parts per 100,000 (or $3 \frac{1}{2}$ grains per gallon). 'The average hardness was only $2 \cdot 5$. Water from the Yoredale, millstone grit and non-calcareous portions of the coal measures and tertiary rocks, although containing rather more total solid impurity than water from the preceding, is nevertheless on the whole fairly soft, and contains rather less total solid impurity than that from the more calcareous rocks.

'That there is a general connection between goitre and the amount of mineral matter in the drinking-water, and its hardness, there seems good reason to believe. But that many waters contain a large amount of such mineral matter, and are very hard, and yet do not produce goitre, seems also to be true. Conversely, I believe that in a few instances I have found that a goitre-producing water was not particularly hard. Thus in one of the Derbyshire villages I found that a water which apparently produced goitre had not more than $7^{\circ}$ of hardness.

But it is probable that goitre-producing waters always contain a large amount of total solid impurity, although the impurity may not necessarily be such as to render the water very hard. This statement appears to be, on the whole, confirmed by published analyses of goitriferous waters in Switzerland and France.

As the chief hardening ingredients of water are bicarbonates and sulphates of lime and magnesia, it is not unnatural that 
these salts should have been considered to be the cause of goitre. But examination of numerous water analyses have failed to confirm these theories.

Another ingredient which is by many believed to be the essential cause of goitre is iron.

This view has received the strong support of St. Lager, whose elaborate researches compel one to receive with much respect any opinion that he has expressed. At first sight the occurrence of goitre upon many ferruginous sands, such as those of the lower greensand, the Weald, and part of the oolite districts, lends support to this view. But, on the other hand, I examined in Derbyshire numerous samples of water which undoubtedly produced goitre; in the majority of these no iron whatever was found, in others only the faintest possible trace. Other observers, too, have tested for iron, with similar negative results.

It should be remembered that in drawing conclusions as to the cause or otherwise of goitre by iron, care should be taken not to pay too much attention to the mere presence or absence of this metal in the rocks upon which goitre is found. A rock may abound in a particular metal, but it does not follow that the water percolating that rock will contain any of the metal, unless the latter happen to exist in a soluble form, which is often not the case.

As regards metallic impurities other than iron, but more or less allied to it chemically, it is not impossible that one or more of them may be found to be the essential cause of goitre, but proof of this is quite wanting; on the contrary the evidence we possess tends to point in the opposite direction.

The suggestion that the cause of goitre may be some organic impurity of water has, within the last few years especially, attracted a good deal of attention, and received a certain amount of support.

Professor Klebs* has examined microscopically the water taken from springs in goitrous districts of Salzburg and Bohemia, and has apparently found in it numerous micro-organisms, chiefly Infusoria. He believes that certain forms called ii. 45 .

* E. Klebs, "Ueber die Ursache des Kropfes," Prag. med. Wochenschr., 1877, 
naviculæ are the essential cause of goitre. Bircher, following Klebs, has made microscopical examinations of the water derived from different geological formations in the neighbourhood of Aarau. He examined waters from springs in the molasse, jurassic, triassic, and crystalline rocks, and found various forms of diatoms in them. But they were not found equally in all the waters. Some of them occurred only in waters from a particular formation. Thus in waters from granitic areas, and from the jurassic and upper fresh water molasse, he found meridion to be extremely plentiful. But in water derived from the trias and from marine molasse, it was absent, or nearly so. On the other hand, eucyonema was found abundantly in waters from the formations on which goitre prevails, while it was absent fiom those from the jurassic and granitic areas, which are free from the disease. Bircher expressly states that he does not maintain that any of these organisms are necessarily the cause of goitre. He simply relates the fact that different kinds of diatoms were found in waters derived from different geological formations.

Besides the above-mentioned forms of diatom, Bircher describes a form of rod shaped micro-organism that he found in waters from goitrous districts, but not in waters taken from regions in which the disease is not prevalent. He found them in the waters of Asp, Oeschgen, Eiken, Mumpf and Habsburg on the trias; also in those of Buchs, Aarau, Grinichen, Suhr, and Brugg on marine molasse: they were most numerous in two springs at Buchs(close to Aarau); here goitre is extremely common. Bircher has searched, without success, for these rod-shaped bodies in the contents of two goitrous cysts in young people.

That goitre can be produced by water has, I think, been shown by experiments that have accidentally been carried out on a large scale upon man himself. I refer to the outbreaks of so-called epidemic goitre that have been so often recorded. For example, a regiment of young soldiers has been quartered in a village, and after a few months, or even weeks, a very large proportion of the men have become goitrous. A town or village has received a new water supply, and shortly afterwards goitre has broken out in a large number of the inhabitants. Conversely, a village affected with goitre has changed its water supply, and goitre has ceased to occur. On the continent there 
are noted goitre wells to which young men resort who wish to obtain exemption from military service. After drinking the water from these wells for a few weeks, they acquire goitres sufficiently large to enable them to obtain their wish.* Bircher $\dagger$ mentions several springs near Aarau which have a local reputation for producing goitre in those who drink of their waters. One of these is at the village of Asp; another is at Buren. At the latter place five children in one family who drank from this spring all became affected with goitre.

In districts where goitre is common, not only man himself but also many of the lower animals become affected with the disease. It has been observed in dogs, cats, horses, cows, pigs, sheep, goats, antelopes, camels and many other animals. Cretinism, too, which always exists where goitre is prevalent, has been noticed among some of the lower animals.

Various attempts have been made to produce goitre artificially in the lower animals.

More than thirty years ago, St. Lager carried out a series of experiments in this direction. He began by feeding two dogs with sulphate of lime and carbonate of magnesia; this experiment was carried on for six months with a negative result. His next series of experiments was upon guinea-pigs, which he fed for several months with salts of various metals mixed with the animals' ordinary food. He does not state exactly what salts were used, but the results were negative. He then tried feeding mice with metallic sulphides and sulphates; after three months, slight swelling of the thyroid was noticed in three of them; these three had been fed upon sulphide and sulphate of iran'. Encouraged by this apparent success, he tried sulphate of iron again upon a dog, giving several centigrammes a day. At the end of four months, he thought that the thyroid had increased in size, but says that it was not prominent enough to deserve the name of goitre. St. Lager alludes to other experiments which had been performed by Bouchardat, with lime and magnesia, and by Maumené with fluoride of sodium, but in neither case with any marked success.

* Further details upon this subject may be found in the elaborate treatises of St. Lager, Baillarger, Nivet, Hirsch, Bircher and others.

$\dagger$ Op. cit. p. 128. 
Bircher experimented upon five puppies three months old, feeding them upon condensed milk diluted with water taken from the spring in which Bircher found his characteristic microorganisms. At the end of five months, the animals were killed and it was found that their thyroids had not undergone any enlargement.

Another series of experiments was carried on in 1890, for nine months, by my brother, Mr. Edward E. Berry, F.C.S., and myself. We took four sets of guinea-pigs. 'To the first set we gave a mixture of various salts of lime, magnesia, potash, and soda; the salts chosen were those obtained by the analysis of waters from two districts in Aurergne where nineteen and ten per cent. respectively of the male population are affected with goitre. To the second set we gave sulphate of lime only; to the third carbonate of iron in the form of saccharated carbonate. The fourth set formed simply a control series of experiments and received nothing but their ordinary food and drink. The animals were all weighed accurately every few weeks, and the doses of salts regulated in proportion to the weights of the animals. After death each thyroid gland was weighed accurately and subsequently exanined microscopically. 'The results were entirely negative as far as the production of goitre is concerned, but they tend at least to show that neither sulphate nor carbonate of lime, nor carbonate of magnesia, nor carbonate of iron is capable of producing goitre in guinea-pigs.*

Lustig and Carle have published some interesting and careful experiments upon the artificial production of goitre in the lower animals. $T$ They made use of water from certain infected parts of the valley of Aosta in North Italy. 'The subjects of the experiments were a young horse and several dogs. The horse after drinking for several weeks water suspected of being capable of producing goitre, developed a slowly progressive and perfectly evident swelling of one thyroid. 'This was removed by operation and the experiment with water was continued. After some weeks the remaining thyroid became still larger. After the adminis-

* Further details of these experiments will be found in the British Medical Journal for June 13, 1891.

† "Sull ptiologia del gozzo endemico." Lustig e Carle, Giorn. d. R. Acrad.d. med. di Torinn, 1890, p. 689-717. 
tration of this water had ceased, the size of the thyroid gradually diminished until eventually the swelling could no longer be felt.

Thirteen dogs, mostly young, were given water from the Buthier stream, a suspected source of goitre. In one of these and perhaps in another, some swelling of the thyroid was produced. From the first of these animals the enlarged left thyroid was then removed and the experiment continued. A month later the right thyroid was visibly enlarged. The administration of natural Buthier water was then discontinued and the same water freed from bacteria was given instead. The result was that the swelling gradually diminished and finally became imperceptible. In some of the thirteen animals, swelling of the lymphatic glands was noticed and in some of them diarrhœa occurred.

Ten young and healthy dogs treated solely with Buthier water, boiled and filtered, did not show any alteration in their thyroids. A young puppy born in an infected region, and the subject of a considerable goitre, was removed to a region free from the disease. Water supposed to be capable of producing goitre was given to it and the goitre became larger; the administration was discontinued in favour of filtered water and the goitre disappeared completely.

These experiments, if confirmed, tend to prove that goitre can be produced artificially by the administration of certain waters. Further, boiling and filtration seem to deprive the water of its goitre-producing elements.

Further experiments in the same direction and upon a larger number of animals are however necessary before they can be considered conclusive. 'The authors themselves seem fully aware of this and speak with praiseworthy hesitation.

Dr. Grasset* has recently stated that the cause of goitre is to be found in certain hæmatozoa which he has found in the blood of patients recently affected with the disease. This microorganism is said to resemble Lavaran's hæmatozöon found in ague, but differs from it in certain minor details. Grasset's observations are interesting but require confirmation.

(4) Habits of Life, Exertion, Strain, etc.-A popular theory attributes goitre to violent muscular exertion such as carrying

* La France Médicale, July 15, 1898, and Glasgow .Medical Journal, Jan. 1899. 
weights on the head, straining, coughing, and blowing wind instruments. It is at least doubtful whether any of these habits ever cause enlargement of a previously healthy gland.

The habit of carrying weights on the head is common in many countries where goitre exists and also in many where it does not. The disease frequently shows itself in quite young children who have never carried upon their heads anything heavier than a hat. I have several times examined large numbers of school children in affected districts* and found a considerable proportion of them affected with the disease. The occurrence of the disease in the lower animals is another proof that carrying weights on the head is not the cause of goitre.

It is possible that although muscular exertion does not itself produce goitre it may aggravate the disease. A thyroid gland already somewhat enlarged may be injuriously pressed upon by violent action of the muscles of the neck. In this manner extravasations of blood within the gland may be produced and cysts may be formed. Nearly all very large goitres contain cysts, and it is possible that some of them may have originated in the manner described.

Intermarriage as a cause of goitre is hardly worthy of serious discussion. Intermarriage is doubtless common in many isolated villages where goitre abounds but is equally noticeable in many similar villages where the disease is quite unknown.

(5) Heredity is supposed by many to play an important part in the causation of goitre. Undoubtedly goitre is often found to occur in many members of one family. Numerous instances in which every member of a family was affected with goitre have been found by myself both in Switzerland and in this country ; also many instances of goitre existing for generations in the same family.

But such facts, however numerous they may be, do not affiord proof that mere heredity is in any way responsible for the disease. There is good reason to believe that the cause that produced the disease in one member of a family caused it in all the others. It is well known that the apparent heredity of goitre is most marked in places where the endemicity is highest.

* e.g., at Triora in N. Italy, and at Chiselborough in Somersetshire. 
In order to place beyond dispute the hereditary nature of goitre, it must be shown that the goitre in the child is not due to the influence of the same exciting causes that produced it in the parent. It is obvious that so long as we are in doubt as to the exact nature of the goitre-producing poison, so long will it be difficult to prove definitely that the disease is or is not hereditary. Nevertheless the evidence that we at present possess tends to show that heredity ought not to be considered as one of the probable causes of goitre. Although mere heredity cannot be considered to be a cause of goitre, it is conceivable that some hereditary tendency may render a person more susceptible to the influence of the goitre-producing poison, but there is little or no evidence of this.

Summing up, there can be no doubt that climatic and atmospheric conditions have little or no share in the causation of goitre. 'That want of air and sunshine has absolutely nothing whatever to do with it is equally certain. Habits, such as carrying weights on the head, violent exertion and the like, play but a secondary part in the production of the disease. That heredity is a cause of goitre is extremely doubtful. Intermarriage has certainly no share in its causation.

That there exists some definite relation between endemic goitre and some poison in the soil upon which it is found is tolerably clear, and there can be no doubt that in the rast majority of cases drinking water is the vehicle by means of which that poison obtains access to the body. Such water is usually, if not always, derived from calcareous soils, but it is probable that the goitre-producing poison is not a salt of lime or magnesia. It has not yet been proved satisfactorily that any salc of iron is the essential constituent. The same may be siid of micro-organisms. 


\title{
CHAP'IER VI.
}

\section{SYMPTOMS AND DIAGNOSIS OF THYROID ENLARGE- MENTS-PHYSICAL SIGNS.}

\begin{abstract}
Mobility-Shape-Size-Position with regard to muscles, great vessels, sternum - Pulsation - Diagnosis from aneurism - ConsistencePressure effects, on veins, recurrent laryngeal nerve, sympathetic, cervical and brachial plexuses, larynx and trachea, wesophagus and pharynx.
\end{abstract}

'JuE thyroid gland may be the seat of various diseases, each of which has some characters peculiar to itself. There are many characters, however, which are more or less common to all forms of enlargement of this organ.

These will be discussed in this and in the following chapter.

In most cases it is not a difficult matter to determine whether a given swelling in the neck does or does not belong to the thyroid. Occasionally, however, the most marked characteristics of a thyroid swelling are absent, $o:$ are closely simulated by other conditions, and thus mistakes may occur.

The diagnosis of an enlargement of the thyroid is made partly by examination of the physical signs of the swelling itself and partly by the pressure effects which it exerts upon surrounding structures. 'To a very small extent the effect of the disease upon the function of the gland may produce signs and symptoms which are of some help in diagnosis.

Physical Signs.-Among these we have to consider, (1) Mobility ; (2) Shape ; (3) Size ; (4) Position ; (5) Pulsation ; (6) Consistence.

(1) Mobility.-Owing to the close connection already described which exists between the larynx and the thyroid gland, the latter follows the former in all its movements. Hence one of the 
most important signs of a thyroid tumour is that it rises and falls with the larynx and trachea during degintition.

In the great majority of cases the presence of this sign alone is sufficient to enable us to form a correct diagnosis of the thyroid nature of the swelling under examination. Care must be taken, however, not to rely too implicitly in all cases upon this sign only. For there are two sources of fallacy with regard to it, that may lead to mistakes.

In the first place a swelling which is not of thyroid origin may present the above sign; and in the second place one which is really thyroid may not present it.

The cases which come into the former category are fortunately rare; and most of them are generally easily distinguished, because the tumour will be found not to occupy exactly the same situation as a tumour of the thyroid.

Such are cysts of the subhyoidean region which lie in the middle line on a level with the upper border of the thyroid cartilage. It is possible that a very large cyst of this kind might be mistaken for a tumour of the upper horn, or of the pyramid of the thyroid, but its high situation in the middle line would almost invariably be quite enough to distinguish it.*

In 1893 I saw with Mr. Bowlby at St. Bartholomew's Hospital a man who had a rounded prominent swelling covering the whole of the front of the thyroid cartilage and firmly fixed to it. It was almost exactly in the middle line, and at first sight closely resembled a subhyoidean bursa. A careful examination, however, showed that it was connected with the left lobe of the thyroid gland.

Tumours, both innocent and malignant, springing from the larynx or trachea and growing outwards, may occasionally simulate swellings of the thyroid gland. They are, however, rare.

Mr. Percy Furnivall has kindly given me notes of the following case that came under his notice in 1893 :

"A gentleman aged 55 had had for thirteen years a swelling on the right side of the neck. In 1887 he had seen Sir Morell Mackenzie, who wished to aspirate and inject it. Later he was

* See a paper by Larrey, Gaz. d. Hôp., 1853, pp. 212, 225. 
seen by another surgeon who also considered that it was 'probably a thyroid cyst.' On the right side of the neck, close to the middle line, was a sausage-shaped swelling, situated partly under the sterno-mastoid at its lower end. The upper part lay between that muscle and the middle line and extended nearly up to the lower jaw. It was well defined, very soft and elastic, and apparently fluctuated. It mored distinctly with the larynx on deglutition. It was removed by operation and was found to be a lipoma attached to the side of the thyroid cartilage."

Several cases have come under my own notice in which malignant growths springing from the lower end of the pharynx and upper end of the osophagus were very difficult to distinguish from growths in the thyroid gland itself.

Tracheal hernia is said by Norris Wolfenden and others to simulate bronchocele very closely.

Dr. Wolfenden * has given an account of three cases supposed to be of this nature, and remarks that " the practitioner is not likely to recognise the true state of affairs unless he has caused the patient to voluntarily distend the tumour."

On the other hand it should be remembered that some goitres are visible only when the patient makes an expiratory effort. Both Wölfler and myself have had to operate upon such cases. I am disposed to agree with Wölfler, who is sceptical about the existence of tracheal hernia resembling goitre. He states $\dagger$ that one of Wolfenden's cases was subsequently proved by operation to be a true goitre and not a iracheal hernia.

Necrosis of a portion of one of the laryngeal cartilages may cause an abscess which sometimes can scarcely he distinguished from a cyst, suppurating or not, of the thyroid gland.

Kohn + has recorded a remarkable instance of such a case :

"A woman had, in the region of the right lobe of the thyroid gland, a swelling which was taken to be a chronic abscess of that organ. But after evacuation of the pus it was found that the

* Journul of Larljngolory, 1888, p. 99. See also a long and very complete japer on the same subject by Dr. J. H. Petit in Rerue de Chirurgie, Paris, February, March, May and June 1889.

† "Die chirurgische Behandlung des Kropfes," Berlin, 1890, ii. p. 2.

+ "Ueber Strumitis und Thyroiditis," Allgem. Wien. Med. Zeitung, 1885, 1. 245 . 
abscess was due to necrosis of one of the laryngeal cartilages and was wholly unconnected with the thyroid gland."*

Various swellings having their origin in tissues external to the larynx and trachea may become adherent to them secondarily and so participate in their movements. Such are affections of the cervical Jymphatic glands. Some years ago while dissecting out a thyroid gland from a dead body in the post-mortem room of St. Bartholomew's Hospital, I came upon an oval swelling, close to the lower part of the right lobe; at first sight this appeared to be an abscess in the thyroid gland. It was firmly connected with the trachea and the recurrent laryngeal nerve was spread out over it. There can be no doubt that, had it been detected during life, it would have been found to follow the trachea in all its movements, and it would almost certainly have been taken for a thyroid swelling. It was, however, simply a chronic abscess that had originated in one of the cervical lymphatic glands.

In 1895 I saw a patient of Mr. Bowlby's, a young man with a mass of enlarged tuberculous glands adherent to the side of the larynx; the resemblance to a tumour of the thyroid was considerable.

In St. George's Hospital Museum is a specimen of a sebaceous cyst situated immediately in front of the larynx. $\dagger$ During life it had been mistaken for a cyst of the thyroid, and had been injected with perchloride of iron with a fatal result.

I have seen one case in which a dermoid cyst lay immediately in front of the larynx and followed its movements during deglutition.

We come now to the second eiass of cases, those that fail to move with the larynx during deglutition although they are of thyroidal origin.

This may occur, first, when the bulk of the tumour is so great as either to conceal or to mechanically prevent the movements of the larynx and trachea; and, secondly, when the tumour is prevented from moving by reason of its adhesions to neighbouring

* A somewhat similar case came under my own notice some years ago; this was one in which a swelling caused by perichondritis of the thyroid cartilage had been mistaken by the surgeon for tumour of the thyroid gland.

$\dagger$ New Catalogue No. $21 \mathrm{~A}$. 
parts. Malignant disease and inflammation are the most common causes of such adhesion.

In the case of the patient depicted in Fig. 82 deglutition failed to make the huge tumour rise as a whole. It did cause, however, what is an almost equally valuable sign, namely a peculiar shake felt in the tumour. The tumour was tilted forwards each time that the larynx, to which it was attached posteriorly, attempted to rise.

In cases then of large tumours that do not rise with the larynx during deglutition attention should be directed to the shaking or tilting caused by this action.

Malignant tumours in their later stages frequently become quite fixed. I have seen several cases both in my own practice and in that of others, in which such tumours were firmly fixed to the vertebral column.

In September 1885, by the kindness of Dr. Reece, then acting as one of the medical officer's at the Kensington Infirmary, I had the opportunity of examining a case of what we, at first, supposed to be a tumour of the thyroid gland. 'The patient was an elderly woman who had a hard oval mass, of the size and shape of a goose's egg, apparently exactly in the position of the right lobe of this gland. It extended from near the middle line of the neck to beyond the outer border of the sternomastoid. It touched the larynx and trachea when these were in their natural position, but it was found possible to push them considerably to the left of the middle line without displacing the tumour. Indeed a finger could be laid in the groove thus produced between them. The tumour did not appear to move during deglutition. For these two reasons, then, it was concluded that the tumour was not of the thyroid gland. No operation was deemed advisable. A few days later the patient died, and on making a post-mortem examination, it was found that the tumour was a mass of malignant growth (probably starting in a lymphatic gland), secondary to disease of the mediastinum. 'The thyroid gland itself was small and had been flattened between the larynx and the growth. 'The latter had displaced the carotid artery and internal jugular vein to the outer side.

It should be remembered, therefore, that a movable tumour 
of the thyroid gland ought to follow, not only the vertical but also the lateral movements of the larynx and trachea.

Large masses of malignant growth may be found in the neck which are adherent to the larynx and trachea and surrounding parts. Occasionally in such cases, it may be difficult to say whether the growth is primarily of the thyroid gland.

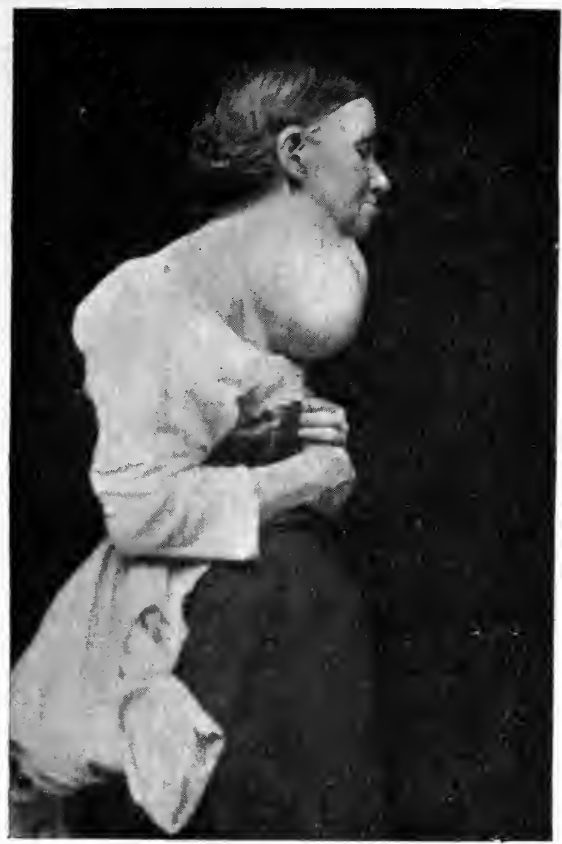

Figs. 34, 35 and 36.-A large Biluteral Parenchymatous Goitre. The right and central lobes were removed by extirpation from a woman aged 52. (See Fig. 37.) The tumour removed weighed 3 lbs. 1 oz., and is now in the Roy. Free Hosp. Musenm, No. xxii. 19. (See also Appendix, Case 119, p. 352.) (From photograplis by Dr. Image.)

A few years ago I had a case in the Royal Free Hospital illustrating this point. A small child had a large mass of lympho-sarcoma in the left side of the neck. 'The larynx and trachea were displaced to the right and so much buried in the tumour that it was difficult to ascertain whether they moved on deglutition or not. The tumour might easily have been mistaken for a sarcoma of the thyroid gland. 
W. Osler has recorded a case of lympho-sarcoma of the deep cervical glands, involving the thyroid and simulating goitre.*

Wölfler† records a case in which a tumour of the right lobe of the thyroid was mistaken by Professor Billroth for a lymphoma. It was not until the operation for its removal was being performed, that the thyroidal nature of the tumour was discovered. In the notes of this case it is stated that there were

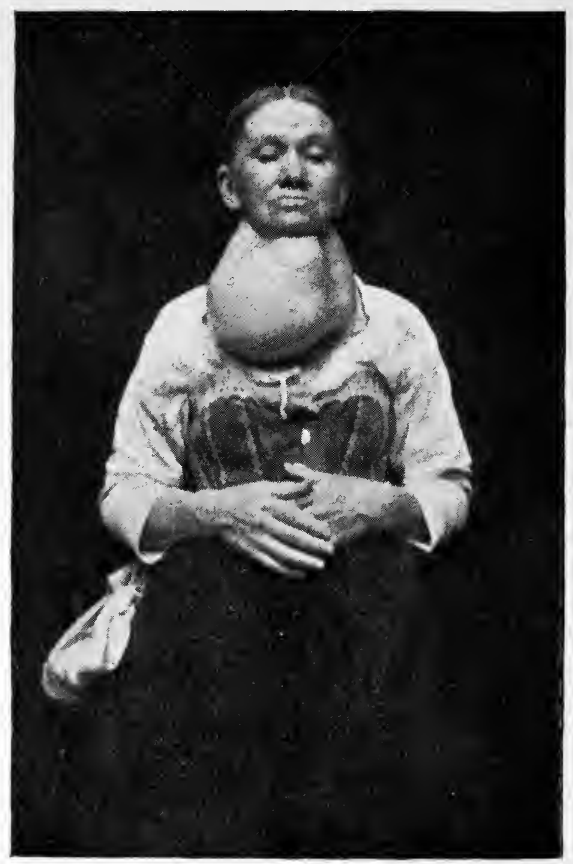

Fig. 35.-For description see pp. 77 and 352.

two tumours, each nearly as large as a goose's egg, and they were only slightly movable. It was probably the absence of the usual mobility of a thyroid tumour that led to the error in diagnosis.

We will now consider some of the other less important signs and endeavour to ascertain their value from a diagnostic point of view.

* Montreal Gen. Hosp. Rep. 1880, i. 340.

† "Ueber der Entwickelung und den Bau des Kropfes," Anton Wölfler, Arch. f. lalin. Chir., Berlin, 1883, vol. xxix. p. 788. 
The shape of an enlarged thyroid may be very characteristic or, on the other hand, it may have no diagnostic value whatever. When the gland is enlarged uniformly as, for example, in the early stage of the simple parenchymatous form of goitre it presents an appearance similar in shape to that of the normal thyroid gland. Allusion has already been made to the resemblance which the latter bears to a horseshoe, with concavity

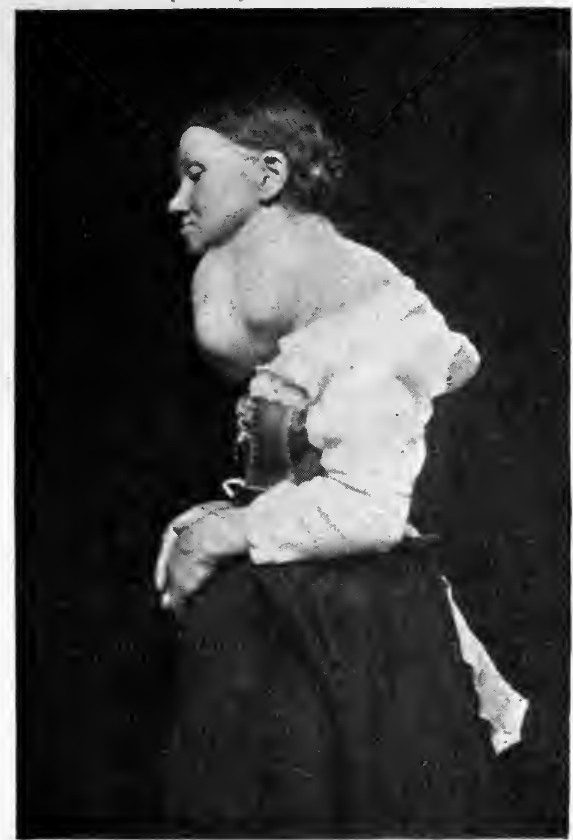

FIg, 36.-For description see pl. 77 and 352.

upwards. But every deviation firom this normal typical shape may be met with when the gland is enlarged asymmetrically, by the formation of a tumour or tumours within it. A portion only of the gland may be enlarged and the resulting tumour will then probably present a more or less round or oval shape.

'The size of a thyroid tumour may be very great; it may even attain that of a man's head.

It is probably among the cases of cystic disease that the 
largest goitres are to be found. Alibert's cases* are among the largest with which I am acquainted. Keser $†$ describes a goitre removed by Professor Socin at Basle; it was as large as a man's head, and came down in front of the sternum to below the level of the xiphoid process.

The largest goitres which have come under my own notice during life, are represented in Figs. 34, 39, 46 and 82.

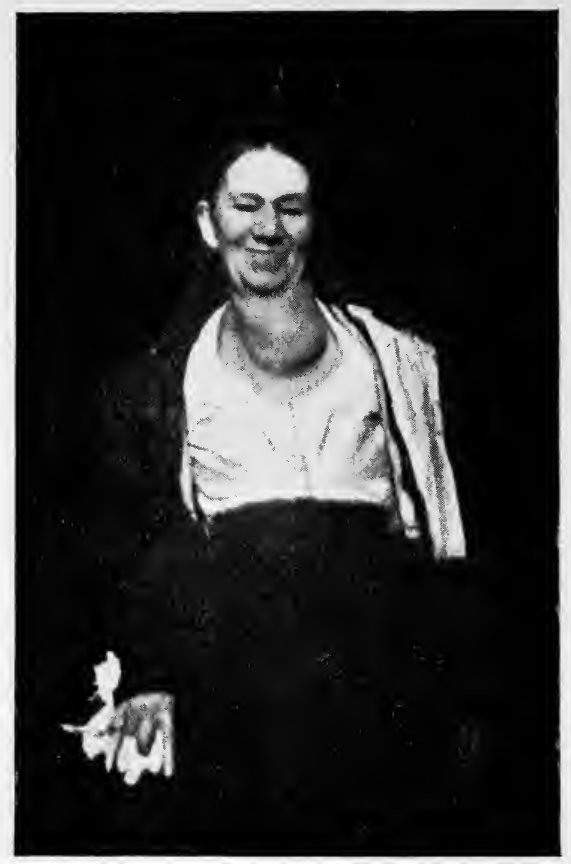

Fre, 37,-The preceling, two months after Extirpation of the whole of

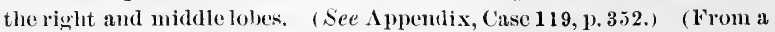
photograph by Dr. Image.)

'The degree of prominence also varies considerably. Some tumours present scarcely any external swelling, others form huge projecting masses which may be more or less pedunculated, and may even hang down over the front of the chest for a considerable distance. Instances of huge goitres, extending as far

* “Nosologie Naturelle," Paris, 1817, i.

† Samuel Keser, "L'énucléation ou extirpation intra-glandulaire du goitre parenchymateux," Paris, 188i, p. 20. 
downwards as the waist have been figured by Alibert.* In one of these, the tumour is curiously elongated and narrow, and unlike any other that has yet come before my notice. $\dagger$

Position.-The position of a thyroid swelling naturally differs according to the part of the gland involved.

'The swelling may be in the middle line of the neck. 'This is

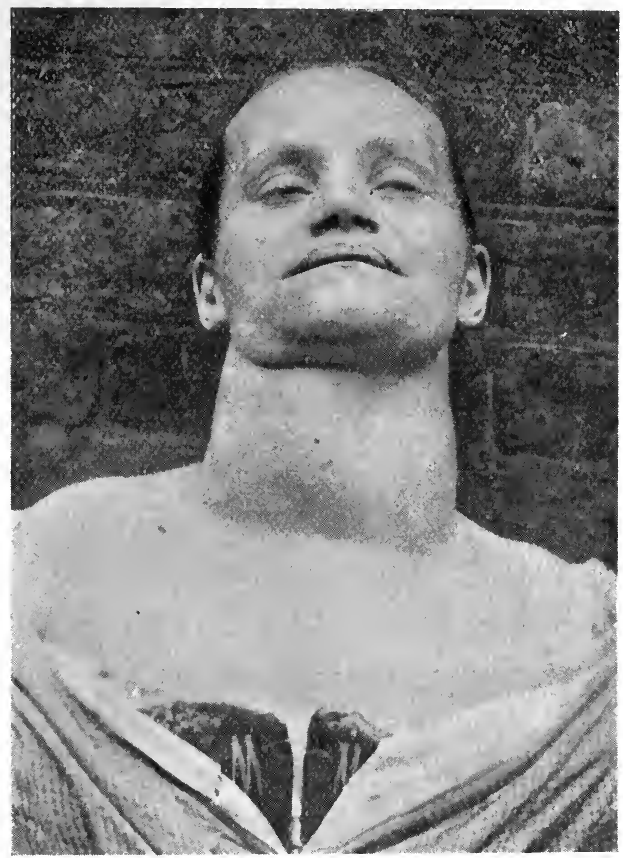

Fig. 38.- I Woman, aged 38, with a Bilateral Goitre. The right lobe, which contained a solid adenoma weighing $7 \frac{3}{4}$ onnces, extended decply behind the sternum and right clavicle, and was extirpated on accont of severe dyspnoea. (See Appendix, Cise 50, p. 346.)

the case when the enlargement affects either the isthmus alone (which is exceedingly rare), or the whole gland, including the isthmus.

* Alibert, "Nosologie Naturelle," i. p. 466, Plates C and D.

$\dagger$ The same author also alludes to, but does not figure, a case in which the tumour was cylindrical and tapering and reached as far down as the middle of the thigh. "Formée comme un long cylindre qui se prolongeoit juscul'à la partie moyenne de la cuisse."-" Nosologie Naturelle," p. 468. 

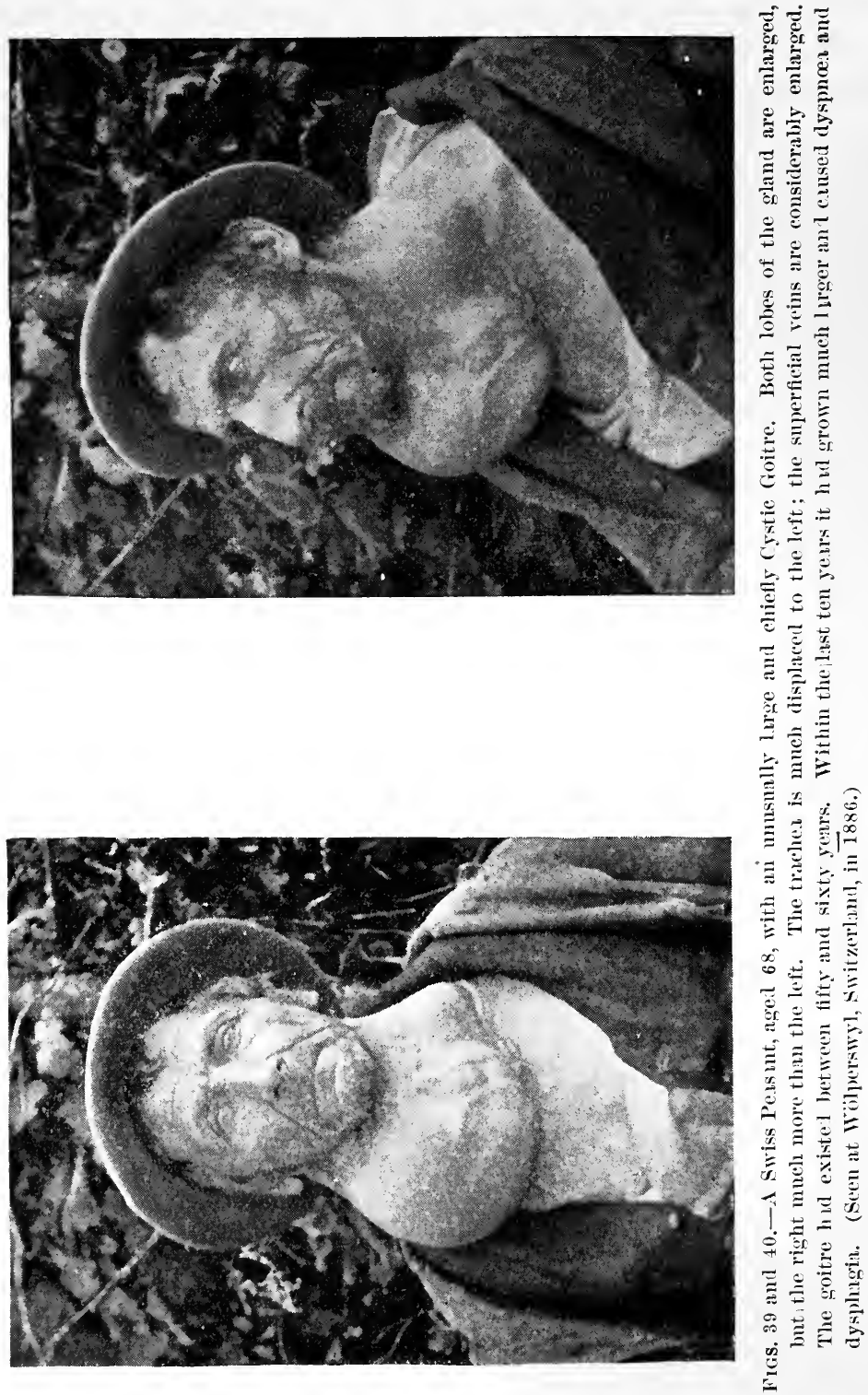
It should be borne in mind also, that a swelling situated in the lower part only of one lateral lobe will often push the trachea over to the opposite side to such an extent that the tumour itself occupies a position in the middle line of the neck. Such a tumour may closely simulate an enlargement of the isthmus itself and is frequently mistaken for this. It is a very common condition. The correct diagnosis is easily made by a careful examination of the exact position of the larynx or trachea. (See Figs. 43, 55 and 65.)

Very frequently, however, a thyroid swelling lies more to one or other side of the middle line, one lateral lobe alone of the gland being enlarged, or the enlargement affecting one lobe more than the other. (See Figs. 87, 103.)

Often, only a portion of one lobe is enlarged by the presence within it of a cystic or solid tumour. Such a tumour may be situated in almost any part of the front of the neck.

It may even lie mainly or entirely within the thorax behind the upper part of the sternum. In this case, the tumour has grown downwards from the lowest part of the gland.

On the other hand a thyroid tumour may involve only the apex of the superior horn of the gland and lie entirely at the upper part of the neck near the angle of the jaw. Of this I have seen several cases, from one of which the photograph shown in Fig. 41 was taken.

It is important to remember that a swelling of thyroidal origin may occasionally occupy such a situation. This high position is frequently a source of erroneous diagnosis. Tumours in such a position are often mistaken for lymphatic glandular swellings or even, as in one case that came under my notice, for a tumour of the submaxillary salivary gland.

In July 1894, I operated with Dr. Eminson at Scotter, Lincolnshire upon a man of 30 who had had for many years a globular swelling nearly two inches in diameter which lay directly in front of the thyroid cartilage and hyoid bone and slightly to the right of the middle line. Its lowest border was on a level with 
the crico-thyroid membrane, that is, wholly above the thyroid isthmus. 'The lateral lobes of the thyroid gland were not enlarged. A process of thyroid gland found at the operation

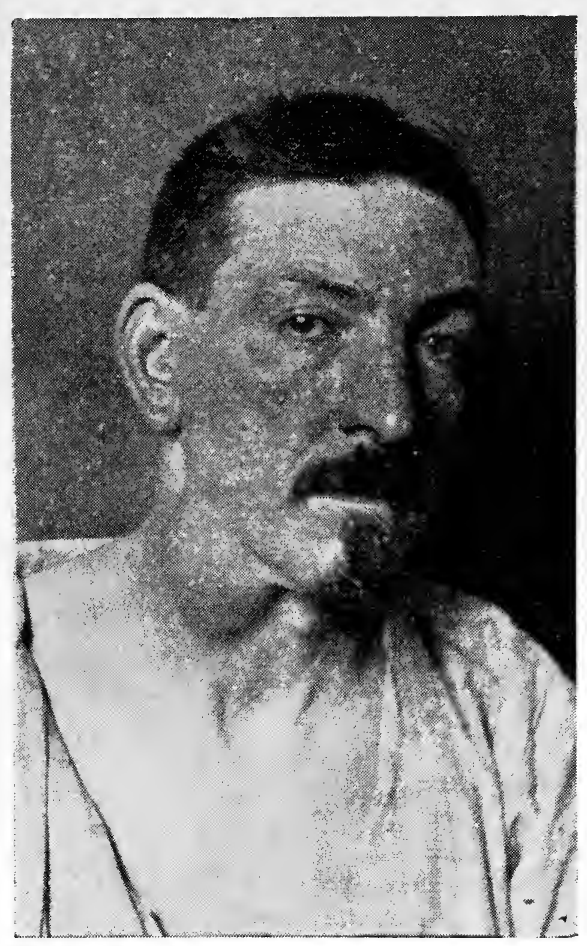

Fig. 41.-A ('ystic Tumour of the Thyroid, ocenpying an musually high position in the neck. (Seen at St. Burtholomew's llospit:ul.) to run up from the tumour behind the hyoid bone, together with the subsequent microscopic examination of the cyst wall, proved the tumour to have originated in the thyroid pyramid. 'The patient made an excellent recovery.

In February 1895, a young woman was sent to me by Miss Aldrich Blake, M.D., on account of an oval tumour as large as a pigeon's egg situated directly over the thyroid cartilageand slightly to the right of the riddle line. On account of a slight band of tissue which could be felt passing downwards from the tumour to the inner side of the right thyroid lobe, the tumour was recognised as one of the thyroid pyramid.

It may be noticed that in both these cases the tumour lay exactly in the line of the right thyroid pyramid.

Sometimes enlarged portions of a thyroid gland occupy still more curious situations. In a case of multilocular cystic goitre shown to me at St. Bartholomew's Hospital by Mr. Butlin, besides a swelling of the whole left lobe of the gland there existed a portion which appeared to extend transversely across the neck at the level of the hyoid bone from the apex of the 
enlarged left lobe to a point beyond the middle line of the neck.

In 1892 there came under my notice another patient of Mr. Butlin's, a young woman who had a movable tumour as large as a hazel nut situated just below the tip of the right great corner of the hyoid bone; after removal it was found to consist entirely of thyroid tissue.

In the very rare cases in which tumours of thyroidal origin exist actually within the larynx it may be impossible to make a correct diagnosis.

The position of a thyroid swelling with regard to the larynx and trachea has already been discussed. It remains for us to consider its position with regard to $(a)$ The muscles of the neck; (b) The great vessels of the neck; (c) The sternum.

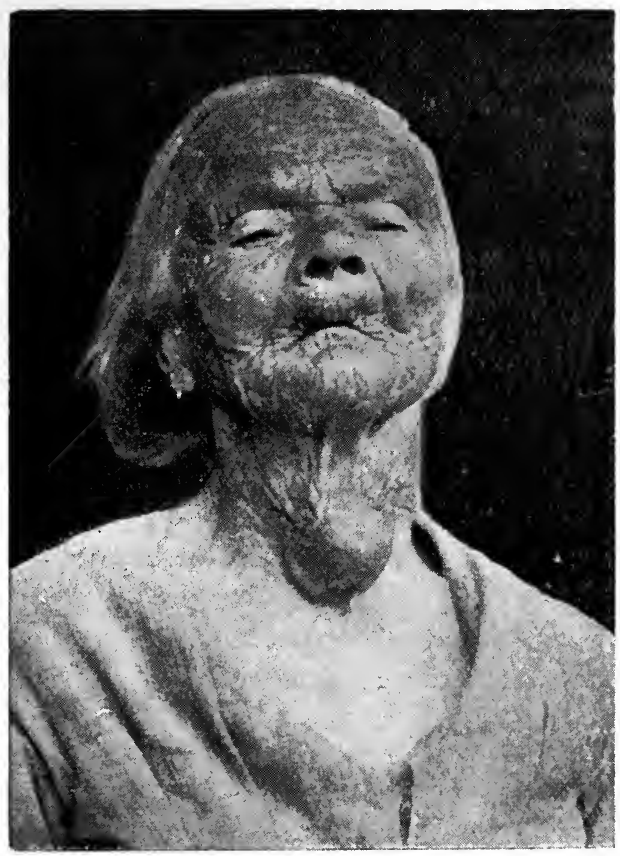

Fig. 42.-An :ge l Swiss Woms with a prominent ('yst" • Goitre of sul tll size. The tumonr had existed for many yeurs but has coused no dyspmoen. (Scen at Filourz, switzerl:ud, in 1×86.)

(a) Position with Regard to Muscles.-The position of the sterno-mastoid first demands our notice. This muscle, if the tumour be sufficiently large, is almost always displaced outwards and forwards. 'The tumour usually lies to its inner side and comes forwards more or less between the muscles of the two sides. If bilateral it displaces both sterno-mastoids.

Now a large number of tumours of the neck, especially those of lymphatic glands which at first sight may closely resemble tumours of the thyroid gland, differ from the latter in that they 

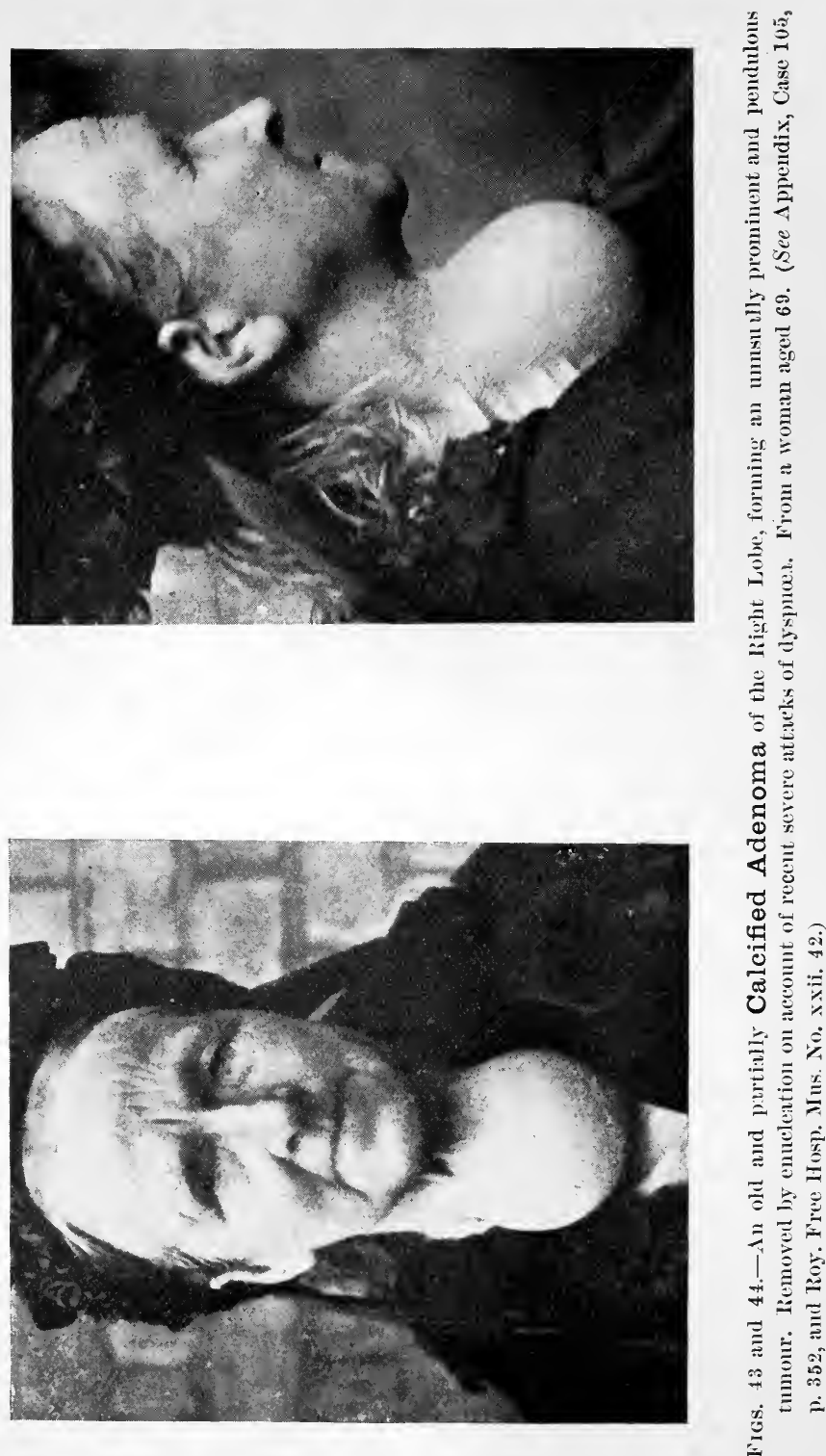
displace the sterno-mastoid to the inner side and consequently project into the posterior triangle of the neck.

At one time $I$ was inclined to attach more importance to this position of the sterno-mastoid in the diagnosis of thyroid tumour than I do now, since I have lately met with cases in which the greater part of the tumour (undoubtedly thyroid) lay to the outer and not to the inner side of the muscle.

I have recently removed the right lobe of a thyroid gland through an incision made wholly in the posterior triangle of the neck, so prominent was the swelling in this region (see Appendix, Case 102).

Sometimes the sterno-mastoid is so much expanded and thinned that it is difficult to determine its exact position.

The infra-hyoid muscles are spread out over the front of the tumour, but their exact position is not easily ascertained and they are of little value for diagnostic purposes. An exception, however, must be made for the omohyoid, the lower belly of which may be made very prominent in the posterior triangle of the neck by a tumour of the thyroid gland. The infra-hyoid muscles frequently lie in deep grooves upon the surface of the gland and may then produce sometimes a false appearance of lobulation in the gland.

Occasionally a thyroid tumour comes forward between the infra-hyoid muscles to such an extent as to lie almost wholly in front of them.

Fig. 42 taken from a patient whom I saw at Fribourg, Switzerland, shows an unusually prominent goitre, most of which lies anterior to the plane of these muscles.

Figs. 43 and 44 from a patient under my care at the Royal Free Hospital show a somewhat similar condition.

(b) Position with Regard to great Vessels of Neck.-As a thyroid tumour originates on the inner side of the carotid sheath, the latter becomes displaced outwards; usually it is also pushed backwards, so that the carotid artery may be felt beating at the posterior and outer part of the tumour. This is its usual position when the thyroid swelling is of an innocent nature. When however the gland is the seat of malignant disease, the 
artery is frequently displaced to a much slighter extent, being simply surrounded by the tumour.

The position of the artery is therefore of some value in the differential diagnosis between innocent and malignant tumours of the gland, but this subject will be discussed more fully in a subsequent chapter.

The following case illustrates the difficulty that sometimes arises in the differential diagnosis between tumours of thyroidal and non-thyroidal origin and shows the value of a careful observation of the exact position of the carotid artery.

In February 1895, a man aged 61 was admitted into St. Bartholomew's Hospital under the care of Mr. Bowlby, suffering from a mass of malignant disease on the side of the neck in the region of the right lobe of the thyroid. It was as large as a man's fist; the larynx and trachea were much displaced to the left, and there was urgent dyspnca and dysphagia. The carotid artery could be felt pulsating in front of the outer half of the tumour. The tumour although at first believed to be probably of the thyroid gland was proved on post-mortem examination to be a mass of epithelioma in the lymphatic glands of the neck, secondary to a growth in the thoracic portion of the osophagus. The right lobe of the thyroid was of normal size and compressed between the tumou and the larynx and trachea.

In this case the unusual position of the carotid artery afforded almost the only clue to a correct diagnosis.

In 1893 I had the opportunity of seeing an almost exactly similar case, also in St. Bartholomew's Hospital. In this case the carotid artery lay between the tumour and the trachea, and this, together with the fact that the trachea and larynx could be moved apart from the tumour, made it clear that the latter was not thyroidal.*

The position of the internal jugular vein is a point that merits special attention since it has important bearings upon the operation for removal of a goitre.

Normally, as every one knows, the internal jugular vein lies external to and slightly in front of, the carotid artery ; but as

* Both specimens are now in the museum of st. Bartholomew's Hospital. 
the artery becomes displaced, this relation is gradually altered. 'The artery is pushed outwards behind the vein, while the latter is carried forwards and is spread out upon the side of the tumour, or may even lie upon the front of it. In extreme cases the artery and vein may be separated from each other by a considerable interval, the vein lying in front of and nearer to the middle line than the artery. Hence it does not follow that the pulsation of the artery will necessarily indicate the position of the vein. A knowledge of this altered relation of the vein and artery to one another is obviously of much importance to the operator who, unless he is aware of it, is likely to wound the vein in an unexpected manner, an unfortunate accident by no means unknown in thyroidectomy.

Liicke offers the following explanation of this altered relation, which seems to me to be undoubtedly correct. The veins which pass from the thyroid plexus to the internal jugular vein exercise a certain amount of traction upon it and tend to prevent its lateral displacement. The common carotid artery, however, being devoid of branches and thus having no such connections with the tumour, is free to move outwards, and accordingly does so when pressed upon by the growth.

The superior thyroid arteries can frequently be felt pulsating at the upper and inner border of the thyroid tumour, and may occasionally be of some slight help towards a diagnosis.

(c) Position with regard to Sternum and Clavicle.The relation of the tumour to the sternum is one of great importance with regard to prognosis in cases of thyroid tumour, although from a diagnostic point of view it is of less interest.

A thyroid tumour, unless quite small, generally extends as low down as the upper border of this bone. It frequently descends below this level. Rarely does the tumour descend in front of the sternum, except in the case of very large goitres. Behind the sternum, however, prolongations often extend downwards for a considerable distance into the mediastinum. McWhinnie, in his lectures upon bronchocele, figures a case of this kind in which the goitrous prolonga- 
tion extended downwards as far as the bifurcation of the trachea.*

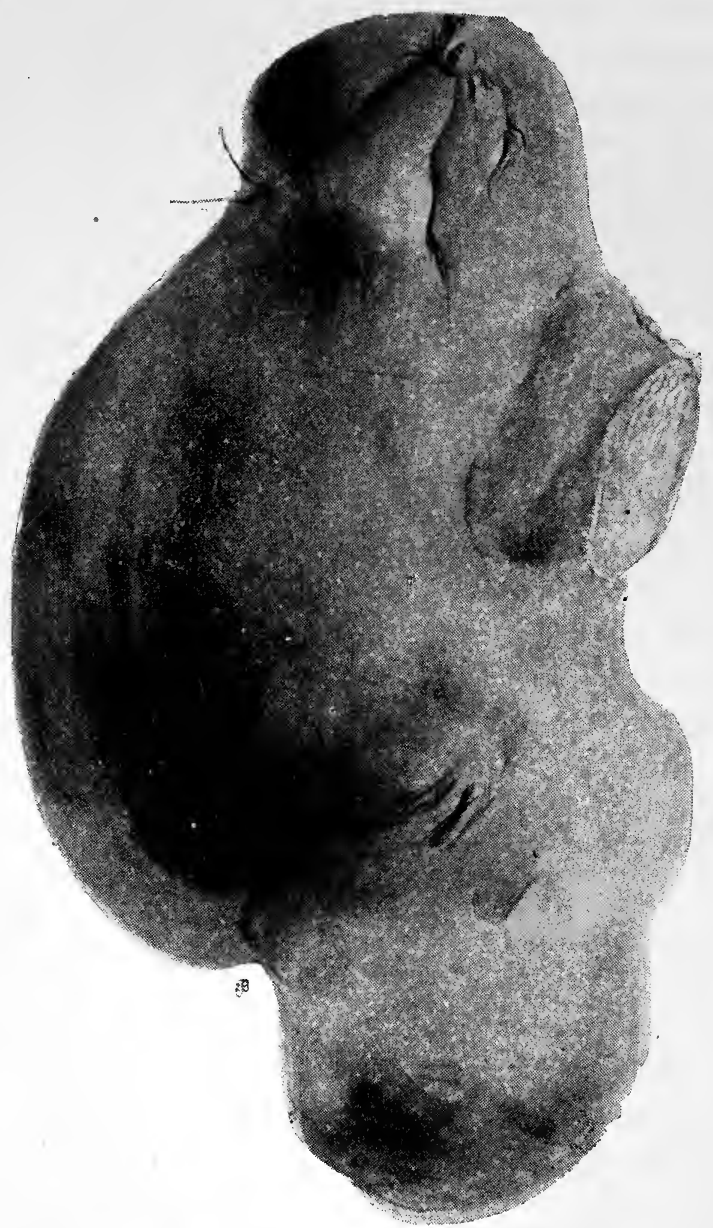

Fig. 45.-The light llalf of a mainly Parenchymatous Goitre removed by Extippation on acsomt of severe Dyspncea. The inferior horn extended deeply into the thorax. The indentation produced by the first rib is very marked. From a woman aged 44 (Case 20t). (Royal Free Hosp. Mus. No. xxii. 58.) (slightly reduced.)

* Lancet, 1861, vol. ii. p. 30.

$\dagger$ This case was published in the Brit. Med. Journ. for July 7, 1900. Owing to foreshortening the inferior horn appears in the figure to be a little wider than it should be. 
In a case of my own in which I removed a substernal goitre that was causing serious pressure upon the trachea $I$ found that the lowest part of the goitre was no less than $3 \frac{1}{2}$ inches below the lower border of the isthmus; in other words between two and three inches of the tumour lay behind the sternum. (See Fig. +5.)

In some cases the goitre lies almost entirely below the level of the upper border of the sternum.

In December 1892, I assisted Mr. Anthony Bowlby at an operation upon a large cystic goitre which lay almost entirely behind the sternum. The upper border of the cyst was about one inch above the sternum, the lower border was in contact with the arch of the aorta, which could be plainly seen and felt at the bottom of the wound.

In 1893 I removed a large, partly solid and partly cystic, goitrous tumour, measuring $2 \frac{1}{2}$ inches in diameter, from the thorax of a man aged fifty-three. During ordinary respiration the tumour lay so deeply in the thorax that there was no perceptible swelling in the neck, and the top of the tumour could only just be felt on palpation. This goitre had caused most severe dyspnœa.*

A case in which the goitre descended as low as the ninth dorsal vertebra has also been recorded. $\dagger$

To tumours such as these the name of "substernal goitre" (goître plongeant) is often applied.+ They form a class of exceedingly dangerous tumours often very difficult to diagnose. Naturally they may easily be confusedjwith various other mediastinal swellings such as enlarged lymphatic glands, thoracic aneurism, or malignant growth.

Wölfler $§$ has recorded a very singular case in which a goitre changed its position from time to time, lying sometimes in the

* This case is described more fully on pp. 105, 106. The tumour is now in the Royal Free Hosp. Mus. No. xxii. 59.

$\dagger$ Kretschy, Wien. Wed. Wochenschr., 1877, No. 1,quoted by Liebrecht, "De l'excision du goitre, sc.," p. $1+6$.

$\ddagger$ Another case of this nature was shown to me in 1886 by Dr. Kottmann in his wards at the hospital at soleure, Switzerland. The goitre lay almost entirely within the thorax and produced most violent dyspnoea.

\$ "Ueber den wandernden Kropf," Wien klin. Wochenschr., 1889, ii. 371373. 
neck, sometimes in the thorax. When in the former situation, it formed an obvious prominent swelling as large as a hen's egg and gave rise to no respiratory trouble. When it slipped down into its thoracic position it could no longer be seen or felt, but it then caused very severe respiratory and circulatory trouble by pressing upon the trachea and upon the innominate vein. The goitre was discovered during the course of an exploratory operation which was undertaken for the relief of the dyspnoa that was threatening the patient's life. A distinct cavity lined by a connective-tissue capsule was found behind the inner end of the clavicle, and here it was that the tumour lay when not in the neck. Another curious feature of the case was that when in its thoracic position the goitre became nearly twice as large as it was when in the neck. 'This was due, according to Wolfler's explanation, to the pressure exerted upon the veins returning from the goitre.*

Pulsation.-This is so commonly described as existing in a thyroid tumour that it deserves brief mention. Pulsation is often due simply to the close proximity of the carotid artery which communicates its pulsation to the adjacent mass. Frequently the pulsation felt is not that of the carotid but of the superior thyroid artery which runs along the anterior and inner border of the lateral lobe of the thyroid; large arterial branches sometimes run over the surface of large goitres and may be easily felt and even seen in this situation. Occasionally the whole tumour appears to have an inherent pulsation and this is especially the case with the goitre of Graves's disease. Inherent pulsation was very marked in the case of the large malignant goitre depicted in Fig. 82. In this case the pulsation was probably due to large vessels ramifying within the unusually vascular growth.

The pulsation of a thyroid tumour has, not unnaturally, led in many cases to an erroneous diagnosis of aneurism. Numerous .cases of the kind have been recorded. One of the most interesting is that of Nélaton's quoted by McWhinnie. $\dagger$ On the right side of the neck just above the clavicle and behind the sterno-mastoid

* An almost exactly similar case of my own is described on pp. 105, 106.

$\dagger$ Lancet, 1862, vol. i. p. (it. 
was a firm tumour which pulsated forcibly. The common carotid artery could be traced over it. It was pronounced to be an aneurism of the aorta. Post-mortem examination showed the presence of a goitre, not of an aneurism. In 1887 1)r. Claye Shaw showed me at Banstead Lunatic Asylum a middle-aged woman who had an oval swelling as large as a hen's egg in the situation of the right lobe of the thyroid gland. It pulsated strongly. It moved with the larynx during deglutition and was clearly an innocent goitre, probably cystic. Nevertheless this had been mistaken for a carotid aneurism by another doctor who had previously seen the case, and it was at first difficult to persuade him that it was only a goitre, and that the pulsation was communicated fiom the carotid.

'The converse may be illustrated by a case I saw with Dr. Gray at the Islington Infirmary in 1886. A middle-aged woman had a pulsating, elastic, oval, deep-seated swelling at the root of the neck just above the episternal notch. In one lobe of the thyroid gland was a small indurated mass, evidently the remains of an old shrunken goitre. The question arose whether the pulsating swelling was derived from the thyroid gland or whether it was an aortic aneurism. Careful examination however showed that the thyroid swelling moved independently of the pulsating mass, and it was decided that the latter was an aneurism. 'There were besides other symptoms of thoracic aneurism.

Dr. Carver of Addenbrooke's Hospital, Cambridge, has kindly communicated to me through Mr. A. G. Francis the particulars of the case of an elderly man who had a malignant cyst of the thyroid gland. He had been sent to the hospital as a case of carotid aneurism. Pulsation was marked but there was no bruit.

In Nov. 1895, I saw with Dr. W. B. Fergusson at Painswick, Gloucestershire, Mrs. ——, aged fifty-nine, who had noticed a month previously a pulsating swelling at the root of the neck just above the sternum. The right carotid artery was displaced forwards and could be moved upon the tumour. 'There was a patch of dulness about two inches in diameter just below the inner end of the clavicle. The right sympathetic nerve was partially paralysed. The thyroid gland appeared to be slightly 
THE THYROID GLAND.
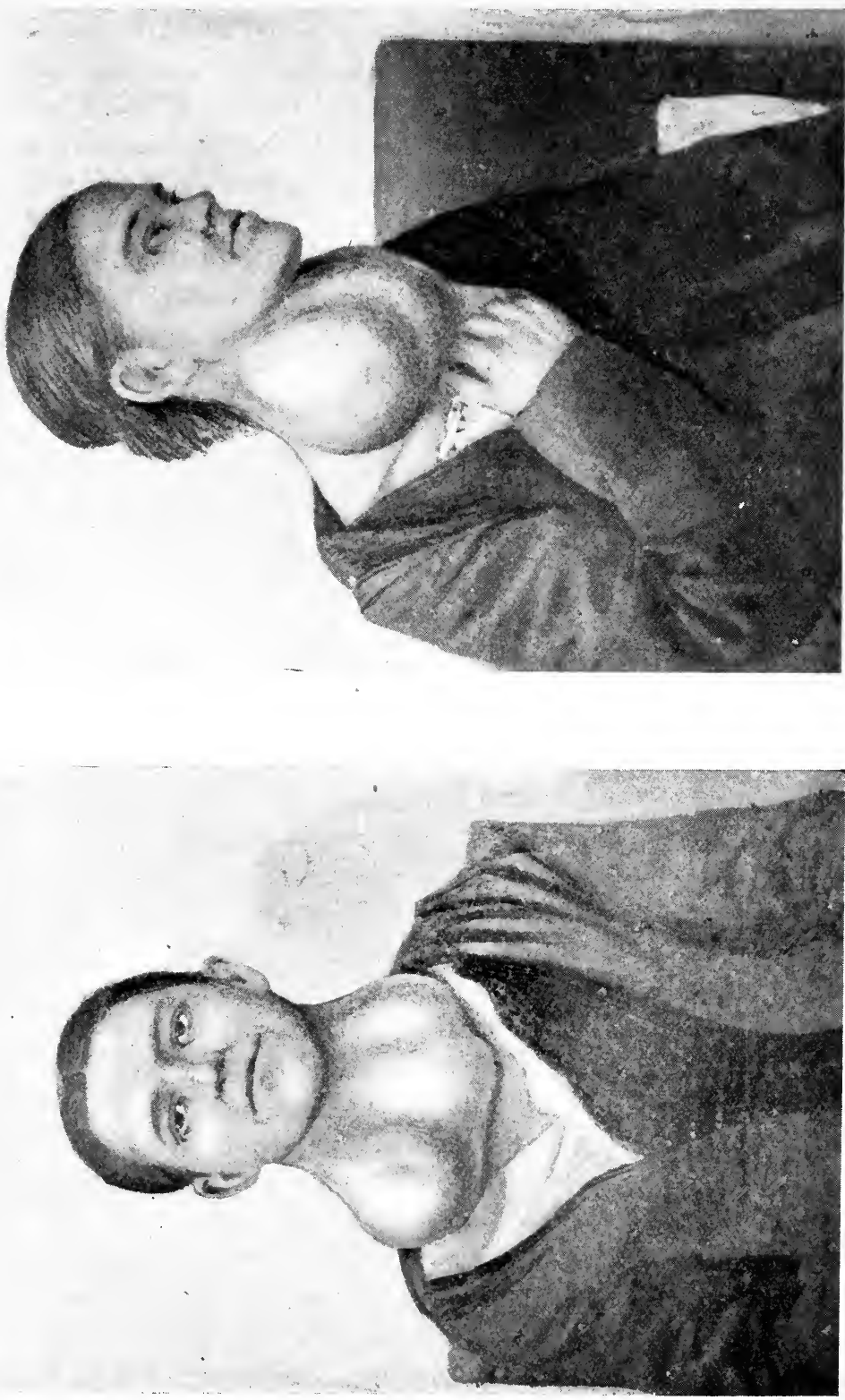
enlarged and had no obvious connection with the tumour. The radial pulses were equal. There was no bruit. When the patient strained, the swelling at the root of the neck became more prominent. There was little or no dyspnoea. In this case I was uncertain whether the patient was suffering from an aortic or innominate aneurism or a substernal goitre transmitting pulsation from the aorta. Three years later (Sept. 1898) the patient was still in good health and the tumour had not increased in size; there was no doubt that the case was one of substernal goitre and not aneurism.

Dalrymple* and Raynaud $\dagger$ have also recorded similar cases of goitre simulating aneurism.

It might be supposed that the presence of a bruit would serve to distinguish an aneurism from a thyroid tumour. This would however be a most fallacious supposition, since a well-marked bruit is often heard in a case of simple goitre. It was partly owing to the presence of a bruit that Nélaton was led to the erroneous diagnosis above mentioned.

In 1886 I saw with Dr. Raglan Thomas at Llanelly an elderly woman with a large right-sided oval goitre which had existed for many years. An exceedingly loud and harsh murmur was audible all over the right side of the tumour. There was no cardiac bruit. Figs. 46 and 47 represent a woman whom I saw at the village of Sevington St., Mary, in Somersetshire. She had a very large goitre, over parts of which a loud harsh murmur could be heard.

In the case of another woman, under the care of Sir 'Thomas Smith in St. Bartholomew's Hospital, a very loud murmur was audible along the inner border of the left lobe of the goitre. In this case over the same region was a very well marked thrill. In all these cases, the murmur was equally audible whether pressure was made upon the tumour by the stethoscope or not.

In many cases however the murmur is simply factitious, produced by the pressure of the stethoscope, but it is not necessary to quote any examples of this common condition.

* Journ. of Morb. Anat., Lond. 1828, i. 43-47.

$\dagger$ Bull. Soc. Anut. de Puris, 1859, xxxiv. 348-350. 
Consistence.-This may be of any degree between extreme softness and stony hardness. Examples of the former may be

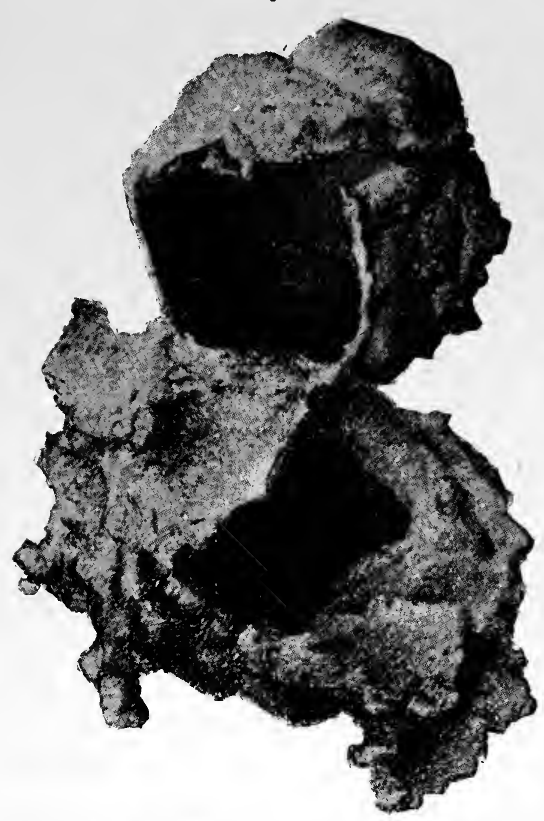

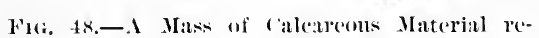
moved, after mereration, from an old Goitre. (St. Bart. Hosp. Mns. No, 2317.) (Enlarged $\left.\frac{5}{2}.\right)$ seen in many cases of soft parenchymatous goitre, in some adenomata and in partially filled thin-walled cysts. Some parenchymatous goitres containing numerous small tense cysts are extremely hard. So are the rare fibrous goitres. 'The hardest goitres are naturally those which have become calcified. Most museums contain specimens illustrating this. One of the best that have come under my notice may be seen in the museum of the Sussex County Hospital at Brighton. A goitre as large as a man's fist has become almost entirely calcified. There are also two beautiful specimens in the Pathological Museum at Prague.*

Pressure Effects. - An enlarged thyroid gland causes pressure upon various surrounding structures. Many of the symptoms thus produced are of the utmost importance.

Pressure on Veins.-This is very common. The veins chiefly affected are those which bring blood from the head and neck, namely the internal, external and anterior jugular. The innominate and even subclavian veins may be compressed by a goitre deeply seated at the root of the neck. The pressure on the jugular veins causes distension and dilatation of them and frequently they become very prominent. Figs. 39 and 56

* For other examples of calcification see Univ. Coll. Mus. No. 1361 ; St. Bart. Hosp. Mus. Nos. 2316 and 2317; Guy's Hosp. Mus. 121, 122, 123 : King's ('oll. Mus. 280 . 
show examples of the venous distension caused by goitres. The obstruction offered to the venous circulation is said by some to cause buzzing in the head, deafness, vertigo and various other symptoms : the accuracy of these statements is, however, questionable. OEdema of the face and even of the arm are said to be produced occasionally by goitre but I have myself never seen an example of either and should doubt whether they ever occur except in cases of malignant or inflamed goitre.

Pressure on Nerves.-An innocent goitre, even though of large size, rarely causes much pressure upon nerves. In cases of malignant disease, however, pressure upon, or involvement of important nerves, often causes early and well-marked symptoms of the affection. (See p. 208.)

The chief nerves pressed upon by an enlarged thyroid gland are $(a)$ the recurrent laryngeal, $(b)$ the sympathetic, $(c)$ the vagus, and $(d)$ occasionally the nerves of the cervical and brachial plexuses.

(a) Recurrent Laryngeal Nerve.-Occasionally, it is found that the recurrent nerve is spread out upon the posterior surface of a goitre. When this is the case, more or less interference with its function may take place. More often, however, the nerve is pushed inwards and is not stretched by the goitre. It is important to bear in mind that the dyspnoea caused by innocent goitre is, in the vast majority of cases, produced by direct pressure upon the trachea, and not, as is sometimes alleged, by irritation of the recurrent nerves causing spasm of the glottis.

In cases of malignant disease, the nerve, as might be expected, is frequently found involved in the tumour.

Complete paralysis of a vocal cord, caused by a thyroid tumour, should always be looked upon with some suspicion, as affording a presumption of the malignant nature of the latter. Too much importance must not, however, be attached to this symptom alone. I have seen several cases of complete paralysis of one vocal cord caused by a goitre undoubtedly not malignant.

Thus, Dr. Rayner Batten sent to me at the Royal Free 

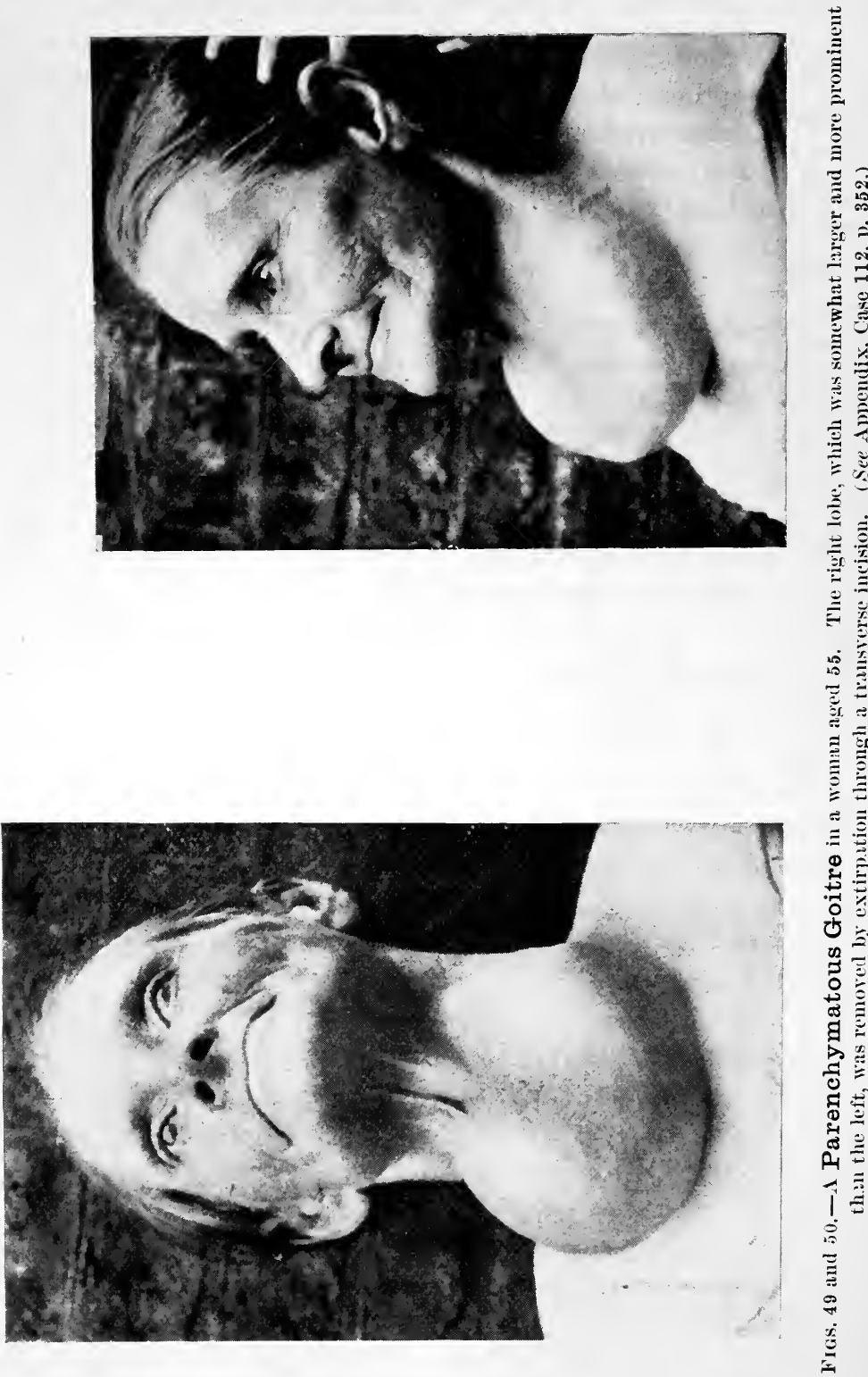
Hospital, a girl who had had, for several years, a right-sided bronchocele as large as an orange. The vocal cord on the corresponding side was completely paralysed. Nevertheless, from the clinical history of the case, it was evident that the goitre was not malignant.

In 1888 I saw, at St. Bartholomew's Hospital, a young man under the care of Mr. Howard Marsh. A moderately large unilateral goitre had caused complete paralysis of the left vocal cord. 'This symptom, together with the comparative fixity of the tumour, and its rather rapid growth raised a suspicion of malignancy. An operation for removal of the tumour showed it, however, to be an innocent cystic adenoma.

Figs. 49, 50, 51, show a woman from whom I removed a goitre of moderate size, on account of dyspnœa. Before the operation one vocal cord was seen to be completely paralysed. The goitre was nevertheless perfectly innocent.

(b) Cervical Sympathetic Nerve.-This, also, is affected rarely by innocent growths of the thyroid, more frequently by malignant disease.

The following is an example of an innocent goitre causing contraction of the pupil by pressure upon the sympathetic nerve :

Miss Alice E_- aged 34, consulted me in October 1887, on account of a small goitre which she had had for at least ten years. In the left lobe of the gland was a rounded cystic adenoma about as large as a hen's egg. It was freely movable and caused little or no inconvenience. The pupil of the left eye was little more than half as large as that of the right side. The palpebral fissure, too, was distinctly narrower on the left side. The patient informed me that she had noticed that during menstruation, when the goitre became larger, the left pupil became still more contracted. I was unable to detect any alteration in the sweating or vascularity of the corresponding side of the head. This lady was seen again in August of the following year. The goitre was unaltered and the difference between the two pupils was just as marked as before. At no time had there been any disease of the eye or anything else, except the goitre, to cause the contraction of the pupil. 
An excellent example of the involvement of the sympathetic nerve by a malignant growth or the thyroid gland may be seen in Fig. 81 (p. 208). I saw this man with Mr. Howard Marsh, at St. Bartholomew's Hospital, in the autumn of 1887. A goitre of many years duration had, within the last few months, grown considerably, and caused the contraction of the right pupil and palpebral

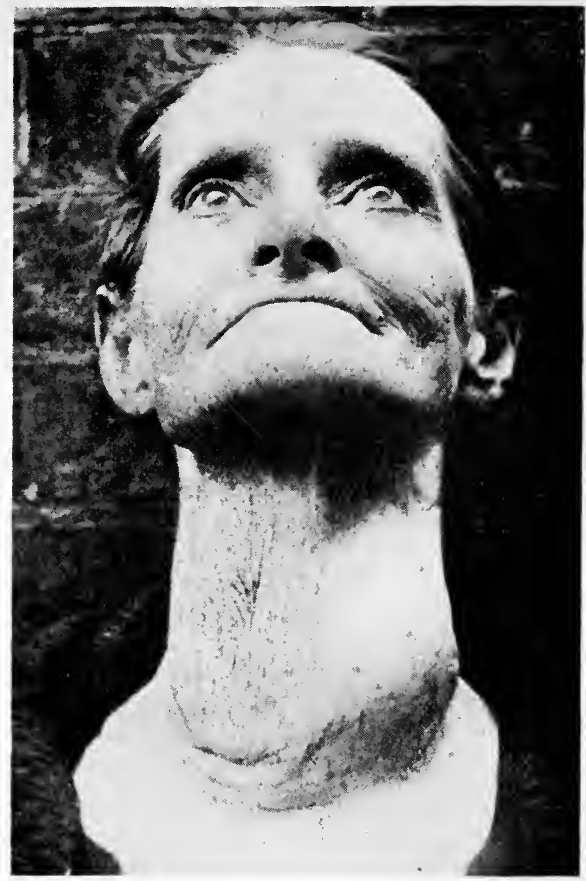

Fig. :1.-The sane (Figs. 49 and 50 ) showing the sen a week after operation. (See Appendix, ('ase 112, 1. 352.)

fissure shown in the photograph. Partly on this, and partly on other grounds, we considered the disease to be malignant, and advised that no operation should be performed. 'I'he diagnosis was subsequently verified, * the patient dying in the course of the following year.

* The subsequent history of this patient has been published by Mr. Syduey Jones and Mr. Battle in St. Thomas's IIospital Reportis, 18889, vol. xviii. p. 233. See also 1. 213. 
It was formerly believed by some that many of the symptoms of Graves's disease were attributable to an irritation of the cervical, sympathetic, and vagus nerves caused by pressure of the goitre upon them. I allude to this theory only to say that evidence in support of it is wholly absent.

(c) Pressure upon the nerves of the cervical and brachial plexus is occasionally produced by innocent goitres, and may cause numbness and tingling or even severe pain in the side of the head and neck, or down the arm. In cases of malignant and inflamed goitres, these symptoms are common. In my lectures * on goitre, delivered before the Royal College of Surgeons in 1891, was recorded the case of a man, aged 64 , from whom I enucleated a large cyst of the left lobe. This had caused, for some months, severe pain in the left side of the head and neck, and I was inclined, at first, to suspect malignancy. The tumour proved, however, to be quite innocent, and after recovery from the operation, the patient remained quite free from pain.

Pressure upon Larynx and Trachea.-The larynx is frequently displaced to one or other side, and is sometimes slightly indented by the long-continued pressure of a goitre.

A good example of deformity of the larynx caused by the pressure of a goitre may be seen in Guy's Hospital Museum. $\dagger$

It is upon the trachea more than any other structure that an enlarged thyroid gland is liable to press, and thus produce injurious effects. This is scarcely surprising when we reflect how intimately the trachea is connected with, and embraced by the thyroid gland. Any enlargement of the latter can, therefore, hardly fail to produce some pressure upon it. Only too commonly is this pressure the cause of serious and even fatal trouble to the patient.

'The pressure which an enlarged thyroid gland exerts upon the trachea may lead to: (i) Displacement; (ii) Compression.

(i) Displacement.-By far the most common displacement caused by the pressure of a goitre is a lateral one, the trachea

* Brit. Med. Journ., June 27, 1891.

$\dagger$ No. 168. 
being pushed over to one or other side by the enlargement of the opposite lobe of the gland.

This displacement is always accompanied by a certain amount of curving of the trachea upon itself, and frequently by some twisting of the trachea upon its long axis.

In very rare cases the trachea is displaced directly or obliquely forwards.

(ii) Compression.-The trachea being composed of incomplete rings of cartilage which are open posteriorly, readily admits of compression and narrowing of its lumen. In proportion as the trachea is diminished in calibre so does the patient's breathing become laboured, and in fact we find that difficulty in breathing is one of the most common symptoms of goitre. 'The brassy nature of the cough caused by the pressure of the tumour is well known to be characteristic of compression of trachea or bronchus and may generally be readily distinguished from that which is due to laryngeal obstruction.**

'That the dyspnoea caused by goitre is due, in most instances, to direct pressure upon the trachea itself, and not to pressure upon the recurrent laryngeal nerves, is shown by the rarity with which dysphonia occurs. Dyspnoea is one of the commonest accompaniments of a thyroid enlargement. Dysphonia is distinctly rare.

The whole subject of displacement and compression of the trachea will be discussed more fully in the next chapter, which deals with the dyspnoea produced by enlargement of the thyroid gland.

It will be sufficient to mention here briefly that the compression of the trachea is almost invariably lateral and not anteroposterior. This has a very important bearing upon the treatment of the dyspnoea produced by goitre.

Pressure upon Esophagus and Larynx.-The osophagus lying behind the trachea is much less often compressed than is the latter. It is not uncommon, however, for one or other lobe of the giand, or even both lobes, to extend behind the trachea

\footnotetext{
* Any one who wishes to produce an exact initation of this brassy cough may easily do so in his own person by making firm pressure with his thumb upon the trachea just above the sternum, and then coughing.
} 
and displace the oesophagus to one side or to compress it on both sides.

In the Museum of King's College Hospital * is a well-marked example of deviation and compression of the osophagus from a prolongation of the left lobe of a goitre which extends behind the trachea.

In the Pathological Museum of Berne is an excellent collection of no less than four well-marked examples of goitre causing pressure upon the cesophagus.

A case which came under my notice several years ago was that of a woman who was admitted into one of the London hospitals and treated for a time by bougies for cesophageal stricture supposed to be malignant. There was, however, no true stricture, the difficulty in swallowing being caused simply by the pressure of a small unilateral goitre which had at first escaped observation.

Kaufman, $\uparrow$ in his article on retro-pharyngo-øesophageal goitre, has collected several cases, one of them under his own care, in which a distinct prolongation of the gland extended behind the pharynx and oesophagus and caused much difficulty in swallowing. In one of these the dysphagia was so great that oesophagotomy was performed, unfortunately with a fatal result. Another case has been recorded in which death by starvation actually occurred from the pressure of a goitre upon the œesophagus. +

In several of my own operations upon parenchymatous goitres I have noticed the existence of small prolongations of the growth behind the pharynx and oesophagus.

In February 1895 I saw a young woman aged thirty-six who was admitted into St. Bartholomew's Hospital under the care of Sir 'Thomas Smith, complaining of dysphagia. 'The passage of a full-sized asophageal bougie showed that no real stricture existed. A small deep-seated goitre involving the isthmus and

* No. 277.

+ Reported by Lotzbeck from Prof. Bruns' wards " Chirurg. Mitth. aus der Klinik von Prof. v. Bruns in T'übingen," in Deutsch. Klin. Jahrg., 18.59, vol. xi. p. 59 .

† P. Koch, "Ann. d. mal. d'oreille et du larynx," Paris, 1881, vii. p. 86. 
left lobe of the thyroid gland, and of the existence of which the patient was quite ignorant, appeared to be the main cause of the dysphagia.

It is by no means uncommon to see a marked bulging inwards of the pharyngeal wall caused by the pressure of a goitre. Sometimes, when the goitre is especially well developed posteriorly, this bulging may be very marked even if the goitre present but little external swelling. 


\section{CHAP'TER VII.}

\section{THE DYSPNOEA CAUSED BY GOITRE.}

Frequency and importance-Pressure upon trachea-Lateral compression-Scabbard-shaped trachea-Effect on trachea of bilateral goitre, unilateral, median-Softening of tracheal wall - Pressure upon recurrent nerves-Direct extension to trachea-Rupture of cyst or abscess-CEdema of glottis-Swelling of tracheal mucous membrane -Varieties of goitre most likely to cause dyspnoa ; relation to age and sex-Danger of bilateral goitre of puberty and of deeply seated goitres - Table of cases of goitre causing death by suffocation.

OF the various symptoms which may be produced by an enlargement of the thyroid gland, dyspnoea is, undoubtedly, by far the most important.

In 95 out of the 126 cases in which I have myself had to remove a goitre the chief reason for the operation was dyspnoea.

In 16 of the other cases, some dyspnoea was also present, although it was not the main reason for the operation.

Frequently, dyspnoea is the only inconvenience of which a goitrous patient complains and for which he seeks advice. Often it is present to such an extent that a constant dread of impending suffocation hangs over the unfortunate sufferer, and prevents him from following any regular occupation.

Only too often is death itself the result of the gradually or suddenly increasing dyspncea. (See table of cases at the end of this chapter.)

It is not very uncommon for a patient to seek advice with regard to dyspnoea, the cause of which is unknown until an examination of the neck reveals the presence of a goitre which had hitherto not been noticed by the patient.

The following is a good example:

Archibald T-, aged 53, was admitted in March 1893 into the Royal Free Hospital under the care of my colleague 
Dr. Sainsbury, suffering from a severe attack of what was at first supposed to be "asthma." The dyspnœa was so extreme that it was thought that the man was about to die and the propriety of performing tracheotomy was discussed by the resident medical officers. The breathing improved somewhat however after a few hours rest in bed. When Dr. Sainsbury saw the patient a slight fulness was discovered at the root of the neck just above the sternum. This was the top of a large substernal goitre of whose existence the patient was quite unaware. I subsequently removed the goitre by operation. The patient made a good recovery and was entirely freed from dyspnœa. Six years after the operation he was still in excellent health and had had no further trouble of any kind.

Cases have come to my knowledge in which dyspnoea has been supposed to be due to asthma or bronchitis, and treated accordingly for months or years, the true cause lying, wholly unsuspected, in an enlargement of the thyroid.

Such mistakes are most likely to occur in cases of small and symmetrical, or deep-seated tumours, and these are especially liable to cause severe dyspnoea.

The following case has been published by Gaucher : *

In May 1842, a man aged 28 was admitted to M. Husson's wards in the Hotel Dieu. He was quite unconscious and was breathing in a laboured manner. It was known that for a long time he had suffered from dyspnoea, although it had never before been so bad as to threaten life. It was said also that he had pain about the region of the ears. Some cerebral affection was diagnosed and leeches were applied to the mastoid processes. No relief followed, the patient became more and more cyanosed and died on the following day. At the post mortem the ordinary signs of death by suffocation were discovered. The thyroid gland was enlarged in all parts and contained also a few small cysts. Death was attributed to pressure upon the trachea.

The remainder of this chapter will be devoted to a consideration of the various modes in which dyspnoa may be caused by diseases of the thyroid and to the varieties of such diseases which are most liable to cause dyspnoea.

* "Asphyxie par hypertrophie de la glande thyroïle," Bull. Súc. Anat. de Puris, 1842, xvii. 178. 
There are various ways in which an enlarged thyroid may cause dyspnœa.

1. Direct pressure upon the trachea.-This is by far the most common and important.

Occasionally other conditions have some share in the production of the dyspnœea, either alone or more often in combination with the preceding. Such are :

2. Pressure upon or other irritation of the recurrent laryngeal nerves.

3. Direct extension of growth into the interior of the trachea or larynx (very rare, except in cases of malignant disease, in which it is common).

4. Rupture of a CYST or abscess into the air passages.

5. Sudden hemorrhage into the gland or from it into surrounding tissues.

6. OEDema of the glottis or of the mucous membrane of the trachea.*

1. Direct pressure upon the trachea may cause: (i) Displacement of the trachea; (ii) Compression of the trachea.

(ii) The subject of displacement of the trachea has already been discussed in chap. vi. p. 101.

(ii) Compression of the trachea may be lateral, anteroposterior, or, according to some authors, circular.

Of these, by far the most important form of compression is the lateral. In comparison with this, both the other forms are exceedingly rare. Indeed, it is doubtful whether a true circular compression has ever been observed.

Among all the thyroid specimens contained in more than twenty British and foreign museums, I have not been able to find more than four in which any antero-posterior flattening of the trachea was present. In the vast majority the compression had been exerted laterally. $\dagger$

A typical example of the common lateral flattening is that from which Figs. 1 and 2 have been taken.+

* Spasm of the muscular fibres at the back of the trachea has by some authors been deemed a factor in the production of the dyspnoea, but this theory does not seem to me worthy of serious consideration.

$\uparrow$ For examples of the rare antero-posterior flattening of the trachea, see St. Bart. Hosp. Mus. No. 2310A ; St. Mary's Hosp. Mus. No. 1031 (very slight).

$\ddagger$ St. Bart. Hosp. Mus. No. 2310. For some examples of lateral flattening 
The patient was a boy, aged 14, who died from dyspncea produced by the goitre. Laryngotomy had been performed, but was useless, doubtless because the tube used was not long enough to reach below the constriction.

The lateral flattening of the trachea, produced by goitre, has long been known. It is commonly stated that attention was first drawn to it by Demme of Zïrich, but it would appear that the credit of having done so belongs more properly to Lullier Winslow.

The latter author, writing more than eighty years ago, speaks in the following terms of the case which came under his observation.

"La trachée artère est comme enchattonnée dans la tumeur. Elle est aplatie latéralement en manière de gaine de sabre dans un étendu d'un pouce et demi, ayant à peine (vers le milieu de cette partie deformée) une ligne et demie posterieurement."*

Here we have apparently the first accurate description of this very important lateral flattening of the trachea. Demme at a much later period again drew attention to this condition. After him Rose (then of Ziirich) pointed out and insisted upon the great frequency with which this condition occurs, and he added a further statement with regard to the changes which occur in the wall of the trachea as the result of long-continued pressure. 'These will be discussed on page 114 .

Both Winslow and Demme compared the shape of the trachea when compressed by a goitre to that of the scabbard of a sword, and the comparison has been adopted by most writers upon the subject. Among some, however, the term "keel-shaped "appears to meet with greater favour.

It will be seen in Fig. 2 that the point of greatest constriction of the trachea is rather more than one inch below the cricoid cartilage. This is the commonest seat of the greatest

see the museums of Roy. Coll. Surg. Eng. Nos. 2895, 2900 ; Unir. Coll. Lond. 1360 ; Guy's Hosp. 116 ; St. Geo. Hosp. 16c, 19A ; St. Mary's Hosp. 1032 ; st. Thomas's Hosp. 1462, 1463, 1465, 1468 ; St. Bart. Hosp. 2310, 2311 ; Oxford University 544A; Roy. Coll. Surg. Edinburgh 1334; also Berne Path. Mus. B. II. 14, B. II. 24.

* "Observation sur un goitre volumineux comprimant la trachée artère," Bull. de l'Athenée de Med., f\%r., Paris, 1816. 
constriction in bilateral goitres of moderate size. 'The constriction frequently involves, as might be expected, a considerable length of the trachea.

Liebrecht in his excellent monograph* mentions that he removed from a dead body a very large goitre which had compressed the trachea in its whole length.

Kocher $\dagger$ gives excellent drawings of cases in which the trachea has been extensively compressed and variously twisted (see Fig. 54). I have myself seen more than three inches of the trachea compressed in cases in which the goitre was unusually large.

Influence which the Shape and Situation of the Goitre has upon the Compression of the Trachea.Bilateral Goitre.-It has often been stated that in cases of parenchymatous goitre, it is the isthmus especially that presses (antero-posteriorly) upon the trachea and causes dyspnoea; this view is certainly erroneous.

If the whole thyroid gland is uniformly enlarged as in the ordinary parenchymatous goitre, the shape of the compressed trachea is always the same. It is compressed laterally, never from before backwards. (See Figs. 52 and 58c.). This lateral flattening should be carefully borne in mind since it has an important bearing upon operative proceedings carried out for the relief of dyspnoea.

In some rare cases of uniform enlargement the whole gland may be rotated to a certain extent upon its vertical axis, so that one lobe projects a little more than the other. In such cases the trachea is also slightly rotated axially with the goitre.

If the gland be enlarged on both sides, but more on one side than on the other, the flattening of the trachea partakes more or less of the character described in the next paragraph, according to the disproportion between the two lobes.

Unilateral Goitre. - When the enlargement affects one lateral lobe only, the trachea is flattened upon the side next to the enlarged lobe. (Figs. 53, 58в.) In these cases the trachea is also more or less curved longitudinally and pushed over towards

* “De l'excision du goitre parenchymateux," P. Liebrecht, Brusse?s, 1883, 1). 1\%.).

† Langenbeck's Archirf. klin. Chir., 1883, vol. xxix. plate xi. 
the opposite side. There is generally also a certain amount of rotation upon a vertical axis, so that the trachea presents an oblique lateral surface against which the enlarged lobe rests.

Fig. 53* was taken from a specimen which I removed post
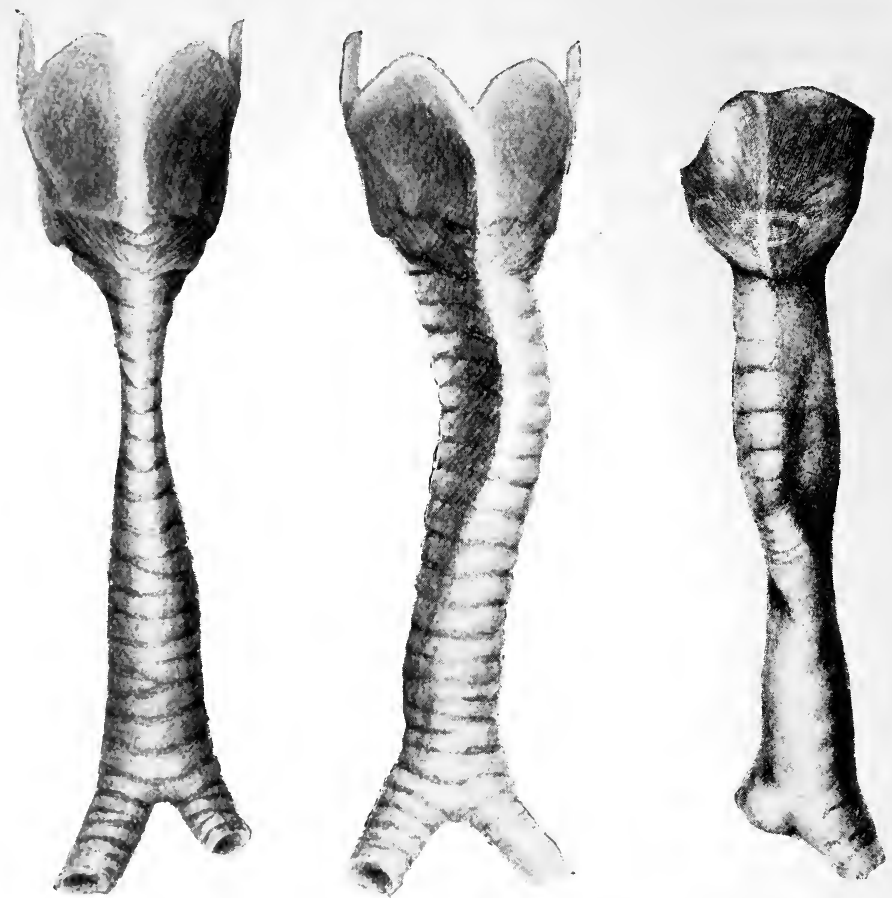

Fig. 52.-Fluw the orlintry Bilater.t Flattening of the Trachea probluecel by parenchyoutoms goitre and other forms of symmetrieal "nl:arement of tlee tlyyroild. From a girl atged 13, who died of suffocation c:nlsid by the soitre.

Fre. 53.-Show the ordintiry Flatening and Curving of the Trachen profures by milateral goitre. From a man aged 49, who died of heart dikcisar.

Fuc. It.- Shows the Irregular Flattening and 'Twisting produced by a hilatcral but asymuretrieal poitre.

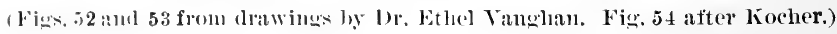

mortem from the body of a man aged forty-nine, who had had a unilateral cystic goitre for many years. It shows well the usual curvature, displacement and oblique lateral flattening produced by a unilateral goitre. Similar specimens may be seen in Guy's 
Hospital Museum,* in the Museum of the Edinburgh College of Surgeons, $\nmid$ and in many other museums.
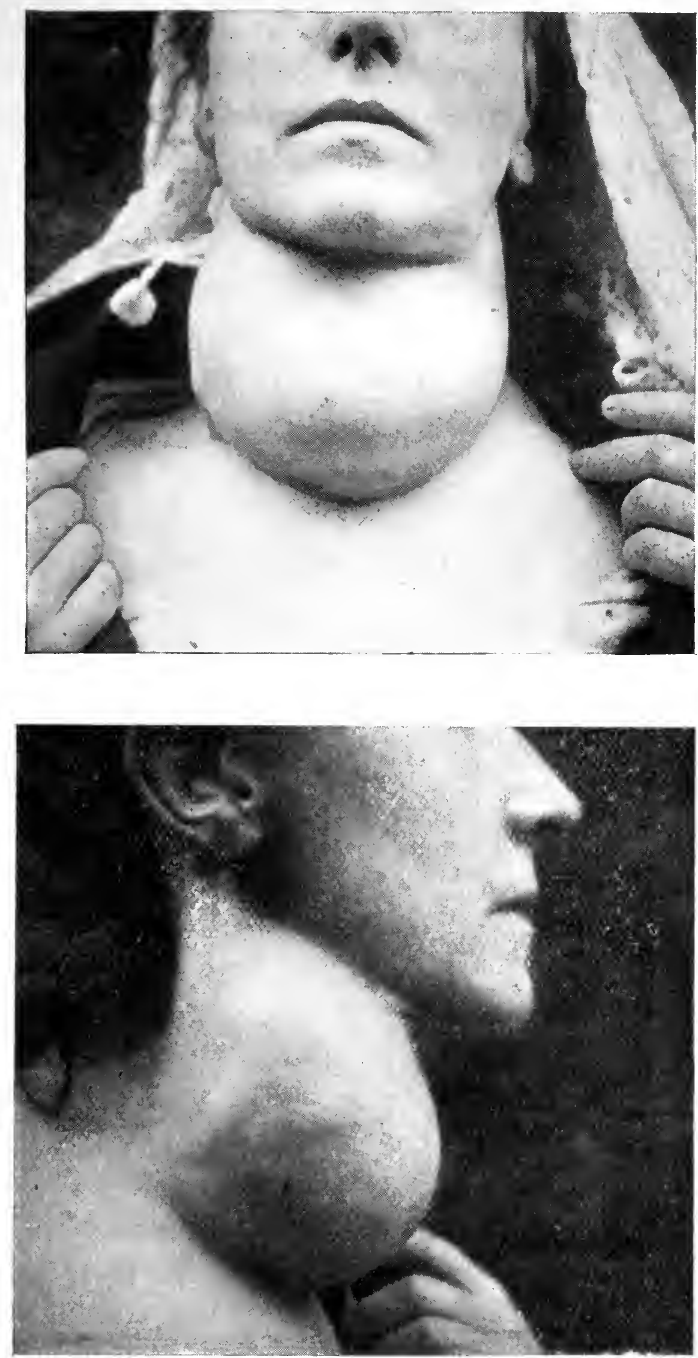

Figs. 55 and 56.-Large solid Adenoma of the Right Lobe, extending across the middle line and simulating a bilateral goitre. (See $\Lambda$ ppendix, Case 90, p. 350.)

* No. $1711^{92}$ (old catalogue). $\quad$ † No. 1336. 
The twisting and curvature of the trachea which are often met with and which have been well described and figured by Professor Kocher,occur almost exclusively either in cases of single unilateral tumour or of bilateral tumour in which the two sides of the gland are unequally enlarged.

Median Goitre in which the enlargement involves the isthmus alone and not the lateral lobes.-In this kind of goitre we

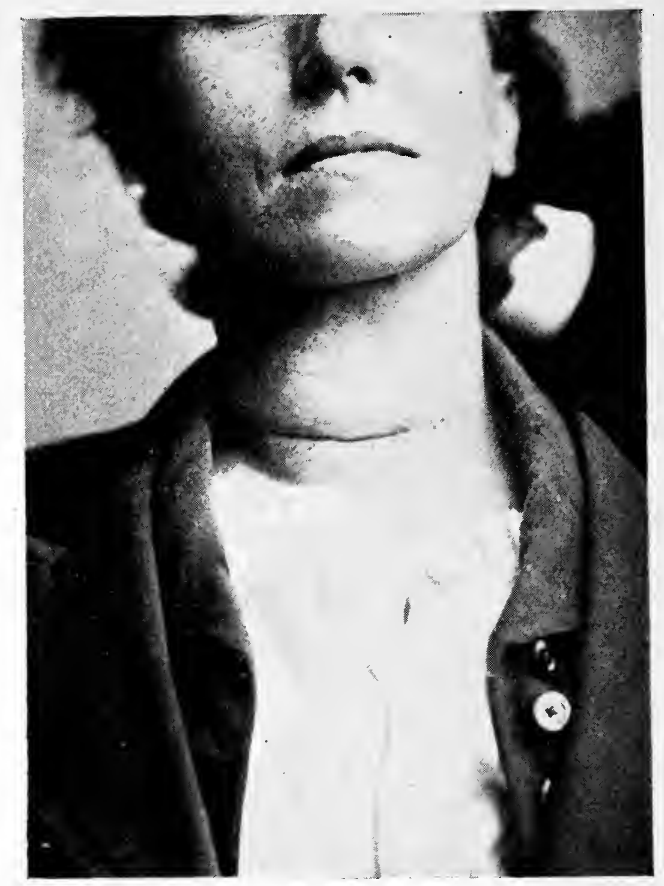

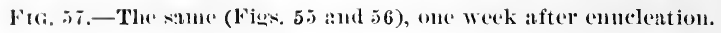

sometimes, although rarely, meet with a slight amount of true antero-postcrior flattening of the trachea. If the tumour be entirely above the upper border of the sternum, then the pressure exerted upon the front of the trachea is very slight. 'The tumour being free to come forwards will obviously do so rather than exert any appreciable degree of pressure upon the trachea. Such goitres searcely ever cause serious dyspnoa.

lig. $42(p .85)$ is taken from an elderly woman whom I saw at the 
Bourgeois Hospital at Fribourg. It shows a prominent median tumour springing from the isthmus alone. It produced no dyspnœa.

It should be borne in mind, however, that a tumour may present exactly in the middle line of the neck between the two sterno-mastoids, and yet not be a tumour of the isthmus. Tumours in this situation frequently spring from the lower part of one or other lateral lobe. (Figs. $43,55,65$.$) 'The$ trachea is pushed over to the opposite side and the tumour, passing in the direction of least

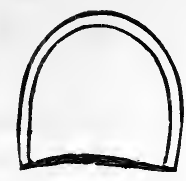

$a$

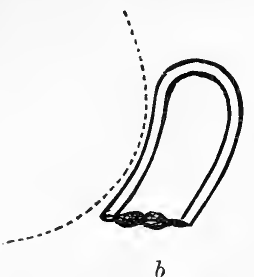

$b$

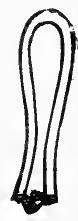

$c$

F'ra. 58.-Dingrams showing Transverse Section of Tracheal Rings. $a$, normal; $b$, flittenetl by unilateral goitre; $c$, flattened by bilateral goitre.

resistance, comes to occupy a position in the middle of the neck, just above the episternal notch. In such cases a careful examination of the position of the larynx and trachea and of the upper portions of the lateral lobes will generally lead to a correct diagnosis.

Occasionally strictly median tumours lie wholly or partly behind the sternum. It is in these cases only that any considerable amount of antero-posterior flattening of the trachea can be produced. The trachea may be pressed directly backwards against the spine by such a tumour engaged between it and the sternum. Far more often, however, the trachea slips to one or other side of the bodies of the vertebrye and becomes twisted and flattened obliquely. In the specimen at St. Mary's Hospital,* in which distinct though slight antero-posterior compression has occurred, the tumour consists of a globular cyst an inch and a half in diameter, situated exactly in the middle line. It descended as low as the tenth ring of the trachea, and it is doubtless owing to its low situation that it was enabled to exert some pressure upon the trachea, being jammed between it and the sternum.

Changes in the Wall of the Trachea produced by the pressure of a goitre.-Professor Rose, then of Ziirich, in an elaborate 
article," "Death from goitre and the radical cure of goitres," published some twenty years ago, first drew attention to these changes.

He asserted that the long continued pressure of a goitre would produce not only alterations in the shape and position of the trachea, but also fatty degeneration, softening and atrophy of the tracheal wall itself. He explained further that owing to this alteration in structure, the trachea is more readily narrowed; indeed that its walls might collapse and entirely prevent the passage of air between them.

It was to this cause that he attributed the frequent occurrence of sudden death among patients afflicted with goitre.

Now there can be no doubt that in the main these assertions are quite justified. 'The trachea, as the result of long continued pressure, does become less resisting and has a tendency to collapse and thus to produce serious trouble. What is probably incorrect is the statement that these results are due to atrophy, degeneration or softening of the tracheal wall itself. At first sight the theory seems plausible enough. It is a well-known law of pathology that pressure tends to produce atrophy if it lasts for a sufficient length of time. 'The pressure of an aneurism against the sternum or vertebre is an example that at once suggests itself.

'The case of a goitre and the trachea is however somewhat different from that of an aneurism and a bone. A bone is an unyielding structure, the trachea is much less so. A very slight amount of pressure is sufficient to cause bending of the tracheal wall. This may be seen, as has been already mentioned, in innumerable museum specimens. Were the trachea as firm and unyielding as a bone then we might expect to find atrophy readily produced, but it is not so.

Again, the same pressure that produces atrophy of a bone such as the sternum will, if it continue long enough, lead to perforation.

In the case of the goitre and trachea, the atrophy of the thin walled trachea, if it exist at all, never leads to actual perforation Nowhere in any museum, so far as I know, is there a specimen in

* "Iner Kropfted mul die Radicalcur der Kröpfe," Arch. f. klin. Chir. vol. xxii. 
which the atrophy has gone so far that a goitre * has actually penetrated the interior of the trachea. Perhaps it may be said that long before this happens the patient is killed by the pressure. Possibly so, but at any rate specimens are common enough in which the pressure has lasted forty or fifty years and produced great distortion and flattening of the trachea without any penetration whatever of the tracheal wall. Such a specimen may be seen in the Museum of the Royal College of Surgeons. $\dagger$ But surely, it will be said, there must be plenty of museum specimens showing the atrophic condition which is said to be so common. A careful search for them, however, has shown me that they are conspicuous by their absence. I know of no case where the existence of this atrophy or fatty degeneration has been verified by microscopical examination.

But the examination has been made sufficiently often. Professor Bruns in an excellent monograph "On the present state of our knowledge concerning the treatment of goitre"+ states that at his request Dr. Miiller made a careful investigation of this subject with the following important result:

"Out of twenty cases showing marked compression"and stenosis, in no case was there any diminution in the size of the rings in any direction nor any microscopical changes in structure (except some calcification); in no case was any inflanmatory atrophy from compression or softening found."

Dr. Krönlein, Professor of Surgery at Ziirich, in the course of a conversation upon the subject, informed me that he had examined a considerable number of specimens of flattened trachea and had never found the atrophy described by Rose.

In the specimens that I have myself examined, the rings were always of normal thickness.

It may be objected that an examination of museum specimens is not a fair test of the presence or absence of softening since these have usually been preserved in alcohol and have become

* It must be remembered that these remarks apply only to innocent goitre : malignant disease of the thyroid commonly infiltrates and sooner or later penetrates the interior of the trachea.

$\uparrow$ No. 2902c.

† "Ueber den Gegenwärtigen Stand der Kropfbehandlung," by P. Brums of Tü̈bingen, Volkmann's Samıkl. klin. Vortroge, Leipzig, 188t, No. 24 . 
hardened by it. On the other hand the actual thickness of the wall cannot be materially altered by the spirit; and also, if such softened areas really exist, surely even after soaking in alcohol there ought to be some difference between the hardness of the affected areas and of the surrounding healthy parts. Besides, many of the above mentioned observations were made upon recent specimens which had never been in contact with alcohol.

The true explanation of the apparent softening of a flattened trachea is probably as follows.

Professor Rose, being a surgeon who had performed many extirpations of goitre, was accustomed to see and feel the trachea as it lay exposed in the wound, and he noticed quite correctly that that part of the trachea which lay in contact with the goitre offered less resistance to the pressure of the finger than did the neighbouring part; in fact it felt softer than the other. 'This feeling of apparent softening due to lessened resistance is produced however not by atrophy or real softening but by the alteration in the curvature of the tracheal rings. The accompanving diagrams (Fig. 58, p. 113) will perhaps serve to explain this more fully. A convex surface offers greater resistance to pressure than does a flat one. The rings of a normal trachea, when exposed in an operation, present a convex surface offering a certain resistance to the pressure of a finger. But let the curvature be lessened, as it is when a goitre presses upon it, and the resistance becomes proportionately diminished. In this way a false sense of softness is produced.*

I have been able to verify this explanation by examining numerous examples of flattened tracheas both in the living subject in the course of operations upon goitre and also in musemms. The flattened surface which had lain in contact with the tumour was found to be less resisting, to feel softer, although no real softening or atrophy was present.

2. We come now to the second mode by which dyspnoea may

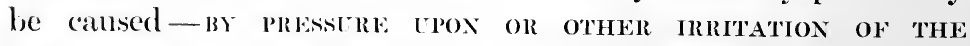
RHCTRLAT LARYALAL NERTES

In i previous chapter, allusion has been made to the fact

* To I'rofessor Krönlein I am indebted for the above explanation which he madr to :ar in the comss of the conversation above mentioned. 
that a goitrous tumour may occasionally cause compression or irritation of the recurrent laryngeal nerves. Judging from the opinion expressed by many English writers, it would appear that this view of the cause of dyspnoea has received more support than has that which formed the subject of the preceding section.

The relation which the recurrent laryngeal nerve bears to a thyroid tumour is of much importance. Most commonly the nerve is pushed backwards and inwards by the growth, and lies in the furrow between the trachea and nesophagus. Rarely is it spread out over the posterior surface of the growth.

The remarkable absence of aphonia and dysphonia in connection with the dyspncea caused by goitre would seem to indicate that the dyspnœa is not often caused by recurrent laryngeal disturbance.

'The paroxysmal nature of the dyspnoea has been thought by some to be evidence of its nervous origin. On the other hand, it might be explained just as well by supposing that some movement on the part of the patient had caused the already narrow trachea to become still further narrowed by slight bending or kinking. It should be borne in mind too, that some kinds of goitre, especially the parenchymatous, may undergo rapid and sudden enlargement from increase of the colloid secretion within it.

That irritation of the recurrent laryngeal nerves may in some cases at least be the cause of the dyspnoea cannot, however, be denied. 'That it may cause death, is also, I think, andeniable.

The following case appears to illustrate this point :

Dr. Johannes Seitz* of Zürich was consulteci by a girl aged 20 who complained of slight dyspnœa. She had a smail goitre which did not appear to be very serious. In the middle of the following night she was suddenly seized with a paroxysm of dyspnoea and died in a few minutes. At the post mortem a small parenchymatous goitre was found, but the trachea appeared to be little if at all compressed by it. No other cause for the dyspnoea could be found. There could be no doubt from the history of the case that the girl had died of dyspnœa. The conclusion, therefore, was that the

* Dr. Seitz has published this case in full in an able paper upon this subject. "Der. Kropftod durch Stimmbandlähmung," Arch.f. klin. Chir., 1883. 
growth of the goitre had irritated the recurrent nerves in such a way as to set up fatal spasm of the glottis.* Dr. Seitz was kind enough to allow me to examine the specimen critically and I could find no evidence to disprove the conclusion at which he had arrived.

There are two theories as to the mode in which the affection of the laryngeal nerves may cause dyspnoea, namely, by causing (a) spasm of the adductors of the vocal cords; $(b)$ paralysis of the abductors.

The first theory is a very ancient one, the second is more especially associated with the name of Sir Felix Semon. 'The latter has shown that in cases where the recurrent nerve has become gradually paralysed by pressure, as, for example, by an aneurism, it is the abductors that are first affected, and that the adductors remain intact for a longer time. The effect of this earlier paralysis of the abductors is to cause considerable and dangerous dyspnoea which may prove fatal if both nerves are affected simultaneously. The dyspnoea tends to diminish as the paralysis advances and the cord assumes the cadaveric position. Of the truth of this assertion there can be no reasonable doubt. But whether this is what usually happens when a goitre presses upon the recurrent nerve is much less certain. 'The paroxysmal nature of the dyspnoea, in many cases, if due at all to an affection of the nerves, would seem to point rather to a spasmodic than to a paralytic affection; in cases where the dypsnoea is more persistent and continuous, it is perhaps possible that the paralytic theory may apply.

3. BY bIRECT ExTENsion INTO THE INTERIOR OF TRACHEA or L.arxx.-In simple goitre, that is, in any non-malignant form of the disease, this never occurs.

In malignant disease of the thyroid, on the other hand, such ingrowth does usually take place, and frequently it is the cause of death. 'The larynx is perforated much less often. 'This is but natural, since the larynx is not situated in such intimate relation with the thyroid as is the trachea.

It would seem that hydatid cysts, unlike other cysts of the

* It is concrivable. however, that the suddenly compressed, elastic trachea of " youm person might regain its nomal calibre when removed from the body and thus relieved from external pressure. 
thyroid, are apt to cause absorption of the tracheal wall. Examples are quoted by Dardel in his thesis on the subject."

4. By RUPTURe OF a CYST OR AN ABscess INTO THE AIR PAssacks. - A few cases have been recorded in which a thyroid cyst or abscess has burst suddenly into the trachea, larynx, or pharynx, and the discharge of pus or other fluid has caused immediate suffocation.

Sir James Paget $\dagger$ mentions the case of an elderly woman under the care of Mr. Vincent; rupture of a suppurating thyroid cyst into the pharynx produced immediate asphyxia and death.

A surgeon who is treating a suppurating cyst should bear in mind the possibility of such a fatal termination.

Cases of sudden death caused by the rupture of a hydatid cyst will be found in the table appended to chap. xi.

5. By causing edema or the gLotris.-OEdema of the glottis sometimes complicates: (i) Inflammation of the thyroid, and (ii) Malignant disease.

It is not difficult to understand how inflammation of the thyroid may easily spread to a part so near to it as the glottis.

Many years ago I had the opportunity of seeing a case in which a swelling of the thyroid gland caused such dyspnoea that an attempt was made to perform tracheotomy. Laryngoscopic examination before the operation disclosed considerable cedema of the glottis. The relief afforded by the incision into the gland and the rapid disappearance of the tumour were supposed to confirm the diagnosis of inflammation of the thyroid. 'This seems to have been a case in which the dyspnoea was produced by œedema of the glottis.

Reverdin $\ddagger$ of Geneva, whose experience of goitre has been very large, remarks that œedema of the glottis does not occur in cases of simple goitre, although it is occasionally met with in malignant disease.

The cedema of surrounding parts produced by the latter disease requires no special explanation or illustration.

* See chap. xi.

+ "Lectures on Surgical Pathology," 1876, p. 401.

† Rerue Médicale de la Suisse Romande, 1882, p. 173. 
6. Br causing swelling of the mucous membrane of the TRACHEA.-It is only in cases where the trachea has already been greatly narrowed by pressure from without that the slight extra amount of narrowing thus produced could lead to dyspnœa.

In cases of inflammation of the thyroid, the mucous membrane of the neighbouring trachea may perhaps be directly affected by extension of the inflammation to it.

Idiopathic bronchitis, or more strictly tracheitis, may also produce dyspncea in cases where the trachea is already narrow. Allusion has already been made to the fact that the trachea may be considerably narrowed by the pressure of a goitre, and yet no dyspnoea be present. But let such a patient be attacked by bronchitis, or even by an ordinary cold, and the dyspnoea may speedily become alarming.

Goitrous patients frequently say that their breathing never gives them any trouble except when they have caught cold.

In the preceding portion of this chapter, we have been engaged in considering the various modes in which the dyspnoea may be produced by goitre.

We have now to consider a subject closely related, namely, the age and sex of the patient and the varieties of goitre that are most likely to produce dyspnœa, and especially such dyspmoea as will endanger life.

Careful study of this subject must obviously have an important bearing upon the prognosis and treatment suitable to any given case.

Although dyspnoea is such a common symptom in patients suffering from goitre, yet it varies greatly in degree in different cases. Moreover, those who have published cases have described the dyspmora in such different terms that it is difficult, from mere published reports to draw accurate conclusions as to the varieties of goitre most likely to cause serious dyspnoea.

The tab!e on pp. 126-129 affords some help in the study of this subject. It includes all those cases, and those cases only that I have been able to find, in which the dyspnoea was clearly so extreme, that death resulted from it and from it alone. It will be seen that it includes cases in which no operation was performed, and also those in which the death seems 
attributable clearly to the dyspnœa, and not to the operation.*

In order to eliminate, as far as possible, any source of error arising from the latter point, no case has been included in which the operation was anything more than a simple tracheotomy or laryngotomy.

If cases in which more severe operations, such as extirpation or enucleation, had been included in the table, the number could have been enormously increased, since it is usually dyspnœa which has led to the performance of these more serious operations. But it is so difficult to be quite sure how far the death in such cases is attributable to the dyspncea and how often to complications arising from the operations themselves, that their inclusion would have seriously impaired the statistical value of the table.

The table gives details of thirty-four cases from the following sources: In eight the actual goitre has come under my notice in museums, the history having been in most cases obtained from the museum catalogue; seven cases have been personally communicated to me by the practitioners under whose care the patients were; the remaining nineteen have been obtained from various medical journals and hospital registers.

In an examination of the table the first point that may be noticed is that of the whole thirty-four cases, no less than seventeen (i.e., just half) occurred in patients of the male sex. It is well known that goitre occurs much more frequently in female than in male patients. It might therefore naturally be expected that cases of fatal dyspnœa would be much more common among the former. Such, however, does not seem to be the case. Fatal dyspnoxa occurs with nearly equal fiequency in both sexes despite the fact that innocent goitre is much more common in the female sex.

The next point to be noticed is that the great majority of the patients were young adults under the age of twenty. Of

* It will be seen also that a large and important class of cases, namely those of malignant disease, has likewise been onitted. These cases have been omitted because dyspnoea of a severe and generally fatal nature is almost always present in patients suffering from malignant disease of the thyroid; the cause of the dyspnoea in these cases is generally different from that which pertains in cases of innocent goitre, being so often due to direct extension of growth into the 
the twenty-nine cases in which the age is given only seven were above twenty, while the youngest was twelve. Three quarters of the patients were between the ages of twelve and twenty, and of these no less than thirteen (more than one third of the total number) were between the ages of thirteen and sixteen. (of the five whose exact ages are not given two were "young adults," and it is at least highly probable that they were under twenty. Of the seven whose ages are stated definitely to be above twenty, one was only 23 , the others 29,30 , and 33 respectively ; it may be noticed that the last four were all women.

If we may draw conclusions from these figures it appears that the age at which fatal dyspnoea is most likely to occur is that of puberty or soon after,* and that at a later age it is women and not men that are most likely to be the rictims of dyspnœa.

In what way may this relation to age and sex be explained?

In most of the above-mentioned cases the goitre was of the parenchymatous variety, that is the enlargement of the thyroid was caused chiefly by an increase in glandular elements attended by an abnormal aceumulation of the colloid contents of the vesicles.

In most cases of goitre occurring in young subjects we find that this is the nature of the tumour. In older patients, on the other hand, we as often, or more often, meet with unilateral swellings, cysts or cystic adenomata.

There cannot be much doubt also that the more acute the goitre, that is the more rapidly it has grown, the more severe will be the dyspnoea.

One reason why young people are more liable to dangerous dyspnoea is because in them the trachea is softer, more yielding, and therefore more easily compressed than in older people. Another reason is that in them the goitre is usually of the bilateral parenchymatous variety which can compress the trachea more effectually than a unilateral goitre. Thirdly, parenchy-

air-passiges. The age of surh patients is usually much greater than those of the vast majerity of patients of the other class. Such a distinct class then do these cases form that by mixing them with the others we should only arrive at more confused and less atecurate deductions.

* It may br adfled that this statement is contirmed by an examination of the murh larger mumber of those ases in which major operations have been performed, but which do not, for reasons stated above, appear in the table. 
matous goitres are especially apt to develop rapidly about the age of puberty. The rapid development at this age may perhaps be due to the close connection which appears to exist between the thyroid gland and the genital system.*

Increasing parenchymatous goitres in persons over the age of twenty are usually seen in women, and in a large number of cases during pregnancy. $\dagger$

The enlargement of the thyroid gland which is said to occur during menstruation has already been mentioned. Certainly at these periods a goitre is very apt to swell and cause respiratory troubles.

In middle-aged and elderly patients a variety of goitre which sometimes leads to serious or fatal dyspnoea is that form of cystic goitre to which the term "hrmorrhagic goitre" has been given.

The tumour generally contains one or more large cysts into which hæmorrhage suddenly occur's (cases 3,5 and 30 in the table), or the tumour may give way at some part, generally the posterior, and blood mixed with the other contents of the cyst may diffuse itself into the surrounding tissues, causing pressure upon the trachea or perhaps upon the recurrent nerves. For examples of this accident see Heidenreich and Dewes. +

Osler has published $\S$ the following case of fatal hrmorrhage into a large bronchocele :

The patient was an insane woman aged 44, who died from spontaneous hæmorrhage into a large bronchocele. While at work she became faint, breathless and blanched, and died in a few hours. An immense goitre which had existed for many years occupied the entire space between the chin and sternum. At the post-mortem examination "a space was opened between the bronchocele and the

* It is possible that the greater enlargenent of the larynx and trachea which takes place at puberty may have some share in the production of the lyspmoa in boys.

+ See Jenks "On the Relation of Goitre to Pregnancy, dec.," Amer. Journ. of Obst., 1881, vol. xiv. p. 1. Also Lawson Tait "On Enlargement of the Thyroid Body in Pregnancy," Trans. Ed in. Obst. Sire. iv. 81-95.

+ " "Schneller Tod durch das Bersten einer schilddriisencyste und die Trachea comprimirende Bluterguss," Correspondenzblatt Bayer. Aerste, $18+1$. quoted by seitz.

§ "Fatal Hamorrhage into a Large Bronchocele," Jolln Hopkins How". Bull., Baltimore, 1889-90, i. p. 23. 
sternum, containing large clots, which on dissection were found to have come from one of the lower cysts of the goitre which had ruptured. The blood extended into the cellular tissue of the neck and beneath the sternum into the anterior mediastinum, covering the aorta and upper part of the pericardium. The hæmorrhage passed behind the pharynx and down the course of the oesophagus for two or three inches. On removal, the windpipe and gullet were found almost completely embedded in the goitre, and the former seemed at its lower part somewhat compressed. The bronchocele weighed $1 \frac{t}{10}$ kilograms, and was of the parenchymatous variety; here and there were cysts."

1)r. Osler in his remarks upon the case says that it was difficult to determine whether this patient died directly from loss of blood or from the mechanical effects of pressure. It is unfortumate that no note has been made of the state of the veins. From the description of the hemorrhage it seems likely that the blood was derived from one of the thimned and greatly distended veins that usually ramify upon the surface of large goitres.

Occasionally a cyst undergoes rapid enlargement owing to excessive inflammatory secretion into its interior. A case that I saw with Mr. Bowlby at St. Bartholomew's Hospital a few years ago illustrates this point.*

A woman was admitted with a tense elastic swelling at the lower part of the thyroid gland. The swelling lay largely behind the sternum. It had recently increased considerably in size and caused extreme dyspnoea. The cyst was incised and found to extend so far down behind the stemum that we could both see and feel the arch of the aorta and the chief vessels arising therefrom. The cyst wall was so intimately comnected with these vessels that enucleation would have been impossible. The huge cavity was packed with gauze and the patient made an excellent recovery.

In this case it seems probable that an inflammatory condition of the cyst led to the hypersecretion into it and the consequent severe dyspnora.

With the exception of these cysts suddenly increasing from hremorrhage or other cause, and tumours which are substernal, unilateral goitres do not often cause fatal dyspnou.

* This case has been published in the Lancet, 1895, i. 1118. 
The degree of prominence of the tumour is of importance in relation to dyspnoea. 'The more firmly a goitre is held down by resisting structures such as fascia or bone (sternum), the more likely is it to cause serious respiratory trouble. Thus, some of the most dangerous tumours are those which lie behind the sternum and which send down prolongations into this region (substernal and aortic goitres, "goîtres plongeants" of French authors).

In countries where goitre is prevalent one often sees huge prominent and even pendulous tumours causing comparativeiy little dyspnoa. Fig. 46 shows such a case. As examples of the opposite condition in which the goitre causes hardly any external swelling may be cited the case recorded on p. 105, and that of the boy whose goitre is now in St. George's Hospital Museum.*

In the latter case although gradually increasing dyspnoea had been present for sixteen months yet no external tumour was noticed until three days before death, which occurred from suffocation.

Strictly median tumours, not involving the lateral lobes, are, as has already been explained, extremely rarely the cause of dyspnœa.

There are some reasons for believing that the bilateral fibrous goitres of adults are especially liable to cause severe dyspnœea. Several cases have come under my observation which seem to support this view.

One was that of an elderly woman seen with Dr. Favre at Fribourg (Switzerland) in 1886. 'This patient had a very small hard goitre which appeared to be shrinking in size and causing increasing and severe dyspnœea as it did so.

Other cases are described in the following chapter.

* No. 19B. Also case 2 in the iable. 


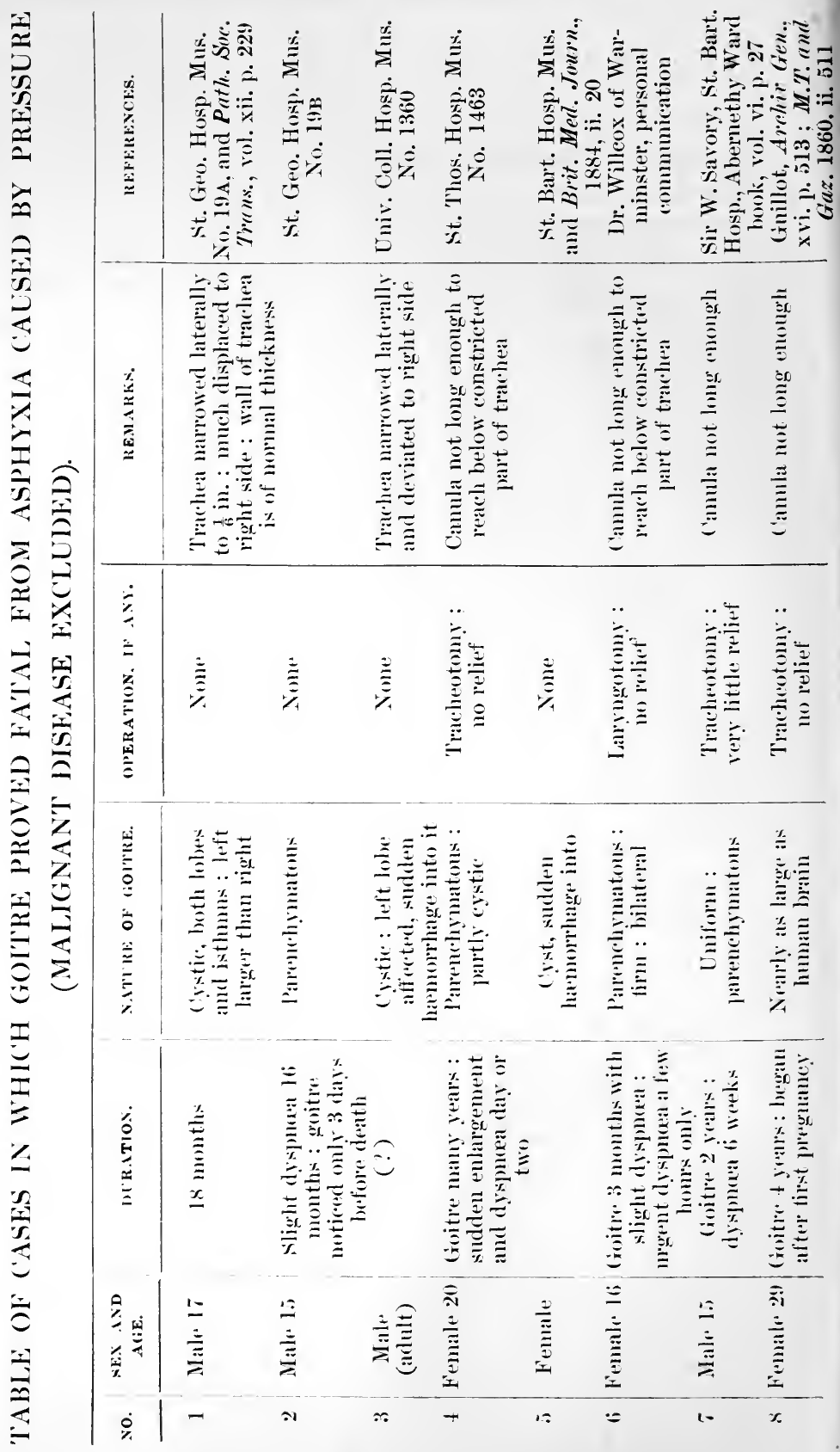




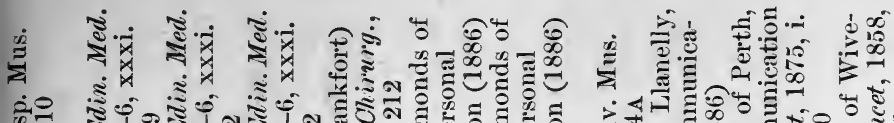

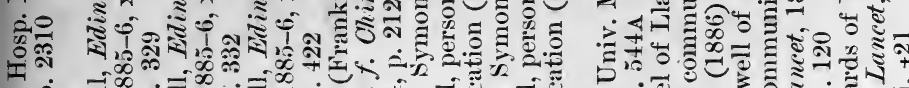

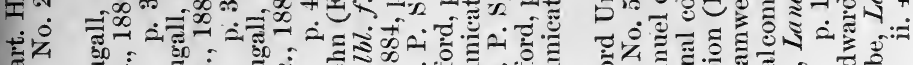

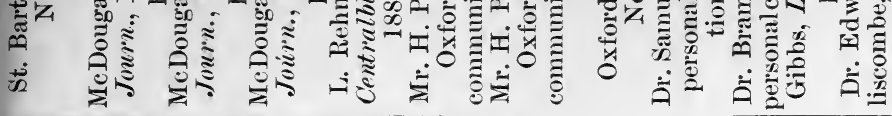
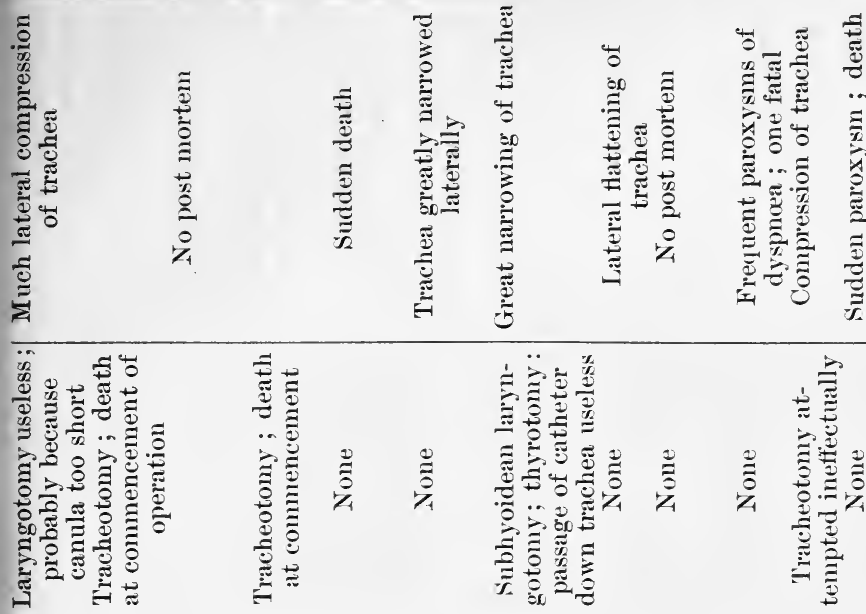

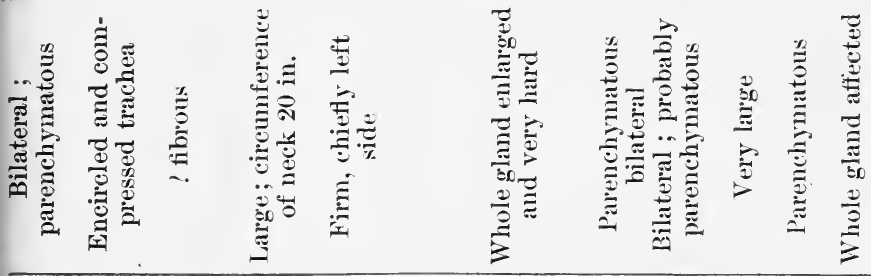

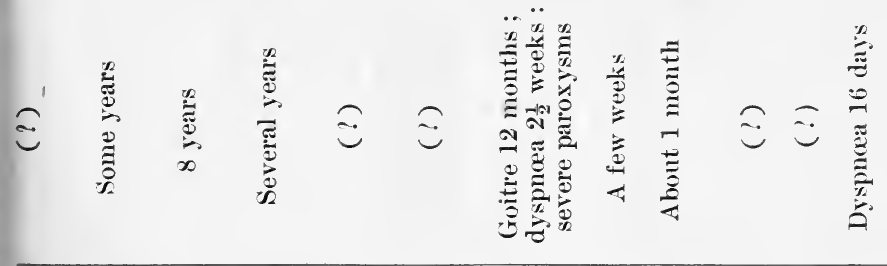

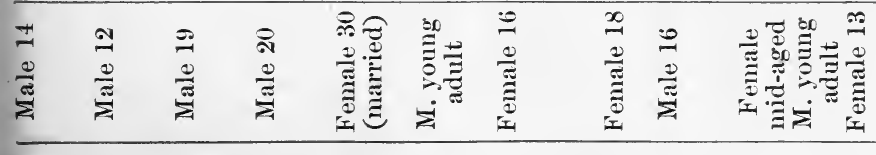

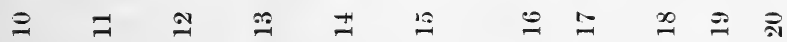




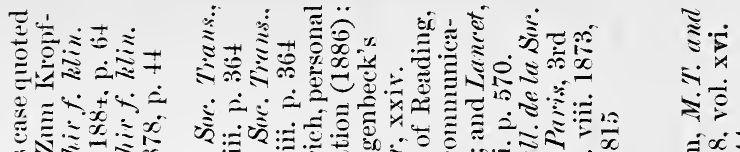

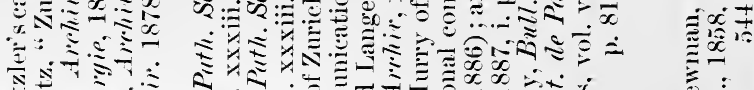

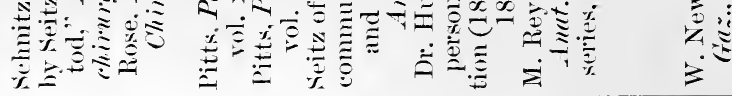

|

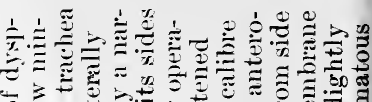

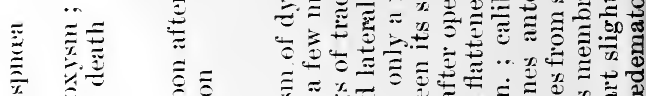

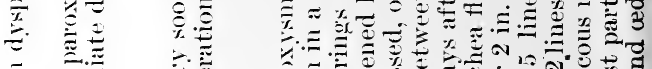

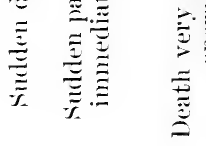

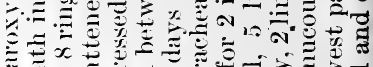

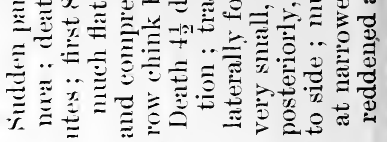
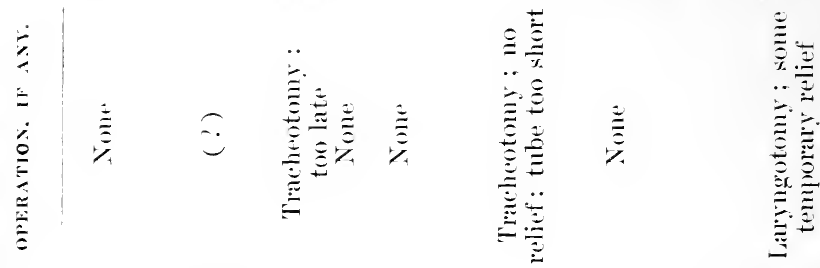

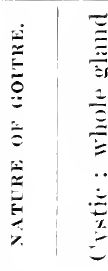

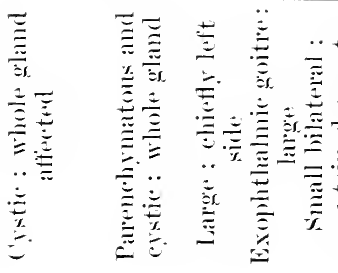

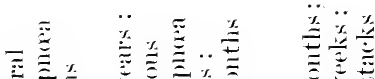

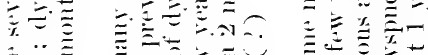

$\div \ddot{z}$

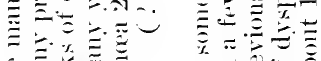

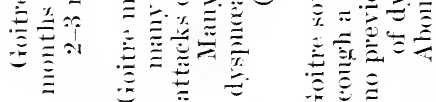

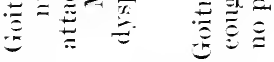

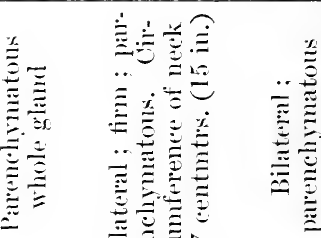

言芯芯

三人

\begin{tabular}{|c|c|c|c|c|c|}
\hline 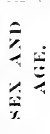 & 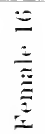 & $\begin{array}{l}\hat{i} \\
\frac{\ddot{z}}{\vec{z}}\end{array}$ & 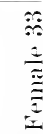 & & \\
\hline : & $\bar{x}$ & $\stackrel{i}{\mathfrak{N}}$ & $\stackrel{\overbrace i}{\circ}$ & & $\overrightarrow{\mathrm{d}}$ \\
\hline
\end{tabular}

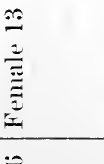
$7-1=$

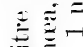

语

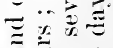

$\approx \ldots+$

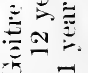


THE DYSPNOEA CAUSED BY GOITRE.

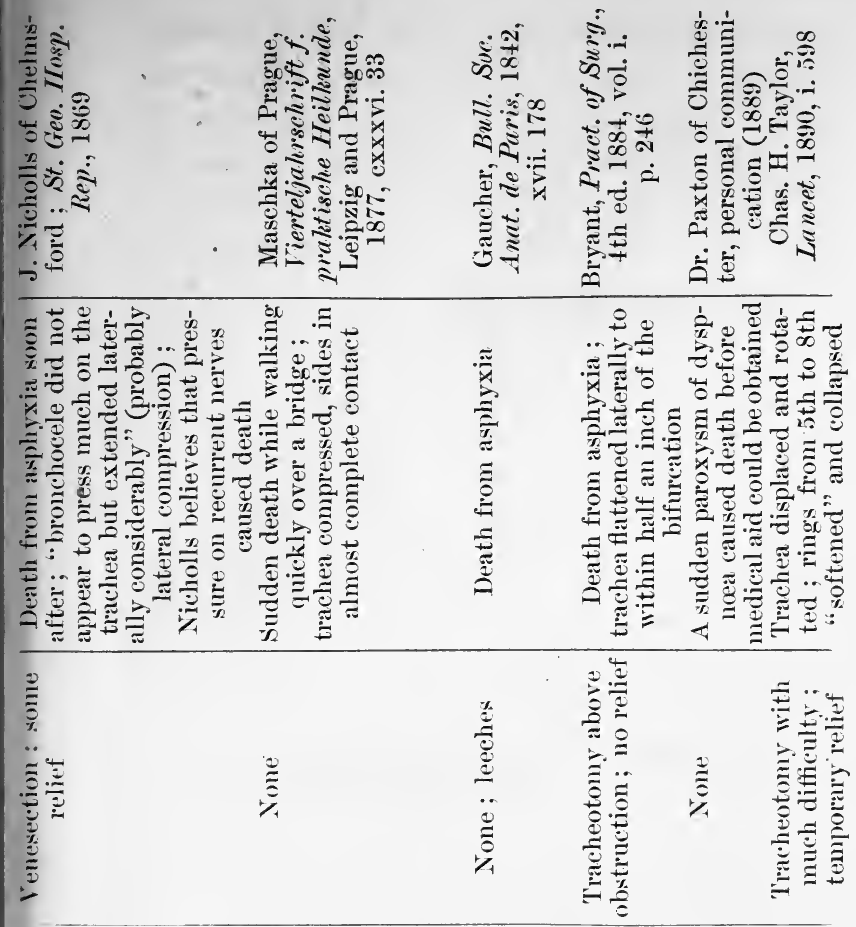

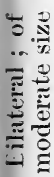

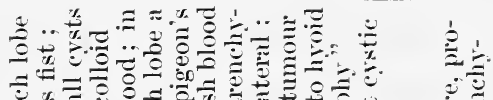

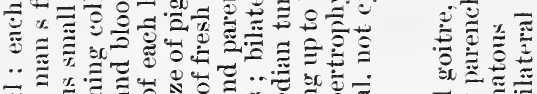

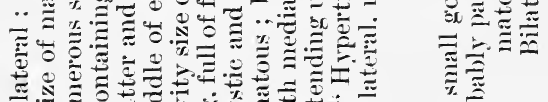

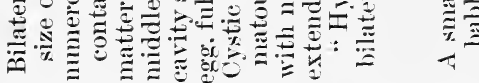

\begin{tabular}{|c|c|c|c|c|}
\hline 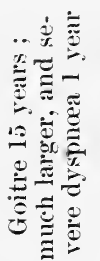 & 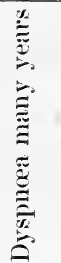 & 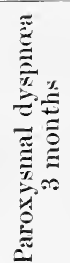 & 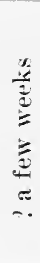 & 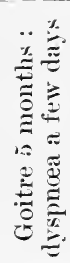 \\
\hline
\end{tabular}

\begin{tabular}{|c|c|c|c|c|c|}
\hline 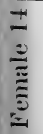 & 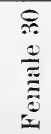 & 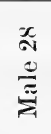 & $\frac{\Xi}{\stackrel{\Xi}{\Xi}}$ & 先 & 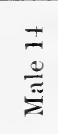 \\
\hline$\Xi$ & $\cong$ & $\bar{n}$ & $\therefore$ & $\hat{\leftrightarrow}$ & $\vec{x}$ \\
\hline
\end{tabular}




\section{CHAP'IER VIII.}

\section{INFLAMMATION.}

Acute idiopathic inflammation-Typhoid fever-Rheumatism-Pyæmia - Traumatic inflammation-Symptoms-Results of suppuration-Diagnosis-Treatment. Chronic inflammation-Primary chronic inflammation-Diagnosis from malignant disease-Treatment.

Acres inflammation may attack a previously normal thyroid or one that is already the seat of goitre. Inflammation of a goitre is most often seen as the result of some operation, such as injection. Inflammation due to any other cause is one of the least common affections of the thyroid.

Idiopathic inflammation, whether of the normal or of the goitrous thyroid, has been observed most often in the course of one of the exanthemata or of some other acute febrile disease and generally at a late stage.

Of these diseases the following are the most important:

Typhoid Fever.- The occurrence of abscess in various parts of the body in the later stages of typhoid fever is such a wellknown complication of that disease that it is not surprising to find that the thyroid gland is sometimes the part affected. The occurrence of this form of thyroiditis was probably first mentioned by Baumann in 1856.*

Abscess of the thyroid is a late complication of typhoid fever, rarely occurring before the fourth week and often very much later.

Rheumatism, first mentioned by Mollière. $\dagger$ 'The inflammation due to this cause appears to differ from that caused by

* “Ceber die Vereiterumg der schilddrïse," Inaugural Dissertation, Zürich, 1..5\%.

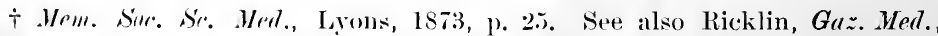
P'alris, 18s5, p. 4+8, and \%oniovitch, " De la thyrödite aiguë rhumatismale," Tiliesin, l'aris, 188.). 
typhoid in that the inflammation rarely proceeds to suppuration, whereas in typhoid fever abscess is frequently the result. Sir Thomas Barlow* has recorded a case which may perhaps be classed as rheumatic. The patient was a boy aged three, previously healthy and just recovering from an attack of erythema nodosum. The whole thyroid gland was enlarged and caused much pain, fever and dysphagia. The acute phase of the disease lasted four days and the total duration of the enlargement was about a fortnight. Much relief was obtained by the application of a single leech to the centre of the swelling.

In most of the recorded cases of rheumatic thyroiditis, the duration of the acute phase appears to have been shorter, lasting not more than two days.

Pyæmia is responsible for a considerable proportion of cases. $\dagger$ A case of abscess of the thyroid that came under my notice in 1886 in the post-mortem room of St. Bartholomew's Hospital was due to this cause.

The patient was a young woman aged 21, who died of pyamia connected with necrosis of the femur. In the lower part of the right lobe was an abscess which had, however, caused no symptoms; during life its presence had not been suspected. Several cases of thyroiditis in the course of puerperal fever have been recorded.+

Malaria,§ Variola $\|$ and Cholera have all been recorded as causes of thyroid inflammation.

Traumatic inflammation is but rarely seen in the previously healthy thyroid. Cases in which it has been caused by attempts at strangulation, rough friction, blows, and other forms of mechanical injury have been cited by Walther ** and others.

* Trans. Clin. SYr., 1888, p. 67.

† H. Lebert, "Die Krankheiten der Schilddrüse und ihre Behandlung," Breslau, 1862. Guthrie "On Gunshot. Wounds," 1827, p. 260.

† Laure, Sor. Méd. de Lyon, Jan. 1873. Lebert, op. cit. Kohn, op. rit.

$\$$ Zesas, "Ueber Strumitis und Thyreoditis bei Malaria," Centralbl.f. Chir., No. 30, 1885 .

\| Liouville, Mém. de Soc. de Biol., 1870.

T Cruveilhier, Gaz. de Hôp. 1849, quoted by M. D. Simon, Thesis, Paris, 1880, ** "Neue Heilart des Kropfes durch Unterbindung des obern Schilddrüsen Schlagadern," Sal:bar.7. 1817, pp. 17-19, quoted by- Lebert. 
Inflammation and suppuration of an enlarged (goitrous) thyroid gland is often seen as the result of tapping, injection, incision, or any other operation which has been performed without sufficient attention to asepsis.

Krieg* says that of twenty-four cases of inflamed goitre olserved by Kocher, in no less than nine the cause was injection.

One of the chief objections to the employment of injection as. a means of treating goitre is that it may set up a dangerous. amount of inflammation.

Symptoms. - The ordinary signs and symptoms of inflammation are met with in the case of the thyroid gland, as they are in that of any other organ of the body. 'The special symptoms which are met with in inflammation of this organ depend upon its close connection with certain important structures in the neck. Of these symptoms the most important are dyspnœea, dysphagia and pain produced by pressure upon, or involvement of, the cervical and brachial plexuses. Dyspnoea is produced by the direct pressure of the swollen gland upon the trachea, and perhaps to a certain extent also.by the involvement of the recurrent nerves in the inflammation. If the trachea be already narrowed by the goitre, the extra swelling caused by the inflammation may lead to very serious respiratory distress. Dysphagia - is caused either by direct pressure upon the resophagus or pharymx, or by the actual involvement of these structures in the inflammatory process. The act of deglutition, by causing movement of the inflamed gland, naturally causes pain. Pain referred to the peripheral distribution of the cervical and brachial nerves is a common symptom of thyroiditis, and affords. an important means of diagnosis. Other forms of thyroid cnlargement, with the important exception of malignant disease, rarely cause severe pain. As the inflammatory swelling of the gland increases, the dyspmoea becomes more and more severe, and attacks of suffocation occur from time to time. Alteration in the voice and in the character of the cough also occur. 'The. cough gradually assumes the peculiar brassy nature so characteristic of tracheal obstruction.

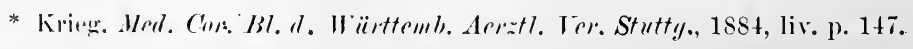


'The pressure symptoms are of great importance since, if unrelieved, they are apt to result in fatal suffocation. Kohn* says that inflammation may also prove fatal by extension to the mucous membrane of the trachea, causing this to swell, and so block up still more its already narrowed lumen. The possibility of the rapid occurrence of oedema of the glottis should also be borne in mind.

If suppuration occur, the pus is exceedingly likely to penetrate the capsule of the gland, and to make its way, either into the cellular tissue of the neck or into the trachea or pharynx. If it pass into the cellular tissue an exceedingly dangerous condition supervenes. The dangers of a diffuse inflammation of the deeper parts of the neck and the mediastinum are too well known to need further description.

Numerous museum specimens illustrate the tendency of pus to make its way from the thyroid gland into the trachea or pharynx. 'The sudden discharge of a quantity of pus into either of these cavities generally leads to the immediate suffocation of the patient, and the liability to its occurrence should not be lost sight of.

In St. Bartholomew's Hospital Museum $\dagger$ is a preparation which shows a large thyroid cyst which suppurated and burst into the pharynx.

"The patient was an elderly woman and the enlargement of the gland had long existed. The cyst at first contained a fluid like serum, which when withdrawn spontaneously coagulated. After being twice emptied the walls of the cyst inflamed, and it was rapidly filled with pus and lymph; its wall ulcerated and the ulceration extending through the adjacent part of the pharynx, the patient was suffocated by a sudden discharge of its contents and the passage of some of them into the larynx."

It will be seen that there is a communication between the uppes part of the cyst and the pharynx, near the arytenoid cartilage.

Lebert cites a curious case taken from Heidenreich's work on goitre. A young man suffered for six months with what was

* Op. rit. p. 216.

$\dagger$ No. 2314. This specimen is probably from Mr. Vincent's case described in Sir James Paget's "Surgical Pathology," 187 (;, p. 401. 
supposed to be stricture of the cesophagus and suppuration of the lungs. It was known that he had a goitre. After death it was found that both cesophagus and lungs were quite healthy. All the symptoms were due to the goitre, which, besides causing marked pressure upon the oesophagus, had suppurated and discharged pus into the trachea, a short distance below the larynx. 'The frequent expectoration of this pus had given rise to the erroneous diagnosis of suppuration of the lungs.

Perforation into the trachea usually takes place in the neighbourhood of the first or second ring.

Penetration of the pharynx usually occurs near the upper opening of the larynx.

Diagnosis.-Acute inflammation of the thyroid gland is likely to be confounded with one or other of the following affections.

1. Simple acute parenchymatous enlargement of the gland, especially that which occurs about puberty or soon afterwards. 'The absence of fever, pain, and tenderness will, however, generally be sufficient for the establishment of a correct diagnosis.

2. Inflammation of neighbouring parts may easily simulate thyroiditis. Such are inflammations of the cervical lymphatic glands, of the cellular tissue of the neck and of the larynx itself. ('areful attention to the exact position of the swelling, and noticing whether or not it moves with the larynx, will probably enable the observer to distinguish the thyroid affection from the others.

An interesting case has been recorded by $\mathrm{Kohn}^{*}$ in which suppurative perichondritis of the larynx was accompanied by a tumour so closely resembling an abscess of the thyroid gland as to be mistaken for it. A fluctuating tumour as large as a walnut lay exactly in the situation of the right lobe of the thyroid, and being attached to the larynx naturally followed its movements during deglutition.

I have myelf seen a case in which suppurative perichondritis of the thyroid cartilage had been diagnosed as a tumour of the thyroid gland. 
3. Sudden extravasation of blood into a cystic thyroid gland may also closely simulate acute inflammation.

4. Malignant disease is often mistaken for inflammation, especially when it occurs in the form of a soft rapidly growing tumour. The diagnosis is especially difficult, when, as often happens, a malignant tumour penetrates the air or food passages and thus becomes the seat of septic inflammation.

Treatment.-In the early stages, before suppuration has occurred, the treatment should consist in the administration of a purgative and the local application of hot fomentations. If the inflammation be due to a specific cause such as rheumatism or syphilis, specific remedies such as salicylate of soda and iodide of potassium must of course be administered. A careful watch should be kept upon the breathing, and if dyspnoea threaten to become severe, the surgeon must be prepared to operate promptly. The danger of suffocation should not be lost sight of.

If the case has gone on to suppuration, the pus should be evacuated as soon as possible. Some have recommended aspiration and the injection of carbolic acid or other antiseptic, but direct incision seems to be preferable. If the suppuration ocenr in a previously healthy gland or in one that is the seat of a general parenchymatous enlargement, the surgeon should usually be content with simple evacuation of the pus. If, however, suppuration take place within a cystic or other encapsuled tumour, as is frequently the case, then it is generally best to perform enucleation of the cyst. Kocher speaks of inflammation as favouring in some cases the operation of enucleation, since thereby the tumour is loosened from its connections. In other cases, however, in which there has been long-continued inflammation, the operation may be rendered very difficult, and when there is much fixity of the cyst it may even be best not to attempt its removal but to be content with incision and drainage.

In all cases of operation for acute abscess the wound should be drained. The necessity for an early operation in cases of abscess of the thyroid gland is obvious when we consider hcw great a tendency there is for the pus to make its way into the 
deeper structures of the neck and thus to set up most dangerous complications.

'The treatment of thyroid fistulæ, the result of inflammation, must be conducted upon general principles. The fistula must be kept as clean as possible by washing and free drainage. If there be much surrounding inflammation, wet antiseptic compresses frequently changed form the best application at first. 'The mouth of the fistula must be opened as much as possible, so as to convert the fistula into an open wound and allow it to heal up from the bottom. The situation of the fistula, in close proximity to large blood-ressels and other important structures, often renders a free laving open of the parts quite impossible. 'The surgeon must then be content with laying open the superficial part and draining the deeper regions. If the fistula have followed an operation in which silk ligatures have been employed, it will often not heal until these have been removed. The casting off of ligatures from an operation wound in this region is a most tedious process, often occupying many months. If the fistula be commected with a hard fibrous or calcareous goitre, its walls may be so rigid that they cannot come together; the fistula will then be a permanent one unless the tumour be remored.

Such fistula are by no means uncommon after the injection of tough walled rysts and old adenomata. Fig. 86 shows a case of this kind in which the fistula had existed for many years.

The following case came under my care some years ago:

Kate C., aged 35, domestic servant, was admitted to the Royal Free Hospital in Nor. 1891, on account of a sinus in the neck, painful swellings of the joints and other symptoms of septic absorption. Eleven months previously, at another hospital, a right-sided goitre had been injected and incised. Much suppuration had followed the operation and a sinus had been present ever since. When the discharge from it was abundant the patient was fairly well. When the sinus, however, became blocked, as it did every few weeks, and the discharge became pent up, the patient had high temperatures and suffered severely from septic absorption. She was consequently unable to follow her occupation. In the right side of the neck wais a thyroid tumour as large as a gooses egg. A sinus led directly into its interior and was about two inches long. Foul 
pus oozed.continually from the opening. The tumour was a good deal fixed by surrounding inflammation.

For a few weeks the sinus was washed out and cleansed as much as possible. On Dec. 8,1891 , the whole of the right lobe was extirpated in the usual manner. Great care was necessary in the operation to prevent contamination of the extensive wound with the septic contents of the sinus. The tumour and surrounding parts were so matted together by old inflammation that the operation was tedious and difficult. The wound was drained and the patient made a rapid and excellent recovery. The temperature never rose above $99^{\circ}$, and the wound healed by primary union. The patient never had any further trouble, and when last heard of, eight years after the operation, was in excellent health. The tumour (now in the, Royal Free Hospital Museum, No. xxii. 3) shows a solid adenoma with much surrounding fibrous tissue and an abscess cavity in the centre.

Still more serious is the condition of affairs when a thyroid fistula opens on to a mucous surface, the trachea or cesophagus.

In the Museum of Charing Cross Hospital is a specimen * of a large solid thyroid adenoma which was removed by Mr. Johu H. Morgan on account of a fistula which opened both externally and also internally into the cesophagus.

The patient was a woman aged 46, whose goitre had been injected four years previously at another hospital. After other methods had failed to cure the fistula, the whole tumour was removed by operation. The opening into the oesophagus which was just below the cricoid cartilage was closed with fine silk sutures, and the wound drained. The patient made an excellent, although somewhat tedious recovery. $\uparrow$

\section{Primary Chronic Inflammation.}

Under this name may be described a remarkable and somewhat rare affection which seems to have attracted but little attention in this country. It is characterised by the development in the thyroid gland of a tumour of exceeding density and hardness, which shows a remarkable tendency to become adherent to, and

* No. 877A.

$\dagger$ A full acconnt of this case has been published by Mr. Morgin in the Illustrated Merl. Veus fo: June 29, 1889. 
even to surround and infiltrate, neighbouring structures. Various names have been given to the affection, the pathology of which is still somewhat obscure.

Tailhefer,* in an excellent paper upon the subject, uses the name " primary canceriform chronic inflammation." Bowlby $\nmid$ has published a typical case under the name of "infiltrating fibroma," and seems to think that the disease is allied to sarcoma. There can, however, be but little doubt that chronic inflammation is the term that is most correct. The remarkable similarity which exists, both clinically and pathologically, between this disease and some of the harder forms of malignant disease is very striking. Indeed almost every case hitherto described has been diagnosed at first as malignant diserse. 'To Riedel $\ddagger$ of Jena we are indebted for drawing attention to the true nature of the disease and in the publication of two cases that came under his care.

I have myself seen three cases. One of these was the case published by Mr. Bowlby, which was under the care of Sir 'Thomas Smith. 'The other two were under my own care at the Royal Free Hospital.

The disease oceurs both in men and in women. It appears to be most common in middle age but cases in childhood have been recorded. A swelling is noticed in one or other, or both, lobes, of the gland. It grows steadily and painlessly, and when it reaches the exterior of the gland it becomes firmly fixed to the trachea, carotid vessels, recurrent nerves, and other structures. It exerts pressure upon all the structures and causes dyspncea, dysphagia, dysphonia, and obliteration of the carotid pulse. If untreated it gradually compresses the trachea more and more and causes death by suffocation. The swelling does not usually attain any great size, the lateral lobe of the thyroid being seldom larger than a goose's egg.

The extreme hardness of the tumour has been likened by

* "Inflammation chronique prinitive 'cancériforme' de la glande thyroüde," ly E. Tailhefer in Mre. de Chir., Paris, March 10, 1898, vol. xviii. p. 224.

+ "Intiltrating fibroma (? sarcoma) of the thyroid gland," Trans. Path. Sore. 1885, vol. xxxvi. 1. 420 .

† "Die chronische zur Bildung eisenharter Tumoren führende Entzündumg

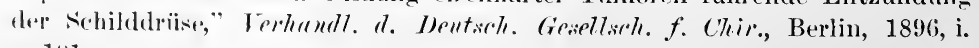
p. 101. 
various observers to that of wood, iron or stone. It is quite distinct from the ordinary fibroid degeneration so commonly seen in parenchymatous and adenomatous goitres. The latter progresses extremely slowly and does not cause infiltration of, or adhesion to, surrounding parts.

The following are the three cases which have come under my own notice :

Mrs. Eliza D—, et. $^{42}$, was admitted into St. Bartholomew's Hospital on Nov. 28, 1883, under the care of Sir Thomas Smith. Three years previously she had first noticed a swelling of the lower part of the neck. During the next year this swelling gradually increased and her breathing then became affected. At this period she consulted a doctor who found that the thyroid gland was "very slightly enlarged, firm, and not at all painful."* A year later it was found that the thyroid was apparently incorporated with the trachea, the place of the gland being taken by a very hard, painless growth. She was treated with iodide of potash and biniodide of mercury ointment, but did not improve. On the contrary her breathing gradually became worse and worse, and she was liable to fits of coughing brought on by active movement. "The stony hardness of the growth was by this time very remarkable and was of such a nature as to suggest the presence of cartilage or bone. In April 1883, the patient was seen by Sir Felix Semon, who expressed the opinion that the disease was of a malignant nature. He found the trachea much narrowed, the left abductor paralysed, and the left vocal cord completely fixed in the middle line." The dyspnoea continued to increase, and at times suffocation seemed inminent. Dysphagia and weakness of voice were now noticed. "On admission to the hospital dyspnœea was very urgent. The front of the neck was occupied by an excessively hard mass, which enveloped the whole of the tissues from the level of the hyoid bone downwards to the episternal notch, and in which it was not possible to recognise any of the normal structures of this region. Free division of the isthmus of the thyroid failing to give any relief, tracheotomy was performed. Some temporary relief was afforded, but the dyspnoa returned and the patient died on Dec. 4." The post-mortem examination was made by Mr. Bowlby who has given the following description: "The viscera generally were healthy. There were no signs whatever of secondary growth and none of glandular affection throughout the body. The thyroid gland and

* The description of this case is largely from the account given by Mr. Bowlby in the Path. Sis. Trans., vol. xxxvi. 
adjacent parts are occupied by a large new growth. The tumour is extremely hard, and of a similar shape to the gland in which it grows, being composed of two lateral lobes of equal size, joined by an isthmus. Its cut surface is fibrous. Each lobe reaches the level of the hyoid bone above and of the bifurcation of the trachea below ; they are joined by a broad isthmus reaching from the cricoid cartilage over the upper half of the trachea. Above, the lobes present a rounded outline, are quite separate from each other and their limits are clearly marked. Behind, below and laterally, the limits of the growth are quite undefined, the surrounding parts being infiltrated by the tumour and not simply pushed aside. Thus the common carotid artery, the external and internal carotids, the internal jugular vein, the pneumogastric, recurrent laryngeal and sympathetic nerves are on each side entirely included in the tumour. The depressor muscles of the hyoid bone are infiltrated and fixed; the cesophagus is infiltrated and so compressed an inch and a half below the cricoid cartilage, that the tip of the little finger can barely be passed. The trachea has been compressed both laterally and in front; in the latter situation by the isthmus of the tumour (which has been divided), while its lower portion, which in life occupied the thorax and root of the neck, is infiltrated with new growth on each side, and so narrowed by lateral compression that the little finger cannot be passed. The aorta and all its branches, the innominate veins, with the superior vena cava and the pulmonary artery, are all incorporated in the tumour to a greater or less extent, but although the calibre of these vessels is more or less diminished by pressure, in none of them is there any ulceration or clotting of blood. The apex of the left lung is closely adherent to, and not separable from, the lowest portion of the growth. The bifurcation of the trachea, with both bronchi, is adherent to the tumour, as are also the bronchial lymphatic glands. Neither in the neck nor in the thorax were these latter at all enlarged or otherwise altered. I made a very careful examination of different parts of the tumour, sections being taken both from the centre and the periphery. The structure was entirely fibrous without the least appearance of either alveolation or of epithelial cells."

The following case was under my own care at the Royal Free Hospital and differs from the others in that spontaneous ulceration of the skin occurred, as may be seen in the accompanying photograph (Fig. 59).

Mary S-_, $w t$. 63, widow, was admitted into the Royal Free Hospital on Jan. 20, 1899, on account of dyspnoea and an enlarged 
thyroid gland. She had had for many years a swelling in the neck which had given her no trouble until about fifteen months before admission. At this time the swelling on- the right side became larger and eventually broke through the skin. An indolent sinus had been present ever since. In the last two months she harl had much severe dyspnoa, especially at night. She had also lost flesh in the last few weeks.

On admission she was found to be pale and thin. She breathed

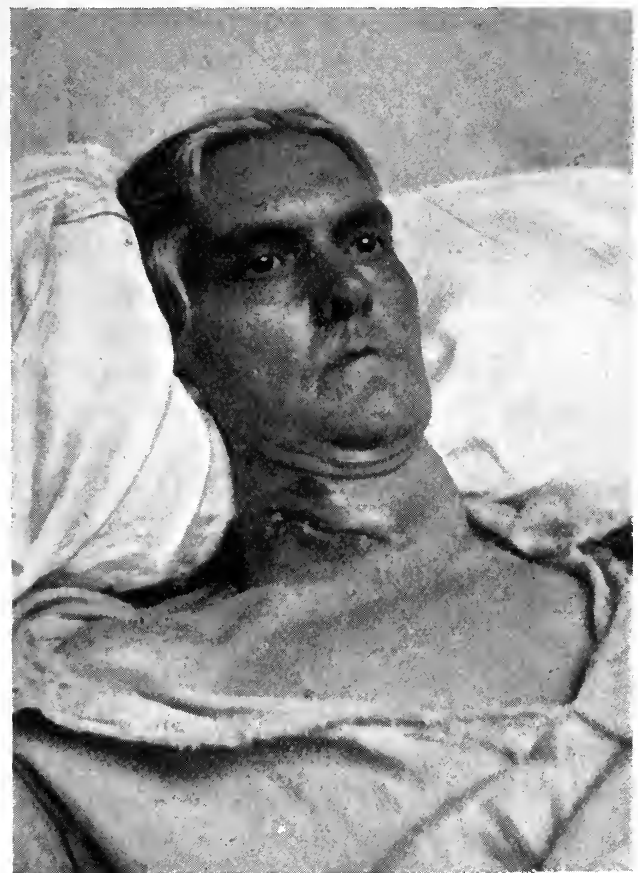

FIG. 59.-Primary Chronic Inflammation of the Thyroid, leading to spontaneons nlecration of the skin. (The darkness of the skin is dne to a photographic (rror.)

with much difficulty and stridor, and had to lie in a semi-recumbent position, as she could not breath while lying down. Temp. $98^{\circ}$, Pulse 120, Resp. 36. There was also a good deal of bronchitis. There was little or no dysphagia.

The right lobe of the thyroid formed a hard irregular mass about as large as a goose's egg. The skin over it was adherent; in the middle of the adherent area was a shallow, narrow, ulcerated surface two inches long by half an inch wide and extending nearly half an 
inch into the substance of the gland. On the left side of the neck was a similar but somewhat smaller swelling not nearly so hard; the skin over this was not ulcerated. The whole swelling moved with the larynx, but not very freely. With the laryngoscope great lateral flattening of the trachea was seen, the walls were about $\frac{1}{6}$ inch wide at the narrowest part. The vocal cords moved naturally.

The diagnosis of the case was not clear; the swelling was believed to be chronic inflammation of a peculiar nature, possibly tuberculous, but the idea of malignancy could not be altogether excluded. It was clear that, owing to the fixity of the growth, no removal was possible. It was thought that tracheotomy would soon be required. The case was seen by my colleague, Mr. Battle, who agreed both with the diagnosis of probable chronic inflammation and also with the impossibility of removing the tumour by operation.

On June 23, the patient having had several attacks of severe dyspnoea, tracheotomy was performed without any general anæsthetic. The operation which lasted ten minutes was difficult owing to the hardness and nodularity of the gland, which made it difficult to distinguish the trachea from neighbouring parts. A long Köenig's canula was inserted. The patient's breathing was easier after the operation. On the following day the tube was removed for cleansing and then replaced. The patient's temperature which had been $100^{\circ}$ before the operation was never afterwards quite normal: her pulse was generally between 120 and 160 . The patient died six days after the operation with symptoms of septic bronchitis.

The post mortem showed a bilateral parenchymatous goitre of moderate size and with a few cysts evidently of long duration. The lower half approximately of the right lobe was occupied by a densely hard, yellowish-white, ill-defined mass, which was firmly adherent to the trachea for about an inch and a half, and also to the left carotid vessels. In the corresponding part of the left lobe is a similar, but much smaller mass of the same nature. The resemblance to a scirhous carcinoma was very great, but careful microscopical examination showed nothing but dense fibrous tissue with remains of thyroid tissue here and there. There was no trace of malignancy anywhere.*

'The third case illustrates a much earlier stage of what I believe to be the same disease, but as the dense fibrous growth had in this case not reached the capsule of the gland, there were

\footnotetext{
* The specimen is now in the Reral Free Hospital Museum, No. xxii. s.
} 
no adhesions to surrounding parts and complete removal of the affected lobe was possible.

Mrs. Charlotte G_—, ${ }^{*}$ at. 40, was admitted under my care into the Royal Free Hospital, on account of a swelling of the right lobe of the thyroid.

Five weeks before admission she had first noticed a lump in this region; it had steadily increased in size. She complained of occasional shooting pains in the lump, and also of a slight "choking" feeling. Otherwise she appeared to be in good health. The extreme hardness of the lump, its slight irregularity together with the history of a rapid growth and sharp pains led to a strong suspicion of malignant disease in an early stage.

Accordingly on May 13, 1898, extirpation of the right lobe was performed. The operation presented no unusual difficulty of any kind ; the subsequent course of the case was quite ordinary : the wound was drained for twenty-four hours and then healed throughout by primary union. The temperature never reached $100^{\circ}$ at any time. The patient left the hospital eleven days after the operation quite well in every respect. She came to show herself from time to time and remained perfectly well. She was last seen about two years after the operation.

The tumour that had been removed was as large as a hen's egg. The peripheral portion to a depth of about a quarter of an inch consisted of normal dark coloured thyroid tissue. All the central part however consisted of a somewhat ill-defined mass of connective tissue, which on section was found to be extremely hard, white, shiny and glistening.

Microscopically it consisted of dense inflammatory tissue with remains of thyroid tissue between the bundles of fibrous tissue.

Riedel $\dagger$ has recorded the following cases:

A man aged 42 had noticed for about six months a swelling of the thyroid gland which caused considerable dyspnoea. The tumour was bilateral, not very large, but extremely hard and fixed. It was believed to be malignant and on November 30, 1883, an attempt was made to remove it by operation. After the gland had been exposed however, it was found to be intimately united on both sides with the carotid artery and jugular vein. The operation for its removal was therefore abandoned, and Riedel contented himself with cutting away a piece of growth as large as a walnut.

* See Appendix, Case s6, p. 346.

+ op. rit. 
The wound healed without any trouble and the patient's breathing improved so much that at the end of six months his dyspnoea had entirely disappeared, he seemed quite well and was able to do his ordinary work. Fifteen months after the operation this patient died of nephritis and apoplexy. There was no post mortem. The portion of tumour that had been removed was examined microscopically. There was no sign of sarcoma or carcinoma. The tumour was composed of chronic inflammatory tissue. There was no evidence of tubercle or syphilis.

'Twelve years later Riedel met with the following case :

A healthy looking woman aged 23 had noticed that for a period of one year her neck had been swollen. In the last two months the swelling had increased tolerably rapidly. The patient had much dyspnoea on exertion. The thyroid gland was enlarged on the right side to the size of a hen's egg, on the left to that of a small apple. The tumour was remarkably hard and fixed. As in the preceding case the operation for removal of the tumour had to be abandoned on account of the extensive adhesions of the tumour with the blood ressels and recurrent nerves. Microscopical examination of a portion of the tumour showed chronic inflammatory tissue. The patient's breathing improved after the operation, she was able to get about and was apparently nearly well. About two months after the operation she was suddenly seized with symptoms of embolism and died in a few minutes. There was no post-mortem examination.

'The case that formed the subject of 'Tailhefer's first paper * was under the care of M. Jeannel of 'Toulouse. 'Tailhefer himself assisted at the operation.

The patient was a man of thirty who for three months had noticed aphonia and a swelling of the neck. The left lobe of the thyroid was found to be occupied by a "very hard, ill-defined, fixed and painless tumour, not involving the skin." The tumour was thought to be malignant and its removal was attempted. The tumour was found, however, to involve the carotid sheath and neighbouring parts so extensively that the operation had to be abandoned, a small piece only of the growth being removed. The operation was followed by secondary hæmorrhage from the carotid, necessitating ligature of that vessel. Suppuration and hemiplegia followed but the patient eventually recovered. Histological

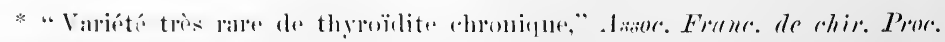
rerl., Paris, 1s!ki, x. p. 32s. 
examination showed the tumours to be composed of "an abundance of fibrous tissue with a few collections of inflammatory cells, but no thyroid vesicles."

Tailhefer in his second communication * on this subject mentions also three other cases of a similar nature communicated privately to him by Riedel and Cordua. All these were diagnosed before operation as sarcoma. All underwent operation which in one case at least was incomplete. Nevertheless the patients recovered and were well at periods varying from some months to several years after the operation.

The cause of this curious disease appears to be quite unknown.

Treatment by drugs such as iodide of potassium seems to be useless. There can be no doubt that if seen at a sufficiently early period, before the disease has penetrated the capsule, extirpation of the diseased lobe of the gland is the best treatment. The surgeon must be prepared, however, to meet with serious difficulties in the course of the operation, owing to adhesions, and must be ready to abandon the operation if these difficulties prove to be insurmountable.

Partial removal of the enlargement has had in some cases such a beneficial effect upon the course of the disease that even incomplete attempts at removal appear to be quite justifiable.

As Riedel says, "Operation should be undertaken, but the operator should know when to leave off." Riedel himself in his first case strove for two hours to remove the tumour. Most surgeons will agree with him in thinking this time excessive. He remarks that in his second case, in which the condition of affairs was more readily recognised, he abandoned the operation at a much earlier period before the main vessels had been damaged.

Tracheotomy in advanced cases may become necessary but is apt to be both difficult and dangerous. Unless the dyspnoea is extremely urgent, a partial removal followed by primary union would appear to be a better operation than tracheotomy with its attendant risk of sepsis.

* "Intlammation chronique primitive cancériforme de la glande thyroüde," Rer. de Chir., Paris, 1898, xviii. No. 3. p. 224. 


\section{CHAP'TER IX.}

\section{TLBERCLE AND SYPHILIS.}

Tubercle: Miliary-Csually secondary-Caseating-Rarity of-Extirpation of tuberculous goitre. Syphilis : frequently affects thyroid in form of slight general enlargement-Gummata rare-Congenital syphilis.

Tubercle.- 'Tubercle is not uncommon in the thyroid gland; but it occurs almost exclusively in the form of miliary tubercle, and usually only as a part of a general acute tuberculosis. Consequently it seldom gives rise to any symptoms during life, and is of very little practical importance. Chiari in one hundred post mortems upon tuberculous patients, found tubercle of the thyroid seren times, in the form either of acute miliary tubercle or chronic infiltration.*

Museum specimens are rare. In the Royal College of Surgeons is a specimen $\dagger$ of a thyroid gland containing a very small tubercle. It was obtained by myself from the body of a child aged four, who had died in St. Bartholomew's Hospital of acute general tuberculosis. In $1890 \mathrm{Mr}$. Bidwell showed at the Hunterian society a sinilar specimen, taken from a child five and a half vears of age, who had died of acute general tuberculosis. In the centre of the right lobe was a caseating tubercle of the size of a large pin's head. I have seen a similar specimen in the musem of the Pathological Institute at Berlin, and have also seen in the Pathological Museum at Prague a specimen ${ }_{+}^{+}$of a thyroid gland infiltrated with tubercle.

In St. George's Hospital Museum $\S$ is a specimen of a small

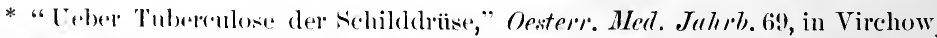
and Hirsch "Jahreshericht," 1878, vol. i. p. 277.

† No. $2906 \mathrm{ir}$. \pm No. 3973 .

$\$$ No. 2t. Sine also a description of this case by Dr. Rolleston in the Trans. Puth. Sur., 18:1, vol. xlviii. p. 1!7. 
tuberculous abscess of the thyroid. It had burst into the (esophagus. It had not been detected during life. The patient was a woman aged twenty-three, who died of paraplegia following caries of the spine. Dr. Rolleston, in the paper mentioned below, alludes to other cases of miliary tubercle of the thyroid observed by Dr. Perry, Dr. Voelcker, and himself.

Tuberculosis of the thyroid occasionally occurs in the form of larger caseating masses. Such cases have never come under my notice.

In April 1873 Dr. Quinlan* showed at a meeting of the Pathological Society of Dublin a much enlarged thyroid. It was taken after death from a man who died of "great weakness and loss of speech." 'The tumour was said to possess the "microscopical characters of tubercle."

Dr. P. Bruns, of Tuibingen, has collected several cases $\dagger$ of tubercle of the thyroid. In some of these the disease occurred in the form of caseous masses of considerable size.

One of these cases occurred in his own practice, and is, so far as I know, the only example of a tuberculous thyroid gland attaining sufficiently large dimensions to cause pressure symptoms, and to require an operation for its removal. It is probably also the only case hitherto recorded of primary tuberculous disease of the thyroid.

'The following is an abstract of this very interesting case :

F. E-, at. 41, a widow, had had from childhood a small, soft goitre which gradually increased in size, but caused no other trouble until six months before admission to hospital. During this latter period it had grown rapidly and caused much pain and dyspnoea.

The patient's general health appeared to be good and she had no cough or expectoration or any other sign or symptom of pulmonary tuberculosis. The thyroid gland was enlarged in all parts; the right lobe formed a swelling as large as a child's fist and extended outwards under the sterno-mastoid and downwards under the clavicle. The tumour was covered by healthy, non-adherent skin. It had an uneven surface and was remarkably firm. The left lobe was soft and only slightly enlarged. In the neighbourhood of the right lobe were a few enlarged glands. The larynx was somewhat pushed over to the left. There was slight paralysis of the right

* Brit. Med. Journ., July 26, 1873, p. 102.

† "Struma Tuberculosa," Beitr. s. Klin. Chir., Tübingen, 1893, vol. x. p. 1. 
recurrent nerve, but the voice was scarcely at all affected. When at rest there was no stridor or dyspnœea, but these symptoms were present on exertion. The recent rapid and painful growth together with the remarkable firmness and irregularity of the tumour and the enlargement of lymphatic glands led to the suspicion of malignancy. Extirpation of the right lobe of the tumour was performed without any difficulty on August 12, 1892, and the patient made a rapid recovery, leaving the hospital ten days after the operation.

"The half of the thyroid that had been removed was of firm consistence and somewhat nodular surface. On section it was seen to consist chiefly of a homogeneous, grey, firm tissue in which were embedded a number of isolated masses. These masses were of two kinds : numerous small circumscribed nodules up to the size of a bean, chiefly near the periphery, represented remains of thyroid tissue, partly unaltered, partly having undergone colloid degeneration, and several dry, yellow masses of the size of walnuts, which had the appearance of unsoftened, cheesy masses like those observed in the so-called granules of large-celled tuberculous lymphomata. At the lower horn of the lobe was a collection of lymphatic glands of the size of cherries, loosely united by connective tissue."

The microscopical examination by Dr. Baumgarten showed tuberculous tissue with the usual epithelioid and giant cells.

On Nov. 2, 1892, the patient returned with an enlarged lymphatic gland in the neighbourhood of the scar. This gland was removed and showed "typically tuberculous" tissue. No tubercle bacilli were found either in the primary growth or in the gland.

Bruns considers the case to be " undoubtedly one of tubercle," and Baumgarten is of the same opinion.

Syphilitic Disease.-Syphilitic disease of the thyroid occurs in the form of a slight general enlargement in the early acute stage of the disease, and also in the form of gummata in the tertiary period.

Engel Reimers * considers that swelling of the thyroid gland occurs in nearly half the cases of syphilis in their early stages. He observed it eighty-six times among one hundred and fiftytwo women, and forty-four times among ninety-eight men in the early stages of syphilis. 'The swelling was always soft and painless and caused no trouble.

* Jalrbluach der Hamlurger Stauts krankenanstalt, vol. iii. p. 189+ (quoted by Füirst). 
In this country, Mr. C. B. Lockwood has drawn attention* to the fact that slight, and generally transient, enlargement of the thyroid gland may be observed in the acute stage of syphilis. Having had the opportunity of seeing Mr. Lockwood's cases, I can fully corroborate his observation.

The enlargement of the thyroid in this early stage of syphilis is comparable to the slight enlargement which is met with in early stages of measles and other acute specific diseases.

Mr. Lockwood observes that after he had learnt to look out for this thyroid enlargement, it was frequently noticed among his venereal cases.

Dr. Moritz Fuirst $†$ of Hamburg has published the case of a child born with a goitre of considerable size which he considers to have been undoubtedly caused by syphilis. 'The father' had suffered from this disease, and the mother was undergoing mercurial treatment during her pregnancy, as she had already given birth to a stillborn syphilitic child. Each lobe of the goitre was as large as a walnut. The swelling almost entirely disappeared spontaneously within six weeks of birth. No treatment was adopted. Dr. Fürst could find no cause for the goitre other than syphilis.

Demme + mentions three cases seen by him at Berne in which children with congenital syphilis had gummatous nodules in the thyroid. In all three cases the liver and skin also presented signs of syphilis.

The only museum specimen of gumma of the thyroid gland with which I am acquainted, is in the Royal College of Surgeons. $\$$ It is thus described in the museum catalogue:

Base of tongue, larynx and thyroid gland, showing gummatous infiltration of the thyroid. The sterno-thyroid muscle is matted to the left lobe of the thyroid, which on section has a white fibrous appearance towards the periphery, while the centre more nearly resembles normal thyroid tissue. The upper end of the trachea is distinctly stenosed, and it, as well as the base of the tongue, shows

* St. Bart. Hosp. Reports, 1895, xхxi. p. 232.

$\dagger$ "Ein Fall von Struma congenita bei elterliche syphilis," Berlin klin. Wochensehr., 1898, xxxv. p. 1016.

† In Gerhardt's Handbuch der Kinderkrankheiten, Tübingen, 1878, vol. iii. pt. ii. p. 413.

$\$$ No. 2905G. 
the effect of past ulceration. Microscopic sections showed a fibroid tissue richly studded with nuclei. From a woman about 60 who was brought into the hospital dead. There were gummata in the liver.

Gummata of the thyroid have also been described by BirchHirschfeld.*

The most marked example of gummatous disease of the thyroid that has come under my own notice was the following:

Mrs. S_, $\alpha t .38$, was admitted into St. Bartholomew's Hospital under the care of Mr. Bruce Clarke, on Dec. 28, 1896, on account of dyspnora and a swelling of the neck. She had been married thirteen years, but had never been pregnant. For the last four vears she had been under treatment for gummata of the face and arm. About six weeks before admission she had first noticed the swelling in the neck. There was no history of any pre-existing goitre. Occupying the middle line of the neck from the thyroid bone to the sternum was a prominent hard mass moving slightly with the larynx on deglutition. The skin over it was of a dull red colour. At the upper part was a deep, circular ulcer, at the bottom of which was a hard, yellowish mass, evidently the isthmus of the thyroid gland. There was no obvious enlargement of the lateral lobes of the gland. On the fourth day after admission the dyspnoea became so bad that laryngo-tracheotomy had to be performed by the house-surgeon, Mr. Pearson. The operation was difficult owing to the thickness of the tissue that had to be divided before the cricoid was reached. The incision was made through a thick mass of gummatous thyroid, most of which subsequently sloughed away. The patient made a good recovery and left the hospital six weeks after admission. The wound had practically healed, but there was still a little cedema of the larynx and the left vocal cord did not move quite freely. It seemed probable that in this case there was come necrosis of the larynx as well as syphilitic disease of the thyroid gland.

Mr. Charters symonds has related to me a similar case of gummatous disease of the thyroid, which necessitated tracheotomy. 'The patient was a man. An incision was made right through the gummatous disease into the trachea. The patient recovered.

*." Lechrburh al. patholog. Anat," the ed., 1894 5, vol. ii. p. 472. 
Dr. Wermann of Dresden has published* the case of a man, aged 24, who had suffered for several years from the usual symptoms of syphilis. He had undergone prolonged mercurial treatment on three different occasions, and was, at the time the goitre developed; undergoing treatment with iodide of potassium on account of a gumma of the soft palate, and other signs of tertiary syphilis.

The thyroid swelling was general, soft and painless. It grew rapidly and subsided again rapidly under mercurial treatment. A very curious point about this goitre is that it developed while the patient was taking iodide of potassium, a remedy usually so effective in the treatment of goitre.

Fraenkel $\uparrow$ and Kuittner ${ }_{+}^{+}$have also written upon the subject of syphilis of the thyroid.

* “Ueber Luetische Struma," Dr. E. Wermann, Berl. klin. Worhenschr., 1900, No. 6, p. 122.

$\dagger$ "Ueber Trachea und schilddrïsen syphilis," Dent:ah. Med. Workensrhr., 1887 , p. 103.).

† "Struma Syphilitica," Beitr. a. klin. C'hir., vol. xxii. part 2. 


\section{CHAP'TER X.}

\section{(:YSTIC DISEASE.}

Freduency-Agt-Modes of origin-Thansition of adenomata into cysts - Single and multiple cysts-Hamorrhagie cysts-Structure of cyst wall-Of contents-Vacololation of rolloid-Intral-cystic growthsMalignant nature of-False intal-crestie growths.

Whex we consider the vesicular structure of the normal thyroid gland, it is not difficult to understand how readily this organ may become the seat of cystic disease. By cystic disease is meant the existence of one or more cysts considerably larger than the normal vesicles.*

A slight degree of the disease is extremely common. Out of screnty-three thyroid glands examined consecutively in the post-mortem room of St. Bartholomew's Hospital, I found that no less than twelve contained well marked cysts. In the majority of these, however, the cysts were small and few in number, and conld not have been detected during life; in others, however, the size was sufficient to cause manifest enlargement of the gland.

As regards the "ge at which rystic disease is most common, it would appear that middle-aged and elderly people are more prone to the affection than are the young. Just as parenchymatous disease of the thyroid is the most common form of goitre in children and young adults, so is cystic goitre the form which is most often met with in people of more advanced age.

Mode of Origin.-Cysts of the thyroid may originate in any of the following ways:

1. By distension of one or more of the natural vesicles, from accumulation of their colloid contents. The intervening walls

* The subject of hydatid rysts is discussed sepanately in chapter xi. 
of contiguous cysts become absorbed and small cysts thus become fused into larger ones.

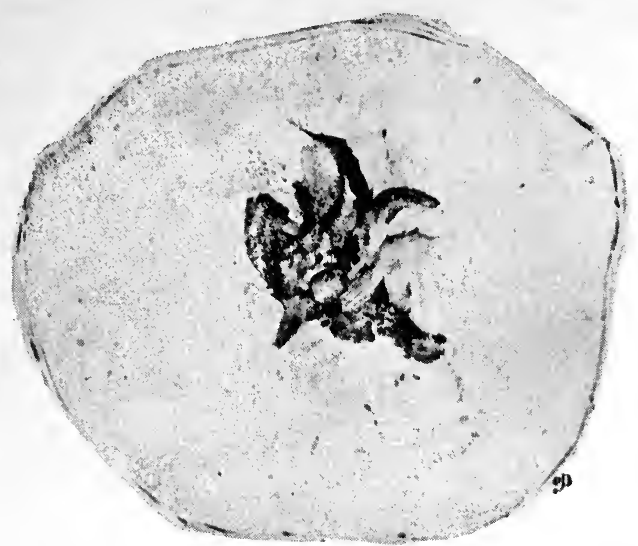

Fig. 60.-From a girl aged 10. (St. Burt. Hosp. Mns. No. $231+$ I.) (Nitt. size.)

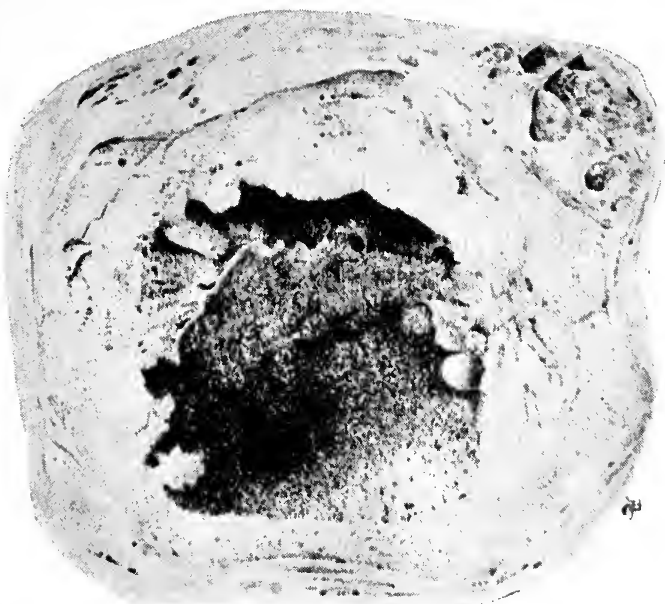

Frg. 61,-From a woman aged 25. (St. Bart. Hosp. Mus, No, 231+k.) (Nat. size.)

Figs. 60, 61 and 62,-Three specimens illustrating the gradnal Transforma tion of a Solid Thyroid Adenoma into a Cyst.

If a thyroid gland which is undergoing cystic degeneration be examined with the microscope, and with the naked eye, it will often be found that all gradations in the size of the cysts may be seen. 
2. Another and much more common mode in which large thyroid cysts are developed is from adenomata already existing in the gland. The interior of the softer forms of adenoma frequently breaks down and liquefies until, eventually, the (apsule of the adenoma forms the wall of the resulting cyst.

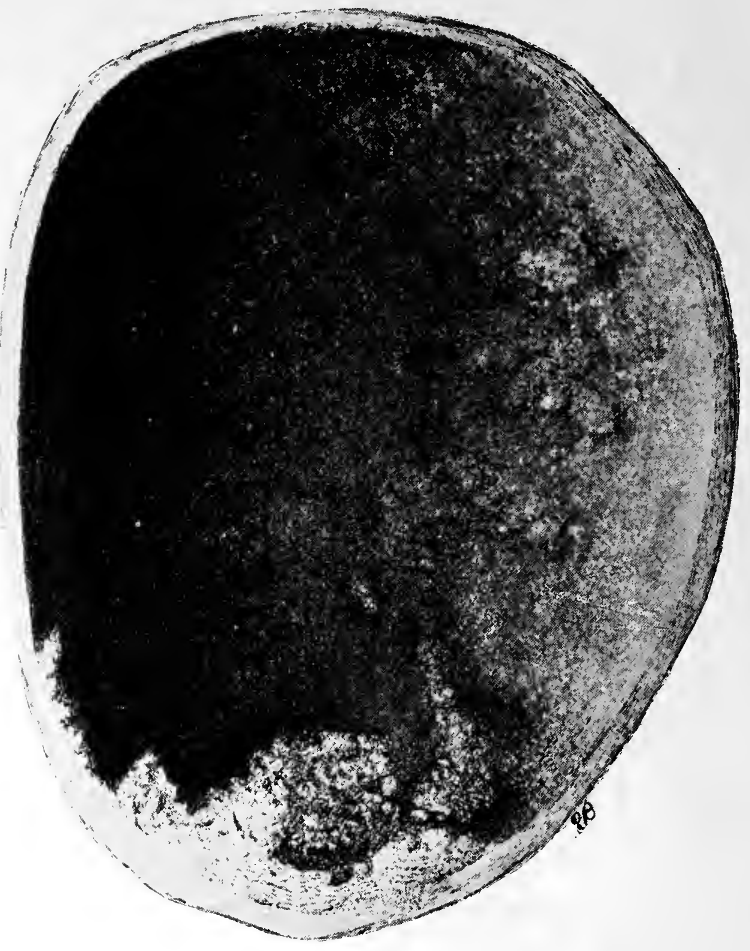

Fleis. 60, 61 and 62.-Three specimens illustrating the gralual Transformation of a Solid Adenoma into a Cyst. Fig. 62.-From a woman anewl 11. (Nt. Bart. Hosp). Mus. No. 231411.$)$ ( $\left.\times \frac{5}{4}.\right)$

All stages between the completely solid adenoma and the pure cyst may be observed.

Figs. 60 to 62 show a series of different gradations in this process. I have frequently demonstrated upon the inner wall of an apparently pure cyst, some portion of adenomatous tissue still adhering to it, and thus indicating the true mode of origin of the cyst. Indeed, careful examination of the cyst wall with the microscope will frequently show traces of thyroid tissue in 
the inside of cysts which at first sight appeared to contain nothing but purely fluid contents.

Fig. 63 is taken from a cyst, which, at first sight, appears to be a simple one. Closer examination, however, reveals traces of the original adenoma adhering to the inner surface of the cyst wall.

Fig. 64, from a specimen in St. Bartholomew's Hospital Museum,* shows a very soft adenoma removed by operation. Before, and at the time of the operation, it was believed to be a pure cyst. It was carefully hardened for some days, and when laid open, was found to have the structure

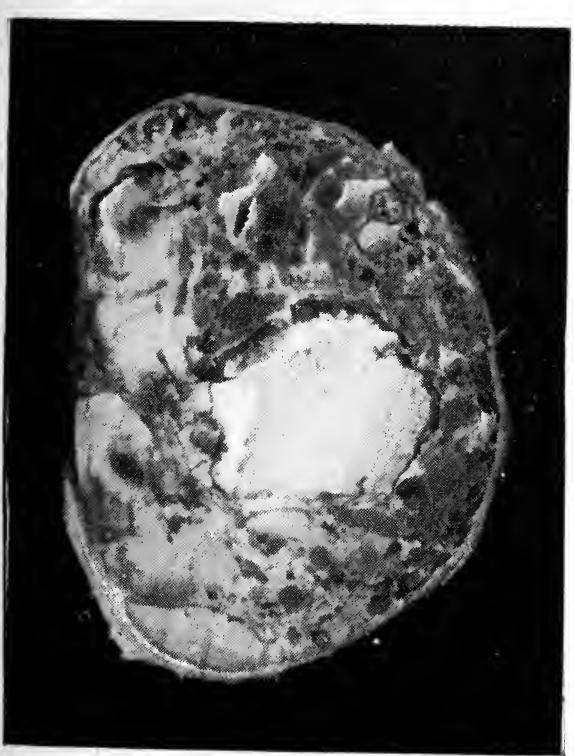

Fig. 64.-A very soft Cystic Adenoma. The white portions show coagulated colloid material. (Nt. Burt. Hosp. Mus. No. 2310G.) (Nat. size.)

shown in the figure. 'The glandular' nature of the tumour is obvious.

Probably all,or nearly all, the larger cysts met with in the thyroid gland originate in this way from the breaking down of a pre-existing adenoma. Such rysts may attain a huge size, measuring several inches in diameter. (See Figs. 65 and $6 \%$ )

Another mode in which a thyroid cystmay originate is from a hanorrhage into the organ.

'The soft, almost friable, nature of the gland, especially marked when parenchymatous enlargement exists, readily permits of the accumulation of blood within it. This 
blood may be extravasated as the result, either of slight injury, or, perhaps, of spontaneous rupture of a small thyroid vessel. I do not consider this, however, to be a common mode of origin.

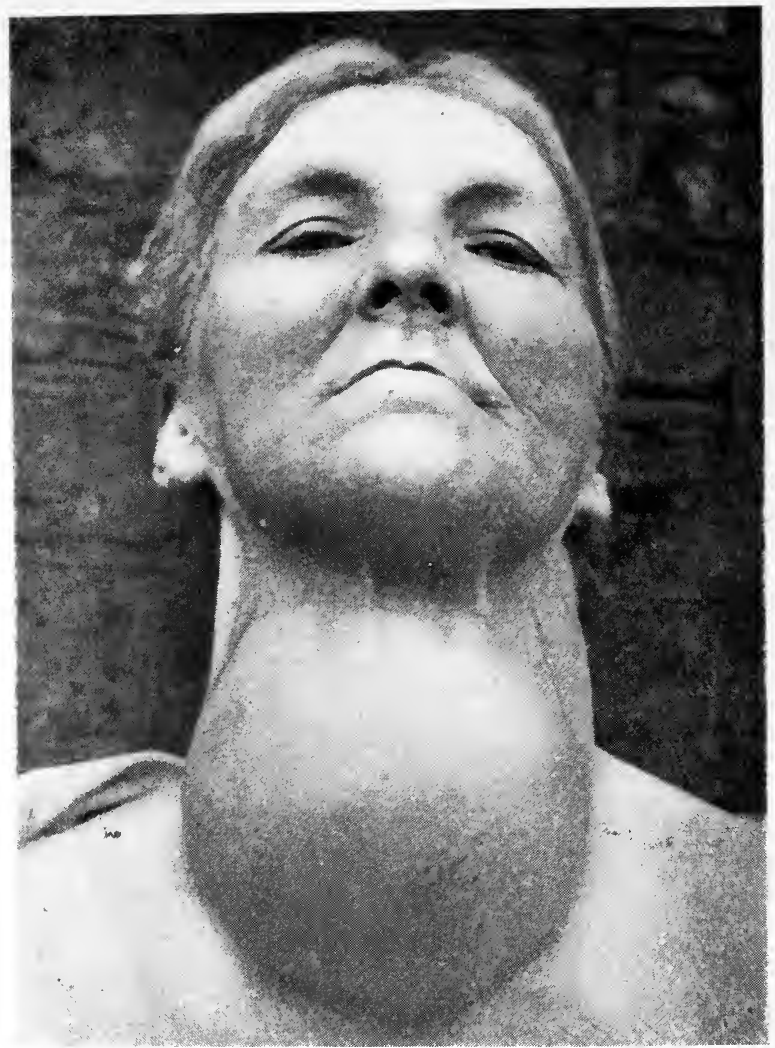

Fra. 65.-I womm, aged 50, with a large Cyst of the Right Lobe. It lad bern growing sowly for more than twenty years and cansed much diseomfort and some dyspure. It was ensily removed by resection-

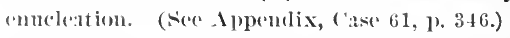

Hamorthage into an adenomatous tumour is, however, very common.

$\Lambda$ convenient and simple classification of thyroid cysts is into single and multiple.

An objection to this classification is that in cases of single cyst, there exist almost always numerous smaller cysts in other parts of the gland. As these however may be quite small and 
insignificant in comparison with the larger cyst, the practical value of the classification is not materially affected.

In cases of multiple cysts, the whole gland is frequently found to be converted into a mass of cysts, no one of which is much larger than its fellows.

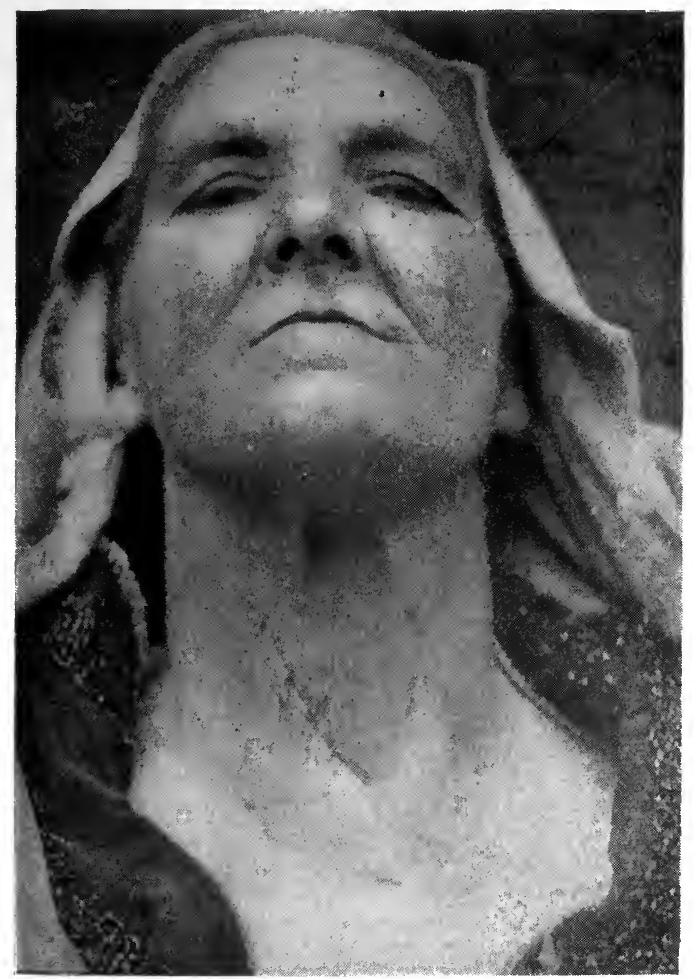

Fig. 66.-The preceling, one week after the operation.

Single cysts form unilateral tumours ; * multiple cysts generally produce bilateral enlargement of the gland. It is mainly on this account that this artificial and to some extent incorrect classification is worthy of adoption, since unilateral and bilateral tumours frequently present much difference with regard to symptoms, prognosis, and treatment.

A term frequently employed is that of Homorrhagic cyst.

* Except when situated exactly in the middle line. which is not common. 
'This may be of the nature above mentioned, but is much more commonly simply an ordinary retention or adenomatous cyst into which hæmorrhage has occurred.

A remarkable peculiarity of thyroid cysts is the unusual tendency to intra-cystic hæmorrhage which they possess.

In no less than six out of twelve cases mentioned on p. 152

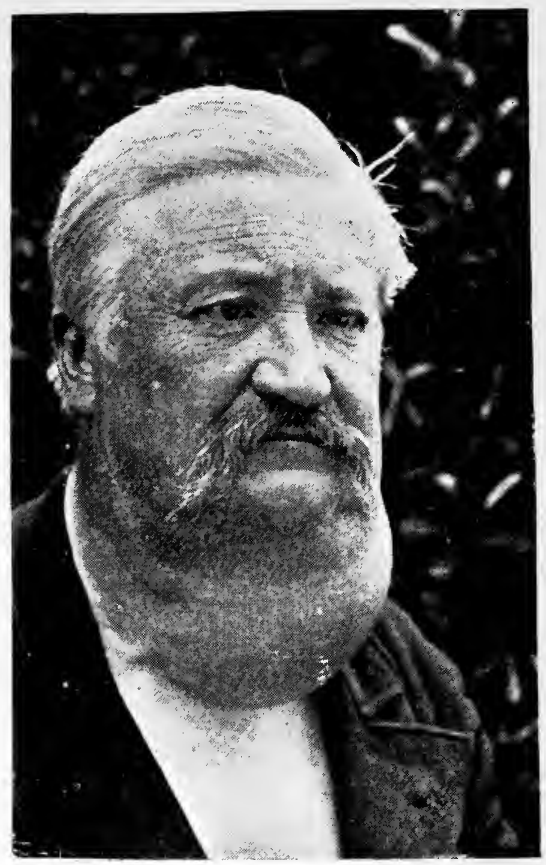

Fiti, 67.- -1 man, aged 50, with a large Ningle Thyroil Cyst springing from the left mper horr. It hul heen growing slowly for more than thirty years. It was easily and suceessfully removed by 1)r. ('omte, and fomm to (ontain over two poumds of somi-solid, partially calcified. colloil eontents. A portion of the cyst wall and its contents are now

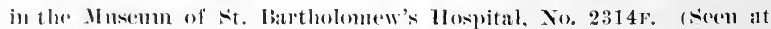
(iv') 1 in in $1 \times 86$.

distinct intra-cystic hemorrhage had occurred, and musemm specimens likewise show how common it is to find blood in the interior of a thyroid cyst. In no other class of cysts is found such a marked tendency to hemorrhage. If a thyroid cyst have been tapped and clear fluid withdrawn, a second tapping is extremely likely to evacuate, not a clear but a blood-stained 
fluid; frequently indeed on the second tapping the fluid consists of nearly pure blood.

It is probable that the explanation of this tendency to blood extravasation is to be found in the fact, already mentioned, that many thyroid cysts are formed from pre-existing adenomata. 'The soft and vascular thyroid tissue within the cyst is naturally very apt to bleed.

Occasionally this unfortunate liability to hæmorrhage leads to serious or even fatal results. Professor Kocher relates* the case of a lady who had a cyst of the thyroid. It was tapped; clear fluid being withdrawn. A second tapping caused the evacuation of pure blood. The intra-cystic hæmorrhage then caused such severe dyspnoea that extirpation of the cyst had to be performed.

Mr. Butlin has kindly comminicated to me a case in which, many years ago, a thyroid cyst was punctured in his out-patient room; such severe symptoms were caused by the intra-cystic hæmorrhage which ensued, that the patient subsequently had to be admitted to the hospital as an in-patient, and the hæmorrhage was controlled with the greatest difficulty.

In the College of Surgeons Museum is a preparation + of a large thyroid cyst. The catalogue states that the cyst was full of coagulated blood, and looked like the sac of an aneurism. During life it was punctured in consequence of the dyspnœa produced by its pressure upon the trachea. A considerable quintity of fluid blood flowed from the wound, and the bleeding continued until the patient died.

The following is a case of hæmorrhagic cyst that I saw in 1885, at the Kensington Infirmary with Mr. Potter and Dr. Reece. (Fig. 33, p. 47.)

Mary McD_—, $e^{2}$. 60, unmarried, had had for many years a swelling in the situation of the right lobe of the thyroid. In the last two months it had become much larger and more prominent. In the above-mentioned situation was an irregular rounded swelling measuring four and a quarter inches transversely, and three and three-quarters vertically. It projected considerably and overlapped the sternum and right clavicle. It was of a dusky red colour, tense and elastic, but with softer spots here and there. At 
the most prominent part was an ulcer with a slough as large as a sixpenny-piece. Puncture gave exit to an ounce and a half of grumous fluid containing much blood. The cyst was dissected out by Mr. Potter and was found to contain a large amount of both fluid and clotted blood.*

The patient made a good recovery.

Hæmorrhagic cysts of other parts of the body sometimes afford a presumption of malignancy, but this is by no means the case with those of the thyroid. Malignant cysts of this organ like those of other parts, may, of course, be accompanied by intra-cystic hæmorrhage. But it is important to bear in mind that the finding of blood in the interior of a thyroid cyst ought not in itself to be taken as pointing towards the existence of malignant disease.

On the other hand malignant disease of the thyroid may produce cysts containing clear fluid. 'Two examples of this have come under my own notice.

The situation in which cysts are most often found is the lower part of one or other lateral lobe, but the only apparent reason for their more frequent occurrence in this part is that the main bulk of the organ is situated here. The isthmus and the comparatively slender upward prolongation of the lateral lobes form but a small part of the whole organ. +

The structure of thyroid cysts may conveniently be considered under two heads :

(a) Structure of the cyst-wall.

(b) Structure of its contents.

(a) Cyst-wall.-In small recently formed cysts, the wall has the same structure as that of the normal vesicle; it consists of an exceedingly thin and delicate layer of connective-tissue lined by a single layer of epithelial cells.

In larger cysts it is more fibrous and tough, being composed mainly of dense layers of fibrous tissue closely packed together.

Sometimes when the cyst is large the wall may measure screral lines in thickness. In these cases there may often be

* This specimen is now in the Musemm of the Royal College of surgeons. No. 290:

$\dagger$ For specimens of ryst in upper part of lateral lobe, see st. George's Hosp. Mus. No. 20A : in isthmus, St. Mary's Hosp. Mus. 1031. see "lso Figs 41 and 6 is. 
found in it spicules or hard flat plates of calcareous matter. In cystic goitres of long standing the whole wall may be one large calcareous plate.

According to Dr. Paul Koch * the calcareous plates consist of a mixture of carbonate and phosphate of lime.

Many hospital museums contain specimens of calcified thyroid cysts. Some of these have been macerated and dried; others are wet preparations. $\dagger$

The inner surface of the cyst-wall varies considerably. In small cysts it is generally of a yellow or brownish colour. In larger ones with thick fibrous walls it is white, smooth and glistening, if the fluid contents have been clear. If the latter have been thick, discoloured and opaque then the cyst-wall may be rough or be lined with layers of fibrin, or colloid material; or with pus, if suppuration have occurred.

(b) Contents of the Cyst.--The simplest cysts contain the ordinary yellowish, slightly viscid, colloid material secreted by the lining membrane. When the cyst is large, however, the contents become more or less altered.

The fluid may be clear and watery. In the case of a man aged $4 \%$, with a single cyst as large as a small orange, I find in my notes that the fluid was thin, of a light straw colour, slightly alkaline. On standing, a small coagulum separated out; the remaining fluid, on boiling, yielded a precipitate of albumen (two-thirds). It also contained a moderate amount of chlorides and some cholesterin. This may be taken as a fair example of the clear fluid contained in a very common class of cyst.

The fluid may, and very commonly does, contain blood which may vary in amount from a mere trace to a quantity which forms a very large proportion of the total fluid. The colour may therefore be almost any shade of red or brown.

Frequently the colloid contents are much more viscid. 'They may then present the appearance of a stiff jelly.

Further changes may have occurred and the jelly-like material have become more or less solidified and dried up.

* "Cas interessant de goître kystique presenté à la soc. des sciences med. de Luxembourg," Ann. des mal. de l'oreille et du larynx, Paris, 1881, vii. 86-90.

$\dagger$ See Univ. Coll. Mus. 1361 ; st. Bart. Hosp. Mus. 2316 and 2317 ; Guy's Hosp. Mus. 122 and 123 ; King's Coll. Mus. 280 ; also an unnumbered specimen in the Geneva Path. Mus. 
Frequently points of calcification may be seen, or these may have developed into large, calcareous masses. A cyst removed by M. Comte of Geneva, which I had an opportunity of examining (see Fig. 6\%), contained more than two pounds of half dried partially calcified colloid material of this nature. A small portion of this tumour is now in the museum of St. Bartholomew's Hospital.*

Sometimes the calcification is so extensive that the whole tumour is converted into a dense calcareous mass. $\dagger^{\dagger}$

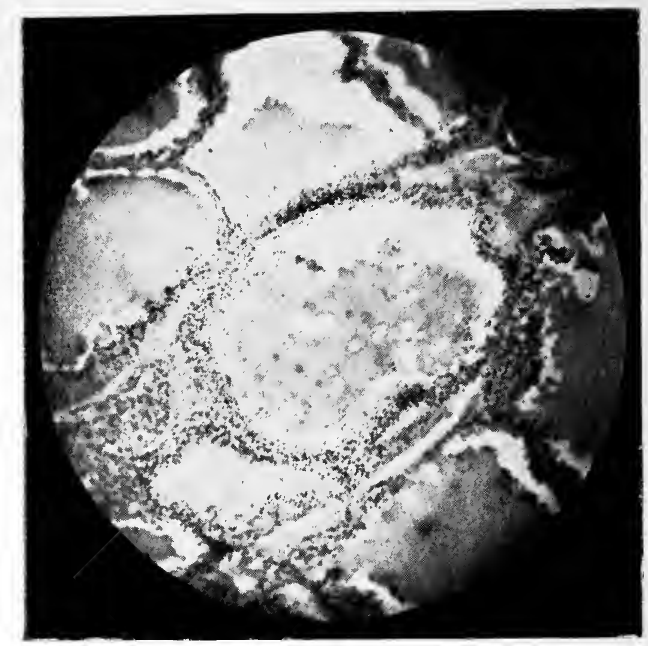

Fiti. 68.-Parenchymatous Goitre from a girl aged 17. Several distended vesicles are seen with colloit that has undergone the changes described on 1. 163. ( $\times 90$ diam.)

It is by no means uncommon to find crystals of cholesterin among the contents of an old thyroid cyst. +

Occasionally the solid contents of a thyroid cyst may be found in the form of loose masses in the interior of the cyst. In the museum of pathology at Geneva is a very remarkable specimen of a large cyst which contained many hundreds of rounded,

* No. $231+\mathrm{F}$.

† An excellent example of this condition is to be seen in the Pathological Musemm at Pramus.

\& For examples of this condition see seven of the cases reported by Keser in his monograph, " li inucléation ou extirpation intra-glandulaire du goitre parenchymatemx." Parris, 1887. 
crenate loose bodies of about the size and shape of blackberries. Two of these bodies together with a small portion of the cystwall may be seen in the Museum of the Royal College of Surgeons.*

Microscopical examination of the colloid material found in the smaller thyroid cysts will generally show a number of little

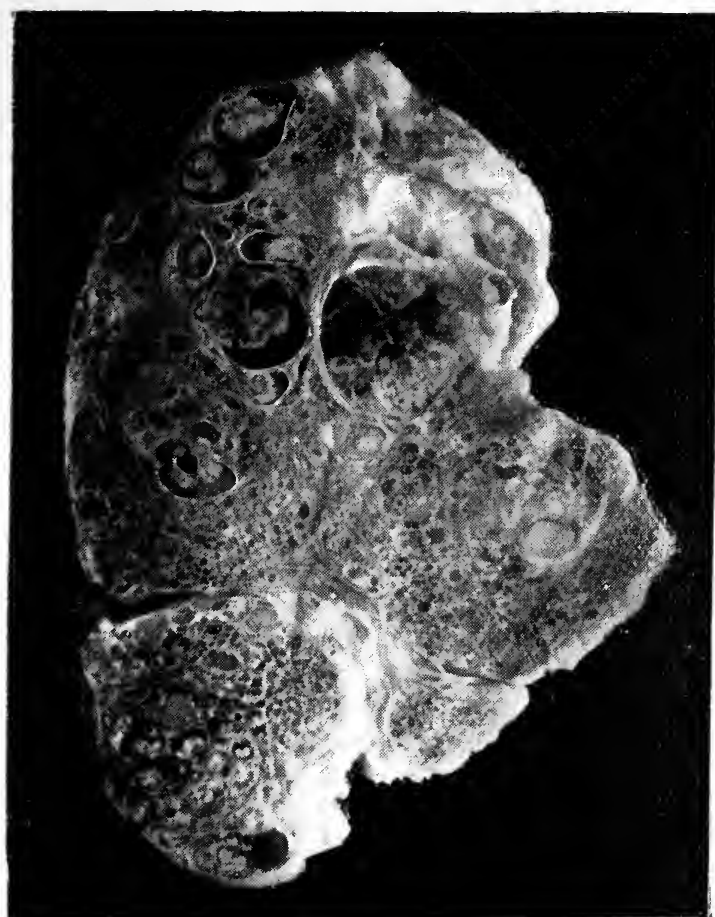

FiG. 69.-Section of a Parenchymatous Goitre with Commencing Cystic Degeneration. Some of the eysts are coalescing and thus produce a false impression of cysts with intra-eystic growths. From a girl aged 17. (St. Burt. Hosp. Mus. No. 2312A.) (Reduced $\frac{5}{6}$.)

round cavities, some at the edge and some in the middle of the mass.

These vacuoles, which are shown in the centre of Fig. 68, are probably due merely to post-mortem changes in the colloid and have no pathological signification.

* No. 2905в. See also a figure in my paper on the "Pathology of Goitre" in the Trans. Path. Soc., 1890, vol. xl. p. 264. 
Intra-cystic growths.-Occasionally papillomatous growths spring from the wall of a thyroid cyst and project into its cavity. A beautiful specimen * of a cyst of this nature was exhibited by Mr. Bilton Pollard, at a meeting of the Pathological Society in $\mathbf{1 8 8 5}$. These papilliferous cysts are distinctly rare. They must be carefully distinguished from the common cysts in which adenomatous tissue is found, which is merely the remains of a pre-existing adenoma.

True papilliferous cysts of the thyroid are analogous to the corresponding tumours of the ovary and breast, and like them have a low degree of malignancy. They tend to recur after removal, and to become eventually distinctly carcinomatous in structure. 'They will be described more fully in the chapter on malignant disease. A false appearance of intracystic growth is often produced by the remains of septa, which existed between small cysts. When these cysts coalesce to form larger cysts, the septa together with adherent masses of thyroid tissue produce a condition which at first sight closely resembles that of a cyst with true intracystic growths.

This appearance is well shown in the upper part of the specimen depicted in Fig. 69.

Remains of adenomatous tissue within a cyst may also present a superficial resemblance to true intracystic growths.

* For a drawing of this specimen see Puth. Suc. Trans. 1886, xxxvii. j11. 


\section{CHAP'TER XI.}

\section{HYDATIDS.}

Rarity of-Museum specimen-Age-Sex-Absorption of gland by pressure - Symptoms - Suppuration - Diagnosis - Urticaria-Rupture into trachea-Treatment-Table of cases.

THE only parasite of importance that is known to occur in the thyroid gland is the echinococcus (hydatid). Even this is not very often seen in this situation.

Most of our knowledge of hydatids of the thyroid has been obtained from the writings of Gurlt, Dardel, and Henle, who have collected and described all the cases known to them, seventeen in all.* To these I have been able to add five others, one of them hitherto unpublished. (See table of cases at the end of this chapter, pp. 172-175.)

These bring the total number of recorded cases up to twentytwo. Short notes of all of them are given in the table at the end of the chapter.

'The only museum specimen of a hydatid of the thyroid with which I am acquainted is in Guy's Hospital Museum. $\dagger$

It is thus described in the museum catalogue :

* Besides these, there are a good many cases of hydatid close to, but not actually in the thyroid gland itself : among these are Dixon's well-known case (Med. Chir. Trans. vol. xxxiv. p. 315), J. L. Reverdin's (Journal de la Suisive Romande, 1885, p. 421), and those of Cloquet, Langenbeck, Laennec, Bock, and Duquet. Other ases again have been described as hydatids of the thyroid in which the evidence of the hydatid nature of the disease was too slender to warrant me in including them in my table. The inclusion of Bock's case in the lists of undoubted hydatids of the thyroid given by Gurlt and Henle is evidently due to a misquotation from the original paper (Lehrb. der Puth. A uat. $u$ Diagnostik, 3rd ed. vol. i. p. 55t). Some of the above may have been cases of. hydatid of the thyroid, but have not been included in my table owing to want of evidence.

+ No. 124. 
"The remains of a hydatid cyst removed from the thyroid gland. Histologically the wall of the cyst is composed of characteristic laminated membrane.

" Fmma W. at 15 was admitted under Mr. Cock for a swelling of the neck of seven years duration. It was thought to be a bronchocele. The swelling was twice incised and pus evacuated; subsequently the cyst was removed, and the patient made a good recovery. See Surgical Reports 1855, case 274; and Trans. Path. Soc. 1890, p. $270 . "$

'The specimen shows pieces of characteristic hydatid membrane without any thyroid tissue.

Hydatids occur with about equal frequency in the two sexes (9 male, 11 female cases).

'Ther have been seen at all ages from 14 (cases 5 and 9) to 60 (case 6 ), but much more often below the age of 40 than above it. Of 21 cases in which the age is known, in 5 only were the patients above the age of 40 .

'The hydatid in most cases presents itself in the form of a single cyst, but occasionally two or more have been found in the gland (case 6). As in other parts of the body, the hydatid may be present with or without daughter cysts. Sometimes it has been found in a calcified condition (case 6 ).

In some of the cases in which post-mortem examinations were marle, hydatids in other organs were found, e.g., in the liver (case 5), liver and uterus (case 8), kidneys (case 6).

In some cases the hydatid has been found in a thyroid which was already the seat of ordinary goitre, but in the majority of the cascen there seem to have been no history of pre-existing goitre.

'The hydatid, as it grows, tends to cause pressure absorption of the lobe of the gland in which it lies, just as an ordinary cyst or adenoma would. In some cases the glandular tissue around the hydatid has thus been converted into a mere capsule of fibrous tissue containing the flattened remains of thyroid vesicles. Henle remarks that this absorption of the gland on one side may leai to a certain amount of compensatory hypertrophy of the opposite lobe, as in case 17.

Symptoms and Diagnosis.-The usual history of a hydatid cyst of the thyroid is that of a slowly increasing painless tumour 
which has existed for months or years; in one case (case 6) it had existed for not less than forty-one years. Like other cysts of the thyroid no symptoms are produced until the tumour has become sufficiently large to press upon surrounding organs. Then pressure symptoms occur which are precisely similar to those produced by ordinary unilateral goitre. In nearly all the recorded cases it is stated that more or less dyspnœa was present sooner or later. In case 1 , sudden death was produced by the rupture of the cyst into the trachea. In case 5, death appears to have resulted from direct pressure upon the trachea. In several other cases the amount of dyspnœa was considerable. Dysphagia and dysphonia are not usually prominent symptoms.

The tumour when small is usually globular or oval, but when large and projecting from the surface of the gland, it may be very irregular in shape. In these cases fluctuation is easily obtained.

A hydatid thrill does not appear to have been noticed in any case.

A tendency to spontaneous suppuration is worth noticing, owing to the danger of suppuration in this region. In at least five of the recorded cases (cases 3,11,17,21, and 22) spontaneous suppuration occurred; in others it occurred only after tapping.

The diagnosis of a hydatid cyst of the thyroid gland is very difficult. Indeed it would appear that a positive diagnosis has not hitherto been made in a single instance without a preliminary puncture, and only a few times even after puncture (cases 10, 19, 20, of Galozzi, Lannelongue, and Karpetchenco).

'The withdrawal by puncture from a thyroid cyst of a clear limpid colourless fluid should raise a suspicion of the hydatid nature of the cyst. If chemical examination show this fluid to contain little or no albumen, but abundant chlorides, or if the microscope show hooklets or bits of membrane, then the diagnosis is confirmed.

In most cases the diagnosis has not been made until characteristic echinoccoci or pieces of hydatid membrane have been evacuated by incision.

'The rapid and irregular enlargement of a tumour that has long been quiescent is not very uncommon with a hydatid of the 
thyroid, and may lead to a suspicion of malignancy.* The youthful age of the patient will, however, usually point in the opposite direction. The diagnosis between a suppurating hydatid cyst and suppuration of a simple thyroid cyst must be well-nigh impossible.

The presence of a hydatid cyst in the liver or elsewhere in the body might throw some light on the diagnosis of the thyroid swelling, but does not actually seem to have done so in any of the hitherto recorded cases.

The presence of urticaria may be of the greatest help in the diagnosis. It was partly from the existence of this symptom that Lamnelongue (case 19), according to Vitrac, arrived at a correct diagnosis. 'This case is so interesting and instructive that it seems worth while to give it at some length.

Hydatid of the thyroid; urticaria; alternating disappearance and re-appearance of the tumour and of the urticaria. Puncture and injection. Cure.

Jean $\mathrm{H}-$, wt. 34, a teacher, was admitted on January 31, 1896 , into the hospital of Saint-André at Bordeaux under the care of M. Lannelongue.

About the middle of 1892, the patient, when buttoning his shirt, noticed in the left antero-lateral region of the neck, a little above the sternum, a tumour as large as an egg. It was a little fixed at its deeper part but was movable under the skin. For four or five months the tumour grew slowly until it had attained the dimensions of a man's fist. It then began to cause hin some local discomfort and soon afterwards he noticed an itching of various parts of the body which led him to scratch himself. Some trouble in breathing and swallowing had lasted about a fortnight when suddenly, in the space of a minute or two, all the local symptoms disappeared, and at the same time the tumour varished so completely that nothing but a very slight amount of local swelling was left. 'The itching however became more intense. The tumour was absent for three months; then during the next four months it gradually returned to its original size. The slight dyspinca and dysphagia also gradually returned but the itching troubled him much less. The intensity of this sympton was always in inverse proportion to the size of the cyst. The patient had abundant opportunities of observing this point, for up

\footnotetext{
* Sere Reverdin's catse of hydatid ryst of the thyroid region, quoted above.
} 
to September 1894, the tumour had thus disappeared and reappeared no less than three times. The patient now consulted a doctor, who with a Pravaz syringe drew off some absolutely limpid fluid. The small quantity withdrawn did not appreciably diminish the size of the swelling. Nevertheless half an hour later, no trace whatever of the tumour could be detected. A violent attack of urticaria followed and for seven months there was no sign of the tumour. But in May 1895, it began to appear again and grew until in August it was again as large as a fist. In December it was not larger than an egg, but then it again began to grow, and he came into the hospital.

On admission the tumour was again as large as a fist and the patient was anxious for treatment, especially as, besides the dyspnœa and dysphagia, there was now some alteration in his voice.

The patient was in other respects healthy. At the root and left side of the neck was an irregular swelling. The thyroid cartilage was displaced $1 \frac{1}{2}$ centimetres $\left(\frac{3}{5} \mathrm{in}\right.$.) to the right of the middle line. The tumour was crossed obliquely by the sterno-mastoid which thus gave it a bilobed appearance. It extended vertically from the sternum to the upper border of the thyroid cartilage, laterally from the middle of the left supra-clavicular fossa to the inner border of the right sterno-mastoid. It was movable laterally with the trachea but not vertically unless the patient swallowed. But when the trachea was raised in the performance of this act, the tumour was tilted from above downwards. There was no pain or tenderness.

The liver was slightly enlarged but there was no evidence of any definite tumour in it.

The diagnosis of a fluid tumour of the thyroid admitted of no doubt. The characters of the liquid previously withdrawn, but especially the phenomena of disappearance and re-appearance of the tumour and the urticaria, were the signs which enabled M. Lannelongue to make the diagnosis of hydatid cyst. The diagnosis was confirmed a few days later by puncture and the withdrawal of 300 grammes $(10 \mathrm{ozs}$.) of a liquid as clear as water, containing 3 grammes of chlorides, no mucin and very little albumen; neither heat nor acetic acid gave any precipitate. There were no hooklets. After the evacuation of the cyst, no tumour could be felt; the walls of the cyst were evidently very thin. Ii was washed out several times with sublimate lotion 1 in 1000. For two or three days there was slight pain, and a little albumen appeared in the urine. The urticaria did not re-appear.

The patient was seen again two months and six monihs later. 
The neck appeared absolutely normal. The patient was considered to be absolutely cured.

Treatment.- 'The treatment of a hydatid cyst must depend to a certain extent upon the nature of the hydatid. If it be an acephalocyst, as in Lannelongue's case just mentioned, a simple tapping and injection with corrosive sublimate solution may suffice to affect a cure.

In most cases, however, the presence of daughter cysts will necessitate some larger operation. The choice of operation will then lie between incision of the cyst with suture of its walls to the skin, and complete removal by enucleation. Extirpation of the whole thyroid lobe is seldom desirable.

If the tumour is small and not inflamed, the best method of treating it is by enucleation, just as would be done in the case of an ordinary thyroid cyst. In fact, owing to the difficulty of diagnosis, it is probable that the operation would be undertaken on the supposition that the tumour was a simple cyst. In M. Peyrot's case (case 12) this was the diagnosis. Enucleation was easily performed, and was followed by primary union.

In most of the cases, however, in which enucleation has been attempted, the operation has been attended with considerable difficulty, owing to the firm connections existing between the cyst and surrounding parts.

In Chavier's case (case 18) the attempt to enucleate had to be abandoned on account of hremorrhage, and the cut edges of the cyst were sewn to the cut edges of the skin.

In $v$. Bergmann's case (case 15) the enucleation was so difficult that it was not considered advisable to complete it, so a part of the cyst wall was left behind; the wound was packed for two days, and then a secondary suture was performed. The patient was cured in nine days.

In 'Loege-Manteuffel's case also (case 16), the inner part of the cyst wall that was adherent to the trachea had to be left behind.

In Mikulic's's case (case 17), the attempted enucleation was replaced by an atypical extirpation; a similar operation was performed by Stanley Boyd (case 22). In both of these cases, the contents of the cyst were purulent. 'Ihe inflammation, 
doubtless, added considerably to the difficulty of the operation.

In cases, therefore, in which the cyst is large, or in which there is or has been much inflammation, it seems best not to make any attempt to remove the whole cyst, but to content oneself either with incising the cyst wall, scraping out its contents and sewing the edges to those of the skin, or with excising the anterior portion of the cyst wall.

It should be remembered that the cyst wall consists of two layers; the inner layer (endocyst) can generally be removed without any difficulty. It is the outer layer only (ectocyst) that is difficult to remove. A portion of this at least must usually be left behind owing to the adhesions and to the danger of wounding surrounding important structures, such as the recurrent laryngeal nerve or the œsophagus. (See case 29.) 


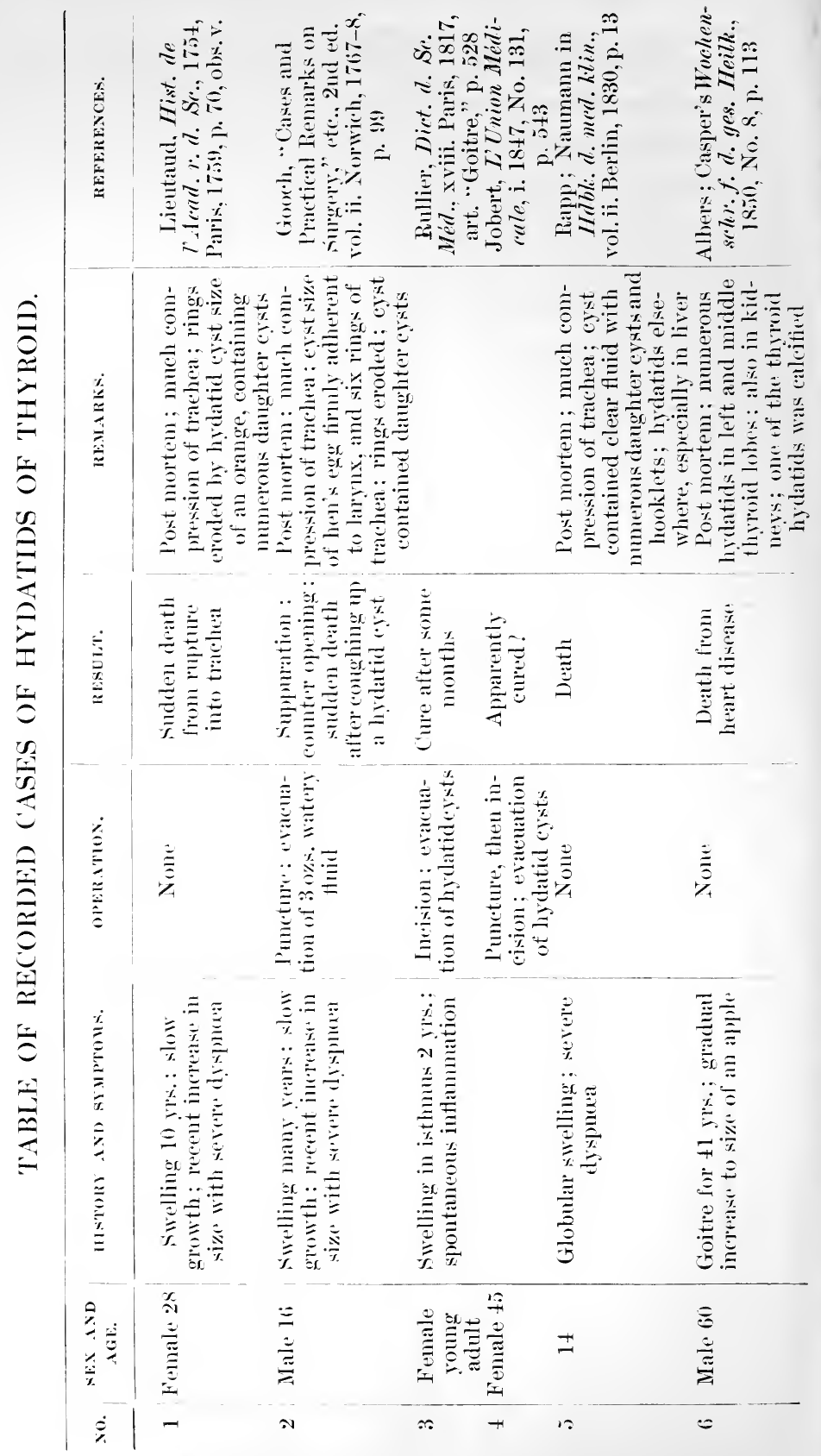



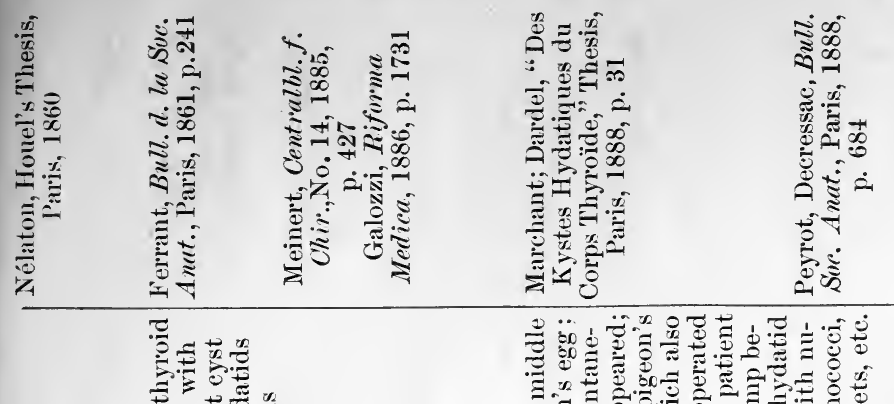

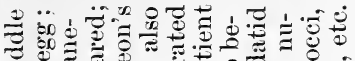

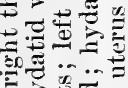

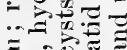

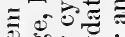

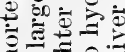
政

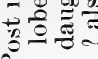

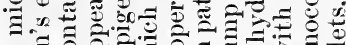

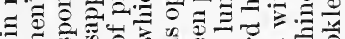

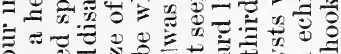

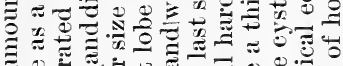
(1) w

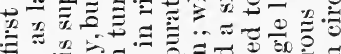

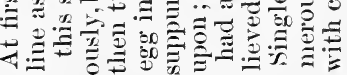

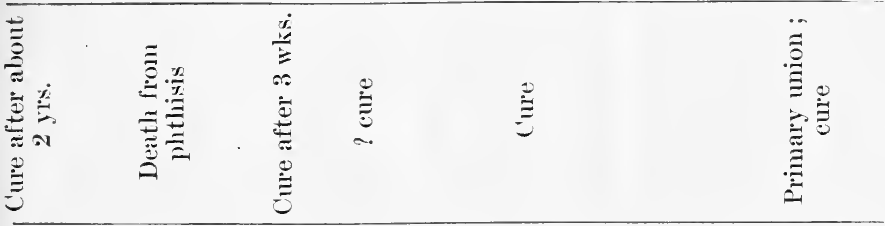
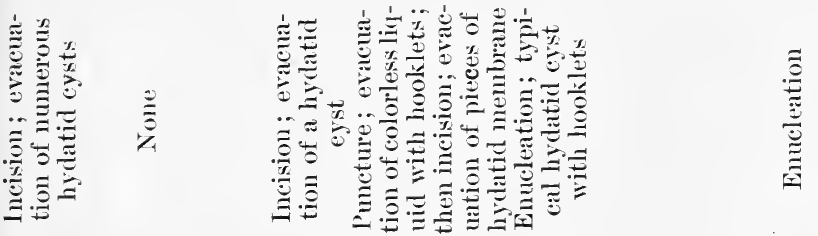

\begin{tabular}{|c|c|c|}
\hline 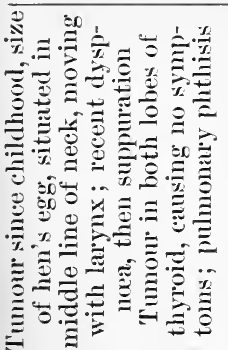 & 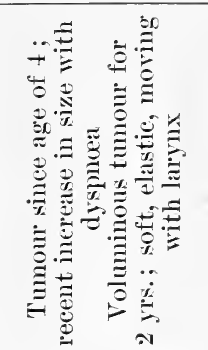 & 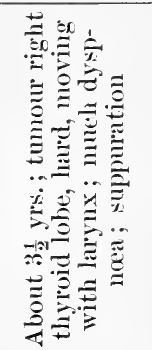 \\
\hline 每 & 范 & 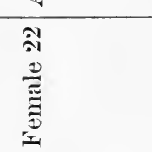 \\
\hline$\infty$ & $\therefore \cong$ & $=$ \\
\hline
\end{tabular}




\section{THE THYROID GLAND.}

\begin{tabular}{|c|c|c|c|c|c|}
\hline & 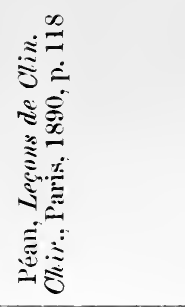 & 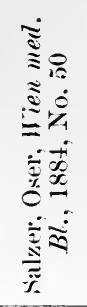 & 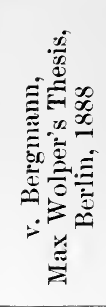 & 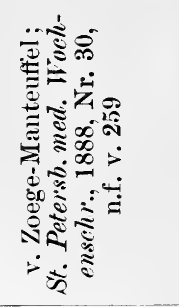 & 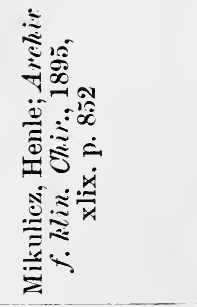 \\
\hline $\begin{array}{l}x \\
\approx \\
z\end{array}$ & 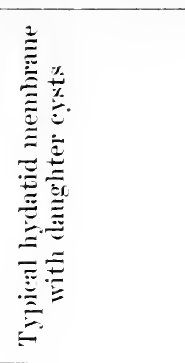 & & 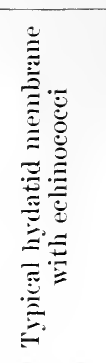 & 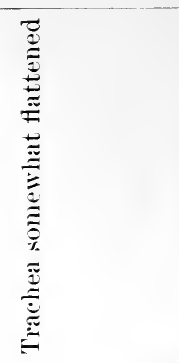 & 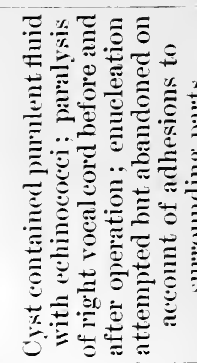 \\
\hline & 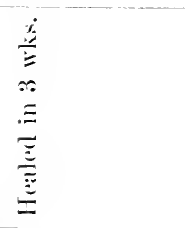 & 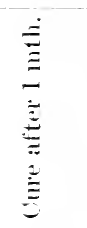 & 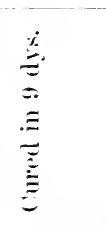 & 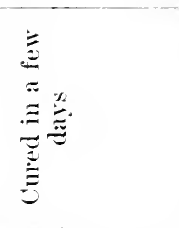 & 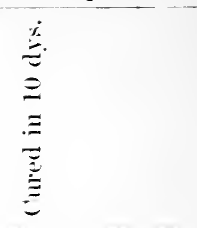 \\
\hline 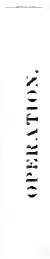 & 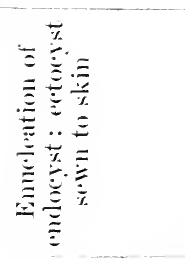 & $\begin{array}{ll} \\
\end{array}$ & 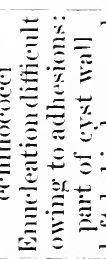 & 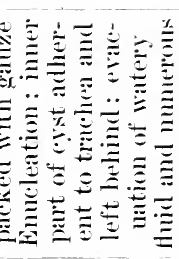 & 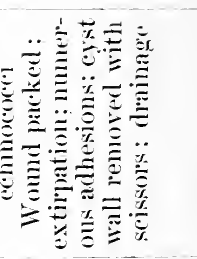 \\
\hline 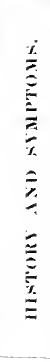 & 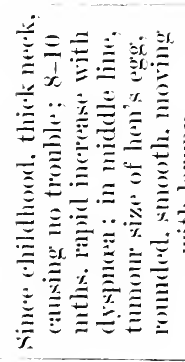 & 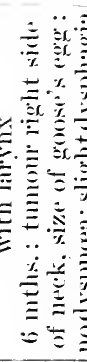 & 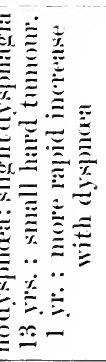 & 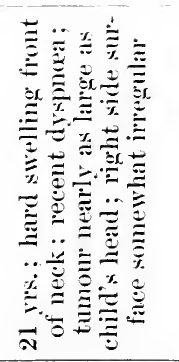 & 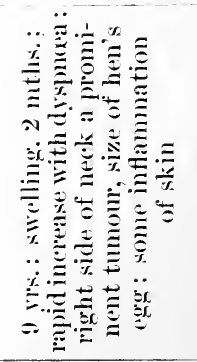 \\
\hline & 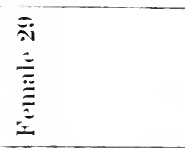 & $\begin{array}{l}\ddot{y} \\
\dot{\bar{y}} \\
\dot{\bar{z}}\end{array}$ & 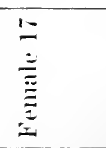 & 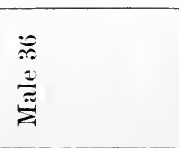 & 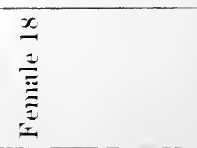 \\
\hline i & $\because$ & \pm & $\Leftrightarrow$ & $\cong$ & $=$ \\
\hline
\end{tabular}




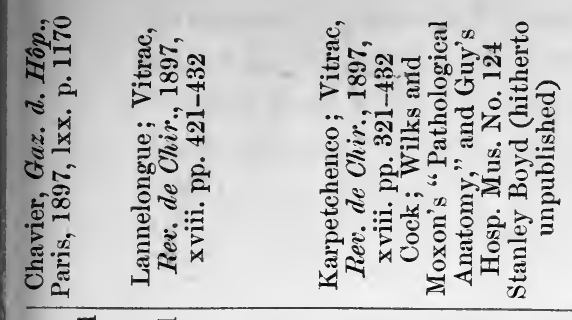

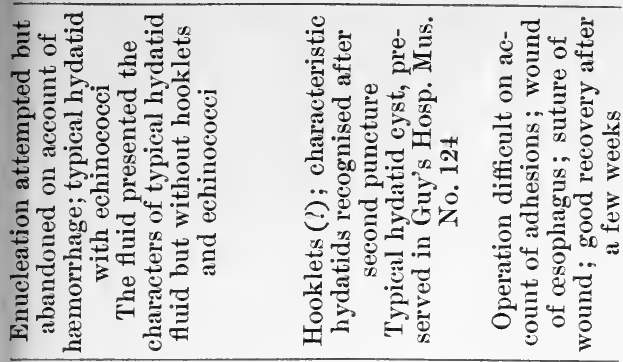

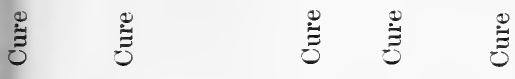

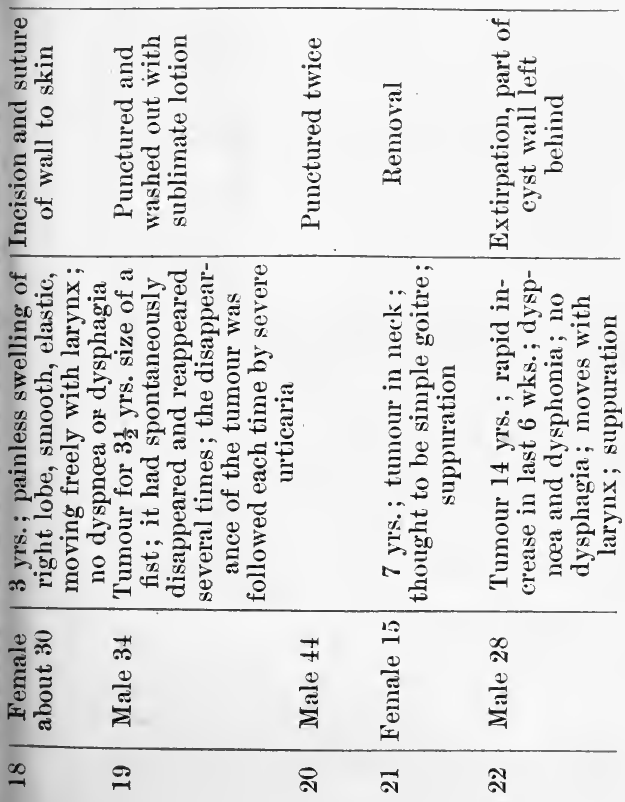




\title{
CHAP'IER XII.
}

\author{
EXOPHTHALMIC GOITRE AND ITS TREATMENT. \\ (GRAVES'S DISEASE; BASEDOW'S DISEASE.)
}

\begin{abstract}
Age_-Sex-Pathology_Morbid anatomy_Characteristic appearance on section-Microscopical appearance-Absence of accumulated colloidSecondary changes-Exophthalmos-Cause of-Enlargement of thymus — Simptoms and Diagnosis - "Formes frustes" - Treatment : Medical. Suroical-Operations upon the thyroid-Extirpation-Results - Exothyropexy-Operation upon vessels-Operation upon sympathetic -Siection - Resection - Unilateral - Bilateral - Results - Mortality Prognosis withont operation-Conchusions.
\end{abstract}

A metaluen description of the remarkable disease known as exophthalmic goitre would be out of place in a book which deals mainly with the surgical aspect of diseases of the thyroid gland. A short description only will be given here.

The disease is found to occur in both sexes, but is far more common in women than in men.

During the fifteen years 1884 to 1898 , there were in the medical wards of St. Barthelomew's Hospital ninety-six admissions for exophthalmic goitre. Of these eighty-eight were female while only eight were male cases.

'True exophthalmic goitre is almost, if not quite, unknown before the period of puberty and rarely begins after middle age. It is confined almost exclusively to the period of sexual activity and is especially common in the earlier part of that period.

Of the above-mentioned ninety-six cases, twelve were, on admission, between the ages of fifteen and twenty, forty-five were between twenty and thirty, twenty-six between thirty and forty, while only thirteen were over forty.

Exophthalnic goitre does not occur as an endemic disease, and is not especially common in districts where ordinary goitre is endemic. Among a thousand cases of goitre seen by Dr. 
Savage in a goitrous district in the north of England, there was not a single case of Graves's disease. Dr. Montoya y Florez, Professor of Clinical Surgery at Medellin, Columbia, tells me that although endemic goitre is extremely common in that country, he has never seen there a case of exophthalmic goitre. My own inquiries in many goitrous districts both in England

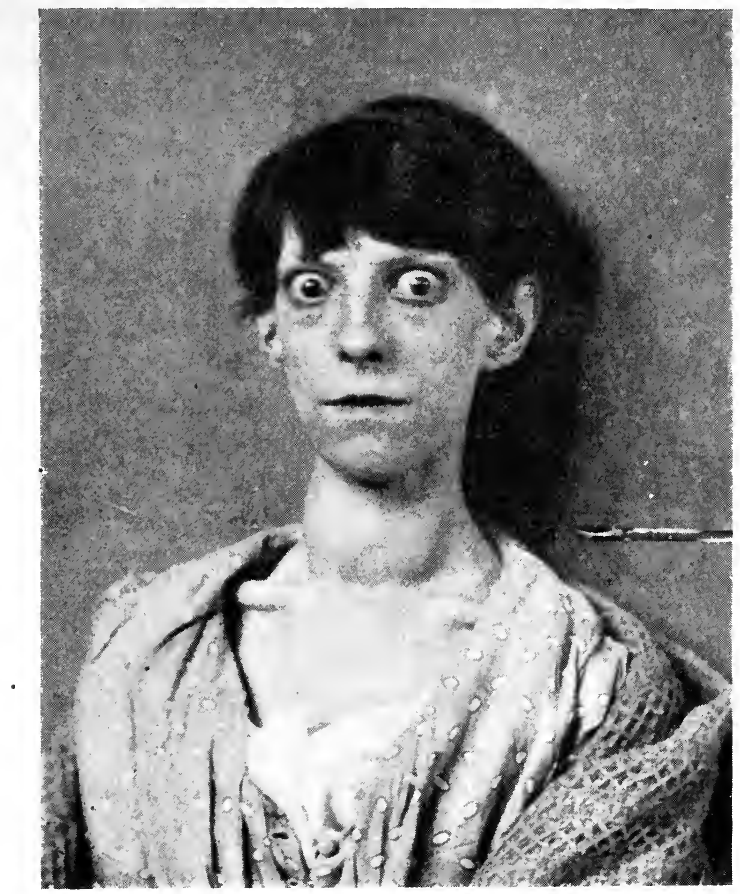

Frg. 70.-A typical case of Exophthalmic Goitre (Grares's Disease) in a yomg womsm. (seen in a medieal ward at st. Bartholomew's Hospital.)

and abroad point in the same direction, and tend to show that exophthalmic goitre is rare in places where ordinary goitre is common, and certainly is often found to exist in places where ordinary goitre is unknown.

Dr. Maude, on the other hand, whose writings on exophthalmic goitre are so well known, appears to think that there is some connection between the distribution of the two diseases. 
Pathology.-It must be confessed that the pathology of the disease is still obscure. The numerous theories that have been brought forward may be divided into three main classes, in which the cause of the malady is attributed to disease respectively of the central nervous system, the cervical sympathetic, and the thyroid gland.

For a full discussion of the various theories reference must be made to works on medicine. With regard to the first two it is sufficient to say that they are unsupported by reliable post-mortem evidence. Slight changes in the brain and the sympathetic nerve have from time to time been described. In the great majority of cases, however, in which post-mortem examinations have been made, no definite lesion has been discovered in either of these structures. Neither an irritative nor a paralytic lesion of the sympathetic will account for the symptoms of the disease. These symptoms, moreover, are not those which we know to be the result of gross lesions of the sympathetic. The idea that the enlargement of the gland is due to vascular dilatation seems to lie at the root of the sympathetic theory.

'This idea has arisen, I am afraid, mainly from clinical examination of the gland; the actual investigations of morbid anatomy do not support it.

Recent researches, especially those of Möbius, Greenfield and Murray point strongly, in my opinion, to the riew that the primary source of the disease lies in the thyroid gland, in which alone definite and remarkable lesions are always found. The complex group of symptoms which characterise the disease are probably caused by an alteration of the internal secretion of this gland.* The secretion appears to be altered in quantity and probably in quality also. 'This altered secretion, when circulating in the body, probably acts directly or indirectly, like many other poisons, upon the heart, upon the nervous system, and upon the nutrition of many tissues in the body.

\footnotetext{
* How far this thyroid disease is dependent upon some unknown disease of the higher centres of the brain is an interesting question which need not be discussed here. There is at least some evidence to show that violent emotions such as fright may be the immediate cause of the disease. (See an excellent palper by Dr. Raymond ('rawfurd, “Graves's Disease : an emotional disorder," King; (all. Horp. Rep.s.. vol. iii. 1897.)
} 
Morbid Anatomy.-A museum specimen of a typical exophthalmic goitre is usually easily distinguished from the other forms of goitre. Like the purely parenchymatous goitre, all parts of the gland are equally enlarged. The enlargement is rarely excessive; each lateral lobe seldom exceeds in dimensions those of a goose's egg, and is often much smaller. The surface is smoother than that of a parenchymatous goitre. It is the cut surface of the gland, however, that presents the most characteristic appearances. This shows a remarkably homogeneous, solid structure, very unlike the vesicular appearance of a parenchymatous goitre. Little or no colloid is visible. The blood-vessels are usually smaller and less numerous than in a parenchymatous goitre of the corresponding size. 'This point is, I think, important, since it is often stated by those who appear not to have investigated

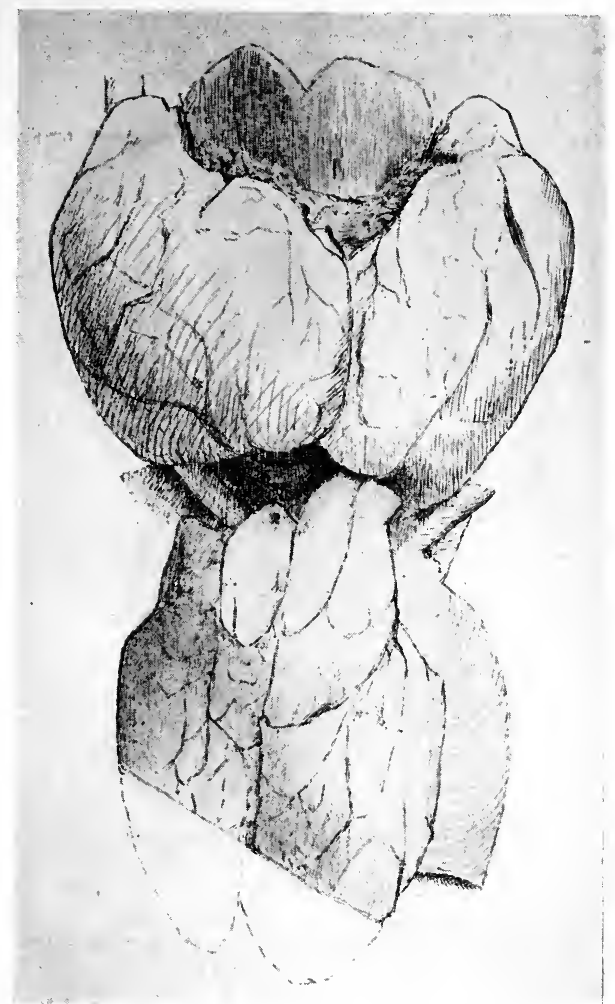

Fig. 71.- Sketch of Thyroid Gland and neighbouring parts, from an unmaried woman aged 19 , the subject of Exophthalmic Goitre. The enlingement of the thymus (the lower part of which has, however, been eut off) is characteristic. (St. Bart. Hosp. MIus. No. 2314 T.) (Reduced $\frac{1}{2}$.)

the matter for themselves that there is "great dilatation of the vessels."*

Microscopical examination of the thyroid shows marked

* I quote here the words of a well-known medical authority who wrote them in 1897 . 
differences between the exophthalmic and the common parenchymatous goitre. Instead of the vesicles distended with colloid secretion and lined with a singie layer of cubical epithelium, which are seen in the parenchymatous goitre, we find in the exophthalmic variety a wholly different appearance. 'The colloid is much reduced in quantity, and indeed is frequently almost entirely absent. 'The resicles are not distended and are not at

all well marked. The

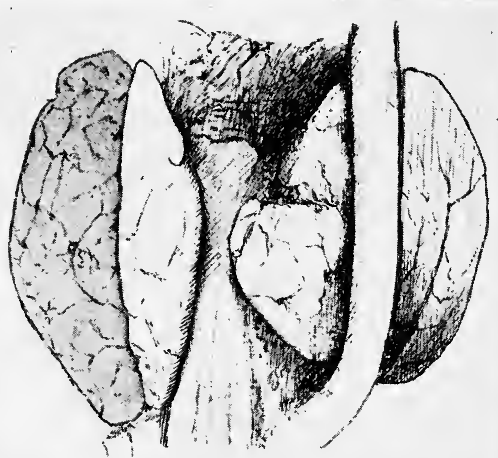

Fis. 72,-The preceling. seen from liehind. I section of the left lobe has been made, showing the homogeneons, solid strneture of the olind. (st. Bart. Hosp. Mus. No. 231tT.) (Reduced $\frac{1}{2}$.) epithelial lining has undergone a marked proliferation so that the place of the vesicle is frequently taken by an irregular mass of round cells with perhaps a trace of colloid. 'There is also a tendency for the epithelium to become columnar. 'The whole gland appears to be in a state of considerable physiological activity, but the secretion, instead of being accumulated in the vesicles, is not to be

seen, having apparently passed into the lymphatics as soon as secreted. An extreme case presents considerable superficial resemblance to a round-celled sarcona.

'The accompanying micro-photographs (Figs. 73 and 74) illustrate the appearance of parenchymatous and exophthalmic goitre respectively.

'The appearances above mentioned are those which are found in all severe cases, that is in all cases in which the disease itself has been the immediate cause of death. They are practically identical in all museum and post-mortem room specimens that I have had the opportunity of examining. There is no museum specimen with which I am acquainted which shows the "great dilatation of vessels" to which allusion has been made.*

* Excellent specimens of exophthalmic goitre may be seen in the following museums : Roy. Coll. Surg. 2894a ; Guy's Hosp. 99, 100, and 101 ; St. Bart. 
If the examination be made of an exophthalmic goitre from a case in which death has occurred not wholly from the disease itself,
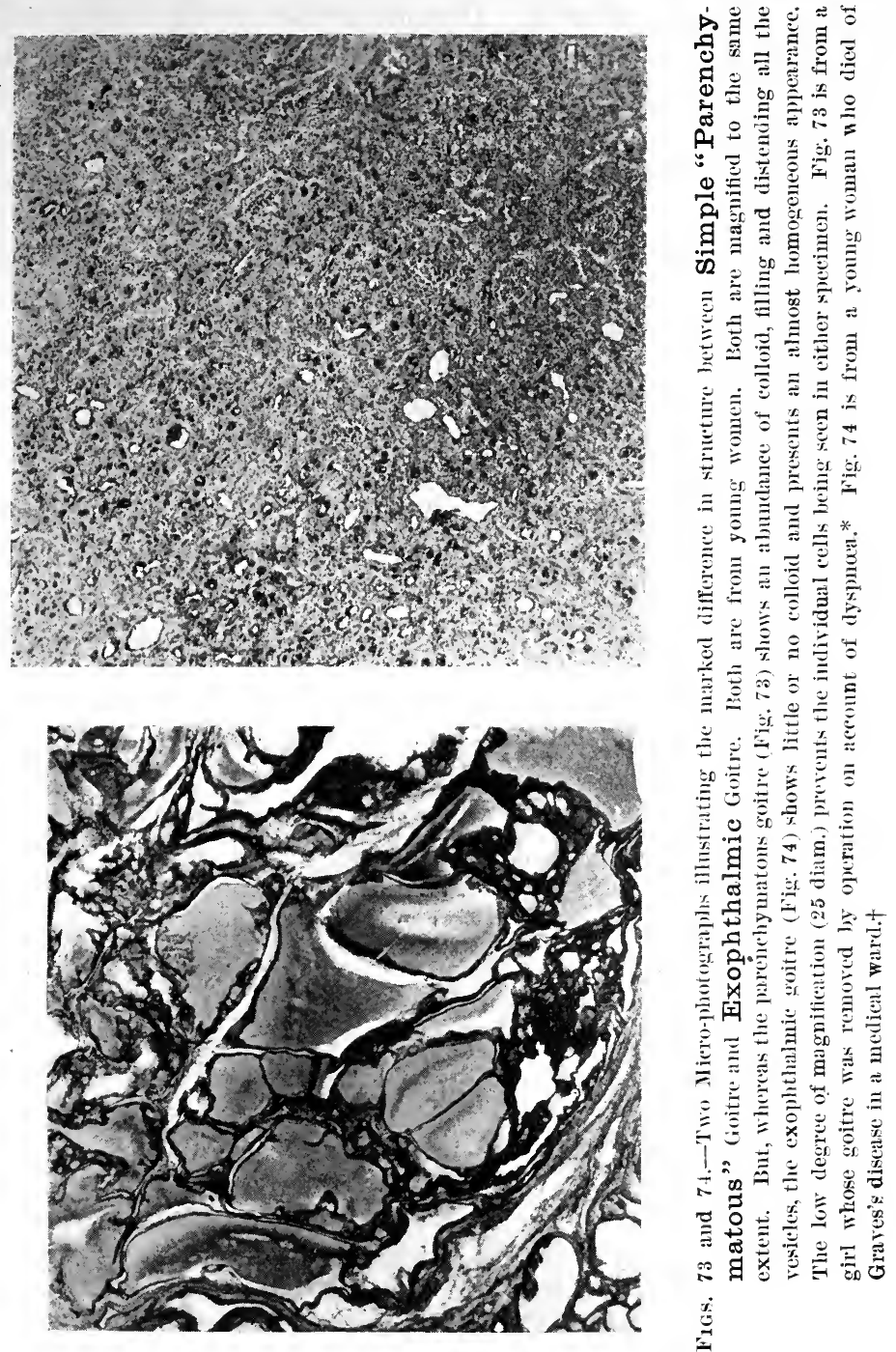

Hosp. 2314s, T, and U ; Char. Cross Hosp. 879A ; St. Mary's Hosp. 1025 ; Univ. Coll. Hosp. 1458D ; St. Thomas's Hosp. 1465A. Somewhat less typical are Guy's Hosp. 102 and Westm. Hosp. 609.

* Case of A. H., at. 15, described in Brit. Med. Journ. July 20, 1891.

+ Unpublished. 
the appearances presented are similar but not so pronounced. A good deal of colloid may be seen and many vesicles may still be easily recognisable. Opportunities for examining such specimens are occasionally afforded at the present time by operations for the removal of the goitre.

Cysts and adenomata are rarely met with in the goitre of Graves's discase, and this is probably one reason why this form of goitre seldom attains a very large size.

A thyroid gland containing a pre-existing cyst or adenoma may, howerer, subsequently develop the characters of Graves's disease, and it is probably such cases that have led occasionally to the description of unilateral exophthalmic goitre. True and uncomplicated exophthalmic goitre, being a disease of the whole organ, is never unilateral.

An exophthalmic goitre of long standing may develop secondary changes, such as fibrosis, similar to those of parenchymatous goitre. Examples of this, however, are rare.

'The exophthalmos is, I believe, due entirely to a local deposit of fat behind the eveball. No reliable post-mortem evidence of its being due to any other cause has ever been brought forward. The absurd theory that it is due to vascular dilatation of the orbital ressels scarcely merits discussion. The vessels that supply the post ocular tissues (branches of the ophthalmic artery) supply also the conjunctiva and eyelids, both of which are easily examined by simple inspection. They do not show any increased vascularity in Graves's disease. On the other hand, increased orbital vascularity is a condition with which we are all familiar. It is often seen in cases of inflammation of the orbit and of tumour or thrombosis at the back of the orbit. In these cases, the proptosis which is often present, is accompanied by suffision of the conjunctiva, and often by swelling of the eyelids. 'This condition of affairs differs widely from that of Graves's disease, in which the visible parts of the orbit are not only not more vascular, but often positively paler or less vascular than in health. Why there should be, in this disease, an increase of orbital fat, is a question that cannot at present be answered. But we do know, at any rate, that there is in Graves's disease a tendency to local deposition of fat in other parts of the body, such as the face and anterior abdominal wall. 
It is not unreasonable to assume that the same cause that leads to local deposition of fat in these regions may also cause its deposition in the orbits.

'The theory that the exophthalmos is due to spasm of muscle is wholly insufficient to account for the amount of exophthalmos that is generally present in an ordinary case of Graves's disease.

A very common, if not constant, accompaniment of the disease, is a great enlargement of the thymus gland, which forms a thick solid mass, sometimes weighing severral ounces. This enlargement may be detected, during life, by careful percussion over the upper part of the sternum. The pathological significance of this undue persistence and enlargement of the thymus is unknown.*

Symptoms and Diagnosis.-The three cardinal symptoms of Graves's disease are :

(1) Prominence of the eyeballs (exophthalmos).

(2) Rapidity of the heart (tachycardia) with palpitation.

(3) Enlargement of the thyroid gland (goitre).

In most cases, however, some or all of the following srmptoms are also present.

(4) Nervous symptoms, especially tremulousness and excitability; often the patient shows a marked change of habits and tastes, and a condition resembling acute mania is by no means unknown.

(5) Diarrhœa.

(6) Glycosuria.

(7) Pigmentation of the skin, usually of a patchy nature.

(8) Local accumulation of subcutaneous fat, especially on the anterior abdominal wall.

(9) Sweating, and consequent lessened electrical resistance of the skin.

(10) Breathlessness.

(11) Slight elevation of temperature.

The clinical picture presented by a patient in the advanced stages of the disease is usually quite characteristic, and there is

* Good specimens of this enlargement of the thymus may be seen in the following museums : St. Mary's Hosp. 1025; Univ. Coll. Hosp. 1358D ; St. Thos. Hosp. 1465A ; St. Bart. Hosp. $2314 \mathrm{~T}$ and $2314 \mathrm{U}$. 
no difficulty in the diagnosis. (See Fig. 70.) In some cases, however, one or more of the three cardinal symptoms is absent, and then there may be much difficulty in the diagnosis.

The enlargement of the thyroid may be so slight as scarcely to attract attention. Even when it is well marked there are no means by which we can distingnish it with certainty from the simple parenchymatous enlargement. The gland usually presents a somewhat smoother and more rounded surface, and, occasionally, a feeling of firmmess, of plumpness and solidity has seemed to me to afford help in the diagnosis. Pulsation in the gland, and the presence of a bruit are not in themselves characteristic, since they are often found in parenchymatous goitres. A thrill is often felt. It is important to bear in mind that the increased pulsation of the thyroid vessels is not greater than that of the other vessels in the body.

The exophthalmos is almost invariably bilateral and symmetrical. C'ases of milateral exophthahmos due to Graves's disease are, howerer, said to occur; but such cases have never come under my notice.

Exophthalmos is by far the most characteristic symptom of the disease, although its presence is not absolutely essential for the diagnosis. When exophthalmos is absent the diagnosis is much more difficult. Ordinary parenchymatous goitre is frequently accompanied by cardio-vascular symptoms. Persistent fiequency of pulse with goitre is sufficient to raise a strong suspicion of Graves's disease, and a careful examination should, in such cases, be made to see whether any of the other symptoms exist.

It is in the early stages of the disease that the diagnosis is most important, especially from the surgical point of view. I have several times seen, and successfully operated upon, patients with goitre and rapidity of pulse, who had been considered, crroneously, to be suffering from Graves's disease. Probably, many of the reported cases of cure after operations for atypical Graves's disease (the so-called formes firustes of the French) have not been cases of Graves's disease at all. This may account for the cures. On the other hand, it is important that the surgeon should not overlook the existence of this disease in its early stage. By doing so, he may make the serious mistake 
of undertaking to treat, by surgical means, a goitre which probably ought not to be interfered with.

In the absence of exophthalmos, the persistently rapid pulse, the clammy, tremulous hand, and the fidgety, nervous manner of the patient afford, according to my own experience, the best means of diagnosis.

Dyspnca is of course a common symptom in both parenchymatous and exophthalmic goitre. In the former disease, however, the dyspncea is always produced by direct pressure on the trachea, and is accompanied by stridor. In the latter, the dyspnoa appears to be due to cardio-vascular changes. An exophthalmic goitre only rarely produces an appreciable degree of pressure upon the trachea, and is consequently not usually accompanied by stridor.

There are, however, rare cases in which an exophthalmic goitre does cause serious pressure upon the trachea and it may even become necessary to perform tracheotomy for the relief of the dyspnoa.

At the meeting of the Pathological Society of London, held on March 3, 1891, Mr. W. G. Spencer showed a specimen of exophthalmic goitre which had caused death by suffocation. 'The patient was a girl, aged 20 , who had suffered for' at least a year from the ordinary symptoms of exophthalmic goitre, namely, prominence of the eyeballs, rapidity of pulse, and thyroid swelling. Dyspnoea became so severe that tracheotomy had to be performed; this was attended with much difficulty; the trachea was opened above the isthmus, and an elastic tube four inches long had to be passed down the trachea beyond the obstructed portion before relief was afforded. In a few hours the dyspnoea returned, the patient was unable to expectorate through the tube, and death occurred, apparently by suffocation from the accumulation of mucus in the trachea and bronchi.

'Ihe goitre, which is at present in the Westminster Hospital Museum,* was a large bilateral one, tolerably homogeneous in structure, but differing from most exophthalmic goitres in containing much fibrous tissue and numerous small cysts. None of these, however, are larger than small peas. 'The trachea was greatly flattened from side to side down to within an inch of 
the bifurcation. The presence of cysts and of much fibrous tissue, and a history of the goitre having been present for very many years ("all her life," it was alleged), show that this case was not entirely typical. It is quite possible that this was really a case of ordinary parenchymatous goitre to which Graves's disease had recently been added.

In the Lancet of February \%, 1891, Dr. Hugh Montgomerie reported "a case of exophthalmic goitre, ending fatally from sudden pressure on the trachea," in a woman of thirty-five. In this case also the goitre was unusually large, and the symptoms do not seem to have been very characteristic of Graves's disease. A low tracheotomy was performed, but without success. A post-mortem examination revealed extreme tracheal stenosis; the goitre was not a symmetrical enlargement of the thyroid, showing that the case was not one of pure exophthalmic goitre.

Treatment. Medical.-Numerous drugs have been recommended for the treatment of this most troublesome malady, but none of them can be considered to be thoroughly satisfactory. Most of them do not do more than alleviate symptoms, especially the palpitation.

something can be done by such hygienic measures as rest and change of surroundings. Removal to a higher altitude often causes considerable relief.

Digitalis is often given to quiet the circulation and diminish palpitation. Belladonna appears to be useful sometimes; it may have some effect in diminishing the thyroid secretion.

Thyroid extract has also been given, but it seems clear that it not only does no good, but is positively harmful. 'This is only what might be expected if the disease is due to over-activity of the gland.

'Thymus feeding has also been tried, but with doubtful benefit; the undoubted connection between enlargement of the thymus and Graves's disease is, however, worth remembering in connection with this method of treatment. Ord and Hector Mackenzie, having made an extensive trial of thymus gland preparations in twenty cases, came to the conclusion that "no appreciable effect followed their administration.*

Iodine and its preparations, so potent in the treatment of * ('lifford Allbutt's "system of Medicine," 1897, vol. iv., p. 507. 
parenchymatous goitre, are not only useless in Graves's disease, but usually aggravate the symptoms. Möbius speaks highly of the value of bromine preparations.* Iron is sometimes beneficial, and seems to be indicated in cases in which there is marked anæmia.

The application of cold to the neck by means of Leiter's tubes appears to relieve the patient's distress in many cases, but does not exert any curative effect upon the disease.

Treatment by electricity, both galvanic and faradic, has been strongly recommended, but does not seem to be of any more use than other remedies. A strong current may have some beneficial influence upon the patient's mental condition.

The medical treatment of a case of exophthalmic goitre does not, however, come within the province of a surgeon, who is content to hand the case over to a physician. For further details of the medical treatment, about which volumes have been written, a work on medicine must be consulted.

Surgical.-Although, in my opinion, the treatment of exophthalmic goitre belongs essentially to the physician and not to the surgeon, it is right that some account should here be given of the various forms of surgical treatment that have been from time to time adopted by surgeons. Especially in the last few years has surgical treatment been recommended and practised by some surgeons. The different forms of operative treatment that have been employed for exophthalmic goitre may be divided into the following groups :

1. Operations upon the thyroid gland itself.

2. Operations upon the thyroid vessels.

3. Operations upon the cervical sympathetic nerve.

4. Operations upon distant parts of the body.

1. Operations upon the Thyroid Gland.-Most of the operations that have been practised for parenchymatous goitre have also been employed for exophthalmic goitre. Those, such as injection with iodine, which act by causing inflammation and obliteration of the vesicles, are not suitable, for the simple reason that in this disease we are not dealing with distended vesicles at all, but with a condition of epithelial proliferation. The absence of colloid in an exophthalmic goitre renders

* Arch. f. Psychiat., Berlin, 1898-9, xxxi., p. 923. 
division of the isthmus also a futile operation; the shrinking of a parenchymatous goitre after division of the isthmus is due, as is shown elsewhere, to the draining away of the contents of the resicles. In an exophthalmic goitre there is no accumulated colloid that can be drained away.

For a similar reason intraglandular enucleation, so excellent for the treatment of many simple goitres, is not applicable here, because there are here no encapsuled tumours, and it is upon these alone that enucleation can be performed. In those atypical cases in which Graves's disease has been superadded to a preexisting adenomatous or crstic goitre, enucleation of these tumours can, of course, be performed.

Removal of a portion of the goitre by the operation of "extirpation" is feasible, and has been frequently performed. Much difference of opinion exists as to the value of this proceeding.

'Those who helieve that Graves's disease is due priniarily to an affection of the thyroid gland, and especially those who look upon the disease as being due to a hypersecretion of the thyroid epithelium, have naturally some " priori grounds for believing that removal of a portion of the gland might benefit the patient. 'lotal extirpation of the gland has been performed, but it is agreed by all that this is neither necensary nor desirable, seeing that very serious results (cachexia strumipriva) follow this operation, whether performed for exophthatmic or for any other kind of goitre.

The operation that has most often been performed is removal of one half of the gland.

It appears that good results have in some cases been obtained by this operation. On the other hand, it must be admitted that the operation is an extremely serious one. The mortality of unilateral extirpation for exophthalmic goitre is far higher than is that of the same operation when performed for simple goitre.

Valuable information on this point has been afforded by Allen Starr, * who has collected from various sources 190 casest of

* .. On the natme and treatment of exophthalmic goitre with especial refer"nce to the thyroid theory of the disease and to the treatment by thyroidectomy." Med. Iom... Philadelphia, 1896. (is. 1. t21.

$\dagger$ All these operations were performed in or before 1895. These cases. however, inchude a certain number of operatiens. such as ligature of the thyroid arteries, in which no part of the goitre was actually removed. 
operations upon exophthalmic goitre; of these no less than 23 ended fatally immediately after the operation. This mortality of 12 per cent. compares most unfavourably with the mortality of $3 \frac{1}{2}$ per cent. afforded by Reverdin's statistics of extirpations of simple goitre.

Sorgo's statistics* embrace 174 operations performed in the years 1884-96. In two cases the result was not known. Of the remaining 172 patients, 27 (15.2 per cent.) were "much improved," 62 (36 per cent.) were "distinctly improved"; [that is, 89 (51.2 per cent.) were improved] 48 ( 27.9 per cent.) were "cured," $11(6 \cdot 4$ per cent.) were not improved or were made worse; while 24 (13.9 per cent.) died soon after the operation. It is said that if the cases of so-called primary Graves's disease are separated from those of secondary disease, the statistics are not materially altered.

Möbius considers that in most cases " the operation will probably result in comparatively rapid improvement, but that it is not without danger." With the latter part of this opinion I certainly feel disposed to agree.

Even in the hands of the most experienced operators upon goitre, such as Kocher, the mortality is considerable. It would appear that Kocher has abandoned the operation of extirpation for exophthalnic goitre in favour of ligature of the thyroid vessels. It is not that the operation is in itself more difficult. But the patients are not good subjects for such an operation. 'They are especially liable to die from shock or from extreme rapidity of pulse. For these reasons I have myself never performed removal of an undoubtedly exophthalmic goitre and am of opinion that its performance should as a rule be restricted to those rare cases in which there is serious tracheal stenosis, threatening the life of the patient. Even in these cases it seems doubtful whether tracheotomy is not sometimes a safer proceeding.

The operation of exothyropexy has been performed many times, especially in France. 'This operation consists in cutting down upon the gland, dislocating it through the wound and then leaving it exposed to the air. The effect of the operation is to cause a certain amount of shrinking of the gland. 'The

\footnotetext{
* Quoted by Möbius, loc. cit. p. 922.
} 
risks of the proceeding and the extremely unsightly nature of the resulting deformity are, in the absence of any strong proof of its efficacy, sufficient to warrant its condemnation.*

2. Operations upon the Thyroid Vessels.-Ligature of the thyroid vessels has often been performed for exophthalmic goitre in the hope that cutting off the blood supply will cause the gland to shrink and produce less colloid secretion.

Ligature of the superior thyroid vessels alone, which are usually much smaller than the inferior, is an easy operation, but does not cut off' enough of the blood-supply to be of any real use. Ligature of the inferior thyroid vessels on one or both sides adds considerably to the difficulty and severity of the operation. Ligature of all four arteries probably entails a risk of the supervention of cachexia strumipriva. Ligature of both superior thyroids and of one inferior thyroid appears to be the best operation and is the one preferred by Kocher. 'This operator has performed ligature of the thyroid vessels for exophthalmic goitre over thirty times.

3. Operations upon the Cervical Sympathetic Nerve.-The operations that have hitherto been performed upon the cervical srmpathetic nerve include:

(1) Simple section of the nerve (sympathicotomy or Jaboulay's operation).

(2) Partial resection, the superior cervical ganglion being resected, either alone or together with the nerve trunk.

(3) Complete and bilateral resection of the whole nerve and all its ganglia.

'These operations appear to be founded partly upon the view that the primary seat of Graves's disease lies in the cervical sympathetic nerves or ganglia, and partly upon the widespread but erroneous idea that the enlargement of the thyroid and the exophthalmos are due to the increased vascularity in the gland and in the orbit respectively. 'There is no doubt that there is a comnection between exophthalmos and the sympathetic, but it is by no means clear that the exophthalmos of Graves's disease is dependent upon this nerve.

The researches of Jessop upon the action of cocaine have shown that the instillation of cocaine into the eye produced

\footnotetext{
* For further details of this operation see chap. xv. p. 244.
} 
among other effects, exophthalmos and enlargement of the palpebral fissure. - It has further been shown by Jessop and by Edmunds that previous division of the cervical sympathetic prevented the occurrence of these phenomena.

Jaboulay of Lyons appears to have been the first to apply these facts to the treatment of exophthalmic goitre in the human subject.

His first operation was performed in February 1896, and his example was rapidly followed by others. The results being, however, not so good as had been anticipated, a further step was taken and in August 1896 Jonnesco of Bucharest excised the superior cervical sympathetic ganglion together with part of the main nerve trunk. This operation in its turn appearing to be insufficient, the total excision of the whole of the cervical sympathetic including its ganglia on both sides of the neck was introduced and is at the present time advocated by Jonnesco and other's.

Whether the theories upon which these sympathetic operations are based be right or wrong, it is well to inquire whether the results obtained by the operations are sufficiently good to justify their performance.

Boissou, in his admirable thesis* on the subject, has collected twenty-seven cases of operations of one kind or another upon the sympathetic nerve for the cure of Graves's disease. 'These cases include nearly all the published and some hitherto unpublished cases, up to the date of July 1898. Full details of nearly all the cases are given in his essay.

From these twenty-seven cases, four must be deducted since they prove nothing and are valueless for our purpose. Eight of the remaining cases are atypical (cas frustes) and should be put aside as inconclusive.

Among the remaining fifteen cases there appear to have been two cases of cure, six of " marked improvement," three of slight improvement, one of failure and three of death.

With regard to the eight atypical cases, one is reported to have been cured, two markedly improved, four slightly improved, while one was a failure.

* "Etude critique des interventions sur le sympathique cervical dans la maladie de Basedow," Paris, Henri Jouve, 1898. 
Among the twenty-three cases there were thirteen partial sympathectomies (including the three reported cures and one death), seven total sympathectomies (with two deaths), and two sympathectomies (with no cures and no deaths).

'The two cases of cure are the following, both of which occurred in the practice of Jonnesco : *

1. A widow aged 30 had noticed for two months a swelling of the thyroid gland. On admission there was some exophthalmos and a pulse of 110-120. Graefe's sign was not present. There was some trembling of the upper limbs and the patient was in a nervous, excitable condition. (On August 5, 1896, bilateral resection of the cervical sympathetic was performed, but the inferior ganglia were not removed. The wound healed by first intention and the patient left the hospital ten days after the operation. The immediate results of the operation do not appear to have been very striking. The pulse remained at 120 , but the exophthalmos disappeared. The trembling had also gone when the patient left the hospital. A month later the circumference of the neck had diminished from 35 to 35 centimetres. Fifteen months later the general condition was reported to be excellent; there was no longer any goitre, exophthalmos, tachycardia, or trembling. The pulse rate was $74-80$.

2. A girl aged 16 was admitted on account of goitre, exophthalmos, trembling, and a rapid pulse (110-120). On August 21, 1896, the whole cervical sympathetic, except the inferior ganglion, was resected on both sides of the neck. The wound healed by first intention and the patient left the hospital nineteen days after the operation. The exophthalmos diminished immediately, but the pulse remained at $110-120$. When last seen, fifteen months after the operation, the exophthalmos and tachycardia had entirely disappeared, the pulse was regular, beating at 90, and the patient's general condition was excellent.

The three fatal cases described by Boissou occurred in the practice of Jaboulay, Faure and Peugniez respectively. $\dagger$

1. A woman aged 30 with exophthalmic goitre of two years duration. Goitre, exophthalmos, tachycardia and trembling were all well marked. The pulse rate was 128-155. On Nov. 24, 1897 , three centimetres of cervical sympathetic were resected on

* Reported in Boissou's thesis above-mentioned, cases xi. and xii. pp. 148-154.

$\dagger$ Boissou, lor. rit., cases x., xyiii. and xxvii. pl. 144, 175 and 206. 
each side of the neck: On one side the superior ganglion was removed, on the other it was not. After the operation the pulse rate was 120. On the following day the temperature rose to 104.5 and the pulse became bad. On the next day blood-stained expectoration and vascularity of the right conjunctiva were noticed. The exophthalmos diminished. In the next few days the pulse rate was $90-105$, and the temperature about $101^{\circ}$. On the twelfth day after the operation the patient died. The post mortem showed congestion of the base of the right lung.

2. A woman aged 24, with all the usual symptoms very well marked. The whole of the right cervical sympathetic, including both superior and inferior ganglia, were removed and the operator had made the skin incision on the left side when the patient suddenly died. The post mortem threw no light on the cause of death, which seems to have been attributed to the chloroform.

3. A woman aged 20 in whom exophthalmos, tachycardia and goitre were all marked. The symiptoms had lasted about four years. Resection of the whole cervical sympathetic was performed, first on the left side then on the right, with an interval of twentythree days between the two operations. After the first operation the exophthalmos of the corresponding side diminished considerably. The tachycardia, however, did not alter, the pulse remained at 144 . After the second operation the pulse dropped to 128. Both wounds healed quickly, and the patient left the hospital apparently slightly improved.

The improvement did not last very long, for on the day after her discharge from the hospital, twenty-four days after the second operation, she complained so much of feebleness and pain in the precordial region that she took to her bed and never again left it. Violent pain in the head and eyes, vomiting and extreme emaciation now became prominent symptoms. A week after leaving the hospital the exophthalmos was very marked, but the eyelids could still be closed. Soon the exophthalmos was so extreme that the patient became completely blind in both eyes, the left eyeball ulcerated and then collapsed, with discharge of the crystalline lens. Finally the patient died comatose on the fiftieth day after the operation.

A careful study of the cases which are reported to have been "improved" does not seem to be at all convincing. Sometimes one symptom, sometimes another is said to have been alleviated. Sometimes the beneficial effect is said to have been noticed 
immediately after the operation, more often the amelioration has occurred only after a lapse of weeks or months.

The cases in which improvement is most likely to occur seem to be those atypical cases to which the term formes frustes is applied by the French. In many of these cases, however, grave doubts exist as to the correctness of the diagnosis. For statistical purposes, it is best to omit such cases altogether from our consideration. Certainly it is not right to include them among the typical caser, the diagnosis of which should be a matter of little or no difficulty, and from which alone conclusions of value can be deduced.

4. Operations upon Distant Parts of the Body.-Many years ago it was noticed that the removal of a polypus from the nose of a patient suffering from Graves's disease was followed by an amelioration of the symptoms of the latter disease. The same sequence of events has been noticed after operations on other parts of the body. Boissou * has collected no less than seventythree cases of Graves's disease in which improvement or cure had followed an operation upon some distant part of the body such as the nasal fossæ, the genito-urinary organs, abdomen, etc.

I have myself, however, had no personal experience of such cases.

Prognosis.-In considering the advisability of a surgical operation for any disease, it is well to ask what would be the course of that disease if no operation at all were performed. Now, in the case of exophthalmic goitre the prognosis, if the disease be not treated by operation, is by no means wholly bad. Although in a few cases the disease ends speedily in death, yet such a termination is the exception rather than the rule.

'The eareful inquiries that have been made by IVilliamson, + of Mauchester, supplemented by those of Ord and Hector Mackenzie, have put us in possession of valuable information as to

* 43 (anses of Jouin, 5 of Stocker. 4 of Teilhaber, 3 of Van der Lenden, 3 of Fodern. 2 of Lethaive. 2 of Odeije, 2 of Bonilly, and those of Hack, Hoffmann. Franenkel, (iottstein. Muschold, Picqué, Turgis, Doleris, and Berger, quoted by Pirre boisson in his - Etude critique des interventions sur le sympathique (•rvical dams la maladie de Basedow," P'aris. 1898. p. 15.

$\dagger$ " Remallis on Prognosis in Exophthalmic goitre," by R. T. Williamson,

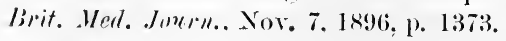


the ultimate result of a large number of cases, none of which were treated by operation. Taking into consideration only those cases which ended either in death or recovery, or which had been under observation for at least five years, the figures of the two sets of observers * are as follows:

\section{RESULT IN FIFTY-SEVEN CASES.}

\begin{tabular}{|c|c|c|c|}
\hline & & & \\
\hline Fatal termination $\ldots$ & 8 & 6 & 14 \\
\hline Recovery complete ... $\ldots$ & $\tilde{j}$ & 5 & 10 \\
\hline Recovery almost complete... & 9 & $\mathcal{2}$ & 11 \\
\hline Improvement considerable... & 9 & 4 & 13 \\
\hline Improvement slight $\quad \ldots$ & 1 & 3 & 4 \\
\hline $\begin{array}{lll}\text { In statu quo } \ldots & \ldots & \ldots\end{array}$ & 1 & 3 & 4 \\
\hline Alive, but exact condition & & & \\
\hline not known $\quad \ldots \quad \ldots$ & 0 & 1 & 1 \\
\hline
\end{tabular}

Conclusions.-Reviewing the whole subject of the operative treatment of exophthalmic goitre, it seems to me that it may reasonably be doubted whether surgical treatment is not on the whole worse than useless.

For it must not be forgotten that in this disease there is naturally a strong tendency towards recovery. Many patients who do not recover completely, nevertheless improve greatly without operative treatment of any kind.

None of the operations that have hitherto been practised upon the gland, the thyroid vessels or the sympathetic are free from risk. Actual proof that any of them really cure the disease is at present wanting. The sympathetic operation, although it may, and probably does to a slight extent, diminish the exophthalmos, does not usually cure it completely, and may be followed by very serious results, such as inflammation of the eye and even blindness.

The larger operations upon the gland itself, such as extirpation, are attended with so much danger as to make them undesirable, unless it can be shown that the results are sufficiently good to justify the risks. At present this has not been done.

* Given in Clifford Allbutt's "System of Medicine," 1897, vol. iv. p. 501. 
With regard to ligature of the thyroid vessels, it still seems to me doubtful whether this proceeding is followed by cure sufficiently often to justify its performance. There seems to be no doubt that if any of the above operations are undertaken by the surgeon, they should be performed in most cases without general anxesthesia, and that they should be performed with as little disturbance as possible to the surrounding parts. 


\title{
CHAP'TER XIII.
}

\section{MALIGNANT DISEASE AND ITS TREATMENT.*}

\begin{abstract}
Affects both normal and goitrous thyroid-Age-Sex-Varieties-Sarcoma and carcinoma-Relative frequency-Symptoms and diagnosisInfiltration of neighbouring parts-Skin rarely involved-Duration of the disease-Mode of death-Unusual forms of malignant disease"Malignant adenoma"-Papilliferous cyst-Treatment-Extirpation Difficulties and dangers-Often incomplete-Results of operationsRecurrence-Statistics-Slowly growing forms-Palliative treatmentPartial removal-simple incision-Tracheotomy-Difficulties-Danger of sepsis-Treatment of dysphagia and pain-Conclusions.
\end{abstract}

Malignant disease of the thyroid gland is in this country a somewhat rare affection. It is fortunate that it is rare, since in the stage at which it is usually seen by operative surgeons it is seldom amenable to surgical treatment.

The disease may occur in a gland that has previously been normal, but it is much more prone to affect one that has already been the seat of innocent goitre. This is doubtless the reason why the disease is much more commonly seen in localities where ordinary goitre is prevalent. Even in cases in which there is no history of pre-cxisting goitre it will often be found, upon examination after removal, that the tumour contains cysts, points of calcification, or some similar evidence of former disease. In several cases, however, which have come - under my own notice, or which I have examined in museums, evidence of the previous existence of a goitre has been wholly absent.

Age and Sex.- The disease is essentially one of advanced life, being rare below the age of forty. Out of thirty-four specimens of malignant disease in the London museums, in which the age

* Most of this chapter has already been published in the chapter on the thyroid contributed by me to the recently published edition of Mr. Butlin's "Operative Surgery of Malignamt Disease." 
of the patient is stated, I have found only three in which the age was below thirty-nine, and of these, one is a somewhat doubtful congenital sarcoma in an infant; another is from a boy aged three, and it is open to doubt whether the growth, described as a round-celled sarcoma, was not secondary to disease of the abdomen. 'The third specimen is in the Royal Free Museum, and is from a patient of my own, aged 25, depicted in Fig. $7 \%$. Here and there in surgical literature are found cases in which the disease occurred in children or young adults, but certainly in the great majority of cases the patients have attained at least the age of forty.

Among fifty cases of undoubted malignant disease that have heen published since 1884, I find only eight in which the age was below forty. In no less than twenty-four of these cases the age was fifty or more; of these, twelve had attained the age of sixty.

As regards the frequency with which the disease affects the two sexes there is not much difference. Some observers have found that males were affected rather more often than females. My own statistics show that of the fifty patients above-mentioned twenty-seven were women; among thirty-nine specimens in the I condon musemin, seventecn are from male and twenty-two from female patients; a very small number of cases overlap, and occur in both sets of figures. Bergeat says that of fifty-five cases seen at 'Tübingen between 1883 and 1894, twenty-three were men and twenty-nine women, but the diagnosis was not in all cases verified.

Varieties.-Both carcinoma and sarcoma occur in the thyroid gland, the former being usually of the alveolar form with cubical cells, the latter either spindle- or round-celled. Various other rare varieties have occasionally been described but are not of sufficient importance to require further consideration here.

It is exceedingly difficult to arrive at a definite conclusion as to the relative frequency of sarcoma and carcinoma. Most writers have asserted that carcinoma is a good deal more common than sarcoma. Thus Kaufmann " among fourteen cases examined microscopically by him in Switzerland, found that

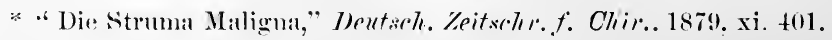


eleven were carcinoma and only three were sarcoma; and subsequently he published six more cases all of which were carcinoma.

Orcel, in his excellent thesis, ${ }^{*}$ gives details of sixteen cases of malignant disease observed at Lyons, a place where endemic goitre is frequently seen. Rejecting one of these, in which the proof of malignancy does not appear to be convincing and omitting five others which, although undoubtedly malignant, do not clearly indicate whether the disease was sarcoma or carcinoma, there remain ten cases; of these five were sarcoma and five carcinoma.

Of fifty-four specimens in London museums, twenty are sarcoma and thirteen are carcinoma, while of twenty-one, owing to want of proper microscopical examination, it is impossible to express a definite opinion. Among fifty undoubted cases found in literature published since 1884 (including Orcel's ten cases) I find twenty-six sarcomata and twenty-four carcinomata. These last two sets of figures, however, probably do not represent the true proportions, since the rapidly growing form of sarcoma is a more striking affection than the ordinary form of carcinoma, and is, therefore, more likely to find its way into museums and into literature.

In compiling the above statistics, I have felt obliged to reject a very large number of cases which in all probability were malignant, because the proof of this was wanting. 'Those cases only have been accepted as genuine in which such proof was clearly afforded either by accurate microscopical examination or by evidence of local infiltration, or of secondary deposits.

'The difficulties which surround the whole subject are considerable, since cases are frequently met with both in literature and in museums in which an obvious sarcoma is described as carcinoma and vice versa. Instances are not unknown of simple adenoma being described as carcinoma, while obviously malignant infiltrating tumours have been pronounced to be adenomata. Even those who have had large experience in the microscopic examination of thyroid tumours will admit that it is often difficult to say where adenoma ends and carcinoma begins.

* "Contribution a l'étude du cancer du corps thyroïde," Lyons, 1889. 

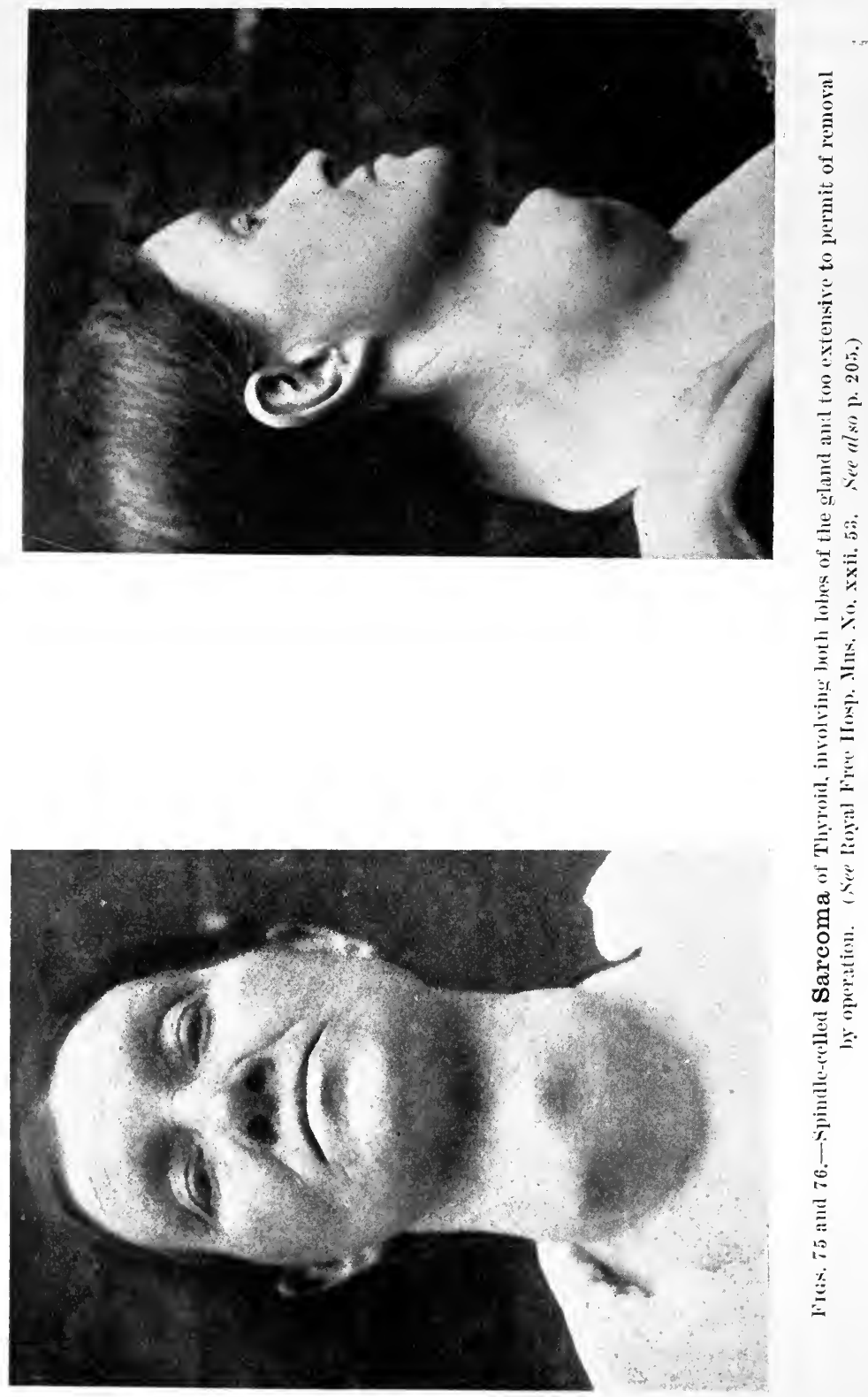
Chronic inflammation has before now been mistaken for sarcoma, as Tailhefer and Riedel have shown.

Symptoms and Diagnosis.-Clinically, it is very difficult to distinguish between 'sarcoma and carcinoma. In many cases it is not possible to do more than guess at the probable histological nature of the malignant growth. I shall, therefore, treat of them together, merely prefacing my remarks by saying that if the tumour has grown very rapidly, and is limited to one lobe of the gland, the disease is more likely to be sarcoma; while if the affection, at a comparatively early stage, involves both lobes and pursues a somewhat slow course, it is not unlikely that it will prove to be carcinoma. Exceptions to both these rules are, however, by no means uncommon.

In its earliest stages, while the growth is still confined within the capsule of the gland, there are no means by which we can make a certain diagnosis of malignant disease. When, however, in the thyroid gland of a person over forty, a tumour appears which is hard, which steadily and rapidly increases in size, and which is not of an inflammatory nature, the malignancy of such a tumour should be strongly suspected. If, moreover, the surface of the tumour is irregular and bossy,* and if there is likewise dysphagia and pain in the neck, shooting up to the side of the head, or to the shoulders, then the diagnosis becomes almost a certainty. It is of the utmost importance that the diagnosis should, if possible, be made at an early period, since it is then alone that operative treatment can be adopted with a reasonable prospect of success. A little later, when the growth has penetrated the capsule, and begun to involve surrounding structures, various other signs appear which make the diagnosis much less difficult. The vocal cord on the corresponding side often becomes paralysed, a condition rarely seen with innocent goitre. Involvement of the trachea, with penetration of its lumen by the growth, is very common, and is abundantly illustrated by specimens in museums. (See Figs. 78 and 80.)

'This penetration of the interior of the trachea is most common at a point about half an inch below the cricoid, and often takes

\footnotetext{
* Figs. 75 and 76 show well the bossy nature of a malignant thyroid tumour.
} 
the form of a small prominent, sometimes even pedunculated, button of growth. It occurs both in sarcoma and carcinoma. Occasionally, a considerable length of the tracheal mucous membrane is involved, as in the specimen depicted in Fig. 80.* Involvement of the muscular wall of the pharynx is very

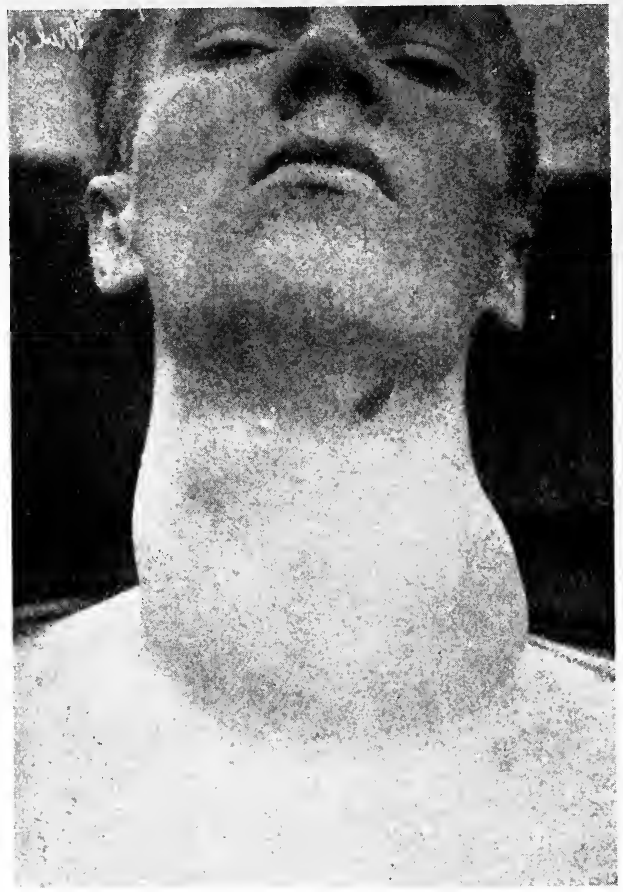

Fic. 77.-Findle-celle S Sarcoma of the left Lobe of the Thy roid. The position of the larym is shown by a slight swelling more than one inch to the right of the millle line. From a patient, aged 25 , who had first noticed the lump, in his neck three months before the photograph was taken. The growth surromule: the curotid artery and was too extensive to permit of any attempt at removal. Tracheotomy soon berame neesssury. (See Royal Free Hosp. Mus. No. xxii. 54.)

common, but actual penetration of its mucous membrane is rare. 'There are but two specimens of this latter condition in the London museums. Kaufmann, in the cases collected by

* From a specimen in the Museum of the Roy. Coll. of Surg. No. 2907. For other specimens of penetration of trachea or larynx, see St. Bart. Hosp. Mus. No. 2319C; st. Thos. Hosp. Mus. Nos. $1470 \mathrm{~A}$ and $1+72$; Westm. Hosp. Mus. No. (i12. 
him, found but one instance in which the mucous membrane was penetrated. Displacement, curving, twisting and flattening of the trachea, although common enough in cases of malignant disease of the thyroid are not.more characteristic of malignant

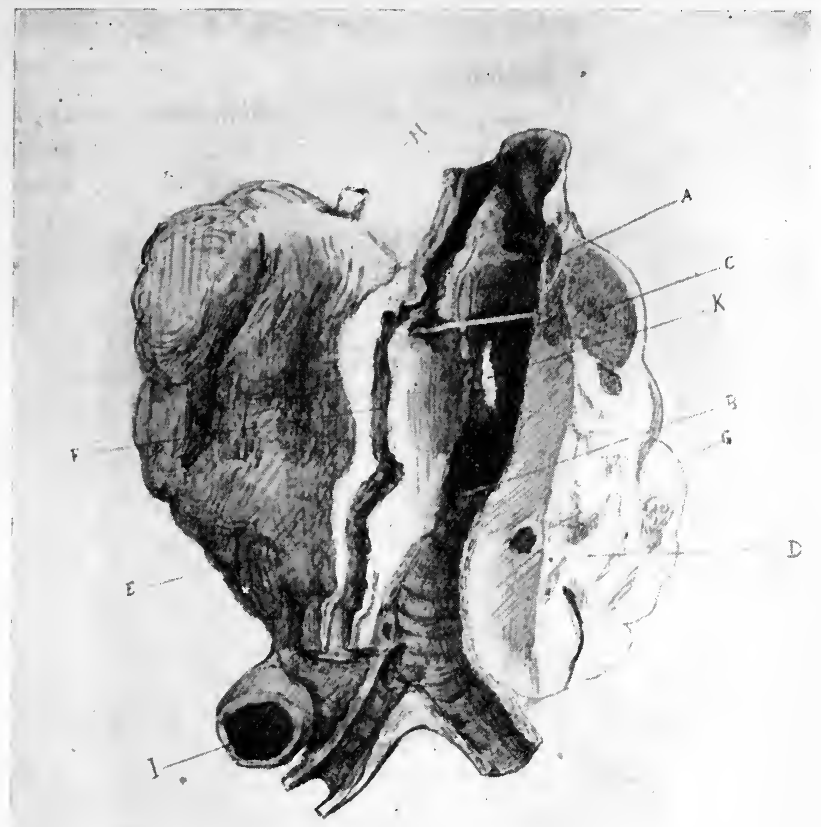

Fra. 78.-Spindle-celled Sarcoma of the Thyroitl, showing the manner in which the growth his extended behind the oesophagus and between it and the trachea. A. Larynx luid open from behind. B. Tracher surroundet and compressed by tumonr. C. Remains of thyroid tissine more or less healthy. D. Right lobe of thyroid infiltrated with sircoma. E. Sarcomi extending between trachea and oesophugus (F). Gand $\mathrm{n}$. Right and left carotid arteries surromeded by growth. I. Aorts. K. Tracheotomy wound. (See $A$ ppentix, (ase 113, p. 352, and Roy. Free Hosp. Mus. No. xxii. 5.5.) (Reduced $\frac{1}{3}$.)

than of innocent goitre; indeed, the tendency of the former to infiltrate, rather than to push aside, causes the displacement or deformity of the trachea to be less marked.

On the outer side, the growth tends to become adherent to the carotid artery and internal jugular vein. . 'The relation of 
the carotid to the tumour may afford valuable evidence of malignancy. An innocent goitre in its growth usually displaces the artery, outwards and backwards; a malignant tumour tends to infiltrate, to overlap and surround it, without causing so much displacement. 'The artery can often be traced by its pulsation, running as far as the tumour, into the interior of which it seems to disappear. Paralysis of the sympathetic, shown by a contracted pupil and narrow palpebral fissure, is not uncommon. (See Fig. 81.)

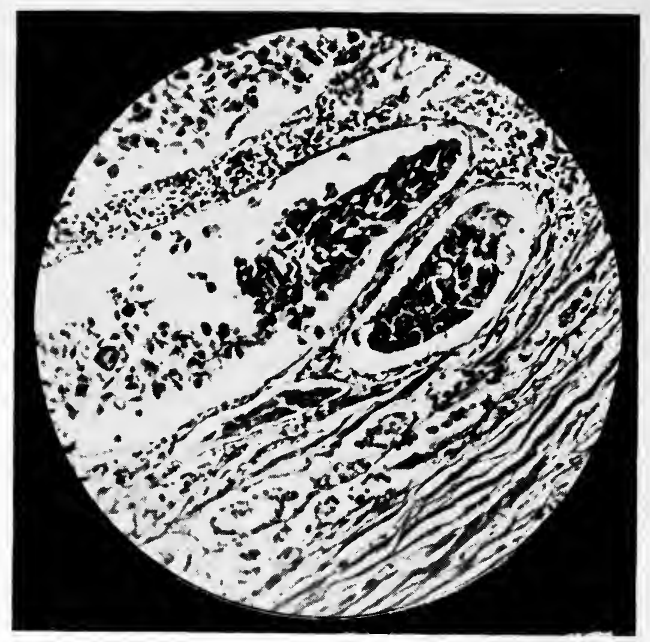

F16. 79.-Microscopical section of a Carcinoma attacking an old goitre which lias also undergone much fibroid degeneration. ( $\times 130$ dim.)

Fixity of the tumour is an important and a very bad sign. It is well to bear in mind that a malignant tumour that has not become fixed to such immovable structures as the sternum, clavicle, vertebrx, or the larger muscles of the neck, may follow the movements of the larynx and trachea with tolerable freedom and yet may be hopelessly incorporated with the latter, or with the wall of the pharynx. Many a time has an operator, deceived by this apparently free mobility of the tumour, been led to undertake an operation for its removal, only to find, when too late, that the adhesions on the inner side were so extensive that complete removal was impossible. 
Involvement of skin and of lymph glands afford but little help in the diagnosis. The skin is seldom involved, even in late stages, except in those cases in which the growth has been punctured or incised.

Exceptionally, spontaneous ulceration of the skin takes place and may be the immediate cause of death, as in the following case :

Harriet F__ aged 53, was admitted to the Royal Free Hospital under my care on March 2, 1899. Since childhood she had had a swelling in the neck, as large as a walnut. It had never caused her any trouble until November 1898 , when it suddenly began to grow. It continued to increase steadily, but gave her no pain and caused little or no trouble in breathing or swallowing.

The condition on admission is shown in Figs. 75 and 76 . A large, hard, irregular, prominent tumour occupied the front of the neck and involved both lobes of the thyroid gland. The carotid could be felt indistinctly on the right side, not at all on the left. The diagnosis of malignant disease was obvious, and owing to the fixity and extent of the tumour, operation for its removal was out of the question. On March 12, she returned to her home, being told to come up again if her breathing gave her trouble. In April she was seen again. She was much thinner and weaker, and the tumour had grown considerably, but there was very little dyspnoa. The skin over the tumour had recently ulcerated. The tumour grew to a very large size, the ulceration extended and was accompanied by very foul discharge. The patient gradually sank and died at home on July 7, 1899, of sepsis and exhaustion. Dyspnoea never became sufficiently bad to call for tracheotomy. The post nortem showed a spindle-celled sarcoma.*

Out of some thirty cases that have come under my own notice during life, there was not a single one in which affection of glands afforded any material help in the diagnosis. By the time that enlargement of the glands can be detected, the nature of the disease is usually sufficiently obvious; it must be remembered that the glands that first become affected are usually very deeply seated, at the root of the neck, or behind the sternum, where their detection is well nigh impossible. I have also been very much struck by the number of cases, especially

* The tumour is now in the Royal Free Ho:p. Mus. No. xxii. 53. 
of sarcoma, in museums, in literature, and in my own practice, in which affection of lymphatic glands was wholly absent, even in the latest stages of the disease.

lixpectoration of blood is an unusual symptom; it generally

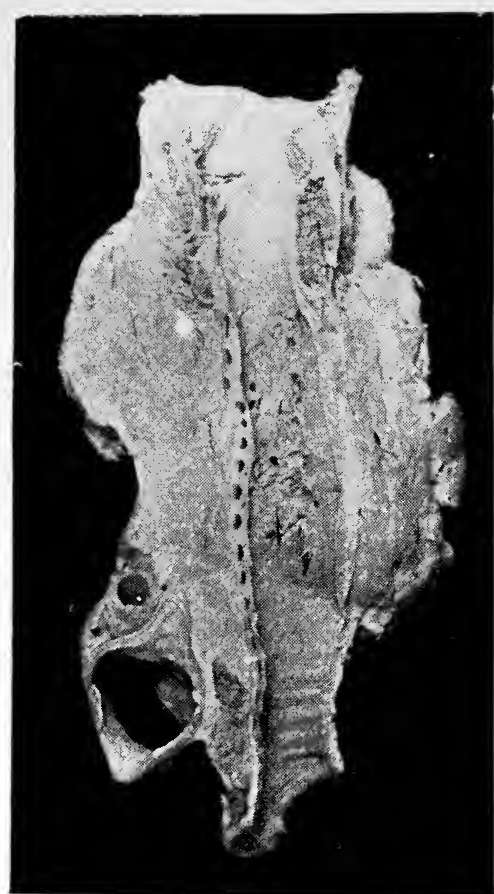

Fen. 80.-Vortical Melian Section throngh Laryn, Trachea, Thyooid (ilaul, de., showing malignant disease fungating into the interior of the trachea in its mperer twothirk. (l'rom a specimen in the lioy. (i)ll. of sure. No, 2907.) occurs late and is of grave import, indicating probable penetration of the trachea, or, possibly, secondary growth in the lungs. Occasionally, it would seem to be a comparatively early sign. In a case of carcinoma, recorded by Mr. Shattock, severe hæmoptysis occurred ten months before death, and seems to have been one of the first symptoms.*

'The course of malignant disease of the thyroid is usually very rapid. Rose, of Berlin, has estimated that theextreme limits of its duration are nine weeks and eighteen months, and in the main he is certainly correct. Many cases run their whole course within six months.

One of the shortest cases that I have myself seen was that of a sarcomatous tumour in a gentleman, aged 68, under the care of Mr. Edgar Willett. When I first saw the patient, the tumour had been noticed only four weeks. It was already $s_{0}$ fixed as to be hopelessly irremovable. No cperation of any kind was attempted; the disease made rapid progress, speedily involved the lungs with sccondary deposits, and death occurred within three months from the time of the first appearance of the tumomr.

'The case depicted in Fig. 17 (p. 202) also ran a very rapid * st. Thos. Hasp. Mus. No. 1472. 
course and is further remarkable for the unusual youth of the patient :

Charles K-- - aged 25, was admitted into the Royal Free Hospital under my care in July 18, 1899, on account of the tumour shown in the photograph.

Three months previously he had first noticed a slight swelling on the left side of the neck. It gave him but little trouble and he paid no attention to it until a fortnight before admission, when it began to grow rapidly. Slight dyspnoea, dysphagia, and huskiness of voice were then noticed for the first time.

On admission, a hard irregular tumour, some four inches in diameter, occupied the left side of the lower part of the neck, displacing the larynx and trachea far to the right. The left carotid artery was completely buried in the tumour and the left vocal cord was paralysed. The tumour, which was obviously malignant, was hopelessly irremovable. The patient became rapidly worse, dyspnoa, dysphagia, and pain in the left arm and shoulder became prominent symptoms. On July 28, an unusually severe attack of dyspnoea necessitated tracheotomy. This gave considerable relief for a few weeks, but the patient gradually succumbed and died on August 30, a little more than four months after the onset of the disease. The immediate cause of death was hæmorrhage from the trachea. The post mortem showed a spindle-celled sarcoma of the left lobe, with extensive involvement of the trachea and pharynx. There were no secondary growths anywhere.

On the other hand, there is no doubt that many cases last considerably longer than eighteen months. I have seen a case in which the disease had already lasted more than two rears, the tumour, having in that time, attained the dimensions of an emu's egg. 'This patient died four months later; no operation was performed.

In all these cases there had been, apparently, no preexisting goitre, so that the onset of the malignant disease could be fairly accurately defined. In the more common cases in which malignancy is engrafted upon innocent goitre, it is often difficult to say at what date malignancy began, especially if the goitre is a large one. Such patients often first present themselves for advice when the tumour has already penetrated the capsule and begun to cause urgent symptoms. I am inclined to think that in some few of these cases the malignant tumour 
may really have existed for several years, although in the great majority of instances, the duration is probably a matter of months rather than of years.

Death is usually caused both in sarcoma and in carcinoma by the extension of the primary growth to the air passages. The

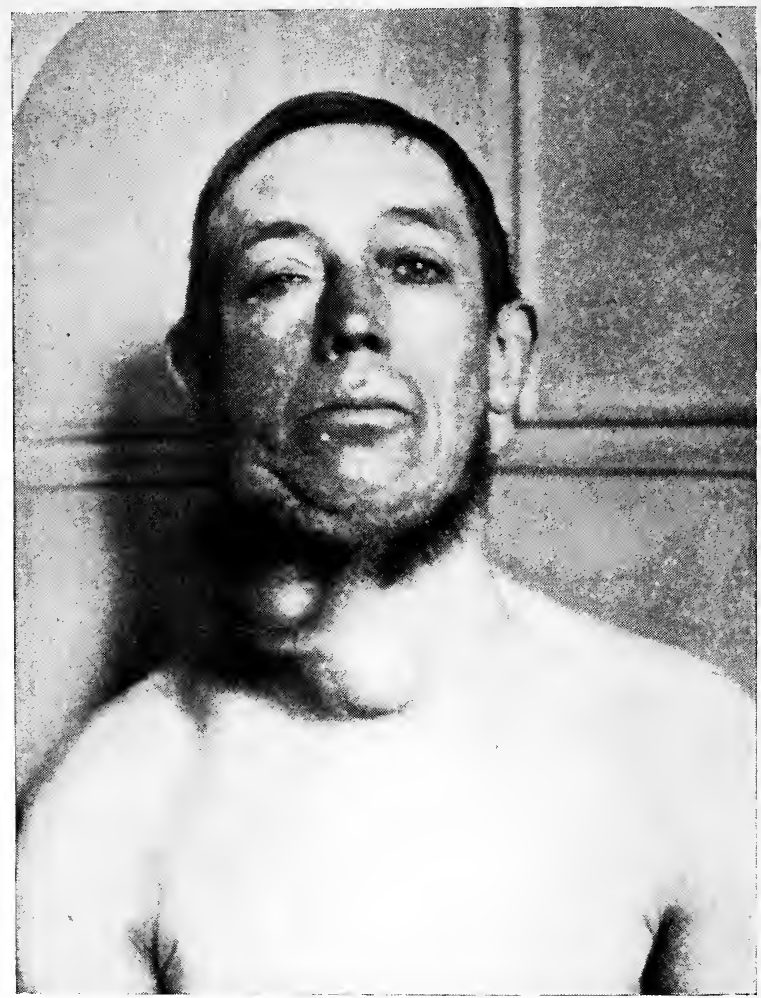

Fua. 81 - - Findle-celled Sarcoma of the Thyroid, with l'aralysis of the right sympathetic nerve (shown hy the narow palpebral fissure and contracted pupil). (From an ont patient seen at St. Bart. Hosp.) (See 1. 213. )

mechanical obstruction of the trachea thus produced may cause fatal dyspnoea. Ulceration into the trachea may set up septic processes in the tumour which rapidly lead to the death of the patient. Bronchitis-or pneumonia, septic in origin, is frequently the immediate cause of death, especially if tracheotomy has been performed. Penetration of the numerous veins in and 
around the tumour, especially in the case of sarcoma, frequently leads to the occurrence of secondary growths in the lungs, Secondary growths in more distant viscera may occur; the bones especially are liable to become the seat of secondary carcinoma-

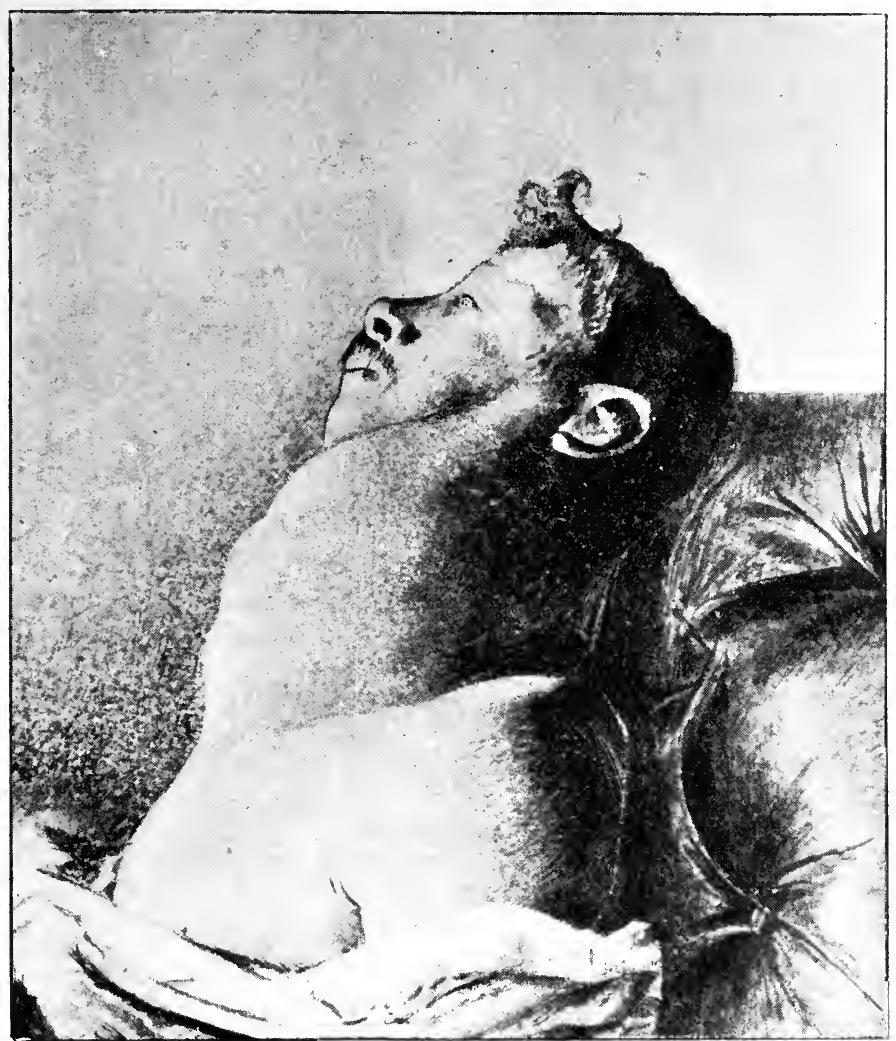

Fig. 82.-Lirge, soft, and very vasenlar Malignant Tumour of the Thyroid. 'The patient died at home of suffocation a few months later. (seen at St. Bart. Hosp. in 1886 .)

tous growths. 'These secondary growths in bone have a remarkable tendency to reproduce the structure of the thyroid gland with its epithelial vesicles containing colloid matter. In some cases the resemblance between these secondary growths and the normal gland is singularly close.

Sudden hæmorrhage into the softened interior of the growth may be mentioned as an occasional cause of death. 


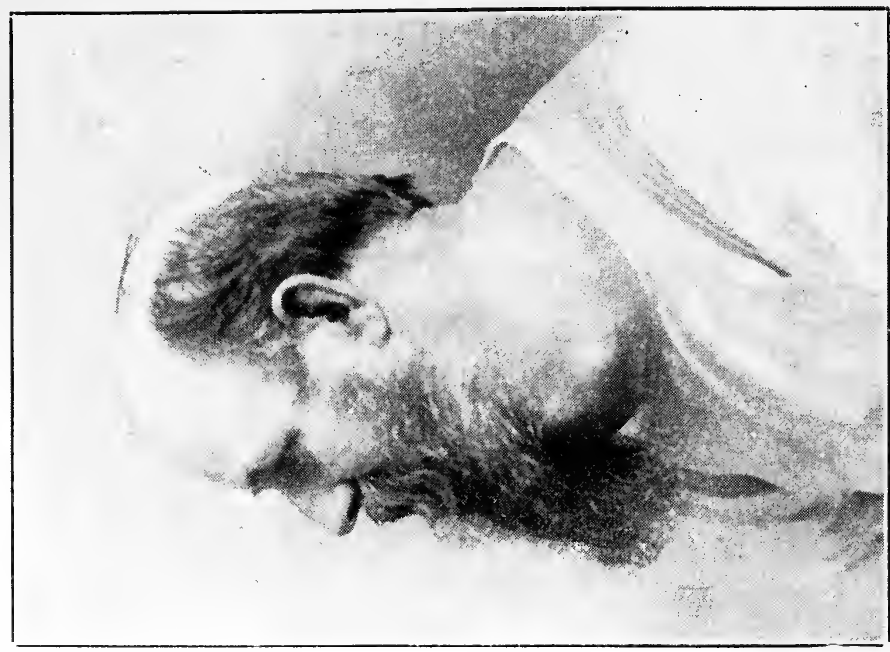

$\doteq$

雚

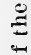

है

照

$\cong$

总

至

至三

要

要

융

용

๒

명 ․ㅗㅇ

夏

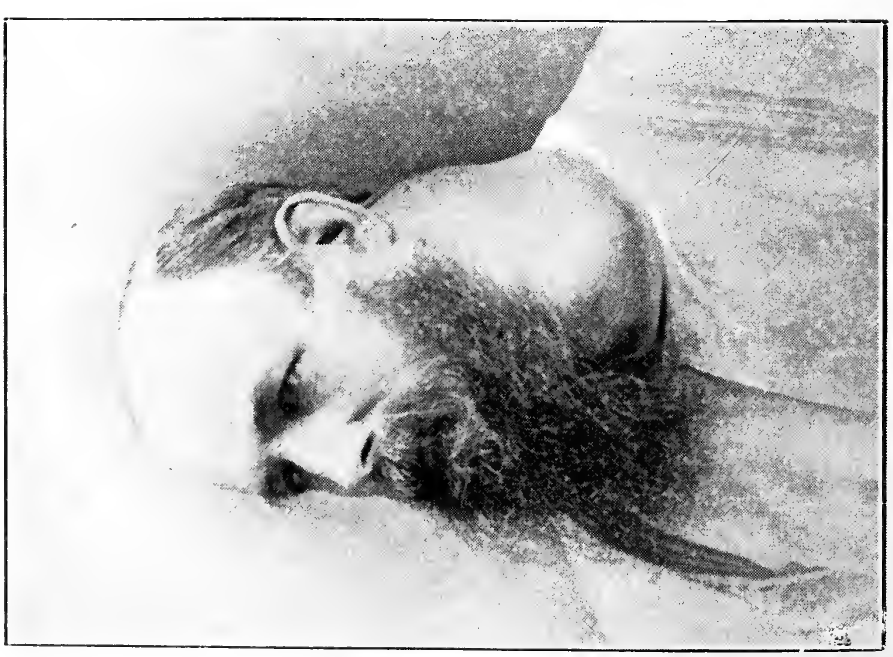

-

0 -

㟧

D্

몰

으

\&્木

至

مै

Aि:

$+$

$\dot{x}$

밀

$\ddot{\infty}$

: 
It is well also to remember that in the later stages nedema of the glottis may supervene very rapidly, and be the immediate cause of death.

A few words may be said about certain forms of malignant disease which deviate from the ordinary type.

Instead of being hard, the tumour may present itself in the form of a soft swelling which is then easily mistaken for a cyst or for an inflammatory swelling. There are cases in which the whole gland becomes the seat of a soft rapidly growing tumour. Such cases, when occurring in young subjects, may be mistaken for the common rapidly growing parenchymatous goitre of adolescents. Cases have been recorded by Boeckel and Tillaux, in which sarcomatous tumours have given rise to many of the symptoms of exophthalmic goitre, for which indeed they were mistaken.

There are, moreover, forms of malignant tumour which must be classed among the carcinomata, although clinically their course is very different from that of the ordinary carcinoma. I refer to the so-called "malignant adenomata," and to the papilliferous cystic tumours. 'The former appear to occupy an intermediate position between innocent tumours and the more typical carcinomata. In general appearance these tumours may closely resemble the innocent adenomata, but differ from them in possessing a tendency to recur after removal, and to disseminate. From their rarity they are of comparatively little importance.

Papilliferous cystic tumours, although rare, are of some importance. They grow slowly, and exhibit but a low degree of malignancy. They are, therefore, far more amenable to treatment by removal, even though they may have attained a large size. Mr. Barker has recorded* a very remarkable case of this kind, which is depicted in Figs. 83 and 84. The patient, whose age was fifty when the photographs were taken, lived no less than eighteen years after the first appearance of the tumour, and underwent in the last ten years of his life numerous operations for the removal, first of the primary growth, and then of locally recurrent tumours. The tumours

* Brit. Med. Journ., June 21, 1890, and Trans. Puth. Soc. Lond. 1896, xlvii. p. 225. 
which were examined by a committee of the Pathological Society were undoubtedly carcinomatous. Cases of a similar nature have been recorded by Berger, Wölfler, Sulzer, and others.

Treatment.-'The only form of treatment of malignant disease of the thyroid that offers any hope of cure consists in free removal of the whole of the disease, if this is possible. Operations for the removal of a portion of a diseased thyroid may be divided into two main classes, that of extra-capsular extirpution and that of intra-glandular enucleation. In the case of malignant tumours, however, one only of these methods is suitable, namely, extirpation. An exception should perhaps be made for certain cases in which malignant disease attacks, and is limited to, an old adenoma with a well-marked fibrous capsule; but as these cases are rare, and can scarcely be distinguished from those of innocent adenoma, the exception is rather apparent than real.

The treatment of innocent thyroid tumours by enucleation is such a very satisfactory operation, and is so widely applicable to them, that attempts have from time to time been made to treat malignant growths in the same manner. This is, however, in my opinion, a grave error. Not only is the hæmorrhage at times so profuse that the operation has to be abandoned on this account alone, but the removal is almost necessarily so incomplete, that speedy recurrence must be expected.

'The only way to remove a malignant thyroid tumour satisfactorily is to do a careful and deliberate dissection, and to avoid hamorrhage by tying the main vessels before they are cut. 'The operator should, at every stage of the operation, be able to see exactly what he is doing. Otherwise he is liable either unnecessarily to wound important neighbouring structures or to leave behind portions of growth which might well have been taken away.

An operation for the removal of a malignant thyroid tumour should, if possible, be a thorough one, and aim at the removal of the whole of the primary disease. When the disease is limited to the gland itself, this complete removal is possible. But. unfortmately, in the vast majority of cases in which 
operations have hitherto been performed, this condition was not present.

In most cases the growth is found at the time of operation to have penetrated the capsule, and to have involved the trachea, the pharynx, or the great vessels of the neck. In such circumstances it has been thought advisable to resect portions of these structures, but such complications naturally add enormously to the danger of the operation. In most cases even after such resections, the whole of the disease will be found not to have been removed, and speedy recurrence takes place. 'The recurrent tumour usually grows much more rapidly than the primary one.

Two cases may here be cited:

In the summer of 1887 I was asked by Mr. Howard Marsh to see a man aged 42 who had had for five years a hard lump in the right side of the neck. This had steadily increased in size, at first slowly, in the last few months more rapidly. A large, irregular, somewhat hard tumour occupied most of the anterior triangle of the neck;* the sympathetic nerve of the same side was completely paralysed. On account of this latter complication and of the probable involvement of the structures on the inner side of the tumour, I advised against any operation. However, a few days later the patient consulted another surgeon who proceeded to remove the tumour, and subsequently published an excellent account of the case. $\dagger$ The operation was long and difficult, and in the account given, it was stated that the tumour was adherent to the larynx. It was not stated that the removal was considered to have been complete. The patient recovered sufficiently to leave the hospital, but in less than sixteen weeks from the date of the operation he returned with a recurrent tumour as large as an orange and ulcerated on the surface. The tumour was again removed, then tracheotomy was performed. Several other partial operations were subsequently performed; sloughing took place, then secondary hæmorrhage, necessitating ligature of the carotid. The patient died very soon after this operation, and just nine months from the date of the first removal. The growth was a spindle-celled sarcoma, and at the post-mortem examination no secondary growths could be discovered.

* Fig. 81 siows the condition at the time when I first saw this patient.

i St. Thomas's Hosp. Rep., 1888-9, n. s. xviii. p. 233. 
The other case is one published by Cramer, ${ }^{*}$ and also illustrates incomplete removal at a rather later stage of the disease.

A woman aged 46 had had for two years a small lump on the left side of the neck; in the last nine months it had grown more rapidly; hoarseness had then set in and lately she had had much pain. On admission there was no dyspnoea or dysphagia. The left lobe of the thyroid was as large as a goose's egg; it was smooth, hard, and a little movable; the skin was not affected. Malignaney was diagnosed and the tumour remover. Hæmorrhage was but slight, but much difficulty was experienced in separating the tumour from the trachea and larynx. The wound healed up quickly and the parient was on the point of leaving the hospital, when the wound suddenly re-opened and some secondary hæmorrhage took place. A few days later the wound was laid open again and the bleeding found to come from a nodule of growth. Severe hæmoptysis then took place. With the laryngoseope a mass of growth penetrating the trachea could be seen. Seven weeks after the original operation the larynx was split open and growth found on the left side extending from the middle of the thyroid cartilage to the fifth tracheal ring. A few days later total extirpation of the larynx was performed; at first the patient seemed to do well, but in the second week recurrences began to be manifest at various places in the wound, pleurisy set in and eventually the patient died just fourteen weeks from the time of the first operation.

I cite these two cases, because I believe them to be fair average examples of the difficulties that a surgeon must be prepared to encounter if he undertakes the removal of a malignant goitre when there is no longer any hope that the growth is still confined within the capsule of the gland.

The operation for the removal of a malignant goitre in its early stage, that is before the capsule has been penetrated, should be performed in exactly the same manner as extracapsular extirpation of an innocent goitre. An incision of sufficient length is made, usually over the long axis of the tumour, the infrahyoid muscles are divided, and the capsule of the gland exposed. Wound of the eapsule with its network of large

* .. Beitrag. z. Kenntniss der Struma maligna." Arrll. f. klin. C'hir.. Berlin $18 \times 7$, xxxvi. p. 259. 
vessels should be carefully avoided. All the main vessels entering or leaving the gland are tied with double ligatures, just outside the capsule, before being divided. After the superior thyroid artery and the superior, lateral, and inferior thyroid veins have been treated in this manner, the tumour should, if possible, be lifted up, and the more deep-seated inferior thyroid artery secured in the same way. This artery may be tied before it reaches the recurrent laryngeal nerve, or its branches may be secured on the inner side of the nerve, just before they enter the gland. Great care must be taken to avoid wounding the nerve. 'The vessels at the upper and lower borders of the isthmus are secured with double ligatures, and the isthmus is then divided. 'The whole lobe is then freed from its remaining' connections and removed. Ligatures are applied to any other bleeding points. After the tumour has been removed the cut surface of the isthmus should be examined to make sure that the whole of the growth has been satisfactorily taken away. If necessary, some more of the isthmus may be removed. It may even be advisable to repeat the operation upon the other half of the gland. Total extirpation of the gland, however, is in my opinion, rarely desirable, since if both lobes are involved in the disease, the growth has almost certainly already involved the trachea, and can no longer be satisfactorily removed. 'The simultaneous removal of both halves of the gland adds very much to the gravity of the operation. It should not, I think, be performed unless the operator feels confident that he can thereby make a complete removal of the whole disease, and that he cannot do this by any smaller operation. It may reasonably be doubted whether the larger operations, which include resection of organs outside the gland, are advisable.

Irrigation of the wound with antiseptic solutions should, if possible, be avoided. Aseptic rather than antiseptic treatment should be aimed at. It is scarcely necessary to add that during the whole operation the most strict asepsis should be maintained. A drainage tube need seldom be kept in the wound for more than twenty-iour hours.

The removal of one half of the thyroid gland, if performed in the manner indicated, upon a suitable case, is not more difficult 
than when performed for an innocent goitre. Upon this point Kocher, whose experience of both classes of operations is very large, says " the prognosis (as regards the operation) in excision of sarcomatous or carcinomatous goitre, if performed at the right time, is not materially worse than that of innocent goitre."

Results of Operations for the Removal of Malignant Goitre. -In the first edition of Butlin's " Operative Surgery of Malignant Disease" published in 1887, statistical information is given in an analysis of fifty cases collected by Braun and Rotter. Thirty of the patients died from the effects of the operation at periods varying from a few hours to eight weeks. Of the remaining twenty there were two in whom the operation was not completed. In four cases the further history was not known except for a very short period after the operation. "In ten cases there was recurrence, which was either fatal or promised rapidly to be so. Only in four instances was a favourable result obtained." Two of these patients died of disease of the lungs one year and two and a quarter years after the operation. One patient was known to be alive and well eleven months afterwards. 'The remaining patient was reported to be quite well nearly four years after the operation, but he too is now known to have died of recurrence not long after the date of this report. So that of the whole number there is not one that can be said to have been satisfactorily cured by the operation.

Statistical information as regards the removal of innocent goitre has within the last few years accumulated rapidly and has shown a marked improvement in this branch of surgery. 'The gross mortality after partial extirpation (not enucleation) of the thyroid for all kinds of innocent goitre, except the exophthalmic variety, is $3 \frac{1}{2}$ per cent., according to the most recent statistics of Reverdin (October 1898). This estimate is obtained from an analysis of 1212 cases reported to him by a large number of surgeons.

Similarly satisfactory improvement cannot however be claimed for the removal of malignant thyroid tumours. Some improvement has, however, taken place in the direction of earlier diagnosis and a lessened mortality from the operation itself. 
Accurate statistical information with regard to the removal of malignant thyroid tumours is not easily obtained. Most of the operators who have published long series of operations for goitre have omitted from their statistics all the malignant cases.

In a few instances, however, a series of consecutive cases has been published and these afford us valuable information. Such are the series published by Sulzer from the Canton Hospital at Münsterlingen (seven cases), by Bergeat from the 'Tübingen Clinic (six cases), by Hochgesand from the Heidelberg Clinic (five cases), and the latest series, published by Kocher and his assistants, from the Berne Clinic (eighteen cases). Besides these I have collected from various sources thirteen isolated cases published by various authors, ${ }^{*}$ since $188 \%$. With the possible exception of some of the operations mentioned by Sulzer, the exact dates of many of which I do not know, all these operations have been performed since 1884. Many of them, including all of Kocher's series, are quite recent, having been performed withir the last few years. Five of Hochgesand's cases I have excluded from my statistics because they were performed before 1884 and have already been included in Braun's statistics above mentioned. I have also excluded cases of papilliferous cyst, on account of its low degree of malignancy. 'The thirteen isolated cases include only those in which there was clear microscopical or other proof of malignancy.

Of the total number of forty-nine cases, there were seventeen in which death occurred as the result of the operation itself. 'This gives us a mortality of thirty-four per cent., a distinct improvement upon the sixty per cent. of the earlier series. Kocher's figures alone, which show six deaths among eighteen patients, indicate a great improvement upon the results of his earlier operations. 'They may be taken as representing the best results that can be obtained at the present day when the operation is undertaken by a surgeon who is especially experienced in this branch of surgery and who does not refuse to operate upon tumours that have already gone beyond the limits of the gland itself. It is the presence of severe complications that makes the

* Cramer, Frank, Petrakides, Buschi, Berry. Jones and Battle, Lentz, Allen Davis, Stonham, Ewald, Orcel, and Kummer. 
operation so fatal in itself and which causes its mortality to be so very much greater than that of operations for innocent goitre. Kocher's own remarks upon this subject are well worth quoting. Speaking in 1898 of the relatively high mortality in his series of eighteen cases, he says :

"It is not the goitre operation in itself which leads to the fatal result, but the severe complications which the resection of neighbouring structures brings with it. In most cases it is necessary in removing a malignant goitre to excise at the same time portions of the trachea or cesophagus, or even the whole of these structures as far as they lie in the neck. Quite common in these operations are resections of the great vessels of the neck, most often the internal jugular vein, occasionally also the carotid. Important nerves too, such as the vagus and sympathetic, must in many cases be wounded or resected. When these severe complications are taken into account, the healing of the wound in two-thirds of all cases of malignant goitre may be considered to be a comparatively favourable result, since the end of such patients, if they do not undergo any operation, is usually preceded by great suffering and distress, either from dysphagia or extreme dyspnoea. It is to be wished that every doctor could be brought face to face with such patients in the later stages of their malady, so that he might thoroughly appreciate the necessity of an early diagnosis and timely operative interference... Every goitre in an adult, and especially in an elderly person, that enlarges without obvious cause, should raise a suspicion of malignancy, even thongh it cause no pain or other trouble; and if at the same time the goitre becomes harder and irregular, and symptoms of increasing distress set in, then the diagnosis becomes almost certain."

We may turn now to the ultimate results of the operation. From the thirty-two patients that recovered from the operation we must unfortunately deduct twelve cases of Kocher's, since with regard to them no information has yet, so far as I can learn, been published. We must also deduct six other cases of which there was no history for more than, at most, four months.

We are left therefore with the comparatively small number of fourteen eases; of these no less than eleven either died within a year or were known to have recurrence. Three only were known to have survived and to be free from recurrence for a 
period of three years and two months, two years and seven months and eight months respectively-truly, not a very encouraging list.

The three cases were:

(1) A man from whom in May 1889 the left lobe of the thyroid was extirpated on account of round-celled sarcoma. When examined in July 1892, this patient showed no signs whatever of recurrence and appeared to be in fairly good health, although suffering to some extent from thyroidal atrophy, symptoms of which had indeed been present before the operation. (Sulzer.)

(2) A boy aged 10 in whom a "hyperplastic" goitre was supposed to have become sarcomatous; there was slight dyspnœa. In July 1885 , the tumour, which contained numerous cysts with hæmorrhagic contents (surely an unusual form of malignant disease!), was removed by what seems to have been an atypical enucleation operation. In February 1888, there was no recurrence and he seems to have been quite well. (Hochgesand.)

(3) A woman aged 54 with a left-sided "malignant" goitre as large as a fist. There was much dyspnoea and dysphagia. In June 1887 the tumour was extirpated, the oesophagus being opened in the course of the operation. Five weeks later œsophagotomy was successfully performed for the closure of the fistulous opening that was present. The patient made a good recovery, and in February 1888 was reported to be in good health. (Hochgesand.)

In neither of the two last cases is it stated that any microscopical examination of the tumour was made.

'The results of the operations in the two series of cases, those collected by Rotter and by myself, are shown in the following tabular form. The two cases in which the operation was not completed have been omitted from Rotter's series of fifty cases, and the whole of Kocher's cases from the second series. 
Earlier series before 1889 . Later series.

Died of the operation $\quad \ldots \quad \ldots \quad 30(62$ p.c.) 11 (35 p.c.)

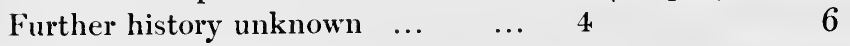

Known to have had recurrence or to

have died within a year $\quad \ldots \quad 10$

Known to have survived without recurrence for periods varying from eight months to two years and a half

… $\quad \ldots \quad \ldots$

Known to have survived without rerecurrence for more than three years

$\begin{array}{lll}\cdots & \cdots & 1 \\ \text { Totals } & & 48\end{array}$

'The statistics given above show clearly that in the vast majority of cases the operation as usually performed does not result in a cure. It is much to be regretted that we have at present no reliable statistical information as to the results of operations undertaken in the early stages only, that is before the penetration of the capsule has occurred.

'These are the cases in which we might reasonably hope that the operation would be of much benefit to the patient.

Cases in which a long period of immunity has followed an operation undertaken at this early stage are occasionally seen.

In the Philadelphia Amuals of Surgery (1893, p. 554) is an account of a discussion which took place at the New York surgical Society in May of that year on a case of malignant goitre. Dr. F. Kanmerer was reported to have then said that "of sereral total extirpations for malignant disease he recalled two in which the growth had not perforated the capsule. One was a very large cancerous thyroid and there was no recurrence after extirpation for four years, when recurrence did take place, and it ran a rapid and fatal course. In another case in which the diagnosis was established without doubt, the patient is still living without any recurrence seven or eight years after total extirpation."

'These remarks, if confirmed, seemed to me to be of such importance that I wrote to Dr. Kammerer asking for further information with which he very kindly supplied me. It appeared, then, that the first case was one of Maas's, already men- 
tioned among Rotter's cases. It is sad to think that the best case of all in this series should eventually have died of recurrence. It is some satisfaction, however, to know that a patient can live without recurrence for as much as four years after the removal of a goitre, the malignant nature of which is established without doubt.

The other case that Kammerer had seen is still more important, as it shows that a patient may survive the operation for a period of not less than eleven years. It is that of a gentleman operated on by Kocher in or before the year 1885. 'The exact date of the operation I have unfortunately not succeeded in obtaining, but it appears to be quite certain that it was not later than 1885, and was probably somewhat earlier. In 1893 this patient was operated upon for the first recurrence by Dr. Lange of New York, under whose care he remained during the next three years. 'Tracheotomy was eventually performed and a long canula inserted. Extensive recurrences took place and the patient died in August 1896, having survived the first operation for a period of at least eleven years. Dr. Kammerer tells me that Kocher had stated that the tumour removed at the first operation was malignant. With regard to the nature of the recurrent tumour I have a report from Dr. Schwyzer, pathologist to the German Hospital, New York, who made the post-mortem examination, and who states that the tumour was a "tubular carcinoma with much interstitial connective tissue."

The tumours known under the names of papilliferous cyst and papilliferous cystic adenoma form a class of malignant tumours that stand somewhat apart from the ordinary carcinoma and sarcoma. They are much less malignant. 'They grow slowly and exhibit much less tendency either to infiltrate locally or to disseminate. In these respects they are analogous to the papilliferous cystoma of the ovary, which they closely resemble. 'The patients are much less liable to speedy recurrence after operation. In Barker's case, already mentioned, the tumour had been growing. for eight years before the first operation was performed. Death did not occur till ten years later still. Berger records the case of a woman aged twenty-six in whom a large tumour of this nature had been growing for six years. It was then removed with some difficulty owing to its intimate adhesions with the 
internal jugular vein ; eight months later this patient was well and had had no recurrence. Wölfler cites from Billroth's practice the case of a woman aged twenty-three in whom the tumour at the time of operation occupied a large part of the neck. It had been growing for one year. 'Two years after the operation no recurrence had taken place.

Palliative Treatment.-Although radical and curative treatment of malignant disease of the thyroid is in most cases impracticable, yet something can be done for these unfortunate patients by palliative treatment.

A partial removal of the disease will occasionally afford relief for a time, especially from the dyspnoea. As the operation is intended only to relieve symptoms, it should not be done until these symptoms are already sufficiently severe to cause considerable distress. Partial and incomplete removal of the disease does nothing to check the progress of the disease itself and, if undertaken too soon, may easily make the patient worse than before. It should seldom be performed unless there is a reasonable prospect that the external wound will heal. It is chiefly useful when a mass of growth is pressing injuriously upon the trachea. Any incision into the growth is apt to lead to fungation into the wound, and if the latter become septic, a contingency often difficult to avoid, the operation may do more harm than good.

The following case is one in which a partial extirpation afforded considerable temporary relief.

Mrs. Fanny $\mathrm{M}$, wt. 50, was admitted into the Royal Free Hospital under my care on July 7 , 1900, suffering from dyspnoea, dysphagia, and a tumour of the thyroid gland.

In September 1899 she had first noticed a swelling of the neck. 'This gradually increased in size and caused her a good deal of pain in the shoulder and neck. In February 1900 she was admitted to King's College Hospital, and on March 1 underwent there an operation for the removal of the tumour. At this time the tumour was hard and irregular and involved both lobes of the gland. It moved with the larynx on deglutition. The growth was found to be a sarcoma. The wound healed quickly, the patient soon left the hospital and was much relieved by the operation. A week or two later recurrence was noticed in the neighbourhood of 
the scar. For three months, however, she remained fairly well. Towards the middle of June dyspnœa and dysphagia again became very troublesome, and for these symptoms she came under my care. At this time the thyroid gland was found to he much enlarged, each lobe being as large as a goose's egg. It was very hard and much fixed. The tumour was very deeply seated, lying largely behind the sternum. There was great dyspnoea with much stridor, and the patient was in great distress. The vocal cords however were still unaffected. On July 14, a palliative operation was undertaken with the view of removing that portion of the tumour that lay behind the sternum, and that was evidently pressing seriously upon the trachea. No hope was held out of performing a complete removal of the disease. A mass of growth as large as an apple and weighing four ounces was removed from the root of the neck and superior mediastinum. The operation presented no special difficulty and bleeding was not excessive. The trachea was found to be greatly compressed but not actually infiltrated. The growth on the left side was extensively adherent to the internal jugular vein, pharynx and œesophagus, and no attempt was made to remove this portion of it. As before, the wound healed by first intention, and on July 25, the patient returned to her home in the country, breathing freely and much relieved. In September the patient came up to see me again. She was breathing comfortably and her general condition was fairly good. She could swallow liquids without trouble, but not solids. Two months later however very severe attacks of dyspnœa occurred and she was re-admitted much exhausted from dyspnoea, pain and recurrence of growth. Tracheotomy was performed in November, a Koenig's canula being inserted. This gave her temporary relief. On November 12, 1900 she died rather suddenly, apparently from exhaustion from the disease and without having had any return of dyspnoea.

The post-mortem examination showed very extensive disease of both lobes. The growth extended downwards to the first ribs and apices of the lungs. Behind the trachea it formed a firm dense plate more than an inch thick, completely surrounding the cesophagus. (See Fig. 78, p. 203, and case 113, p. 352.) There were no secondary growths. Microscopical examination showed spindle-celled sarcoma.

A simple incision down to or into a goitre that is the seat of irremovable malignant disease will occasionally relieve the dyspnoea. This is effected doubtless by causing shrinking of the non-malignant portions of the goitre. This operation has 
been practised for malignant disease more often in France than elsewhere.* Mr. George 'Turner has recorded an interesting case in which he had to perform tracheotomy for a malignant goitre. 'The operation caused almost complete disappearance of all swelling in the neck. So remarkable was this disappearance that the correctness of the diagnosis was questioned. But a subsequent recurrence of the growth placed its malignant nature beyond dispute. $\dagger$

Tracheotomy often affords the only means open to us of alleviating the dyspnoea from which these unfortunate patients suffer. As a rule it should be performed only when the dyspnœa has become a source of considerable distress to the patient. Occasionally it may be performed early, if there are any indications that redema of the glottis is likely to supervene. It should be remembered that this complication may occur without much warning and may rapidly prove fatal if not relieved by a timely tracheotomy.

The difficulties of a tracheotomy may be considerable. If the growth is not large and does not displace or cover up the trachea, then the operation is generally easy to perform. 'The close proximity of the growth however is apt to cause enlargements of the veins of the neck and this may render the operation difficult. 'The trachea may be so much displaced that the incision has to be made far away from the middle line. Thus in the case depicted in Fig. $7 \%$ I had to make the skin incision nearly an inch and a half to the right of the middle line. In another case in which, some years ago, I helped my friend Mr. stanley Boyd at a tracheotomy for a sarcoma of the thyroid, the incision had to be made equally far out on the left side of the neck.

It should be borne in mind that when the trachea is much displaced its relation to the carotid becomes seriously altered. In both these cases the trachea had been pushed outwards under the carotid artery. The tracheotomy was done just below the aricoid. Had it been done lower down the carotid would have been encountered, since it was found, when the patients eventually

* S.e Alenot. " Liberation longitudinale do la trachée comme traitement

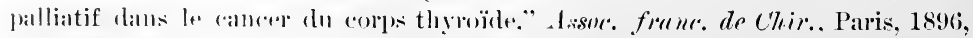
x. 1.. 32011.

† Tran. Clin. str.. Lomrlon, 1s90, xxiii. p. 226 . 
died, that it lay directly in front of the trachea, more than an inch above the sternum.

Frequently the tracheotomy has to be done directly through the growth if the latter covers the front of the trachea; or, as in a recent case of my own, it may be necessary to remove some portion of the growth in order to reach the trachea. Sometimes the tracheotomy can be done above the growth, rarely is it possible to do it below the tumour.

The difficulty of finding the trachea, imbedded as it may be in a mass of hard growth and much distorted and flattened, is often very great. An ordinary tracheotomy tube is frequently not long enough to reach the trachea or to pass beyond the lowest point of constriction. 'The long flexible silver tube of Koenig I have found useful in such cases (see Fig. 85). If this is not at hand a flexible catheter may be used as a substitute.

Tracheotomy does not usually prolong the patient's life for more than a few weeks at most, but it may add considerably to his comfort. If the growth has been incised, as it probably has been in the performance of the operation, then septic changes are apt to occur sooner or later in the tumour. Bronchitis, pneumonia or other septic pulmonary troubles are frequently theimmediatecause of death.

In the case of some slow-growing malignant tumours the duration of life after the tracheotomy may be much longer, especially if it has been possible to avoid cutting into the growth itself. Sir Felix Semon has recorded a very remarkable case of a lady aged 52 , upon whom he performed a low tracheotomy a few weeks after the first symptoms of the disease had been noticed. She survived the operation 
more than two years. In this case, however, the amount of dyspnoea at the time of operation does not seem to have been very great. The case was in other respects, too, a very unusual one.*

If dysphagia be a marked symptom, as it often is, special means may have to be taken to feed the patient. This is best effected by means of an resophageal tube. Gastrostomy even has been performed in such a case.

Finally, morphia and other sedatives may have to be administered freely in the later stages of this most distressing and painful disease.

Conclusions. - Theoperation for removal of the ordinary forms of malignant disease of the thyroid gland, unless performed at a very early stage of the disease, is attended by a high mortality from the operation itself.

The danger lies chiefly in the involvement of important neighbouring structures, portions of which must often be cut away if the primary disease is to be thoroughly removed.

The diagnosis of the earlier stages of the disease is not easy and it is especially difficult to say with certainty that the trachea and pharynx are not already involved.

If the disease has not already penetrated the glandular capsule, the operation is not particularly difficult or dangerous, if the dissection is performed carefully and with due regard to the anatomical relations of the parts.

Recurrence after operation is usually local and due to incomplete removal of the primary disease.

In the later stages of the disease secondary deposits are likely to be found in the lungs and bones.

'There are certain forms of slow growing malignant disease such as the papilliferous cyst, in which the tendency to local and general malignancy is but slight and in which treatment by operation affords satisfactory results, even when the tumour has attained a very large size.

In the majority of cases of malignant disease of the thyroid, the only treatment that can be adopted is but palliative, and consists chiefly in relieving the patient from dyspnoea, dysphagia and pain.

* .. A Case of Malignant Disease of the Thyroid Gland with most unusual course," Med. Chlir. Trans., 1892-3, lxxvi. p. 375 . 


\section{CHAP'TER XIV.}

TREATMEN'T OF INNOCENT GOITRE-NON-OPERATIVE.

General-Removal of cause-Medicinal-Iodine-Thyroid extract -Other drugs-Cases suitable for-Local-External applicationsIndian method.

TyE non-operative measures that may be adopted for the treatment of innocent goitre may be classified as follows :(1) General ; (2) Medicinal; (3) Local.

(1) General.-It is obvious that if the cause of goitre be known, the patient should, as far as possible, be removed from its influence. This is especially important in the early stages of the parenchymatous form. 'Tumours of the gland, such as cysts or adenomata, although they may have originated in a gland that was the seat of parenchymatous enlargement, are not likely to be influenced in their course by the removal of the original cause. Goitres in which other secondary changes, such as fibrosis and calcification, have occurred, are naturally not amenable to any such treatment.

But in the case of early parenchymatous goitres, care should be taken to remove, if possible, the cause of the disease. If the patient be living in a district where goitre abounds, it is well that he should, if possible, remove to a district where the disease is not prevalent.* When such removal is not convenient or possible, as is generally the case, then particular attention should be paid to the drinking-water, since this is, in the great majority of cases, the cause of the affection. So long as we are ignorant of the exact nature of the poison that produces goitre, it is difficult to say definitely how the drinking-water should be

* I have known several instances in which young girls had been sent to school in a goitrous district and had there developed the disease. Upon leaving the district the goitre disappeared spontaneonsly. 
treated, in order to render it innocuous from this point of view. It is well in most instances, however, to recommend that water suspected of being the cause of goitre should not be drunk without previous filtration and boiling.*

As a general rule it may be stated that the younger the patient and the smaller the goitre, the more likely is a cure to be affected by such measures as removal from the affected district or by alteration of the drinking-water.

(2) Medicinal.-Numerous medicinal remedies have been employed for the treatment of goitre. By far the most important are iodine and its various preparations, and thyroid extract, thyroidin, and the other preparations of the thyroid. gland itself. For parenchymatous goitre I usually recommend about five minims of the tincture of iodine together with four or five grains of iodide of potassium, the doses being gradually increased until the patient is taking three or four times as much. For the iodine treatment to be efficacious, it is desirable that the drug be administered in sufficiently large doses. Care should be taken, however, to diminish or stop the administration if symptoms of iodism are produced or if the digestion be upset. If iodine in full doses does not produce a marked diminution in the size of the goitre in the course of two or three weeks, it is not likely that it will be of much use.

The preparations of thyroid gland are also extremely useful in the treatment of parenchymatous goitre. I have sometimes found thyroid extract useful in cases that have not yielded to iodine and vice versa. As thyroid extract is a potent and sometimes even dangerous drug, it is well to be cautious in its administration and to begin with small doses.

Arsenic, mercury, strychnia, and various other drugs have been recommended, and have sometimes appeared to me to be of use.

Medicinal treatment is most efficacious in the case of general enlargement of the gland, that is, of parenchymatous goitre. Upon encapsuled adenomata it has little or no influence, and for cysts it is equally useless. Many cases, however, of parenchymatous goitre do not yield at all to medicinal treatment.

The following case may be cited as an illustration of the use of iodine and thyroid extract in parenchymatous goitre:-

\footnotetext{
* See Lustig and Carle's experiments, pp. 68, 69.
} 
Alfred A-, at. 17, came under my care at St. Bartholomew's Hospital in January 1900, on account of dyspnœa and enlargement of the thyroid gland. The thyroid swelling had been first noticed eighteen months previously and had been gradually increasing in size. It had caused difficulty in breathing, especially at night and on exertion.

The patient was a deaf mute, somewhat mentally deficient, but not showing any signs of cretinism. He was found to have a large bilateral, nearly symmetrical, goitre. Each lateral lobe was as big as a goose's egg; the right was slightly larger than the left. The gland was moderately firm, slightly nodular, and moved freely with the larynx. There was a moderate amount of tracheal stridor.

The diagnosis was parenchymatous goitre, with perhaps a few adenomata deeply buried in it.

Tr. Iodi $m v$. and Pot. Iod. gr.iv. were given three times a day with a tabloid of thyroid extract ( $\left.\mathrm{gr} \cdot \frac{1}{2}\right)$ every other day. The dose of each drug was increased every week. This treatment was begun early in January. By the end of the month the goitre had diminished to half its original size and was much softer. All dyspnoea had disappeared. The administration of thyroid extract was now discontinued and the doses of the other drugs increased to $m$ xii. of Tr. Iodi and gr.xi. of l'otassium Iodide. By the end of February the general swelling of the gland had almost disappeared, but at the lower part of the right lobe a rounded firm tumour as large as a marble could be felt very easily. This was evidently a cyst or an adenoma. As it caused no trouble no further treatment seemed necessary.

(3) Local.-A common and often useful method of treating parenchymatous goitre consists in painting the neck with tincture or liniment of iodine, or in rubbing the swelling with ointments of iodine or mercury.

It is possible that the mechanical pressure may also do some good by favouring the absorption of the accumulated colloid. Violent rubbing should, however, be avoided, as it is apt to damage the softened gland and to lead to extravasation of blood within its substance.

I have occasionally endeavoured to diminish the size of a soft parenchymatous goitre by continuous gentle pressure applied by means of a broad elastic band, but without very satisfactory results.

The Indian method consists in smearing the goitre thickly 
with biniodide of mercury ointment and then exposing the patient's neck to the rays of a hot sun. The treatment is said to be very successful in India, but in this country, where the rays of the sun are less powerful, the beneficial effects are not so marked. I have been informed by surgeons who have employed this method in India that the patients are exposed to the sun for an hour or more, and that the ointment has to be well rubbed into the neck. The result is that the neck is terribly blistered, but the goitre is frequently eured.

I have tried to imitate this Indian process by making the patient sit for an hour or more at a time with the face covered and the neck exposed before a very hot fire. But I cannot say that I have met with much success. 


\title{
CHAP'TER XV.
}

\section{TREATMENT BY TAPPING-INJECTION_INCISION- SETON-LIGATURE OF THYROID ARTERIES- EXOTHYROPEXY.}

\begin{abstract}
Tapping : For cystic goitre-Occasionally cures-Risks of-Hæmolrhage. Injection: Of parenchymatous goitre-Directions-RisksFatal cases-Of cystic goitre-Directions-Risks-Results. Incision : Rarely desirable-Cases suitable for. Seton: Dangers of. Ligature of thyroid arteries; Historical-Recent revival-Methods of operating. Exothyropexy : Historical-Objects of-Objections -Methods of operating-Results-Complications-Mortality.
\end{abstract}

Tapping.-Like most other cystic tumours, those of the thyroid are frequently submitted to the operation of simple tapping with a trocar and canula. The object of this proceeding is, of course, to empty the cyst, and so to cause its collapse and cure. In many cases this result does really take place, and the cure may be permanent. Not uncommonly, however, a much less favourable result ensues. 'The cyst rapidly fills again, this time usually with blood, and the patient's condition may be worse than it was before, especially if the cyst be large. 'This remarkable tendency to intra-cystic hremorrhage on the part of thyroid cysts has already been mentioned in the chapter on cystic disease, and several cases have there been related in which serious and even fatal results have followed a simple tapping. The occurrence of serious harm may to some extent be obviated by keeping up a certain amount of gentle pressure upon the cyst during and after the tapping, so as to prevent the sudden diminution of intra-cystic tension. It must be borne in mind, however, that it is often difficult to apply satisfactory pressure to the soft yielding structures of the neck.

For single cysts of small size in which the walls appear to be thin, the operation of tapping may be occasionally performed; but 
if the cyst be multilocular, or if it have thick unyielding walls which cannot collapse, or if the contents be solid, then tapping should not be attempted, as it is almost certain to fail.

It is occasionally advisable to tap a thyroid tumour for diagnostic purposes, to see whether the contents be cystic or solid.

For parenchymatous goitres, where no cysts of large size are present, a simple tapping is naturally of no use, since the viscid contents of the minute intercommunicating vesicles drain away very slowly. If, however, the canula be left in situ for several days after the operation, a considerable decrease in the size of the goitre may occasionally be observed. But this proceeding is obviously not without dainger, as it is likely to set up suppuration. It should not be attempted without due consideration of its risks.

In any case in which tapping is performed the strictest attention should be paid to asepsis.

'Tapping of a goitre of any kind is a proceeding which, in $\mathrm{my}$ opinion, should rarely, if erer, be adopted.

Injection.- The object which is aimed at in the injection of a goitre is to cause sufficient inflammation to obliterate some of the minute vesicles of a parenchymatous goitre or the larger cysts of a cystic goitre. Possibly, also, there is some direct solvent action upon the colloid contents of the resicles, which may promote absorption.

It is obvious, therefore, that parenchymatous and eystic goitres are more amenable to treatment by injection than are the harder and more solid forms. It has often been stated that "fibrous" goitres can be treated with advantage by injection, but it may reasonably be doubted whether this is really the case. 'Truly fibrous goitres are by no means so common as is generally supposed.

Many of the very hard goitres which I have often seen diagnosed as fibrous goitres proved eventually to be parenchymatous or cystic-parenchymatous. 'The hardness in such cases is due to the tension of the fluid within the small vesicles, or to the solidification of the contents themselves. This is probably the true explanation of the benefit that has been supposed to result from injecting so-called fibrous goitres. 
The materials that have been used for injection are numerous. The one which occupies the foremost rank is undoubtedly iodine. 'This may be used either in the form of simple tincture or in combination with other drugs.

Arsenical solutions, perchloride of iron, ergot, osmic acid, and iodoform have all been recommended, but probably not one of them is superior to iodine.

Method of performing Injection in Cases of Parenchymatous Goitre.-The best directions that I have seen for the performance of the injection of iodine into parenchymatous goitres are those given by Sir Felix Semon, who has written as follows :

1. Select suitable cases only, i.e., cases in which the gland substance is so thick that one may be fairly certain that the injection can be made into the parenchyma proper and in which, on the other hand, the interstitial fibroid change has not progressed too far.

2. Inject every third day into the gland substance proper a quantity from twenty to thirty drops of an alcoholic iodine solution (one part of iodine in twelve parts of absolute alcohol) with a wellmade and well-cleaned hypodermic and screw syringe.

3. Vary as much as possible the place of injection and never inject into the same neighbourhood on two consecutive occasions.

4. Avoid wounding superficial veins and injecting air. A piece of tape may be tied round the neck below the tumour so as to compress the superficial veins.

5. Neither insert the point of the needle too timidly, when the injection fluid will very likely pass into the cellular tissue, suppuration resulting; nor too violently, when it may completely perforate the gland and the injected fluid may be thrown into other important tissues. It is a good plan to let the patient swallow when the needle has been inserted, before the injection is proceeded with, the body of the syringe being held quite loosely in the operator's hand; if the point of the needle is in the gland substance the foremost point of the syringe will rise with the rising gland ; if it be in front of the gland no movement will ensue; if it have perforated the gland the hindermost part of the syringe will chiefly rise.

6. Never inject in such a direction that the point of the needle points directly towards the trachea or towards the great vessels and nerves of the neck.

7. Inject very slowly and watch especially the effect of the injection of the first few drops. Select the place of injection care- 
fully beforehand by palpation and steady the tumour with the left hand whilst making the injection. Previous freezing of the surface with anæsthetic ether* round the point selected for injection may be resorted to, but is not necessary.

'That the directions given above are excellent, there can, I think, be little doubt; and any one who is about to treat a goitre by injection of iodine cannot do better than follow them.

There can also be but little doubt that in a large number of (ases, a successful result ensues, at any rate, for a time. 'There is, however, equally little doubt that very often the treatment is unsuccessful. A considerable number of cases have been recorded in which various complications, including death itself, have followed the operation.

The injection may, and in most cases probably does, at first produce increased swelling of the gland. This may cause dyspnoed or aggravate that which is already present. The injection may cause suppuration, which in its turn may lead to death.

Obalinski relates the case of a man who had a large goitre; a single injection of iodine caused suppuration, together with such increase in the size of the tumour that it was deemed necessary to remove part of it. The man died of pyamia on the tenth day.

Liebrecht relates a case which occurred in the practice of 1)r. Albert of Innsbriick; injections of iodine into the goitre led to suppuration and other severe symptoms; the tumour was removed but the patient succumbed.

Instances such as the above are numerous, and, were it necessary, many more might be cited here.

In the above cases the evil results were due to inflammation and suppuration occurring in the neck.

A considerable number of cases have, however, been recorded in which death ensued much more speedily, before suppuration had had time to manifest itself.

Dr: Rose, formerly of Ziurich, says that he himself knows of

* This was written before the introduction of cocaine and eucaine as local anesthetics; at the present day these would be preferred.

$\dagger$ '. Der Kropftod und die Radicalcur der Kröpfe,", Archir f. Klin. Chir. vol. xxii. 
not less than six cases in which surgeons have lost healthy patients from injection of iodine into a goitre, death occurring either upon the operating table or within a few hours of the injection.

Dr. Johannes Seitz, ${ }^{*}$ in a monograph upon death from goitre, mentions the following cases:

The first is that of a woman under the care of Dr. Schwalbe ; the injection of ten drops of tincture of iodine into a small goitre caused after a few minutes numbness and then paralysis of the left arm and leg, partial loss of speech, slight facial paralysis, general convulsions and death at the end of twenty hours. No post-mortem examination was made. After this case Dr. Schwalbe gave up the use of iodine injections and employed alcohol instead.

The next case is that of a young woman into whose goitre iodine had many times been injected; after the last injection she took violent exercise for some hours; the tumour then began to cause great pain; the goitre became greatly swollen, and in three days the patient was dead.

The third case occurred in the practice of Dr. K. St—. The patient was a woman of 27 , the goitre was as large as a small apple, moderately hard, and affecting the right lobe of the gland. A common Pravaz syringe of small size was three-quarters filled with tincture of iodine, and the injection made in the ordinary manner. Immediately after the injection the patient complained of pain in the right eye. She then began to sway about in her chair, and quickly lost all power of speech. 'The right upper and lower eyelids became cedematous, and the right eye appeared to be pushed forwards. In the right half of the face appeared several blue spots, which increased in size until death occurred. In the first half-hour she was very restless, then became more quiet; the breathing was quiet and regular, the pulse rather slow ( 48 to 50 ). The pupils were natural, and there was no facial paralysis. The patient remained in the above condition for about three hours; then the pulse became much more rapid, and breathing became deeper and irregular Death occurred eight hours after the injection. $\uparrow$

The post-mortem examination was unsatisfactory. In the vessels of the brain and its membranes no thrombosis or embolism was

* . Der Kropftod durch Stimmbandlähmumg," Langenbeck's Arrlir f. lilin. Chir. xxix. 1.

$\dagger$ Dr. K. St. — alludes to another case which appears to have occurred at Berne and in which similar symptoms oceurred; no particulars, however, are given. 
found; on section the right side of the brain showed numerous bloody points; the choroid plexus was of a darker colour than natural. Several ounces of serous fluid were found in the pleural and pericardial cavities. The goitre was chiefly parenchymatous, but contained also a small cyst, of the size of a hazel nut, in the posterior wall of which was a large vein, into which it seemed possible that the iodine had been injected. Chemical examination of the contents of the cyst showed no iodine to be present.

In 1884, 1)r. Krieg* related to the Medical Society of Stuttgard, a case in which sudden death had followed the injection of two drops of tincture of iodine into a goitre:

The patient was a cretinous girl, aged fifteen. Dyspnoea had been present for many years, but had increased considerably in the last fortnight. Two drops of tincture of iodine were injected into the middle of the goitre and the syringe withdrawn. In less than a minute the dyspnoea became much more severe, and the right side of the neck began to swell. The child became livid, lost consciousness, and in two minutes was dead.

At the post-mortem examination it was found that the goitre consisted of a nodule as large as a hen's egg, involving the right lobe of the thyroid gland. The injection had been made quite correctly into the centre of it. The small wound made by the syringe had led, however, to considerable hæmorrhage into the tismes between the tumour and its capsule. The extravasated blood, pressing upon the already much narrowed trachea, and upon other surrounding structures, had been sufficient to cause death. The trachea opposite its second, third and fourth rings was so narrow that its walls were almost in contact. It was found, however, that this extreme narrowing was dne, not merely to the pressure of the goitre, but also to the presence of a firm papillomatous fibrous tumour, which grew from the left wall of the trachea and filled up more than half its lumen.

These cases show pretty clearly that injection of iodine into a parenchymatous or adenomatous goitre, is an operation by no means devoid of danger, even when performed carefully, and when only a small quantity of fluid is injected, as in Krieg's case.

* .. Plötzlicher Tod durch parenchymatöse Injection von Iodtinctur in einen

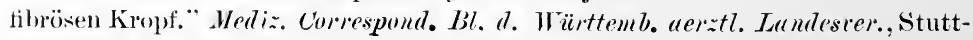
gard, 1884 , liv, 1p. 145-149. 
Professor v. Mosetig-Moorhof* advocates the injection of a solution of iodoform for the treatment of soft parenchymatous goitres. Formerly he used tincture of iodine but this caused suppuration in one of his cases. He, therefore, gave up the use of it and used, instead, one of the following solutions :

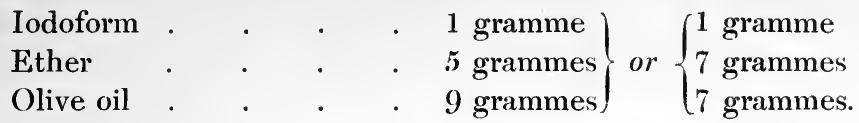

The solution should be freshly prepared,and is then of a light yellow colour and transparent. On exposure to light it is apt to become brown from liberation of free iodine, and should not then be used. It should therefore be kept in the dark when not required for use. v. Mosetig-Moorhof injects one gramme (15 minims) or more at a time, and usually makes from five to ten injections in each case. The reaction after each injection is usually very slight and does not prevent the patients from following their ordinary occupations.

He has performed, altogether, some 400 injections upon seventy-nine patients, and says that he has always succeeded in reducing the size of the swelling. He has never had any bad result. He recommends this treatment only for soft parenchymatous goitres, and not for the fibrous, cystic, or any other kind.

Injection of Cystic Goitre.-For the injection of cystic goitre, iodine has been largely employed. It is open to the same objections that have been mentioned in connection with the injection of parenchymatous goitre. 'The use of perchloride of iron, instead of iodine, has been recommended for cystic goitre, and is often employed. The chief advantage of employing perchloride of iron is that hemorrhage is more readily checked. The injection of perchloride of iron has been especially advocated in England by Sir Morell Mackenzie, $†$ and as his description of the method is the best with which I am acquainted, the directions that he gives may be quoted here:

"The cyst is first punctured and emptied with a trocar at its most dependent part, a drachm or two of the solution of perchloride

* Wiener Med. Presse, 1890, xxxi. p. 1.

$\dagger$ Heath's "Dict. of Surgery," Art. Diseases of Thyroid Gland. 
of iron* is then injected, the canula with its plug and the iron solution being left in the cyst. After twenty-four hours the plug is removed, and the contents of the cyst withdrawn. If the fluid be then found to contain much blood, or if it be thin and serous in appearance, a second injection must be made. In other words, while hæmorrhage must be carefully prevented, a slight inflammation of the lining membrane of the cyst is essential. One injection is generally sufficient, but if the first injection fluid be too quickly removed, the process may have to be repeated three or four times at intervals of two or three days. When reaction has taken place and the discharge is free from blood, the canula with its plug must still be kept in the cyst. Poultices of linseed meal should be kept constantly applied for three or four weeks, sometimes longer. When suppuration is well set up the plug may be removed; the canula, however, being allowed to remain until the secretions become limited in amount and thin in consistence. When the cyst is very large it is best to try to reduce the quantity of fluid before injecting. This can often be done by drawing off a small amount, say two or three drachms, at intervals of a day or two on several occasions. No attempt must, however, be made to empty the sac entirely, for if this is done hæmorrhage takes place from the lining membrane of the cyst into its cavity, which soon becomes full again. The duration of the treatment is from three weeks to four months, according to the size of the cyst, the usual time being six to eight weeks."

'Those who desire further information concerning the details of Mackenzie's method of treating thyroid cysts will do well to read a paper by Mr. Mark Hovell on the treatment of cystic goitre. $†$

I have never employed this method myself, as I consider it to be too dangerous. Suppuration appears to be a necessary part of the curative process, and having been once started, may be very difficult to control. It is very apt to lead to death from septic absorption. 'The dangers of suppurating goitre are, however, too well known to require further comment.

Although there can be no doubt that this method does, in many cases, effect a cure, yet there is equally little doubt that it often fails. Either the patient is left with a fistula or the tumour returns after a while. A more or less permarent fistula

* A watery 25 per cent. solution of perchloride of iron is used.

† Lancet, 1888, p. 264. 
is especially likely to be produced if the walls of the cyst be firm and unyielding. Of this $I$ have seen several distressing examples. (Fig. 86.)

Another objection to injecting encapsuled thyroid tumours is that if the injection fails to cure, and enucleation becomes necessary, the latter operation may be rendered more difficult owing to the adhesions set up round the tumour. Some of the most troublesome enucleations that I have had to perform have been in cases in which injection had previously been performed. Nevertheless, the method has its advantages. It is simple and requires no great knowledge of aseptic surgery for its performance. Moreover, if successful, the scar that is left may be much smaller than

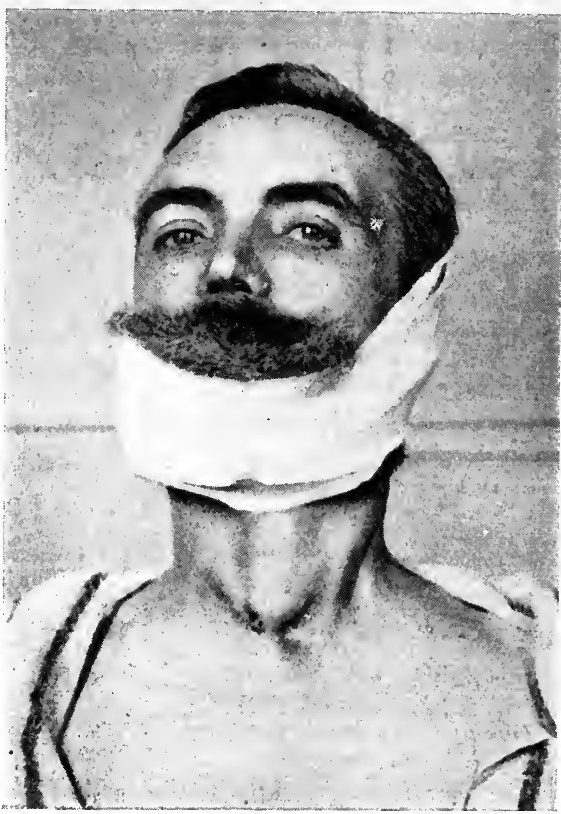

Fic. 86.-A man in whom a cystic goitre had been tapped aud injected some years previously (at another hospital). A fistnlons opening had existed ever since the operation. (Seen at St. Bart. Hosp. in 1886.)

that produced by any cutting operation.

At the present day this method of treating thyroid cysts is employed chiefly by those who are not familiar with the details of modern aseptic surgery, and upon those who, being exceedingly anxious to avoid a linear scar, are willing to incur a greater risk in order to attain this object.

Incision.-Direct incision of a goitre is a method employed chiefly in cases of cysts and is of very limited applicability. The practice of incising thyroid cysts, and stitching their cut edges to those of the skin, is one which has now been almost entirely superseded by the much safer and more rapid method 
of enucleation. It is still, however, to be recommended for certain cases in which, from old or recent inflammation or other cause, the cyst is too adherent to surrounding parts to permit of enucleation. Some cases of suppurating goitre have to be treated, at any rate at first, by incision. Enucleation or extirpation may have to be undertaken later.

Incision of the isthmus as a means of treating parenchymatous goitre will be discussed separately in the next chapter.

Seton.-A method of treatment of goitre formerly much in vogue, but now happily becoming obsolete, is that of the introduction of a seton. A piece of silk or some similar material is passed right through the substance of the goitre and left in situ for days or weeks. Usually the goitre shrinks in size and may become permanently cured.

This method is obviously open to two serious objections.

First, there is considerable danger of transfixing some large vein and thus causing serious or fatal hæmorrhage.

Secondly, there is very serious risk of setting up septic inflammation in the goitre, and in the cellular tissue of the neck, and this, in its turn, is very likely to lead to pyæmia.

A case, illustrating this latter danger, has been kindly communicated to me by Dr. Bankart of Exeter :

A young man had a goitre, probably parenchymatous in nature, into which a seton was inserted on account of the dyspnœea from which he was suffering. Suppuration in the neck and mediastinum quickly ensued; necrosis of several rings of the trachea took place and the patient died.

In the museum of the Royal College of Surgeons is a specimen * of a thyroid cyst some three inches in diameter. "A seton introduced through the cyst by the surgeon in attendance caused diffuse inflammation, resulting in the death of the patient."

There is also a similar specimen in the museum of St. George's Hospital. $†$

A seton is probably more efficacious in the case of a cystic goitre than in that of a parenchymatous one. In the former case, the fluid would be drained away by the side of the seton.

$*$ No. 2904 .

$\dagger$ No. 20A. 
The method is, however, too dangerous to warrant its recommendation for any kind of goitre.

Ligature of Thyroid Arteries.-This operation has been recommended and performed many times in the hope that by cutting off the blood supply to the goitre, its size might be diminished.

The operation is by no means a new one.

In 1814, Walther* of Landshut tied both superior thyroid arteries in a young man, the subject of dyspnoa caused by goitre.

Four years later, Mr. Coates of Salisbury tied the left superior thyroid in a similar case. In a case of Sir William Blizard's, the operation was followed by sloughing and death from secondary hæmorrhage.

McWhinnie, $\uparrow$ in his lectures upon goitre, delivered at the Royal College of Surgeons, mentioned a case in which Mr. Earle tied this artery, at St. Bartholomew's Hospital.+ Günther has, according to Liebrecht, $\|$ collected twenty-one cases of ligature of the superior thyroid artery for the cure of goitre. In two cases a cure is said to have been the result; in fourteen there was some improvement; in two there was none, and in three death ensued. All, or nearly all, the preceding cases, occurred before the days of antiseptic surgery. In all of them it was the thyroid artery alone that was tied, on one or on both sides of the body.

For many years the operation was completely out of fashion, and was never performed.

Of late years, however, it has been revived by Wölfler and Billroth, who have recommended that not only the superior but also the inferior thyroid arteries should be tied. By this means the blood supply to the gland is cut off far more effectually than by ligature of the superior arteries alone, which are considerably smaller than the inferior.

Ligature of the superior thyroid arteries was recommended

* "Neue Heilart des Kropfes durch die Unterbindung der oberen Schlagadern," Salzbach, 1817, p. 25, quoted in Cooper's Dict. of Surgery.

$\dagger$ Lancet, 1861 , ii. 30 .

† See also cases by Downes at the Kashmir Hospital, Lancet, 1881, i. 4.8 ; temporary benefit is said to have occurred.

|| "De l'excision du goitre parenchymateux," 1883, 170. 
largely on the ground that it is a simple operation and tolerably easy to perform. The same argument can hardly be urged in favour of ligature of the inferior thyroid arteries. From their deep situation, lying as they do upon the vertebral column at the back of the goitre, and from their close proximity to the sympathetic nerve, it is evident that the operation of tying them is one of much difficulty; in fact it may be more difficult than that of removal of the goitre.

Valuable information upon the subject of simultaneous ligature of both superior and inferior thyroid arteries, is to be found in two papers by Rydygier* of Cracow. He publishes sixteen cases in which he had performed the operation. In the first case, the two arteries were tied only on one side of the neck. In the others all four arteries were tied at one operation. He operated by Drobnik's method at the posterior border of the sternomastoid in all cases except the last two; in these he used a horizontal incision in order that the scar might be less visible. All the wounds, with one exception, were treated without drainage. 'The results were good in all cases except two. One of these was that in which the arteries of the right side only had been tied; only slight diminution occurred in the size of the goitre, which was a parenchymatous one. 'The other case was one in which one lobe only of the gland diminished in size and it was then discovered that the opposite lobe contained a cyst. 'This was subsequently enucleated and the patient made a good recovery. In one case only did troublesome hæmorrhage occur. In this case the right superior thyroid artery gave way while the ligature was being placed upon it. Violent hæmorrhage took place, and could be controlled only by leaving pressure forceps in the wound for more than a week. The patient eventually made a good recovery, and the goitre diminished in size. In several cases there was a slight rise in temperature (in one case up to $102^{\circ}$ ), but this quickly subsided.

Rydygier discusses the question whether it is enough to tie the arteries on one side of the neck only, and expresses himself strongly in favour of simultaneous ligature of all four arteries.

Whether the operation can lead to the subsequent occurrence of cachexia strumipriva is a point which seems doubtful. 
The cases that appear to be most suitable for ligature of the thyroid arteries are early cases of parenchymatous enlargement and cases of exophthalmic goitre. With regard to the former, however, it seems to be better to treat them by medical means or, if operation is demanded, to do some more radical operation such as unilateral extirpation or resection, the results of which are extremely satisfactory. Ligature of the thyroid arteries for exophthalmic goitre has received the support of Kocher, who is, however, in favour of tying three only of the four arteries.

It is obviously useless to treat cases of cystic, fibrous, or fibro-adenomatous goitre by ligature of the arteries.

Ligature of the superior thyroid artery is best performed through an incision along the anterior border of the sterno-mastoid opposite the great cornu of the hyoid bone. The artery may be tied either near the tip of the great cornu of the hyoid or at the inner edge of the omo-hyoid muscle. The latter method is said to be the better when the goitre is large and the artery consequently much displaced. The apex of the upper horn of the gland is naturally a good guide to the vessel.

Ligature of the inferior thyroid artery is much more difficult. This operation may be performed by one or other of three principal methods.

(1) Internal to the sterno-mastoid (Velpeau's method). An incision is made along the anterior border of this muscle. The veins passing from the thyroid gland to the internal jugular vein are tied and divided. The carotid sheath is drawn outwards away from the gland. The thyroid artery is then found at the inner border of the scalenus anticus muscle. The artery should be tied just where it changes its direction from the vertical to the horizontal.

This operation is usually difficult. Many veins have to be tied. The artery is much overlapped by the goitre. The latter has to be lifted up out of its bed before the artery can be exposed.

(2) Through the sterno-mastoid (Langenbeck's method, modified by Wölfler). The incision is made over the sterno-mastoid. Its lower end is at the junction of the inner sixth of the clavicle with the remainder. The fibres of the muscle must be partially 
divided. Several large veins, including the external jugular, usually require ligature. Search is now made for the tendinous part of the omo-hyoid, an important guide to the artery. 'The tendon is drawn upwards or divided. 'The carotid sheath is drawn inwards, the phrenic nerve outwards. The artery is then seen lying at the inner edge of the scalenus anticus. If necessary this muscle must be drawn a little outwards.

(3) External to the sterno-mastoid (1)robnik's method,* as practised by Rydygier). 'This appears to be the best method, at any rate for cases in which the gland is much enlarged.

'The incision is made at the posterior border of the sternomastoid. It begins at the clavicle or a little above it and is carried upwards to the point at which the external jugular vein crosses the posterior border of the sterno-mastoid, usually on a level with the lower border of the thyroid cartilage. The sterno-mastoid muscle and carotid sheath are drawn inwards and the artery found as above. It is best tied immediately above the place where it is crossed by the omo-hyoid muscle.

Rydygier t has proposed a slight modification of Drobnik's original operation. He makes the skin incision not vertically, but horizontally, a little above the clavicle. By this means the scar is rendered less visible.

Exothyropexy.- This operation consists in cutting down upon the thyroid gland, dislocating it through the wound, and then leaving it exposed to the air.

It has a twofold object, that of mechanically relieving the tracheal pressure and that of inducing atrophy of the exposed gland.

First practised by Jaboulay of Lyons in 1892, the operation has been performed much more often in France than in any other country. It is especially at Lyons that it is apparently in greatest favour. (Our knowledge of it is due mainly to the expericnce of the surgeons of that town. In this country exothyropexy has not become popular, and it does not seem to me at all likely that it ever will.

'The best account of exothyropexy that has come under my notice is that of Dr. Leon Bérard, who in his excellent work on

* Wien. medl. Wowhensehr., 1887, p. 65.

† Centrullulutt für Chirurgie. 1889, 1. 241. 
goitre * has published many cases of exothyropexy ; nearly all of these occurred at Lyons in the practice of Poncet, Jaboulay, and their colleagues.

The operation has been performed upon various kinds of goitre. It appears to have been performed most often upon, and to be most suitable for, the more solid and vascular forms of parenchymatous goitre and exophthalmic goitre. It is intended to obviate the risks of extirpation of such goitres. The proceeding has, however, risks of its own, and the objections to it are considerable and obvious. I have never myself performed an exothyropexy, believing extirpation, if properly performed, to be a safer, more satisfactory, and altogether better operation.

'The principal objections to exothyropexy are the mechanica difficulties of effecting the dislocation in cases in which the goitre is deeply seated and causing much dyspnœea, the risk of venous hæmorrhage and sepsis, the long time occupied by the healing process, the liability to recurrence, and the very considerable deformity which is necessarily produced by the operation. The cases in which it is most likely to be justifiable scem to me to be those of prominent and bilateral goitres of a parenchymatous nature, in patients who are not suffering urgently from dyspnoea, and who do not object to the unsightly appearance of the resulting scar.

It may perhaps be justifiable in certain unusual forms of prominent exophthalmic goitre of large size.

It has also the advantages of being usually a short operation and one which requires very little of that exact knowledge of anatomy so essential for the successful performance of extirnation.

Method of Operating.-A median incision of suitable length is made in the middle line of the neck. 'This should extend downwards as far as the episternal notch. Any large superficial veins that may be encountered are clamped, cut, and tied. The incision is carried through the skin, fascia and layers of cellular tissue, until the capsule of the gland has been exposed. 'The wound is then enlarged with the fingers, which are insinuated gently between the surface of the goitre and the superficial tissues until the lateral borders of the goitre have been reached.

* " Therapeutique chirurgicale du goitre," Paris, 1897. 
At this stage no instruments should be used for fear of tearing or cutting veins and other important structures. If, owing to the size of the goitre, the fixity of the structures over it, or any other reason, the edges of the goitre cannot easily be reached with the fingers, the operator must not hesitate to divide transversely the skin and muscles, so as to give more room. Each lateral lobe of the goitre has now to be dislocated forwards. This is effected by hooking one or more fingers round the external border of the lobe and then drawing it forwards. As a rule each lateral lobe must be disloeated separately, one after the other. Occasionally it is possible to dislocate both lobes simultaneously by widely opening the wound with the thumbs, while pressure is exerted upon the back of the lobes by fingers placed upon the skin at the sides of the neck. This proceeding, howerer, exposes the trachea to serious risk of dangerous or even fatal eompression. 'The moment of affecting the dislocation, even of one lobe, is always a dangerous one, owing to the increased pressure exerted upon the trachea. The greatest care should be taken that the thyroid gland itself or the thyroid veins be not torn by the finger's. 'The fingers should be inserted at the sides of the gland, and not beneath its lower horn, where the veins are usually large and numerous. The fingers must never penetrate the thyroid capsule.

The goitre having been dislocated, strips of sterilised gauze are now packed round the tumour in the eleft between the goitre and the edges of the skin wound. An antiseptic dressing is then placed over the whole of the exposed surface of the goitre.

'The strips of gauze which have been placed in the grooves between the goitre and the edges of the skin are intended to protect the mediastinum from infection by the fluids which exude abundantly at first from the exposed surface of the gland. These strips may be removed on the fourth day and need not be replaced. The skin is then allowed to unite with the goitre, and gradually re-covers it. Great care must be taken to keep the whole of the exposed surface aseptic during the process of cicatrisation. "Cutaneous eicatrisation is complete, on the average, by the end of six weeks or two months."* 
During the first few days after the operation there is a copious exudation of serous fluid from the exposed surface of the gland. This exudation comes partly from torn lymphatics, partly from the turgid veins compressed by the edges of the cutaneous wound, and consists also in part, no doubt, of the colloid secretion of the gland itself.

After a day or two the veins on the surface of the tumour, which are at first swollen and prominent, become thrombosed. 'They then gradually become smaller, until at the end of about a week they appear only as small brownish cords.

It is worthy of note that Bérard states that elevation of temperature is almost always ("presque constamment") present during the first eight or ten days after exothyropexy. He explains this as "thyroid fever" due to absorption of secretion from the interior of the gland.

In the course of several weeks after the operation the exposed gland gradually shrinks and recedes behind the skin. The latter encroaches upon the surface of the tumour, which becomes covered with a decreasing area of granulations, and finally by a scar. With regard to the ultimate appearance of the cicatrix, Bérard expresses himself as follows: "What is usually found at the end of some months (after exothyropexy) is a decolorised disc, the dimensions of which vary from those of a two-franc piece $\left(1 \frac{1}{16}\right.$ inch) to those of a five-franc piece ( $1 \frac{1}{2}$ inch), very smooth and shiny or else bossy, and which is adherent to the deeper parts of the neck, fixing them to the skin. Sometimes the appearance is still more ugly; the little cysts which form during the shrinking of the tumour become adherent to the skin and project externally like true grafts of thyroid tissue, resembling grapes embedded in the skin."

Bérard gives an excellent photograph of a scar produced by an exothyropexy. It is certainly more ugly than any scar I have ever produced by any extirpation or enucleation operation.

Complications of the Operation. - With regard to serious hæmorrhage, Bérard is of opinion that with ordinary care it may usually be avoided, except in the case of very vascular goitres and of those which are very adherent to surrounding parts. He lays down a rule with regard to hæmorrhage due to wound of capsular veins, namely that the lobe that bleeds should be 
immediately luxated externally. This tends to obviate dangerous bleeding into the cellular tissue of the neck. 'The hæmorrhage moreover tends to stop spontaneously after dislocation has been effected. If bleeding still continue, it can more easily be arrested by pressure or ligature. If luxation of the lobe prove to be impossible, the bleeding must be arrested by leaving clamp forceps applied to the bleeding points.

Secondary hænorthage appears to be rare, occurring only when the wound has accidentally become infected.

Painful dysphagia appears to be common during the first two or three days after the operation. In about one-third of the cases bronchitis appears to be troublesome.

Complications due to the mechanical disturbance and displacement of the trachea appear to be not uncommon, although as a rule after exothyropexy the dyspnoea is relieved. In some ases of exothyropexy not only has the dyspnoea not been relieved but it has positively been aggravated. 'This will readily be believed by those who, like myself, have had practical experience of the injurious effect of traction upon the trachea in the course of an ordinary operation of extirpation. If the dyspnoea be aggravated by exothyropexy it is recommended that the goitre be replaced, the surgeon contenting himself with the benefit that may follow mere division of the tissues in front of the goitre: or tracheotomy may become necessary. This is, however, always a very serious complication of any operation upon a goitre, owing to the danger of setting up sepsis in the wounded cellular tissue of the neck.

In at least one case, that of Jaboulay, removal of the manubrium of the sternum has been performed to obtain aecess to a substernal goitre that was causing severe dyspnoea and that could not be reached by any other means. 'This is however a very serious complication and one that can be very rarely necessary.

In some cases in which exothyropexy was found impracticable, owing to the impossibility of effecting the dislocation, the tumour has merely been laid bare by the operation. 'The wound has been packed with gauze. Shrinking of the goitre may follow this simple operation just as it may after a simple division of the isthmus. 'The possibility however of serious 
increase in the amount of dyspnœa due to inflammatory swelling must be borne in mind. Infection of the wound is obviously a serious danger and one which is not easy to avoid. Even Bérard, who is on the whole a warm advocate of exothyropexy, is obliged to admit that "it is very difficult to keep the dislocated goitre free from all infection." It is in the later stages of the healing process, when antiseptic precautions tend to become relaxed, that infection is apt to be produced. It may be followed by sloughing of the exposed gland and extension of the inflammatory process to the deeper parts of the neck and chest.

Mortality after Exothyropexy. - It is difficult to judge of the true mortality after this operation. Bérard has collected sixtyfive cases of exothyropexy performed * chiefly upon parenchymatous goitre but also upon several exophthalmic goitres. In four of these cases death resulted from pneumonia, septic infection with hæmorrhage and acute Graves's disease (two cases) respectively.

Among the sixty-one cases that recovered were cases in which sloughing occurred, in which tracheotomy became necessary, or in which other operations such as extirpation or enucleation were subsequently performed. Many of the cases appear to have benefited greatly by the operation, others seem to have been improved but little if at all.

* By Poncet (15 cases), Jaboulay (35), Pollosson (.5), Blanc (3), Guillemot (3), Rocket, Albertin, Buchanan, and Hartmann (1 each). 


\section{CHAP'TER XVI.}

\section{DIVISION OR RESECTION OF THE THYROID ISTHMLS.}

Early cases-" Atrophy" of lateral lobes-Explanation of-Dyspnoea not due to backward pressure of isthmus-Results of the operationReappearance of goitre-Conchusions.

This operation is performed much more often in England than in other countries, and has been more highly praised by English than by Continental surgeons.

Duncan Gibb appears to have been the first to advocate its performance. In the Lancet for 1875 he published two cases in which Mr. Holthouse, of the Westminster Hospital, had put into practice the operation suggested to him by his medical colleague. The first case was that of a cook, aged 29, who had had a goitre for about two years. Both lobes and the isthnus were affected. 'The amount of dyspnoea does not seem to have been great. On July 11, 18\%4, Mr. Holthouse exposed the thyroid isthmus, passed a ligature round each end of it, and removed the intervening portion. On July 17 the last ligature came away, and the woman subsequently made a good recovery. Four months later she was in good health; the goitre was smaller and caused no trouble.

The second case was that of a girl, aged 17, who had had a goitre for many years. The whole gland was enlarged, and caused dysphagia, dyspnoea, and cough. Some severe paroxysms of dyspnoea which had recently occurred made surgical interference desirable. On December 15, 1874, an operation somewhat similar to the last was performed by Mr. Holthouse. Instead, however, of dividing with the knife that portion of the gland that lay between the ligatures, he left it to slough away. After the operation the circumference of the neck 
DIVISION OR RESECTION OF THE ISTHMUS. 251

diminished from $14 \frac{1}{2}$ to $13 \frac{1}{2}$ in. The patient recovered, apparently much relieved.

For a period of nearly nine years the operation appears to have attracted very little notice, no cases having been published during that period. About the year 1883 M. 'Tillaux, of Paris, began to perform the operation, and soon afterwards Mr. Sydney Jones followed him and published some cases. ${ }^{*}$ From this time onwards the operation has been practised extensively in this country.

I have collected twenty cases firom various sources published and unpublished. In eight at least of these the goitre diminished in size and the improvement lasted many months, in several cases more than a year. In four cases death occurred. In two at least of the cases the dyspncea had been very severe; in one of them death occurred during the operation. In one case the operation failed to relieve the dyspnoea, and removal of one lobe had to be performed.

Mr. Jones has pointed out that the operation not only often gave relief from the dyspnoea, but that it caused a remarkable diminution in the size of the goitre, or, to use his own words, "an atrophy of the lateral lobes."

That both these results-namely, relief from the dyspnoea and diminution in the size of the goitre, at any rate for a time -do usually follow the operation there can be no doubt, judging from the twenty cases before mentioned.

Two questions may be discussed in connection with this operation: "What is the mode in which the relief from the dyspnoea is effected?" and "Is the diminution in the size of the goitre, and with it the relief from dyspnæa, permanent?"

It is frequently stated that as the isthmus is a band uniting the two lateral lobes, division of it will allow these lobes to separate from each other and so relieve the dyspnoea. This seems at first sight a plausible explanation, but it is, nevertheless, probably not usually the correct one. That this may be the result of the operation in some cases is not improbable. 'That it is so in all or nearly all cases cannot be admitted. I have seen the operation performed many times, and have frequently

* Full details of Mr. Jones's cases will be found in the Lancet, 1883, ii. 900, and 1884 , ii. 367 . 
noticed that after the division has been effected the cut surfaces have not separated from each other at all. Sometimes; not only has the isthmus been divided but a considerable portion of it removed. What frequently happens, then, is that the lateral lobes, far from receding, actually come closer together to fill up the place of that portion of the gland that has been removed.

Mr. C. A. Morton, ${ }^{*}$ describing a case in which he operated for severe dyspnoea caused by a parenchymatous goitre, says that "after excision of more than an inch of the median part of the gland the lateral lobes came together in the middle line."

'Then again, the relief from the dyspnoea frequently does not occur immediately, but only after the lapse of some hours or days. In several of the cases before mentioned no relief whatever followed the operation. 'Thus, in an operation that I witnessed at University College Hospital some years ago upon a boy with a large parenchymatous goitre causing considerable dyspnoea, a portion of the isthmus was removed. 'The cut surfaces on either side immediately came into contact, and the boy died of dyspncea a few hours later.

But relief from the dyspnoea should occur immediately after division if the constricting isthmus were the cause of the dyspnoea.

Gibb, in his remarks upon the two cases published by himself, savs that his object was "to divide or remove that portion of the goitre which was in relation with the trachea itself, namely, the isthmus, before it had commenced to encircle the tube or had become too firmly adherent." Speaking of his first case, he says that he considered that "the cure of the attacks of dyspnoea was impossible without the removal of that portion of the tumour over the windpipe."

It is clear, then, that he had fallen into the rather serious mistake of supposing that the cause of the dyspnoea lay in the direct pressure of the isthmus upon the front of the trachea. Hence that division or removal of the isthmus relieves the trachea from pressure.

I venture to think that this view is wholly untenable.

* ." The Causation and Treatment of sudden Dyspnoea in Goitre," Bristol lyed. Chir. Journ., 1896. p. 221. 
The pressure of the goitre upon the trachea does not cause an antero-posterior but a lateral flattening of the trachea, as may be seen in Fig. 2. In this case the patient died from suffocation, and it will be seen that the trachea is greatly flattened laterally like the scabbard of a sword, as Demme long ago explained.

The trachea is never flattened antero-posteriorly by any parenchymatous goitre or by any other form of general and uniform en!argement of the gland. When the isthmus alone is involved without the lateral lobes, as by the presence of a tumour within it, there may be a slight amount of anteroposterior flattening; but such goitres never cause serious dyspnoea unless the tumour lies actually behird the sternum, and even then the pressure is usually oblique rather than antero-posterior.

The cause of the dyspnoea must be sought, not so much in the condition of the isthmus, as in that of the lateral lobes of the goitre. In suffocating parenchymatous goitre, all parts of the gland are swollen and exert pressure upon everything in contact with them. 'That is, they exert pressure not only upon the muscles and other structures outside of and around them, but also upon the trachea which lies between the two lateral lobes. Hence, it happens that mere division of the isthmus will not of itself free the trachea from the inward pressure of the lateral lobes.

'The effect of removal of the isthmus may even be, as in the cases mentioned above, to cause the lateral lobes to come nearer to each other and so to increase the lateral flattening of the trachea.

The real cause of the relief from the dyspnoea lies chiefly in the shrinking of the gland which follows the operation, and not in the mere mechanical separation of the two halves of the goitre.

The next question is, "How is this shrinking caused?"

We must bear in mind that the enlargement of the gland in parenchymatous goitre is very largely due to over-distension of the vesicles with secretion; therefore it is easy to understand that removal of that secretion will naturally cause diminution of the swelling. 'This is shown by the fact that the diminution 
does not occur at once but in the course of the few days following the operation. During this time the viscid colloid secretion has had time to ooze slowly away from the surface of the wound. Indeed, I have more than once, after operations upon parenchymatous goitre, seen this colloid secretion coming away from the gland. Thus in one case there formed in the neck, under the recently healed skin wound, a fluctuating swelling which was at first thought to be an abscess, but which, when opened, was found to contain a quantity of viscid colloid material that had evidently drained from the gland into the wound. Notes of a similar occurence will be found in a good many published cases.

Again, the more fibrous the goitre the less the diminution in size that will take place. In a rare case of truly fibrous goitre on which division of the isthmus was performed some years ago at St. Bartholomew's Hospital by Sir 'Ihomas Smith, little or no diminution in size followed the operation and the dyspnæa was not relieved.

Lastly, as the wound in the gland heals, and the further escape of colloid material is thus stopped, the goitre often slowly reappears, if the conditions which originally produced it continue to act. The reappearance of the goitre is doubtless due to reaccumulation of its colloid contents.

'The following case, which came under my notice in St. Bartholomew's Hospital in 1886, affords a good illustration of this point. 'The patient was a girl, aged 17 , with a bilateral parenchymatous goitre, causing such extreme dyspnoea that she was almost suffocated by it. Division of the isthmus was performed by Mr. Langton. Not the least relief followed and immediate tracheotomy became necessary. Within a week from the time of the operation the goitre had shrunk so much that scarcely any swelling of the neck was noticeable. Then as the wound in the gland healed, the goitre gradually re-enlarged until, at the end of some weeks, it had nearly regained its former size. As dyspnoea was found to occur whenever the tracheotomy opening was closed, it became necessary to do some further operation and the right half of the gland was removed. The same sequence of events now occurred in the remaining half of the goitre. At first it gradually diminished in size, and then, as 
the wound healed, it gradually and slowly enlarged again. In most of my own cases of unilateral extirpation of parenchymatous goitre, the operation has been followed by marked diminution in size, and then by re-enlargement, of the remaining half of the goitre.

The exact manner in which the colloid of the vesicles passes from them to the cut surface of the gland is a point upon which it seems unwise to express a definite opinion. There is some evidence in support of the view of Boéchat and others, that all the thyroid vesicles communicate with each other. If this be so, it follows that any incision into the gland will tend to drain all the vesicles. Possibly, however, the drainage is effected, not directly but indirectly, through the medium of the lymphatics.

All these facts seem to point to the following conclusions :

(i) That division of the thyroid isthmus usually relieves dyspnœa, not by mechanically allowing the two halves of the goitre to separate, but by draining the gland of its colloid secretion.

(ii) That the relief afforded may be permanent, but that frequently the goitre reappears when the wound has healed and the secretion is again pent up in the gland.

(iii) That in many cases in which very urgent dyspnœa is present, a mere division of the isthmus will not relieve the dyspnoa sufficiently quickly, and it becomes necessary to do some further operation, either tracheotomy or, better, removal of some considerable portion of the goitre.

The operation is therefore not one which can now be recommended, except perhaps in certain exceptional cases. For parenchymatous goitre without dyspnœa it is not necessary, because such cases are better treated by medical means, such as the administration of iodine or thyroid extract. Cases of parenchymatous goitre in which dyspnoea is considerable and which do not yield to medical measures generally recuire removal of a considerable portion of one or other lateral lobe. The possible danger of trusting to a mere division of the isthmus has already been mentioned. When the dyspnoea is very severe and urgent, division of the isthmus cannot be relied upon to give relief sufficiently quickly. In some few such cases however, it may be advisable to divide the isthmus and then to 
watch carefully the effect of this before doing tracheotomy. But tracheotomy is scarcely ever desirable for parenchymatous goitre, except at the hands of those who do not feel able to perform the larger but much safer operation of aseptic unilateral extirpation.

The dangers of an open wound such as that produced by division of the isthmus, or of the necessary septic wound of a tracheotomy, are obviously greater than those of a properly performed aseptic extirpation of one lobe.

An extensive resection of the isthmus may sometimes be preferable to unilateral extirpation, in some cases of parenchymatous goitre in which the goitre is unusually prominent in the middle line. Such an operation is however usually more serere than a simple unilateral extirpation.

For all cases of adenoma or cyst, division or resection of the isthmus is msuitable, being far inferior to enucleation. 


\section{CHAP'TER XVII.}

\section{TREATMENT BY EXTIRPATION (THYROIDECTOMY).}

Difference between extirpation and enucleation-Partial extirpationPreparation of patient-Question of general anæsthetic-Local anasthetic-Position of patient-Skin incision : oblique, vertical, transverse -Treatment of infra-hyoid muscles-Recognition of gland-Isolation of lobe-Ligature of thyroid vessels-Veins often thin and liable to tear-Treatment of inferior thyroid artery-Avoidance of recurrent nerve-Treatment of isthmus-Arrest of hamorrhage-Cleansing of wound-Asepsis better than antisepsis-Suture of muscles, of skinQuestion of drainage-Dressings-Use of sponge-Fixation of head and neck-Position of patient after operation-After-treatmentConvalescence.

The removal of a goitre by a surgical operation may be performed by one or other of two widely different methods. These two operations are known by the names of extirpation and enucleation and it is highly important that the difference between them should be clearly borne in mind.

By extirpation is meant the removal of the gland or some part of it (generally one half) by an operation conducted as far as possible outside the capsule. The principal vessels are all tied or clamped before they are cut. 'The operation is performed deliberately, step by step, by careful dissection. 'The wound being kept free from blood, the operator is enabled to see exactly what he is doing. He thus avoids wounding, on the one hand the plexus of veins which lie on the surface of the gland beneath its delicate investing capsule, on the other hand the important anatomical structures which lie in close proximity to the gland.

Enucleation, on the other hand, consists in the shelling out of a tumour from the interior of the gland. The removal of the tumour is usually effected rapidly and no attempt is 
made to tie the vessels until after the tumour has been removed.

The difference between the two operations is analogous to the difference between the removal of a breast as performed for carcinoma and the removal of a fibro-adenoma from that organ ; or to the difference between a hysterectomy and the enucleation of a fibro-myoma from the uterus.

Each of these operations has several modifications which will be described later.

Total Extirpation.- This operation is one which is not now to be recommended on account of the grave after-results which are known to follow if the patient be deprived of the whole thyroid gland. Moreover it is in my opinion never necessary, except possibly in some very exceptional cases of malignant disease involving both sides of the gland.

The performance of total extirpation differs in no way from partial extirpation, except that both halves of the gland are removed.

Partial Extirpation.-In the great majority of cases extirpation is performed upon one lateral lobe and it is this operation therefore that will be described in detail. In some cases extirpation of one lobe is followed by extirpation of a portion of the opposite lobe.

The preliminary preparation of the patient includes the administration of a purgative on the day before the operation and the preparation of the skin of the neck. The skin of the whole of the front and sides of the neck must be thoroughly scrubbed with hot water and soap, and then washed with spirit, ether or turpentine to remove all greasy matter. An antiseptic dressing of carbolic acid lotion 1 in 30, or perchloride of mercury 1 in 2000 is then applied for several hours before the operation and is to be removed only when the operation is about to be commenced.

Anæsthetic.-'The question of the administration of an anæsthetic is an important one. If the patient has little or no dyspnoea or stridor, and if there is no history of paroxysms of dyspncea, then there can be no objection to the administration of a general anæesthetic.

But if, on the other hand, there seems to be any probability 
that serious dyspnœa may occur during the course of the operation, then it is certainly better to dispense altogether with a general anæsthetic and to do the operation under cocaine or eucaine. In cases where severe dyspnœea is actually present at the time of operation the use of a general anæsthetic involves much danger. Many cases have been recorded in which sudden death from the anæsthetic has occurred in the course of the operation or even before the operation has actually begun. With the help of cocaine or eucaine the removal of a goitre may be effected with very little pain. Patients upon whom I have operated without the use of general anæsthesia have, after the operation, always assured me that the amount of pain felt by them was really quite trivial. Directly the tumour has been removed, and the danger of suffocation is over, an anæsthetic may be given, if it be thought desirable, while the wound is being sewn up. I have been in the habit of offering an anæsthetic to the patient at this stage, but up to the present time in no case has the offer been accepted, the patient always saying that the pain was not sufficiently great to demand it. Even if no anæsthetic of any kind, either local or general, be used, the pain of an operation for goitre is confined chiefly to the beginning and the end of the operation, when the skin is being incised or sewn up. The patients often complain also when traction is exerted upon the tumour or upon the deeper parts of the wound. In cases of severe dyspnœa there is a great advantage in the patient being conscious, since he can then immediately give warning if the operator be pressing unduly upon the narrow trachea. Patients suffering from suffocative goitre have on several occasions informed me that they dreaded the taking of an anæsthetic more than the actual operation and have felt relieved at being informed that the administration was neither necessary nor desirable. At the same time probably few patients will go so far as to declare, as one of Kocher's patients did, that it was a real pleasure to be operated upon! By this he meant no doubt that the relief produced by the removal of a suffocating goitre was so great that the discomfort of the operation was as nothing to him.

A minor advantage in dispensing with the use of an anæsthetic is that the patient is saved much of the retching and vomiting 
that frequently follow a prolonged operation performed under general anæsthesia. The rapid healing of the wound is thereby facilitated.

If a general anæsthetic be employed it is well to give as small a quantity of it as possible, and to keep the patient only lightly under its influence.

If cocaine be used, a solution containing not more than half a grain should be injected in several places in the line of the proposed incision. The use of cocaine in larger doses is apt to be followed by faintness or even by more dangerous symptoms. liucaine may be used in much larger doses and has further the advantage that it can be sterilised by borling. Both solutions decompose easily and should therefore be freshly prepared shortly before use. An injection of a quarter or a third of a grain of morphia about twenty minutes before the commencement of the operation is a useful adjunct to the use of the local anxsthetic.

Position of the Patient.--Sone surgeons prefer to have the patient in a half-sitting position. For myself, I prefer that he should be in the recumbent position, but with the shoulders well raised. The head should be extended as far as is compatible with safety, so as to draw the goitre as much as possible away from the thorax. Much extension of the head, however, may interfere seriously with the patient's respiration. It is well to ascertain, before the operation is begun, in what position the patient can breathe most comfortably, and then to get an assistant to hold the head firmly in that position throughout the operation. By these means the trachea, often greatly narrowed, is less likely to become kinked and occluded.

Skin Incision.-Many different skin incisions have been practised. 'The choice depends largely upon the size and shape of the goitre.

There are three chief varieties: (1) 'The oblique incision in the long axis of the tumour that is to be removed; generally along the imner border of the sterno-mastoid muscle. This is the incision that should be adopted in most cases of extirpation and in those generally in which the operation is likely to be difficult or dangerous. It gives the operator plenty of room, and enables him to reach the upper horn of the gland without undue 


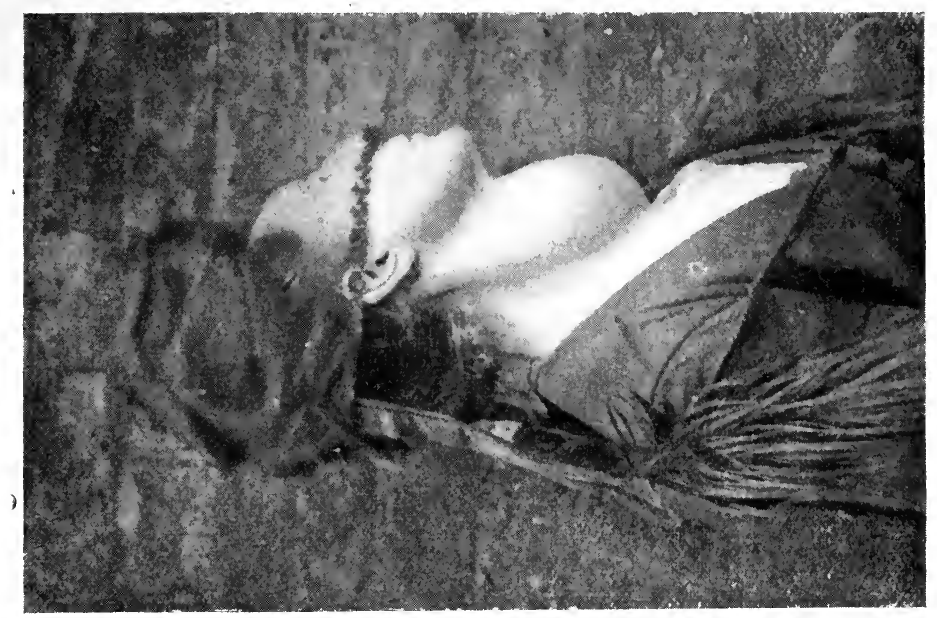

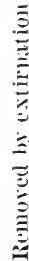

ํำ

望

承

๑

of

ชี

雨

ำ

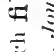

恶

立

竎

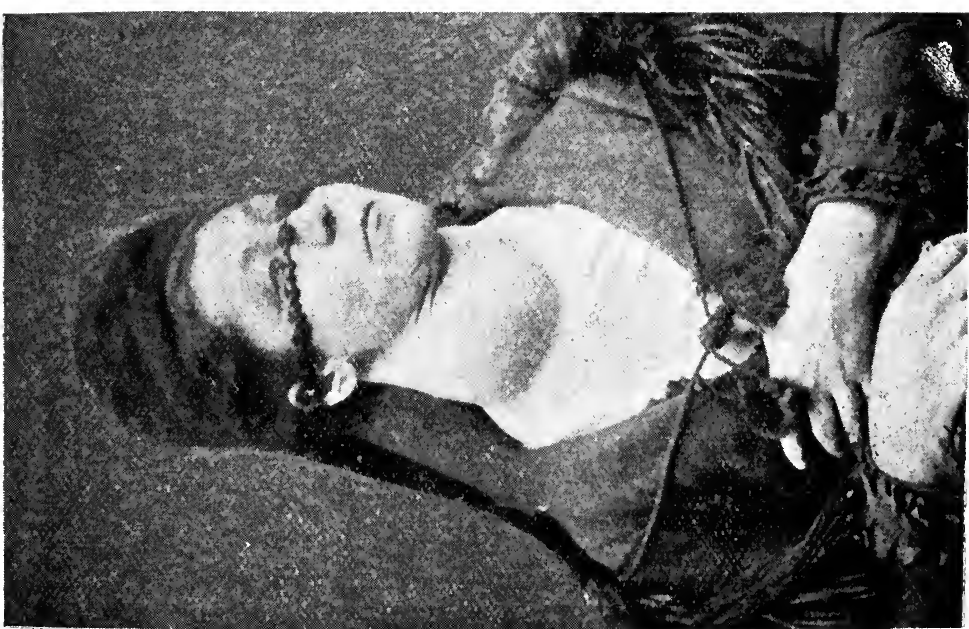

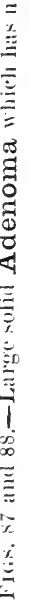


difficulty. The lower end of the incision should, in almost all cases, be carried down to the upper border of the sternum. If it be intended to operate upon both lobes of the thyroid, the incision should be made in a more slanting direction, the lower part of the incision being carried well across the middle line at a somewhat higher level than the top of the sternum. In some cases of bilateral extirpation the angular or $\mathbf{Y}$-shaped incision, with the point of the angle opposite the cricoid cartilage, originally recommended by Kocher, may be employed, but is seldom necessary. I have never yet found any difficulty in getting easy access to both lobes through a single incision, and have rarely employed the angular incision.

Occasionally, when the tumour is very large, it is desirable to make an elliptical incision, so as to remove a large portion of skin. Thus in the patient from whom I removed the large goitre shown in Figs. 34-37 (pp. 78-80), an oblique incision was made across the front of the tumour and a second curved one along the right and lower borders. As a rule, however, no excision of skin is required, even in removing goitres of considerable size. 'The redundant skin soon contracts. (See Figs. 87, 103, and 111.)

(2) 'The rertical incision may be used for' goitres situated in or near the middle line of the neck, especially if they be small. It involves less interference with the infra-hyoid muscles, but, on the other hand, renders access to the region of the superior thyroid artery less easy. In some cases of deep-seated tumour behind the sternum in which the operator is uncertain which half of the gland should be removed, the vertical incision may be employed for exploratory purposes, the incision being subsequently prolonged obliquely upwards to the right or left, as desired.

It has the disadvantage that in young people the resulting scar is apt to become contracted and ugly.

(3) 'The transverse incision a little above the upper border of the sternum gives the best results as regards the scar, but, on the other hand, it does not give the operator nearly so much room. It is consequently less easy to reach the upper horn of the gland unless the goitre is large and prominent. To obtain sufficient room, it is often necessary to divide very freely the infra-hyoid and even the sterno-mastoid !muscles. It is most suitable for 


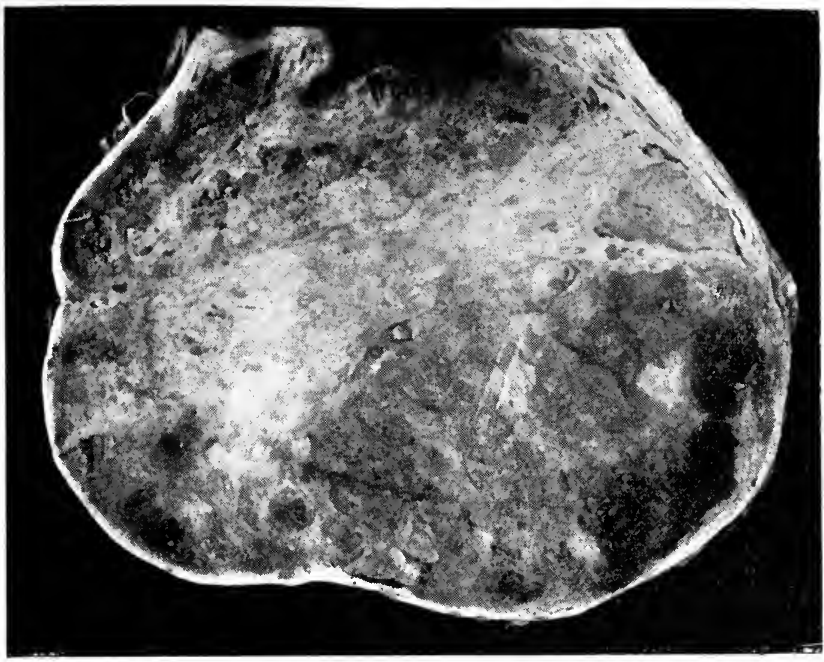

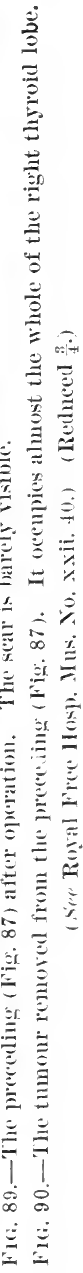

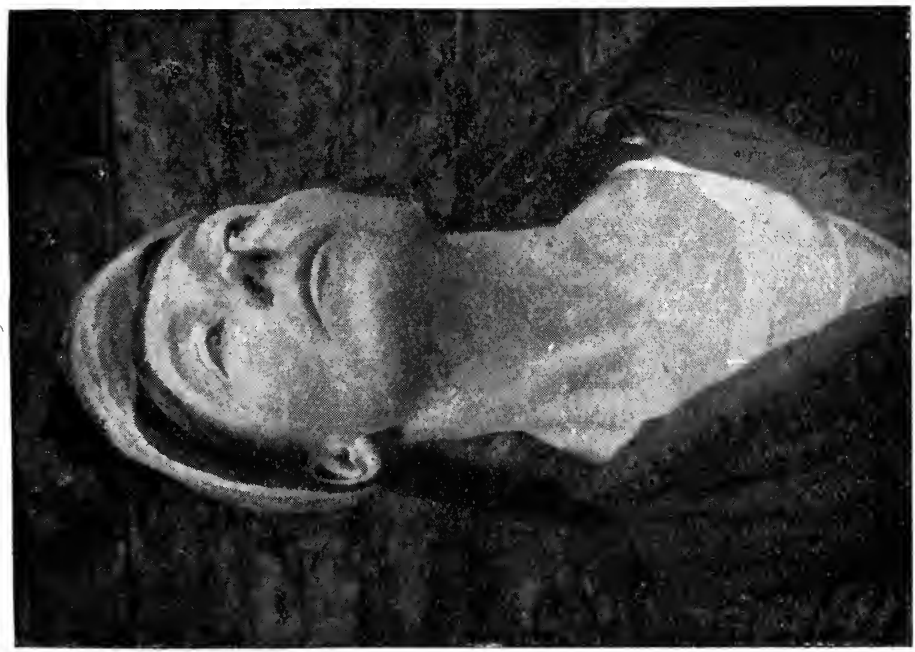


prominent goitr'es, for small goitres low down in the neck, and for easy cases of enucleation in general. It is, in my opinion, not to be recommended, as a rule, to those operators who have had but little experience in removing goitres.

If care be taken to place the incision in the line of one of the natural creases of the skin, the subsequent scar will be scarcely visible, and can, moreover, be easily concealed by the dress. In the case of ladies who wish to wear low dresses the scar can be casily hidden by a necklace or a band of velvet.

After division of the platysma and fascia, the superficial veins of the neck are exposed, and several of them will probably require ligature. 'The oblique anterior jugular vein will generally be found rumning along the inner border of the sterno-mastoid, and should be tied. Care should be taken in making the oblique skin incision not to split open this vein. At the lower end of the incision, just above the sternum, a transverse vein will generally be found, requiring a double ligature.

'The infra-hyoid muscles must now be dealt with. In the case of small goitres near the middle line, it may be possible to draw these muscles aside without dividing them. Care should be taken, whenever possible, to draw them outwards, not inwards, in order to aroid dividing the nerves which enter their outer borders. If these nerves be divided the muscles atrophy, and afterwards cause an unsightly hollow in the neck. For the same reason, if the muscles have to be divided, as is usually the ase, they should be cut near their upper ends, close to the hyoid bone, and then thrown downwards and outwards. At the end of the operation they can then be replaced and sutured without much harm having been done to them. If the operation is likely to be a difficult or dangerous one, it is not worth while to spend time over a comparatively unimportant point like this; in such cases the muscles may be divided wherever it seems most convenient to do so. When the transverse incision is used, the skin should be drawn upwards (or downwards) before the muscles are divided, so that the wounds in the skin and muscles do not correspond. Otherwise the muscles are likely to adhere to the cicatrix and cause a certain amount of deformity.

The infra-hyoid muscles are often very much thinned and spread out over the surface of the goitre. I have even seen them 

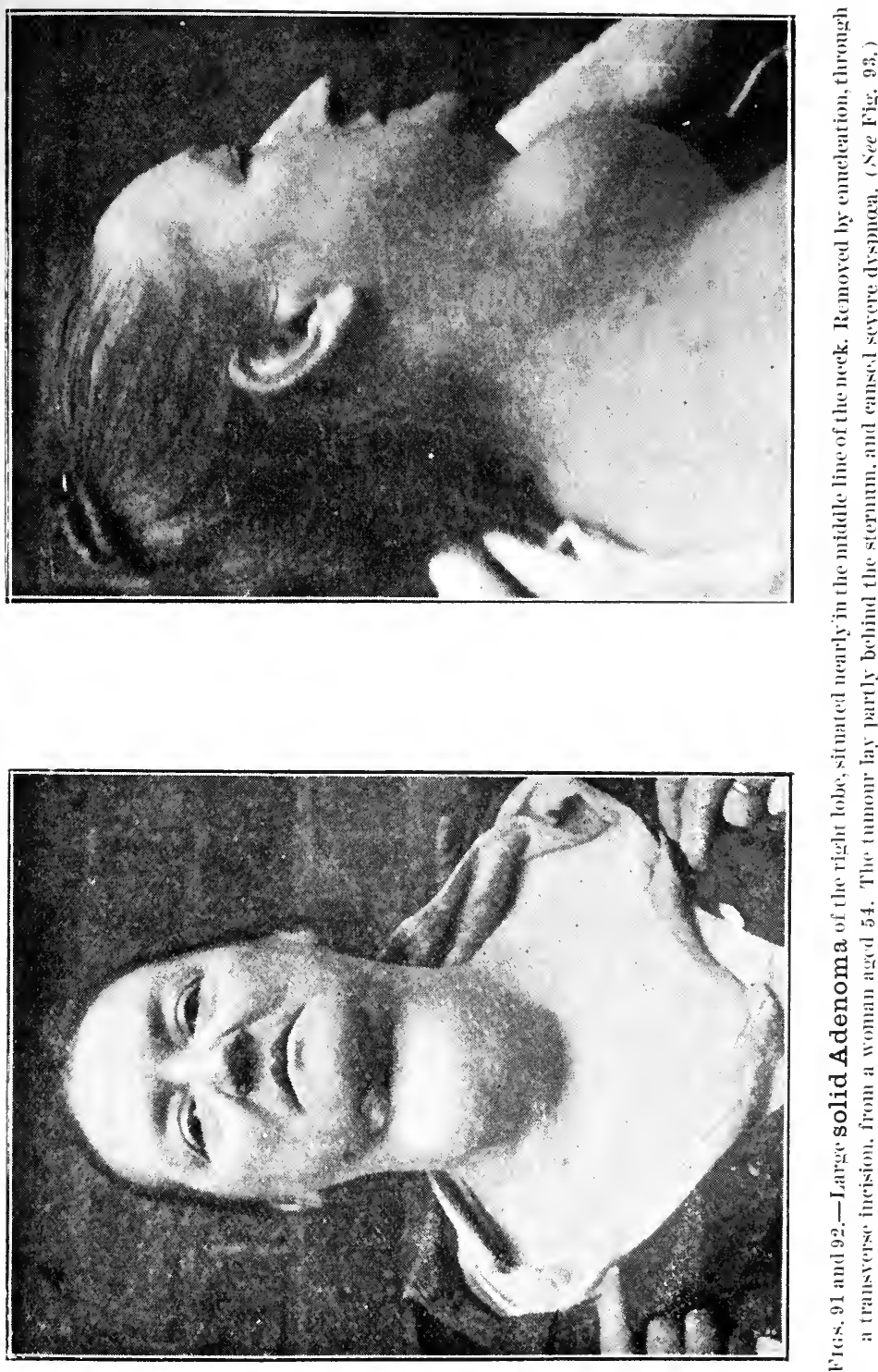

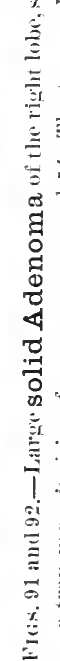


mistaken by an inexperienced operator for the proper capsule of the goitre. Sometimes they lie in deep grooves on the surface of the gland, and must be carefully lifted out of these.

The surface of the thyroid gland has now been laid bare. It is covered by a layer of loose connective tissue lying immediately outside the capsule of the gland. This layer is very

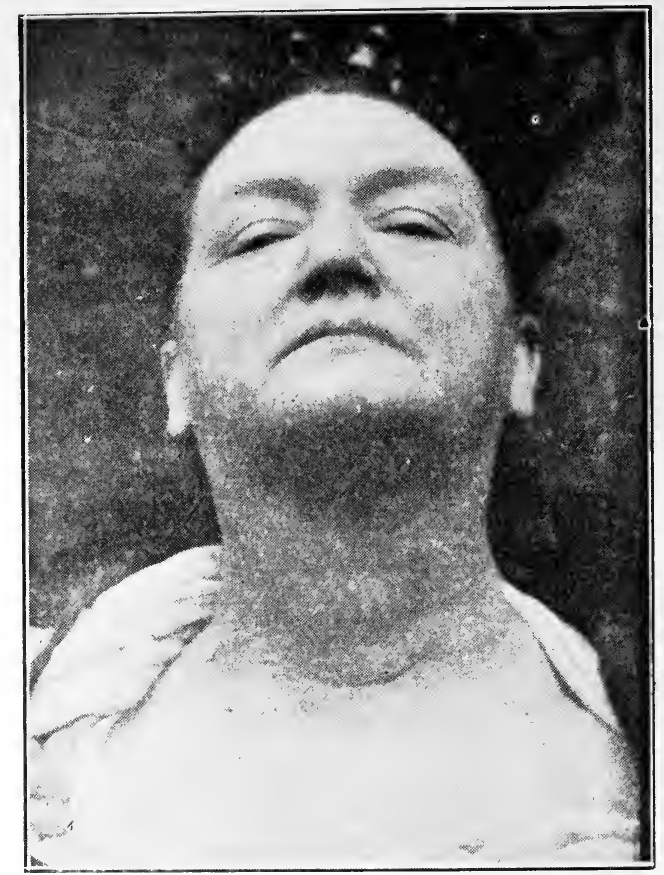

Fig. 93.-The preceling (Fig. 91), three weeks after operavion. Showing small transwerse scar low down in the neck. (See Appendix, Case 53, p. 346.)

distinct and easily recognised in all cases except those in which previous inflammation has matted the parts together: 'Ihis is likely to be the case when the goitre has been subjected to injection, or if suppuration has taken place in it.

'The capsule of the gland can usually be recognised without difficulty by the network of large veins that ramify beneath it.

'The gland together with its capsule has now to be separated from the surrounding parts, and in performing this part of the 
operation the greatest care must be exercised not to wound, on the one hand the plexus of the vein lying beneath the capsule, on the other hand the important structures lying in close contact with the gland.

If the capsule and its veins be wounded the hæmorrhage may be very difficult to control. If forceps be applied, the vessels or the glandular tissue are very apt to tear, and further hæmorrhage takes place. Often the wounded gland oozes blood in an alarming and uncontrollable manner, the wound is obscured with blood and the subsequent steps of the operation become much more difficult. Eren rough handling of the gland may lead to tearing of its thinned and dilated veins. The greatest care should therefore be taken to conduct the dissection with the utmost carefulness and delicacy. Should a vein be wounded accidentally, it may be possible to stop the hremorrhage by means of a ligature carefully applied. But in cases in which a small puncture only has been made it is often better to get an assistant to put one finger on the bleeding point and to continue the dissection.

'The front of the gland is easily cleared and the muscles being held on one side by retractors, search is made for the principal vessels, which must be tied just outside the points at which they penetrate the capsule.

It is generally best to begin by clearing the upper horn and placing ligatures upon the superior thyroid artery and vein. But if severe and dangerous dyspnoea be present it may be best to begin by disengaging the lower horn, so as to relieve the trachea from pressure. If the ressels are small they may be tied in a common ligature, but if they are large they should be tied separately. It is often best to tie the artery before the vein, so as to diminish the amount of blood in the gland.

'The artery will generally be found without much difficulty at the inner border of the apex of the upper horn. It is desirable to tie it rather high so that the ligature may be above the origin of a large branch which is frequently found rumning from near the apex down the back of the gland.

Sometimes when the goitre is large and extends nearly to the lower jaw, there is considerable difficulty in obtaining access to the artery, which lies at the bottom of a narrow space between 
the tumour and the jaw. 'This difficulty is increased if the head, on account of the dyspnœa, cannot be thrown well backwards.

Both veins and arteries are secured with double ligatures and the ressels then divided.

'The superior thyroid artery and vein having been secured, attention is next directed to the middle and accessory thyroid veins. The most conımon situation of these veins is shown in Fig. 7 . They should be carefully isolated and tied with double ligatures before being divided; they should be tied just where they leave the capsule of the gland.

In dissecting towards the outer border of the goitre, care should be taken to aroid wounding the internal jugular vein, which is frequently expanded over the side of the tumour and may easily be wounded. It frequently lies in front of or even internal to the carotid artery and the pulsation of this ressel is consequently not a safe guide to the position of the vein.

The branches of the inferior thyroid veins running downwards from the lower part of the goitre must now be dealt with in a similar manner. Here, again, there may be much difficulty in obtaining access to the veins if the goitre be a large one and extend down behind the sternum. The importance of raising the goitre so as to obtain as much room as possible is obvious. Care should be taken not to cut or tear any of these veins before they are tied, lest they should retract into the cellular tissue behind the sternum and there give rise to troublesome hæmorrhage.

The goitre having been completely freed from its rascular connections above, below, and on the outer side, should now, if possible, be lifted up out of its bed and turned over towards the opposite side, ${ }^{*}$ in order that the inferior thyroid artery and accompanying veins may be dealt with.

If the fixity of the tumour be such that the latter cannot be lifted out of its bed, then the difficulty of tying the artery is

* In some arses, and especially whon the goitre is a prominent one, this dislocation of the tmmour ont of the wound may be effected with advantage at at much earlicr stage of the operation, before the superior thyroid vessels and inferior thyroid voins have been tied. In these cases the lateral thyroid veins must be tied before the dislocation is effected. The early dislocation of the tumour has the advantage of affording relief to the pressure on the trachea. 
much increased. Access to the artery is favoured by drawing the sterno-mastoid muscle well outwards, or even by dividing some of its fibres. Or it may be advisable to postpone ligature of the artery until the isthmus has been cut through, and the tumour thus rendered more movable.

The inferior thyroid artery may be tied in one or other of two situations. The main trunk may be tied at the inner border of the scalenus anticus muscle, just at the point where it changes its direction from vertical to horizontal, curving inwards to enter the gland. Or the branches may be tied close to the gland itself.

If the main artery be tied, care must be taken not to wound the sympathetic nerve which lies in very close relation to it. It is quite possible also to mistake the vertebral for the thyroid artery.

The branches of the artery are more easily found, and should be tied inside the line of the recurrent laryngeal nerve. Whichever method be adopted, the position of this nerve should be constantly be borne in mind lest it be accidentally cut or included in a ligature. It lies, most commonly, superficial to the artery, but may pass behind it. It may lie among the branches, some of these passing in front of and others behind the nerve.

Some operators recommend that search be made for the nerve and that it be dissected out and held on one side. If the operator is doubtful about the position of the nerve, he may do well to follow this advice. It is better, however, to know exactly where the nerve should be and to avoid it without unduly exposing it. The wound must be kept as free as possible from blood while this stage of the dissection is being carried out.

In removing the posterior border of the gland from the pharynx and other structures on its inner side, the anatomical arrangement of the fascia at the back of the gland (described on p. 7) must not be forgotten. In those cases especially in which the goitre sends a prolongation inwards behind the pharynx and oesophagus, the arrangement of the fascia is liable to deceive the operator, and to carry him, in his dissection, away from the surface of the gland. It is probably a want of due 
appreciation of this important anatomical point that has led in some recorded cases to an unexpected wound of the pharynx or trachea.

The next step in the operation is the division of the isthmus. The principal vessels lie along its upper and lower borders and should be secured in these situations with double ligatures. Any veins visible upon the anterior surface may be clamped. The isthmus is then freely divided with knife or scissors. The few vessels that bleed from the cut surface of the isthmus must be picked up with forceps and tied. If the isthmus is small, it may be included in a single ligature, which is drawn tight as the glandular tissue is divided. This proceeding tends to prevent the escape of colloid into the wound. If the isthmus is very thick it may mechanically prevent the goitre from being turned over in the manner previously described.

In such a case it may be impossible to reach the inferior thyroid artery satisfactorily, and the isthmus must then be divided at an earlier stage of the operation before search is made for the artery.

I have never found the hrmorrhage from the substance of the isthmus to be serious. 'The principal vessels lie upon the surface immediately beneath the capsule.

After the isthmus has been divided, the few remaining connections of the tumour may be severed and the tumour removed.

In dividing the band of comnective tissue that unites the gland to the cricoid cartilage, care must again be taken to avoid wounding the recurrent nerve which lies in close proximity.

Indeed, at this, the final stage in the removal of the tumour, it is frequently a good plan to carry the knife a little outwards into the gland itself. By thus making the section a little outside the nerve and leaving a small portion of the gland and its capsule to protect it, the risk of wounding the nerve is still further obviated.

The goitre having been removed, the treatment of the extensive wound of the neck next demands attention.

All hxmorrhage must be scrupulously arrested. It is especially on the inner surface of the wound that several small bleeding points may be found to require ligature. 
Any bits of blood-clot that may remain in the wound must be carefully removed by sponging.

If perfect asepsis has been maintained throughout the operation, as it should have been, the wound requires no further cleansing than is afforded by gentle sponging with sterile saline solution, or by laying against it a sponge that has been wrung out of weak sublimate solution. Irrigation of the wound with strong solutions of carbolic acid or perchloride of mercury should be avoided as being unnecessary and harmful. It is aseptic rather than antiseptic treatment that is desired in the removal of a goitre.

In order to preserve asepsis during the course of the operation it is desirable that as little as possible of the wound should be exposed at any one time. While the operator is working at any one part of it his assistant should take care to cover the rest of it with layers of sterilised gauze. 'This not only keeps the wound clean but also checks hæmorrhage from minute vessels.

The dangers of sepsis in an extensive wound involving the cellular tissue of the neck are too well known to require further mention.

If the infra-hyoid muscles have been divided, the cut ends are replaced and accurately united by fine buried sutures. A few points of suture may also be used to unite the cut edges of the platysma.

It is generally advisable to drain the wound for twenty-four hours. This is best effected by laying in it a sterilised strip of gutta-percha tissue or gauze, or a drainage-tube.

In cases in which the asepticity of the wound is doubtful, as in some cases of suppurating goitre, the safest course to pursue is to pack the whole wound with strips of gauze. For such cases it has been recommended to cover the whole internal surface of the wound with a layer of iodoform gauze and then to place inside this, strips of gauze wrung out of some antiseptic solution. The latter must be changed daily, but the former may be left in for many days until it becomes loose and can be removed without difficulty.

The edges of the skin wound must be accurately united by fine sutures of silk or fishing gut.

The wound is then covered with strips of antiseptic gauze 
wrung out as dry as possible. Following the practice of Julliard and others, I usually place outside the first layer of gauze one or more marine sponges at the sides of the neck. These tend to keep the surfaces of the wound in contact and also help to keep the trachea in place.

Outside the gauze dressing a thick layer of cotton-wool must

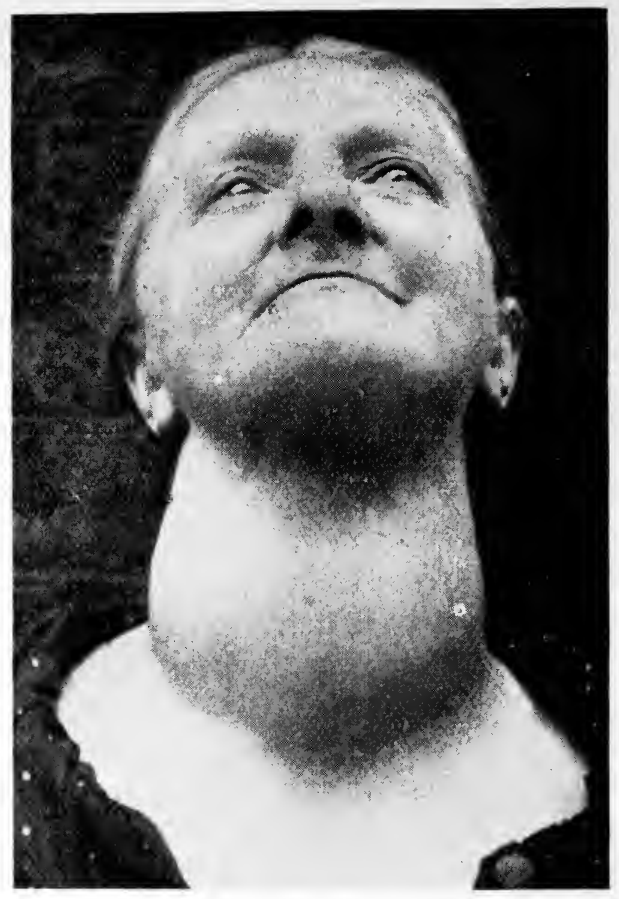

Fur: 9 1.-Dilateral Parenchymatous Goitre. The right lobe was cxtirpated on aceount of dyspmoen.

be placed. 'This should cover a large area, from the chin to the lower part of the sternum, and laterally as far as the shoulder on either side.

It is important that the bandages should be applied so as to fix the head, neck, and shoulders, and thus keep the wound as quict as possible. It has been recommended that strips of plaster of Paris be applied to the sides of the head and neck toensure rest to these parts. I have never adopted this plan. 
I make a point, however, of always impressing upon the patient before the operation the great importance of keeping the head and neck as still as possible for the first two days after the operation.

After the effects of the anæsthetic have passed off', unless collapse contraindicate this position, the patient should lie in

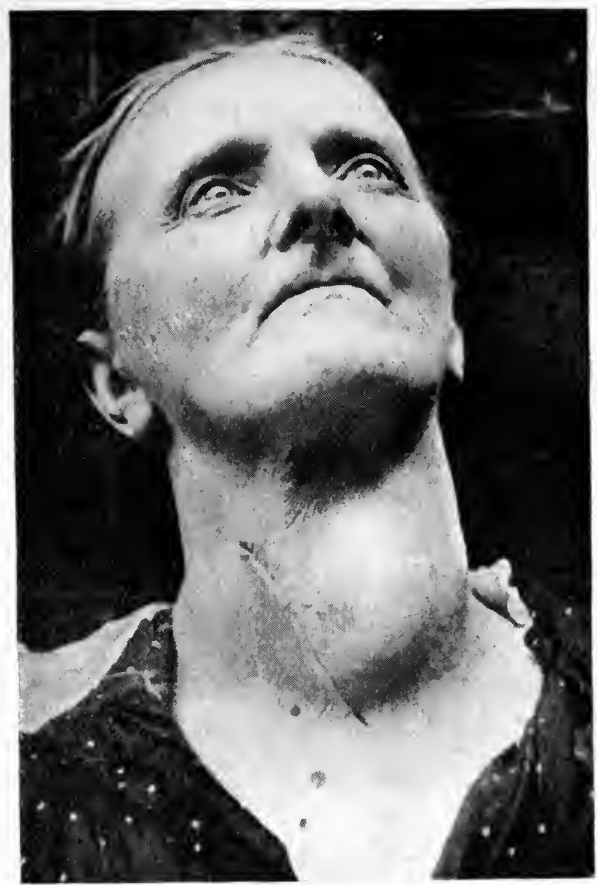

Fic. 95.-The preceding (Fig. 94), six days atter operation. (Se Appendix,

(ase 111, p. 3.52, and hoyal Frec llosp. Mus. No. xxii. 21.)

a semi-recumbent position, the head and shoulders being well propped up with pillows. Most patients after an operation for goitre are much more comfortable in this position than when kept lying down.

A sandbag on either side of the head heljs to steady it and keep it in position.

'The after-treatment of the case is usually simple. For several hours after the operation no food should be given; then milk. 
beef-tea, and other fluids may be given for a day or two, unti! the patient can swallow solid food without difficulty.

Deglutition is usually somewhat painful for the first day or two. It is occasionally advisable, in bad cases, to feed a patient partly or wholly by the rectum for a few days.

My patients are almost always allowed to get up on the second or third day after the operation, but occasionally bad cases are kept in bed a little longer than this.

The drainage-tube is always removed at the end of twentyfour hours, except in the few cases in which primary union is not to be expected.

'The stitches should be removed on the third or fourth day after the operation. By the end of a week the patient is usually completely well and able to return home. 


\section{CHAPTER XVIII.}

\section{MODIFICATIONS OF EXTIRPATION_RESECTION- RESECTION-EXTIRPATION-AMPUTATION.}

Mikulicz's resection-Description-Results-Kocher's resectionextirpation-Comparison of the two operations-Advantages over other operations-Amputation.

Resection.-Mikulicz of Cracow has given the name of resection to an operation which is particularly suitable for cases of parenchymatous goitre. The object of it is to remove the chief part of one or both lobes and to avoid any risk of wounding the recurrent nerves. At the same time enough thyroid tissue is left behind to carry on the functions of the gland.

The following is Mikulicz's description of the operation as he performed it upon a boy of sixteen who had a large bilateral goitre causing much dyspnœe : *

"I began the operation," he says, "intending to perform the ordinary one of removal of the left lobe, and hoping to be able to leave the right intact. In the course of the operation, however, it became evident that the right lobe lay partly behind the sternum, and would, if left, prove a source of danger to the patient. So instead of doing the usual extirpation, I resected this lobe in the following manner. First of all it was isolated as far as possible in the usual way with blunt instruments. The smaller blood vessels were tied with double catgut ligatures. I then tied the superior thyroid artery and vein in the ordinary manner at the summit of the lobe; also the superficial vessels passing to the lower part of the gland. I now, by means of short snips of the scissors, freed that portion of the tumour which was adherent to the front and side of the trachea, but took care not to go too far back, so as not to come into collision with the recurrent laryngeal nerve.

* "Ueber die Resektion des Kropfes nebst Bemerkungen neber die Folgezustände der Totalexstirpation der Schilddrïse," Centralblatt f. Chir., Dec. 19, 1885. 
Eventually the whole tumour was attached only to the angle between the trachea and osophagus, where it covered the recurrent nerve and inferior thyroid artery. This attached portion, the hilus of the gland, I treated like the short thick pedicle of an ovarian tumour. I had already on previous occasions convincer myself that the parenchyma of the gland was extraordinarily tolerant of mechanical injury, and this knowledge led me without scruple to put a row of ligatures upon the gland substance itself. While my assistant with his fingers compressed the vessels entering the hilus, I split the pedicle lengthwise with blunt scissors into several portions, seized each of these in a strong pair of pressure forceps and placed catgut ligatures in each of the clefts so formed. Then the goitrous mass was cut off with scissors, leaving a pedicle of $5-10 \mathrm{~mm}$. ( $\frac{1}{3}-\frac{2}{5}$ inch) in length. The forceps squeezed out nearly all the glandular tissue, leaving in their grasp little but connective tissue. The result was that the catgut ligatures could easily and safely be placed round the separated portions of the pedicle. Not a drop of blood came away from the cut surfaces; only here and there in the intervals was a little oozing; this slight hæmorrhage was easily stopped by the application of a few ligatures. The remainder of the gland had now shrunk to a lump about as large as a chestnut, which lay in the angle between the trachea and osophagus. Neither recurrent nerve nor inferior thyroid artery came into view on this side."

'The wound healed by first intention and the patient was discharged ten days after the operation. Breathing was easy, the roice was weak but clear and the vocal cords were intact. Four months later the patient was seen again; there was not the slightest trouble in breathing and the voice had regained its strength; the neck was slender and presented no sign of swelling. At the time of the last report seven months after the operation, the condition of the patient was in every respect satisfactory.

Results of Mikulicz's Resection.-'Trzebicky* has published details of twenty-three cases of Mikulicz's resection performed by Mikulie or himself. 'The patients were nearly all young subjects, fifteen of the number being under twenty-five years of age. In all cases dyspnoea was present, in many it was very severe.

* .. Writome Erfahrmangen äber die Resection des Kropfes nach Mikulic\%,"

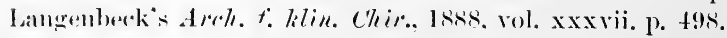


In the first five cases, one lobe of the gland was completely removed, then the other was resected.

Nine times resection of one lobe only was performed, nine times both lobes were simultaneously resected.

The only fatal case occurred among those in which both lobes were resected. 'The patient was a girl aged 16 ; after resection of the right lobe and during the separation of the left lobe an attack of severe dyspnœa occurred which necessitated the performance of tracheotomy; the operation was hurriedly concluded and the wound packed with iodoform gauze. 'T'wo hours later severe recurrent hæmorrhage took place from the right side of the wound, the bleeding could not be controlled and the patient died. At the post mortem, it was found that the ligature had slipped from the superior thyroid artery.

Of the remaining twenty-two cases, in one tracheotomy had to be performed; this necessarily prevented primary union in the wound, which nevertheless healed by second intention without any trouble.

Twenty-one times the wound was closed and drained; in only one of these did the wound fail to heal by primary union; this was a case in which artificial respiration had to be performed several times in the course of the operation. Perfect asepsis could not be maintained and in consequence, suppuration, with necrosis of the stump, took place, and recovery was delayed for about ten weeks.

In the remaining twenty cases, with the exception of two in which a little stiperficial suppuration occurred, healing by first intention was perfect. In three cases, the otherwise normal convalescence was complicated by an attack of slight inflammation of the iungs which however exerted no deleterious effect upon the healing of the wound. As regards the vocal cords in the twenty-two cured cases, they were intact both before and after the operation. In nine cases there was either marked or slight paralysis of the cords before operation; in four of these the paralysis remained after operation; in two cases it disappeared immediately after the operation, in two other cases, only after the lapse of a few months. In no case did the operation produce any deleterious effect upon the voice, or injury to a previously healthy vocal cord.

As regards after-results, in three cases no information could 
be obtained. The others were known to be in excellent health, in eight cases two to three and three-quarter years after the operation, in five cases one to two years, and in six cases six months to a year afterwards.

The dyspnœa in all cases disappeared almost immediately after the operation and, so far as is known, did not return. In one case, an attick of suffocative dyspnœa occurred immediately after the operation. In no case was there any report of a return of the goitre in that part of the gland which was left behind, although many of the cases were examined personally, and in many others information upon this point was obtained from the local doctor.

In no case did any impairment of general health (cachexia strumipriva or tetany) follow the operation. Of the fourteen patients on whom the operation was performed on both sides, twelve are known to have remained in good health.

Resection-extirpation.-This name has been given by Kocher* to an operation similar to that of Mikulicz. As the name implies, the operation is a combination of two operations. Kocher first solates the lateral lobe of the gland as in extirpation, tying the superior and inferior thyroid arteries and their corresponding veins. Then the isthmus is cut through at its thinnest part. The vessels at the upper and lower borders are tied. Then a section is made through the gland from before backwards, begimning near the junction of the isthmus and lateral lobe and ending on the posterior surface of the gland outside the line of the recurrent laryngeal nerve.

It should be borne in mind that the nerve is sometimes drawn out of its normal groove between the trachea and oesophagus and is stretched over the posterior surface of the gland. (are should therefore be taken, in making the section through the posterior surface of the gland, to keep well away from the nerve lest it be accidentally wounded. Kocher lays stress on the importance of making the section on the inner side of the upper horn well above the level of the cricoid cartilage, so as to avoid any possibility of wounding it.

'The whole of the mass external to the line of section is then removed and any bleeding vessels are tied.

* Correspondenzblutt f. schueiz. Aer.ste, Basle, 1889, p. 38. 
During the whole operation the isolated thyroid lobe lies in the operator's left hand so that even if the main arteries have not previously been tied, the bleeding can be cantrolled by digital compression, and ligatures are then required only for the cut surface of the stump.

Comparing Mikulicz's with Kocher's operation, it will be seen that both agree in leaving intact that portion of the gland that lies nearest to the recurrent nerve. But the latter surgeon avoids separating the gland from the surface of the trachea and especially refrains from tying up masses of thyroid tissue, a practice which he, quite rightly I think, strongly condemns. He says that not only does this practice tend to prevent that primary union which is all important, but that the application of the ligatures is apt to endanger the safety of the nerve. Such an accident may occur even when the greatest care is taken. With reference to this point Kocher says that formorly, when he had had less experience in removing goitres, he had sometimes, when attempting to remove one, been obliged on account of bleeding or dyspnoea to ligature the pedicle in one or more masses, in order to cut short the operation. But he had noticed tolerably often that hoarseness, from paralysis of the vocal cord, was produced at the moment of applying the ligature.

The chief advantages of resection and resection-extirpation are :

(1) That they enable the operator to remove, when necessary, both lobes of a goitre and yet to leave behind sufficient gland tissue to carry on the function of the organ.

(2) By leaving intact that portion of the gland which covers the recurrent nerve, they lessen the risk of injuring that structure.

'The operation of resection-extirpation is the one which I myself now usually adopt when removing a parenchymatous goitre. I find it to be a very satisfactory operation.

Amputation.-This is a term used for an operation the indications for which are rarely present. It consists in simply cutting off, with knife or scissors, the projecting portion of the goitre. It is suitable only in some few cases in which the tumour forms a prominent more or less pedunculated mass. 


\title{
CHAP'IER XIX.
}

\section{TREATMEN'T BY INTRA-GLANDULAR ENUCLEATION ANI) ITS MODIFICATIONS.}

\begin{abstract}
Intraglandular enucleation: History-Cases suitable forlescription of operation-Hemorrage-siture of gland. Resectionenucleation: Gisess suitable for-Description--Advantages and disidlintilges. Intracapsular enucleation. "Bloodless" enucleation. "Évidement" : Cases suitable for.
\end{abstract}

Br intra-glandular enucleation is meant the removal of a cystic or solid tumour from the interior of the thyroid gland, the surrounding glandular tissues being left intact.

Enucleation of cysts appears to have been performed as long ago as 1840 by Porta of Pavia.*

Billroth, too, more than thirty years ago practised a similar operation.

More recently, enucleation of cysts was recommended and practised, with success, by Julliard of Geneva and Kottmann of solcure. Burchkardt of Stuttgart, Miiller of 'Tübingen and many others have also written upon the subject of enucleation of 'ystic goitres.

Solid tumours of the thyroid gland were, however, rarely treated in this way until Professor Socin of Basle, some twenty vears ago, began to practise enucleation upon these also. Dr. Kener of Vevey contributed materially to our knowledge of the operation by the publication in 1887 of an excellent monograph upon the subject. $\dagger$ He gave full details of thirty-seven enucleations performed by Socin. Of these, seventeen were for "rstic and twenty for solid tumours.

In this country Mr. Charters Symonds, in 1889, brought the

* - 1)enle malattie + delle operarioni della ghäandola tiroidea," Luigi Porta, Milan. 1s+!).

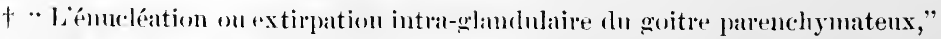

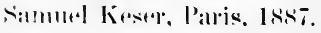


subject prominently before our notice by publishing an excellent series of cases.*

In the last few years the operation has been practised exten-

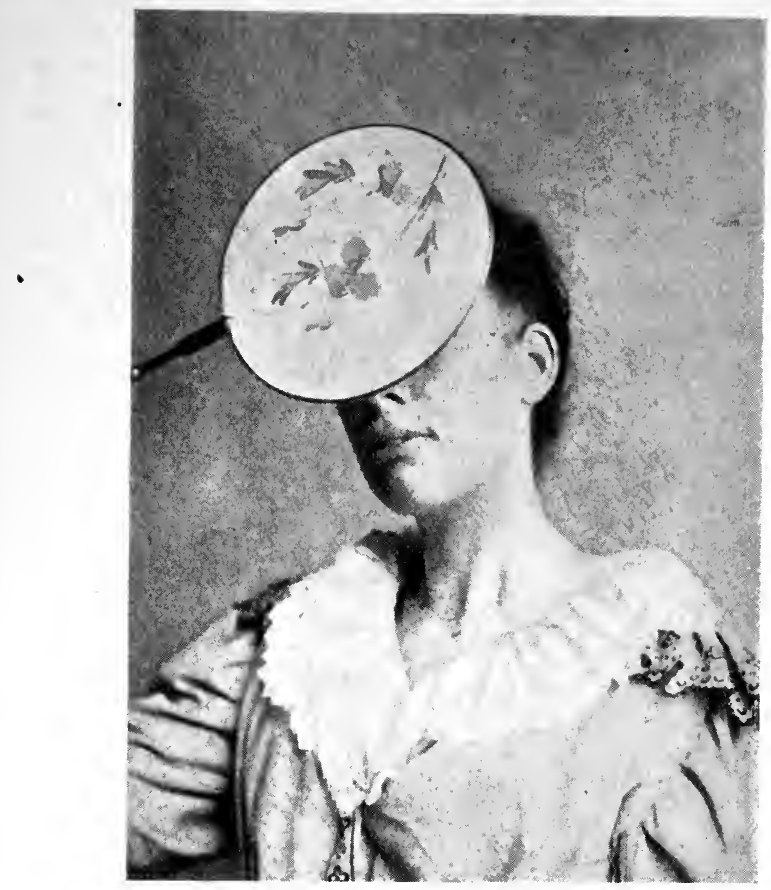

Frc. 96.- Showing a Transverse Scar low down in the neck, one mouth after enucleation of a left erstic adenoma as latroe as a duck's egg. The tumour had cansed considerable dyspnoa. (Sep Appendix. Case 54, p. 346.)

sively by very many surgeons and its excellence thoroughly proved.

The operation of enucleation depends for its feasibility upon the following facts :

Many goitres consist, not of an enlargement of one or both lobes of the thyroid gland, but of a circumscribed tumour lying in more or less healthy gland tissue. Sometimes the tumour is a cyst, unilocular or multilocular ; sometimes it is solid, of an

* "Eight Cases of Thyroid Cysts and Adenomata treated by Enucleation," Trans. Clin. Sor. vol. xxiii. p. sı. 
adenomatous nature, like the corresponding tumours which are found in the breast and other glandular organs.

Of whatever nature, the tumour is surrounded by a wellmarked capsule composed of connective-tissue, and of thyroid tissue altered and atrophied by pressure.

It is owing to the existence of this capsule that enucleation can be performed, the tumour alone being shelled out without interference with the remainder of the gland.

The nature of the capsule surrounding the goitrous tumour varies according to the size and position of the tumour. If the latter be small and deeply seated, it is surrounded by what is obviously, to the naked eye, thyroid tissue. If, on the other hand, the tumour be large and project much, it will probably be covered on its superficial aspect by what appears, at first sight, to be merely connective tissue, but which is really a thin layer of thyroid tissue. Whether thick or thin, then, the capsule of the tumour is composed everywhere of thyroid tissue, the presence of which can easily be demonstrated by means of the microscope.

It is very important that the distinction between the connective tissue capsule of the gland and the glandular capsule of the tumour proper, should be carefully borne in mind.

The earlier stages of the operation, that is down to the exposure of the thyroid gland, are the same as in extirpation already described.

An incision is now made through the capsule of the gland and through the gland itself, until the surface of the tumour has been reached.

Any large vessels that may be seen on the surface of the gland may be clamped before this incision is made, or they may, perhaps, to some extent be avoided by placing the incision in a part where the ressels are least conspicuous. As a rule, the incision should be made directly over the most prominent part of the tumour without much attention to the vessels.

If the capsule of the tumour be very thin and transparent, as is often the case, it may be closely adherent to the capsule of the gland and the two inay appear to form but a single layer, which may be closely adherent to the tumour itself. As it is very important that the surface of the tumour be distinctly 
recognised, it is sometimesadvisable to begin the incision somewhat higher up, where the glandular layer is thicker and more easily distinguished by its reddish colour from the subjacent tumour. The tumour itself is most easily recognised by its colour, which is almost invariably different from that of the healthy gland.

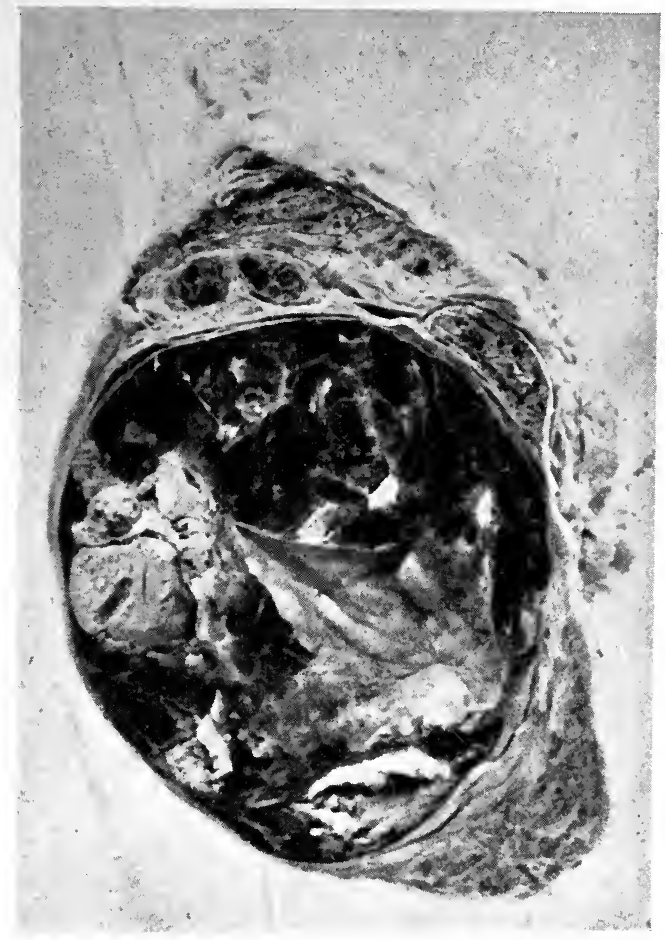

Fig. 97.-Right lobe of the thyroil, removel by extirpation, on aceount of dyspmoea, from a womanaged 25. It contains a Cystic Adenoma, which might, with advantage, have been removed by enucleation. (Case 11.* See Royal Free Hosp. Mus. No, xxii. 44.) (Natural size.)

It is generally of a dark blueish hue from the presence of blood-stained fluid within it; it is frequently of a light yellowish colour, especially if the tumour be old and have thick walls. It is only in the case of soft, very vascular, solid adenomata that the colour of the tumour at all resembles that of the healthy gland.

* Published in the Brit. Mer. Journ., July $7,1800$. 
The operator must cut boldly through the gland until the surface of the tumour has been clearly defined. He must be careful, however, not to cut into the tumour itself, and thus miss the proper layer between tumour and gland, in which alone enucleation can be properly performed.

As soon as the tumour has been reached, the knife is laid aside and the tumour shelled out of its bed with fingers or with a blunt instrument, such as a goitre scoop (see Fig. 98). In the
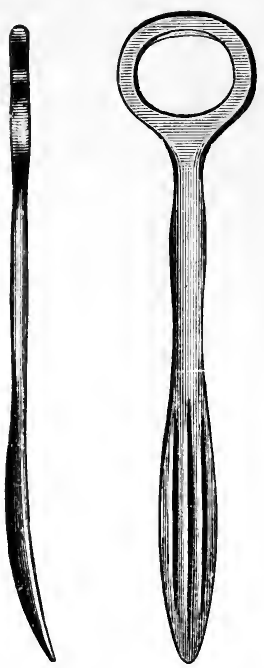

$\boldsymbol{1}$
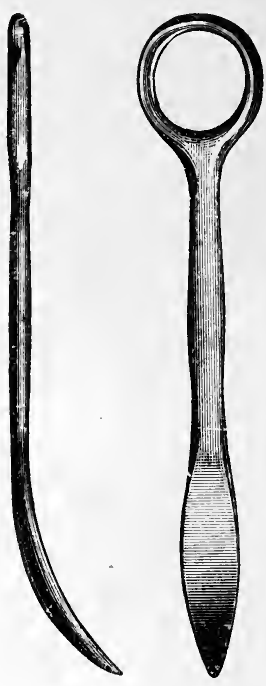

13

Fra. 98.-Goitre scoops, used chicfly for the enucleation of eysts and allenomata. A. Kocher's. B. The same, slightly modified.

absence of a better instrument, the handle of a scalpel or a closed pair of curved, blunt pointed scissors, will do very well for the enucleation.

Some operators think it desirable to remove the tumour in an unbroken condition. I attach, however, but little importance to this. If the tumour is soft and contains fluid, as is very often the case, it is very liable to be ruptured during the removal. In the case of a tumour which is suspected to contain fluid, I often begin by plunging a knife or some blunt instrument into the interior to let out this fluid. 'Through the 

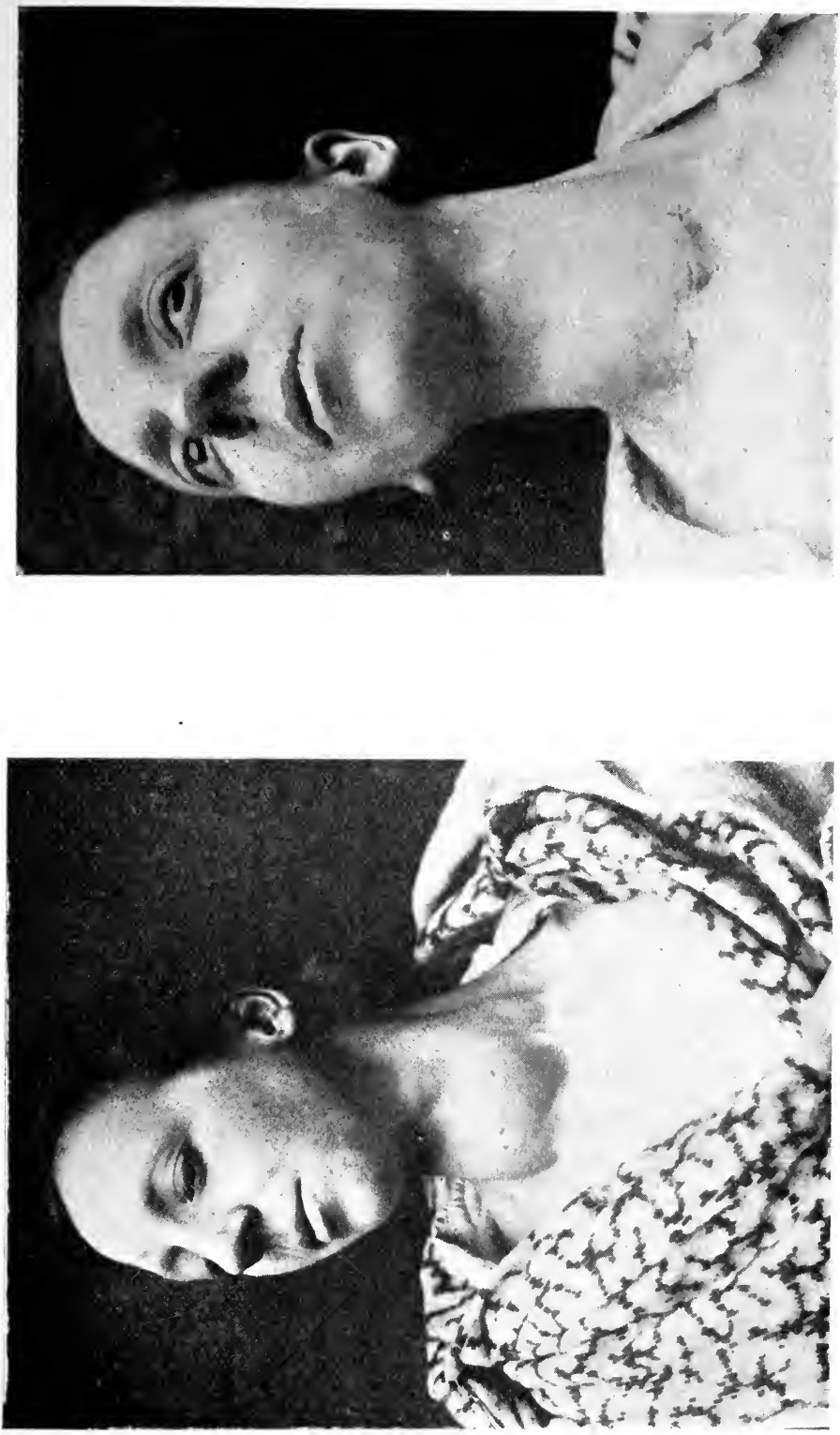

$\vdots \doteq$

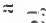

$\stackrel{3}{*}$

$=\frac{\bar{z}}{\pi}$ 
opening thus made I put the left forefinger and thus grasping the wall of the tumour between the finger and thumb, draw it forwards and effect the rest of the enucleation by peeling the gland away from the tumour with a pair of dissecting forceps held in the right hand.

Or the wall of the tumour may be grasped with broad forceps instead of with the finger and thumb.

In many cases of soft solid tumours and in some cysts, the wall is so thin that it tears readily when traction is made upon it. In these cases it is best to place several pairs of forceps on the cut edges, so as not to exert too much traction upon any one point.

'The preliminary evacuation of the contents of the tumour, by diminishing its size, often enables the operator to draw the tumour well forwards o'st of the wound through a comparatively small incision. I have often, by adopting this manœuvre, succeeded in removing large cystic and even solid tumours through skin incisions considerably shorter than the diameter of the tumour itself. It must be remembered, however, that interference with the interior of the tumour often eauses smart hemorrhage, and that no attempt can be made to control this hamorrhage until the tumour has been removed. Before attempting to enucleate a tumour through a small incision, the operator should feel certain that the tumour will permit of rapid and easy enucleation; otherwise he may get into serious trouble with the hemorrhage.

In performing the enucleation, whether by finger, scoop, or forceps, the operator must be careful to keep always close to the external surface of the tumour, and not to let the point of his instrument wander through the gland tissue into the tissues outside the gland. 'This is easily done if the gland be much atrophied and form only a thin layer over the tumour.

Directly the tumour has been removed attention must be directed to the hremorrhage, which is often profuse during the few moments occupied by the actual enucleation. A sponge should be placed in the cavity formerly occupied by the tumour and the whole cavity drawn forwards, either by means of the forceps previously placed on the cut edges, or by forceps applied to the inner surface of the posterior wall. It is often a good 


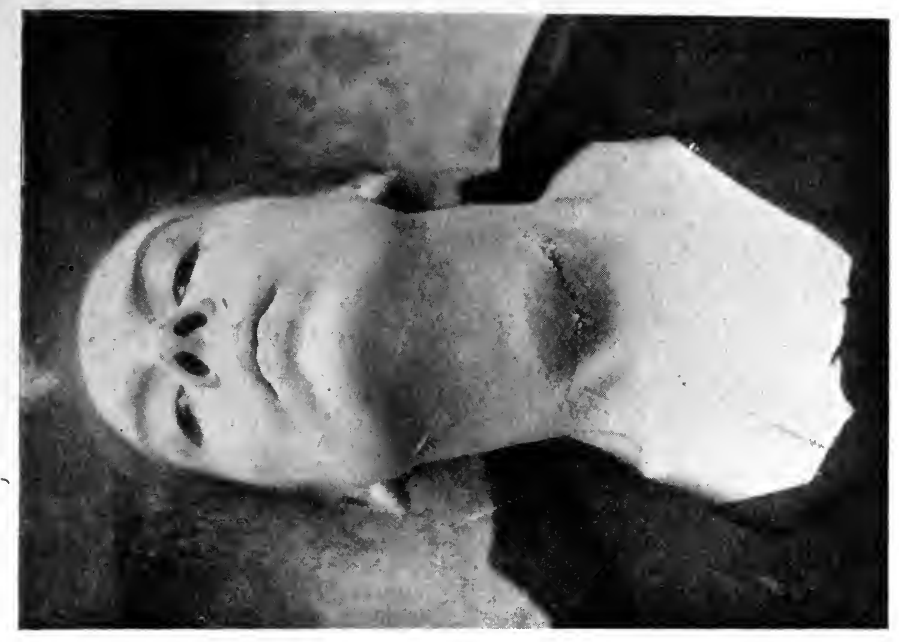

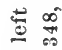

$\cong$

$\varpi$ की

赵

밀

串:

ব行

㻖资

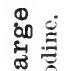

ฮై

๘ $\equiv$

40

멸

怘茌

o w

อ

ตี

节导

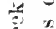

.

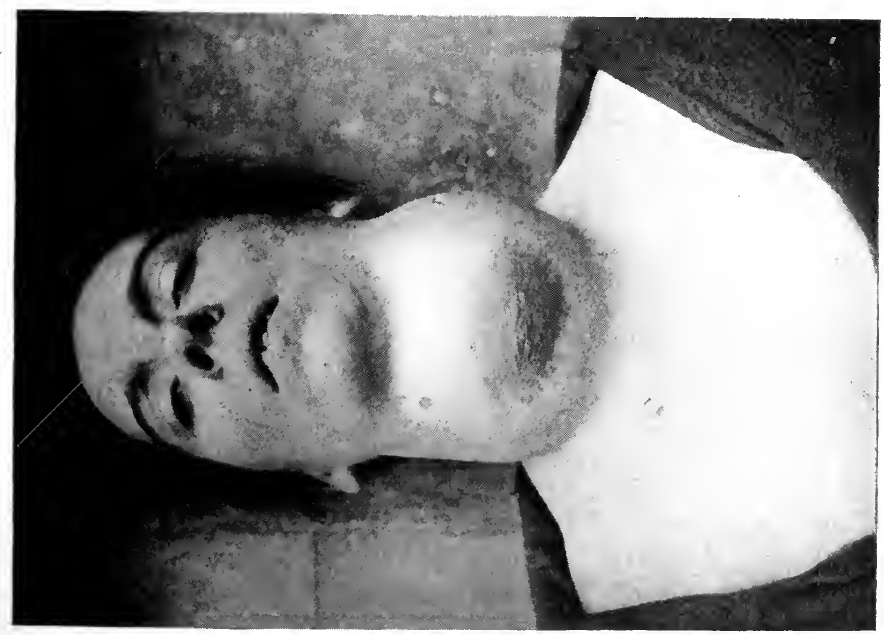

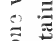

อ ซ

突

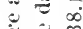

它芯

क : $x$

๓

范

些方苛

苛完

崩

$1 \pm$

สิ के

芯焉

实咅

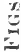


plan to evert the bottom of the cavity by pushing its posterior wall forwards from behind by fingers placed outside the gland, or even in the posterior triangle of the neck. The hæmorrhage is thus kept well under control, while the bleeding vessels are picked up one after another and securely tied.

It is of the greatest importance that all homorrhage should be completeiy arrested before the wound is closed. If oozing be allowed to take place into the wound primary union is prevented and serious trouble may follow.

When the wound is quite clean and free from blood it must be closed. This is best effected by three layers of fine sutures, one in the gland, one in the muscles, and a third in the skin. The sutures in the gland should be passed transversely in and out several times through the wall of the cavity, so as to obliterate as far as possible the space in which the tumour lay, and thus prevent the accumulation of blood within it. 'The layer of gland forming the wall of the cavity may be very thin, and care must therefore be taken not to transfix or include in the suture any of the structures lying immediately outside it, especially the internal jugular vein and the recurrent laryngeal nerve. 'The subsequent steps of the operation are the same as in extirpation. If the cavity to be closed is small and the wound is a perfectly clean one, drainage need not be employed. If the cavity is large, drainage for twenty-four hours is advisable.

The after treatment of the case differs in no essential point from that of extirpation.

\section{Modifications of Enucleation. Resection-enuclea-} tion.--The most important modification of enucleation, and one which I frequently employ, is that which has been described by Kocher under the name of resection-enucleation. Just as resection-extippation is an extirpation in which the inner and back part of the lobe is left intact, so is resection-enucleation an enucleation which leaves behind this portion of the lobe but removes all the rest. It is suitable, of course, only for encapsuled tumours, and is most useful in cases of very large tumours. 'The enucleation of a very large thyroid tumour, if performed in the ordinary manner, may involve considerable hrmorrhage from the surface of the vast cavity in which the tumour lay. 


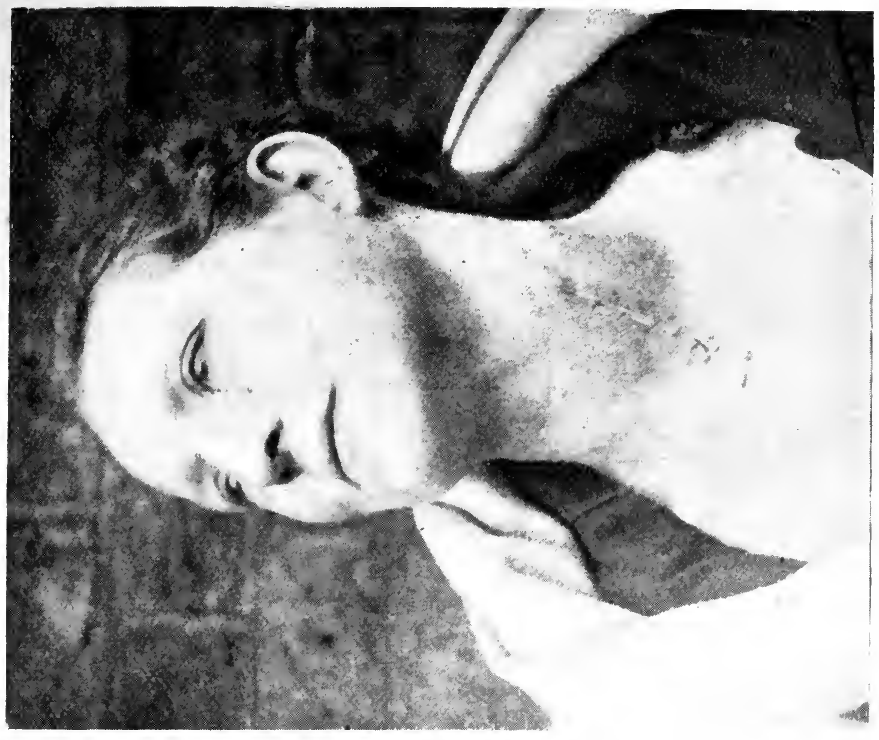

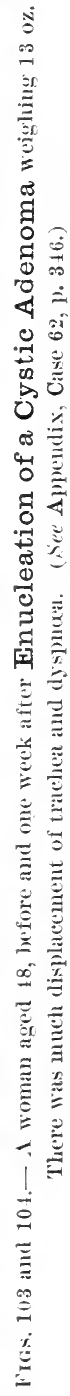

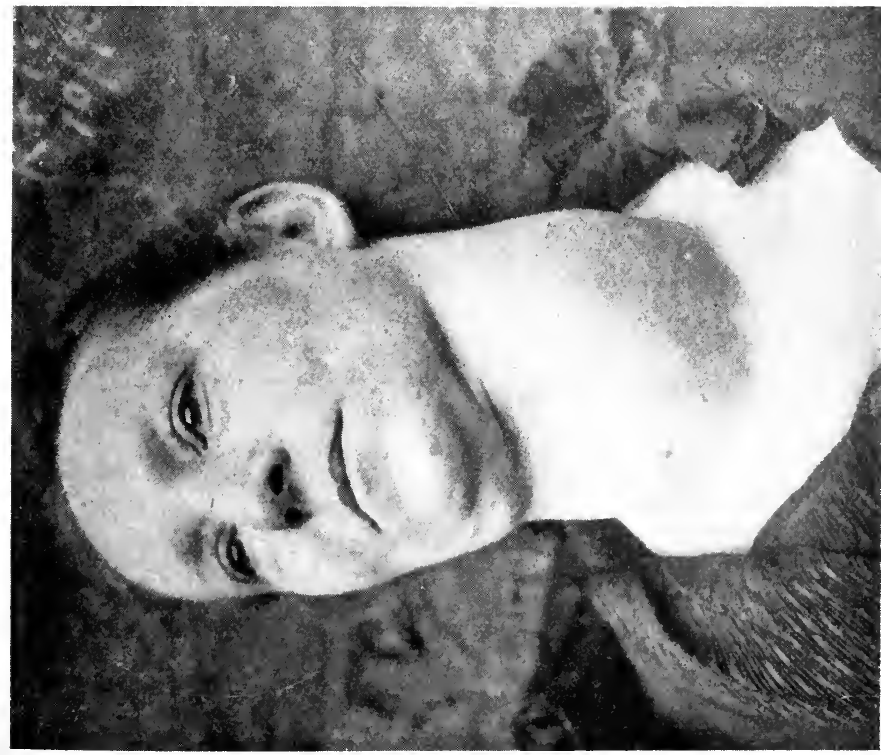


Moreover, a very large tumour has in its growth so compressed the gland tissue lying over it, that the latter is functionally well nigh useless. In resection-enucleation a large portion of this thinned glandular capsule is removed with the tumom. The latter is enucleated only from its connections at the inner and

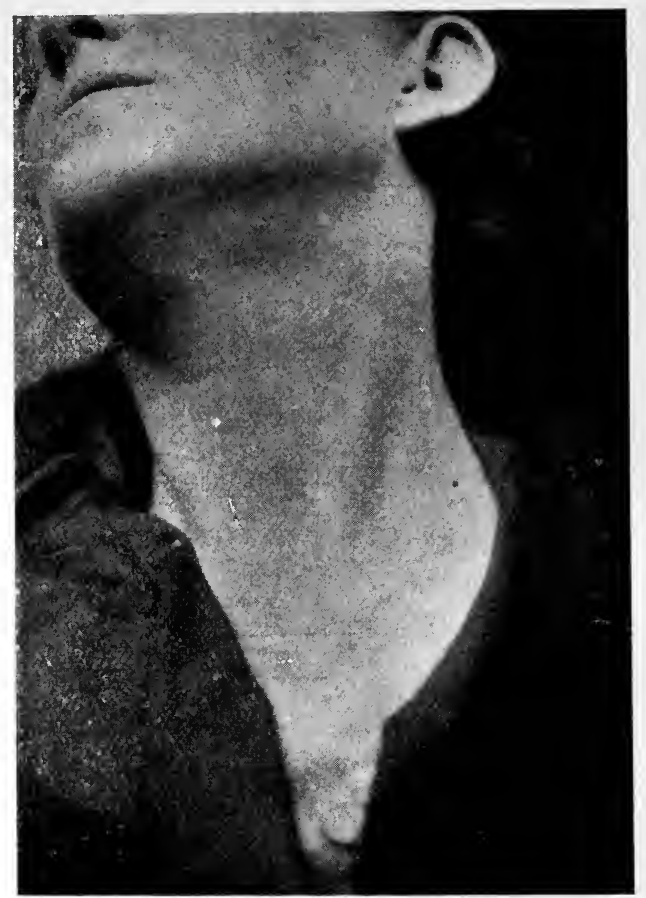

Fir. 105,--The preceding ( Fig. 103) one year after operation. (See Ippendix. ('ase 62, 1. 346, and lioyal Free Hosp. Mus. No. xxii. 47.)

back part. Reference to Figs. 106 and 107 will make the steps of the operation clear.

A rertical incision is made along the line $a a^{*}$ on the front and inner part of the tumour. Enucleation is then performed on the inner side only of the tumour. When the posterior wall of the tumour has been reached the glandular capsule is again cut through, at a point well external to the recurrent laryngeal

* I usually make this incision a little further outwards than is shown in the timure. 


\section{MODIFICATIONS OF ENUCLEATION.}

nerve. The tumour, with all the rest of its glandular capsule

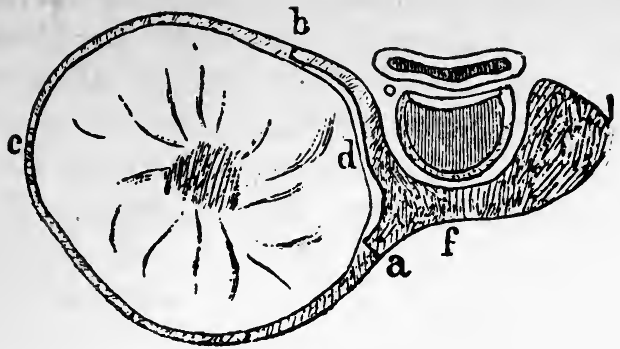

Frg. 106.-Diagrammatic horizontal section through the thyroid gland, trachen, œsophagus, and reeurrent nerve, to illnstrate Resection-Enucleation. The right lobe of the gland is oceupied by an encapsuled tumour which is embedded in a thin layer or eapsule of gland tissue $(c)$. At $a$ is seen the place on the front of the gland where this gland capsule shonld be cut vertically. At $b$ is the corresponding place where the gland is cut posteriorly. Along the line $a d b$ the surface of the tumour has to be separated from the healthy gland tissue on its inner side. The rest of the grlandular eapsule $a c b$ is removel with the tumour. (. Ifter Kocher.)

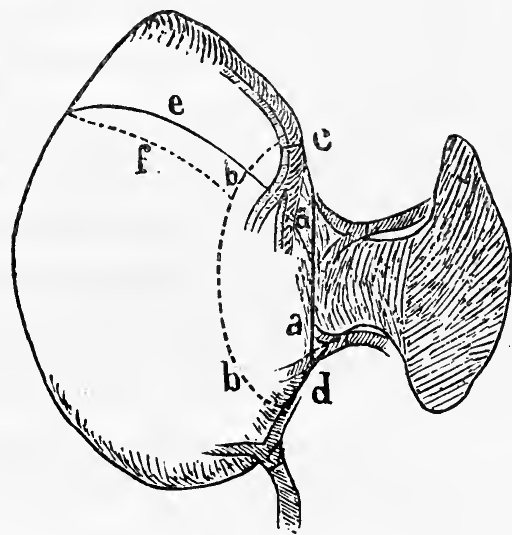

Fra. 107.-Front view of a goitre similar to that of Fig. 106. The vertieal line aa shows the position of the incision throngh the anterior part of the gland capsule. The dotted line $b b$ shows the line of incision throngh the posterior part of the capsule. If the upper horn of the gland is not to be removed, the incisions are made along the lines a ae in front and $f b b$ behind. (After Kocher.)

still attached to it, is then removed. Various thyroid vessels have to be ligatured in the course of the operation, as is done in extirpation. 
'The operation may be variously modified according as the tumour lies at the upper or lower part of the gland (see Fig. 107), the object always being to leave behind healthy gland tissue and to remove the tumour and the atrophied glandular tissue lying in immediate contact with it. After removal of the tumour I frequently unite with a few points of suture the anterior and posterior edges $(a a, b b)$ of the remaining gland. This tends to diminish still further the size of the wound. Resection-enucleation, when compared with simple enucleation, has therefore the advantages that:

(1) It lessens the severe hrmorrhage that often occurs in the separation of the tumour from its capsule.

(2) 'The capsule of functionally useless gland tissue is not left in the wound. 'Thus the very deep sutures necessary to bring the sides of this capsule into contact to secure primary union may be avoided.

On the other hand, the cellular tissue of the neck is opened up more freely in resection-enucleation than in enucleation.

Intra-capsular Enucleation (Julliard). - Julliard of Geneva * has adrocated a method of removing goitres which, in his hands, appears to have proved very successful. Instead of keeping outside the capsule as Kocher does in his operation of extirpation, Julliard removes the tumour from within the capsule. 'This proceeding must not however be confounded with Socin's enucleation. Socin removes the goitrous tumour from within its glandular capsule, that is the capsule formed by thyroid tissue. Julliard's operation is really not a true enucleation but a variety of extirpation, the tumour being however removed from within its capsule.

For my own part I camnot but think that Julliard's operation is inferior to Socin's on the one hand and to Kocher's on the other. Inferior to Socin's in that it removes not merely the tumour but also surrounding tissues: inferior to Kocher's, because by opening the capsule, hrmorrhage is produced which might have been avoided by keeping outside the capsule.

"Bloodless ", Enucleation (Bose).-Bose of Giessen $†$ has

* .. Trente et une extirpations de goitres," Rer. Ae Chir., Paris, 1883, iii. 585.

† " Dit kunstliche Bhutleere bei Ausschälung von Kropfkuoten," Centralbl. $f$. Chir.. 188!, xvi. p. 1. 
devised a so-called "bloodless method of performing enucleation." It is intended to facilitate enucleation by enabling the operator to see more clearly the limits between healthy and diseased thyroid tissue. He isolates one lobe of the gland sufficiently to enable it to be raised up from its bed. The amount of blood in it quickly diminishes as is the case when one of the limbs is held in the vertical position for a few minutes. An elastic ligature is then passed round the tumour at a point a little beyond its widest part and then fastened. A piece of ordinary rubber drainage tubing is used for this purpose.

The gland thus emptied of much of its blood can then be incised and the tumour or tumours dissected out withont difficulty. 'The elastic ligature also assists by squeering the tumours out towards the wound. The bleeding which occurs after the ligature has been relaxed is said to be but trifling. Bose's method is of course not applicable to cases in which the goitre is deeply seated and fixed. The whole proceeding seems to be somewhat rough and unsurgical and is open to the serious objection that it involves far more disturbance of the gland and more opening up of the cellular tissue of the neck than in the ordinary enucleation. I have myself never employed this method of enucleation.

Evidement. - Inder the name of éridement (cracuatio struma) Kocher has described a proceeding which differs slightly from enucleation.

In the latter operation the capsule only is at first divided, the tumour being then isolated and removed.

In evacuation, the tumour itself is "cut across in its whole thickness, the two halves being then extracted by means of fingers and sharp spoons."

This operation is however of only limited applicability. According to the originator of it, it may on account of its simplicity be employed with adrantage in : (1) Isolated small or large tumours of soft consistence, lying in comparatively healthy gland tissue; (2) Large tumours lying in goitres not freely movable, even though the goitres may contain numerous other nodules, a condition which, had the goitre been movable, would have demanded extirpation; in order to justify the performance of evacuation, however, the tumour 
must be soft and have numerous vascular connections with surrounding parts.

I have myself employed this method in a few cases. These have been chiefly cases of very soft adenoma in which owing to the friability of the tumour simple enucleation would have been difficult. (See cases 72 and 80 on p. 348.) 


\section{CHAP'TER XX.}

\section{COMPLICATIONS OF OPERATIONS FOR REMOVAL OF NON-MALIGNANT GOITRE.}

I. Accidents occurring during the operation : sudden death-Causes of-Cases-Importance of avoiding tracheotomy, if possible-Primary hemorrhage in extirpation. in enucleation-Injury to nerves-Recurrent laryngeal nerve. sympathetic, vagus-Injury to trachea, pleura, pharynx and esophagus. II. Complications occurring shortly after the operation: Secondary hemerrhage-Recurrent hemorrhage-Sepsis-Treatment of-Rapid pulse with restlessness-Causes of-Late compression of recurrent nerve by scar-Tetany.

These may conveniently be divided into the following groups :

I. Accidents occurring during the operation.

II. Complications occurring shortly after the operation.

III. Remote complications.

\section{Accidents occurring during the Operation.-} 'These are generally caused by dyspnœa, by the anæsthetic, or by injury of blood-ressels, nerves or other important structures in close proximity to the goitre.

Sudden death during the operation is the most serious of these accidents. It occurs almost exclusively in cases in which severe dyspnoea is present before the operation has been begun, or in which there is a history of severe paroxysmal attacks of dyspnœa. Many such cases have been recorded and many others remain unrecorded. This calamity is due usually either to the administration of an anæsthetic in an unsuitable case, to the severity of the dyspnoea or to syncope. Very severe dyspnoea may have been present before the operation and may lead to death before the operator has had time to give any relief; or dyspnœa may be suddenly induced by undue traction or pressure upon the trachea during the course of the operation; or may be 
caused by spasm of the glottis from irritation of the recurrent laryngeal nerves (a rare cause). Finally dyspnœa may be due to syncope caused by irritation of the vagus or its cardiac branches, acting perhaps upon a heart already much damaged by prolonged respiratory distress.

Sometimes death occurs at the very beginning of the operation inmediately after the first incision through the skin has been made. Julliard records a case of this kind. The patient was a man aged 26 with severe dyspnoea. I have recorded * a similar case which unfortunately occurred to myself many years ago. The patient was an elderly woman who had had a large goitre for many years. In the last few months it had given her much more trouble and she had had many severe attacks of dyspnoea. An attack which occurred just before I first saw the patient was so severe that her medical attendants who witnessed it told me that they did not expect she would have survived it. An operation for the removal of the goitre was undertaken. Chloroform was administered and the usual oblique incision had just been made when breathing suddenly stopped. 'Tracheotomy was immediately performed and artificial respiration kept up for some time, but without avail. I have no doubt now that it would have been better to have done this operation without chloroform, using only a local anxsthetic. The only other case of death during a goitre operation that has occurred to myself was that of a woman aged 43 who had a parenchymatous goitre and had had severe paroxysms of dyspnoea. Chloroform was administered and the superior thyroid vessels and middle thyroid reins had been tied and divided. The tumour was being lifted up out of its bed preparatory to tying the inforior thyroid artery when the patient suddenly died, twelve minutes after the beginning of the operation. In both these cases the chloroformists, although anæsthetists of considerable expcrience, had, I believe, never before given an anæsthetic for a goitre operation. Both cases were among my earliest operations.

The following case, of which I was a witness, although taking no part in the operation, occurred at St. Bartholomew's Hospital

* "Lectures on Goitre at the Royal College of Surgeons," Brit. Med. Jiur"., June 1891 . 
in 1896: "A woman aged 26 had had for four years a swelling of the thyroid with some dyspnœa, especially at night. She was a healthy young woman with a cystic adenona as large as a hen's egg at the lower part of the right thyroid lobe. When quiet she had no stridor, but after exertion or on taking a deep breath the tumour descended behind the sternum and caused audible stridor. When the tumour was in the latter situation it was no longer visible. Intra-glandular enucleation was performed; the operation lasted only a few minutes, but in the course of it the patient stopped breathing and could not be brought round again, in spite of tracheotomy and other efforts to restore her. The cessation of respiration occurred just at the moment when the tumour was being enucleated with the finger." *

In King's College Hospital Reports $\dagger$ is a brief account of a similar death during the removal of a fibro-adenoma from a female patient. "The death was due to sudden dyspnœa owing to the pressure of the growth during the operation."

The knowledge of these cases and of a good many others, some published and some communicated privately to me, have led me to take a somewhat serious view of the question of a general anæsthetic in cases where there is much dyspnoea. I believe that when dyspnoea is severe there may be grave danger in the administration of a general anxesthetic, especially if the administrator is not thoroughly familiar with goitre operations. Whenever possible I prefer either to have a skilled anæsthetist thoroughly familiar with these operations, or in some cases of bad dyspncea to dispense altogether with general anasthesia, using only cocaine, eucaine, or morphia.

The danger of the supervention of sudden dyspniea or syncope appears to be specially great just at the moment when the tumour is being lifted up or turned over. It is at this time that the flattened and narrowed trachea is most likely to be still further compressed. It is well, therefore, that, at this stage of the operation, both operator and anæsthetist should pay especial attention to the respiration and circulation.

If the dyspnoea becomes very urgent, tracheotomy may become

* St. Bart. Hosp. Reps., xxxiii. 1897, appendix ii. p. 17 .

+ Vol. ii. 1894-5. 
imperative. But it is very rarely necessary, and it should be remembered that the performance of tracheotomy greatly increases the danger of the operation, since the all-important primary union is thereby necessarily prevented.

It is obvious that in some cases in which the operation is unusually severe and prolonged, or in which the patient's general condition is very bad, death may occur from shock, dyspnœa, or hremorrhage before or very soon after the conclusion of the operation.

The danger is naturally greater if the goitre be of enormous size, or very fixed, or if the patient be very old. 'The following' case is an example of what may occur when the operation is postponed until the patient is in extremis. It has been kindly communicated to me by Mr. Stanley Boyd, who was present at the operation, although he was not himself the operator:

The patient was a middle-aged lady who had had a large bilateral goitre for many years. In the last ten years she had been under the care of a physician who had from time to time injected tincture of iodine without, however, causing any decrease in the size of the tumour.

Breathing had for some years been getting gradually worse, and there harl been much stridor for a year or more. In the autumn of 1890 she had an attack of bronchitis, and her condition rapidly became extremely serious. It was then recommended by the injector of iodine that one half of the gland should be removed, and a well-known London surgeon, now deceased, was asked to go down into the country to perform the operation.

The patient was found sitting up in bed with a livid face, gasping for breath. Loud stridor was present, and it was obvious that the trachea was greatly compressed by the goitre.

It seemed evident that unless something was speedily done to relieve the dyspnoea, the patient would certainly die very soon.

The extreme gravity of the case having been explained to the patient's friends, and it being their wish that the attempt, however hizardous, should be made to save her life, extirpation of the goitre was begun. The difficulties of the operation were, however, so wreat, and the dyspnoea became so severe, that tracheotomy seemed imperative. A deep incision was therefore made through the very broad isthmus down to the trachea, which was found to be so much compressed that its walls were almost in contact. Tracheotomy 
and artificial respiration were performed, but in vain. The unfortunate patient gave a few gasps and expired.

Primary Hæmorrhage may prove to be a serious complication, if the operation be a very long and tedious one, or if the goitre be very large. In extirpation, hæmorrhage ought never to be severe, if sufficient care be taken to tie or clamp all the principal vessels before they are cut. The surgeon who operates by cutting freely, and then picking up and tying the vessels that bleed, will cause a great deal of unnecessary loss of blood, and often seriously endanger the life of his patient. It cannot be too strongly insisted upon that in this operation every vessel of importance must be tied or clamped before it is divided. In this way even large and very vascular goitres may be removed with the loss of less than an ounce of blood. A knowledge of the exact position in which the principal vessels are to be found, is, of course, of much importance.

With enucleation the case is, of course, different. 'The tumour is in this operation generally enucleated rapidly, without regard to the vessels. The hæmorrhage is often considerable for a few moments. But by rapidly removing the tumour and then drawing forward the bottom of the wound, control of the bleeding points is soon obtained, and the hemorrhage arrested. It should be borne in mind that if the tumour to be enucleated is very large, and especially if it be solid, a very considerable amount of blood may be lost in a very few minutes. If it seems likely that an enucleation would be attended with great loss of blood, it may be better to perform an extirpation rather than to attempt enucleation. With regard to hæmorrhage in enucleation operations, Bruns, speaking of 200 enucleations performed by him, says that " in seventy per cent. the bleeding was unimportant, in twenty per cent. considerable, and in ten per cent really profuse, so that many times the enucleation had to be abandoned altogether." * My own experience of enucleation operations is more favourable, as I have but rarely met with hæmorrhage that could be described as really profuse. I have never had to abandon an enucleation on account of hæmorrhage. On one occasion only (in 1890) did I begin an enucleation

* Verll. d. deutsch. Gesellseh. f. Chir., Berlin, 1896, xxv. pt. ii. p. 37. 
and then, finding that the tumour was not sufficiently encapsuled, perform an extirpation instead. On one single occasion only have I had to pack the wound with gauze on account of hæmorrhage and this was one of my earlier operations, performed when I had had but little practical experience; the patient made a good but somewhat tedious recovery.

Hæmorrhage from veins is more to be feared than hæmorrhage from arteries. The former are often greatly dilated and their walls may be so thin that they tear very readily. The application, even of a ligature, may sometimes lead to the vein being cut through by it.

A Swiss surgeon has related to me that, on one occasion, when removing a deep-seated goitre, he was unfortunate enough to tear a large hole in one of the innominate veins. Blood poured out, the hemorrhage could not be controlled, and the patient died on the table.

Veins, even large veins, may be so pressed upon by the goitre that they are emptied of their blood. 'They may then resemble bits of fascia, and the operator may easily tear them across if he is not very careful. 'The torn end of a vein may retract into the cellular tissue of the neck or mediastinum. It may then be very difficult to secure the bleeding vein. The blood extravasated into the cellular tissue renders recognition of the various structures difficult, and the operator may be seriously embarrassed. Such accidents, however, may with ordinary care be avoided.

l'minary hemorrhage in a goitre operation is not, at the present day, very greatly to be feared, provided that due care be taken to avoid it. At the same time it must be remembered that any goitre operation, whether extirpation or enucleation, if carelessly or improperly performed, may be attended by great and even fatal loss of blood.

Injury to Nerves.-Wound of the recurrent laryngeal nerve is an important and serious complication of the operation of extirpation, although it cannot occur in a well executed enucleation. Although I have never yet had the misfortune to cut this nerve in any operation for goitre, yet several cases have come under my notice in which the nerve has been cut by others. As the nerve lies in contact with the goitre at its inner 
and back part, it will readily be understood that unless considerable care be taken when dissecting in this region section of the nerve may easily occur. This danger, in most cases, can, without difficulty, be avoided by keeping close to the surface of the goitre. Sometimes it is advisable to dissect out the nerve and hold it aside, but it is better, if possible, not to expose it at all. It should be remembered that the nerve is occasionally displaced from its normal groove between trachea and œsophagus, and may lie spread out upon the posterior surface of the gland even as much as half an inch outside its normal position. When in this abnormal situation it runs much risk of being wounded.

Section of the nerve leads, of course, to paralysis of the corresponding vocal cord and consequent alteration of voice.

I have once seen an unfortunate patient whose recurrent nerves had been wounded on both sides of the neck.

The patient was a man aged 32, admitted to St. Bartholomew's Hospital on account of severe dyspnœa. Four years previously a large parenchymatous goitre, which had lasted for at least thirteen years, had been removed at a hospital in the country. Dyspnœa and dysphonia were the immediate result of the operation. The latter was permanent. The former was at times so bad that eventually tracheotomy was performed. Subsequently the larynx was laid open, and the paralysed vocal cords were cut away. The wounds were then allowed to heal, but dyspnœa again returned, and for this he came to the hospital. Tracheotomy was again performed, and subsequently all the old scar tissue within the larynx was freely removed, after the latter had again been split open. The tracheotomy tube was worn for sixteen days, and then discontinued. The patient made a good recovery from this operation, and left the hospital six weeks later with a false glottis of farr size.*

Short of actual section of the nerve, it may be damaged during the operation by undue traction, by clamping with forceps, or by inclusion in a ligature. Washing out the wound with strong antiseptic lotions has probably in some cases been the cause of transient paralysis of a vocal cord.

* St. Bart. Hosp. Reps. vol. xxxiii., 1897, p. 179. I was subsequently informed that shortly after leaving the hospital the dyspnœa returned and tracheotomy was performed for the third time. 
Wound of the cervical sympathetic nerve has been recorded a few times.

It is most likely to occur when the main trunk of the inferior thyroid artery is being tied.

In several of Rydygier's cases (see p. 242) the sympathetic was injured.

Wound of the vagus is a rare accident. Bramwell* records one case of the kind. After death the nerve was found to have been included in a ligature.

Another case in which the nerve was cut occurred at a provincial hospital in England and has been reported privately to me. The patient died.

Even the hypoglossal nerve has been wounded on at least one occasion. ${ }^{\dagger}$

Injury to the trachea.-Chis is fortunately a rare accident. Liebrecht records four cases in which it occurred. A fifth case has been communicated to me privately by a surgeon who was present at the operation. A considerable portion of the trachea was removed with the goitre. The patient died soon afterwards. Berard $_{+}^{+}$mentions another case which occurred to Billroth. This accident can scarcely occur except firom gross carelessness, or from want of knowledge of the anatomy of the parts.

A goitre is closely connected with the trachea and often very firmly adherent to it. Frequently a careful dissection is required to separate these structures. Again, the trachea is often much displaced, and my ne more or less surrounded by the goitre, in such a mamner that the operator, if inexperienced, may suddenly meet with the trachea quite unexpectedly. If the goitre be hard and the trachea soft and flattened, wound of the latter may thus sometimes occur.

In Guy's Hospital Museum is a specimen which is thus described in the museum catalogue;

No. 13\%.-A trachea with an enlarged thyroid gland, of which the right lobe has been removed by operation. There is an oval perforation of the trachea situated one and a half inches below the

* Brit. Merl. . Jenrm. 1886.

+ llatas alludes to a case in which this accident occurred. Tew Orleam:

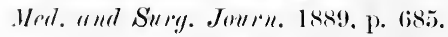

+ ".Thérapentiplue Chirurgicale du Goitre," Parris, 1897, p. 225. 
glottis, which was produced by the pressure of the end of a clamp. Mary W., at. 17, was admitted under Mr. H., for an enlarged thyroid gland. The right lobe was removed, and a clamp applied to the pedicle. The patient died on the seventh day after the operation, from acute bronchitis.

The application of a clamp to a thyroid pedicle is not, however, to be recommended. Bérard* mentions a curious case of Poncet's. In the course of the operation tracheotomy was performed on account of urgent dyspnoea; the canula was pushed through the posterior wall of the trachea into the cesophagus, and the patient succumbed.

Injury to the Pleura. - The lower horn of a goitre descending towards the thorax is frequently in contact with the pleura. In removing this part of a goitre it is possible to wound the pleura. This serious accident is, however, not likely to occur unless inflammation or malignant disease have caused adhesions.

Liebrecht records an early case of Nussbaum's in which one lobe of the goitre was adherent to the pleura. In effecting its detachment pneumothorax was produced and the patient died.

'The only case that has occurred in this country, so far as I know, is an unpublished one, of which notes have been sent to me privately. The patient died very soon after the removal of the goitre, and at the autopsy one pleural cavity was found to be full of air. Doubtless there had been a wound of the pleura, although my informant tells me that the actual opening was not detected.

There are many museum specimens of malignant disease of the thyroid which show involvement of the pleura in the morbid growth.

In both the above-mentioned cases death resulted from the pneumothorax that was produced. Yet it is quite possible that a wound of the pleura might be caused and the patient nevertheless survive.

Some twenty years ago I was myself a witness of a puncture of the pleura in an operation for ligature of the subclavian artery. Although alarming symptoms at once manifested themselves, the patient nevertheless eventually recovered. 
Injury to the Pharynx and Gsophagus.-Bérard* mentions a case communicated by Roux, in 1894, to the French Congress of Surgeons. Old inflammation of the goitre had so altered the wall of the pharynx that the latter was accidentally opened.

A case that occurred at Charing Cross Hospital a few years ago was that of a hydatid of the thyroid. During the operation for its removal the osophagus was opened. The wound was sutured. Both these patients recovered.

Collapse of the trachea is a serious complication that occurs occasionally in very bad cases. The trachea, which has been greatly flattened and has lost its resiliency, may, after removal of the goitre, fail to expand. Its walls become sucked together by the movements of respiration, and death may ensue suddenly during or soon after the operation. This complication is fortunately very rare; in most cases the trachea quickly or gradually expands when the pressure of the goitre has much removed. Attempts have occasionally been made to separate the flaccid walls of the trachea by passing a suture through its walls on either side and tying these sutures across the front of the trachea. 'The results obtained, however, are not altogether satisfactory; it may be necessary to perform tracheotomy if the collapse of the trachea is extreme and suffocation is imminent. 'Tracheotomy should, however, if possible be avoided, on account of the grave risk of sepsis which it entails.

II. Complications occurring shortly after the Operation.

Secondary hæmorrhage, once a serious danger of thyroid operations, has now, since the introduction of aseptic methods of treating wounds, become almost a thing of the past. Liebrecht, writing of the operations performed before 1883, mentions no less than thirty-one cases in which this serious complication occurred. At the present time it is to be feared only in some few cases of operation for malignant disease of the thyroid, for suppurating goitre and in the rare cases in which serious sepsis follows extirpation of an innocent goitre.

I have never seen secondary hæmorrhage after any thyroid operation. 
Recurrent hæmorrhage is, however, a real and sometimes a serious danger. From an artery it is rare, although it may sometimes occur from the slipping of a ligature which has been insecurely applied.

It need scarcely be said that the greatest care should always be taken to tie all the arteries firmly and with a sufficiently stout ligature.

Recurrent hæmorrhage from veins is more common than from arteries, because it is more easy at the time of operation to overlook a wound of a vein than one of an artery.

It is especially after enucleations that recurrent hæmorrhage is apt to occur. A wounded vein may, while the patient is under the anæsthetic, give rise to no hæmorrhage. But subsequently, especially during the coughing or vomiting that may follow the operation, the temporarily closed mouth of the vein may re-open and allow of serious hrmorrhage.

'Troublesome recurrent hæmorrhage may occur, too, in the form of a general oozing from numerous small vessels.

It has already been mentioned that it is of the utmost importance to see that all bleeding has been completely arrested before the wound is closed.

Sometimes, especially after enucleation of a large goitre, it is well to let the patient recover partially from the anæsthetic before the wound is closed. 'The straining that attends efforts at vomiting thus tests the efficiency of the hrmostasis.

Some years ago I was watching the performance of a large goitre operation. The operation had been successfully accomplished, all bleeding had apparently been arrested, and the last sutures were being inserted. 'The patient then began to retch. Suddenly blood poured out from between the stitches all along the wound. 'This was rapidly opened, and it was then found that a large vein at the root of the neck had escaped ligature. Until the patient began to retch it had lain collapsed and did not bleed. The rein was tied, and no harm ensued. But had this accident occurred an hour or two later, after the patient had returned to bed, the result might have been very different.

Dr. A. H. Corley* has recorded in full an interesting case of a very large thyroid tumour removed by " rapid enucleation

* Trans. Rony. Acul. of Med. in Irelant, Dublin, 1889, vii. 169-175. 
with the finger and director." After the sutures had been inserted, and the patient was about to be transferred to bed, " a sudden, most alarming gush of hæmorrhage took place; the blood welled up in dark streams between all the points of suture, the patient's face blanching and his pulse becoming feeble." The sutures were immediately cut and pressure applied to the interior of the wound by means of sponges. After ineffectual attempts had been made to secure the bleeding vessel or vessels with ligatures, it was decided to plug the wound with gauze and wool. The plugs were left in for several days, and the wound healed eventually by granulation.

If the wound has to be opened up some hours after the operation, it is frequently a matter of the greatest difficulty to find the bleeding point. The tissues are so infiltrated with blood that the actual bleeding point or points cannot be seen. Under these circumstances it is generally best to pack the wound with gauze.

Recurrent hæmorrhage is dangerous not only on account of the loss of blood which it occasions. By filling up the cavity previously occupied by the goitre, the blood may press most injuriously upon the trachea and set up serious, or even fatal, dyspnoea.

Mr. Stanley Boyd has been kind enough to give me the following details of a case that occurred at Charing Cross Hospital :

A young woman had an adenoma of the thyroid. The tumour was removed by operation without any difficulty. Bleeding was not excessive, and was easily controlled. The wound was sewn up without drainage. A few hours after the operation an urgent message was received from the house surgeon, saying that the patient had severe dyspnoea. The patient was found to be livid, and in great distress. The stitches were at once removed and the whole wound opened up. A handful of blood clot was taken away, and the dyspnoa immediately relieved. Considerable oozing of blood was found to be still going on, and could not be controlled by ligature. Eventually the bleeding was arrested by plugging, and the patient made a good recovery.*

\footnotetext{
* See also a somewhat sinilar case described in my Lectures at the Royal
} College of Surgeons, Brit. Med. Journ., June 1890. 
An almost identical case came under my notice when Surgical Registrar at St. Bartholomew's Hospital.

Sepsis.-It is of the utmost importance that the wound produced by a goitre operation should heal by primary union. The greatest care should therefore be taken to maintain the strictest asepsis throughout. It is mainly owing to great improvements in the aseptic details of the operation now performed, that the removal of a goitre at the present day is no longer as dangerous as it used to be twenty or thirty years ago. Indeed, the danger from sepsis is now so slight that serious complications due to this cause are very rarely seen. Out of the 126 operations for the removal of goitre that it has fallen to my lot to perform, there has not been one in which I have lost a patient from any kind of sepsis. Occasionally a mild amount of sepsis has occurred, and has been sufficient to prevent primary union of the wound. Very rarely, indeed, has the sepsis been sufficiently marked to cause any real anxiety on this score. Reference to the table of cases in the Appendix will show that in the last hundred operations primary union took place in 91 cases.

The extensive involvement of the cellular tissue of the neck in the operation of extirpation renders sepsis, should it unfortunately occur in this tissue, a matter of grave danger. The serious nature of cellulitis at the root of the neck and in the mediastinum is well known. Such cellulitis is the more to be dreaded, as it is very insidious in its onset and consequently its existence is apt to be overlooked in its earliest stages. There may be very little elevation of temperature, and acute symptoms of inflammation may be conspicuous by their absence. A persistently rapid pulse may be the most important early symptom. Later, pleural friction, cough, and other signs of septic trouble in the chest may render the diagnosis only too clear; but at this period treatment is usually of but little use in stopping the progress of this very fatal complication.

If, shortly after: the performance of an extirpation or an enucleation of a goitre, decided symptoms of sepsis occur, the wound should at once be thoroughly opened up. Strips of antiseptic gauze should be laid in it and the wound treated as an open one, all attempts to procure primary union being abandoned. 
'The most troublesome case of a sinus that has occurred in my own practice is that recorded in the table on p. 350 (case 97).

The patient was a lady, aged 28 , upon whom I had to perform a double enucleation. The tumours were solid and very deeply seated on either side of the trachea, and behind the sternum. They caused a good deal of respiratory trouble. The operation presented no special difficulty, and was performed in the usual manner. The wound was sewn up and a small drain inserted into the superficial part of it through a separate opening in the skin. The drain was removed on the day after the operation. The condition of the patient in the next five days was not altogether satisfactory. On two occasions during this period the temperature was a little over $100^{\circ}\left(100.4^{\circ}\right.$ and $\left.100.2^{\circ}\right)$. During the same period the pulse was almost constantly a little over 100. On the sixth day after the operation the temperature suddenly rose to 102.2, the pulse rate being 118 . The wound was then immediately opened up to a certain extent, but as it seemed healthy and contained little or no fluid, the deeper parts were not disturbed. Wet dressings of perchloricle of mercury were applied, and the temperature and pulse rapidly subsided. Two days later the temperature was normal, and it never afterwards rose above the normal. Three weeks after the operation the patient went back to her home in the country; she was in good health, but a small sinus was still present, which appeared to be on the point of healing. It did not heal, however; silk ligatures from time to time came away, and there was constantly a small amount of discharge from the sinus. 'Three months after the first operation, the sinus was opened up again, and found to extend to a depth of nearly an inch on either side.

During this time the patient was not confined to bed or even to the house; she went about as usual, or rather, far more than she had been accustomed to do before the goitre was removed. She was able to ride, play lawn tennis, and take active exercise of all kinds. After the second operation the left portion of the sinus healed up, and never afterwards gave any further trouble. The pocket, however, that led towards the right lobe of the gland still refused to heal. The patient was very averse to a further operation, especially as the sinus appeared to be almost healed. She then went abroad for several weeks, the sinus being dressed and plugged with gauze every day. Finally, seven months after the original operation, the sinus was again opened up. It was plugged with gauze and dressed twice a day, and at the end of four weeks it was 
at last soundly healed. Much of the trouble in this case was due to the fact that the patient was exceedingly anxious about her scar, which had been placed transversely at the root of the neck, and was but little over two inches in length. Neither of the three secondary operations involved any of the surrounding skin. Had the whole wound been freely opened at an early stage without any regard to the situation or extent of the scar, no doubt healing would soon have taken place. As it was, the patient was eventually left with a short and not very wide scar, but at the cost of a considerable amount of time and trouble.

Deep-seated suppuration in the neck is extremely likely to extend to the thorax and cause fatal mediastinitis. In some cases the pus makes its way into the trachea or œsophagus. The following* is an example of such a case. It occurred at St. Bartholomew's Hospital in 1886, and is the only example that I have myself witnessed of a death due directly to sepsis after removal of a goitre. It is a very good illustration of what may happen when this operation is performed without antiseptic precautions.

Edward B., at. 41, was admitted into St. Bartholomew's Hospital under the care of Sir William Savory on account of a goitre that he had had for some four years. The tumour, which was partly cystic and partly solid, was situated unusually high up on the right side of the neck. (It is depicted in Fig. 41.) It had been tapped on more than one occasion.

On October 16, 1886, the tumour was removed by Sir William Savory. A portion, which was thought to be adherent to the great. vessels of the neck was left behind. "A plug of dry unsterilised lint was placed in the cavity and the wound stitched up, except at its lowest part, and dressed with carbolic oil lint."

The operation was followed immediately by a rise of temperature to $102^{\circ}$. On October 18 the plug of lint was removed. The temperature remained at about 102 until October 21 , when it began to fall, and it became normal on the 24th. The patient was thought to be doing well until November 2 , when his "temperature began to rise again, and loss of appetite, sleeplessness, furred tongue, pain in the wound and right side of the neck, and slight difficulty of swallowing ensued. On the 4th of November these

* This case has been published in full by Mr. C. A. Parker in St. Bart. Mosp. Reps., 1887, xxiii. p. 218. The particulars given above are taken partly from his and partly from my own notes. 
symptoms had increased in severity, and there was a good deal of heat, redness and swelling about the wound and extending across the middle line to the left side of the neck. The wound was slightly enlarged and examined with a probe, but no collection of pus could be found. . . On November 6 the temperature was 102.8, and a cough with pneumonic expectoration made its appearance. On examination impairment of resonance at both bases, with fine crepitations, was found. The swelling of the neck and difficulty of deglutition having much increased, the patient was anæsthetised and the wound freely reopened. No collection of pus was discovered. A long incision was also made in the middle line to relieve tension. .. By November 11 the swelling and inflammation of the neck had almost entirely subsided, and the wounds looked perfectly healthy. The temperature, however, had risen again to $102.6^{\circ}$, and the patient's general condition was decidedly worse. He was very weak and prostrate. His cough got more troublesome, and was accompanied by an abundant and offensive expectoration. Pulse weak, 112." On November 16 it was noticed that air was passing in and out of the wound. Next day the patient had a severe rigor and a temperature of $104.8^{\circ}$. He gradually became weaker and weaker, and died on November 19.

The post mortem showed a minute opening between the unhealed portion of the wound and the interior of the trachea. This opening was between the second and third rings.* There was pneumonia of both lungs, with pus in the tubes and a gangrenous condition of a small portion of the right base.

Rapid Pulse and Restlessness.-A very serious complication, which is fortunately rare, is characterised by two prominent symptoms: restlessness and great rapidity of the pulse.

Very soon after the operation the pulse is noticed to be rapid. It rises quickly to 150 or even 200 , and then becomes so feeble that it camnot be counted. At the same time the patient is rery restless and excitable. Death may occur within a few hours, or at most a day or two.

Post mortem little or nothing may be found to account for the death.

I have never met with this fatal complication in my own practice, and have seen but little of it in the practice of others. Occasionally a minor degree of restlessness and a pulse of 120

* The specimen is now in st. Bart. Hosp. Mus. No. 2319D. 
or 130 in cases of my own have caused me some little anxiety for a few hours or even a day or two.

The following case is one that I witnessed in St. Bartholomew's Hospital in 1889 :

A young man was admitted to the hospital on account of an innocent tumour of the left lobe of the thyroid. It was about as large as an orange. It had caused some trouble in respiration, and had caused paralysis of one vocal cord.

The left lobe was removed by extirpation, and the wound washed out with carbolic acid lotion. The operation presented no especial difficulty, and was not an unusually long one. Immediately after the operation, the patient's condition was good. But very soon the pulse became very rapid, and the patient showed great restlessness. The rapidity of the pulse increased quickly until it was over 200, and could scarcely be felt. This continued until the patient died on the second day after the operation.

At the post-mortem examination, which was performed by Mr. Bowlby, nothing of importance was discovered. The wound had nearly healed by first intention. No nerves of importance had been cut, nor was there any obvious bruising of them. The vagus nerve was carefully examined and found intact. There was no evidence of septicæmia. The tumour * that was removed consisted of a number of adenomata, some of which were solid while others had undergone cystic degeneration.

Dr. Rodocanachi has published in full $\uparrow$ an interesting case of a similar nature which occurred in University College Hospital during his house-surgeoncy there. The following is an abstract of his report:

A married woman, aged 49, was admitted to the hospital on February 20, 1896, on account of a very large cystic goitre, involving both lobes of the gland, and causing serious dyspnoea from pressure on the trachea. When the patient was quiet the pulse was 116 and the respiration 40 per minute. On the day after admission "the right lobe of the gland, which was the larger, was dissected out through a free incision, all the vessels being clamped before they were cut. A cyst on the left side was afterwards

* St. Bart. Hosp. Mus. No. 2310D.

+ "On!Four Cases of Goitre Treated by Operation and Certain Dangerous Symptoms which may follow the Operation," by A. J. Rodocanachi, M.D., Lancet, 1897, ii. 911. 
enucleated, but it was ruptured during removal, and a good deal of the pale brown contents necessarily escaped into the wound. No irrigation was employed, but the wound was closed, a small drainage tube being inserted in the lower end." After the operation, which appears to have been uncomplicated, the patient's condition seemed to be quite satisfactory. She was quiet and comfortable, and continued to be so until about ten hours after the operation, when "suddenly her symptoms changed completely. She became extremely restless, tossing herself about in bed. This was the most striking symptom, as previously she had been a most tractable patient. The pulse ran up to about 180 ; the respiration became very rapid, from 50 to 60 , and shallow, but not embarrassed; there was no stridor. The temperature was found to be $99.2^{2}$. Whereas previously she had been hopeful, she now declared that she was about to die." Although a little quieter after a hypodermic injection of morphia, the symptoms soon returned in all their intensity, and death occurred some fifteen hours after the operation.

The post-mortem examination showed but little. 'The tumour removed seems to have been an ordinary parenchymatous one, with mumerous small cysts and much fibrous tissue, as might have been expected in a woman of her age. The remaining portion of the gland was exactly similar. A careful dissection of the neck showed that there had been no damage to any of the main nerves. There appears to have been no evidence of septicæmia, and it was clear that the death was not due to hremorrhage.

Mr. F. 'T. Paul* of Liverpool has resorded a somewhat similar case :

The patient was a girl aged 15, with a rather large parenchymatous goitre. The tumour was soft, and did not pulsate; it inrolved both lobes about equally. The heart was excitable, the impulse diffused, and there was a soft systolic bruit at the apex. The patient appeared to be quite strong enough to bear a serious operation. The left lobe and isthmus of the thyroid gland were removed. "The operation was perfectly straightforward, and the patient left the theatre in excellent condition. All details as to dressing`, drainage, \&i., were carried out in the usual manner. l)uring the night she became restless and uneasy, an irritable cough set in, with a mucous rattle in the throat. The temperature was 100 , the pulse 130 , and the respiration 26 and laboured. On the morning after the operation the same condition was present; the

* "A Fiatal ('isere of 'Thyroidectomy," Brit. Meel. Jomrn., Jan. 1, 1898, p. 17. 
wound was dressed and appeared perfectly healthy. In the afternoon the temperature rose to 103 , and fearing that the ether inhalation had set up ether bronchitis, steam and eucalyptus vapour were used, with stimulants and extra nourishment. Subsequently the restlessness, anxiety, distressed breathing, and frequency of the pulse increased, and the temperature was generally between $101^{\circ}$ and $102^{\circ} \mathrm{F}$. There was no further evidence of bronchitis ... the Graves's disease-like symptoms increased in severity, the pulse became uncountable, and the patient died just two and a half days after the operation."

A post-morlem examination showed the following: "In regard to the wound, there was a want of healing action, and the fluid contained in it was of a very watery character, but there was nothing suggestive of septic changes. The divided surface of the thyroid looked quite fresh, as though repair had not yet commenced. The bases of the lungs were congested, and there was a little tenacious mucus in some of the tubes, but no general bronchitis. The heart and all the other internal organs were healthy, except the liver, which was very fatty and perfectly nodulous throughout from idiopathic cirrhosis."

In St. Thomas's Hospital Reports is an account of another fatal case in which the operation was excision of the isthmus only of a large parenchymatous goitre. The patient was a woman aged 33. Before the operation the pulse was 108. Double ligatures were applied to the isthmus before its removal. The wound was drained. 'The patient was extremely restless after the operation and was little relieved by morphia. 'The pulse was very rapid, reaching 160 , and nine hours after the operation the patient died suddenly.

In St. Bartholomew's Hospital, in 1899, the same group of symptoms-restlessness and rapid pulse-set in after division of the sympathetic nerve on both sides of the neck. 'The patient was a young woman with well-marked symptoms of Graves's disease. In this case the temperature also rose to a great height $\left(105 \cdot 6^{\circ}\right)$, and the patient died a few hours after the operation.

Instances in which similar fatal symptoms have occurred after operations upon the thyroid gland in Graves's disease are too well known to require detailed notes of cases.

Sometimes severe symptoms have followed operations both upon exophthalmic and simple forms of goitre, but have subsided 
after a short time, and the patients have recovered. Rodocanachi* reports the case of

a woman aged 35, from whom a thyroid cyst was removed, the cyst being ruptured in the course of the operation. Thirty hours later the temperature, pulse, and respiration were respectively $101.3,136$, and 36 , and there was much restlessness. The symptoms all subsided after a dose of morphia, and the patient made a good recovery.

Pault also narrates a case in which he operated for chronic Graves's disease, removing one half of the gland:

The patient was a woman aged 43 . When the pulse and temperature began to rise and restlessness set in, the wound was freely opened up and packed with salicylic wool. Nevertheless, the temperature subsequently rose to $104.8^{\text {? }}$, the pulse became almost uncountable, and the respirations were 36 . There was in this case a profuse discharge of watery secretion from the wound. The packing in the wound was frequently changed-about every two hours-and by the fourth day after the operation all alarming symptoms had subsided.

The cause of the alarming group of symptoms in these and similar cases is not altogether clear. That such symptoms are sometimes due to sepsis there can be no doubt. It must be remembered that sepsis may occur and rapidly prove fatal without causing any very obvious changes that can be detected post mortem.

Bacteriological examination alone may afford the necessary proof of sepsis, but sepsis will certainly not account for the symptoms in a great many of the cases.

It has been supposed by some that they are due to athyroidism. But if this were the true explanation we should expect to find these symptoms more common than they are in cases where large portions of both lobes have been removed, as for example in cases of double resection. It is difficult, also, on this supposition to explain their occurrence after comparatively small operations like division of the sympathetic nerves and resection of the isthmus.

A more probable supposition is that they are due to hyper-

$$
\text { * op. cit. }
$$$$
\dagger \text { op. cit. }
$$ 
thyroidism, that is, to sudden absorption of a large quantity of thyroid secretion.

This is the view taken by Rodocanachi and Paul in their excellent papers upon the subject. This absorption may be caused by prolonged and rough manipulation of the gland during the operation, whereby the colloid is squeezed into the lymphatics. Or possibly it may be caused by the exudation of colloid into the wound firom the cut surface of the gland.

To the theory of hyperthyroidism, however, it may be objected that the same group of symptoms may supervene after operation upon tumours by no means very full of secretion - e.g., old fibrous goitres and malignant tumours. Further it would not account for their occurrence after division of the sympathetic, or ligature and resection of the isthmus. If secretion from the cut surface of the gland into the wound were the cause, then drainage would surely suffice to prevent their occurrence. But in some of the recorded cases drainage has been employed throughout, and yet this complication set in.

Again, I find it difficult to understand why I have never witnessed this complication in the numerous cases of my own in which I have removed large parenchymatous goitres without any ligature of the isthmus. I have seldom tied the isthmus en masse. Indeed, in very many cases where the isthmus is thick, measuring two or more inches in diameter, it is quite impossible to place such a ligature satisfactorily upon it.

The question may be raised whether the rapid action of the heart may not be caused by some irritation of or injury to the cervical cardiac nerves.

It is at least conceivable that such injury might be caused either by rough manipulation, by sepsis, or by irritating antiseptic lotions. It seems clear that the use of antiseptic lotions in operations upon exophthalmic goitre has a marked tendency to produce these dangerous symptoms.

Against this cardiac nerve theory must be placed the undoubted fact that these symptoms are far more likely to follow operations upon the thyroid gland than those performed upon other tumours at the root of the neck.

It is, perhaps, best to admit that the exact cause of this group of unpleasant symptoms is not yet thoroughly understood. 
'The theory of hyperthyroidism, tempting as it is, can hardly be considered as proved.

It is well, however, as a matter of practical importance, to bear in mind that restlessness and extreme rapidity of pulse are more likely to follow operations upon the goitre of Graves's disease than upon any other kind of goitre; that they are by no means unknown in operations upon parenchymatous goitre, and that they may even occur in other thyroid operations. They can best be aroided by taking care to handle the gland as gently as possible, and by exercising the most rigid asepsis in the performance of the operations.

Drainage of the wound is probably advisable in cases where the supervention of these symptoms seems likely.

Patients who have a somewhat rapid pulse before the operation are those in whom the symptoms are most likely to occur.

In my own practice I am in the habit of giving three grains of quinine every four or six hours in every case in which, after a goitre operation, the pulse or temperature reaches 100 . If the patient shows any sign of restlessness, a moderately large dose of morphia is given at once.

Whether this treatment is really efficacious in warding off further development of these dangerous symptoms, whether their absence is due to the technique employed at the operations, or whether it is simply that I have been more fortunate than sone other'surgeons in not having yet lost a patient from this cause, are points upon which I hesitate to express a definite opinion.

Compression of Recurrent Laryngeal Nerve by Scar.-As the wound heals, it will occasionally be found, after extirpation, that paralysis of a vocal cord ensues.

'This late paralysis is especially apt to oceur in cases in which the nerve has been exposed or dissected out in the course of the operation. It is due to involvement of the nerve in the deeper portions of the scar.

Tetany is a serious complication which has been recorded many times, but chiefly in the earlier history of the operation before total extirpation had been given up. Liebrecht mentions seven cases which occurred in the practice of Albert, Billroth, and Schoenborn. Weiss has collected thirteen cases.* Reverdin 
noticed this complication in three cases.* Kocher has had several examples in his practice. Szumann has published one case. Schramm and Hicguet $\uparrow$ have also recorded cases.

Most of the cases have occurred in women and after total extirpation of the gland. Reverdin's three cases and Billroth's ten cases were all of this kind. One of Kocher's patients was a boy. Hicguet's patient was also a boy.

Symptoms.-Liebrecht, speaking of the seven cases recorded by him, says, "The attacks began by pain, twitchings and tingling sensations in the upper limbs, followed by intermittent and clonic spasms, very painful and of varying duration and intensity. The spasms were sometimes limited to the upper limbs and sometimes extended thence to the lower limbs and even to the muscles of the trunk, to those of respiration and of the face. In the intervals between the attacks there was complete intermission of the symptoms."

In some of the cases the symptoms appeared immediately after the operation, in others not until several days had elapsed.

Some of the older authors considered that the cause of the tetany lay in the circulatory troubles, others that the symptoms were of "reflex spinal origin." There can, however, now be no doubt that the symptoms are due to loss of function of the thyroid gland. Similar symptoms have been produced by Horsley in monkeys and other animals by complete removal of this gland.

* Journ. de la Suisse rom., 1883.

† Bull. de l'Acad. de méd. Belg. xvii. 


\title{
CHAP'TER XXI.
}

\section{REMOTE COMPLICATIONS-CACHEXIA STRUMIPRIVA.}

\begin{abstract}
Historical - Reverdin and Kocher-Horsley's experiments - Early observation of Paul sick-Symptoms-Relation to complete removal, to partial removal-Hypertrophy after partial removal-Treatment of cachexia strumipriva.
\end{abstract}

III. Remote Complications.-The remote complications of a goitre are those which are due to loss of function of the thyroid gland, and are comprised under the terms cachexia strumipriva, cachexia thyreopriva, and operative myxœdema. These are but different names for the same disease.

In its most typical form this complication is seen only after complete extirpation of the whole gland, and as this proceeding is now known to be seldom if ever necessary, the complication is one that is chiefly of historic interest.

'The credit of the discovery of this remarkable affection belongs to Drs. Reverdin of Geneva and Kocher of Berne.

In September 1882, Reverdin * drew attention to a peculiar group of symptoms which he had observed after some of his operations for goitre. Kocher then took up the subject, instituted an inquiry among his own patients and found that a large number of them presented symptoms similar to, or identical with, those described by Reverdin. In April 1883, Reverdin $\dagger$ published an excellent description of these symptoms and shortly afterwards Kocher $\ddagger$ brought the matter still more prominently forward in an admirable paper which he read at the twelfth Congress of Surgeons held at Berlin in 1883, and

* soc. de Méd., Geneva, Sept. 7, 1882.

$\dagger$ "Note sur vingt-deux operations de goitre," par J. L. et A. Reverdin, Rer. med. de la Suisse romande, Geneva, April 15, 1883.

+ "Ueber Kropfoperationen und ihre Folgen," Th. Kocher, Archir f. klin. Chir., 1883, vol. xxix. pp. 254-337. 


\section{REMOTE COMPLICATIONS.}

which naturally attracted great attention. Kocher gave the

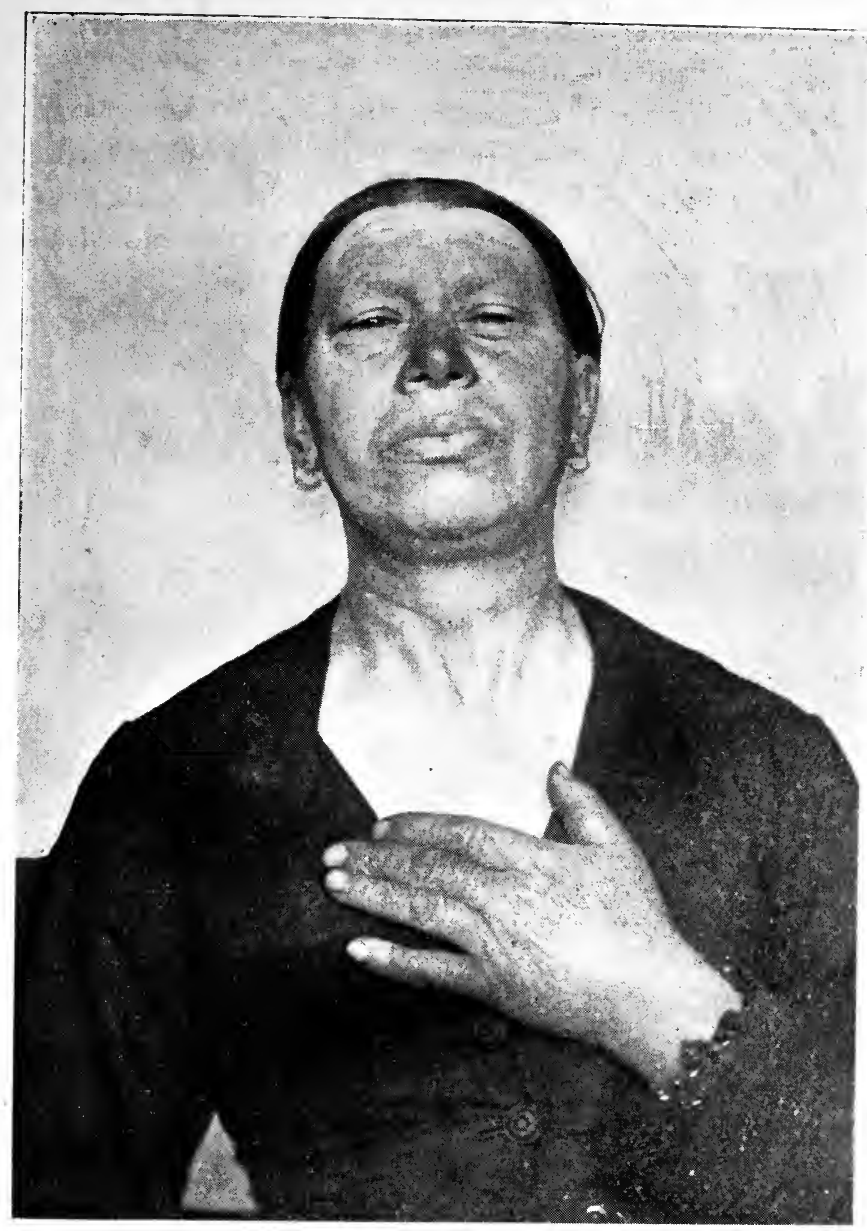

Fig. 108.-A middle-aged woman with Cachexia Strumipriva (operal. tive myxodema), eleven years after complete removal of al goitre. One year later this patient died of cerebral hemorrhage, the general condition having remained unchanged. (Scen at kast Linton, X.B., in 1887.)

name of cachexia strumipriva ${ }^{*}$ to the disease, while Reverdin, in a paper published in June 1883, $†$ suggested that in some

* From Germ. struma = goitre, and priva = privative.

† Rérue Médicale, June 15. 1883, p. 360. 
respects the symptoms observed by him in man after removal of the thyroid gland resembled those of idiopathic myxoedema, and he consequently introduced the name of operative myxcedema (myxoedème opératoire).

In this country Sir Felix Semon* appears to have been the first to make the definite statement that " cretinism, myxœedema, and cachexia strumipriva were merely different phases of one and the same condition and due to one and the same causeviz., to arrest of the function of the thyroid gland."

Numerous experiments upon animals performed on the continent by schiff, Zesas, Wagner and others, had led to the belief that the symptoms of cachexia strumipriva were produced by and were due to, the loss of the thyroid gland itself.

Still further proof of the connection between cachexia strumipriva and myxoedema was afforded by the well-known and admirable researches of Mr. Victor Horsley. 'This observer, experimenting upon $\log s$ and monkeys, found that complete removal of the thyroid gland produced symptoms identical with those seen in man after complete removal of a goitrous thyroid. Moreover, he found that in animals so treated there was an accumulation of mucin in the subcutaneous tissues and elsewhere, thus definitely correlating their condition with that of myxoedema described by Gull and Ord.

Although Reverdin and Kocher were the first who gave a full description of cachexia strumipriva, and connected it definitely with removal of the thyroid gland, yet a previous observer had noted the occurrence of very remarkable symptoms in a patient from whom he had removed a goitre: These symptoms are now seen to be the same as those of the disease described many years later by Reverdin and Kocher. The case is of such interest that a short account may here be given.

'The case occurred in the practice of Dr. Paul sick of Wurtemberg, and was published by him in the Wurtemberg Correspondenzblatt for $186 \%$, vol. $3 \%+$

The patient was a boy aged ten, who had a goitre as large as an apple, which caused severe dyspnoea. On September 11, 1866,

* Trums. Clin. Sim, 1883.

$\dagger$ I have been unable to procure a copy of the original paper, but an excellent

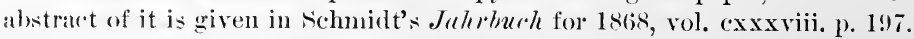


both lobes of the gland were completely removed. 'I'he operation was a very severe one, and was followed by suppuration. By November 4 the wound was completely healed, and the boy had left the hospital. During convalescence the patient had had several attacks of bleeding from the nose.* By December 12 these attacks had ceased, but there was considerable discharge from the nose of a thin acrid fluid looking like the washings of meat (fleisch

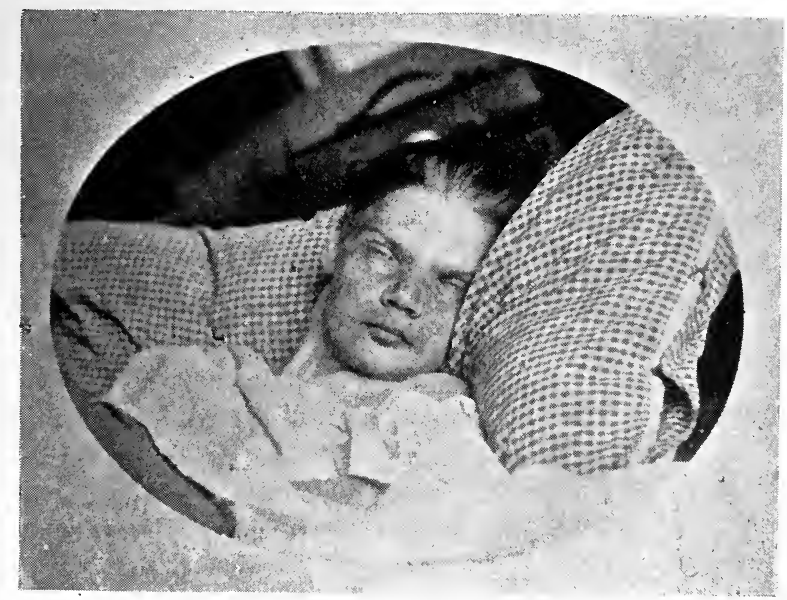

Fig. 109.-A woman aged 23 in a late st ige of Cachexia Strumipriva. A goitrous thyroid gland hat been completely removel four years previously, the left half being extirpated in .Jannary 1882 , the right half in the following November, by Prof. Kocher of Berne. The photograph shows the eondition in August 1886. Death ocenred shortly afterwards.† (Seen at Berne.)

wasserähnlich). On June 1, 1867, Dr. Sick saw the patient again. He was completely cured; he had had no further trouble with respiration, but according to his father's account he had become remarkably taciturn and wrapped up in himself; but as regards capacity and willingness for work no change had been noticed. The discharge from the nose had ceased. Both tonsils showed considerable enlargement.

Sick explained all these phenomena by assuming that there. was increased pressure in the cerebral circulation, an explanation

* A point worthy of note in connection with the tendency to hrmorrhage observed in myxodema and some other thyroid affections.

+ This is one of the 18 cases of cachexia strumipriva originally described by Prof. Kocher in his well-known paper. 
now known to be utterly erroneous. If we turn to another German paper we find the description of this same patient's condition eighteen years later, when he was visited by Prof. Bruns of 'Tübingen.

This author writes as follows : *

"Being curious to find out the condition of this patient, I ascertained that he still lived, a cretinous dwarf, in his native village. Upon a stout and boyish body stands the head of a beardless man. His height is 51 inches. Although the head is normal in size for a man of his age, yet the body is that of a boy of ten, in whom the trunk and legs are well proportioned. The growth of the body vertically since the operation has been nil. There is a markedly idiotic expression on his face, caused by much puffiness of the whole face, especially the lips and lower eyelids. The skin and visible mucous membranes are of a pale colour. The skin of the whole body is dry and scaly. The hair of the head is very thick and scattered. There is no beard, but the pubic hair and the genital organs are fully developed. The speech is slow, and evidently made difficult by the swelling of the tongue, palate and tonsils. On the neck are found the scars of the operation. The thyroid gland is entirely absent. The trachea and larynx are normal; breathing easy; action of the heart weak; spleen natural ; increase of white blood corpuscles.

"A further characteristic feature of the case is well marked, namely, that while sensibility and muscular power are preserved, yet the patient cannot do work requiring delicacy and skill, and he can scarcely walk fifty yards. This incapacity did not become complete until some years had elapsed; for when he left school at the age of fourteen he was incapable of learning any trade, but employed himself industriously for many years in netting, until he became incapable of doing even this. A remarkable impairment in his intelligence has since occurred. While the boy before and just after the operation was one of the best pupils in his school, now his mental faculties are less developed than those of a boy of ten. His reasoning powers are extremely weak and slow. There is also a marked impairment of sight and hearing."

Since the date at which the above was written the patient has died.

* "Ueber den gegenwärtigen Stand der Kropfbehandlung," by Dr. P. Bruns, summl. klin. Fortraege, Leipzig, 1884, No. 244. 
The resemblance of the above case to one of ordinary cretinism is obvious.

Symptoms.-The symptoms of a well-marked case of cachexia strumipriva are thus given by Reverdin : *

"It is usually in the course of the second or third month after the operation that the patient begins to complain of a feeling of weight and fatigue in his limbs. Walking becomes difficult. The patient's limbs seem to him heavy and indolent, and respond but slowly to the patient's will. He is easily tired and obliged to rest frequently. His hands are often swollen and clumsy. One patient is unable to do her usual work of embroidery or crotchet; another is apt to drop objects which she is holding. At the same time the skin becomes pale and slightly swollen. The pallor is general and has a slightly yellowish white tinge like that of anæmia. The swelling, which may be general, appears first of all in the face and extremities, especially in the hands. It is usually very marked in the eyelids, and at once suggests the idea of some renal disease; nevertheless the urine when examined is found to contain no albumen; besides, if the swelling be examined carefully, it is found that it is not true odema. The finger makes no impression upon it. The swelling involves the forehead, the cheeks, it may even extend to the tongue. The features, swollen and fixed, give to the patient an expression of dulness and vacancy which recalls that of a cretin. The swollen fingers are hampered in their movements, and can no longer be flexed completely; and to this mechanical hindrance must be added a muscular weakness which makes all actions difficult. Intellectual actions are as slow as the movements of the limbs. If a question be asked, the correct answer to it will be given, but not at once. It will come slowly. It seems as if the patient had to make some effort to collect his ideas. Words do not come all at once, but gradually. Speech is slow. Very commonly the memory is more or less affected; and this symptom often remains when the others have more or less disappeared.... Generally the skin becomes dry ; perspiration is suppressed; then the epidermis becomes coarse and desquamation is seen in the extremities, especially in the palms of the hands, but also at times on the rest of the body. The state of the skin resembles slightly that of ichthyosis. The hairs become dry ; they break and fall off readily."

There is great chilliness and sensibility to cold. Even in summer this is very marked. The organs of sense are occasion-

* In a clinical lecture delivered Nov. 12, 1885, Lyon médicale, 1886. 
ally affected - taste may be diminished, vision weakened, hearing less acute; in one case there was absolute disappearance of feeling of hunger and thirst. Nervous symptoms may be well marked. Some patients have vertigo. They dare not venture into the streets. Various hallucinations may be present. Epilepsy may be present in some cases, also various hysterical symptoms. Examination of the viscera reveals nothing abnormal. The spleen is not increased in size. Examination of the blood has shown that the red corpuscles are sometimes decreased in number, sometimes normal. There is no increase in the number of the white.

The symptoms of the affection, as observed by Kocher, are practically identical with the above, which will be seen to be those of myxoedema. A few other symptoms are usually also present and may be added to those already given. The abdomen is often much distended, probably from flatulence. Constipation is generally a marked and troublesome feature of the complaint. The temperature of the body is almost always below normal. 'The urine is generally considerably diminished in amount.

It is now well established that cachexia strumipriva in its most marked form occurs only after bilateral and complete removal of the whole thyroid gland. If sufficient gland substance be left behind to carry on the function of the organ then the symptoms of the disease either do not occur at all or are merely slight and transient. It is certain that this serious complication always occurs when the removal of all the thyroid tissue has been complete. In cases in which the whole gland has apparently been removed without the production of cachexia strumipriva, it may be taken for granted either that some portion of the gland was left behind at the time of operation or that an accessory thyroid gland is present.

If the portion of gland left behind be very small, it may be insufficient to do the work of the entire gland. It will then usually undergo compensatory hypertrophy and the supervention of cachexia strumipriva is thereby prevented. Sometimes if the patient be old or feeble or if the operation be very severe, death may occur from cachexia strumipriva in an acute form, before the remaining gland has had time to undergo compensatory 
hypertrophy. Sir W. Stokes * has recorded, under the name of acute myxœedema, an instance of this kind.

In his case, that of a woman aged 18, first the left and then the right half of a parenchymatous goitre were removed with an interval of three and a half months between the two operations. The patient died twenty-one days after the second operation; at the post mortem it was found that a "small nodule of the tumour" had been left behind on the front of the trachea and that this consisted microscopically of "glandular tissue resembling that of the thyroid body."

Figs. 19 and 20 (pp. 32, 33) represent the condition of a young woman several years after what was at first supposed to have been a complete removal of a parenchymatous goitre. The specimen is in the Middlesex Hospital Museum $†$ and shows apparently a complete thyroid gland. The patient recovered from the operation and left the hospital six weeks later. She was at that time in a feeble state of health. For the next two years she presented symptoms of cachexia strumipriva shown by feebleness, anæmia, inability to work, etc. Soon after leaving the hospital a small lump was noticed at the upper part of the neck on the left side. This slowly increased in size until at the end of two years, when I first saw the patient, it had attained the dimensions of a walnut. By this time the symptoms of cachexia strumipriva were already beginning to pass off. A few years later still the tumour had grown much larger and the patient's health was in every way excellent. The compensatory hypertrophy which had occurred in the small portion of thyroid accidentally left behind at the time of operation, had restored the function of the gland and all danger of cachexia strumipriva had disappeared.

Fig. 110 shows another girl whom I saw at the Radcliffe Infirmary, Oxford. Six months before this photograph was taken both lateral lobes of a parenchymatous goitre had been removed but the isthmus had been left. This had undergone compensatory hypertrophy and formed the tumour visible in the photograph. No cachexia strumipriva had occurred and the girl's health was excellent.

* Brit. Med. Journ., Oct. 16, 1886.

+ No. $16+5$. The operation was performed in $188+$ by Mr. Henry Morris, to whom I am indebted for permission to publish the case. 
The only case of my own in which I have observed any symptoms of cachexia strumipriva is that of the lady shown in Figs. 120 and 121, and in this case the symptoms were slight and transient. 'The operation was undertaken for severe dyspnœa.

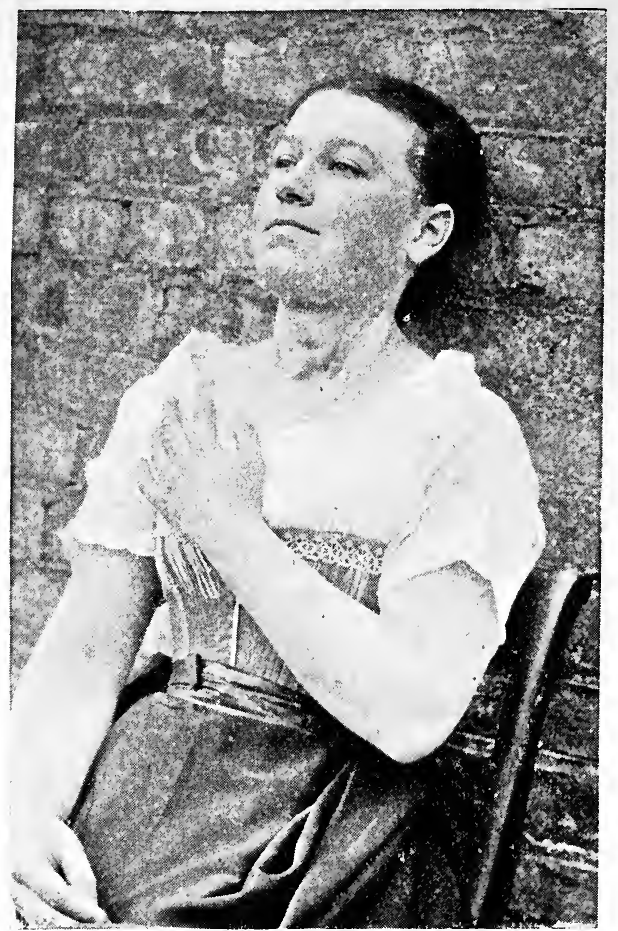

FIa, 110.- I youme woman six mollths after removal of all parts of a parenchymatous goitre, except the istlumus, showing the Re-enlargement of the latter. There were no signs of eachexia strumipriva. (Seen at Oxford, by the kindness of Mr. H. P. Symonils.)

The whole of the right and about two-thirds of the left lobe were removed. The operation was a severe one and the wound had to be drained owing to the existence of a large cavity behind the sternum which had been occupied by the lower part of the left lobe. 'The wound healed slowly by granulation. During convalescence the patient showed a considerable degree of mental and bodily dulness and apathy; some of the hair fell out and the skin became rough and dry. 
After three or four months all these disagreeable symptoms passed away and the patient made a complete recovery.

In 1886 I had the opportunity of seeing at the village of Lützelfluh in Switzerland a remarkable case of Professor Kocher's. One lobe only of the thyroid was removed but it was noticed towards the end of the operation that the opposite lobe of the gland was atrophied or absent. Typical symptoms of cachexia strumipriva set in but the patient was subsequently cured by appropriate thyroid treatment.

'The treatment of cachexia strumipriva like that of cretinism and myxœedema is at the present day comparatively simple. It consists in the administration in one form or another of thyroid gland substance (see chap. iii. pp. 22, 23). In any case in which large portions of both lobes of a goitre have been removed, I am in the habit of administering small doses of thyroid extract for several weeks in order to prevent the occurrence of those slight and transient symptoms of cachexia strumipriva which might otherwise occur. 


\title{
CHAP'TER XXII.
}

\section{RESULTS OF OPERATIONS.}

\begin{abstract}
Gradual improvement-Mortality after renoval of innocent goitreLiebrecht's and Reverdin's statistics-Mortality after partial extirpation. after enucleation-Complicated cases-Anthor's results-Canses of death-Relief from dyspmon-Question of recurrence after extirpation. after enucleation-Effects unon voice-Effect upon general health Healing of the wound-icar.

APPENDIX. - Table of one hundred consecutive cases of removal of goitre by extirpation or enucleation.
\end{abstract}

Like many other branches of surgery, that which deals with the thyroid giand has in the last twenty or thirty years advanced very rapidly. Operations such as removal of large goitres, formerly considered to be dangerous and desperate proceedings only to be undertaken in cases of urgent necessity, may now be performed with comparatively little risk and in the vast majority of cases with very great benefit to the patients. 'The frequency with which operations upon the thyroid are now undertaken by a very large number of surgeons affords evidence of the progress which has been made in this department of surgery.

We have to consider now what is the average mortality of operations upon goitre and what are the results that may be expected from these operations.

'The results as regards exophthalmic goitre and malignant diseases of the thyroid have already been discussed in the chapters which deal with those affections. We are now concerned only with the results of operations upon innocent goitres.

Various operations in which the goitre is treated, not by direct operative removal, but by other proceedings such as tapping, injection, incision, etc., have been sufficiently discussed in chap. xv. As most of these proceedings are now well nigh obsolete, or are, at any rate in my opinion, of but limited 
applicability, nothing more will be said of them. We have to consider the results that follow removal of innocent goitre by the two important operations of extirpation and enucleation together with their various modifications.

Mortality.-In discussing the mortality of operations upon innocent goitre it is interesting to notice the gradual diminution in the gross mortality during successive periods. Liebrecht in his exhaustive work published in $1883,{ }^{*}$ has collected as far as possible all the cases recorded up to that date and has given us the following figures for successive periods.

\section{Operations for Removal of Innocent Goitres.}

Before 1851 :

54 cases, 35 recoveries, 17 deaths (31.48 per cent.)

Two results unknown.

From 1851 to 1876 :

133 cases, 101 recoveries, 27 deaths (20.30 per cent.)

Three results unknown, two incomplete operations.

From 1877 to 1882 :

164 cases, 140 recoveries, 24 deaths (14.63 per cent.)

J. L. Reverdin, of Geneva, in a recent and very valuable report published in 1898 has given us figures for the more modern period up to that date. $\dagger$

The cases that he has been able to collect amount to 6103 (including a good many operations performed before 1882) and among them were 176 deaths, a mortality of 2.88 per cent. These figures + show a very great improvement upon those of the earlier periods.

Too much faith must not however be placed in statistics of this kind, especially when derived from the records of published cases. Successful cases naturally find their way into literature more readily than do the unsuccessful ones.

* "De l'Excision du Goitre Parenchymateux," P. Liebrecht, Brussels, 1883, p. 248.

+ "Rapport sur le Traitement Chirurgicale du Goitre (Cancer et Goitre Exophtalmique Exceptés)" J. L. Reverdin, Paris, 1898.

¥ These figures include, however, a certain number of cases of exothyropexy and ligature of thyroid arteries with which we are not now concerned. They also include at least 137 cases of total extirpation, an operation that has now been abandoned and which alone accounts for 26 of the 176 deaths. 
Reverdin's 6103 cases were obtained from three sources. Published statistics, 2120 cases with 43 deaths; statistics communicated privately to him, but without details as to the exact nature of the operation, 575 cases with 15 deaths; and statistics communicated privately with such details, 3408 cases with 118 deaths. The third group of figures is the most important and seems worthy of further consideration.

Deducting all cases of total extirpation, and all of exothyropexy and mere ligature of arteries we are left with 3254 cases with 91 deaths, a mortality of $2 \cdot 79$ per cent.

'These statistics were obtained by Reverdin as the result of a laborious inquiry instituted by him among a very large number of surgeons of various nationalities who were known to have operated upon goitre and a large number of whom replied to the inyuiries put to them. It may perhaps be suggested that those who did not reply to Reverdin's circular may have had worse results than those who did. On the other hand many of the operator's reported operations that had been performed as far back as the early eighties and seventies and even, as in one of Kappeler's cases, from as early a year' as 1868. The results of these earlier operations were obviously worse than those from a more recent period.

A very large proportion of these 3254 operations were typical enucleations or typical partial extirpations, and it is instructive to compare the figures for these two operations. The number of each is nearly the same.

There were 1212 partial extirpations with 42 deaths (mortality 3.46 per cent.) and 1276 enucleations with 10 deaths (mortality 0.78 per cent.) 'The extirpation operation is attended, as would naturally be expected, with a higher mortality. But it must not be forgotten that the conditions requiring extirpation, parenchymatous goitre with severe dyspsnoea for example, are usually far more serious than those for which enucleation is demanded.

It is certain that if the surgeon have a choice, that is if enucleation be feasible, it is usually a safer and in this respect a better operation.

Enucleation being an operation of much more recent date than extirpation, it follows that a larger percentage of extirpa- 
tions will be found in the earlier years of the operation, at a time when goitre operations in general had attained a lower degree of perfection than is now the case.

Many of the operations in the above statistics were very serious ones, performed upon patients suffering from severe dyspnæa, upon large goitres and upon goitres situated partly or wholly within the thorax, and many of the operations were attended with serious complications, such as tracheotomy wounds, thyroid fistulæ and cardiac and pulmonary complications. There can be no doubt that if we were to exclude from our statistics all complicated cases and all cases in which the operation had been postponed until the patients were in extremis, the average mortality both of extirpation and of enucleation would be still further reduced.

Reverdin's own words are: " in practised hands, goitre operations at the present day are almost free from danger. If we excluded from our statistics cases of long standing on the one hand and complicated cases on the other, it is probable that the general mortality would be but little above $0 . "$

Turning now to the statistics of my own operations the total number of operations performed for the removal of goitre of all kinds up to the present time (end of December 1900) is a hundred and twenty-six.

They include operations upon patients of all ages firom ten to sixty-nine, undertaken for the most part on account of dyspnoea, often very severe. The tumours removed were of various sizes and up to more than three pounds in weight (see Fig. 34). A large number of them extended partly or even largely into the thorax. In eleven out of the hundred and twenty-six cases the operation was performed upon both sides of the gland at once.* The mortality in the earlier cases was considerably greater than in the later ones.

Among the first twenty-six cases there were four deaths (all extirpation cases). All these cases have been mentioned in chap. $x x$. In two of them the operations were formidable ones and were performed upon large goitres; one of the patients

* Cases in which extirpation was performed on one side and enucleaticn on the other are included among extirpations only. 
had also valvular disease of the heart. Among the last hundred

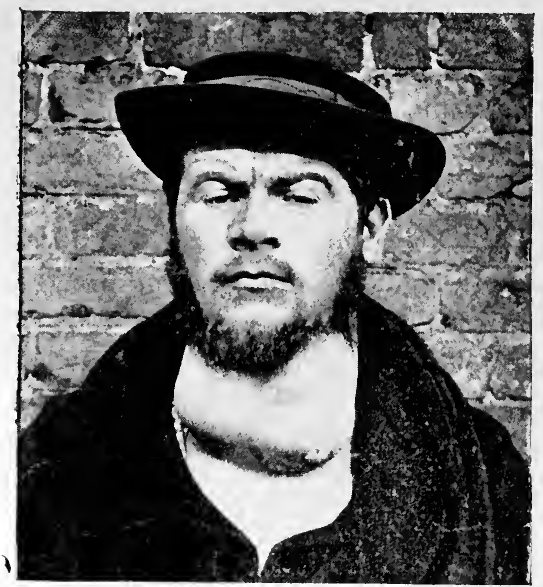

Fici. 111.-Larere bilateral, mainly adenomatous, goitre, in a man aged $2 \pi$.

The loft lobe (see Fig. 114) was extirpated ou aceount of dyspnoea.

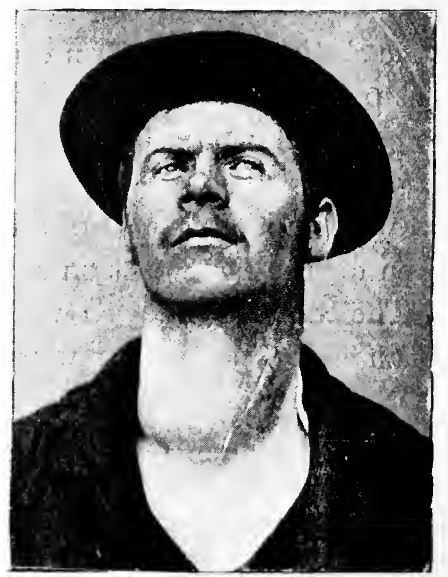

Fic: 112.-The same patient twelve days after the operation.*

cases, details of which are given on pp. 343-345, there was but one death. 'This was in the case of a boy aged eighteen (case 46),

* A full account of this case has been published by Dr. Edward Jessop and myself in the St. Burt. Hosp. Reps. 1889, xxv. p. 97. 
who had a large bilateral parenchymatous goitre. Death was due to recurrent arterial hæmorrhage caused by faulty ligation

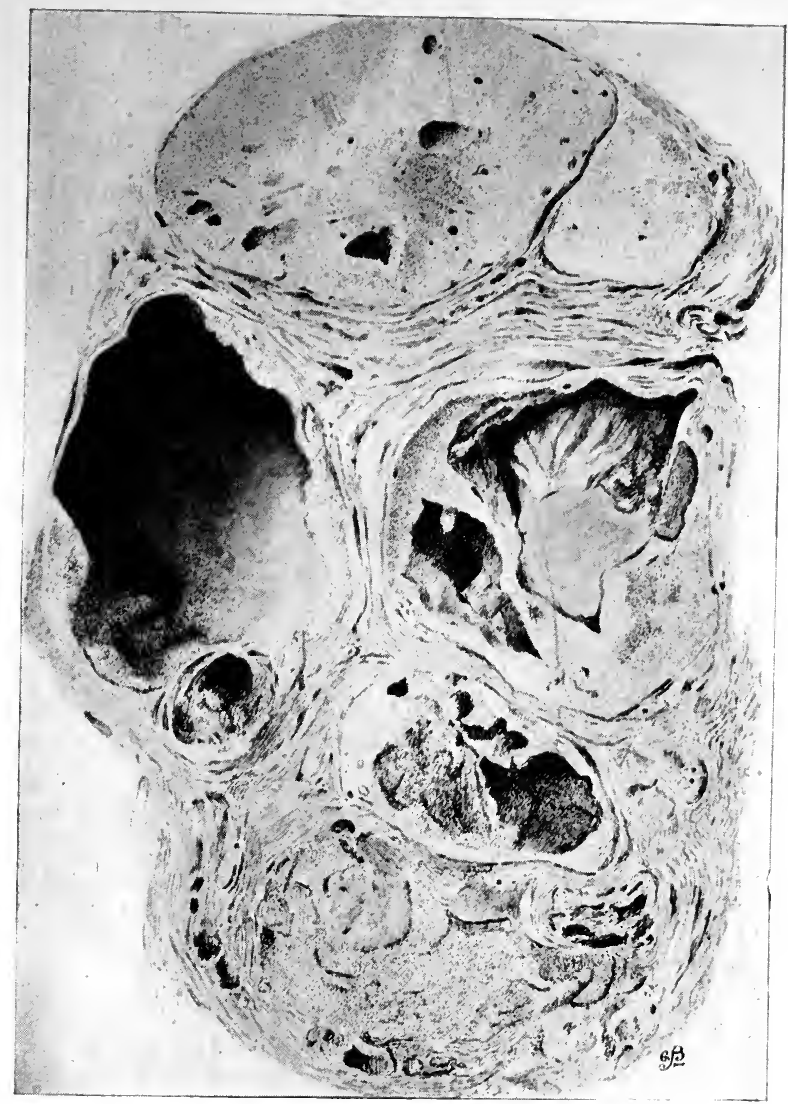

FIg. 113.-Section of the goitre shown in Fig. 111. In the npper third of the specimen are two large alenomata almost wholly solid. In the middle third are two adenomata which have broken down and formed eysts. One of these is nearly filled with a mass of coagulated colloild. In the lower third are other adenomata with a good deal of fibrous tissue. (St. Bart. Hosp. Mus. No. 2310c.) (Reduced $\frac{3}{4}$.)

of an abnormally situated thyroid artery. 'The last eighty cases have been attended by no death or serious complication of any kind.

The high mortality among the earlier cases is to be attributed 
undoubtedly to personal inexperience and want of dexterity in operating. It is not due to any essential difference in the nature of the cases operated upon. Indeed the largest operations and those attended by most dyspnoea have been among those of the later series.

Causes of Death.--Reverdin in his report gives an instructive table showing the causes to which the deaths were attributed. The following is that part of it which relates to partial extirpation and to enucleation.

\begin{tabular}{|c|c|c|c|c|c|c|}
\hline \multirow{4}{*}{\multicolumn{5}{|c|}{ 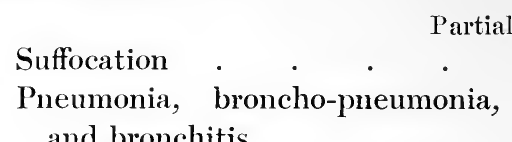 }} & 1 Extirpation. & \multirow{2}{*}{$\begin{array}{c}\text { Enucleati } \\
4\end{array}$} \\
\hline & & & & & \multirow[t]{2}{*}{1} & \\
\hline & & & & & & \multirow[b]{2}{*}{3} \\
\hline & & & & & . 18 & \\
\hline \multirow{2}{*}{\multicolumn{4}{|c|}{$\begin{array}{l}\text { Syncope. } \\
\text { Lesions of recurrent nerve }\end{array}$}} & . & . 2 & - \\
\hline & & & & . & 1 & - \\
\hline Collapse . & . & . & . & . & 1 & - \\
\hline Tetany . & & . & . & . & 1 & - \\
\hline Myxœedema a & nd $t$ & $\tan y$ & . & . & 1 & -. \\
\hline Hæmorrhage & . & . & . & . & 6 & - \\
\hline Septicæmia & . & . & . & . & 7 & - \\
\hline Mediastinitis & & . & . & . & 1 & - \\
\hline \multirow{2}{*}{\multicolumn{3}{|c|}{ Various and unknown }} & . & . & 3 & 3 \\
\hline & & & & & 42 & 10 \\
\hline
\end{tabular}

It will be seen that pulmonary complications and septicemia account for more than half the total number of deaths, while next to these in importance comes hæmorrhage. Doubtless many of the eighteen cases under the heading of pulmonary complications might fairly be classed among septic complications.

If the carlier cases could be separated from the later ones we should find that the complications more or less under the control of the surgeon, namely septic complications and hrmorrhage, were less frequent in the later cases.

With regard to this point, Reverdin quotes the statistics of Krönlein, who in his first series of cases had four deaths, of which two were due to suppurative mediastinitis, one to pneumonia and one to collapse; in his second series he had three deaths, none of which were due to sepsis; one was due to cardiac trouble and two occurred in patients who were the subjects of suffocating goitres. 


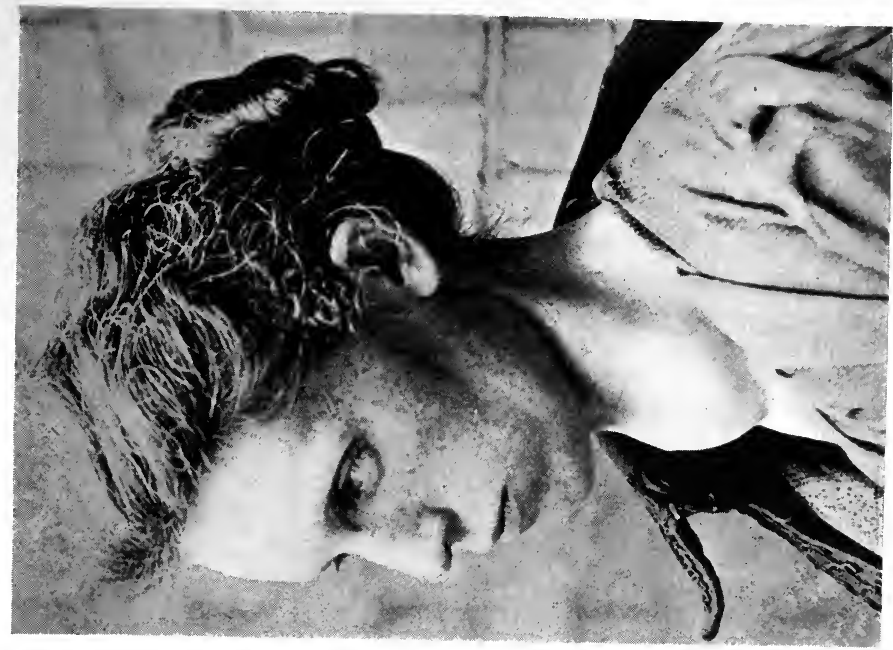

בั

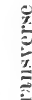

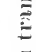

$\stackrel{\pi}{3}$

吾

$\pm$

芒

हैं

离

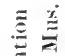

产

政

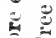

(

政

.

突

잉

บ

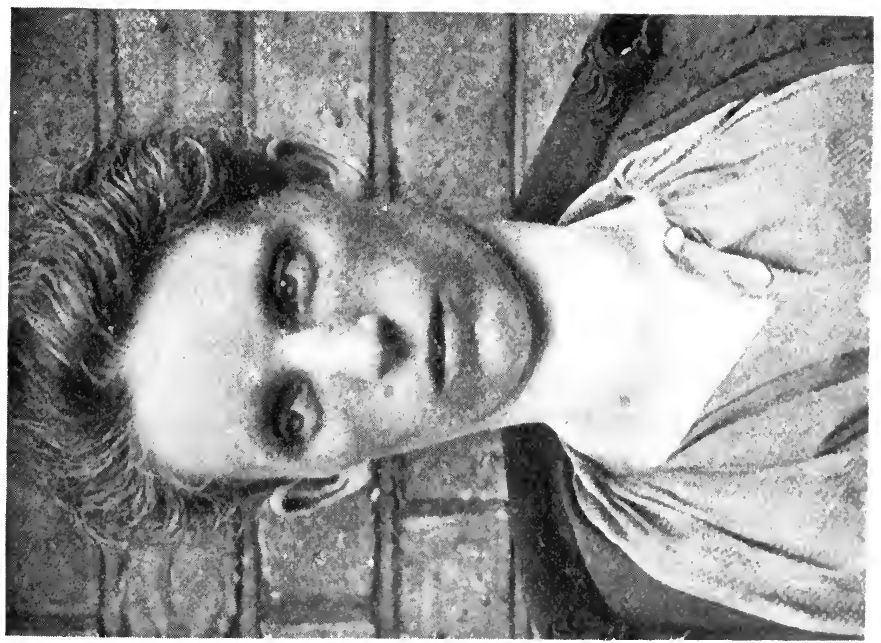

을

芒完

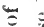

๘

घี

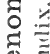

흘

4

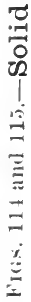


The five deaths in my own practice were due, as already mentioned, to chloroform, shock and hæmorrhage, while none were attributable to any form of sepsis or pulmonary trouble.

Turning now to the results of the operations in cases that recovered, and referring only to my own operations, we have to consider various points.

Relief from Dyspnœa.-In all my cases, hitherto, the relief from dyspnoea has been complete and permanent, so that a second operation has never yet been necessary. In a very small percentage of cases operated upon by others, second operations have been necessary. These have generally been in cases in which the first operation has been upon one lobe only, and in which disease of the opposite lobe has subsequently demanded operative interference.

Recurrence of the Goitre.-This naturally depends largely upon the nature of the goitre and of the operation performed.

Unilateral extirpation of one lobe of a parenchymatous goitre is almost invariably followed, at first, by diminution in the size of the opposite lobe. 'This diminution in size is usually followed after some months, by re-enlargement of the remaining lobe up to a certain point. If the cause which originally produced the goitre continues to act, the remainder of the goitre may continue steadily to increase in size, but rarely to such a point as to render further operation necessary. To a certain extent, the re-enlargement of the remaining lobe may be regarded as compensatory hypertrophy. (See remarks on p. 31.)

The question of recurrence after enucleation depends mainly upon the state in which the remainder of the gland is left. The adenoma or cyst that has been removed cannot of course return.* But an adenoma is frequently surrounded by other smaller adenomata or cysts, and these may continue to grow after the enucleation has been performed, or an adenoma may be imbedded in a parenchymatous goitre, and after the removal of the adenoma, further growth of the parenchymatous portion may take place.

It is in young people more especially that such recurrence of the goitre is apt to occur. One of the objections that may be

\footnotetext{
* .. Malignant adenomata" and papilliferous cysts are of course not now under
} consideration. 
raised to the operation of enucleation is that sometimes it does not remove enough of the goitre.

In a case of multiple adenomata it is often difficult to decide whether it is better to perform enucleation of one, two, or more, of the tumours * knowing that others will be left behind, or whether an extirpation of the whole lobe, tumours and all, is not a preferable, although probably a more serious, operation.

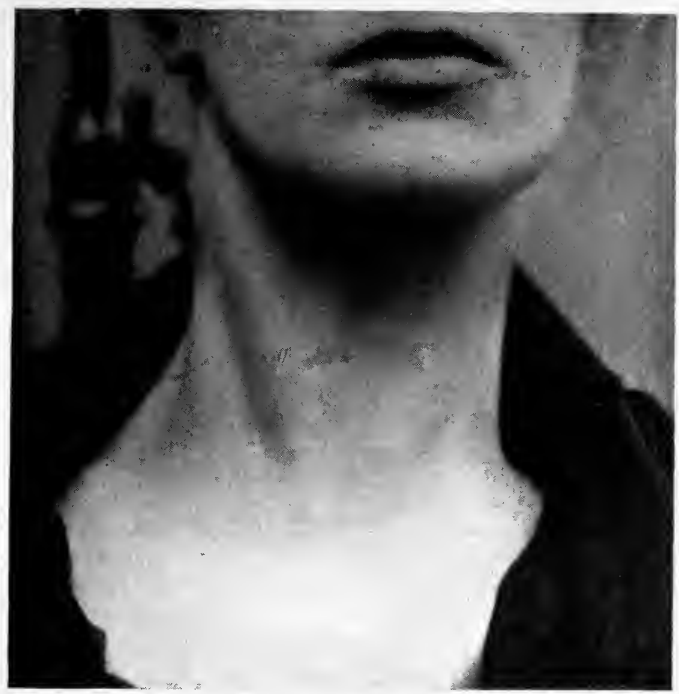

Fig. 116.-A patient aged 31, showing a Transverse Scar, eleven months after enucleation of a eystic adenoma as large as a hen's egg. (See Appendix, Case 94, p. 350.)

As a general rule, if there is a small number of relatively large adenomata, it is best to perform enucleation. If, on the other hand, numerous adenomata exist which are of nearly the same size, then extirpation of one lobe, combined if necessary, with enucleation of one or more tumours from the other lobe, is generally the best operation.

Effect upon the Voice.-Damage to the recurrent nerve may produce paralysis, partial or complete, of a vocal cord. It is exceedingly rare after enucleation, but it is not very uncommon

* See Case 88, p. 350 , in which I enucleated no less than five adenomata at one sitting. 
after extirpation, in which the nerve is more liable to injury. I have already mentioned that in one only of my 126 cases, so far as I am aware, did paralysis of a vocal cord supervene soon after the operation. This was a case in which some suppuration took place after a bilateral operation (case 41) in which extirpation was performed on one side and enucleation on the

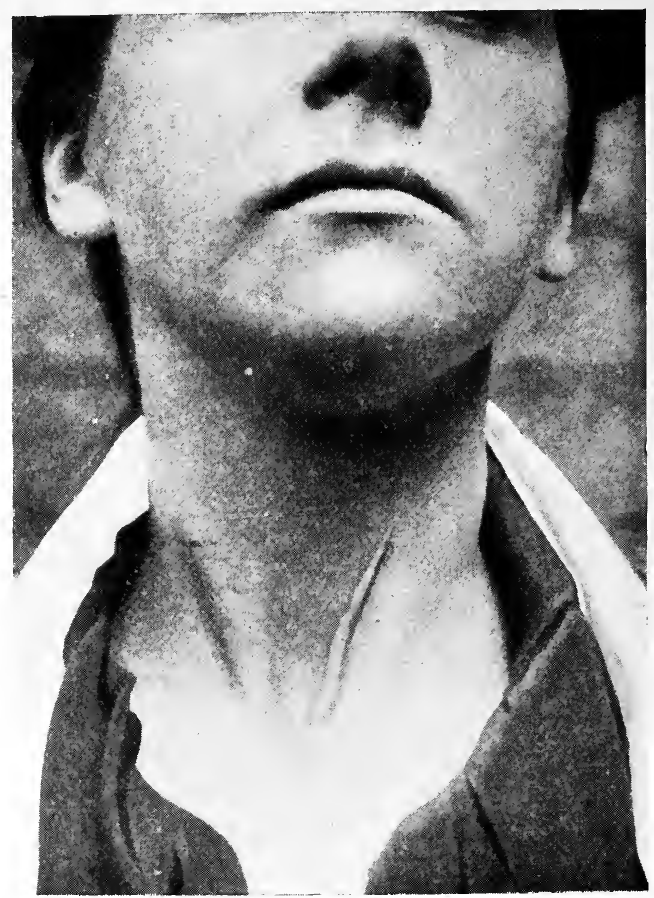

Fra. 117.-Showing a Bad Oblique Scar in a woman aged 32, six months after enneleation of an allenoma of the left lobe. The sear is wide and somewhat thick. (sire Appendix, Case 67, p. 348.)

other. In three other cases, however, paralysis of a vocal cord was found to have gradually occurred as the result of compression of the nerve by the scar. Compensation was, however, so perfect that no alteration in the voice was noticeable. Two of these were cases of extirpation, and were among my earlier operations. It is possible that some similar instance of paralysis of a cord may have occurred unknown to me, since I have not been 
able to examine all my patients long after the operation. But this has been done in the great majority of my cases, and up to the present time the above-mentioned cases are the only instances of paralysis of a cord that have been detected.

Effect on the General Health.-Total removal of the

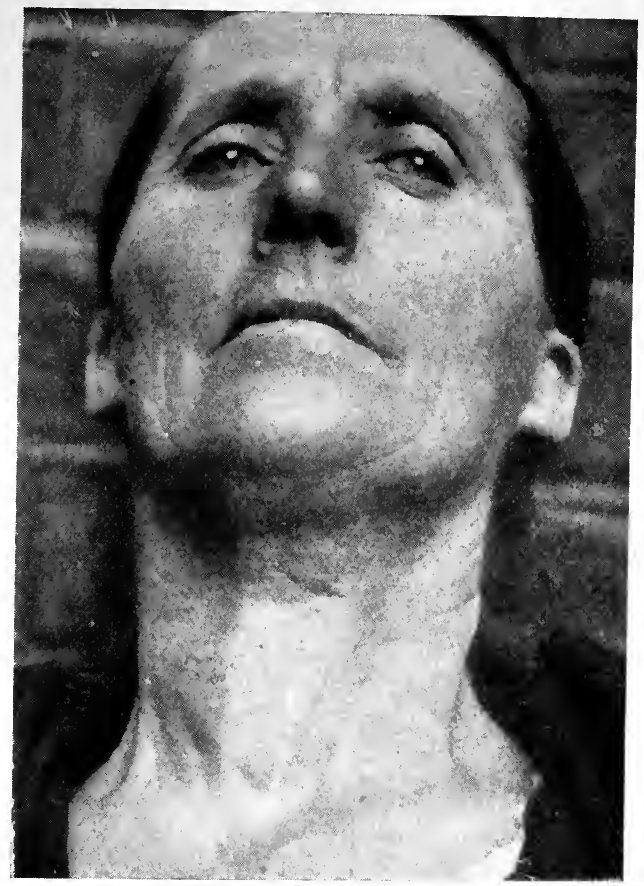

Fra. 118.-A woman aged 51, six years after removal of a bilateral goitre (extirpation on the right side, enucleation on the left). The Scar, although vertical, is fine, linear, and scarcely visible. (Case 17. See Royal Free , Hosp. Mus. No. xxii. 22.) *

thyroid gland having never been performed by myself, I have no case of pronounced cachexia strumipriva (myxœedema) to record. One case in which slight and transient symptoms of this affection lasted for a few months after a severe operation upon both lobes of the gland has been recorded on p. 326 (case 41).

In a few cases in which extensive operations were performed

* Published in Brit. Med. Journ., July 7, 1900. 

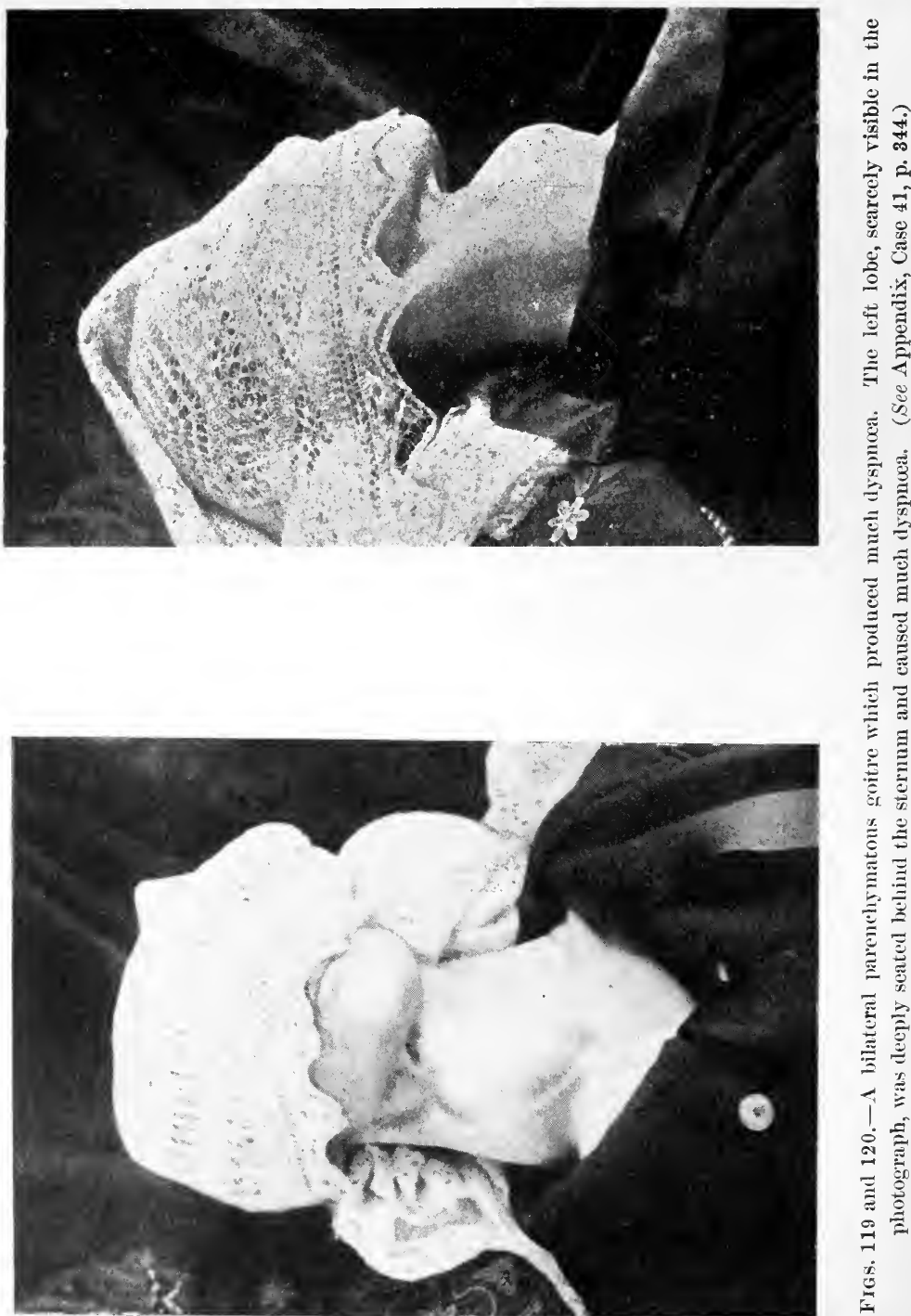
upon one or both lobes of the goitre, pallor and general weakness have been noticed, which have seemed to be greater than those which usually follow operations of similar magnitude upon most other parts of the body. These symptoms, which were probably due to temporary interference with the functions of

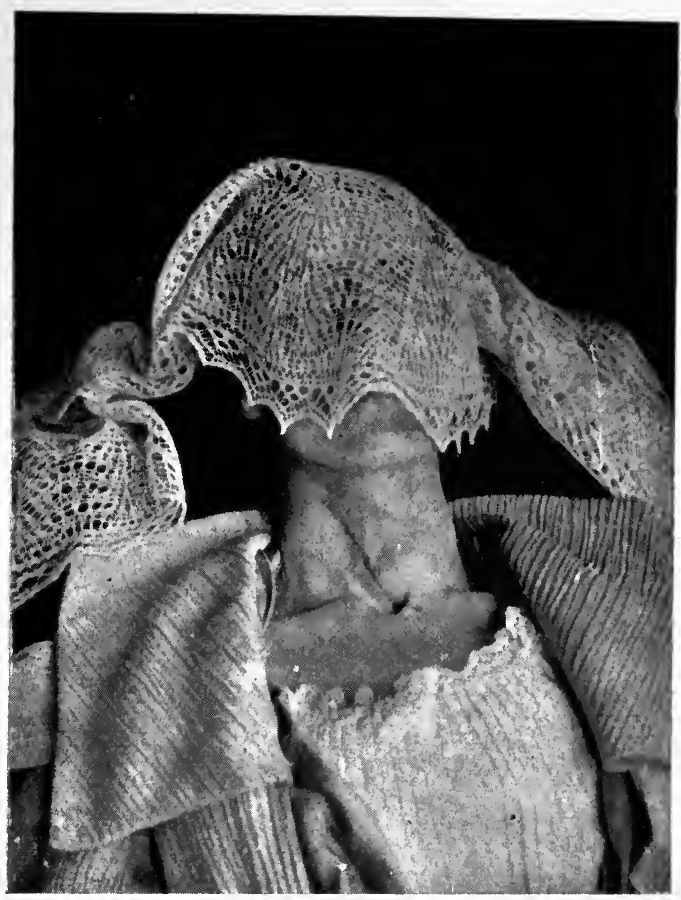

FIG. 121.-The preceding (Fig. 119), several months after extirpation of tho whole of the right lobe and most of the left lobe. The infra-hyoid muscles were not sntured, and the Scar is consequently deoply depressed and ugly. (See Appendix, Case 41, p. 344.)

the gland, have invariably been transient and have given rise to no anxiety or alarm. 'They have rarely lasted more than two or' three months. They have usually been treated by iron, strychnia, and other general tonics.

In the great majority of cases, the general health of the patient has been improved by the operation. Palpitation, lassitude, and other symptoms that have frequently been 
prominent before the operation, have in most instances either greatly diminished, or completely disappeared, after the removal of the goitre. These beneficial effects following the removal of a local disease are to be explained, I believe, chiefly by the removal of local pressure. The freedom from dyspnœa enables the patient to take far more exercise than before, and thus improves the general health.

Healing of the Wound.-In 104 of my 126 cases, the wounds healed by primary union throughout. In ten cases the wounds healed almost by primary union, but a small sinus, generally in the track of a drain, remained open for a few days. In seven cases a sinus resulted which remained open for periods varying from several weeks to several months (in one case nearly a year). In all these latter cases the suppuration was of a very mild type and, except for a short time after the operations, the patients were able to go about and pursue their ordinary arocations during the slow healing of the sinus. Of profuse and really dangerous suppuration I have no case to record. A permanent fistula, such as is seen sometimes after injection and of which Fig. 86 is an example, is a condition that has never occurred after any of my operations.

The Scar.-As has already been mentioned in chap. xvii. the nature of the scar depends to a considerable extent upon the direction in which the skin incision has been made. Transverse wounds healing by primary union almost invariably leave fine linear scars often scarcely noticeable when the redness has passed off. Such scars are shown in Figs. 96 and 116. Vertical and oblique scars in young people, even when the wounds have healed by primary union, have a considerably tendency to widen and become unsightly. (See Fig. 11\%) They sometimes become thick, prominent and ugly, assuming a keloid nature. In elderly people, on the other hand, this tendency is very slightly marked. (See Figs. 105 and 118.) Wounds that heal by granulation naturally leave worse scars than those that heal by primary union. 


\title{
APPENDIX.
}

\section{ONE HUNDRED CONSECUTIVE* CASES}

\author{
oF
}

\section{REMOVAL OF GOITRE BY OPERATION (EXTIRPATION AND ENUCLEATION)}

PERFORMED BY THE AUTHOR SINCE FEBRUARY 1894.

\section{SUMMARY OF THE FOLLOWING TABLE.}

TOTAL
CASES.
ERIES. DEATHS.

Extirpations

$\begin{array}{lllllrrr}\text { Bilateral . } & \cdot & & & . & 5 & 5 & 0 \\ \text { Unilateral } & \cdot & \cdot & . & . & 21 & 20 & 1\end{array}$

Extirpation on one side combined with

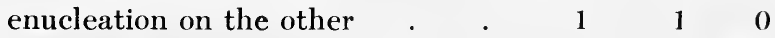

Enucleations

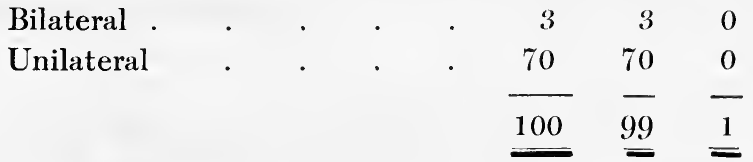

* One other case, of a large, fixed and hopelessly irremovable, malignant goitre, in which a portion of the tumour was removed merely to allow of access to the trachea for the purposes of an immediate and urgent tracheotomy, has not been included in the list. 
ONE HUNDRED CONSECUTIVE CASES OF REMOVAL OF Performed by the Author between

\begin{tabular}{|c|c|c|c|c|c|c|c|}
\hline No. & $\begin{array}{l}\text { Date of } \\
\text { Opera- } \\
\text { tion. }\end{array}$ & Name. & $\underset{8}{8}$ & $\begin{array}{l}\text { Chief Reason for } \\
\text { Operation. }\end{array}$ & Operation. & Nature of Goitre. & 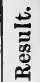 \\
\hline $27 *$ & $\begin{array}{c}1894 \\
\text { March 17 }\end{array}$ & $\begin{array}{l}\text { Barkland } \\
\text { C. (male) }\end{array}$ & 15 & $\begin{array}{l}\text { Dyspnoa, } \\
\text { dysphagia }\end{array}$ & $\begin{array}{l}\text { Extirpation, } \\
\text { whole of right, }\end{array}$ & Parenchymatous ; $8 \mathrm{oz}$. & R. \\
\hline 28 & Narch 27 & James H. & 21 & Dyspnoa & $\begin{array}{l}\text { one third of left } \\
\text { Extirpation, } \\
\text { right lobe and }\end{array}$ & Parenchymatous ; $6 \mathrm{oz}$. & $\mathbf{R}$. \\
\hline 29 & July 1 & Mr. R. B. & 30 & Deformity & $\begin{array}{l}\text { isthmus } \\
\text { Enucleation }\end{array}$ & $\begin{array}{l}\text { Prominent cyst size of golf ball } \\
\text { in front of larynx }\end{array}$ & R. \\
\hline 30 & July 20 & Mary $\mathrm{H}$. & 39 & Severe dyspnœa & $\begin{array}{l}\text { Extirpation, } \\
\text { right }\end{array}$ & $\begin{array}{l}\text { Parenchymatous with cystic } \\
\text { adenomata; } 4 \frac{1}{2} \times 3 \mathrm{in.} ; 8 \mathrm{oz} \text {; }\end{array}$ & R. \\
\hline 31 & Oct. 13 & $\begin{array}{l}\text { Constance } \\
\quad \text { R. }\end{array}$ & 10 & Dyspnœa & $\begin{array}{l}\text { Extirpation, } \\
\text { right and part }\end{array}$ & $\begin{array}{c}\text { Parenchymatous; } 44_{4}^{1} \times 2 \frac{1}{3} \text { in. ; } \\
\text { weight of right } 40 \mathrm{z} \text {. }\end{array}$ & R. \\
\hline 32 & Nov. 3 & Kate M. & 20 & $\begin{array}{l}\text { Dyspnoea, } \\
\text { dysphagia }\end{array}$ & ", & $\begin{array}{l}\text { Parenchymatous; } 4 \frac{1}{2} \times 3 \frac{1}{2} \text { in. } \\
13 \frac{1}{3} \text { oz. ; partly sulosternal }\end{array}$ & R. \\
\hline 33 & $\begin{array}{l}\text { Dec. } 5 \\
1895\end{array}$ & Ellen s. & 15 & Dyspnoea & 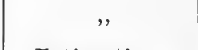 & $\begin{array}{c}\text { Parenchymatous; extending } \\
\text { into thorax }\end{array}$ & R. \\
\hline 34 & March 7 & Ellen N. & 43 & Severe dyspnœa & $\begin{array}{l}\text { Extirpation, } \\
\text { right and isthmins }\end{array}$ & $\begin{array}{c}\text { Parenchymatous; } 4 \times 5 \text { in.; } \\
\tau \text { oz. }\end{array}$ & R. \\
\hline 35 & March 31 & Miss $\mathrm{S}$. & 25 & Deformity & Enucleation & $\begin{array}{l}\text { Cystic adenoma (one-third } \\
\text { solid); } 2 \frac{1}{2} \text { in. in diameter }\end{array}$ & R. \\
\hline 36 & May 18 & $\begin{array}{l}\text { Margaret } \\
\text { L. }\end{array}$ & 15 & Dyspnoaa & Extirpation, left & $\begin{array}{c}\text { Parenchymatous; very large } \\
\text { goitre (Figs. 2.2, 23) }\end{array}$ & R. \\
\hline 37 & Sept. 20 & Mrs. B. & 41 & Dyspncea & $\begin{array}{l}\text { Extirpation, left } \\
\text { and part of right }\end{array}$ & Parenchymatous; $4 \frac{1}{4} \mathrm{oz}$. & R. \\
\hline 38 & Dec. 16 & Hannah D. & 50 & Malignancy & $\begin{array}{l}\text { Extirpation, left } \\
\text { and isthmus, and } \\
\text { small part of right }\end{array}$ & \begin{tabular}{|l|}
$2 \times 1 \frac{1}{4} \times 3$ in.; pale non-encap- \\
suled tumour, surrounded by \\
thick layer of healthy thyroid \\
gland; microscopically
\end{tabular} & R. \\
\hline 39 & Feb. 1 & Mrs. W. & 38 & $\begin{array}{c}\text { Deformity; } \\
\text { slight dyspnoa }\end{array}$ & Enucleation, left & Cystic adenoma size of wahnut & R. \\
\hline 40 & Feb. 29 & Clara $\mathrm{s}$. & 16 & $\begin{array}{l}\text { Dyspnoea, } \\
\text { dysphagia }\end{array}$ & $\begin{array}{l}\text { Enucleation, } \\
\text { right }\end{array}$ & $\begin{array}{l}\text { Cystic adenoma; } 1 \frac{1}{2} \text { in. in dia- } \\
\text { meter; partly substernal }\end{array}$ & R. \\
\hline 41 & March 8 & Miss $\mathrm{H}$. & 43 & Dyspnoxa & $\begin{array}{l}\text { Extirpation, } \\
\text { right and most } \\
\text { of left }\end{array}$ & 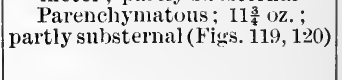 & R. \\
\hline 42 & May 28 & Sarah $P$. & 25 & $\begin{array}{l}\text { Deformity, dis- } \\
\text { placement of } \\
\text { trachea }\end{array}$ & $\begin{array}{l}\text { Enucleation, } \\
\text { right }\end{array}$ & $\begin{array}{l}\text { Cystic adenoma, one-third } \\
\text { solid; size of hent's eygr }\end{array}$ & R. \\
\hline 43 & $\begin{array}{l}\text { Oct. } 3 \\
1897\end{array}$ & Kate C. & 26 & Dyspncea & $"$ & $\begin{array}{l}\text { Cystic adenoma, two-thirds } \\
\text { solid; } 2 \text {, } 10 \text { oz. }\end{array}$ & R. \\
\hline 44 & March 27 & Lilla W. & 14 & Slight dyspnœa & , & Cystic adenoma size of orange & R. \\
\hline 45 & May 17 & Mrs. J. & 37 & Severe dyspnœa & ," & $\begin{array}{l}\text { Solid adenoma; } 3 \times 21 \text { in. ; } \\
\text { largely substernal }\end{array}$ & R. \\
\hline 46 & May 22 & Francis L. & 18 & $\begin{array}{l}\text { Slight dyspnoea; } \\
\text { tracheal stenosis }\end{array}$ & $\begin{array}{c}\text { Extirpation, } \\
\text { right }\end{array}$ & Parenchymatous; $10 \frac{1}{2}$ oz. & D. \\
\hline
\end{tabular}

- Cases 1 to 26 have already been published in the British Medical Journal, June 1891 and July 1900. 


\section{GOITRE BY OPERATION (EXTIRPATION AND ENUCLEATION).} February 1894 and January 1901.

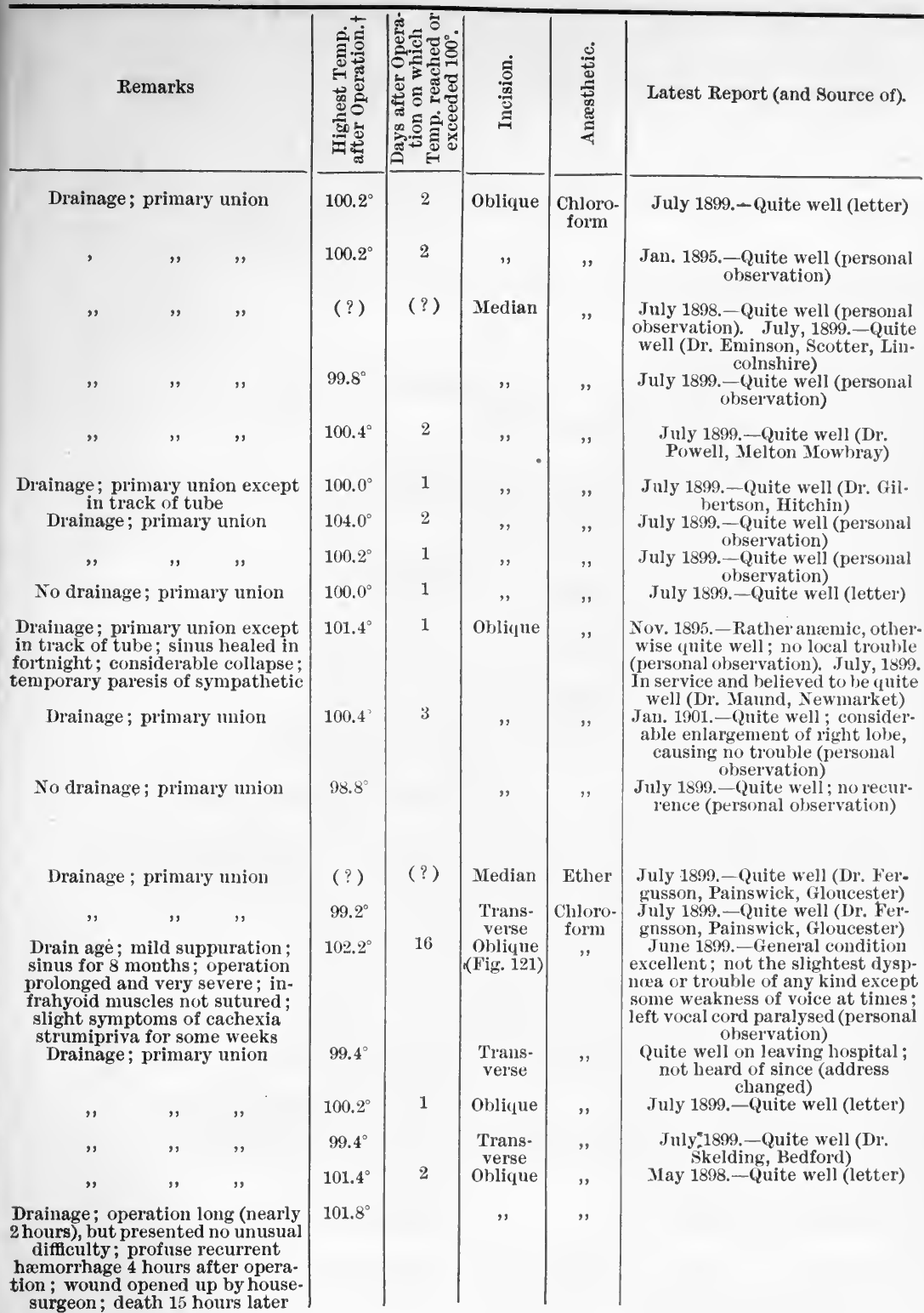

$\uparrow$ Temperature taken every four hours. 


\begin{tabular}{|c|c|c|c|c|c|c|}
\hline No. & $\begin{array}{l}\text { Date of } \\
\text { Opera- } \\
\text { tion. }\end{array}$ & Name. & $\sum_{i}^{\circ 0}$ & $\begin{array}{l}\text { Chief Reason for } \\
\text { Operation. }\end{array}$ & Operation. & Nature of Goitre. \\
\hline 47 & July 17 & Albert $\mathrm{R}$. & 22 & Dyspnoea & Extirpation, & Parenchymatous; $7 \frac{1}{2} \mathrm{oz}$ \\
\hline 48 & July :2: & $\begin{array}{c}\text { Sarah Ann } \\
\text { H. }\end{array}$ & 40 & & , & $\begin{array}{l}\text { Parenchymatous with adeno- } \\
\text { matous nodules; partly } \\
\text { substernal ; } 11 \mathrm{oz} .\end{array}$ \\
\hline 49 & Sept. 16 & Eliza B. & 46 & $\begin{array}{l}\text { Dyspnoea, dys- } \\
\text { phagia; recent } \\
\text { increase in size; } \\
\text { suspected malig- } \\
\text { nancy }\end{array}$ & $\begin{array}{l}\text { Extirpation, } \\
\text { right, enuclea- } \\
\text { tion, part of left }\end{array}$ & $\begin{array}{l}\text { Solid adenomata } ; 3 \frac{1}{2} \text { oz. ; right } \\
\text { size of orange, left of walnut }\end{array}$ \\
\hline 50 & Sept. 30 & Lucy s. & 38 & Dyspncea & $\begin{array}{c}\text { Extirpation, } \\
\text { right }\end{array}$ & Solid adenoma; $7 \frac{3}{4} \mathrm{oz}$. \\
\hline 51 & Oct. 16 & Edith W. & 18 & $\begin{array}{l}\text { Dyspnoea, } \\
\text { dysphagia }\end{array}$ & Enucleation, left & $\begin{array}{l}\text { Two tumours. - } 1 \text {. Hremorrha- } \\
\text { gic cystic adenoma, size of wal- } \\
\text { 1nit. 2. Solid adenoma, size of } \\
\text { hazel nut }\end{array}$ \\
\hline $5:$ & Jall. 23 & Mrs. F. & 39 & Dyspunca & $\begin{array}{l}\text { Enucleation, } \\
\text { right }\end{array}$ & $\begin{array}{l}\text { Solid adenoma, size of large } \\
\text { walnut; deeply-seated and } \\
\text { projecting from back of gland }\end{array}$ \\
\hline 53 & Jan. 29 & Louisa H. & 54 & Severe dyspnoea & , & $\begin{array}{l}\text { Solid adenoma, size of large } \\
\text { lemon; partly substernal; } 6 \mathrm{oz} \text {. } \\
\text { (Figs. 91,92) }\end{array}$ \\
\hline 54 & Irarch 2 & Miss P. & 25 & Dyspncea & Enucleation, left & $\begin{array}{l}\text { Cystic adenoma, one-third } \\
\text { solid, size of duck's egg }\end{array}$ \\
\hline 55 & May 7 & Rénée C. & 27 & Dyspncea & $\begin{array}{l}\text { Enucleation, } \\
\text { right }\end{array}$ & $\begin{array}{l}\text { Solid adenoma, size of an } \\
\text { orange; the twmonr was broken } \\
\text { "1p and removed through an } \\
\text { incision } 2 \frac{1}{\text { in }} \text {. long }\end{array}$ \\
\hline 56 & May 13 & $\begin{array}{l}\text { Charlotte } \\
\text { G. }\end{array}$ & 40 & $\begin{array}{l}\text { Rapid growth; } \\
\text { hardness; sus- } \\
\text { pected malig- } \\
\quad \text { nancy }\end{array}$ & $\begin{array}{l}\text { Extirpation, } \\
\text { right }\end{array}$ & $\begin{array}{l}\text { A hard, white, shiny solid } \\
\text { tumour, size of a hen's egg, } \\
\text { microscopically not malignant }\end{array}$ \\
\hline 57 & Maty 13 & Alice B. & 30 & $\begin{array}{l}\text { Dyspncea, } \\
\text { dyspluagia }\end{array}$ & $\begin{array}{l}\text { Enucleation, } \\
\text { left (atypical) }\end{array}$ & $\begin{array}{l}\text { Solid tmmour, not well encap- } \\
\text { suled; about } 1 \frac{1}{2} \text { in. in diameter }\end{array}$ \\
\hline 58 & May 21 & Emily M. & 33 & Dyspnoa & $\begin{array}{l}\text { Enucleation, } \\
\text { right }\end{array}$ & $\begin{array}{l}\text { Solid adenoma, size of orange; } \\
\text { broken up and removed through }\end{array}$ \\
\hline 59 & Nay 21 & Harriet $\mathrm{s}$. & 25 & Dyspnoea & $\begin{array}{l}\text { Enucleation. } \\
\text { right and left }\end{array}$ & $\begin{array}{l}\text { R. hamorthagic cyst, size of } \\
\text { hen's egg. L. cystic adenoma, }\end{array}$ \\
\hline 60 & July 9 & $\begin{array}{l}\text { Charlotte } \\
\text { J. }\end{array}$ & 54 & Dyspncea & $\begin{array}{l}\text { Enucleation, } \\
\text { right }\end{array}$ & $\begin{array}{l}\text { Cystic adenoma with hemor- } \\
\text { rhage; three-fourths solid ; } \\
3 \times 2 \text { in.; patient also had }\end{array}$ \\
\hline 61 & Oct. 6 & Eliza J. & 50 & $\begin{array}{l}\text { Dyspnoea, great } \\
\text { deformity }\end{array}$ & Enucleation & Cyst 5 in. in diameter (Fig. 65) \\
\hline 62 & Oct. 6 & Harriet M. & 48 & $\begin{array}{l}\text { Tracheal dis- } \\
\text { placement; in- } \\
\text { creasing size; } \\
\text { slight dyspnoea }\end{array}$ & Enucleation, left & $\begin{array}{l}\text { Cystic adenoma, chicfly fluid; } \\
\text { maximum diameter } 5 \text { in.; } \\
13 \mathrm{oz} \text {. (Fig. 103) }\end{array}$ \\
\hline 63 & Nov. 26 & Rhoda S. & 59 & Dyspnoea & Enucleation, left & $\begin{array}{c}\text { Cystic adenoma, mainly fluid; } \\
4 \times 2 \frac{1}{2} \text { in.; patient has valvular } \\
\text { disease of heart }\end{array}$ \\
\hline
\end{tabular}




\section{( 347$)$ \\ GOITRE BY OPERATION (EXTIRPATION AND ENUCLEATION). February 1894 and January 1901.}

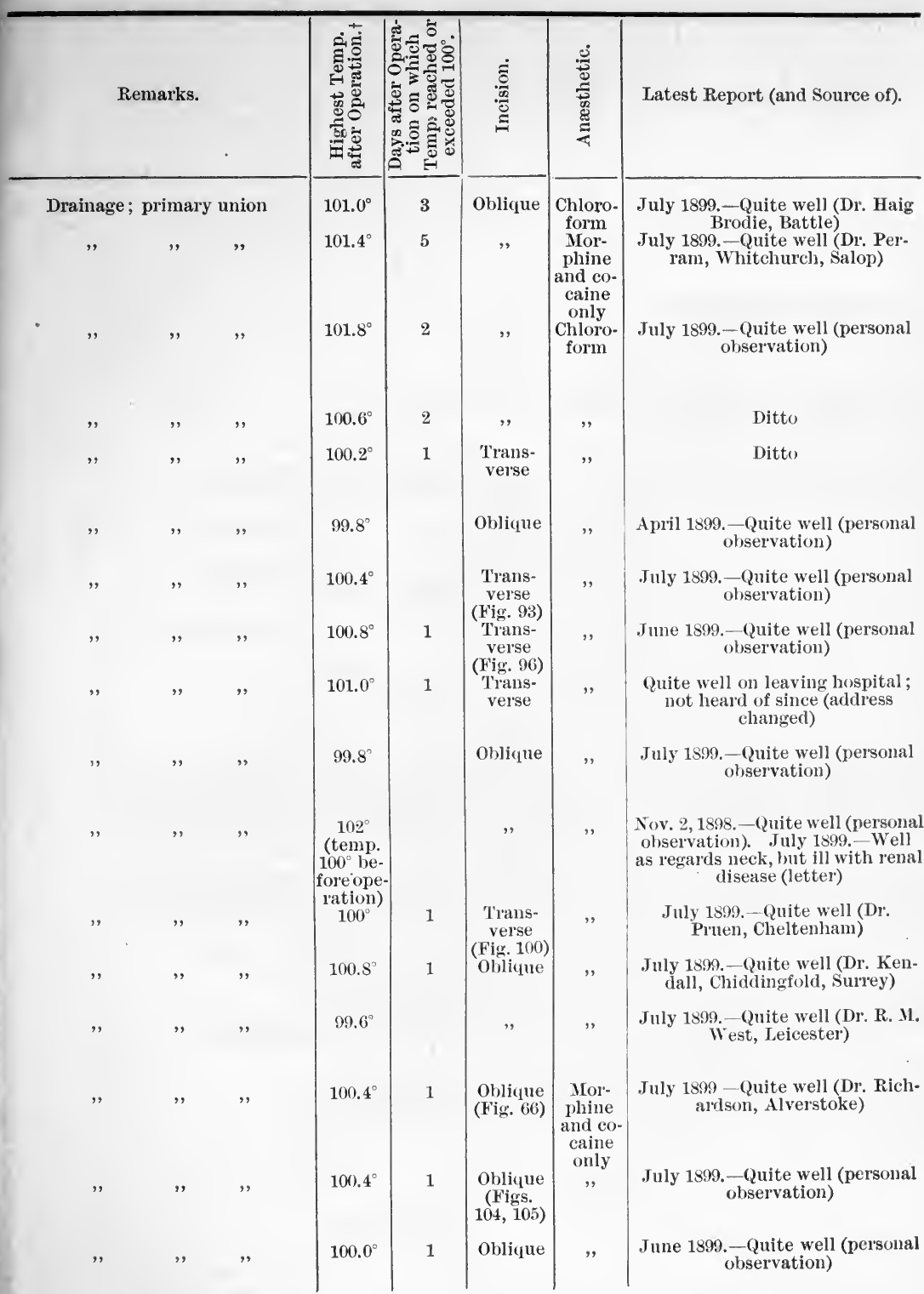

† Temperature taken every four hours. 


\begin{tabular}{|c|c|c|c|c|c|}
\hline $\mathrm{No}^{2}$ & $\begin{array}{l}\text { Date of } \\
\text { Opera- } \\
\text { tion. }\end{array}$ & Name. & $\sum_{i}^{\infty}$ & $\begin{array}{c}\text { Chief Reason for } \\
\text { Operation. }\end{array}$ & Operation. \\
\hline 64 & Nov. 26 & Edith C. & 27 & $\begin{array}{l}\text { Dyspnoea; } \\
\text { dysphagia }\end{array}$ & $\begin{array}{l}\text { Enucleation, } \\
\text { right }\end{array}$ \\
\hline 66 & $\begin{array}{l}1899 \\
\text { Jall. } 7\end{array}$ & Amnie L. & 30 & $\begin{array}{l}\text { Extreme bi- } \\
\text { lateral tracheal } \\
\text { stenosis; old } \\
\text { tracheotomy } \\
\text { fistula } \\
\text { Tracheal } \\
\text { narrowing }\end{array}$ & $\begin{array}{c}\text { Enucleation, } \\
\text { right (March 14, } \\
\text { 1899, plastic } \\
\text { operation on } \\
\text { tracheal fistula) } \\
\text { Enucleation, } \\
\text { right }\end{array}$ \\
\hline 67 & Jan. 7 & Ada $\mathrm{H}$. & 32 & $\begin{array}{l}\text { Steady increase } \\
\text { in size }\end{array}$ & Enucleation, left \\
\hline 68 & Jan. 13 & Miss $\mathrm{S}$. & 35 & $\begin{array}{l}\text { Deformity, dis- } \\
\text { placement of } \\
\text { trachea }\end{array}$ & Enucleation \\
\hline 69 & Jan. 14 & Caroline $\mathrm{T}$. & 43 & Dyspnoea & $\begin{array}{l}\text { Enucleation, } \\
\text { right }\end{array}$ \\
\hline 70 & Jan. 28 & Phobe H. & 14 & Dyspnoea & $\begin{array}{l}\text { Extirpation, } \\
\text { right }\end{array}$ \\
\hline 71 & Jan. 28 & Ernest W. & 14 & $\begin{array}{l}\text { Slight dyspncea; } \\
\text { deformity }\end{array}$ & , \\
\hline 72 & Feb. 17 & Miss N. & 26 & Deformity & $\begin{array}{l}\text { Enucleation, left } \\
\text { (évidement) }\end{array}$ \\
\hline 73 & Iarch 18 & Mrs. M. & 29 & $\begin{array}{l}\text { Deformity; } \\
\text { slight dyspncea }\end{array}$ & $\begin{array}{c}\text { Enucleation, } \\
\text { right }\end{array}$ \\
\hline 74 & April 22 & Alice $\mathrm{E}$. & 33 & Dyspnoea & Enucleation, left \\
\hline 75 & April 22 & Hilkiah W. & 20 & $\begin{array}{l}\text { Deformity } \\
\text { dyspnoea }\end{array}$ & $\begin{array}{c}\text { Extirpation, } \\
\text { right }\end{array}$ \\
\hline 76 & May 14 & Mrs. D. & 40 & Dyspnoea & Enucleation, left \\
\hline 77 & June 3 & Beatrice C. & 20 & Dyspnoea & $\begin{array}{l}\text { Enucleation, } \\
\text { right }\end{array}$ \\
\hline 78 & July 6 & Lucy H. & 35 & Dyspmoea & , \\
\hline 79 & July 13 & Rose $\mathrm{S}$. & 27 & Slight dyspnoea & Enucleation, left \\
\hline 81 & $\begin{array}{l}\text { July } 22 \\
\text { Sept. } 7\end{array}$ & $\begin{array}{l}\text { Caroline } \\
\text { W. } \\
\text { Martha M. }\end{array}$ & $\begin{array}{l}35 \\
27\end{array}$ & $\begin{array}{l}\text { Slight dyspncea } \\
\text { going abroad } \\
\text { Dyspncea }\end{array}$ & $\begin{array}{c}\text { Enucleation, left } \\
\text { (évidement) } \\
\text { Enucleation, } \\
\text { right }\end{array}$ \\
\hline 82 & Oct. 14 & $\begin{array}{c}\text { Elizabeth } \\
\text { T. }\end{array}$ & 35 & $\begin{array}{l}\text { Great deformity; } \\
\text { discomfort; dys- } \\
\text { nœa and stridor }\end{array}$ & Enucleation, left \\
\hline 83 & Oct. 21 & $\underset{\text { B }}{\text { Elizabeth }}$ & 28 & Dyspnoa & $\begin{array}{c}\text { Enucleation } \\
\text { (évidement) }\end{array}$ \\
\hline
\end{tabular}

Cystic adenoma, two-thirds solid, size of walnut; deeply seated

Cystic adenoma, two-thirds solid, size of hen's egrg Solid adenoma, size of hen's egg

Solid adenoma, $2 \frac{1}{2} \times 1 \frac{1}{2}$ in.

Parenchymatous; $3 \times 2$ in. ; $3 \mathrm{oz}$.

Parenchymatous ; $3 \frac{1}{2} \times 2$ in. $3 \mathrm{oz}$.

Solid adenoma, size of walnut

Cystic adenoma; $3 \frac{1}{2}$ in. in diameter (removal through incision $2 \mathrm{in.} \mathrm{long)}$

Solid adenoma, size of duck's egg; $1 \frac{1}{2} \mathrm{OZ}$.

Parenchymatous; $10 \frac{1}{\mathrm{oz}}$. (Fig. 21)

Parenchymatous; abont 5 oz.

R.

Cystic adenoma, one-third solid, size of duck's egg; partly substemal

Two solid adenomata, size of hen's egg and cherry respectively

Solid adenoma, size of duck's egg, broken up and removed through incision $2 \frac{1}{4} \mathrm{in}$. long

Cystic adenoma, size of bantam's egg, two-thirds solid Solid adenoma, size of walnut

Solid adenoma, size of cocoanut ; $5 \frac{1}{2} \times 4$ in. ; 16 oz. (Fig. 101)

Solid adenoma, size of large walnut; partly substernal 
GOITRE BY OPERATION (EXTIRPATION AND ENUCLEATION). February 1894 and January 1901.

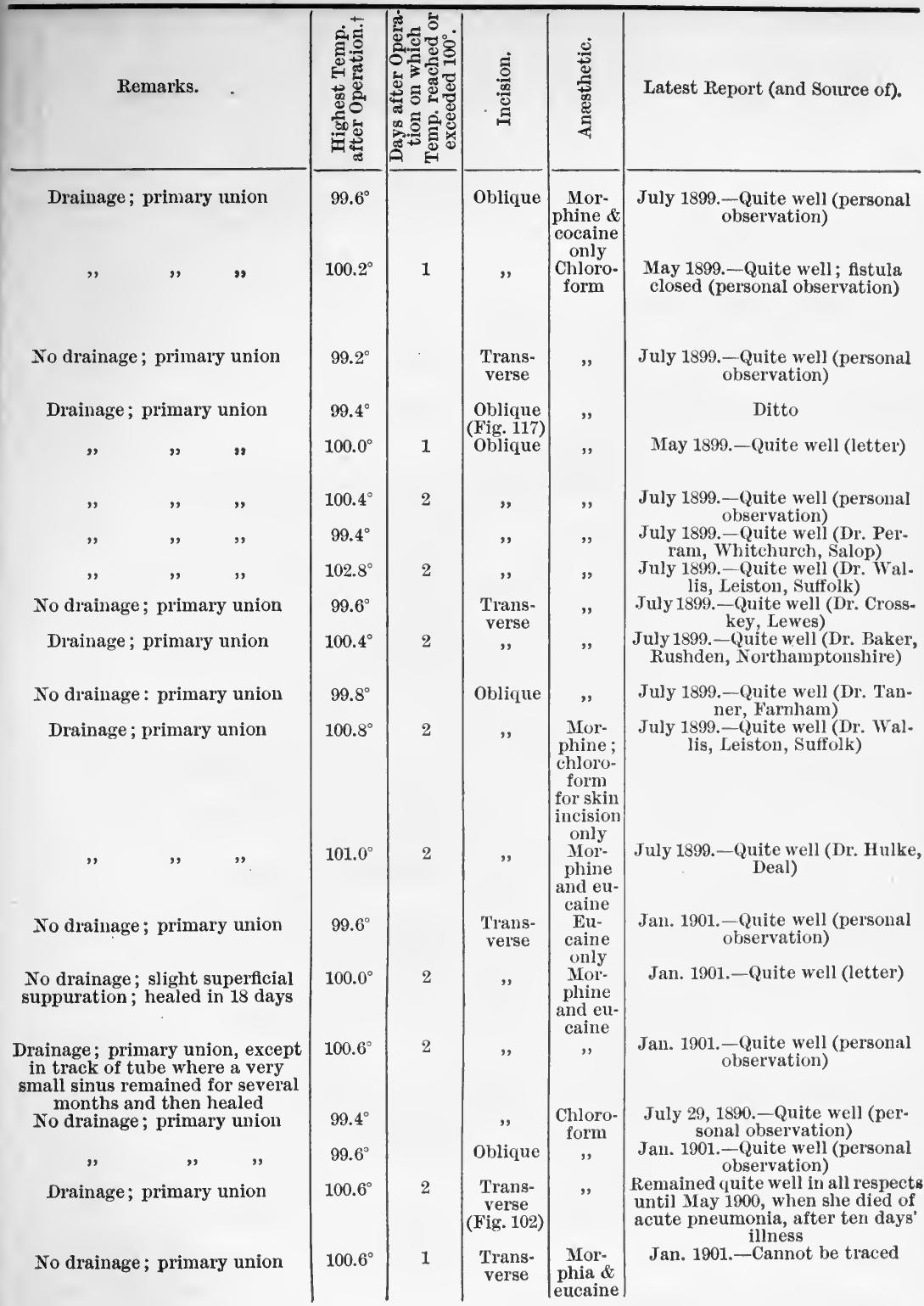

$\dagger$ Temperature taken every four hours. 


\begin{tabular}{|c|c|c|c|c|c|c|c|}
\hline No. & $\begin{array}{l}\text { Date of } \\
\text { Opera- } \\
\text { tion. }\end{array}$ & Name. & $\sum_{i=0}^{\infty}$ & $\begin{array}{l}\text { Chief Reason for } \\
\text { Operation. }\end{array}$ & Operation. & Nature of Goitre. & 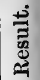 \\
\hline 84 & Nov. 11 & Ellen G. & 49 & Dyspnca & Enucleation, left & $\begin{array}{l}\text { Solid adenoma, size of hen's } \\
\text { egg; partly substernal }\end{array}$ & R. \\
\hline 85 & Nov. 30 & Miss $W$ & 26 & $\begin{array}{l}\text { Deformity } \\
\text { dysphagia }\end{array}$ & $\begin{array}{l}\text { Enncleation, } \\
\text { right and left }\end{array}$ & $\begin{array}{c}\text { Two adenomata. R. solid, size } \\
\text { of walnut. L. four-fifths fluid, } \\
\text { size of orange }\end{array}$ & $\mathbf{R}$. \\
\hline 86 & Dec. 9 & Anllie $\mathrm{F}$. & 23 & Dyspnoea & Enucleation & $\begin{array}{l}\text { Cystic adenoma, size of chest- } \\
\text { nut; very deeply seated and at } \\
\text { the back of the oland }\end{array}$ & $\mathbf{R}$ \\
\hline 57 & Dec. 16 & salah s. & 47 & $\begin{array}{l}\text { Dyspmoea, } \\
\text { dyspluagia }\end{array}$ & Enucleation, left & $\begin{array}{l}\text { Four adenomata, largest solid } \\
\text { and size of walnut and sub- }\end{array}$ & R. \\
\hline ss & $\begin{array}{l}1900 \\
\text { Jan. } 6\end{array}$ & Emmia M. & 45 & Dyspmoea & $\begin{array}{l}\text { Enucleation, } \\
\text { right }\end{array}$ & $\begin{array}{l}\text { sternal; very deeply seated } \\
\text { Five adenomata; all solid; } \\
\text { largest, size of tangerine orange }\end{array}$ & R. \\
\hline $8 !)$ & Jan. 11 & Harry $\mathrm{S}$. & 21 & Dysincea &, & Solid adenoma; $3 \mathrm{oz}$. & R. \\
\hline 90 & Jan. 1s & $\begin{array}{l}\text { Elizalueth } \\
\text { I. }\end{array}$ & $4 \div$ & $\begin{array}{l}\text { Bulk; discomfort } \\
\text { and deformity }\end{array}$ &, & $\begin{array}{l}\text { Solid adenoma, size of cocoa- } \\
\text { nut; } 16 \mathrm{oz} \text { (Figs. } 55,56)\end{array}$ & R. \\
\hline 91 & Jan. 20 & Marion E. & 26 & $\begin{array}{c}\text { Nlight dyspliagia; } \\
\text { deformity; } \\
\text { steady growth }\end{array}$ & , & $\begin{array}{l}\text { Cystic adenoma, size of hen's } \\
\text { egra }\end{array}$ & R. \\
\hline 99 & Fels. 10 & Eleanor G. & 20 & $\begin{array}{l}\text { Low situation: } \\
\text { slioght dysponoa }\end{array}$ & Thes & $\begin{array}{c}\text { Cystic adenoma, size of eggr; } \\
\text { partly sulisternal }\end{array}$ & R. \\
\hline 93 & Fels. 10 & Marie M. & 15 & Dyspllica & $\begin{array}{l}\text { Extippation, } \\
\text { right }\end{array}$ & Parenchymatous; $6 \frac{1}{2} \mathrm{oz}$. & R. \\
\hline$! 4$ & Feb. 17 & Emily $\mathrm{H}$. & 31 & Dysplucat & $\begin{array}{l}\text { Enucleation, } \\
\text { right }\end{array}$ & $\begin{array}{c}\text { Cystic adenoma, size of hen's } \\
\text { egg }\end{array}$ & R. \\
\hline 95 & Fels. 17 & Elizabetlo & 40 & $\begin{array}{l}\text { Low situation; } \\
\text { slight dyspmoci }\end{array}$ & Enucleation, left & Solid adenoma, size of turkey's & R. \\
\hline 96 & Marclu 16 & linse l'. & 44 & $\begin{array}{l}\text { Dyspuna: } \\
\text { deformity }\end{array}$ &, & $\begin{array}{l}\text { Two adenomata; left lolse; size } \\
\text { of cocoanut and chestmut } \\
\text { respectively; } 16 \text { and } 20 z \text {. }\end{array}$ & R. \\
\hline 9 & March $2 \cdot 2$ & Mrs. K. & 28 & Dyspmoxa & $\begin{array}{l}\text { Enucleation, } \\
\text { right and left }\end{array}$ & $\begin{array}{l}\text { Small solid adenomata } \\
\text { deeply seated }\end{array}$ & $\mathbf{R}$. \\
\hline 95 & April 9 & Elizabeth & 38 & byspncea & Extirpation, left & $\begin{array}{l}\text { Parenchymatous, with adeno- } \\
\text { mata; } 11 \mathrm{oz} \text {. }\end{array}$ & R. \\
\hline $9 y$ & April 25 & Emily IV. & 21 & Deformity & $\begin{array}{l}\text { Enucleation, } \\
\text { pyramid }\end{array}$ & $\begin{array}{c}\text { Cystic adenoma of pyramid, } \\
\text { size of walnut (Fig. 31) }\end{array}$ & R. \\
\hline 100 & April 27 & Dr. $\mathrm{K}$. & 40 & $\begin{array}{l}\text { Occasional } \\
\text { dysplucea }\end{array}$ & $\begin{array}{l}\text { Enucleation, } \\
\text { right }\end{array}$ & Cyst, size of hen's egg & R. \\
\hline 101 & Ilay 26 & Betsy Z. & 33 & Deformity & 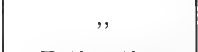 & $\begin{array}{c}\text { Cystic adenoma, size of hen's } \\
\text { egry }\end{array}$ & R. \\
\hline 102 & May 26 & $\begin{array}{c}\text { Beatrice } \\
\text { K. }\end{array}$ & 27 & $\begin{array}{l}\text { Deformity and } \\
\text { dyspmoea }\end{array}$ & $\begin{array}{c}\text { Extirpation } \\
\text { through right } \\
\text { posterior triangle }\end{array}$ & $\begin{array}{l}\text { Parenchymatous, with adeno- } \\
\text { mata; about } 5 \mathrm{oz} \text {. }\end{array}$ & R. \\
\hline 103 & May 27 & $\begin{array}{l}\text { Christine } \\
\text { H. }\end{array}$ & 26 & $\begin{array}{l}\text { Dyspmoxa and } \\
\text { leakage from } \\
\text { previous tapping } \\
\text { Deformity }\end{array}$ & $\begin{array}{l}\text { Enucleation. } \\
\text { right and isthmus }\end{array}$ & $\begin{array}{l}\text { Large cystic adenoma with } \\
\text { thick fibrous and calcified wall, } \\
\text { size of large orange } \\
\text { Solid adenoma, size of orange }\end{array}$ & R. \\
\hline
\end{tabular}




\section{GOITRE BY OPERATION (EXTIRPATION AND ENUCLEATION). February 1894 and January 1901.}

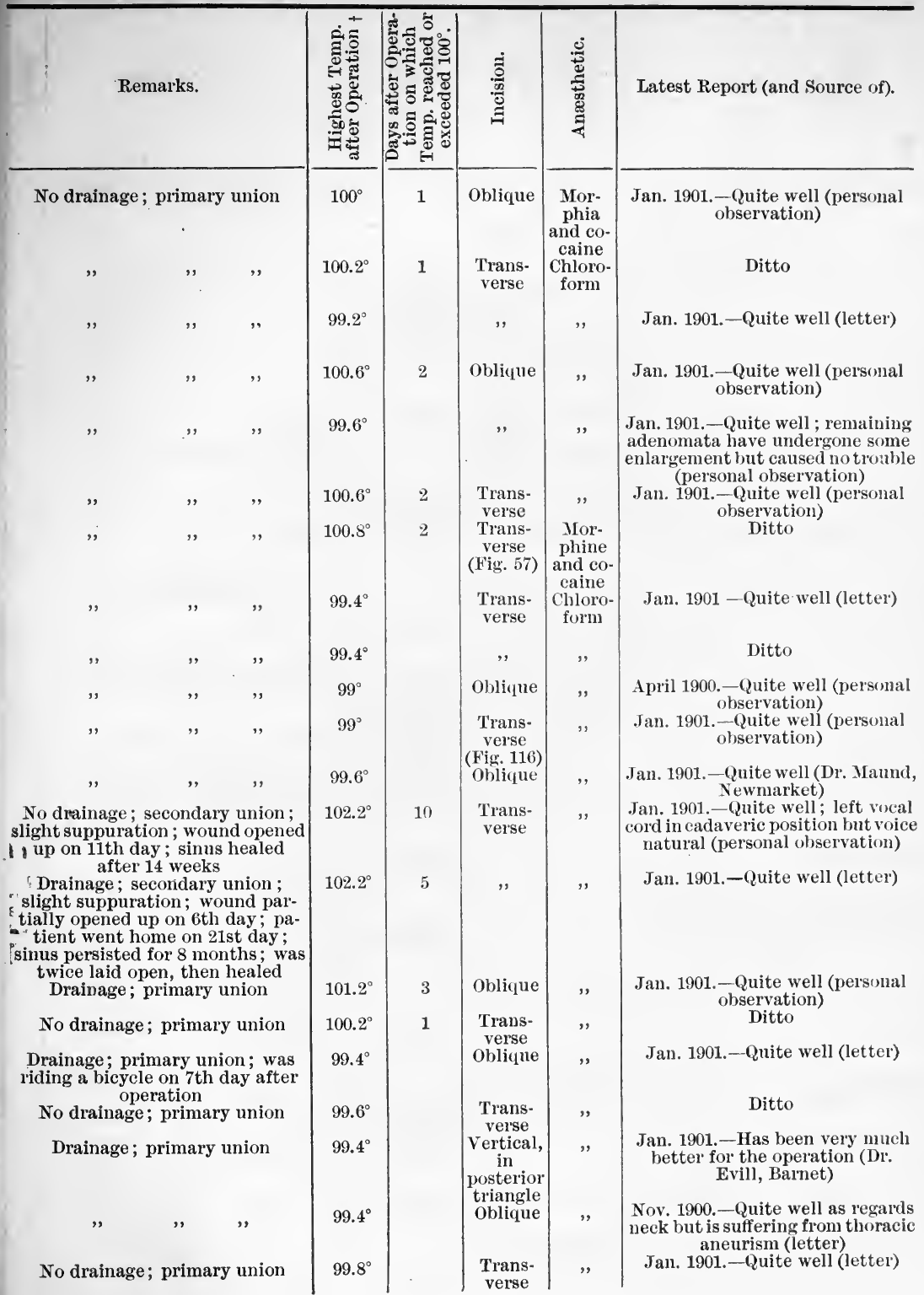

† Temperature taken every four hours. 
ONE HUNDRED CONSECUTIVE CASES OF REMOVAL OF Performed by the Author between

\begin{tabular}{|c|c|c|c|c|c|c|}
\hline No. & $\begin{array}{l}\text { Date of } \\
\text { Opera. } \\
\text { tion. }\end{array}$ & Name. & $\stackrel{8}{4}_{i}^{\circ}$ & $\begin{array}{l}\text { Chief Reason for } \\
\text { Operation. }\end{array}$ & Operation. & Nature of Goitre. \\
\hline 105 & June 3 & Amn C. & 69 & Dyspncea & $\begin{array}{l}\text { Enucleation (re- } \\
\text { section enuclea- } \\
\text { tion), isthmus } \\
\text { and right }\end{array}$ & $\begin{array}{l}\text { Old calcified adenonia, size of } \\
\text { an orange (Figs. } 43,44)\end{array}$ \\
\hline 106 & Jume 7 & Eliza van $\mathrm{I}$. & 39 & Dyspnoea & Enucleation, left & $\begin{array}{c}\text { Cystic adenoma, one-tenth } \\
\text { solid; size of hen's egg; deeply } \\
\text { seated }\end{array}$ \\
\hline 107 & June 12 & Caroline $\mathrm{T}$. & 43 & Dyspncea & , & $\begin{array}{c}\text { Cystic adenoma, size of small } \\
\text { orange ; one-quarter solid; } \\
\text { deeply seated }\end{array}$ \\
\hline 108 & June 23 & Jane W. & 23 & Dyspnœa & $\begin{array}{c}\text { Enueleation, } \\
\text { right }\end{array}$ & $\begin{array}{l}\text { Cystic adenoma, size of walnut; } \\
\text { two-thirds solid; deeply seated }\end{array}$ \\
\hline 109 & June 23 & Emily $\mathbf{H}$. & 30 & Deformity & Enucleation, left & $\begin{array}{c}\text { Solid adenoma, size of a small } \\
\text { orange (Figs. 114, 115) }\end{array}$ \\
\hline 110 & June 28 & Mary L. & 17 & Dyspnoea & $\begin{array}{l}\text { Enucleation, } \\
\text { right }\end{array}$ & Cystic adenoma \\
\hline 111 & July 5 & Fanny F. & 64 & Dyspncea & $\begin{array}{l}\text { Extirpation, } \\
\text { right }\end{array}$ & $\begin{array}{l}\text { Parenchymatous; } 10 \mathrm{oz} . \\
\text { (Fig. 94) }\end{array}$ \\
\hline 112 & July 5 & Sarah M. & 55 & Dyspmoea &, & $\begin{array}{l}\text { Parenchymatons, with much } \\
\text { fibrous tissue; } 16 \mathrm{oz} \text {. } \\
\text { (Figs. } 49,50,51 \text { ) }\end{array}$ \\
\hline 113 & July 14 & Fanny M. & 50 & $\begin{array}{l}\text { Severe dyspnoea } \\
\text { malignancy }\end{array}$ & $\begin{array}{l}\text { Partial extirpa- } \\
\text { tion, left and } \\
\text { middle }\end{array}$ & $\begin{array}{l}\text { Spindle-celled sarcoma; tum- } \\
\text { our removed size of apple; } 4 \mathrm{oz} \text {. }\end{array}$ \\
\hline 114 & July 16 & Mrs. G. & 39 & Dyspncea & Enucleation, left & $\begin{array}{c}\text { Cystic adenoma, size of orange; } \\
\text { two-thirds solid }\end{array}$ \\
\hline 115 & Sept. 7 & Ellen $\mathrm{H}$. & 37 & Dyspuncea & $\begin{array}{l}\text { Enucleation, } \\
\text { right }\end{array}$ & $\begin{array}{l}\text { Three cystic adenomata, lar- } \\
\text { gest size of walnut }\end{array}$ \\
\hline 116 & Sept. 8 & $\begin{array}{l}\text { Elizabeth } \\
\quad \text { R. }\end{array}$ & 17 & Dyspncea & , & $\begin{array}{l}\text { Two solid adenomata, largest } \\
\text { substernal; size of goose's egg }\end{array}$ \\
\hline 117 & Sept. 15 & $\begin{array}{l}\text { Elizabeth } \\
\text { C. }\end{array}$ & 36 & Dyspnoa & , & $\begin{array}{l}\text { Solid adenoma, size of goose's } \\
\text { egg }\end{array}$ \\
\hline 118 & Oct. 17 & Miss A. & 36 & $\begin{array}{l}\text { Deformity } \\
\text { palpitation }\end{array}$ & Enucleation, left & $\begin{array}{l}\text { Cystic adenoma, size of hen's } \\
\text { egg; mainly solid; much } \\
\text { fibrous tissue }\end{array}$ \\
\hline 119 & Oct. 20 & Eliza H. & 52 & $\begin{array}{l}\text { Bulk, weight, } \\
\text { and deformity }\end{array}$ & $\begin{array}{l}\text { Extirpation, } \\
\text { right and middle }\end{array}$ & $\begin{array}{c}\text { old parenchymatous goitre; } \\
\text { weight of tumour after re- } \\
\text { moval, } 49 \text { ozs. } \\
\text { (Figs. } 34,35,36 \text { ) }\end{array}$ \\
\hline 120 & Oct. 25 & Mrs. L. & 39 & $\begin{array}{l}\text { Bulk, weight, } \\
\text { and deformity }\end{array}$ & $\begin{array}{l}\text { Enucleation, } \\
\text { right }\end{array}$ & $\begin{array}{c}\text { Cystic adenoma, size of large } \\
\text { orange }\end{array}$ \\
\hline 121 & Nov. 3 & Grace B. & 35 & Drsumoag & Emmcleation & $\begin{array}{c}\text { Cystic adenoma, size of hen's } \\
\text { egg }\end{array}$ \\
\hline 122 & Nov. 10 & Ellen L. & 33 & $\begin{array}{l}\text { Dyspnoea and } \\
\text { and anemia }\end{array}$ & Enucleation, left & $\begin{array}{l}\text { Solid adenoma, size of a } \\
\text { turkey's egg }\end{array}$ \\
\hline 123 & Nov. 10 & Jemima S. & 43 & Dysuncea & $\begin{array}{l}\text { Enucleation, } \\
\text { right }\end{array}$ & $\begin{array}{l}\text { Solid adenoma, with much fib- } \\
\text { rons tissue; size of orange ; } \\
\text { very adherent }\end{array}$ \\
\hline 124 & Nov. 10 & Albert D. & 18 & $\begin{array}{l}\text { Deformity; dis- } \\
\text { comfort; slight } \\
\text { dysploea }\end{array}$ & ", & $\begin{array}{l}\text { Cystic adenoma, size of small } \\
\text { orange; mainly fluid }\end{array}$ \\
\hline 125 & Nov. 26 & Miss S. & 32 & $\begin{array}{l}\text { Dyspnce; } \\
\text { discomfort }\end{array}$ & Enucleation, left & $\begin{array}{c}\text { Cystic adenoma, with hamor- } \\
\text { hage; four-flfths solid; size of } \\
\text { a lemon }\end{array}$ \\
\hline 126 & Dec. 8 & $\begin{array}{l}\text { Gertrude } \\
\quad \text { A. }\end{array}$ & 29 & Dyspnoea & $\begin{array}{l}\text { Enucleation, } \\
\text { right }\end{array}$ & $\begin{array}{c}\text { Solid adenoma, size of duck's } \\
\text { egg; contained also a cyst size } \\
\text { of cherry }\end{array}$ \\
\hline
\end{tabular}




\section{GOITRE BY OPERATION (EXTIRPATION AND ENUCLEATION). February 1894 and January 1901.}

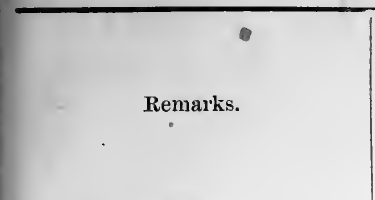

Drainage; primary union

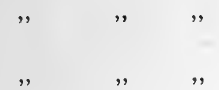

No drainage; primary union

Drainage; primary union

No drainage; primary union

Drainage ; primary union

No drainage; primary union

Drainage; secondairy union; slight suppuration for about a fortnight; left hospital on 17th day after. operation ; wound almost healed Drainage; primary union

No drainage; primary union

Drainage; primary mion

No drainage; primary mion

Drainage; primary union

No drainage; primary union
Latest Report (and Souree of).

Jan. 1901.-Quite well (per'sonal observation)

Ditto

Jall. 1901.-Quite well (Dr. Tolputt, Kettering)

Jan. 1901. —Quite well (persona] observation) Ditto

Ditto

Dec. 1900,-(Qnite well (letter)

Jan. 1901.-Quite well (Dr. Mlar. shall, Bexhill)

Nov, 1900 - Re-admitted for tracl1eotomy and died soon afterwarels with extensive recurrenee (Fig. $7 s$ )

Nov, 1900.-(Qnite well (personal observation)

Jan. 1901. - Well; still several small adenomata in both lobes: respiration easy

Jan. 1901.-Re-armitted with a small sinus which soon healed; otherwise well (personal observation)

Quite well on leaving hospital on 9th day; (1uite well when last seen several weeks later (Dr. Barron. Ascot)

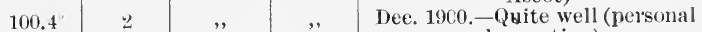
observation)

Jan. 1901.-Quite well (Dr. Image Bury St. E(mumes)

Dec. 1900 . - Quite well (letter)

Jan. 1901.-Qquite well (Dr. Rohertson, Gosport)

Jan. 1901.-Qnite well (Dr. Raglan Thomas, Exeter)

Jan. 1901,-Ouite well (Dr. Marshall, Bexhill)

Jan. 1901. -Quite well (per'sonal observation)

Jan. 1901.-Qnite well (Dr. Stack, Bristol)

Jan. 1901.-Quite well (lèter) 



\section{N D E X.}

ABscess of thyroid, 130-45

Accessory thyroid vein, 268

thyroids,

anatomy, 12-13

compensating hypertrophy, 15

Acute goitre, 48

Adenomata,transition into cysts, 154-5

Adenomatous goitre,

colour of, 283

cystic, $42-3$

enucleation of, 280 et seq.;-versus extirpation, 337

évidement of, 294

fatal case of removal of, 311

fœtal, 39-42

malignant,

- diagnosis from innocent, 98, $199,211,221$

results of operations on, 221-2

Air and sunshine, supposed effect on goitre, 53-5

Amputation of goitre, 279

Amyloid goitre, 48

Anæsthetic, use of, in thyroid operation, 257-60, 295-7

Aneurism, diagnosis from thyroid tumour, 92-96

Animals,

cretinism in, 67

goitre in, 67

symptoms following removal of thyroid in, 320

Antisepsis-versus asepsis, in thyroid operations, $215-16,270-1$

Arteries,

carotid,

relation-to thyroid, 5-to thyroid tumour, $87-9,92,140,204$ - to trachea, in malignant goitre, 224

resection of, 218

inferior thyroid,

ligature of, danger to sympathetic in, 302 history of operation 241-3
Arteries, inferior thyroid, ligature of, in, extirpation, 268-9

in, resection-extirpation, 278 method, 243-4

recurrent hæmorrhage from, 305

relation to thyroid, 5,9

superior thyroid,

ligature of, history of operation, 241-3

in extirpation, $26 \bar{T}-8$

in resection, 275

in resection-extirpation, 278 method, 243

relation to thyroid, 8-9

relation to enlarged thyrcid, 89,92

thyroidea ima, 9

Aseptic treatment, value of, in thyroid operations, 215-16, 270-1,304

Asphyxia, due to congenital goitre, 15,19

Asthma, simulating goitre, 106

Atmosphere, relatior to goitre, 51-2

Atrophy of thyroid,

in cretinism, 26,30

in myxœdema, $21-2$

senile, $20-1$

Atrophy of tracheal wall, 114-16

Austria, goitriferous waters in, 65-6

BASEDow's disease (See Exophthalmic Goitre)

Bedfordshire, goitre in, 51,58

Belladonna, use of, in Graves's disease 186

Blood, expectoration of, in malignant goitre, 206

hæmatozoa in goitrous, 69

Blood-vessels (See under Arteries and Veins)

Bloodless enucleation, $292-3$

Bohemia, goitre in, 65

Bone, growths secondary to malignant goitre in, 209 
Brachial plexus (See under Nerves) Brain, relation to exophthalmic goitre, 178

Brecknockshire, goitre in, 63

Bromine, use of, in Giaves's disease, 187

Bronchitis,

causing death :fter thrroid operations, $208,225,334$

complicating exothyropexy, 248

dyspnoea from, 120

goitre :imulating, 106

Bronchocele (ser Goitre)

Buckinghamshire, goitre in, 51

\section{CACHexia strumipriva}

avoided by compensating hypertrophy of thyroid, 15, 31, $324-5$

due to absence of thyroid, 14, 188, 320,324

due to ligature of thyroid vessels. 190

history of, 31822

Horsley's experiments, $: 20$

relation to myxudema, $3: 20$

symptoms, $3 \dot{2} 34$

temporary, $326-7$

treatment, 327

Cachexia thyreopriva, 318

Calcareous rocks, distribution of goitre on, 55-6, 58-63, 64

Cambrian rocks, distribution of goitre on, 63,64

Cancer, condition of thrreid in. 3.5

Carboniferous rocks, distribution of goitre on, $62-4$

Carcinoma (Sie Malignant Disease of Thyroid)

('ardiac nerves, injury of, in thyroid operation, 31:

Carotid artery (See under Arteries)

('ellulitis, complicating thyroid operations, 307

Cervical lymphatics, abscess of, simulating goitre, 75 inflammation of, simulating thyroiditis, 134

Cervical plexus (So under Nerves) sympathetic (s'ce under Nerves)

Chalk districts, goitre in, 58

Chloroform, fatal cases of thyroid operation under, 296

Cholera, cansing thrroiditis, 131

Chronic inflammation of thyroid, $136-7$

simulating sarcoma, 199

Climate, influence on goitre, 50-2

Coal measures, goitre on, 6*, 64

Cocaine,

effect of injection into eye, 190-1
Cocaine, use of, in thyroid operations, 259-60

dose, 260

Colloid goitre, $46-7$

Colloid secretion, 12

abnormal accumulation, 122, 152-3

absence of, in exophthalmic goitre, $180,187-8$

in myxœdema, 21-3

absorption of, 314-15

character of, in cystic disease,

$161-2,167,169,172-5$

in exophthalmic goitre, 178

diminution of, $253-5$

in senile atrophy, 20

relation to fat formation, 35

Congerital goitre,

cases of, $15-16$

in animals, $17-18$

treatment, 18-19

sarcoma, 198

Cough, in tracheal obstruction, 102, 132

Cretaceous formation and goitre, 56 , $58-9$

Cretinism,

atrophy of thyroid in, 26,30

cause of, 14,320

connection with cachexia strumi. priva, 320

endemic goitre, $24,26,29-30$

myxœdema, 23-4, 320

enlarged thyroid in, 25-6, 30

fatty tumours of, $2 \overline{7}-\mathrm{S}$

in animals, 67

sporadic (Sce Sporadic Cretinism) treatment, 30

Cricoid cartilage, division of, in extirpating goitre, 270

Crystalline rocks, goitriferous waters in, $66^{\circ}$

Cysts,

simulating thyroid enlargement, $7: 35$

thyroid of,

adenoma (Sere that name)

classification. $156-\bar{\tau}$

colour, 283

description, $37-8$

developmenr, 154-5

diagnosis from malignant goitre, 210

hæmorrhagic, 46, 123

hydatid (See Hydatid Cysts)

intra cystic growths, 164

hæmorrhage, 158-60

origin of, 152-6

position of, $82-3,84-5,91$

papilliferous (Sce Papilliferous Cysts)

structure, $160-4$ 
Cysts, thyroid of, suppurating (See Suppurating Cysts) treatment, enucleation, $280 \mathrm{et} s \mathrm{se}$. incision, 239-40

injection, 237-9

seton, $240-1$

tapping, 231-2

DEATH,

during thyroid operation, causes of, and cases, 295-9

following thyroid operation, causes of, 314-16, 334-5 symptoms, 310-14

from dyspnoea (See Dyspnoea)

Derbyshire, goitre in, 52, 61-5

Devonian and old red sandstone, goitre in region of, $63-4$

Devonshire, goitre in, 58,63

Diarrhœe, in Graves's disease, 183

Digitalis, administration in Graves's disease, 186

Dysphagia,

due to goitre, 102-3 thyroiditis, 132

following exothyropexy, 248

treatment of, 226

Dysphonia;

due to goitre, 102

extirpation of goitre, 301

Dyspnœa in goitre,

analytical table of fatal cases, $126-9$

causes of, $9 \overline{7}, 102,10 \bar{\imath}-20,132$, 295-9, 306

influence of age and sex on, 121-3 occasional effect of exothyropexy, 248

relief of,

by resection of isthmus, 251-3, $255-6,278$

results of operations in, 336

varieties of goitre producing, 15,19 , $91,92,105-6,122-25,185$

Dyspnoea in malignant goitre, 205, $207,208,214,219$

relief of, $222-6$

EChinococcus, 165

Electrical treatment of Graves's disease, 187

Endemic goitre,

alleged causes, $52-71$

basis of European statistics, 50

connection with cretinism, 24,26 , 29-30

geographical distribution, 51-5 geological distribution, 55.65

use of term, 48
England,

distribution of goitre in, 15, 16, $34,51-4,58-65,83,92,93,95$ geological formation and goitre, 57-63

Enucleation (See Intra-glandular Enucleation)

Epidemic goitre, 48

cause of, 66

Essex, goitre in, 58

Eucaine, use of, in thyroid opcration, $259-60$

Évidement, 293-4

Exophthalmic goitre,

diagnosis and symptoms, 92, 101, 183-6

dissimilarity to other forms of goitre, 44,49

distribution, $176-7$

fatal symptoms following removal, $313-14,316$

influence of age and sex on, $176^{\circ}$ morbid anatomy, $31,47-8,179-8 \cdot 2$ pathology, 178

prognosis without operation, 194

simulating malignant disease, 210

treatment,

medical, $186-7$

table of result *, 194-5

surgical, $187-96,243,245,249$

Exophthalmos,

cause of, in Graves's disease, 182-:3

effect of operation on sympathetic, $190: 3$

from injection of cocaine into eye, $190-1$

unilateral, 184

Exothyropexy,

complications in, $247-9$

for congenital goitre, 19

for exophthalmic goitre, 189-90

history and method, 244- 7

mortality after, 249

Extirpation,

after treatment, 273-4

anæsthetic, use of, in, 258-60

compared with exothyropexy, 245

with resection of istlumus, $256^{\circ}$

complications of,

cachexia strumipriva (see that name)

hemorrhage, primary, 299

recurrent, $305-\overline{7}$

secondary, 304

injury of nerves in, $300-2,338$ of surrounding structures, $302-4$

late paralysis of vocal cord, 316 rapid pulse and restlessness, $310-10^{\circ}$

sepsis, $30 \bar{t}-10$ 
Extirpation, complications of, sudden death, 295-9 tetany, 316-17

difference between enucleation and, $257-8$

method of operation,

blood-vessels, ligature of, 264 , $267-9$

dissection from surrounding structures, $266-70$

drainage of wound, 271,274

incision of skin, $260-4$

infra-hyoid muscles, treatment of, $262,264-6$

position of patient, 260

of exophthalmic goitre, 188-9

statistics of results,

partial extirpation, causes of death (table), 334 of exophthalmic goitre, 188-9 of innocent goitre, 189, 216, 329-42 (rice also Appendix)

total extirpation, of malignant goitre, $216-22$ total, 258

of exophthalmic goitre, 188 of malignant goitre, $212-22$

Eye, contraction of pupil from goitre, $99-100$

FA'T formation, relation to thyroid, 35 relation of Graves's disease to. $18 \cdot-3$

Fatty degeneration of trachea, due to goitre, 114, 115

tumcurs, of cretinism, $2 \overline{\boldsymbol{t}}-\mathrm{\&}$

Fibrous goitre, $43-4,96,125$

Fistula after injection of goitre, $136-7,238-9$

Fretal adenoma ('see Adenoma)

"Formes frustes," 184, 194

France,

distribution of goitre in, 52, 199

exothyropexy in, 244

goitriferous waters in, 64,68

GAULT, distribution of goitre on, 58-9

Geological formations, connection with goitre, 55-69

Glamorganshire, goitre in, 52,62

Glottis, dyspnœa due to œedema of, 11 !

Gloucestershire, goitre in, $52,60,61$, 9:)

Glycosuria, in Graves's disease, 183

Goitre.

condition of blood in, 69

diagnosis by dysenuea, 105-29

physical signs, 72-96
Goitre, diagnosis by pressure on surrounding structures, 96-104

diseases simulating, 73-8, 92-4

distribution of, $50-71$ (See also under Various Countries)

in animals, $6 \overline{\mathbf{T}}-9$

inflawmation of, 130-45

influence of pregnancy on, 33-4 of puberty on, 34

of sexual excitement on, 34

meaning and use of word, 36

mixed forms, 44

relation to fat formation, 35

simulating asthma, 106

treatment,

division or resection of isthmus, $250-6$

exothyropexy, 244-9

extirpation (See that name)

incision, 232-3

injection, 233-41

intra-glandular enucleation (See that name)

ligature of thyroid arteries, $241-4$

non-operative, $227-30$

resection, $275-9$

seton, 240

tapping, 231-2

tracheotomy (See that name)

varieties, $36-48$

scoops, 284

wells, 67

Graves's disease (See Exophthalmic Goitre)

Greensand, lower, 65 ; upper, 58-9

Gummata of thyroid, $149-51$

HAMPSHIRE, goitre in, 58

Hæmorrhage,

into malignant goitre, 209

primary, avoidance of, in resection of gland, 276

arrest of, in enucleation, 286-8, 299-30

in exothyropexy, $247-8$

in extirpation, 299

recurrent, after thyroid operation, $305-7$

relation of pregnancy to, 34

secondary, after thyroid operation, 304

Hæmorrhagic cyst, 155-60 goitre, 46,123

Heart, lapidity of, in Graves's disease, $183-5$

Heredity of goitre, $70-1$

Herefordshire, goitre in, 16

Hertfordshire, goitre in, 58

Hilus of thyroid, 5

Hydatid cysts, 118-9, 165-75 
Hyoid bone, relation to enlarged thy. roid, 84,85

Hypertrophy of thyroid, 31-5 compensating, 31, 166, 324-5, 336 restriction of term, 31

Hypoglossal nerve, wound of, in extirpation, 302

IDIOPATHIC inflammation, 130-1

Igneous rocks, distribution of goitre on, $56,63,64$

Incision of cystic goitre, 239-40 of skin, in extirpation, 260

Indian method of curing goitre, 229-30

Inferior thyroid (See under Arteries and Veins)

Inflammation of thyroid, 130-45

Infiltrating fibroma, 138

Infra-hyoid muscles

in relation to extirpation of goitre, $262,264-6$

relation to thyroid tumour, $86-7$ suture of, 271

Injection,

cystic goitre, of, 237-9

in thyroiditis, 135

parenchymatous goitre, of, 23237

Intermarriage, relation to goitre, 70

Internal jugular vein (See under

Veins)

Intra-cystic hæmorrhage, 231

Intra-glandular enucleation, after injection, 239

cases suitable, 281-2

compared with intra-capsular and resection-enucleation, 292

complications,

hæmorrhage ; primary, 299-300

recurrent, 305-6

sepsis, $307-10$

sudden death, 295-8

difference between extirpationand, $257-8$

history of, $280-1$

injury to recurrent nerve in, 339

method of operating, 282-8

modifications,

bloodless, 292-3 .

évidement, 293

intra-capsular, 292

resection-enucleation, 288-92

of innocent and malignant goitre, 212

recurrence after, $336-\tau$

results and mortality statistics, 329-34 (See also Appendix)

unsuitability in exophthalmic goitre, 188
Iodine,

injection of, in cystic goitre, 237-9;

in parenchymatous, $228-9,233-7$

use of, in Graves's disease, 186-7

Iodoform solution, injection, for Iron, parenchymatous goitre, 237

perchloride of, injection in cystic goitre, 237-9

relation to goitre, 65,67

use of, in Graves's disease, 187

Isthmus of Thyroid,

absence of, 14

compensating hypertrophy, 325

division of, in extirpation, 250-6, 270

enlargement of, 81-2, 112-13

excision of, fatal case of, 313

in resection extirpation, 278

position and relations of, 1-2

relation to tracheal compression,

Italy, 251-3

distribution of goitre in, 53

goitriferous waters in, 68-9

JABOULAY's operation, 190-1

Jurassic formations and goitre, 56 , $59-61,66$

KENT, goitre in, 58

Kidneys, hydatid cyst in, 166,172

Kœnig's tracheotomy tube, 225

\section{LARYNX,}

displacement by goitre, 101

perforation by goitre, 118

relation to thyroid, $3-4,6-8$

to enlarged thyroid, $72-3,76-7$, $82,85,113$

rupture of abscess into, 119

total extirpation in a case of malignant goitre, 214

Laryngeal diseases, simulating goitre, $73-4$

thyroiditis, 134

Lias formation, distribution of goitre on, $60-1$

Ligature.

of gland substance in resection of goitre, 276

of thyroid arteries,

for exophthalmic goitre, 190

for innocent goitre, 241-t

Lime salts, relation to goitre, 64-5, 67,68

Limestone districts (See Calcareous Rocks)

Lincolnshire, goitre in, 15, 83 
Liver, hydatid cyst of, $166,168,172$, 173

Lungs,

growtbs secondary to malignant goitre in, 206, 209

sepsis following tracheotomy, $2 \cdot 25$

Lymph glands, involved in malignant goitre, 205-6

Lrmphatics,

of thyroid, 11

tumours of, diagnosis from thyroid tumour, 83, 85-6

Lympho-sarcoma, simulating goitre, $77-8$

Lyons, exothyropexy at, 244-5

MAGNESIUM salts, relation to goitre, $64-5,67,68$

Magnesian limestone districts, goitre in, 61-2

Malaria, a cause of thyroiditis, 131

Malignant crsts, contents of, 160

Malignant disease of thyroid, adenoma (sce that name)

(leath, causes of in, 208-10

diagnosis, 88, 97-101, 199-206

from adenoma, 199

chronic inflammation, 199

exophthalmic goitre, 210

innocent cyst, 210

parenchymatous goitre, 210

duration of, 206-8

influence of age and sex on, $197-8$

papilliferous cysts (see that name)

treatment,

by extirpation,

complications, 21:3-14, 218

danger of recurrence, $213-1 \mathrm{f}$, $219-21$

method, $215-16$

mortality statistics, 216-21

prognosis, 216

palliative,

incision, $2 \cdot 2 \cdot 3-4$

partial extirpation, 222-:3

tracheotomy, 2.24-6

varieties of. $210-12$

relative freqtiency of sarcoma and carcinoma, 198-9

Manubrium of the sternum, complication in snbsternal goitre, 248

Medlian goitre. 112 13

Mediastiniti-, 1:3:3, 209

Menstruation, enlargement of thyroid during, :3:2

Mercury ointment, use of in goitre, $2: 29.30$

Micro-organisms, in goitre-producing water, $65-6$
Middle thyroid vein (See under Veins)

Middlesex, goitre in, 58

Mikulicz's resection (See Resection)

Millstone grit, 62, 64

Molasse, geological structure and goitre, 56, 66

Morphia, use of, in operation on thyroid, 260

Mountainous districts, goitre in, 51-3

Mountains, geological structure and goitre, 55-6

Murmur in thyroid tamonr, 93-5

Muscles (See also Infra-hyoid, Scalenus anticus, and Sternomastoid)

relation to thyroid, $5,6,8$

to enlarged thyroid, $85-7$

Muscular exertion, relation to goitre, 69,70

Myxiedema,

atrophy of thyroid in, 21

cause of, 14,320

occasional enlargement of thyroid, 22

relation to cachexia strumipriva, 320

cretinism, 23-4, 320

fat formation, 35

treatment of, 22-3

Nerves,

brachial plexus, involved in thyroiditis, 132

pressure of goitre on, 101

cardiac, injury of, in thyroid operation, 315

cervical plexus, involved in thyroiditis, 132

pressure of goitre on, 101

cervical sympathetic,

fatal symptoms following division, 313,315

involved in thyroid tumour, 99-101

operations on, in exophthalmic goitre, 190-4

relation to exophthalmic goitre, 178

wound of, in extirpation, 302

involved in chronic inflammation, 138,140

of thyroid gland, 11

recurrent laryngeal,

compression by scar, 316,338

danger to, in extirpation, $300-1$

danger to, in removal of hydatid, 171

dyspnoxa, dne to irritation of, $116-18,295-6$ 
Nerves, recurrent, effect of injury, $337-9$

in relation to ligature of inferior thyroid artery, 269 , 270

involved in chronic inflammation, 138, 140

involved in thyroiditis, 132

protection of, in resection, $275-6$

protection of, in resectionextirpation, 275-6

relation to thyroid, 5-6, 8 thyroid tumour, 97-9

vagus, 302

Nervous symptoms, in Graves' disease, 183,185

Norfolk, goitre in, 58

Northamptonshire, goitre in, 54, 60

Northumberland, goitre in, 63

Norway, scarcity of goitre in, 52-3, reason of, 55

Nottinghamshire, goitre in, 61

(EDEMa,

of face and arm, from goitre, 97

of glottis,

causing death in malignant goitre, 210

dyspnix'a due to, 119

(Esophagus, in thyroiditis, 133

infiltration in chronic inflammation, 140

injury in thyroid operation, 171, 304

partial excision in thyroid operation, 218

pressure from goitre, $102-4$; from inflamed thyroid, 132,134

relation to thyroid, 6,7 ; importance of in extirpation, $269-70$

thyroid fistula opening into, $13 \pi$

Oolite rock, distribution of goitre on, $59-60,65$

Operative myxoedema (See Cachexia strumipriva)

l'ALAEOZOIC formation and goitre, 56 , $61-3$

Papilliferous cysts,

description, 164, 211-12

treatment, 221-2

Parathyroids, 13

Parenchymatous goitre,

cause of enlargement of gland in, $36,253-4$

consistency, 96

description, 36-7

dyspnœea from, 109, 122-3, 126- 7

rapid enlargement of, $117,122-3$
Parenchymatous goitre, shape of compressed trachea in, 109

symptoms and diagnosis (See goitre, diag.)

diagnosis from exophthalmic, $179-80,184$

diagnosis from malignant disease, 210

diagnosis from thyroiditis, 134 symptoms of death following removal, 312-13, 316

treatment (See Goitre, Treatment of)

Perchloride of iron, injection in cystic goitre, 237-9

Permian rocks, goitre in region of, 61-2

Pharynx,

injury to, in removal of goitre, 304 involvement of muscular wall, 202 penetration in thyroiditis, 133-4 penetration by malignant growth, $202-3$

pressure of goitre on, 103-4

pre-sure of inflamed thyroid on, 132

relation to thyroid, 6,7 ; importance of, in extirpation, $269-70$

Phthisis, condition of thyroid in, 35)

Pleura, injury in thyroid operation, 303

Pneumonia, following tracheotomy, 225

l'ost-tertiary formations, absence of goitre on, 56

Potash salts, relation to goitre, 68

Pregnancy, relation to thyroid, 324 , 123

Puberty, relation to thyroid, 34 ; to tatal dyspnoea, 122-3

Puerperal fever, thyroiditis in, 131

Pulsation of thyroid tumour, 92-6

Pulse, rapid, following thyroid operation, causes of, 314-16

danger of, fatal cases, 310-14

Præmia, causing thyroiditis, 131

Prramid of Lalouette, 3-4

tumour of, 84

RAINFALL, influence on goitre, 51

Recurrent laryngeal nerve (s'ee uuder

Nerves)

Resection,

advantages, 279

description, 275-ti

enucleation, 288-92

extirpation, advantages, 279

compared with resection, 279

description, 278-9

results, $276-8$ 
Restlessness following thyroid operation, causes of, $314-16$ danger, 310-14

Rheumatic thyroiditis, $130-1$

SAlzBURG, goitriferous waters at, $65-6$

Sandstone districts, goitre in, 55-6, 61,63

Sarcoma (Sce Malignant Disease)

Scalenus anticus muscle, in relation to ligature of thyroid artery, 269

Scar, after thyroid operation, $262-3$, 342

Scotland, scarcity of goitre in, 52

Sepsis, danger of and treatment, $307-10$

Seton method of treating goitre, $240-1$

Sexual excitement, relation to thyroid, 34

Silurian rocks, goitre on, 63,64

Skin,

condition in cachexia strumipriva, 323

in Graves's disease, 183

incision of, in extirpation, $260-4$

involvement of, by malignant goitre, 205

spontaneous ulceration, $140-2$, 305

Soda, salicylate. use in thyroiditis, 135

Sodium salts, relation to goitre, $6 \bar{\gamma}$, 68

Somersetshire, goitre in, $16,59-60,63$, 95

Sporadic cretinism,

distinguished from endemic, 27.9

due to absence of thyroid, 24,25

Sporadic goitre, use of term, 48

Staftordshire, goitre in, 63

Sterno-mastoid muscle,

in relation to extirpation of goitre, 260,262

to ligature of inferior thyroid artery, $243-4,269$

relation to thyroid tumour, $86-i$

Sternum, relation to thyroid tumour. $8,88-92,113$

Submaxillary, tumour of, simulating goitre, 8:3

Substernal goitre,

diagnosis from aneurism, 93

position of, $89-91$

relation to fatal dyspnoea, 124

Suffocating goitre, 48

Suffolk, goitre in, 58

Sunshine and air, supposed effect on goitre, 5:3-5
Superior thyroid (Sce under Arteries and Veins)

Suppurating cyst, asphyxia due to rupture of, 119 penetration into trachea and pharynx, 133-4 treatment, 135

Suppuration,

due to injection, 234, 238

into trachea after thyroid operation, 309-10

Surrey, goitre in, 58, 59

Suspensory ligament of thyroid, 8

Sussex, goitre in, 58, 59

Switzerland,

distribution of goitre in, 15, 51-4, $91 n$

geological structure and goitre, $55-6$

goitriferous waters in, 64-7

Sympathetic nerve (See Cervical sym. under Nerves)

Sympathicotomy, 190

Syncope, in goitre operation, 48, $148-51$

TAPPING of cystic goitre, $231-2$

Temperature, after extirpation and enucleation (See Appendix)

in Graves's disease, 183

rise after exothyropexy, 247

Tertiary rocks, goitre in region of, 56 , $5 \overline{7}-8,64$

Tetany, complicating thyroid operation, 316-17

Thymus,

administration of preparations, 186

enlargement in Graves's disease, 183

Thyroid gland,

absence of, effect on, $24,25,31 \overline{-}$ $318,320,324$

absorption from pressure of hydatid, $166^{\circ}$

administration of extract, 23,30 , $186,228-9,327$

atrophy, 20-30

blood-vessels, 8-10

ligature of, $190,26 \bar{\imath}-9$

congenital diseases, 15-19

malformations, 14-15

cystic disease (Śce Cysts)

disease of (See Goitre)

extirpation, 257-70 (See also this name)

hypertrophy, 31-5, 166

inflammation, 130-45

influence of menstruation, 32 pregnancy, 33-4 
Thyroidgland, influence of puberty, 34 sexual excitement, 34

innervation, 11

isthmus, 1-2

lobes of, 1, 3-4

lymphatics, 11

operations on, for exophthalmic goitre, $187-90$

relations, 5- 8

structure, 11

syphilitic disease of, $148-50$

tubercle, 146-8

variations in human, 34-5

weight of,

congenitally diseased, 16

normal, 1

relative weight in old age, 20

Thyroidea ima, 9

Thyroidectomy (See Extirpation)

Trachea,

adhesion of thyroid abscess to, 138

altered relation to carotid, in malignant goitre, 224

collapse of, in removal of goitre, 304

complication in exothyropexy, 248

compression, causing dyspnœa from goitre, 16, 97, 102, 107-16, 120,253

due to hydatids, $167,172,174$

displacement, 82, 101-2, 113, 203

infiltration, 139-40

injury to, in removal of goitre, $218,302-3$

mucous membrane involved by malignant goitre, 201-2

penetration by thyroid abscess, 133-4

malignant growth, 118-19, 201-3, 208

pressure of enlarged thyroid, $72-3$, $74,76-7,132,203$

relation to thyroid, 6,7

rupture of hydatid into, 167,172

Tracheal diseases simulating goitre, $73-5$

Tracheal wall, changes in, due to goitre, 113-16

'Tracheotomy,

danger of, during thyroid operations, 298

in exophthalmic goitre, 198

malignant goitre, $224-6$

Tracheotomy, danger in, parenchymatous goitre, 256
Tracheotomy, danger in, primary chronic inflammation, 145

Traumatic inflammation, 131-7

Triassic formation and goitre, 56,61 , 66

Tuberculous goitre, $48,146-8$

'Tumours, of thyroid (See Goitre, rarieties) simulating goitre, $73,76-8,83$

Typhoid fever, thyroiditis complicating, 130

UNILATERAL goitre, relation to fatal dyspnœa, 124

Urticaria, in hyảatid cyst, 168-9

VAGUS, wound of, in extirpation, 302

Valleys, prevalence of goitre in, $53-5$

Variola, causing thyroiditis, 131

Vascular goitre, $47-8$

Veins,

accessory thyroid, 268

inferior accessory thyroid, 10 thyroid, 10,278

internal jugular,

relation to thyroid tumour, $88-9,96-7,140,204$

resection in goitre operation, 218

ligature of, in extirpation, 264, $267-8,275,278$

middle thyroid, 10,268

recurrent bæmorrhage from, 305

superior accessory thyroid, 10

thyroid, $10,267-8,275,278$

thyroidea ima, 10

Vocal cords,

effect of resection of goitre on, 277

paralysis of,

after thyroid operation, $337-9$

cause of late, 316

clue to goitre, $97,98,201$

WALES, goitre in, 52, 62, 63-4, 94

Warwickshire, goitre in, $60-1$

Water,

microscopical examination of goitriferous, 65-6

supply, influence on goitre, 55 . $57,62,64-9$

Wealden area, goitre in, 59, 65

YOREDALE rocks, 62,64

Yorkshire, goitre in, 15, 16, 34, 58, $59,60,61,62$ 


\section{INDEX OF NAMES.}

ALBEKS, 172

Albert, $2: 34,316$

Albertin, 249

Aldrich-Blake, 84

Alibert, 80, 81

Atkinson, 16

BACH, 19

Ballager, 50,67

Bankart, 240

Barker, 212, 221

Barlow, 131

Batten, 97

Battle, 142

Battle and Jones, 217

Baumann, 1:30

Baumgarten, 148

Beach, 24

Bérard, $: 44,246,247,249,30 \cdot 2,303$, 304

Bergeat, 19:, 217

Berger, 194, 21\%, 2.21

Berry, E. E., 68

Bidwell, 146

Billroth, 78, 222, 241, 280. 302, 216

Birch-Hirschfeld, 150

Bircher, $50,52,56,66,67,68$

Blanc, 249

Blizard, 2 11

Bock, 165

Boéchat, 255

Boeckel, 210

Boissou, 191, 1912

Bose, 2928

Bonchardat, 67

Bonilly, 19.4

Bowlby, 73, 88, 91, 124, 138, 139, 311

Boycl, 170, 175, 224, 298, 806

Bramwell, $12 \%, 302$

Braun, 216,217

Bruns, 115, 147, 148, 299, :322

Brsant, 129

Buchanan, 249
Burckhardt, 280

Buschi, 217

Butlin, 84. 85, 159, 216

CARle, 68

Carver, 93

Chavier, 170, 175

Chiari, 146

Cloquet, 150

Coates, 241

Cock, 166, 175

Colby, 15

Comte, 160

Cordua, 145

Corley, 305

Cramer, 214,217

Crawfurd, 178

Crisp, 17

Cruveilhier, 1:31

Curling, 24, 27

DALRYMPLE, 94

Dardel, 165

Davies, 51

Davis, 217

De Rance, 57

Demme, 15, 108, 149

Dewes and Heidenreich. 12:3

Dixon, 165

Dolerio, 194

Downes, $2 \pm 1$

Drobnik, 242, 244

Duquet, 165

EARLE, 241

Edmunds, 1:3, 191

Edwards, 127

Eminson, 15, 83

Ewald, 217

FAGGE, 24, 25

Faure, 192 
Federn, 194

Fergusson, 93

Ferrant, 173

Florez (Dr. M. Y.), 177

Fraenkel, 151, 194

Francis, 93

Frank, 217

Furnivall, 73

Fürst, 149

GALlOZZI, 167, 173

Gaucher, 106, 129

Genevet, 19

Gibb, 250, 252

Gibbs, 127

Gooch, 172

Gottstein, 194

Grasset, 69

Gray, 93

Greenfield, 178

Guillemot, 249

Gull, 320

Giinther, 241

Gurlt, 165

Guthrie, 131

HACK, 194

Hanau, 26

Hartmann, 249

Heidenreich. 133

Heidenreich and Dewes, 123

Henle, 165, 174

Hicquet, 317

Hirsch, 67

Hochgesand. 217

Hoffmann, 194

Holthouse, 250

Horsley, 317, 320

Hovell, 238

Hurry, 128

Husson, $106^{\circ}$

JA BOULAY, 192, 244, 245, 248, 249

Jeannel, 144

Jenks, 32, 34

Jessop. 190-1, 332

Jobert, 172

Jones, 251

Jones and Battle, 217

Jonnesco, 191, 192

Jouin, 194

Julliard, 272, 280, 292, 296

KAMMERER. 220, 221

Kappeler, 330

Karpetchenco, 167, 175

Kauffman, 103, 198, 203

Keser, 80, 162, 280

Klebs, 65
Koch, 103, 161

Kocher, 109, 132, 135, 159, 189, 190, $216,217,218,219,221,262.278-9$, $288,291,292,293,317,318-20,324$, 327

Kohn, 74, 131, 133, 134

Kottmann, 91, 280

Krieg, 132, 236

Krönlein, 115, 334

Kummer, 217

Küttner, 151

LAEX்NEC, 165

Lange, 221

Langenbeck, $165,243-4$

Langton, 254

Lannelongue, $16 \overline{7}, 168,169,170$, 175

Larrey, 73

Laure, 131

Lavaran, 69

Lebert, 131, 133

Lediard, 16

Leflaire, 194

Lentz, 217

Liebrecht, 109, 2:34, 241, 302, 303, 304, 316,329

Lieutaud, 172

Liouville, 131

Lockwood, 149

Lücke, 89

Lugentiihl, is

Lustig, 68

MAAS, 220

MacClelland, 55

McDougall, 127

Mackenzie, Hector, 186, 194

Miackenzie, Morell, $73,237-8$

McWhinnie, 89, 92, 241

Madelung, 18

Maidlow, 15

Malgaigne, 19

Marchant, 173

Marsh, 98, 100, 213

Marshall, 3, 4, 6, 7

Maschka, 129

Mason, 51

Maude, $17 \tau$

Maumené, 67

Meinert, 173

Mikuliez, 170, 174, 275-)

Mobins, 178, 187, 189

Mollière, 130

Montgomerie, 186

Morgan, 137

Morris, 325

Morton, 252

Mosetig-Moorhof, 237

Moxon and Wilks, 175 
Müller, 115, 280

Murray, 178

Muschold, 194

NAUMANN, 172

Nélaton, $92,94,17 \cdot 2$

Newman, 128

Nicholls, 129

Nivet, 50, 52, 67

Nussbaum, 303

OBALINSKI, 234

Odeije, 194

Orcel, 199, 217

Ord, 186, 194, 320

Ormsby, 15

Oser, 174

Osler, $78,123-4$

PAGET, 119, 133

Parker, 309

Paul, 312, 314, 31.

Paxton, 129

Péan, 174

Pearson, 150

Perry, 147

Petrakides, 217

Peugniez, 19\%

Peyrot, 170, 17:3

Picqué, 194

Pitts, 128

Pollosson, 19, 249

Poncet, 245, 249, 303

Porta, 2s0

Potter, 159, 160

\section{QUiNLan, 147}

\section{RAPP, 172}

Raynaurl, !4

Reece. 76,159

Rehn. 127

Reimers, $11 \mathrm{~S}$

Reverdin, A., 11:4, 1s9, 2216, :316, :32:3, :3:34

Reverdin, A. and J. L.. $318-20$

Reverdin, J. L., 165, 32:9-31

Rey, 128

Rice, io

Riedel, 138, 14:3, 141, 145, 199

Robinson, 21

Rocket, $24 ! 9$

Rodocanachi, :311, 314, :31.)

Rolleston, 147

Rase, 108, 11:3-14, 116, 206, 2:34

Rotter, $216,219,221$

Roux, 301

\author{
Rullier, 172 \\ Rydygier, 242, 244, 302
}

ST. LAGER, 50, 65, 67

Sainsbury, 106

Salzbach, 131

Salzer, 174

Samuel, 127

Savage, 177

Savory, 126, 309

Schiff, 320

Schimmelbusch, 19

Schnitzler, 128

Schoenborn, 316

Schramm, 317

Schwalbe, 235

Schwyzer, 221

Seitz, 117-18, 128, 235

Semon, 118, 139, 225, 23:3-4, 320

Shattock, 206

Shaw, 92

Sick, $320-2$

Smith, 95, i 03, 138, 139, 254

Socin, 80, 280, 292

Sorgo, 189

Spencer, 185

Starr, 188

Stocker, 194

Stokes, 325

Stonham. 217

Sulzer, 212,217

Symonds, C., 150, 280

Symonds, H. P., 127

Szumann, $: 317$

TAIlHeFer, 138, 144, 145, 199

Tait, 34

Taylor, C. H., 129

Taylor, E., 34

Teilhaber, 194

Thomas, 94

Tillaux, 210, 251

Trzebicky, 276

Turgis, 194

Turner, 224

VAN der Lenden, 194

Velpeau, 243

Vincent, 119, 133

Vitrac, 168, 175

Voelcker, 147

Von Bergmann, 170, 174

Von Zoege-Manteuffel, 170, 17 t

WAGNER, 320

Walther, 131, 241

Webster, 16 


\section{INDEX OF NAMES.}

Weiss, 316

Wermann, 151

Wilks and Moxon, 175

Willcox, 126

Willett, 206

Williamson, 194

Winslow, 108
Wolfenden, 74

Wölfler, 21, 74, 78, 91, 212, 222, 241. 243

Wolper, 174

Woodward, 57

Zesas, 131, 320 





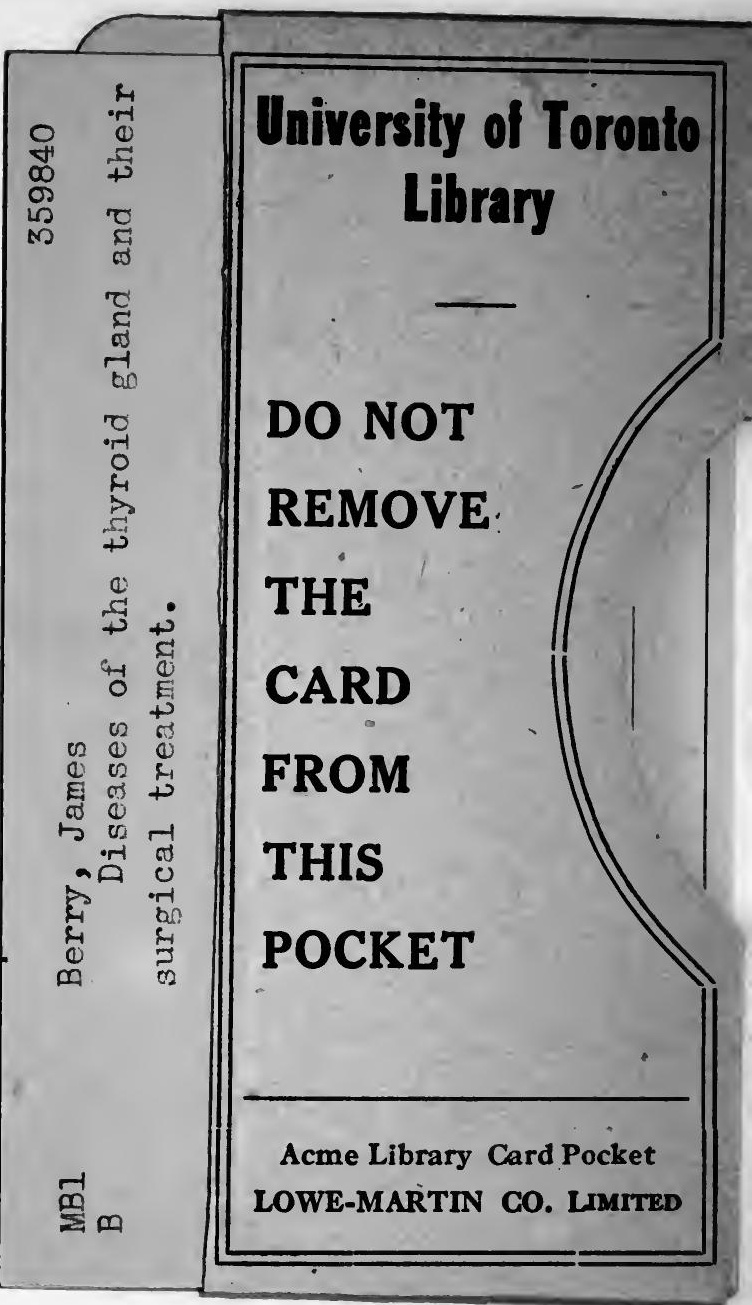


